$$
R F P-E N V-q 3
$$

\title{
Rocky Flats Plant Site Environmental Report
}
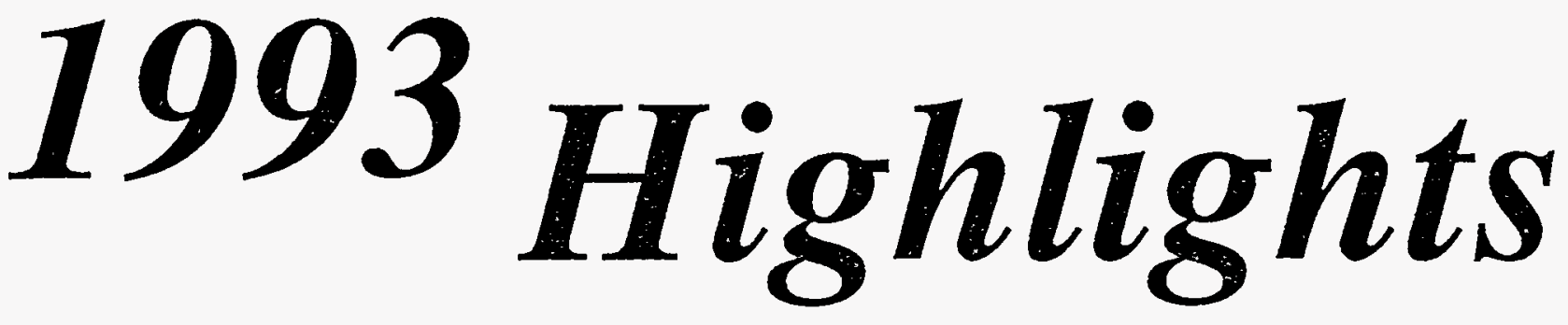

The Rocky Flats Plant Site Environmental Report is developed each year as a means of informing the Department of Energy, federal and state regulatory agencies, and the public, of environmental activities performed at the Rocky Flats Plant. The report provides detailed technical data on environmental monitoring and remediation programs, resulting in an overall insight on the impact that those activities have on the environment and on public health.

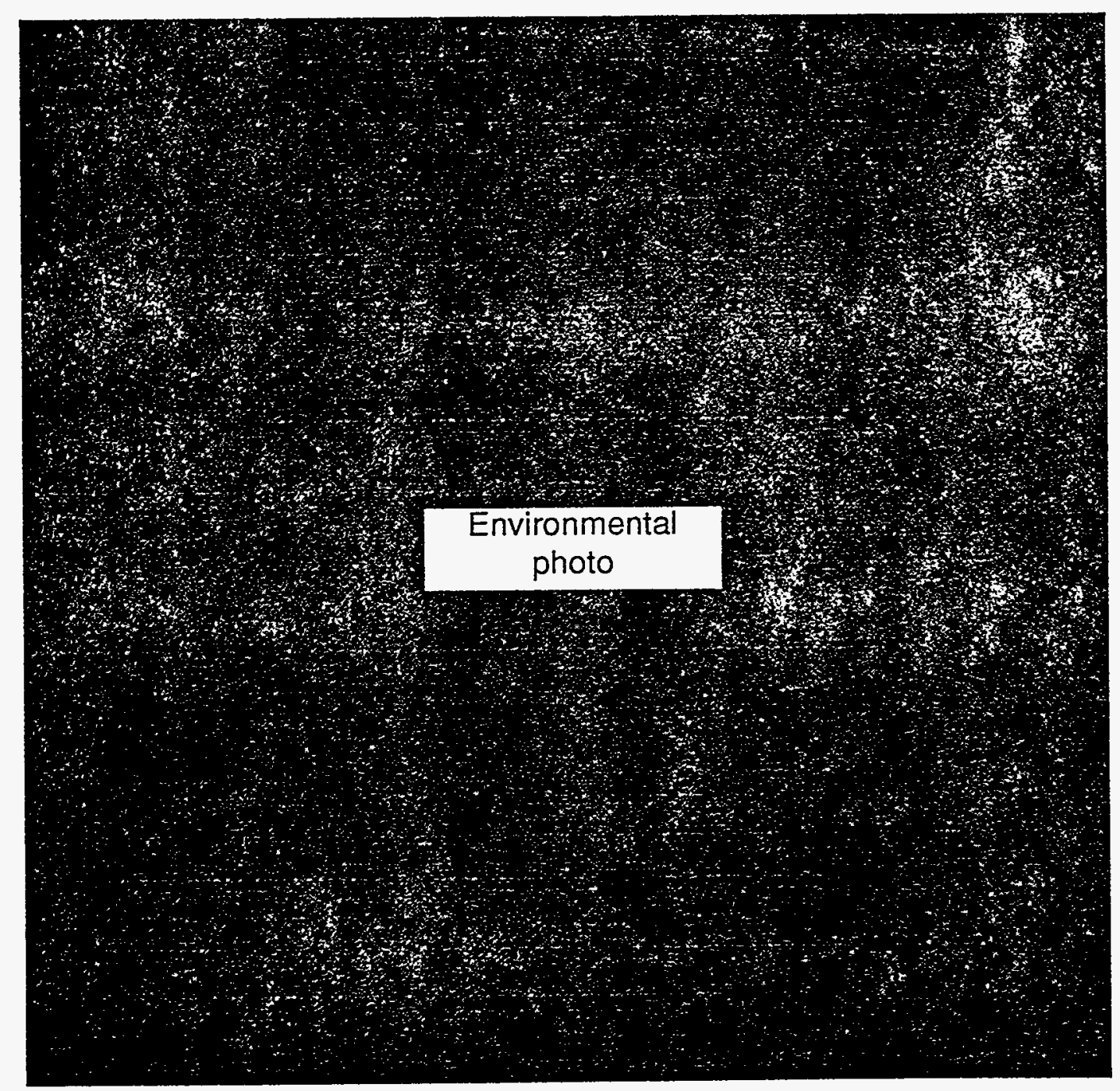




\section{The Rocky Flats Plant}

\section{at a glance...}

O Built in 1951, began operations in 1952.

O Owned by the Department of Energy as one of several historically constructed production plants in the weapons complex.

L Located 16 miles northwest of Denver, Colorado, on 6,550 acres in northern Jefferson County.

O Situated within a 50-mile radius of approximately 2.1 million people.

O Curtailed many production activities in 1989.

O Operated by $E G \& G$, Inc., as of January 1990.

$O$ Began new mission of environmental restoration, waste management, decontamination and decommissioning, and economic development in January 1992.

O Employed 6,512 persons as of December 1993.

The historical mission of the Rocky Flats Plant has been to develop and fabricate nuclear weapons components from radioactive and nonradioactive materials. Its manufacturing and production activities were crucial to the nation's nuclear weapons defense system. The plant was responsible for fabricating plutonium, uranium, beryllium, and stainless steel. Primary production activities included metal fabrication and assembly, metal recovery and purification of nuclear materials, and related quality and environmental control functions.

This mission changed in January 1992 when President Bush announced that certain planned weapons systems had been canceled. Rocky Flats no longer produces nuclear weapons components and is now in transition to a new mission focusing on environmental restoration, waste management, decontamination and decommissioning, and economic development. Primary objectives of this new mission include achieving and maintaining compliance with applicable restoration schedules and environmental laws and regulations, including multi-party agreements.

Historically, Rocky Flats managed both radioactive and potentially hazardous chemical materials, including acids, bases, industrial solvents, machining lubricants, and nonradioactive materials such as beryllium. Many of these materials will continue to be managed at Rocky Flats during the plant's transition phase 


\section{DISCLAIMER}

This report was prepared as an account of work sponsored by an agency of the United States Government. Neither the United States Government nor any agency thereof, nor any of their employees, make any warranty, express or implied, or assumes any legal liability or responsibility for the accuracy, completeness, or usefulness of any information, apparatus, product, or process disclosed, or represents that its use would not infringe privately owned rights. Reference herein to any specific commercial product, process, or service by trade name, trademark, manufacturer, or otherwise does not necessarily constitute or imply its endorsement, recommendation, or favoring by the United States Government or any agency thereof. The views and opinions of authors expressed herein do not necessarily state or reflect those of the United States Government or any agency thereof. 


\section{DISCLAIMER}

\section{Portions of this document may be illegible in electronic image products. Images are produced from the best available original document.}


and throughout the decontamination and decommissioning process. A comprehensive environmental protection program is in place to ensure that these materials are managed safely with minimal impact to worker and public health and the environment.

Included in this program is monitoring of air, soil, and water for radioactive and

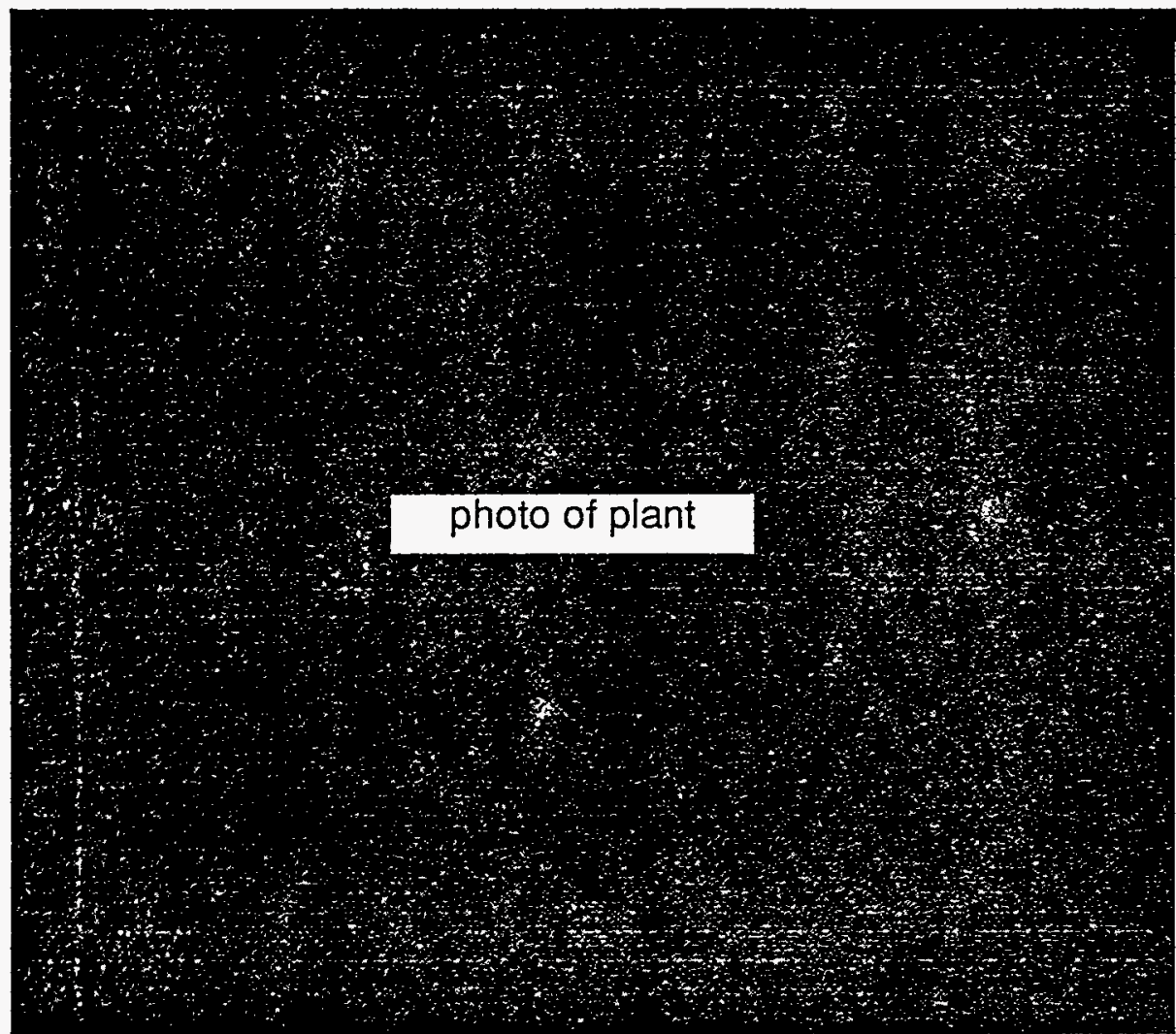

hazardous materials at onsite locations, at the plant boundary, and in surrounding communities.

Additional independent monitoring is performed by outside Department of Energy agencies, the U.S.

Environmental Protection Agency, the Colorado Department of Health, and nearby communities. Data collected as part of this monitoring have been reported in monthly public meetings since the early

1970's and in numerous public documents, including the Rocky Flats Plant Site Environmental Report.

Rocky Flats Plant monitoring programs satisfy multiple objectives. Monitoring serves as a check on the protective measures and engineered controls in place at Rocky Flats, measuring the effectiveness of those controls to isolate hazardous and radioactive materials from employees, the public, and the environment.

Monitoring also supports regulatory compliance issues, demonstrating that plant operations are performed in accordance with the requirements of federal and state environmental laws and Department of Energy Orders. 


\section{Laws and Regulations Protect the Environment}

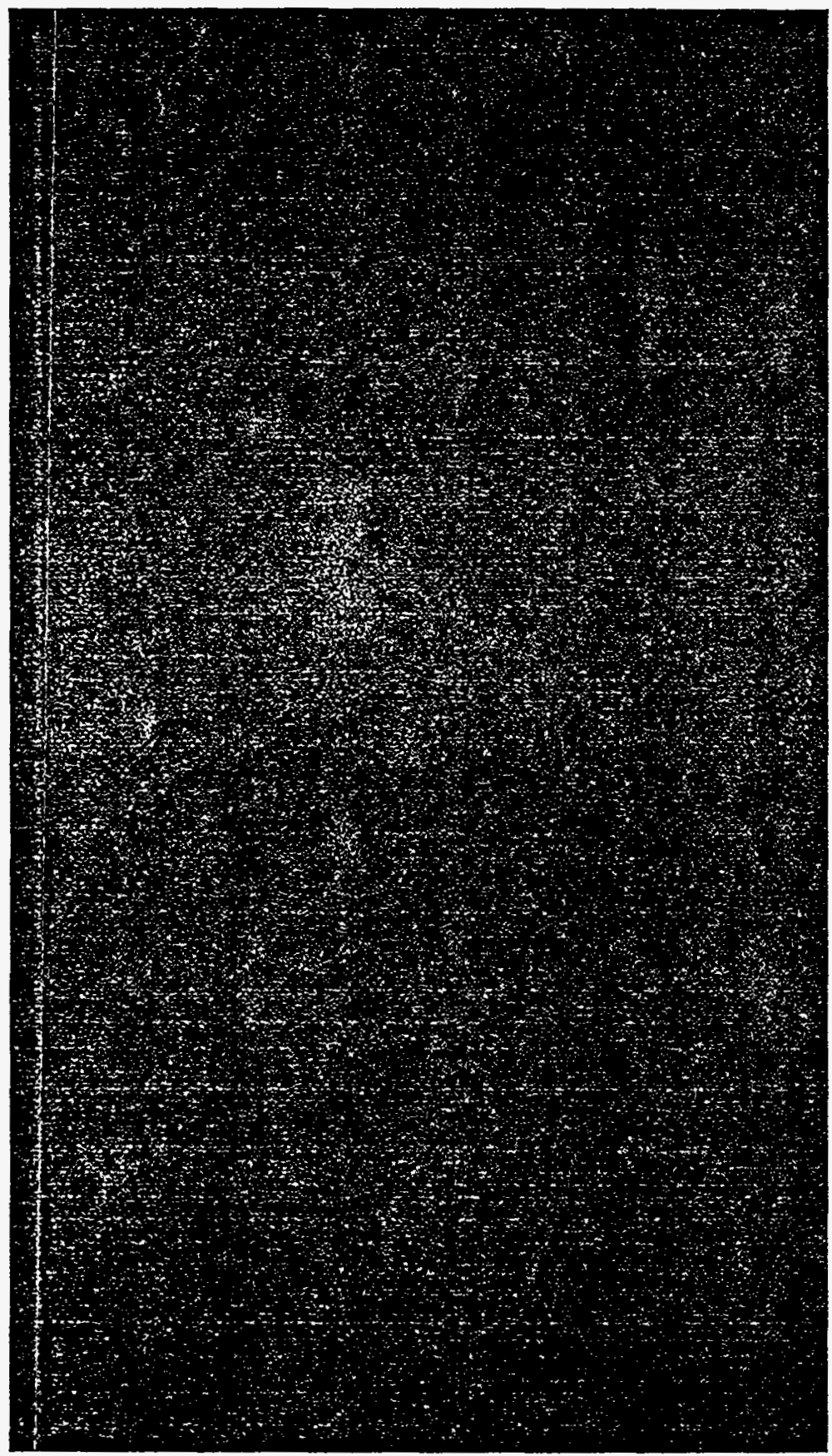

Increasing public awareness and environmental concern in recent years prompted Congress to pass increasingly stringent laws aimed at protecting the environment. In 1986 Rocky Flats became the first federal facility in the nation to accept state oversight when the Department of Energy, Environmental Protection Agency, and Colorado Department of Health signed an historic Resource Conservation Recovery Act/Comprehensive Environmental Response, Compensation and Liability Act (RCRA/CERCLA) compliance agreement, which gave the state authority to regulate hazardous components of Rocky Flats waste. The philosophy of environmental compliance at Rocky Flats is, quite simply, to comply fully with all environmental rules and regulations, while protecting employee and public health and the environment. 


\section{LAWS}

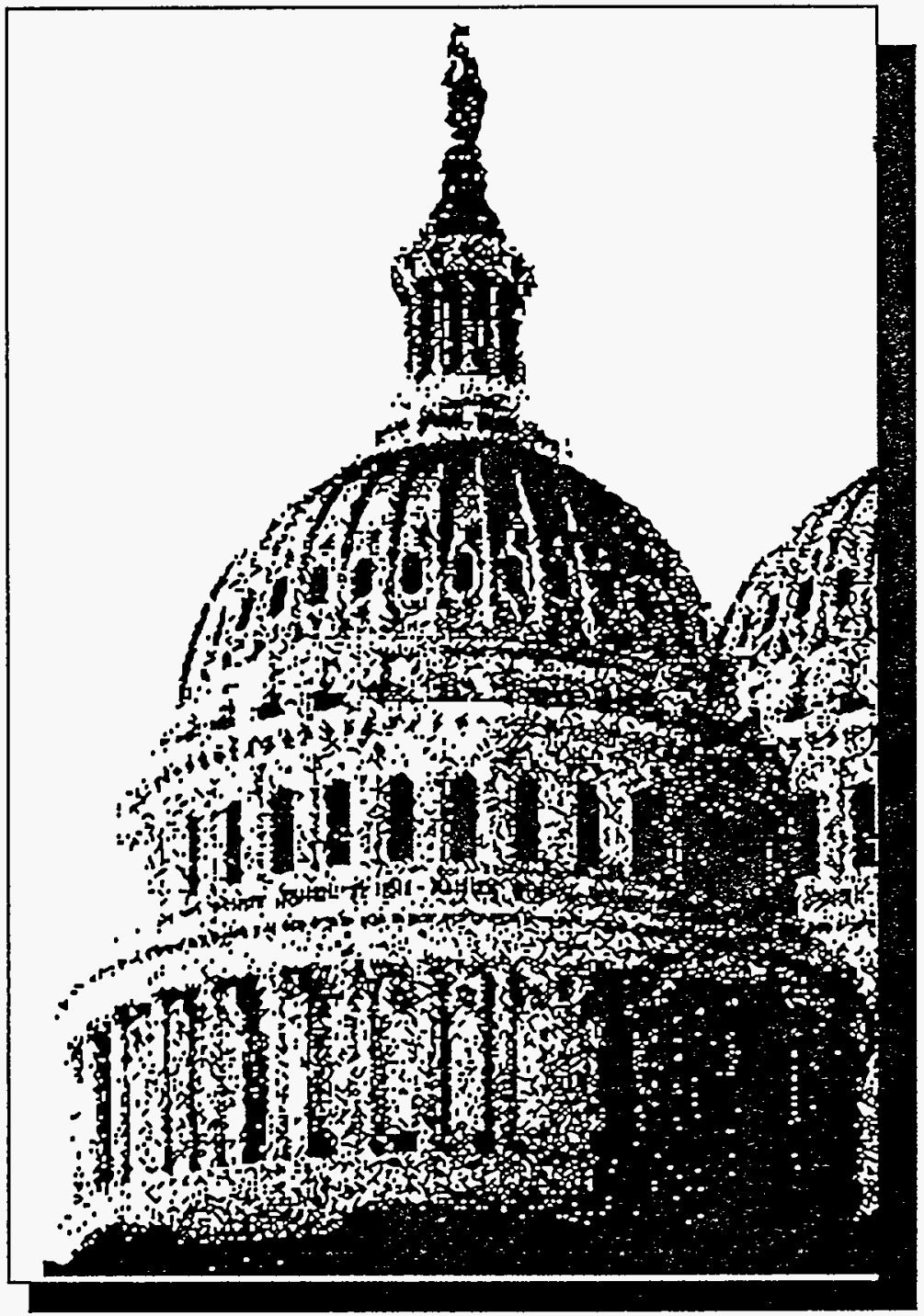

Rocky Flats Plant is committed to ensuring compliance with federal, state, and local environmental laws, Department of Energy 'Orders, various agreements, and consent decrees that protect the environment and public health. All these laws, orders, and agreements mandate specific actions. The following list presents major federal laws that apply to the plant.

Clean Air Act

Clean Water Act

Resource Conservation and Recovery Act

Emergency Planning and Community Right-to-Know Act

- Federal Insecticide, Fungicide, and Rodenticide Act

National Environmental Policy Act

Toxic Substances Control Act

Comprehensive Environmental

Response, Compensation, and Liability Act

Safe Drinking Water Act

Hazardous and Solid Waste Amendments

Endangered Species Act

Migratory Bird Treaty Act

Fish and Wildlife Coordination Act

Bald and Golden Eagle Protection Act

Compliance with Floodplain/ Wetlands Environmental Review Requirements (10CFR1022) 


\section{Understanding Radiation}

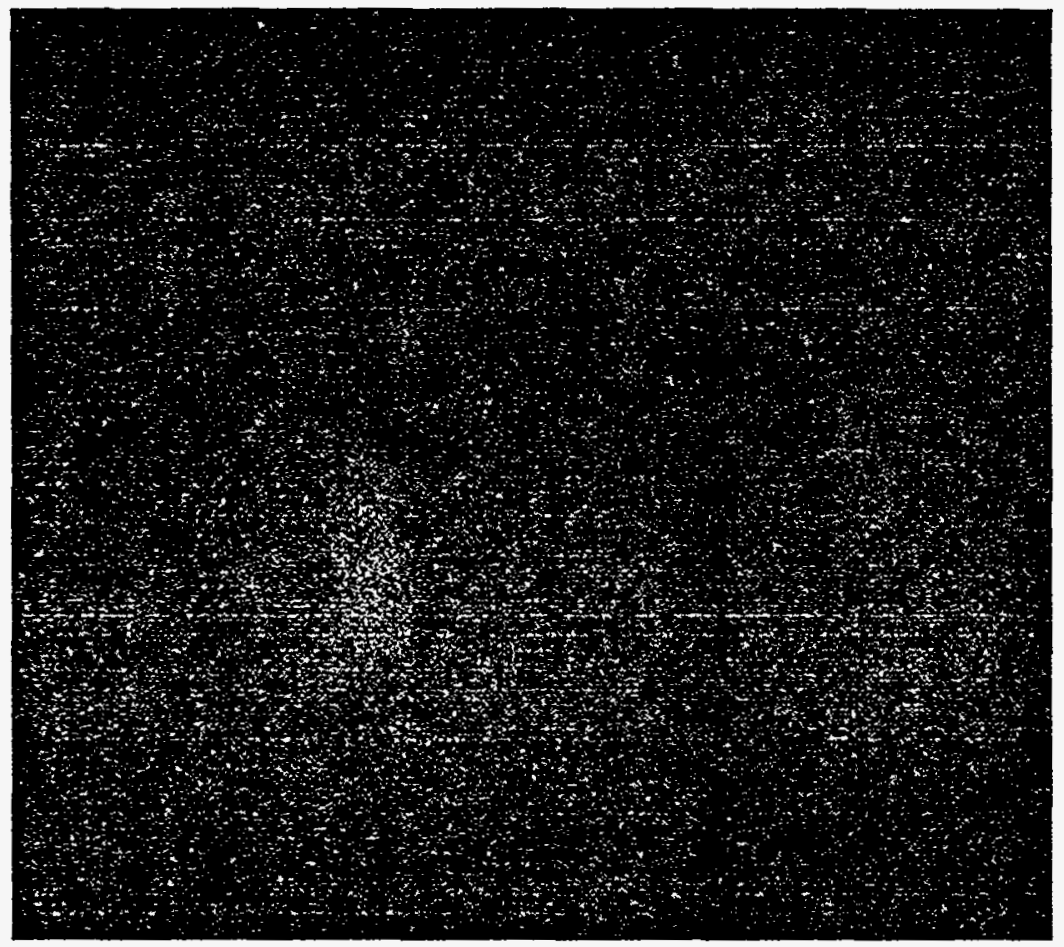

To better understand the safeguards in place at Rocky Flats to protect employees, the public, and the environment, a basic understanding of radiation is useful. The term "radiation" can include heat, sound, and visible light. Radiation exists naturally, in the form of cosmic radiation from space, from naturally occurring radioactive materials in soil and building materials, and from naturally occurring radioactive materials in food and air. Even some atoms in the human body are radioactive. In

addition to natural sources of radiation, artificially produced sources are part of everyday life. These sources include medical $x$ rays and equipment used in the diagnosis and treatment of diseases; consumer products such as smoke detectors, tobacco products, and fertilizers; industrial sources such as industrial $\mathrm{x}$-ray equipment and soil moisture and density meters; nuclear reactors; and defense-related manufacturing. 
Radioactive elements such as plutonium, uranium, radium, and thorium share an important quality: they are unstable. Unstable atoms attempt to become stable by getting rid of unwanted particles and/or energy. As these particles are ejected, invisible energy called ionizing radiation is released. Ionizing radiation has enough energy to separate electrons from atoms of material. It can change the chemical composition of atoms that it strikes, causing them to become electrically charged or "ionized." In some circumstances, the presence of such ions can disrupt normal biological processes and can present a health hazard to humans.

Common types of ionizing radiation are alpha particles, beta particles, $x$ rays, and gamma rays. The main potential radiation hazard to the public associated with materials handled at the plant is from alpha radiation, which is primarily an internal hazard -- the radioactive material itself must get inside the body and be in direct contact with living tissues for the alpha radiation to cause damage. Radioactive material may enter the body through such pathways as inhalation, ingestion, or a wound in the skin.

Rocky Flats Plant's environmental protection program is well suited for minimizing any releases of radioactive materials to the environment and for monitoring environmental pathways by which inhalation or ingestion might occur. Radioactivity concentrations are measured in air, water, and soil at numerous plantsite locations. Penetrating gamma radiation is also monitored at several locations, even though this gamma radiation is not an important component of the materials handled at the plant.

Alpha particles are the slowest of the three types of ionizing radiation. Despite a speed of approximately 10,000 miles per second, they can only travel a few centimeters in the air. Alpha particles lose their energy almost as soon as they collide with anything, and can easily be stopped by a sheet of paper or human skin tissue.

Beta particles are much smaller than alpha particles. With a speed of up to 100,000 miles per second, they can travel in the air for a distance of approximately 10 feet. Beta particles can pass through a sheet of paper, but can be stopped by a thin sheet of aluminum or glass.

\section{$X$ rays and Gamma rays} are waves of pure energy and travel at the speed of light (186,000 miles per second). $X$ rays and gamma rays are penetrating and require a thick wall of concrete, lead, or steel to stop them. 


\section{Monitoring Our Environment}

At Rocky Flats, we monitor the environment to reduce and, where practical, eliminate the release of radioactive and nonradioactive hazardous materials, and to enhance and restore the environment in and around the plant. Routine reports to local, state, and federal agencies and to the public provide information on how these programs perform in maintaining and improving environmental quality. Specific monitoring programs generate this information.

\section{We Examine the Air}

\section{at a glance...}

Air monitoring measures radiological and nonradiological air emissions from individual buildings and specific plant locations and in the surrounding communities.

Air monitoring has been expanded and upgraded through the years to meet current state and federal requirements.

Air monitoring programs provide information to protect the health of plant workers and the general public, and to demonstrate compliance with state and federal air quality regulations.

Just What Is the Difference Between Effluent and Ambient Air?

When we speak about air, the term "effluent" refers to air that flows from a source out into the environment. The term "ambient" means the air that exists in the surrounding environment.

At Rocky Flats, the air effluent control program actually begins in buildings where radioactive materials are handled. These buildings contain ventilation and filtration systems that constantly filter the air before it leaves the building; at the same time, monitoring equipment samples releases, if any, to the environment. 
Plutonium, uranium, and americium, the primary radioactive materials managed at Rocky Flats, are in a solid form. As a result, filtration is an effective way to control the release of materials into the environment. Radioactive particles from sealed glovebox systems enter exhaust air streams where the particles are removed by High Efficiency Particulate Air filters. These fire- and chemical-resistant filters must meet strict construction and performance standards before they are accepted for use. Upon arrival at the plant, filters are tested to ensure a minimum efficiency

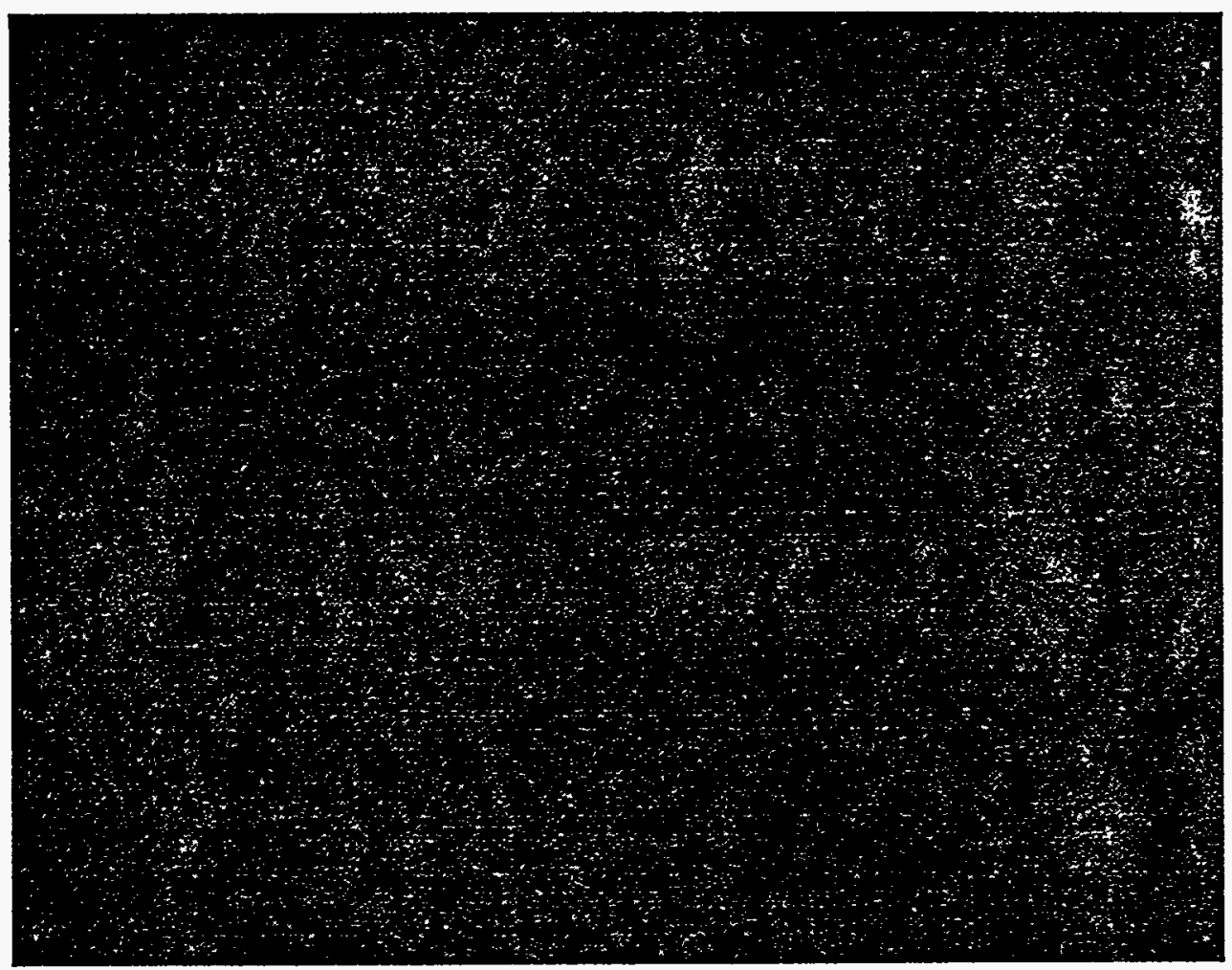

of 99.97 percent for all particle sizes.

After installation, filters are tested again for leaks that may have developed during installation. Multiple banks of filters, called filter plenums, are installed in air exhaust systems. In general, plutonium processing exhaust systems are equipped with four to six stages of filter banks; uranium

Radioactive materials at the Rocky Flats Plant are handled in sealed glovebox systems (pictured above) to isolate the material from the environment and to protect employees from unnecessary exposure to radiation. The atmosphere within the glovebox system enters exhaust air streams where particulate materials are removed by highly efficient filters. processing exhaust systems are equipped with a minimum of two stages of filter banks.

Air emissions are continuously monitored at 63 emission points in 17 buildings. Selective Alpha Air Monitors, sensitive to specific alpha particles and set to detect plutonium-239 and -240 , can provide immediate detection of abnormal conditions in plutonium-handling facilities. These detectors are subject to daily operational checks, monthly performance testing and calibration for airflow, and an annual radioactive source calibration for sensitivity and reliability. Monitors are set up to alarm automatically at the detector location, at the Radiation Monitoring office, and at selected Utilities offices if an out-of-tolerance condition were to occur. No such condition occurred during 1993. 
Rocky Flats stopped its main plutonium recovery activities in September 1989. Since then, overall radionuclide emissions from the plant have decreased and have continued to decrease during 1993. Following are the results of effluent air monitoring efforts for radioactive materials for 1993; some values are represented in units called microcuries, and others are represented in curies or grams. "Micro" is a prefix representing one-millionth, and a curie is a unit of activity of radioactive substances. These results are well below all allowable concentration guides.

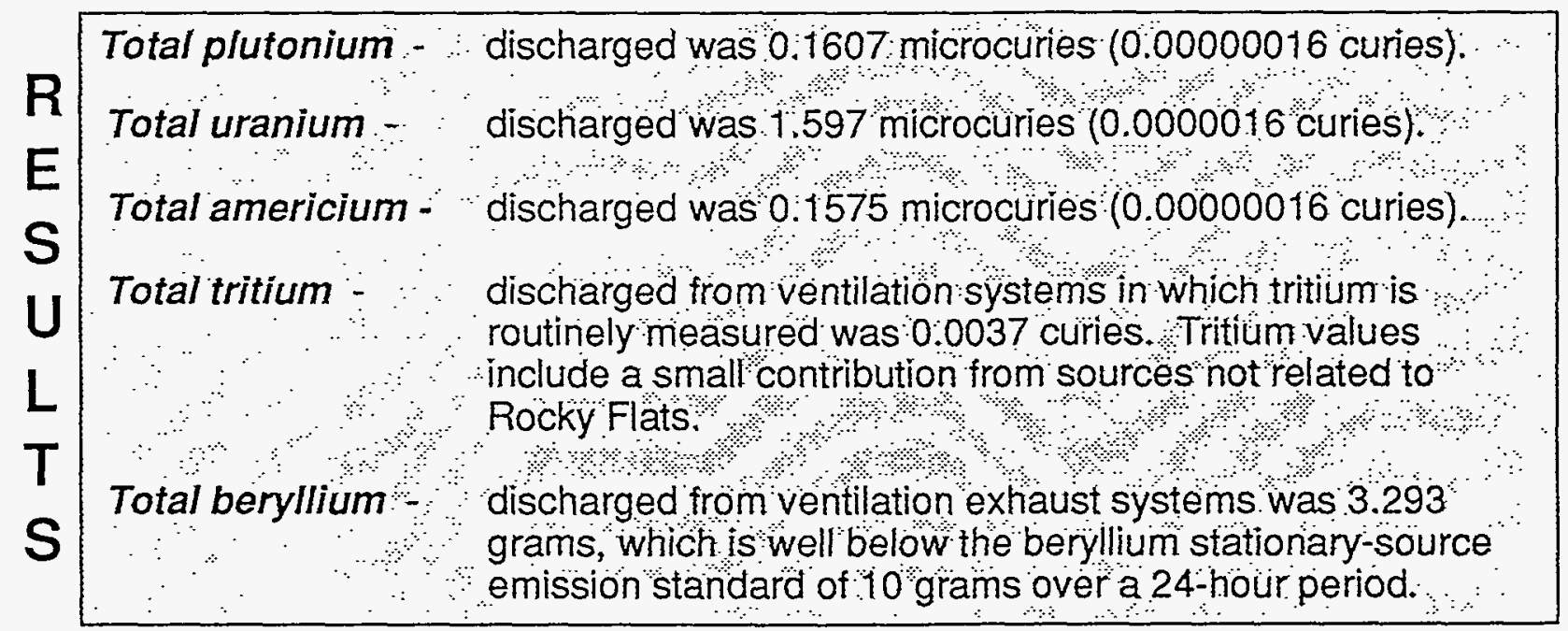

In addition to effluent sampling from individual buildings, Rocky Flats also performs monitoring of ambient air. This includes sampling for nonradioactive as well as for radioactive materials. 


\section{Monitoring Ambient Air for Radioactive Materials}

Ambient air samplers located on the plantsite, at the plant perimeter, and in surrounding communities measure plutonium air particles that may originate from plantsite. These samplers are positioned at 21 locations on the plantsite, at 14 locations around the plant boundary, and in 11 neighboring communities. The Colorado Department of Health also maintains an independent sampling network with a different instrument design in and around the plantsite to verify the Rocky Flats data. Ambient air filters are collected biweekly and composited monthly by location before analysis. All routine ambient air filters are analyzed for plutonium-239 and -240 .

Following are the 1993 overall average plutonium concentrations for samplers at the plant and in surrounding communities. So that these values are easier to understand, concentrations are expressed in percentages of the offsite Derived Concentration Guide (DCG) for plutonium in air. DCGs are defined on page 12.

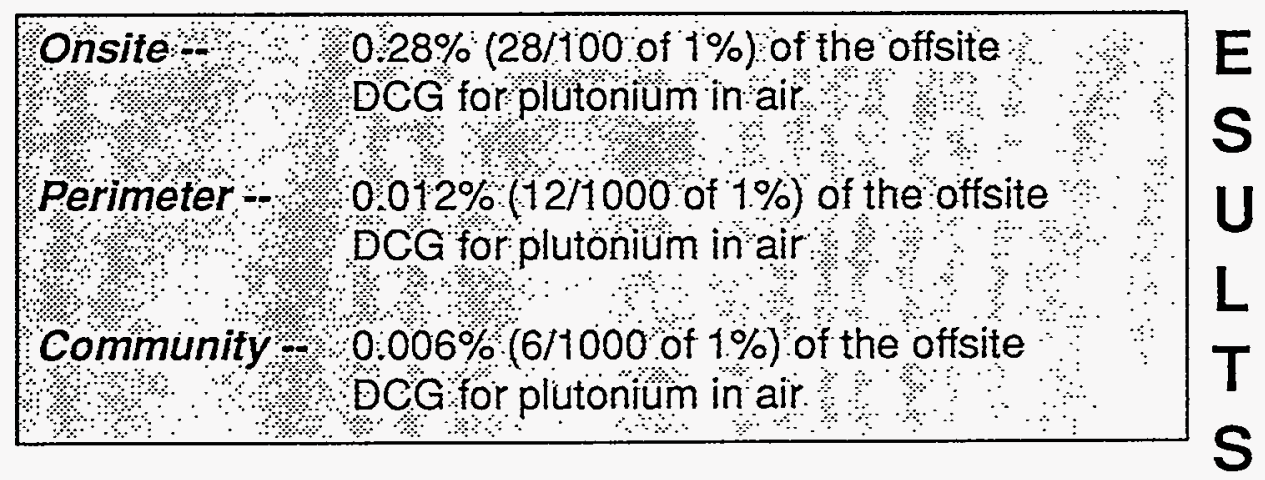

Typically, plutonium air concentrations at the plant perimeter locations are not measurably different from background plutonium air concentrations at more distant communities. These more distant locations generally would not be affected by Rocky Flats Plant. 
Nonradioactive ambient particulates, such as dust particles in the air, are regulated by the Colorado Department of Health and the Environmental Protection Agency. Results of Rocky Flats sampling of nonradioactive particulates conducted during 1993 showed that these concentrations were below applicable standards.

Nonradioactive ambient air monitoring at the plant provides baseline information on amounts of distinct particles in the air.

Employees monitor nonradioactive ambient air with both TSP and PM-10 samplers. TSP, or Total Suspended Particulates, refers to total particles, and PM-10 refers only to particles that are smaller than 10 micrometers in diameter.

These smaller PM-10 particles are of special interest because they are more likely to be retained in the deep regions of the lungs, where greater damage to lung tissue could occur.
Radiation Dose is a way to express the amount of damage or risk of ionizing radiation. The primary standards for protection of the public from radiation are based on radiation dose; it is a calculated value and the commonly used unit of measure is the rem, or the millirem (1 $\mathrm{rem}=1,000$ millirem). Radiation protection standards for the public are based on 1 year's exposure to radioactive materials.

Dose Equivalent is a way to calculate radiation dose that accounts for the differences in the biological damage caused by different types of radiation (for example, alpha, beta, or gamma).

\section{Effective Dose Equivalent (EDE)} is a way of calculating radiation dose that allows comparisons of health risk from exposures of different types of radiation to different body organs. The health risk is based primarily on cancer mortality. As a result of this method of calculation, 1 millirem EDE from natural background radiation would have the same health risk as 1 millirem EDE from an artificially produced source of radiation.

Derived Concentration Guides $(D C G s)$ are guides provided by the Department of Energy and are used as comparison values for measured radioactivity concentrations. DCGs are concentrations that would result in an effective dose equivalent of 100 millirem from 1 year's chronic exposure or intake. 


\section{Monitoring Ambient Air for Nonradioactive Materials}

Following are the results of ambient air monitoring efforts for nonradioactive materials for 1993.

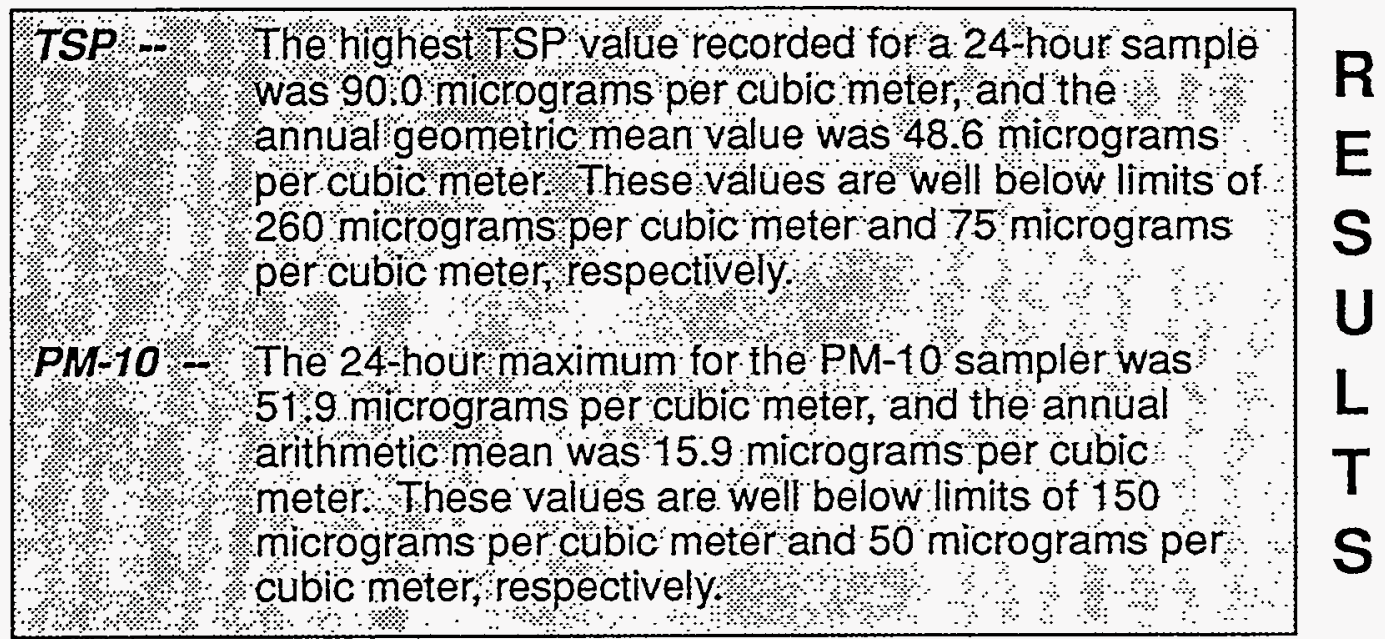

\section{Involving Local Communities}

The Community Radiation Monitoring program, called ComRad, is a joint effort of the Department of Energy, EG\&G Rocky Flats, Inc., and local communities. ComRad involves citizen-operated environmental air surveillance stations located in various communities that surround the plant. Each ComRad station consists of equipment to sample the air and measure environmental radiation exposure levels. This program resulted in an increase in public awareness and improved communication with the communities.

\section{the bottom line . . .}

Distinct protective measures and controls are in place at Rocky Flats to minimize any release of radioactive or hazardous material to the environment.

O All monitored substances in 1993 were far below any action limits or safety standards.

Plutonium production operations that were curtailed in late 1989 resulted in reduced production activities and the overall decrease in radionuclide emissions. 


\section{$\checkmark$ We Examine the Surface Water}

\section{at a glance...}

$\bigcirc \quad$ Rocky Flats monitors and controls 12 ponds located on the plantsite. These ponds provide protection in case of a spill or unexpected release of a controlled or hazardous material (or excessive water because of a major storm).

Surface water quality testing programs look for over 330 different elements, industrial chemicals, radioactive components, inorganic elements, and organic compounds.

Surface waters at the plant are analyzed to ensure that water quality standards are met, to describe background water quality, to evaluate potential contaminant releases, and to comply with monitoring requirements of regulations, permits, and agreements.

Water that originates from Rocky Flats is carefully controlled and monitored as part of the plant's environmental protection program. Two types of water, treated sanitary waste water from places such as drinking fountains and cafeterias, and surfacewater runoff originating from rainfall and snow melt, are collected, controlled, and monitored in a series of ponds before being discharged offsite by pipeline to the Broomfield Diversion Ditch and around Standley Lake. Water used in processing operations is not released to the environment but is recycled or reprocessed as required. 
The sampling and release of surface and sanitary waters are regulated under an Environmental Protection Agency Region VIII National Pollutant

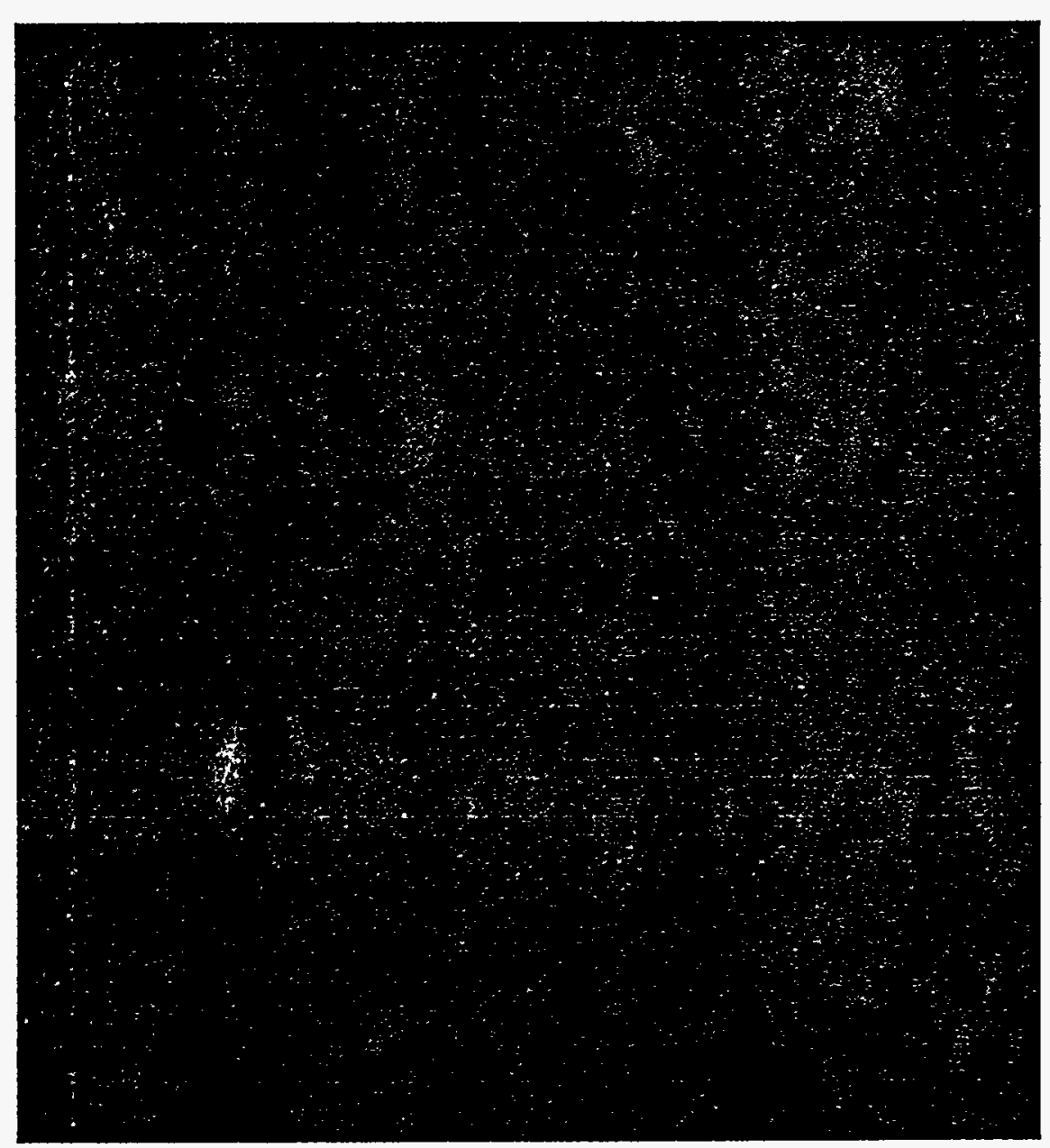

Discharge Elimination System permit program. Before discharge from holding ponds, samples are collected and split between the Colorado Department of Health, and EG\&G Rocky Flats or subcontracted laboratories. In addition, water quality is tested before release to ensure that the water meets standards established by the Colorado Water Quality Control Commission. This commission's standards imposed on drainages at and downstream from Rocky Flats are more stringent than the standards imposed on Denver tap water.

Of the local water supplies, only Great Western Reservoir, formerly a drinking water supply for the city of Broomfield, and Standley Lake, a drinking water supply for the cities of Westminster, Northglenn, Federal Heights,

A series of holding ponds (shown above) help control surface-water runoff at the Rocky Flats Plant. and Thornton, have the potential to receive runoff from Rocky Flats drainage systems. Water diversion projects have been in place since 1989 to divert Rocky Flats discharges around those reservoirs. 
Surface-water monitoring is divided among the following five programs.

Regulatory Compliance Monitoring of discharges for chemical, biological, and radioactive parameters.

Routine Operational Monitoring to identify the quality of water that flows from source areas and eventually discharges to Walnut Creek and Woman Creek.

Sitewide Surface-Water Monitoring of springs and drainages within the plantsite.

Sitewide Storm-Event Monitoring of surface-water quality during times of precipitation.

Sediment Sampling within Rocky Flats to determine source areas of contaminants.

Water sampling has historically gone beyond Rocky Flats' boundary and included analyses of tap water in nearby communities and annual background samples from Ralston, Dillon, and Boulder reservoirs, at distances ranging from 1 to 60 miles from the plant. Samples were collected from reservoirs to determine background levels for plutonium, uranium, americium, and tritium in water.

Beginning on October 1, 1992, sampling at offsite locations was discontinued. It was determined that sampling at these offsite locations was no longer needed because there were no regulatory requirements for the program, and enough historical data were already available. Typically, concentrations of radioactive materials in water discharged from Rocky Flats have been at or near the concentrations of radioactive materials that are generally found in these reservoirs. 
Following are results of surface-water sampling for 1993.

Pjutonium, uranium, and americium concentrations for terminal ponds samples was $0: 24 \%$ or less of the derived concentration guide (DCG) For water, calculation of DCG assumes that the exposed individual ingests 730 liters of water per year at the specified radioactivity $(100 \% \mathrm{DCG})$ with a resulting dose of $01 \mathrm{rem}(100 \mathrm{mrem})$ effective dose equilivalent (EDE)

A verage tritium concentration in the terminal ponds samples was $11 \times 109: \mathrm{uci} / \mathrm{ml}$ T The DOE DCG fortritium in water available to members of the public is $2,000,000 \times 10^{9} \mathrm{ici} / \mathrm{ml}$.

\section{the bottom line ...}

$\bigcirc$ Concentrations of plutonium, uranium, americium, and tritium in water samples from the outfalls of onsite holding ponds and from Walnut Creek at Indiana Street were less than $0.24 \%$ (24/1000 of 1\%) of the applicable guides set by the DOE. 


\section{$\checkmark$ We Examine the Groundwater}

Groundwater monitoring for radioactivity has been ongoing since the first monitoring wells were installed at Rocky Flats in 1960. Since then, new wells have been added, and old wells abandoned and replaced, as the program was expanded. Monitoring is done to provide information on the presence, extent, and transport of contaminated groundwater; to provide data for evaluating trends, site characterization, and treatability studies; to provide data to government agencies and surrounding communities; and to maintain a database of analytical results. To

\section{at a glance...}

Through sampling the groundwater, Rocky Flats is able to evaluate the impact of plant operations and thereby limit activities that might have an adverse effect on the quality of groundwater in the area.

Major federal regulations specify actions to be followed in the groundwater monitoring program.

Since 1985, Rocky Flats groundwater wells have been sampled for certain substances that easily evaporate called volatile organic compounds (VOCs), trace metals, and major ions (which are electrically charged atoms or groups of atoms), as well as for radioactive elements. "characterize" ground-

water means to describe its attributes.

Characterization is done to identify distinct geological layers that contain water, evaluate groundwater pathways and migration tendencies, learn about the relationships between groundwater and surface water, and help determine concentrations of elements of concern that already exist in the environment.

By the end of 1993, the groundwater monitoring program included

approximately 676 wells, of which some 430 are sampled regularly.

Approximately 150 new wells were installed during 1993. Much of the monitoring is done to satisfy RCRA/CERCLA and plant protection guidelines for monitoring groundwater at hazardous waste sites. Groundwater investigation and restoration follow a five-phase approach to identify contamination, design and implement treatment procedures, and observe restoration efforts within specific areas called Operable Units. Past contamination areas have been grouped into 16 Operable Units based on cleanup priorities, waste types, and locations. 


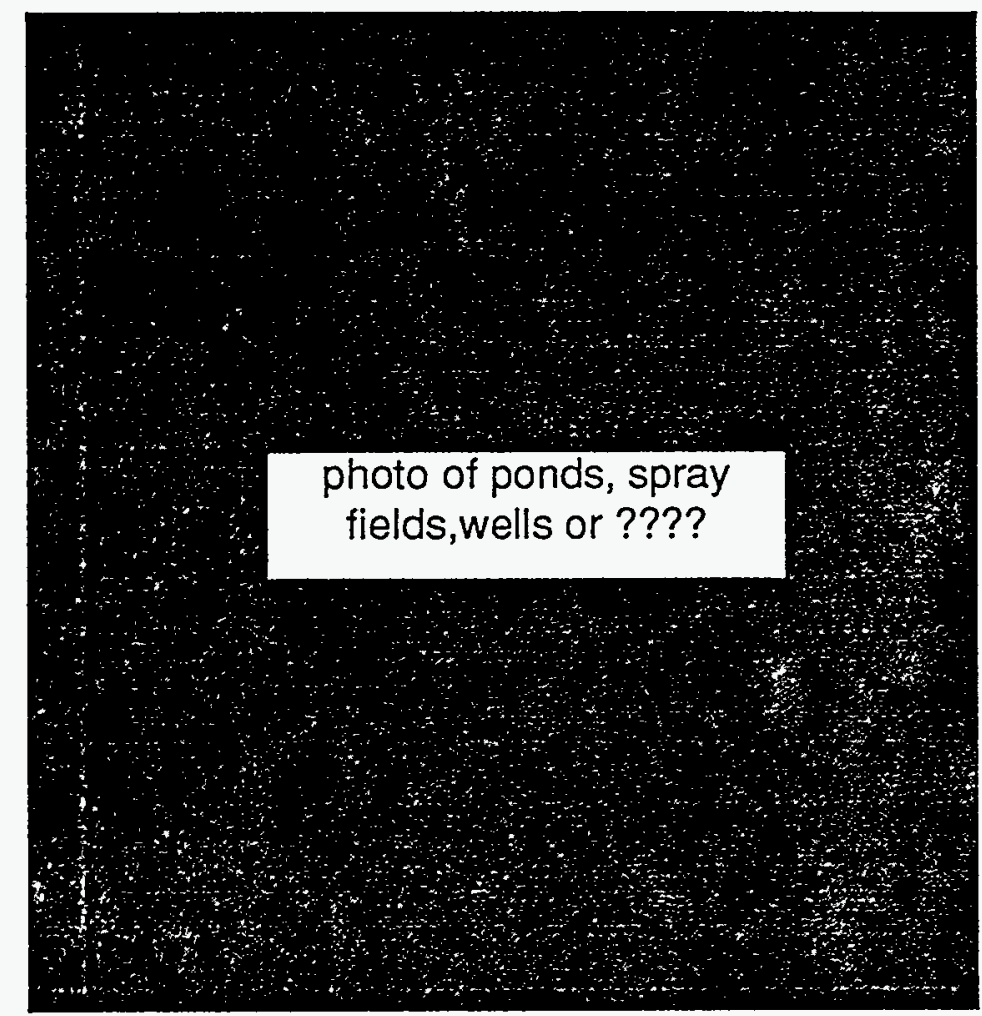

Samples have been analyzed for radioactivity since the beginning of the groundwater monitoring program. Analysis for chemical contaminants occurred in 1974, 1979, and 1985. In the mid-1980s, sampling for chemical contaminants was increased because of newer federal regulations. The monitoring program detected contaminants in shallow groundwater within certain Operable Units, including the 881 Hillside Area, 903 Pad, Mound, and East Trenches Areas, the Solar Evaporation Ponds, Present Landfill, and West Spray Field. In most cases, the contaminants of concern are associated with VOCs, which include chemical products previously used as cleaning and degreasing solvents. Inorganics, dissolved metals, and some radionuclides also have been detected in localized areas.

\section{the bottom line...}

There is no indication of plant contamination of any offsite groundwater drinking water supply.

Migration studies performed in the past have estimated that it could take 40 to 80 years for groundwater contaminants to reach the plant boundary. Meanwhile, ongoing environmental restoration activities will deal with the sources of the contamination.

At the present time, there is no indication that a groundwater pathway exists through which contamination can leave the plant and migrate directly offsite into any of the deep layers of rock under the Denver area. 


\section{$\checkmark$ We Examine the Soil}

The soil monitoring program determines the extent of plutonium and americium in soils at Rocky Flats, studies the physical and chemical association of plutonium and americium in soils, and studies the movement of water and radioactive elements down the soil column.

\section{at a glance...}

Soil contamination is highest east and southeast from the temporary storage area (903 Pad)

The soil monitoring program involves yearly soil sampling at 40 sites located on concentric circles approximately 1 and 2 miles from the center of Rocky Flats Plant.

P Plutonium concentrations might change as a result of soil being airlifted by winds or other means of transport. Soil is monitored to evaluate these changes and to compare plutonium concentrations in soils. where steel drums were used to store plutonium-contaminated industrial oils from 1958 to 1968 . Some plutonium particles entrapped in the fine fraction of top soil were airlifted by winds and deposited on soils in an east-southeast direction.

Soils were sampled in

December 1993 at 40 sites located at approximately 1- and 2-mile radii from the center of the plant. Laboratory analysis was performed to determine plutonium concentration, expressed in units of $\mathrm{pCi} / \mathrm{g}$ (picocuries per gram). The highest plutonium concentrations were found in soil samples from the eastern portion of the Rocky Flats Buffer Zone, which is the area between the central facility security fence and the plant boundary perimeter fence. 


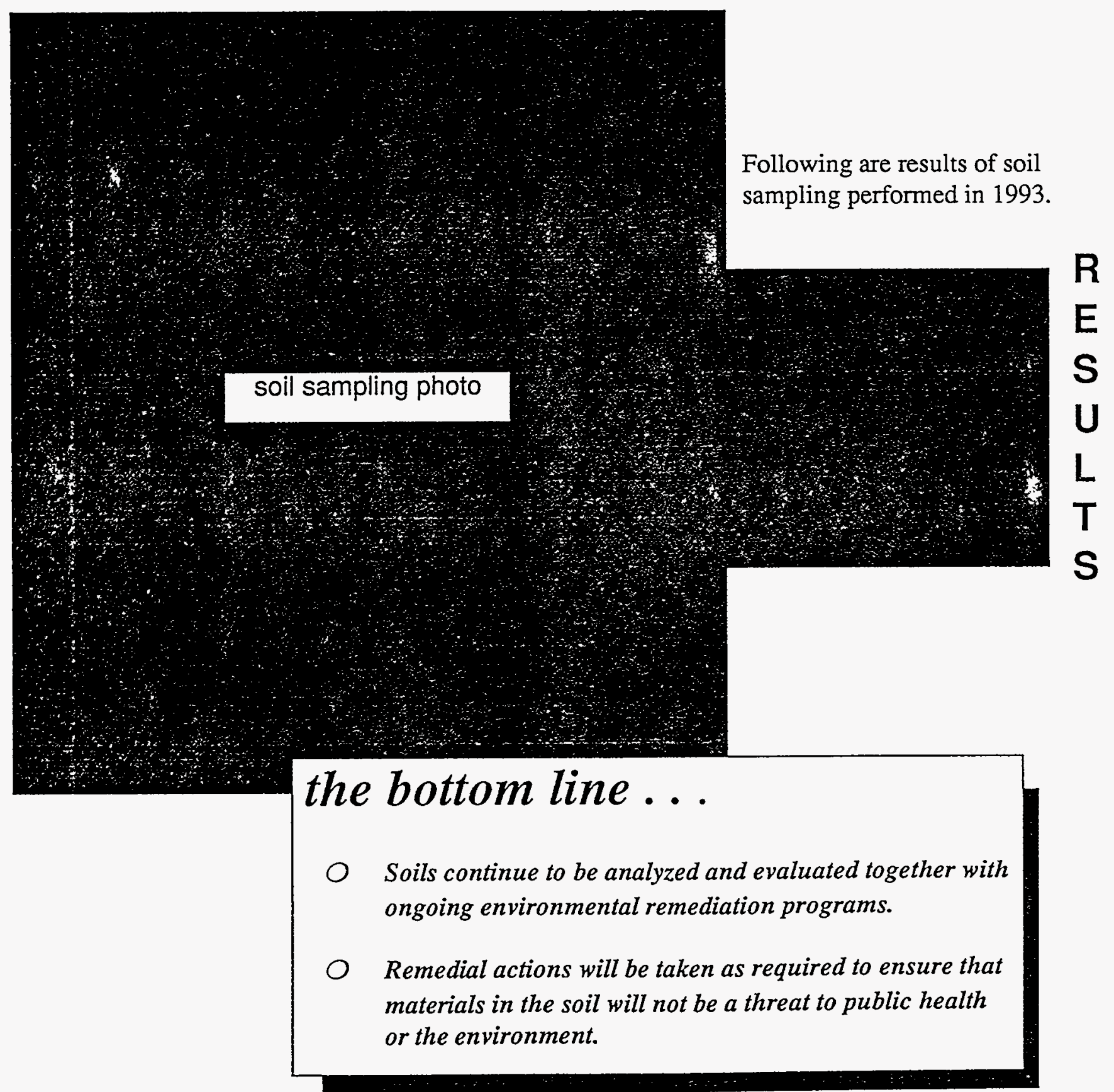


We Monitor the Weather

at a glance...

Weather information is routinely collected at Rocky Flats to strengthen the environmental monitoring program and for emergency situations.

Data collected are used to help analyze surface water and groundwater transport.

Daytime winds at the plant most frequently blow from the northeast and southeast sectors; nighttime winds blow from the southwest and northwest sectors.

The main purpose of the meteorological monitoring program is to provide information to help assess the transport, dispersion, and deposition of pollutants actually or potentially released into the atmosphere by plant operations. This in turn helps to protect the health and safety of the public, employees, and the environment. Meteorological information is necessary for developing site-specific weather forecasts.

Meteorological data are also used to analyze the climate surrounding the plant for studies dealing with the waters of the earth and its atmosphere, for construction activities, and for various engineering studies. 
In the event of an emergency situation, the plant's Emergency Operations Center can be activated to coordinate response activities. Weather data could be used to track the direction and potential impact of any release to the environment.

Meteorological data are routinely collected from instruments installed on a 200 -foot tower approximately 6,140 feet above sea level and located west of the main facilities area (pictured at right). This tower has instruments at three different heights, where measurements are taken of horizontal wind speed and direction, vertical wind speed, and ambient air temperature. Dew point temperature is measured at the 33-foot level, and solar radiation is measured at 5 feet above the ground surface. A 33-foot tower is located near the 200-foot tower to provide backup data if monitoring fails at the 200 -foot tower.

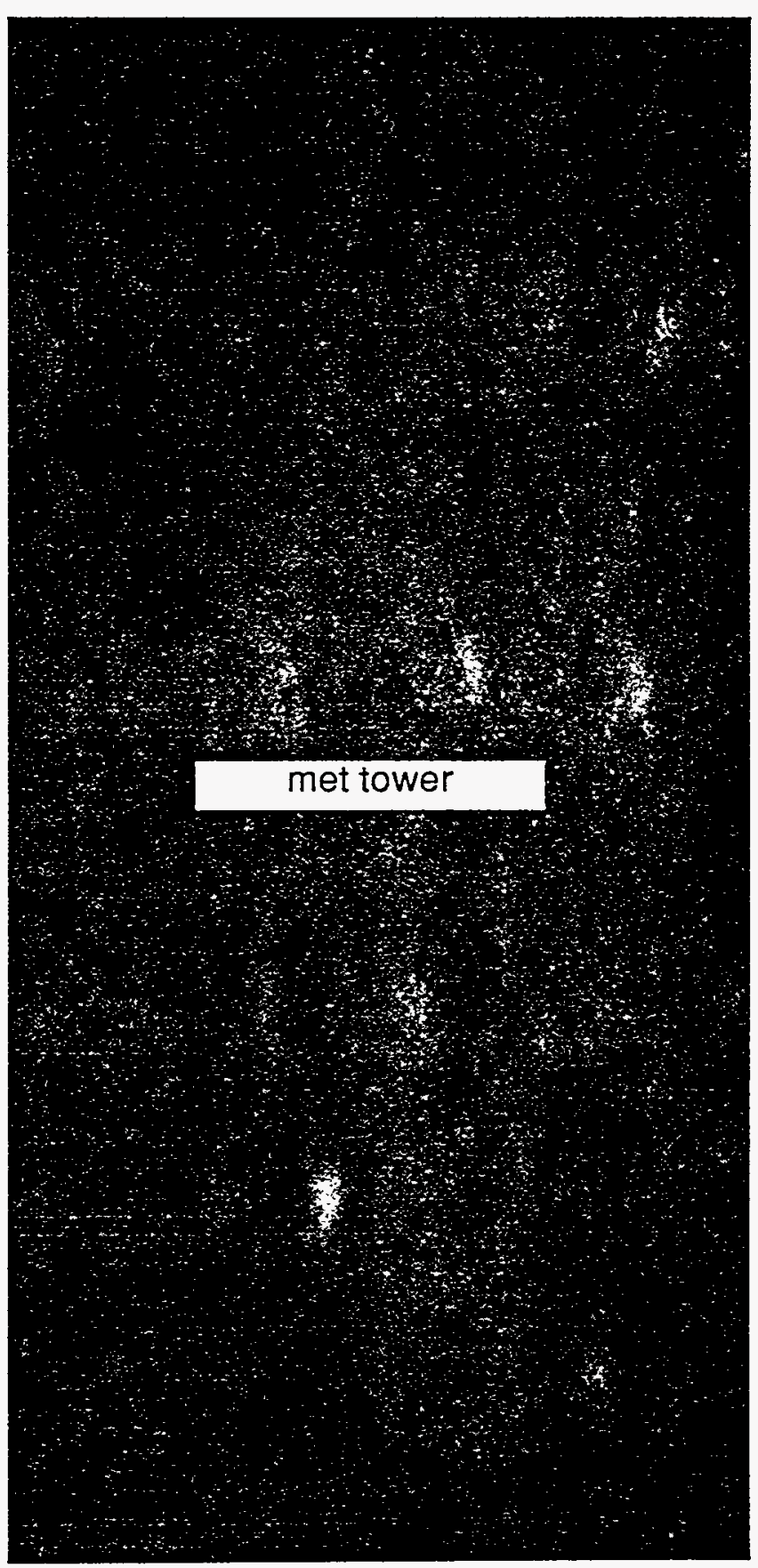


Meteorological data are sampled twice per second and complied into 15-minute intervals, 24 hours a day, 7 days a week. This information represents instantaneous data that are compiled, averaged, and stored, and may be accessed by way of a keyboard and displayed at any time.

Routine weather forecasts are prepared and issued four times a day, or more frequently during severe weather or emergency response situations. Two meteorologists work overlapping shifts, allowing forecasting capability from 6 a.m. to 10 p.m. each workday. Forecasts primarily support emergency response, plant health and safety, and plant operations.

In general, winds at the plant occur most often from the west through northwest, especially when speeds are greater than $6.7 \mathrm{mph}$. At wind speeds of less than 6.7 $\mathrm{mph}$, the distribution of wind direction is more even.

The sloping terrain causes local and regional winds to form during conditions with fair skies and light, large-scale winds. A broad, downvalley wind blows northward up the South Platte River Valley Basin at night. However, a shallow (approximately 100 feet) drainage wind flows eastward simultaneously over the plantsite.

The flow reverses during the day, with northeasterly winds often blowing up the South Platte River Valley, while a smaller scale wind from the southeast flows over Rocky Flats. 
Following are results of meteorological monitoring for 1993.

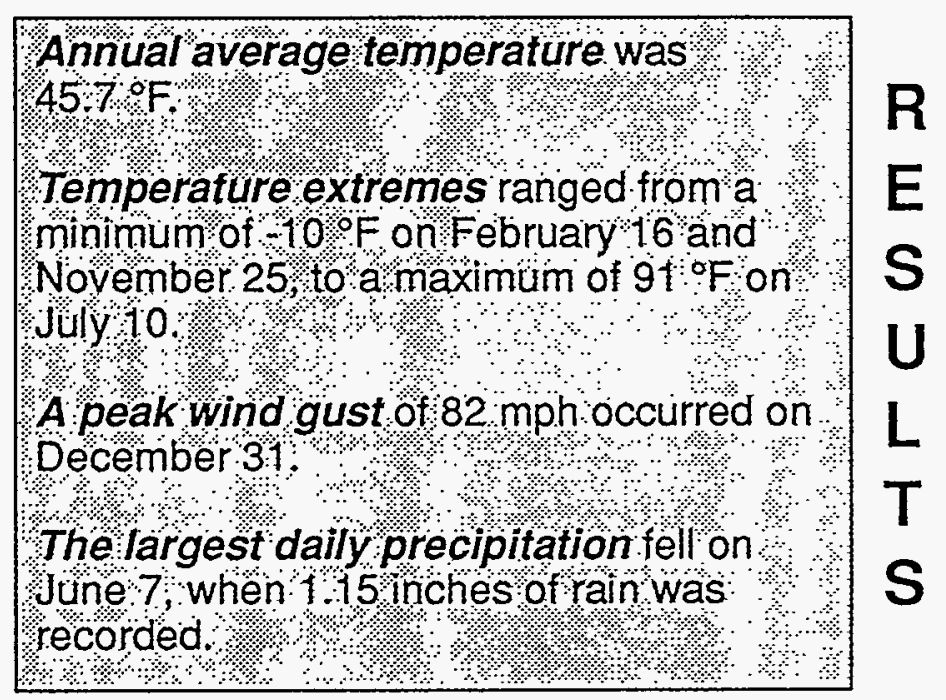

\section{the bottom line...}

Rocky Flats' climate is temperate and semiarid, characteristic of Colorado's Front Range.

The thin, dry atmosphere at the 6,000-foot elevation of the plant causes wide daily temperature ranges, with daytime warming and nighttime cooling.

Knowledge of the winds at the plant is important in determining the potential for release of materials offsite. 


\section{$\checkmark$ We Study Ecology}

\section{at a glance ...}

Rocky Flats is one of the few currently undisturbed areas on the eastern slope of the Rocky Mountains where some native animals still live.

Although ecological studies have been an ongoing part of routine operations, formalized ecological monitoring began in 1992 when the Ecological Monitoring Program was designed and implemented.
The emphasis of ecological studies at Rocky Flats is on the presence, quantity, and location of vegetation and animal life and on any impact that plant activities might have regarding the National Environmental Policy Act (NEPA) and other state and federal regulations and guidelines. NEPA is the nation's most widely

applied federal environmental law. It requires federal agencies to show that they have considered environmental impacts and public comments on proposed actions or projects. During 1993, the Rocky Flats Plant NEPA Compliance Committee provided information and recommendations on approximately 50 projects that involved construction, refurbishment, or upgrades of plant facilities.

Effects on ecological resources and systems may have occurred at Rocky Flats as a result of past operations that generated radioactive and chemical wastes. To assess these possible effects, ecological studies are an ongoing part of routine operations. Specialized studies, including floodplain identification and radioecological studies, continue to investigate the unique ecological features of the plant.

Ecological studies that took place in 1993 investigated plants and animals living in water and on land at Rocky Flats and established a basic standard of ecological conditions on plantsite. 
Investigations were performed, examining deer, small mammals, soil, and vegetation to evaluate absorption of radioactive materials in these plants and animals and to establish remediation standards.

Finally, Environmental Evaluations were performed to evaluate the actual or potential effects that contamination at a hazardous waste site may have on plants and animals. These evaluations provide information to determine whether the environment has been, or has the potential to be,

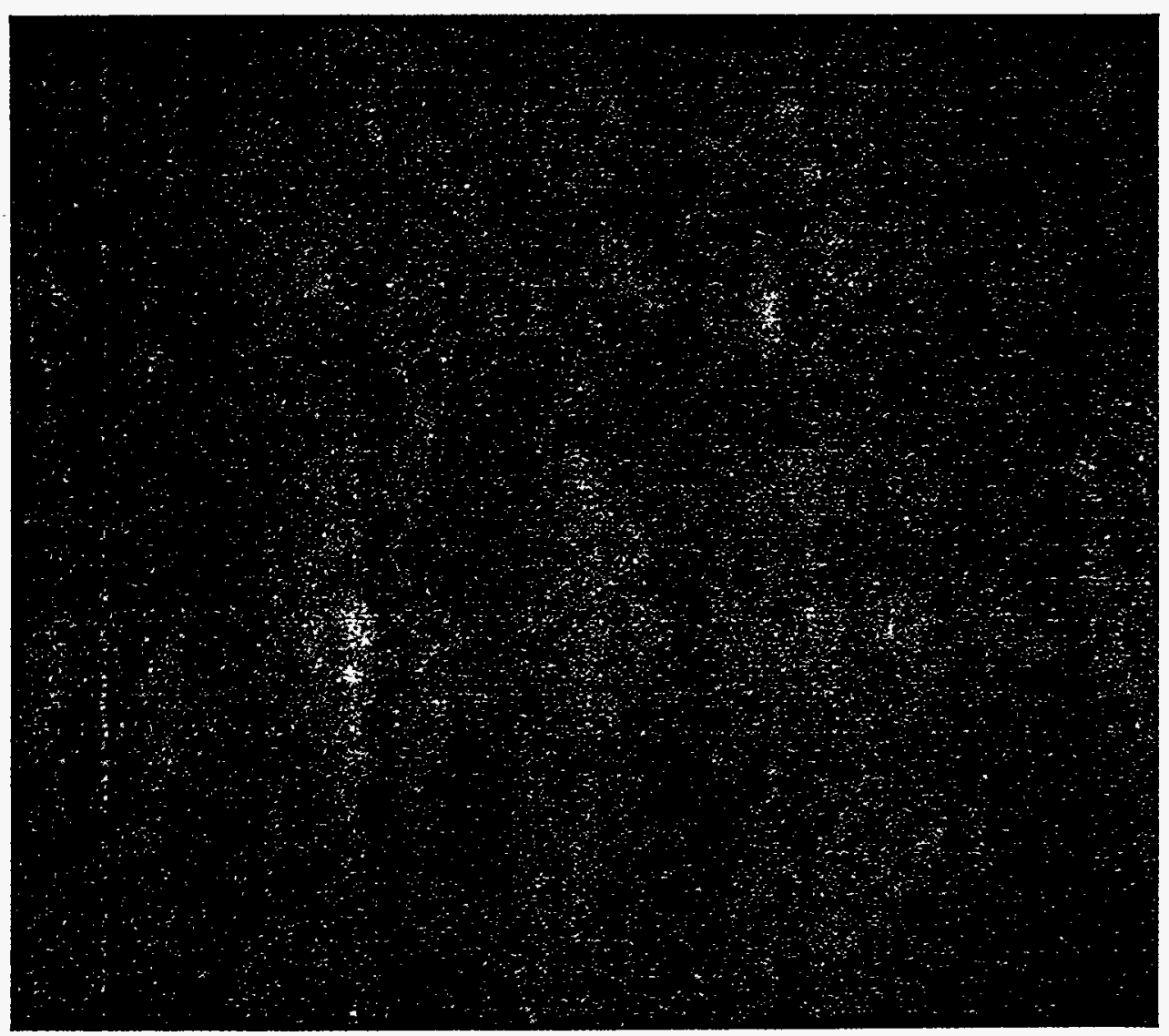
damaged by hazardous substances and/or wastes released from certain areas of the plant.

Current information on specific natural resources at RFP results from studies such as the Threatened and Endangered

Species

Evaluation.

Rocky Flats

Plantsite, 1991. 
Wildlife surveys conducted throughout the year included: birds, breeding birds, water fowl, migratory birds, raptors, nocturnal animals, big game carnivores, and small mammals. A prairie dog census was performed to identify the prey-base for the visiting eagles at Standley Lake.

In 1993, a pair of bald eagles built a nest at Operable Unit 3 near Standley Lake. The Colorado Bird Observatory was contracted to collect behavior and habitat-use data. The birds abondoned the nest in mid-March but had returned to the RFP vicinity by November 1993.

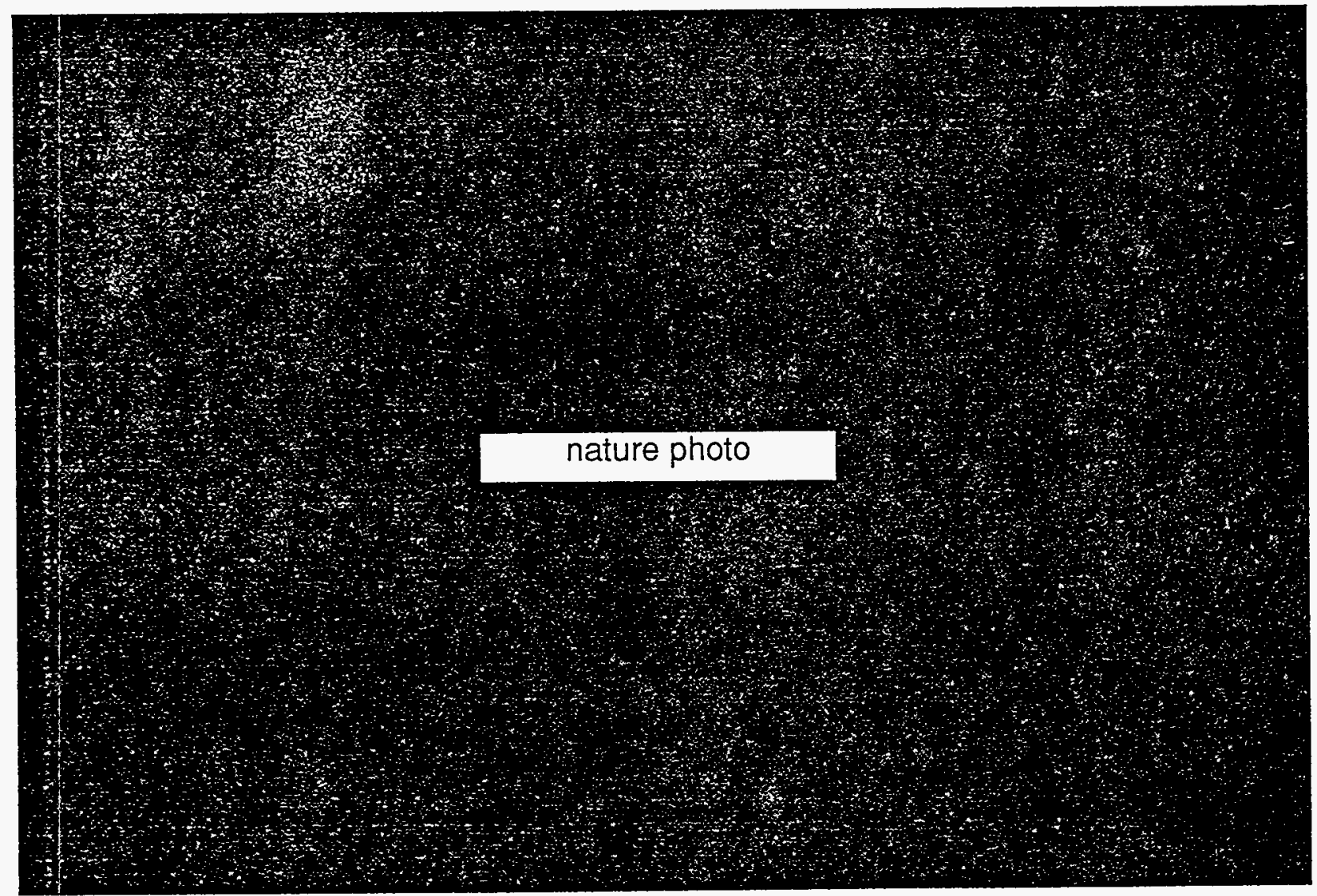




\section{the bottom line...}

- Ecological studies show that small mammals are not accumulating significant amounts of plutonium or americium in their bodies.

O Deer use the Operable Unit areas at Rocky Flats as habitat but do not absorb significant amounts of plutonium, americium, or uranium.

O Preliminary study results indicate that minute amounts of plutonium concentrations in the vegetation have decreased by approximately 84 percent from their original levels from the 1972 to 1974 period to 1989. Likewise, plutonium accumulations in the soil showed a general decline from the 1972 to 1974 period to 1989. However, because of differences in technology used to analyze the samples and the resulting data, some comparative results were inconclusive in the studies.

The Army Corps of Engineers completed the field portion of a Wetland Delineation Project to identify all of the wetlands on plantsite. A map and report are expected to be finalized by mid-1994. The map will aid project managers for remediation and other activities in avoiding wetland impacts. 


\section{We Work Toward Restoring the Environment}

\section{at a glance... \\ O The Environmental Remediation Program began at Rocky Flats in 1986 and has continued to grow in recent years. It was established as a separate program in October of 1992. \\ The program specifically includes activities such as identifying and analyzing inactive waste sites, designing actions to remedy and clean up these sites, and monitoring the sites after closure. \\ Throughout its history, Rocky Flats has employed a conscientious workforce. Various safety controls were}

in place to protect employees, the public, and the environment, and as newer technology was developed, more advanced safety controls were put in place. Despite these efforts, some incidents occurred that resulted in releases of radioactive or hazardous materials to the environment. Some disposal practices also were followed in the plant's early years that would not be acceptable today. These included the burial of certain materials on plantsite which are now the focus of environmental restoration efforts.

Various environmental laws, regulations, Executive Orders, Department of Energy Orders, and state and federal facility agreements and consent orders apply to environmental restoration activities. One of these is the Comprehensive Environmental Response, Compensation, and Liability Act (CERCLA) and its major amendment (Superfund Amendment and Reauthorization Act), which provide funding and enforcement authority for restoration of hazardous substance sites and for response to spills of hazardous substances. Sites contaminated by past activities must be investigated and remediation plans put into place. This is done to minimize the release of hazardous substances, pollutants, or contaminants. 
Rocky Flats Plant was added to the National Priorities List for Superfund sites on October 4, 1989. This list is an ordered ranking of CERCLA sites evaluated using what is called a Hazardous Ranking System. If a site scores above a certain level established by the Environmental Protection Agency, the site is placed on the National Priorities List.

CERCLA activities at Rocky Flats are established by the Interagency Agreement (IAG), which was signed by the Department of Energy, Environmental Protection Agency, and Colorado Department of Health on January 22,

Solar Evaporation Ponds (shown below) in the northeast portion of the Rocky Flats Plant make up Operable Unit 4. The ponds, initially used to store low-level radioactive liquid waste, are being emptied and the area remediated.

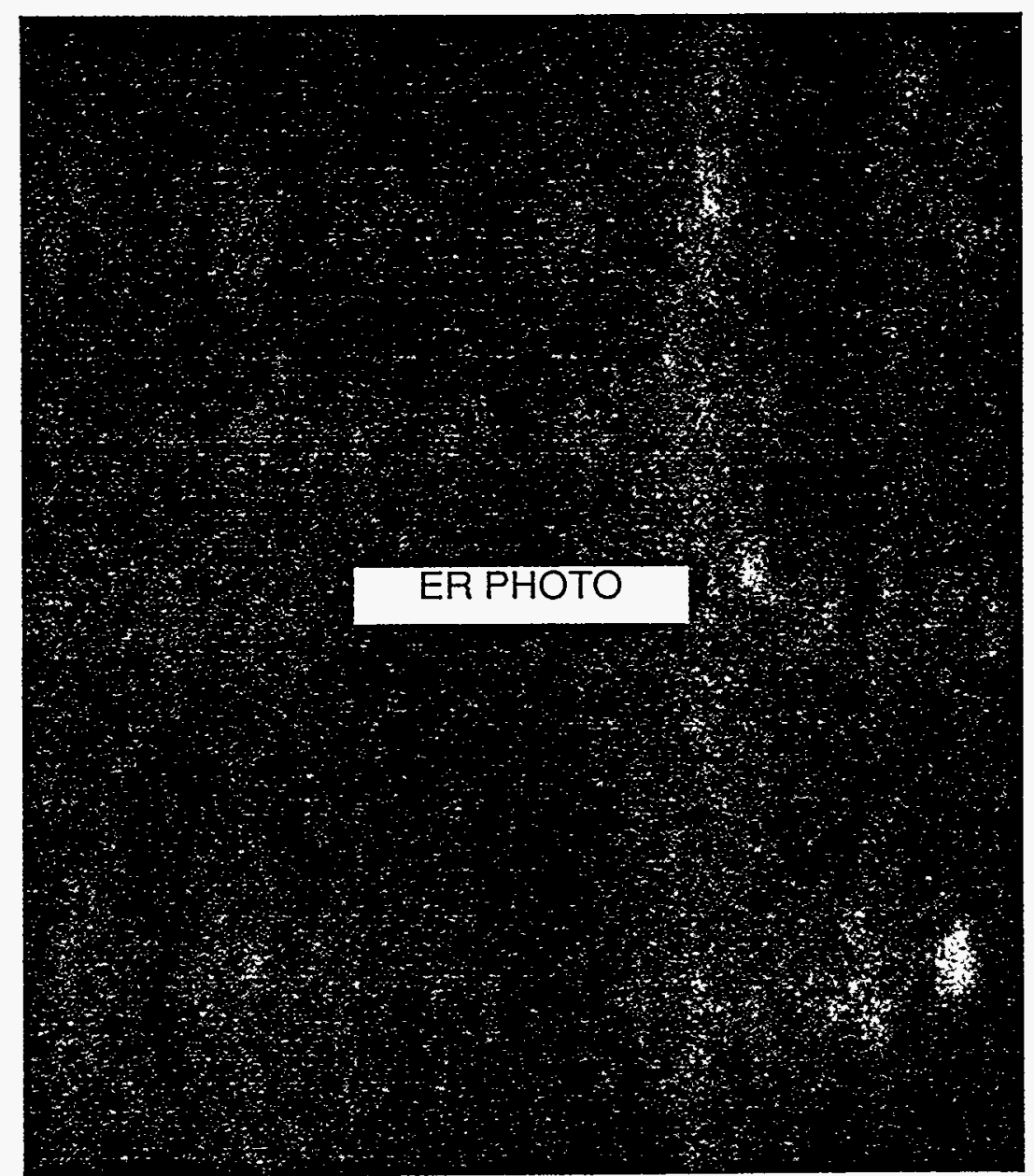

1991. This agreement replaced the 1986 RCRA/CERCLA Compliance

Agreement and clarified the responsibilities and authorities of the three agencies, standardized requirements, described procedures to be followed, and helped to ensure compliance with various orders and permits. The agreement further specifies delivery of major reports, project management activities and milestones, and includes involving the community in decision-making. 
The IAG and its attachments include details on specific response requirements that must be met during the CERCLA and RCRA processes used to assess and remediate Individual Hazardous Substance Sites (IHSSs) that are on or border the plant. A total of $178 \mathrm{IHSSs}$ were identified and prioritized at Rocky Flats. These IHSSs then were grouped into 16 Operable Units (OUs) based on cleanup priorities, waste type, and location. As of the end of FY93, 66 IAG milestones were met, 22 were extended and met, 6 were extended to a future date, and 1 milestone was denied an extension and missed.

Much progress has been made in the remediation efforts directed at several OUs. Among those is OU 1, referred to as the 881 Hillside Area and containing 11 IHSSs. Shallow groundwater at the 881 Hillside was contaminated in the 1950s, 1960 s, and 1970s with solvents and some radioactive materials. Naturally occurring uranium also is present. The interim remedial action at OU 1 involved constructing an underground drainage system called a French drain to intercept and contain contaminated groundwater flowing from the OU 1 area. The contaminated water is treated in a specially designed facility before it is released into the South Interceptor Ditch. The French drain and treatment facility (Building 891) were completed in early 1992, allowing treatment of contaminated groundwater to begin. Approximately 1.7 million gallons of water have been treated and released through the end of FY93.

Interim remedial action also began at OU 2, known as the $903 \mathrm{Pad}$, Mound, and East Trenches areas. Contamination at the $903 \mathrm{Pad}$ is mostly from storage in the 1950 s and 1960 s of waste drums containing cutting oils and carbon tetrachloride contaminated with plutonium. The drums were removed in 1967 and 1968; however, drums that had corroded allowed hazardous and radioactive material to leak onto the surrounding soil. Additional contamination may have resulted from wind dispersion during drum removal and soil movement when the area was covered with an asphalt pad in 1969 . In the 1960 s, barrels contaminated with uranium were stored in the Mound Area. 
Preliminary cleanup of the Mound Area was accomplished in 1970, and the barrels and material removed were packaged and shipped offsite. The East Trenches Area was used for disposal of plutonium- and uranium-contaminated waste and sanitary sewage sludge from 1954 to 1968 .

The IAG requires that site characterization and monitoring requirements for each OU be identified in a RCRA Facility Investigation/Remedial Investigation work plan. These work plans describe procedures to fully determine the nature and extent of the threat to public health or the environment caused by the release or threatened release of hazardous substances.

\section{the bottom line ...}

O Contamination in the OUs is being assessed and cleanup activities are being implemented. Sites with potentially higher health and environmental risks are attended to before sites with potentially lower risk.

Eighty-eight IAG milestones were completed by the end of Fiscal Year 1993 representing measurable achievements toward the assessment and cleanup of Rocky Flats. 


\section{We Study Radiation - Its Sources, Its Effects}

\section{at a glance...}

O Activities at Rocky Flats involve handling radioactive materials and operating radiation-producing equipment.

O The Radiation Dose Assessment Program evaluates possible radiation doses to the public from routine operations of the plant and assesses and records compliance with regulations for radiation protection of the public and the environment.

The most important potential source of radiation dose to the public from plant activities is the alpha radiation that could potentially result from inhalation or ingestion of plutonium, americium, or uranium.

Thousands of samples of air, soil, and water are analyzed each year at Rocky Flats. This information is used to determine the radiation dose that a maximally exposed, hypothetical individual could receive in a year as a result of plant operations. Plutonium, uranium, americium, and tritium are the radioactive materials that are important when considering radiation dose to the public from plant activities. Alpha radiation from plutonium, uranium, and americium are the main contributors to the projected radiation dose. 
The plutonium and americium in the Rocky Flats Plant environment are the combined result of fallout from past global atmospheric nuclear weapons testing and from past releases from the plant. Uranium is a naturally occurring element native to many parts of Colorado and is also used at the plant. Tritium, which is both naturally occurring and produced artificially, may be handled at Rocky Flats. Assessment of radiation is based on monitoring data from air, water, and soil sampling programs.

The 1993 assessment of dose to the public from plant activities indicates that the radiation dose to the maximally exposed individual in the public is estimated to be 0.48 millirem EDE (millirem and EDE are explained on page 12). The standard for protection is 100 millirem per year. For comparison, the average person in the United States receives approximately 300 millirem EDE from natural radiation sources. Because of Colorado's high altitude and large amount of natural uranium and thorium in its soils, it is currently estimated that the typical Denver resident receives approximately 350 millirem EDE each year from natural sources. Investigations are being conducted to determine whether any regional differences in indoor radon exists. Once these studies are published, estimates of natural background radiation dose for the Denver area may be modified to reflect indoor radon doses specific to this region. Indoor radon concentrations tend to be higher in the Denver region than in other areas of the country.

Collective population dose is the total of individual radiation doses in a specific area (a dose of 1 rem to 10 individuals results in a collective dose of 10 personrem). In estimating the collective population dose to the public within a 50-mile radius of the plant, the assessment focuses on radioactive materials emitted from the plant by air. The collective population dose within 50 miles of the plant for 1993 was calculated as 0.1 person-rem. Most of this collective population dose is from estimated contaminated soil resuspension from the Operable Unit areas. A very small contribution for 1993 is attributed to air emissions from Rocky Flats buildings. These calculated radiation doses are believed to be conservative estimates that would be the maximum of any radiation dose actually received by the public. 


\section{What are Some Sources of Radiation?}

Naturally occurring, medical, and consumer product sources contribute more than 99 percent of the average radiation dose that a person living in the United States receives each year. Other sources such as facilities like the Rocky Flats Plant, contribute less than 1 percent of the average radiation dose to a person living in the United States. 


\section{the bottom line...}

The 1993 assessment of dose to the public from plant activities is estimated to be 0.48 millirem EDE to the maximally exposed individual. This estimation is well under the standard for protection from regulated sources, which is 100 millirem per year.

The maximum radiation dose to a member of the public as a result of airborne emissions from the plant is well below the National Emission Standards for Hazardous Air Pollutants and Department of Energy standards of 10 millirem per year.

0 The average radiation dose to a person in the United States from naturally occurring sources is about 300 millirem per year.

A person who takes an airline flight from Denver to San Francisco will receive about I millirem of radiation dose. This dose is typically more than Rocky Flats contributes to a member at the public over an entire year.

Although alpha radiation is the most important source of radiation dose to the public from plant activities, Rocky Flats has a network of 50 instruments called thermoluminescent dosimeters on the plantsite, at the plant's perimeter, and in area communities. These dosimeters measure external penetrating gamma radiation. Gamma radiation measured as part of the Rocky Flats program is primarily from naturally occurring cosmic radiation from space and from radioactive materials originating from the earth's crust. 


\section{We Take Steps to Ensure Quality}

\section{at a glance...}

E Every year, approximately 83,000 analyses are performed on air, soil, and water samples from within and surrounding the plantsite.

O Quality assurance demands continuous improvement in performance in Rocky Flats' comprehensive environmental programs.

The Quality Assurance Program ensures that environmental restoration, monitoring, and protection programs are conducted according to specific requirements and continuously improves performance. This pro-

gram reaches all environmental program activities that are conducted to meet environmental requirements of federal, state, and local statutes, regulations, and agreements. Quality Assurance requirements include those established by the Department of Energy, Rocky Flats Plant, Colorado Department of Health, and the Environmental Protection Agency. The Rocky Flats Quality Assurance Manual consists of 22 quality requirements that are potentially applicable to all programs, including environmental restoration and monitoring programs.

Implementation of requirements, controls, and methods is verified by conducting internal readiness reviews, surveillances, and inspections of environmental program and project work activities. Inspections consist of observations of activities and examination of records. These oversight inspections are performed in the field at sampling and test sites, at the main decontamination facility, and at field trailers. 


\section{Analytical Laboratories are Part of Quality Assurance}

Analyses of samples are performed by the Rocky Flats Plant Analytical

Laboratories, which are made up of subordinate laboratories: the

Environmental Radiochemistry Laboratory and the General Organic,

General Inorganic, and

General Radiochemistry

Laboratories, which

comprise the General

Laboratories.

Detailed quality control for the reliability of analytical data is provided in each analytical operating procedure. Any unusual condition that may affect analytical results, observed during sample collection, analysis, or quality assurance review, is reported to management. If there is any indication that a process is not in control, Quality Assurance requires that the process or analytical operation must be stopped until review and corrective action can be taken.

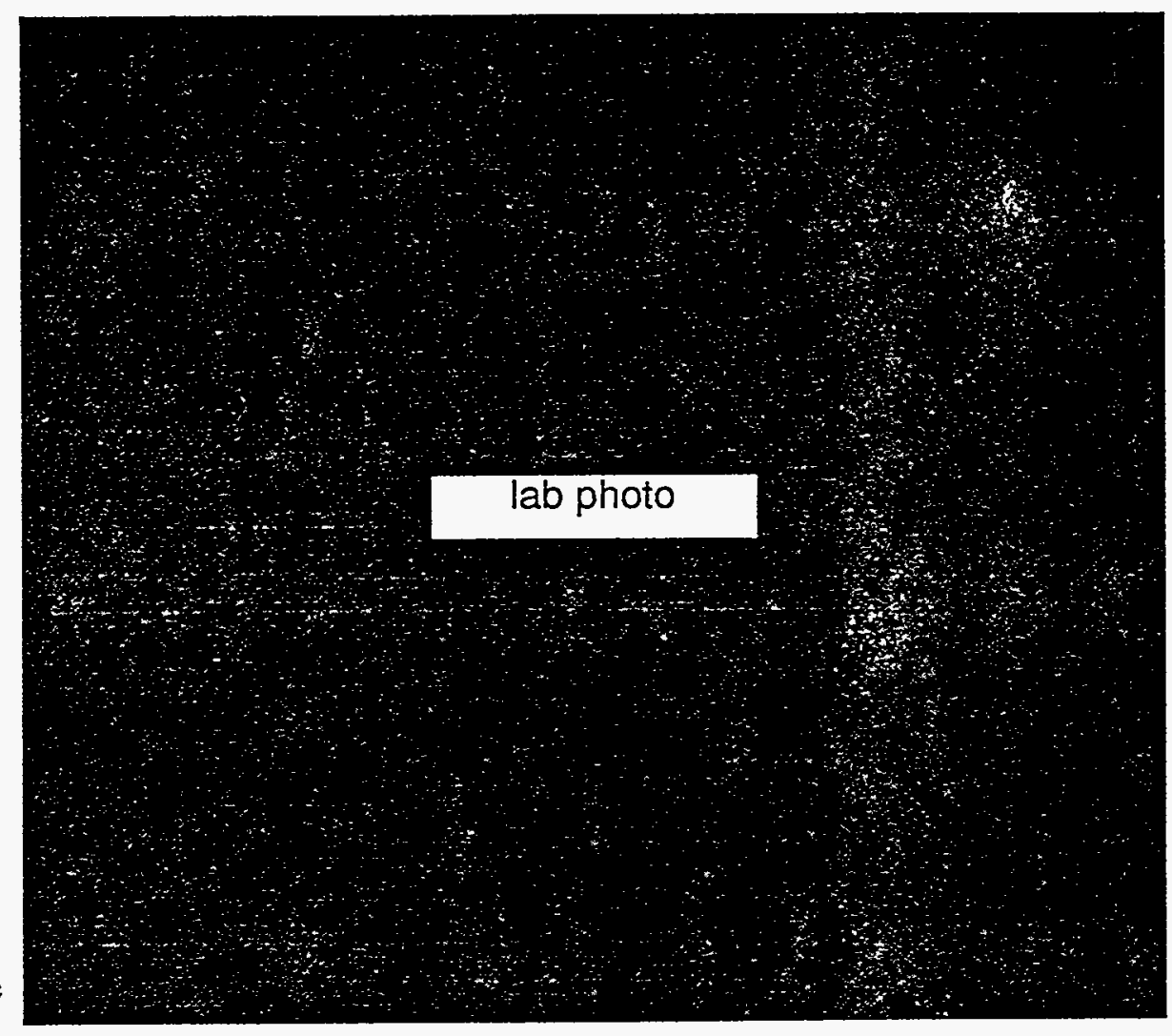

\section{the bottom line...}

The Quality Assurance Program ensures continuous and aggressive improvement in Rocky Flats' comprehensive environmental monitoring efforts. 


\section{So. .. What Does}

\section{It All Mean?}

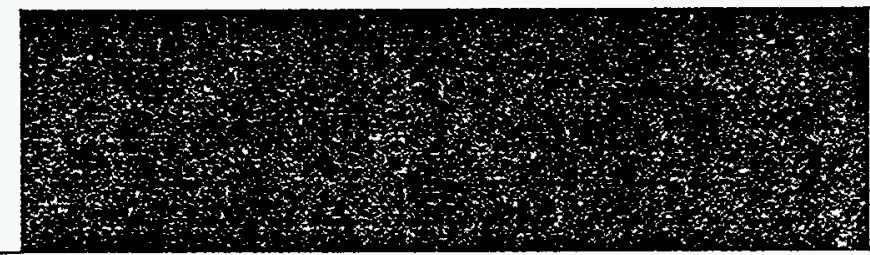

As Rocky Flats transitions to its new mission that focuses on environmental restoration, decontamination, and decommissioning, the Department of Energy and EG\&G Rocky Flats, Inc. remain committed to ensuring that future work is performed in a manner that protects the worker, as well as the public and the environment. This goal will be accomplished by keeping emissions as low as reasonably achievable, enhancing strict safety controls that are already in place at the plant, and using state-of-the-art technology to complete environmental remediation projects in the most cost-effective and efficient manner possible. Although the plant's national defense mission has ended, its new mission remains just as essential as the nation moves forward to restore and preserve the environment for future generations of Americans.

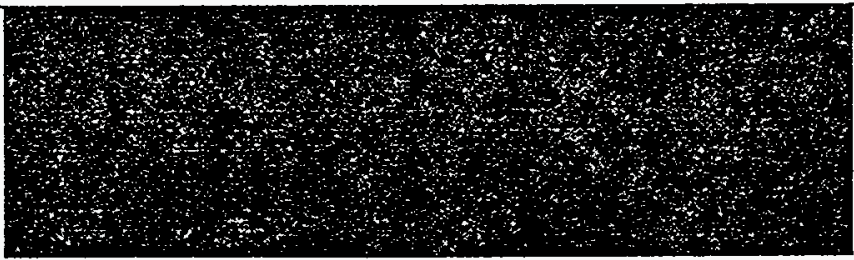




\section{? \\ RFP-ENV-93

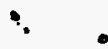 \\ ROCKY FLATS PLANT SITE ENVIRONMENTAL REPORT FOR 1993}

\section{EERE ROCKY FLATS}

Rocky Flats Plant

P.O. Box 464

Golden, CO 80402

Prepared for the U.S. Department of Energy

Under control contract No. DE-AC34-90RF62349
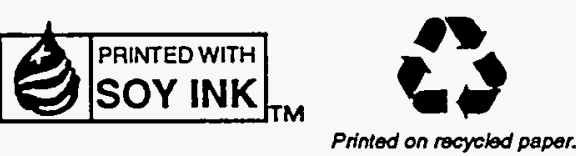
$\because$ 


\section{TABLE OF CONTENTS}

Preface .xi

Executive Summary xiii

1.0 Introduction. 1

2.0 Compliance Summary ...............................................................................

National Environmental Policy Act .........................................................................11

Ecological Environmental Statutes And Regulations ................................................13

National Historic Preservation Act ..............................................................................14

Clean Air Act ................................................................................................................

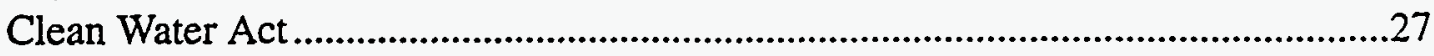

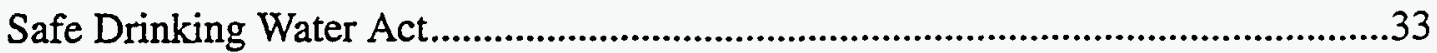

Federal Insecticide, Fungicide, And Rodenticide Act ..................................................33

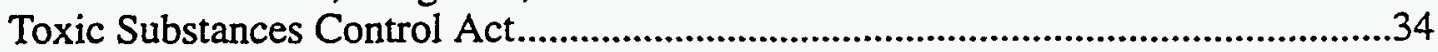

Resource Conservation And Recovery Act ...............................................................34

Comprehensive Environmental Response, Compensation, And Liability Act..........49

Interagency Agreement...........................................................................................50

Emergency Planning And Community Right-To-Know Act .......................................53

Agreement In Principle ...............................................................................................56

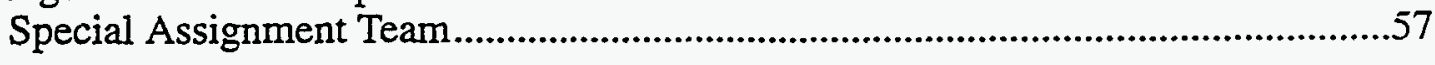

3.0 Environmental Monitoring Programs ……………............................................61

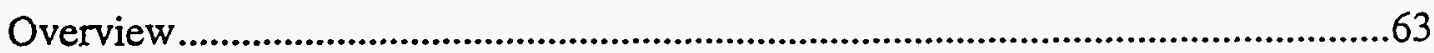

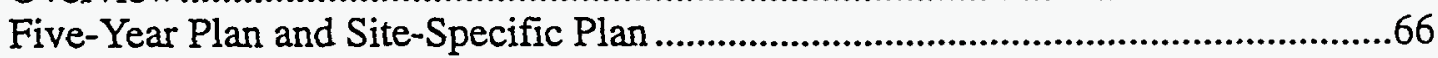

3.1 Meteorological Monitoring And Climatology ………............................................67

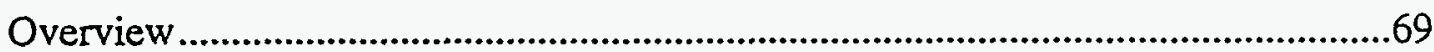

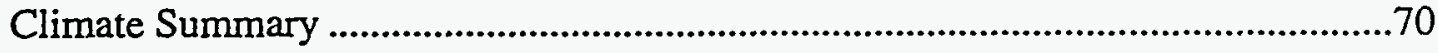

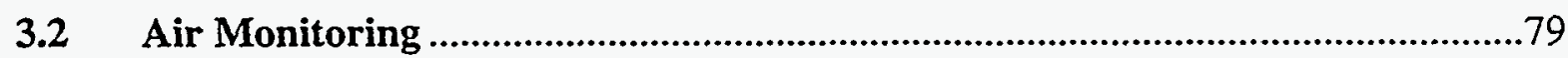

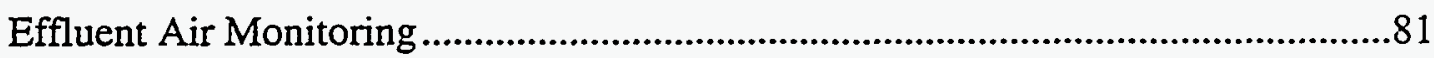

Nonradioactive Ambient Air Monitoring …............................................................91

Radioactive Air Monitoring .......................................................................................94

3.3 Surface Water Monitoring ………………………...............................................101

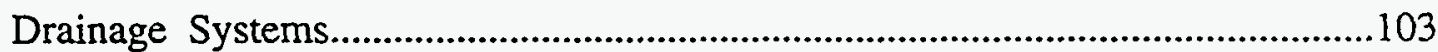

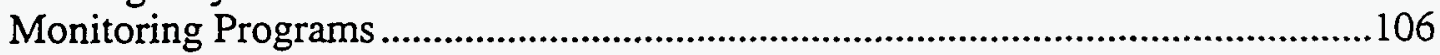

Hydrological Characterization .............................................................................112

Monitoring Results...............................................................................113

Watershed Management Plan ....................................................................................116 


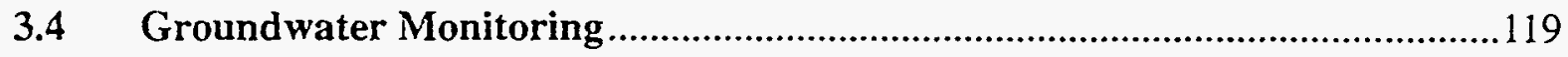

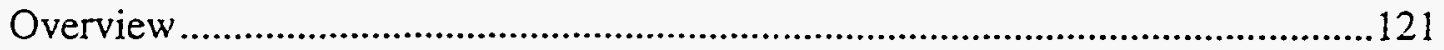

Results 126

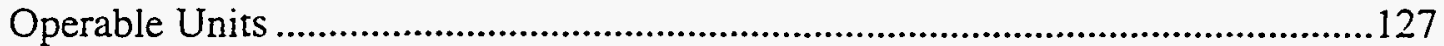

Boundary Wells .......................................................................................... 141

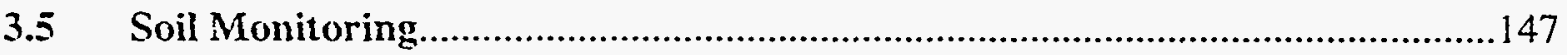

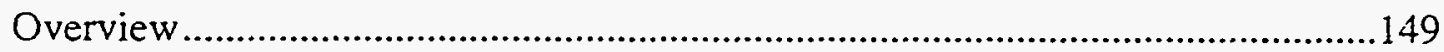

Results 149

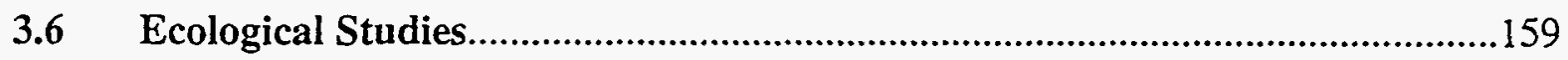

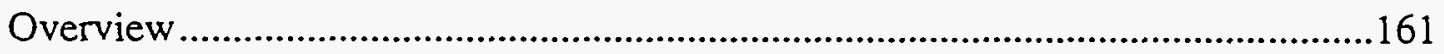

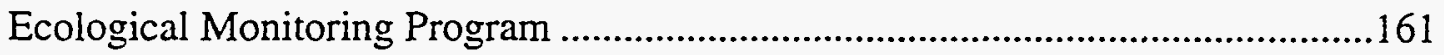

Resource Protection Program .................................................................................163

Environmental Evaluation Program............................................................................ 164

4.0 Environmental Remediation Programs …….................................................167

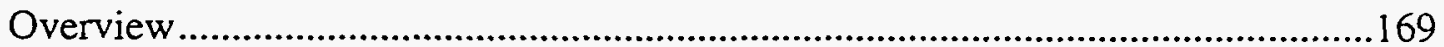

OU 1 - 881 Hillside

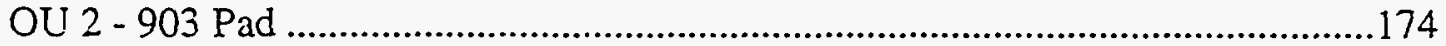

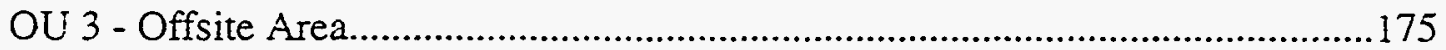

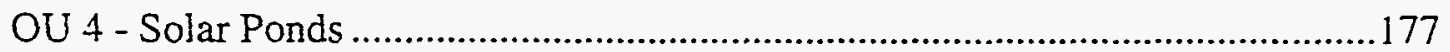

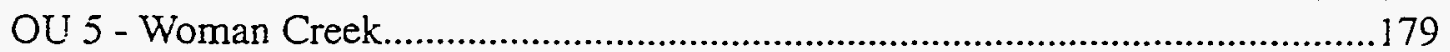

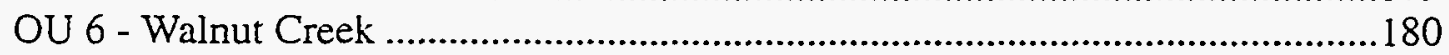

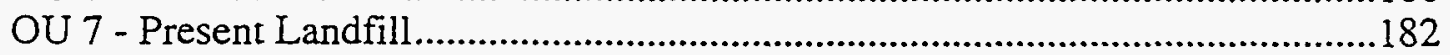

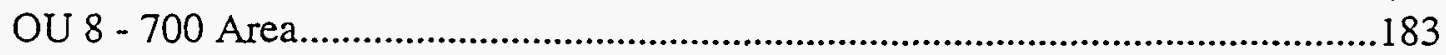

OU 9 - Original Process Waste Lines ................................................................185

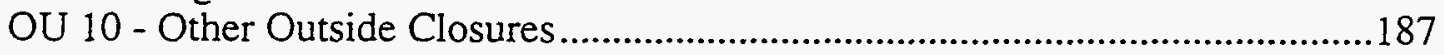

OU 11 - West Spray Field ...................................................................................188

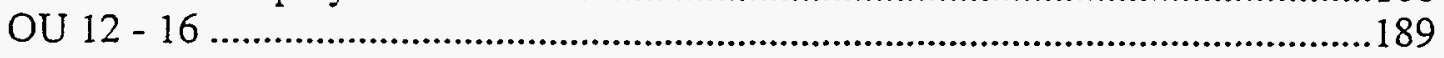

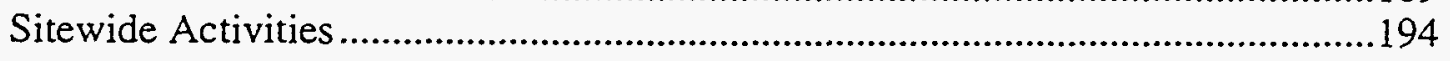

5.0 External Gamma Radiation Dose Monitoring ............................................207

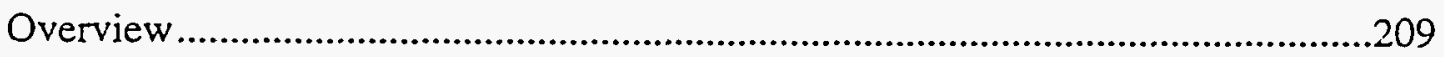

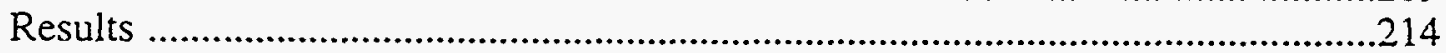

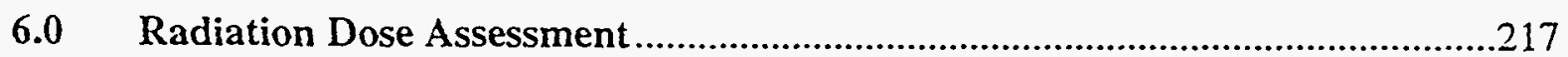

Rocky Flats Plant Radioactive Materials .......................................................219

Radiation Protection Standards for the Public .............................................221

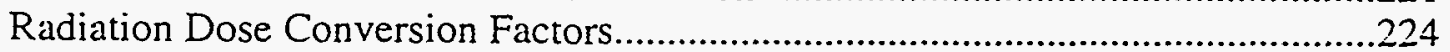

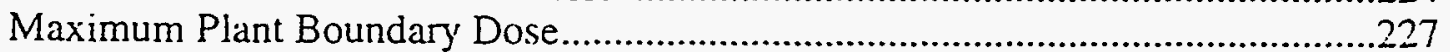

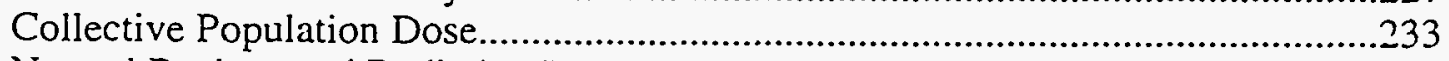

Natural Background Radiation Dose ............................................................2. 
7.0 Quality Assurance And Quality Control ....................................................239

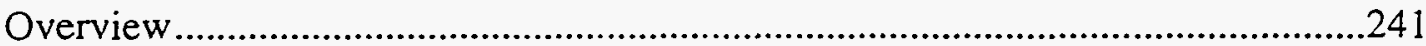

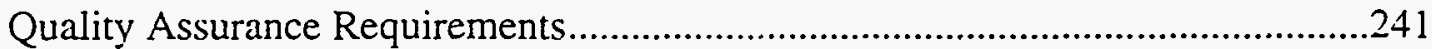

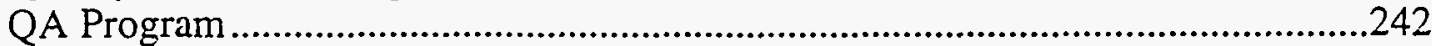

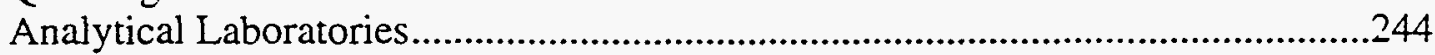

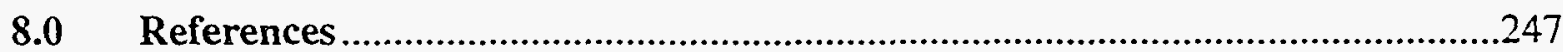

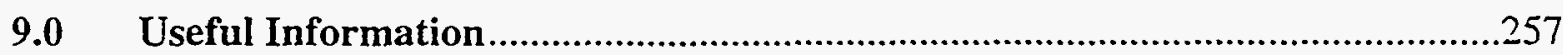

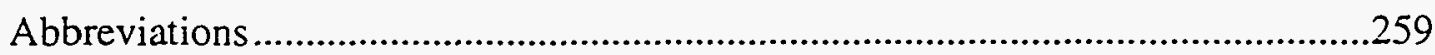

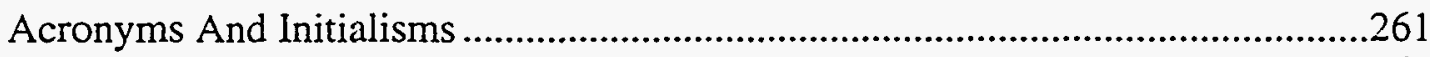

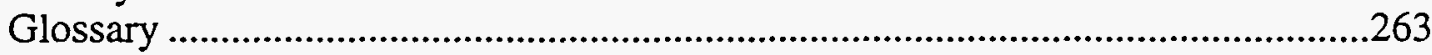

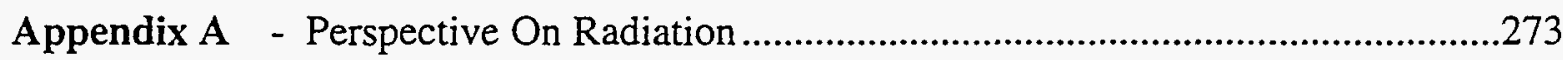

Appendix B - Applicable Guides And Standards ..................................................283

Appendix C - Wind Stability Classes .......................................................297

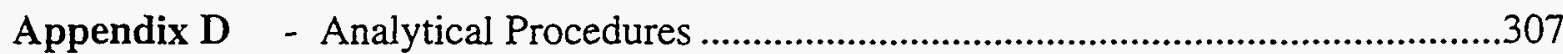

\section{FIGURES}

Figure 1-1 Area Map of RFP and Surrounding Communities..................................3

Figure 3.1-1 Location of the RFP 61-Meter Meteorological Tower .............................71

Figure 3.1-2 1993 RFP Climate Summary .........................................................72

Figure 3.1-3 RFP 1993 Wind Rose - 24 Hour .......................................................75

Figure 3.1-4 RFP 1993 Wind Rose - Day..........................................................76

Figure 3.1-5 RFP 1993 Wind Rose - Night ..................................................76

Figure 3.2-1 Glovebox Ventilation/Filtration Exhaust System...................................82

Figure 3.2-2 High Efficiency Particulate Air Filter Banks ...........................................84

Figure 3.2-3 Radiological Effluent Air Sampling System (top)

Selective Alpha Air Monitor (bottom) ..............................................8

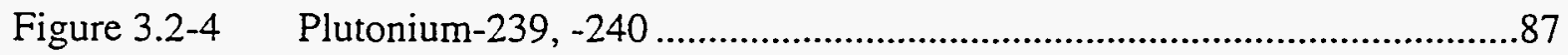

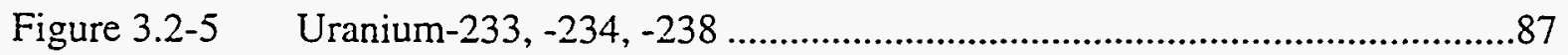

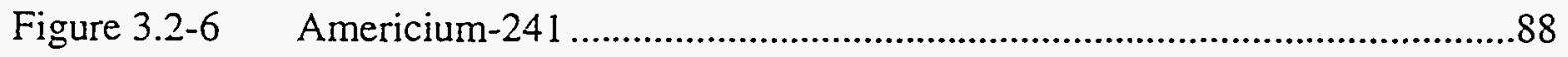




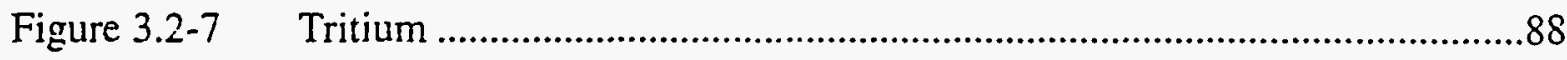

Figure 3.2-8 Beryllium ...........................................................................................

Figure 3.2-9 TSP and PM-10 .............................................................................92

Figure 3.2-10 1993 Onsite and Perimeter Air Samplers.................................................95

Figure 3.2-11 Community Air Samplers ......................................................................96

Figure 3.2-12 Plutonium-239, -240 (Onsite Samplers) ...................................................99

Figure 3.2-13 Plutonium-239, -240 (Perimeter and Community Samplers) .....................99

Figure 3.3-1 Holding Ponds and Liquid Effluent Water Courses...................................104

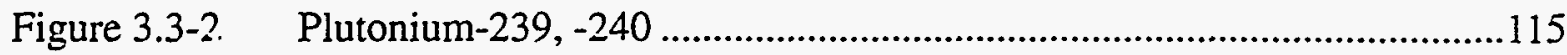

Figure 3.3-3 Uranium-233/-234, -238 Composited ...................................................115

Figure 3.3-4 Americium .......................................................................................115

Figure 3.4-1 Generalized Cross Section of the Stratigraphy Underlying RFP ..............122

Figure 3.4-2 Location of Monitoring Wells...............................................................124

Figure 3.4-3 Location of Areas Known To Have Groundwater

Contamination Plumes

Figure 3.4-4 Solar Evaporation Ponds Potentiometric Surface in Surficial Materials

Figure 3.4-5A Solar Evaporation Ponds Dissolved Plutonium-239, -240,

Americium-241, and Tritium Detected in the Uppermost Aquifer...........132

Figure 3.4-5B Solar Evaporation Ponds Dissolved Uranium-233/-234,

Detected in the Uppermost Aquifer.

Figure 3.4-6 Solar Evaporation Ponds Volatile Organic Compounds Detected in the Uppermost Aquifer ....

Figure 3.4-7 Present Landfill Potentiometric Surface in Surficial Materials ................135

Figure 3.4-8 Present Landfill Radionuclides in the Uppermost Aquifer.......................137

Figure 3.4-9 Present Landfill Volatile Organic Compounds Detected in the Uppermost Aquifer

Figure 3.4-10 West Spray Field Potentiometric Surface in Surficial Materials ..............140

Figure 3.4-11 A West Spray Field Radionuclides Plutonium-239, -240

Americium-241 and Tritium Detected in the Uppermost Aquifer 142 
Figure 3.4-11B West Spray Field Radionuclides Uranium-233, -234, Uranium-236, and Uranium-238 Detected in the Uppermost Aquifer.

Figure 3.5-1 Soil Sampling Locations ................................................................. 150

Figure 3.5-2 Locations of Soil Pits ........................................................................ 155

Figure 3.5-3 Data Collection and Processing Schematic.........................................156

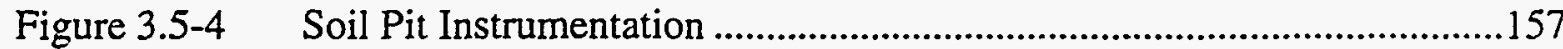

Figure 4-1 Operable Unit 1 - 881 Hillside.......................................................198

Figure 4-2 Operable Unit 2 - 903 Pad, Mound, East Trenches ...............................198

Figure 4-3 Operable Unit 3 - Offsite Releases ..................................................199

Figure 4-4 Operable Unit 4 - Solar Evaporation Ponds.........................................199

Figure 4-5 Operable Unit 5 - Woman Creek...................................................200

Figure 4-6 Operable Unit 6 - Walnut Creek ........................................................200

Figure 4-7 Operable Unit 7 - Present Landfill ...................................................201

Figure 4-8 Operable Unit 8 - 700 Area...........................................................201

Figure 4-9 Operable Unit 9 - Original Process Waste Lines .................................202

Figure 4-10 Operable Unit 10 - Other Outside Closures ........................................202

Figure 4-11 Operable Unit 11 - West Spray Field ..................................................203

Figure 4-12 Operable Unit 12 - 400/800 Area......................................................203

Figure 4-13 Operable Unit 13 - 100 Area..........................................................204

Figure 4-14 Operable Unit 14 - Radioactive Sites...................................................204

Figure 4-15 Operable Unit 15 - Inside Building Closures.....................................205

Figure 4-16 Operable Unit 16 - Low Priority Sites ...................................................205

Figure 5-1 22 TLD Locations Within the Main Facilities Area .............................211

Figure 5-2 16 TLD Locations Within a 2- to 4-Mile Radius of RFP ......................212

Figure 5-3 12 TLD Locations in Communities Located Within a 30-Mile Radius of RFP

Figure 6-1 1993 Demographic Estimates for Areas $0-10$ and $10-50$ Miles from RFP. 
Figure A-1 Contribution of Various Sources to the Total Average Radiation Dose to the United States Population .....................................................................281

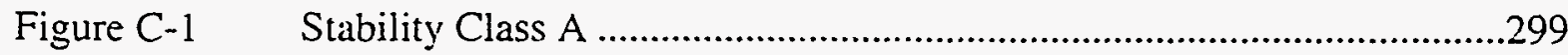

Figure C-2 Stability Class B

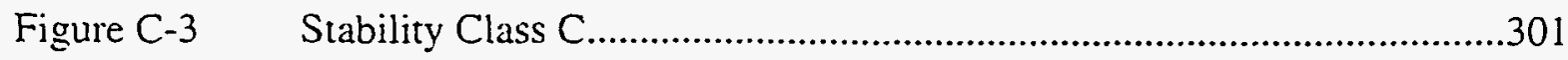

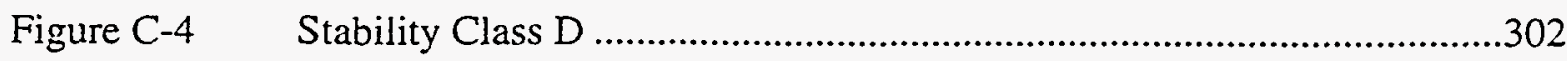

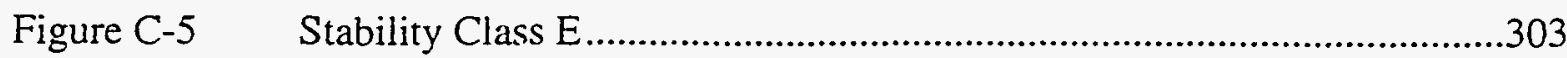

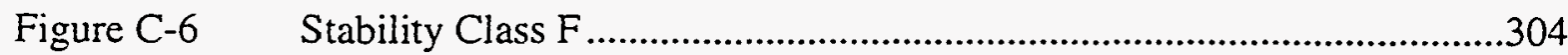

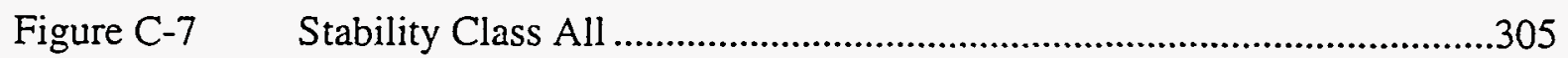

\section{TABLES}

Table 2-1 Air Pollutant Emission Notices and/or Reports

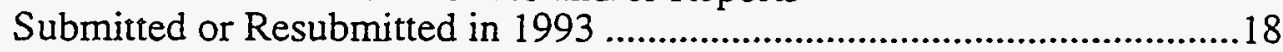

Table 2-2 Air Permits and Permit Applications .......................................................20

Table 2-3 Prioritization of Operable Units by the IAG.............................................51

Table 2-4 IAG Milestones Completed in 1993 .....................................................52

Table 2-5 Chemicals and Quantities (lbs) Released to the Environment in 1991 and 1992 as Reported on Form R ..........................................................56

Table 3-1 RFP Environmental Reports …………...................................................64

Table 3-2 Primary Compliance Standards and Applicable Regulations for Environmental Monitoring Programs.....................................................65

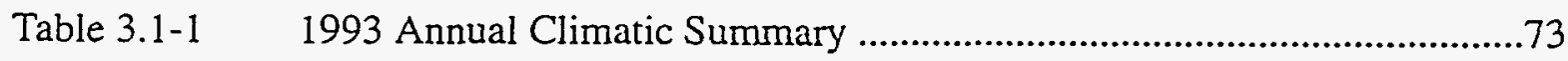

Table 3.1-2 RFP Wind Direction Frequency (Percent) by Four Wind-Speed Classes..................................................................................

Table 3.1-3 Percent Occurrence of Winds by Stability Class ........................................77

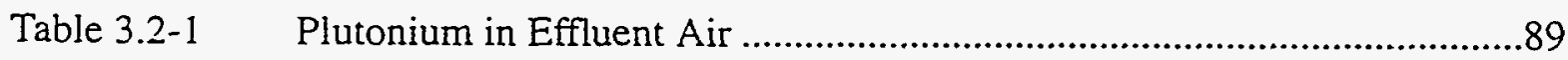

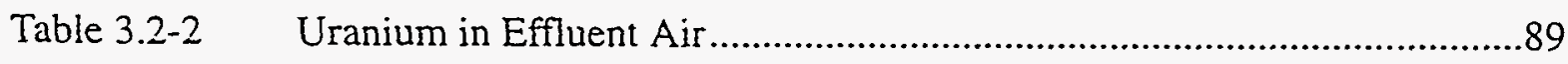

Table 3.2-3 Americium in Effluent Air ....................................................................90

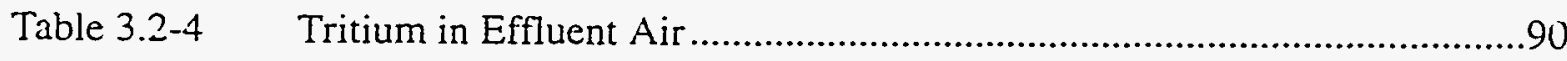

Table 3.2-5 Beryllium in Effluent Air................................................................. 
Table 3.2-6 Ambient Air Monitoring Detection Methods .93

Table 3.2-7 Ambient Air Quality Data for Nonradioactive Particulates. .93

Table 3.2-8 Onsite Air Sampler Plutonium Concentrations. .97

Table 3.2-9 Perimeter Air Sampler Plutonium Concentrations, Community Air Sampler Plutonium Concentrations 98

Table 3.3-1 Monthly Flow and Discharges for 1993 (gallons) 108

Table 3.3-2 Chemical and Biological Constituents in Surface-Water Effluents at NPDES Permit Discharge Locations, 1993

Table 3.3-3 Plutonium, Uranium, and Americium Concentrations in SurfaceWater Effluents.

Table 3.3-4 Tritium Concentrations in Surface-Water Effluents

Table 3.3-5 _. Plutonium, Uranium, and Americium Concentrations in the Raw Water Supply.

Table 3.4-1 Hydraulic Conductivities of Lithologic Units.

Table 3.4-2 Site Chemical Constituents Monitored in Groundwater

Table 3.4-3 Volatile Organic Compounds Detected in Boundary Wells 144

Table 3.4-4 Dissolved Metals of Interest Detected in Boundary Wells 144

Table 3.4-5 Total Radionuclides Greater Than Background Upper Tolerance Limits Detected in Boundary Wells

Table 3.5-1 Plutonium Concentration in Soil Samples at 1 and 2 Miles from the Plant Center.

Table 4-1 Organization of Individual Hazardous Substance Sites (IHSSs) into Operable Units (OUs)

Table 5-1 CY 1993 Environmental Thermoluminescent Dosimeter Measurements by Location Category.................................................................210

Table 5-2 CY 1993 Onsite Environmental TLD Measurements.............................210

Table 5-3 CY 1993 Perimeter Environmental TLD Measurements........................215

Table 5-4 CY 1993 Community Environmental TLD Measurements .....................215

Table 6-1 Isotopic Composition of Plutonium Used at RFP ..............................225

Table 6-2 Dose Conversion Factors Used in Dose Assessment Calculations for RFP in 1993 
Table 6-3 Radioactivity Concentrations Used in Maximum Site Boundary

Dose Calculations for All Pathways for 1993

Table 6-4 50-Year Committed Dose Equivalent from 1 Year of Chronic Intake/Exposure from RFP in 1993

Table 6-5 Radionuclide Air Emissions for Input to CAP88-PC

Computer Code in 1993

Table 6-6 Calculated Radiation Dose to the Public from 1 Year of Chronic Intake/Exposure from RFP in 1993

Table 6-7 Estimated Annual Natural Background Radiation Dose for the Denver Metropolitan Area ........................................................................238

Table B-1 DOE Radiation Protection Standards for the Public .286

Table B-2

National Ambient Air Quality Standards (NAAQS) for Particulates ......286

Table B-3

DOE Derived Concentration Guides for Radionuclides of Interest at RFP

Table B-4 NPDES Permit Limits and Reporting Requirements as Modified by the FFCA Effective April 1991 .............................................................28

Table B-5 Water Quality Standards at Rocky Flats Plant ..................................289

Table C-1 Wind Frequency Distribution by Percent in 1993, Stability Class A ......299

Table C-2 Wind Frequency Distribution by Percent in 1993, Stability Class B......300

Table C-3 Wind Frequency Distribution by Percent in 1993, Stability Class C.......301

Table C-4 Wind Frequency Distribution by Percent in 1993, Stability Class D ......302

Table C-5 Wind Frequency Distribution by Percent in 1993, Stability Class E.......303

Table C-6 Wind Frequency Distribution by Percent in 1993, Stability Class F .......304

Table C-7 Wind Frequency Distribution by Percent in 1993, Stability Class All ....305

Table D-1 Formulas for Activity and Uncertainty Calculations for the Alpha Spectral Analysis Systems

Table D-2 Typical Detection Limits for Radioactive and Nonradioactive Materials 
The 1993 Rocky Flats Plant Site Environmental Report provides information to the public about the impact of the Rocky Flats Plant (RFP) on the environment and public health. The report contains a compliance summary, a description of environmental monitoring programs, and radiation dose esiimates for the surrounding population for the period January 1 through December $31,1993$.

An environmental surveillance program has been ongoing at RFP since the 1950s. Early programs focused on radiological impacts to the environment. The current program examines the potential radiological and nonradiological impacts to air, surface water, groundwater, and soils. It also includes meteorological monitoring, ecological studies, and environmental remediation programs.

Environmental operations at RFP are under the jurisdiction of several local, state, and federal authorities, particularly the Colorado Department of Health, the Environmental Protection Agency, and the Department of Energy. A variety of reports are prepared at different intervals for these and other agencies in addition to the annual environmental report. A list of these reports is provided in Section 3, Table 3-1. 


\section{Executive Summary}

The Rocky Flats Plant Site Environmental Report provides summary information on the plant's environmental monitoring programs and the results recorded during 1993. The report contains a compliance summary, results of environmental monitoring and other related programs, a review of environmental remediation activities, information on external gamma radiafion dose monitoring, and radiation dose estimates for the surrounding population. This section provides an overview of these topics and summarizes more comprehensive discussions found in the main text of this annual report. 


\section{OVERVIEW}

\section{COMPLIANCE SUMMARY}

\author{
National Environmental \\ Policy Act
}

The purpose of the Rocky Flats Plant Site Environmental Report is to present summary environmental data to help characterize site environmental management performance, confirm compliance with environmental standards and requirements, and highlight significant programs and efforts. This report represents a key component of the Department of Energy's (DOE's) effort to keep the public informed about the environmental condition at the Rocky Flats Plant (RFP). The Site Environmental Report helps characterize both the radiological and nonradiological condition of the site environment and helps identify trends with regard to effluent releases and environmental conditions.

This Executive Summary provides an overview of the report including a compliance summary for activities related to environmental statutes, regulations, orders, and agreements. Section 3 of this report provides a discussion of environmental monitoring programs at RFP and includes data on meteorological, air, surface water, groundwater, soils, and ecological monitoring. Environmental Remediation programs are reviewed in Section 4 , followed by discussions on external gamma radiation dose monitoring and radiation dose assessment. Section 7 includes a review of RFP's Quality Assurance program. Four appendices provide additional information on applicable guides and standards, analytical procedures, wind stability classes, and the basic concepts of radiation to assist in the understanding and interpretation of monitoring information and radiation dose assessment.

More comprehensive discussions on each topic can be found in the main text of this report. 
Ecological Environmental Statutes and Regulations
Progress continued in 1993 on preparation of Environmental Assessments (EAs' for the new Sanitary Landfill. Surface Water Structures Maintenance, the Drill Cuttings Drum Storage Facility, and resumption of Thermal Stabilization of Plutonium Oxide in Building 707. An EA is prepared to determine whether a proposed federal action will require preparation of an Environmental Impact Statement (EIS). Before preparation of an $E A$, the proposed federal action is evaluated as a possible Categorical Exclusion (CX), which is a category of actions that do not individually or cumulatively have a significant effect on the human environment and do not require either an EA or an EIS. Sixteen CXs were approved during 1993, and a contract was awarded by DOE for a new sitewide EIS.

In 1992, RFP initiated the Ecological Monitoring Program (EcMP) to demonstrate compliance with the Bald and Golden Eagle Protection Act; the Endangered Species Act; the Fish and Wildlife Coordination Act; the Migratory Bird Treaty Act; the Colorado NonGame, Threatened and Endangered Species Conservation Act; and Code of Federal Regulations (CFR) 10 CFR 1022, Compliance with Floodplain/ Wetlands Environmental Review Requirements.

Two 3-year surveys, initiated in 1992, continued in 1993 with the addition of the Colorado Butterfly plant to the survey for Ute Ladies'-Tresses. A permit from the Colorado Division of Wildlife to trap small mammals also was obtained to facilitate the survey, and monthly surveys on migratory birds were conducted.

In 1993, a pair of bald eagles built a nest at Operable Unit (OU) 3 near Standley Lake. The Colorado Bird Observatory was contracted to collect behavior and habitat-use data. The birds abandoned the nest in midMarch but had returned to the RFP vicinity by November 1993.

National Emissions Standards for Hazardous Air Pollutants (NESHAPs) govern radioactive and other hazardous air pollutants. Under regulations promulgated in 1989, NESHAPs limited the radiation dose to the public from airborne radionuclide emissions from DOE facilities to 10 millirem per year (mrem/yr) effective dose equivalent (EDE). RFP 1993 data indicate an EDE of 0.0016 mrem from radiologically contaminated 
soil and building emissions. Dose calculations for the 1993 calendar year (CY) are provided in Section 6, "Radiation Dose Assessment."

Duct assessment reports (DARs) based on several air quality studies were submitted to EPA as required by a March 1992 Administrative Compliance Order. A Clean Air Act Section 114 letter requesting additional information about RFP sampling systems was issued by EPA in September 1993. EG\&G provided the requested information in November 1993. EPA Region VIII is still considering whether the monitoring procedures are acceptable.

The calculated beryllium discharged from RFP during 1993 was 3.293 grams (g), compared to the daily stationary source limit of $10 \mathrm{~g}$ over a 24 -hour period set by Colorado Air Quality Control Commission Regulation No. 8.

Air Pollutant Emission Notices (APENs) are required by Colorado Air Quality Control Commission (CAQCC) Regulation No. 3 for all sources that generate regulated nonradionuclide air pollutants. The air pollutant emissions reported on the source-specific APENs comprise the nonradionuclide air emission inventory for RFP A list of the buildings and operations for which APENs and reports were submitted in 1993 is provided in Table 2-1.

Under the provisions in the 1992 Colorado Air Pollution Control and Prevention Act, RFP will need to develop a facility operating permit that includes all emissions limitations and standards applicable to plant sources, record-keeping and reporting requirements, and provisions to demonstrate that RFP is in compliance with all applicable air quality requirements. A planning effort is underway to identify and resolve the issues associated with this operating permit application which is to be submitted one year after EPA approval of the Colorado permit program. For planning purposes, the submittal date for RFP's operating permit application to Colorado Department of Health $(\mathrm{CDH})$ is assumed to be November 1995 .

CAQCC Regulation No. 7, "Regulation to Control Emissions of Volatile Organic Compounds," was revised in 1993 and with one exception, applies only to ozone nonattainment areas. Requirements for disposal 
of volutile organic compounds (VOCs) apply statewide. The ozone levels of the air quality control region in which $\mathrm{RFP}$ is situated are within attainment requirements. However, RFP is still subject to Regulation No. 7 until EPA reclassifies the region. All new sources of VOCs at RFP must comply with the work practice standards and control technology provisions of the regulation on commencement of operations.

Regulations concerning the use of ozone-depleting substances (ODSs) at RFP include 40 CFR Part 82, "Protection of Stratospheric Ozone," and CAQCC Regulation No. 15, "Regulation to Control Emissions of Ozone Depleting Compounds." CAQCC Regulation No. 15 became effective in January 1993 and was revised in May and November 1993. ODSs include halons, hydrobromofluorocarbons (HBFCs), carbon tetrachloride $\left(\mathrm{CCl}_{4}\right), 1,1,1$-trichloroethane (TCA), and many commonly used refrigerants or cholrofluorocarbons (CFCs), and hydrochlorofluorocarbons (HCFCs). RFP Procedure 1-D61-EPR-AQ.01, Stratospheric Ozone Protection was finalized in December 1993 and describes the responsibilities and requirements at RFP to demonstrate compliance with regulations.

Summaries of RFP usage of ODSs and the compliance activities related to stratospheric ozone protection regulations are provided in the Compliance Summary of this report.

\section{Clean Water Act}

The Clean Water Act (CWA) provides for the National Pollutant Discharge Elimination System (NPDES), a program requiring permits for discharges from a point source into surface water of the United States. RFP's permit, which expired in 1989, was extended administratively until renewed. An updated renewal application was submitted in March 1993.

The NPDES permit identifies seven monitoring points for control of discharges, three of which are capable of discharging water offsite. In July 1993, EPA began to draft a renewal of the RFP NPDES permit and stated that there will be a change in the number of discharge points, limiting new permit coverage to the Waste Water Treatment Plant (WWTP) and storm water monitoring locations. Potentially, other discharge locations will be 
regislated under the Comprehensive Environmental Response, Compensation and Liability Act (CERCLA) and will require Pond Managernent Interim Measure/Interim Remediation Action (IM/IRA). Permit preparation continued throughout the year but EPA had not released a draft permit by the end of 1993.

Updates to the Spill Prevention Control and Countermeasures/ Best Management Practices Plan (SPCCl BMP) were initiated in 1993 to meet anticipated requirements of the Oil Pollution Act of 1990 and the Storm Water Pollution Prevention Plan (SWPPP) provision expected in the renewed NPDES permit.

Federal Insecticide, Fungicide, and Rodenticide Act

Toxic Substances Control Act

Resource Conservation and Recovery Act
The Federal Insecticide, Fungicide, and Rodenticide Act (FIFRA) governs the registration and use of pesticides, herbicides, and rodenticides. The FIFRA program at RFP tracks the materials from their initial purchase to final disposal and helps ensure that all pesticides on plantsite are EPA-registered, applied by licensed contractors, and disposed of properly. Approval of the FIFRA Program Management Plan, drafted in 1993, is anticipated by mid-1994.

Compliance with the Toxic Substances Control Act (TSCA) at RFP is directed at management of polychlorinated biphenyls (PCBs) and containerized waste asbestos from abatement projects. In 1993, 49 drums of radioactive asbestos were shipped to the DOE Hanford site in Washington, where RFP has smallquantity generator status. RFP continues in its efforts to ship low-level asbestos to the Nevada Test Site (NTS) for disposal. Radioactive PCB wastes continue to be stored at RFP under a 1993 draft compliance agreement among EG\&G, DOE, and EPA Region VIII until offsite disposal for radioactive PCB wastes can be achieved. Finalization of the compliance agreement is expected in 1994.

During 1993, the Resource Conservation and Recovery Act (RCRA) Part A permit was revised three times to request changes to interim status and to support Part $B$ permit modification requests. Four requests for modifications to the RFP RCRA Part B Operating Permit were submitted to $C D H$. Part $A$ and Part $B$ revisions 
National Response Center (NRC) Notifications

\section{Waste Minimization}

submitted in 1993 are described in Section 2 , Compliance Summary. There were no NOVs issued under the Colorado Hazardous Waste Act (CHWA) in fiscal year (FY) 93.

The Interagency Agreement (IAG) requires RCRA Facility Investigations/Remedial Investigations (RFI/RI) Workplans as a function of characterizing the source of the contamination and the soils of an interim status closure unit. The Draft Phase I RFI/RI Report for the Solar Evaporation Ponds was submitted to DOE, RFO in September 1993. A preliminary submittal date of October 1993 for the draft Phase I RFI/RI for the Present Landfill is being renegotiated in an effort to combine multiple scopes which will ultimately compress the IAG milestones. There were no IAG milestones for either the Original Process Waste Lines or the West Spray Field during FY93.

In 1993, the RCRA Contingency Plan was implemented on 10 occasions as compared with 23 occasions in 1992. Descriptions of each of the releases are found in the RCRA portion of Section 2, Compliance Summary.

In 1993, the National Response Center was notified of six releases at RFP. Of these notifications, five were the result of release of ethylene glycol from automobile antifreeze. Two incidents involved privately-owned vehicles, two incidents involved government-owned vehicles, and one incident involved a portable piece of equipment. The sixth incident was from the release of mineral oil that caused a sheen on surface water. In contrast, there were 32 notifications to the NRC in 1992.

Waste minimization at RFP continued to improve in 1993. The carbon dioxide pellet cleaning system cleaned and decontaminated over 22,000 kilograms $(\mathrm{kg})$ of scrap metal, the Dustless Decon System (DDS) was procured and tested, and the "Zero Waste" machine coolant management program reduced coolant waste and through reuse eliminated approximately 5.000 gallons of coolant waste during 1993.

In 1993, the plant's waste minimization and pollution prevention efforts were recognized by two external a "ards; the 1992 Colorado Center for Environmental 
Maragement Certificate of Achievement for its "Zero Waste" coolant management, and a DOE, HQ Office of Envirunmental Restoration and Waste Management $\bullet$ award for its recycling achievements.

Total radioactive waste generation increased 4.6 percent from $1,141.56$ cubic meters $\left(\mathrm{m}^{3}\right)$ to $1,194.33 \mathrm{~m}^{3}$. TSCA waste increased over 600 percent from $1,506.39$ $\mathrm{kg}$ to $10,904.2 \mathrm{~kg}$. Total nonhazardous wastes increased 32 percent from $21,786.5 \mathrm{~kg}$ to $28,774.9 \mathrm{~kg}$. The increases in waste generation reflect the beginning of clean-up activities at the site. RFP is ir the process of redefining its waste minimization goals to account for the change in the plant's mission. Nonradioactive and nonhazardous waste materials that can not be eliminated from gencration will continue to be recycled through the plant's highly successful program.

\section{Compliance Issues.}

Since 1989, the management of RFP's mixed residues has been governed by a series of administrative and judicial orders issued in response to allegations by $\mathrm{CDH}$ and the Sierra Club that residues mixed with hazardous waste are subject to Colorado's RCRA regulations. In Settlement Agreement and Compliance Order on Consent No. 89-10-30-01 (November 11, 1989), CDH directed DOE to develop a Mixed Residues Compliance Plan by September 28, 1990. Subsequent to DOE's timely submission of the plan, $\mathrm{CDH}$ issued Settlement Agreement and Compliance Order on Consent No. 91-07-31-01 (July 31, 1991), instructing DOE to remove all backlog mixed residues from RFP by January 1, 1999. This order was superseded by Settlement Agreement and Compliance Order on Consent No. 93-04-23-01 (April 23, 1993), which directed DOE and EG\&G to implement a Mixed Residue Reduction Program (MRRP).

A citizen's enforcement action filed by the Sierra Club during this same time frame was subsequently amended, and on August 13, 1991, Judge Lewis T. Babcock directed DOE to obtain a RCRA permit for the existing inventory of certain mixed residues within two years (by August 21, 1993), or suspend all operations that generate mixed wastes.

Although DOE submitted a RCRA permit modification request to $\mathrm{CDH}$ on June 30,1992 , the outstanding mixed residue storage issues were not resolved, and $\mathrm{CDH}$ did not issue a modified RCRA permit by the 
Federal Facility Compliance Agreement
August 1993 deadline. In response to the missed deadline, Jucige Babcock issued a new judicial order on February 17, 1994, mandating a new permit schèdule and requiring DOE to submit several technical documents to $\mathrm{CDH}$. including revised room drawings, results from smoke and air flow pattern tests, proposed permit conditions for relabeling, and a schedule for container closure activities. Efforts are now underway to meet the requirements of this new order.

The NPDES Federal Facilities Compliance Agreement (FFCA) of March 1991 modified the permit terms and also required submittal of three compliance plans addressing administrative and physical changes to the plant. The Groundwater Monitoring Plan for the Sewage Treatment Plant (STP) Sludge Drying Beds and the Final Chromic Acid Incident Plan have been submitted and approved. The third plan to bring the Wastewater Treatment Plant (WWTP) (also known as the STP) into compliance with the FFCA is awaiting approval.

No Notices of Violation (NOVS) were issued to RFP in 1993 for violation of NPDES standards. During 1993, project work continued to progress in relation to the three compliance plans required by the NPDES FFCA. The FFCA requires submittal of quarterly progress reports to the EPA updating the status and schedule of projects within each compliance plan.

Accomplishments and activities that occurred in 1993 on the compliance plan are provided in Section 2, Compliance Summary.

The FFCA dealing with land disposal restricted (LDR) waste was signed by DOE, EPA and the State of Colorado in September 1989, and was followed by a second compliance agreement, referred to as Federal Facilities Compliance Agreement-II (FFCA-II). During the period of FFCA-II, DOE agreed to take all feasible steps to ensure accurate identification, safe storage, and minimization of restricted waste prohibited from land disposal.

The 1993 expiration date for FFCA-II was reached before negotiations on a replacement agreement could be completed. RFP is still pursuing the requirements of FFCA-II as if it were still in effect and is implementing programs initiated under FFCA-II to achieve LDR compliance. 
Interagency Agreement

Emergency Planning and Community Right-to-Know Act
The Interagency Agreement (IAG) for environmental restoration activities at RFP was signed on January 22, 1991 , by DOE, EPA, and CDH. The agreement clarified the responsibilities and authorities of the three agencies related to environmental restoration, standardized requirements, described the procedures to be followed, and helped ensure compliance with orders and permits. Section 4, "Environmental Remediation Programs," describes remediation activities accomplished during 1993.

During 1993, there were no releases of extremely hazardous substances or CERCLA hazardous substances that posed a potential impact beyond RFP boundaries and required notification to the State Emergency Response Commission (SERC) and Local Emergency Planning Committee (LEPC).

RFP submitted the "Tier II Emergency and Hazardous Chemical Inventory Forms" report to emergency planning agencies for the State of Colorado, Jefferson and Boulder counties, and the RFP Fire Department in 1993. The report is required under Section 312 of EPCRA and lists quantities and locations of hazardous chemicals. The RFP also submitted the "Toxic Chemical Release Inventory" (Form Rs) to the EPA and the State of Colorado in 1993 as required under Section 313 of EPCRA. This report contains information on quantities of routine and accidental releases of chemicals, the maximum amount of chemicals stored, and the amount of chemicals contained in wastes transferred offsite.

An Agreement in Principle (AIP) was executed between the DOE and CDH in 1989. In this agreement DOE committed to an expanded environmental monitoring program at RFP, acceleration of cleanup activities at some contaminated sites, and allocation of additional funds to the State of Colorado to administer RFP oversight programs, including the splitting of samples of water proposed for discharge from terminal ponds. Part of that agreement also provided for $\mathrm{CDH}$ to conduct the Rocky Flats Toxicologic Review and Dose

Reconstruction Study (CDH92). The intent of this study is to examine chemical and radionuclide emissions from RFP and assess what health impacts, if any, may have occurred to the public. Phase I of the study, the final 
Special Assignment Team draft report of the Reconstruction of Historical Rocky Flats Operations \& Identification of Release Points, was issued in August 1992. This is being followed by Phase II of the study, which will provide estimates of exposure risks. Completion of Phase II is not anticipated until 1995 or later.

On June 6, 1989, DOE mobilized a Special Assignment Team (Tiger Team and currently known as Progress Assessment Team) to provide an independent audit of operations and practices at RFP. The environmental portion of the audit focused on determining whether RFP activities created an imminent threat to the public or environment, whether operations were conducted in accordance with environmental requirements and best management practices, and the status of previously identified environmental concerns. Results of the original Tiger Team audit were reported in the Assessment of Environmental Conditions at the Rocky Flats Plant (DOE89). In April and May of 1993, a 17-member DOE Progress Assessment Team did a follow-up to the 1989 "Tiger Team" as well as to past Technical Safety Appraisals. This independent assessment focused on the environment, safety and health issues, corrective actions, and programs across plantsite. The team concluded that while "significant progress" had been made in correcting the deficiencies identified in the 1989 Tiger Team assessment, much remained to be done. All issues have corrective action plans in progress.

The 1993 mean temperature of $45.7^{\circ} \mathrm{F}$ was over $2^{\circ} \mathrm{F}$ below normal. The annual temperature extremes ranged from a high of $91^{\circ} \mathrm{F}$ on July 10 and July 29 to a low of $-10^{\circ} \mathrm{F}$ on February 16 and November 25. The 1993 peak wind gust of 82 miles per hour (mph) occurred on December 31. Precipitation during the year, total 12.07 inches, was over 3 inches below normal. The largest daily precipitation fell on June 7 with 1.15 inches of rain. The largest 15 -minute rainfall of 0.15 inches was recorded on March 28. Monthly precipitation ranged from 1.79 inches in June to 0.13 inches in January. 


\section{AIR MONITORING}

\section{Effluent Air Monitoring}

Nonradioactive Ambient Air Monitoring

Radioactive Air Moniforing
An overall decrease in radionuclide emissions seen at RFP is a reflection of reduced production activities as a result of the curtailment of plutonium production in late 1989. Production operations have not resumed because of the cancellation of new weapons systems and the shift in mission to environmental restoration and decontamination.

During 1993, total quantities of plutonium and uranium discharged to the atmosphere from RFP processing and support buildings were 0.1607 microcurie $(\mu \mathrm{Ci})$ and $1.597 \mu \mathrm{Ci}$, respectively. Total americium discharged in 1993 was $0.1575 \mu \mathrm{Ci}$. Total tritium discharged during 1993 from ventilation systems in which tritium is routinely measured was $0.0037 \mu \mathrm{Ci}$. The total quantity of beryllium discharged from ventilation exhaust systems was $3.293 \mathrm{~g}$, which was not significantly above background levels associated with the analyses.

The maximum total suspended particulate (TSP) value (24-hour sample) recorded in 1993 was 90.0 micrograms per cubic meter $\left(\mu \mathrm{g} / \mathrm{m}^{3}\right)$, which was 35 percent of the former TSP 24-hour primary standard. The annual geometric mean value was $48.6 \mu \mathrm{g} / \mathrm{m}^{3}$, which was 65 percent of the former TSP primary annual geometric mean standard. The observed 24-hour maximum for PM-10 sampler was $51.9 \mu \mathrm{g} / \mathrm{m}^{3}$ (34.6 percent of the primary 24-hour standard), and the annual arithmetic mean was $15.9 \mu \mathrm{g} / \mathrm{m}^{3}$ (31.8 percent of the primary annual arithmetic mean standard). Mean annual concentrations of particulates for onsite ambient TSP samplers and PM-10 samplers for the period 1989 to 1993 are shown in Section 3.2, Air Monitoring.

Overall mean plutonium concentration for onsite samplers was $0.056 \times 10^{-15}$ microcuries per milliliter $(\mu \mathrm{Ci} / \mathrm{ml})(2.07$ $\times 10^{-6} \mathrm{Becquerel}$ per cubic meter $\left[\mathrm{Bq} / \mathrm{m}^{3}\right]$ ), which is 0.28 percent of the offsite Derived Concentration Guide (DCG) for plutonium in air. Overall mean plutonium concentration for perimeter samples was $0.002 \times 10^{-15} \mu \mathrm{Ci} / \mathrm{ml}(5.5 \mathrm{x}$ $10-{ }^{8} \mathrm{~Bq} / \mathrm{m}^{3}$ ), which is 0.012 percent of the offsite DCG for plutonium in air. Overall mean plutonium concentration for community samplers was $0.001 \times 10^{-15} \mu \mathrm{Ci} / \mathrm{ml}(3.7 \mathrm{x}$ $\left.10^{-8} \mathrm{~Bq} / \mathrm{m}^{3}\right)$, or 0.006 percent of the offsite DCG for plutonium in air. 


\section{SURFACE-WATER MONITORING}

Rocky Flats Plant Site Surface-Water Monitoring
Maximum volume-weighted average concentrations and percent of DCG for plutonium, uranium, americium, and tritium of sampled effluents from North and South Walnut Creeks and Woman Creek are listed below.

\section{Surface-Water Effluents Percent Average Concentrations of

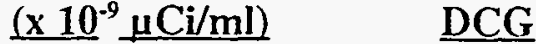

Plutonium

(Pond C-2)

$$
0.022 \pm 0.003
$$

Uranium-233/-234

(Pond C-2)

$$
1.08 \pm 0.10
$$

Uranium-238

(Pond C-2)

$$
1.22 \pm 0.09
$$

Americium

(Walnut Creek)

$0.018 \pm 0.001$

0.06

Tritium
(Pond A-4)
$11 \pm 9$
0.0 uranium and americium for samples of raw water taken from Ralston Reservoir and South Boulder Diversion Canal are listed below.

$\begin{array}{lrrr} & \begin{array}{c}\text { Raw Water Supply } \\ \text { Average Concentrations } \\ \left(\mathbf{x ~} \mathbf{1 0}^{-9}\right.\end{array} & \begin{array}{c}\text { PCi/ml }) \\ \text { Percent } \\ \text { of } \\ \text { DCG }\end{array} \\ \text { Plutonium } & -0.002 \pm 0.003 & -0.01 \\ \text { Uranium-233/-234 } & 0.45 \pm 0.20 & 0.09 \\ \text { Uranium-238 } & 0.36 \pm 0.15 & 0.06 \\ \text { Americium } & 0.002 \pm 0.004 & -0.01\end{array}$

GROUNDWATER MONITORING
RFP's current Groundwater Monitoring Program was established to characterize groundwater quality and hydrogeology for purposes of site characterization, containment plume monitoring and prediction, remediaiion planning, and monitoring requirements. Groundwater data is provided monthly to government agencies and surrounding communities.

Of the 676 wells in existence at RFP at the end of 1993, 430 were sampled on a regular basis. Approximately 150 of these wells were new installations 
during 1993. Groundwater monitoring wells are classified as background, RCRA regulatory, RCRA characterization, CERCLA, boundary, or special purpose, according to the regulatory requirement or purpose they meet.

Groundwater investigation and restoration activities at RFP include establishment of groundwater quality standards that are specific to each Operational Unit (OU) and reflect state and federal requirements. Given the present understanding of hydrogeologic relationships, there are no known bedrock pathways through which groundwater contamination can directly leave RFP and migrate into a confined aquifer system offsite. Information specific to each OU is found in Section 3.4, "Groundwater Monitoring."

SOIL MONITORING

\section{ECOLOGICAL STUDIES}

Soil samples taken in 1993 to determine plutonium concentration at a 1-mile radius from RFP ranged from 0.04 $\mathrm{pCi} / \mathrm{g}$ to $18.8 \mathrm{pCi} / \mathrm{g}$. Soils sampled at a 2 -mile radius from RFP ranged from $0.02 \mathrm{pCi} / \mathrm{g}$ to $4.5 \mathrm{pCi} / \mathrm{g}$. Baseline soils data from background areas are needed to evaluate the effects of RFP on the soils at the site. A Background Soils Characterization Project will determine background concentrations of various soil constituents accurately and will compare them to concentrations found in and around RFP. Locations which have topography, soil type, and climate similar to RFP will be sampled during the 1994 field season.

Ecological studies focus on the presence, abundance, and spatial distribution of onsite plant and animal life in order to identify impacts of RFP activities on compliance with the National Environmental Policy Act (NEPA) and other related statutes and regulations. To provide comprehensive ecological information about RFP, the Ecological Monitoring Program (EcMP) was initiated in 1992. Much of the first full season of sampling took place in the nonimpacted areas to assess baseline conditions.

Information stored in seven newly developed technical modules and databases will be available for future land use studies, feasibility studies, and risk assessments, as well as for compliance purposes. 
ENVIRONMENTAL REMEDIATION PROGRAMS
Three sirveys related to the Endangered Species Act were conducted in 1993, and the Army Corps of Engineers completed the field portion of a Wetland Delineation Project to identify all the wetlands on plantsite.

Environmental Remediation (ER) Programs were established to comply with regulations for characterization and cleanup of inactive waste sites at RFP. The legal framework that establishes the scope and schedule for projects in the ER Program is the IAG. The IAG addresses details on specific response requirements that must be met during the CERCLA and RCRA processes used to assess and remediate identified IHSSs on or adjacent to RFP. These IHSSs have been categorized into 16 OUs. These OUs, along with activities that occurred during 1993, are detailed in Section 4, "Environmental Remediation Programs."

The IAG Statement of Work (SOW) provides details on the activities that must occur and the sequence of those activities to satisfy the requirements of the IAG. As of the end of FY93, a total of 66 milestones were met, 22 were extended and met, 6 were extended to a future date, and 1 milestone was missed, for a total of 95 IAG enforceable milestones scheduled to date. The need to bring the regulatory agencies to the negotiating table to develop a more workable agreement became more crucial as it became apparent that no future IAG milestones would be met on the original IAG schedule because of increasing scope, changing requirements, and technical and policy issues. Negotiations are currently ongoing.

The 1993 average annual environmental gamma dose equivalents, as measured onsite, in the perimeter environments, and in local communities using model UD802AS Panasonic Thermoluminescent Dosimeters (TLDs) were 137, 122, and 132 millirem (mrem), $(1.37,1.22$, and 1.32 milliSieverts [mSv]), respectively. "This dose is ation naturally occurring sources of radiation, and is similar to doses reported by the National Council on Radiation Protection and Measurement (NCRP) for background gamma radiation in the Denver area." 
RADIATION DOSE
ASSESSMENT
Maximum radiation dose from all pathways to a hypothetical individual continuously present at the site boundary was 0.48 mrem Effective Dose Equivalent (EDE). The maximum radiation dose to an individual from RFP air emissions of radioactive materials, as determined by the CAP88-PC meteorological dispersion/radiation dose computer code, was $1.7 \times 10^{-5}$ mrem EDE from measured building air emissions and $1.6 \times 10^{-3}$ mrem EDE from estimated soil resuspension. Collective population dose to a distance of 50 miles was estimated as 0.1 person-rem EDE.

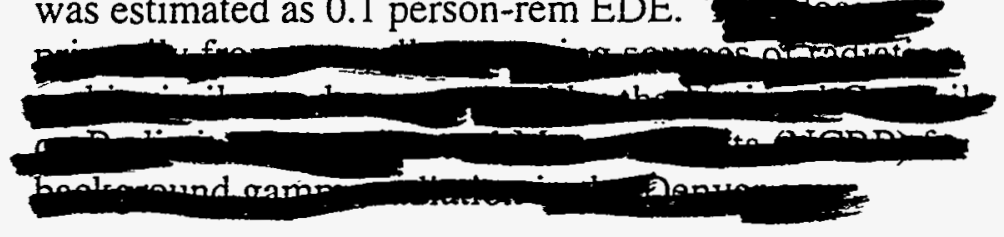




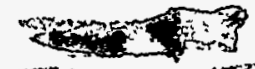

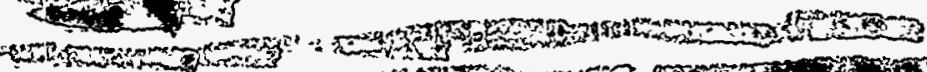

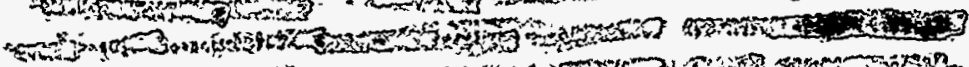

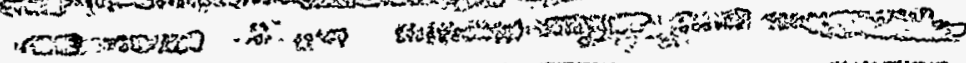

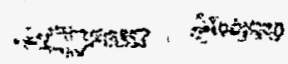

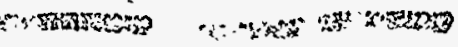




\section{Introduction}

The Rocky Flats Plant is owned by the U.S. Department of Energy and operated by EG\&G Rocky Flats, Inc. Located on approximately 6.550 acres in northern Jefferson County, the plant is transitioning from its historical production mission to a new mission focusing on environmental restoration and waste management, decontamination of facilities, and economic development. The following section provides a description of the plant's environment, its historical mission, its new mission, and current operations. 
ROCKY FLATS SITE ENVIRONMENT
The Rocky Flats Plant (RFP), owned by the U.S. Department of Energy (DOE) and operated by EG\&G Rocky Flats, Inc., is located on approximately 6.550 acres in northern Jefferson County, Colorado. The facility is approximately 16 miles northwest of downtown Denver (Figure 1-1). Primary facilities are located on approximately 384 acres near the center of the plantsite within a fenced security area. The remaining plant area contains limited support facilities and serves as a buffer zone to the former production areas (DOE80). (NOTE: Literature citations abbreviated within this report are alphabetically listed in Section 8, "References.")

Approximately 2.1 million people live within a 50-mile radius of RFP. Adjacent land use is a mixture $0{ }^{\circ}$ agriculture, open space, industry, and low-density residential housing.

Figure 1-1. Area Map of RFP and Surrounding Communities 


\section{Climate}

Topography

\section{Geology}

\section{Hydrology}

The cliniate at RFP is temperate and semiarid, characteristic of Colorado's Front Range of the Rocky Mountains. Elevation and major topographical features significantly influence climate and meteorological dispersion characteristics of the RFP site. Winds, although variable, are predominately northwesterly. Annual precipitation measures nearly 16 inches, with more than 40 percent occurring from April through June. Maximum and minimum temperatures average 76 degrees Fahrenheit $\left({ }^{\circ} \mathrm{F}\right)$ and 22 ${ }^{\circ} \mathrm{F}$, respectively (DOE80). Meteorological and climatological information for 1993 is provided in Section 3.1.

Located at an elevation of approximately 6,000 feet, the RFP is on the eastern edge of a geological bench known locally as Rocky' Flats. This bench, approximately 5 miles wide in an cast-west direction, flanks the eastern edge of the abruptly rising foothills of the Front Range. To the east, topography slopes gradually at an average downgrade of 95 feet per mile. Approximately 20 miles to the west, the continental divide rises to elevations exceeding 14,000 feet.

RFP is situated on the Rocky Flats Alluvium, an alluvial fan deposit, varying in thickness from approximately 103 feet to less than 10 feet and providing a gravelly cover over bedrock. Underlying bedrock formations consist primarily of claystone with some siltstones. Seismic activity of the area is low, and the potentials for landslides and subsidence are not likely at RFP (DOE80). Additional information on the geology of RFP is contained in the Geologic Characterization of the Rocky Flats Plant (EGG91f).

Surface drainage generally occurs in a west-to-east pattern along five short-lived streams within RFP. North Walnut Creek, South Walnut Creek. and Woman Creek drain the main plant facilities area. The other two drainages are Rock Creek and an unnamed tributary that flows into Walnut Creek. Water from Woman Creek drains into Standley Lake, which is used as a municipal water supply. Surface runoff from RFP is collected in an interceptor ditch before it enters Woman Creek, diverted to a temporary holding pond, and piped into the Broomfield Diversion Ditch, which bypasses Great Western Reservoir, a water supply for the City of Broomfield. Water from North Walnut Creek and South Walnut Creek discharges into the Broomfield Diversion Ditch. 
Groundwater systems consist of a shallow, unconfined system in the Rocky Flats Alluvium and a confined system in deeper sandstone units within the underlying bedrock. The flow of groundwater is locally controlled by the topography and subcropping sandstone channels (refer to Figure 3.4-1, Generalized Cross Section of the Stratigraphy Underlying the RFP).

The plant and animal communities in woman Creek, and Walnut Creek watersheds were characterized at RFP during field studies in 1991 through early 1992. Terrestrial plant (including emergent wetland vascular plants) and animal taxa numbered 532 and 300, respectively. Aquatic plant species (non-vascular only) and animal taxa numbered 236 and 164 respectively. The most important factor affecting species diverse in communities is the amount of mosture available (xeric zone - dry; mesic zone - moderate mosture; and hydric zone - wet) to support plant growth, the primary producers in the food chain. Grasslands cover 82.3 percent of RFP zones; disturbed areas like industrial complex and clay pits that formerly were grasslands account for 12.0 percent of the area. The remaining areas are covered by marshlands, shrublands, and woodlands.

Identifying adverse or positive impacts of RFP activities on the ecological resources of the plantsite is an on-going and routine part of NEPA-related operations and is described in Section 3.6, Ecological Studies.

The United States Atomic Energy Commission (AEC), the early predecessor to the DOE, originally announced plans to construct the RFP in 1951. Construction of the facility began in 1952, and the first components were completed and shipped offsite in 1953. The primary mission of the facility was to produce components for nuclear weapons from materials such as plutonium, uranium, beryllium, and various alloys of stainless steel. Additional plant missions included plutonium recovery and reprocessing, and waste management. Production activities included metal fabrication and assembly, chemical recovery and purification of process-produced transuranic radionuclides, and related quality control functions. 
The oricinal plantsite represented a total area of 2.520 acres, with the early buildings constructed within a controlled area of less than 400 acres. Approximately 700,000 square feet $\left(\mathrm{ft}^{2}\right)$ of building floor space was available in 20 structures. Through the years, the plant's environmental buffer zone was enlarged, and additional structures were built. Today, approximately 140 structures contain nearly 2.76 million $\mathrm{ft}^{2}$ of floor space. Of this space, major manufacturing, chemical processing, plutonium recovery, and waste treatment facilities occupy approximately 1.6 million $\mathrm{ft}^{2}$.

RFP is a government-owned, contractor-operated facility. The AEC was the responsible government agency at RFP until 1974, when the United States Energy Research and Development Administration (ERDA) succeeded the AEC. The ERDA, in turn, was succeeded by the DOE in 1977. Within DOE, administrative responsibility for RFP historically was delegated to the Albuquerque Operations Office, which established the Rocky Flats Area Office (RFAO) for day-to-day contact at RFP. In 1989, the RFAO was upgraded to the Rocky Flats Office (RFO), reporting directly to DOE Headquarters (HQ) in Washington, D.C.

The Dow Chemical Company was the first prime contractor for operations at RFP. Rockwell International replaced the Dcw Chemical Company in 1975 and operated RFP through 1989. EG\&G Rocky Flats, Inc., replaced Rockwell International in 1990. EG\&G Rocky Flats employed 6,512 people in December 1993.

The plant's historical production mission was officially discontinued in 1992 with the end of the Cold War and the administration's decision not to resume weapons component production activities at RFP. EG\&G formed a Transition Management organization to help RFP undertake a new mission focusing on environmental restoration, waste management. decontamination and decommissioning (D\&D) of facilities, and economic development. The focus of the transition process during 1992 was the development of the Rocky Flats Plant Mission Transition Program Management Plan. The plan described a strategy and outlined schedules for preparing facilities for cleanup, deactivation, decontamination, and alternate uses. Waste and environmental facilities at the plant continued to operate in support of transition efforts, including decontamination of facilities. Consolidation of special nuclear material, classified documents, and other sensitive 
material into fewer, more centralized locations on planisite was an important element of the plan.

In 1993, activities at Rocky Flats have continued in environmental cleanup and restoration, waste management, consolidation of materials, and economic development. In addition much work has been accomplished in the areas of site planning and integration.

RADIATION AT THE ROCKY FLATS PLANT
Radioactive materials and radiation-producing equipment are managed at the RFP. Radiation-producing equipment includes $\mathrm{X}$-ray machines and linear accelerators. Primary radioactive materials include plutonium, americium, uranium, and tritium. Many of these materials will continue to be handled at RFP as the plant proceeds with decontamination of facilities and consolidation of materials for safe storage and eventual transfer offsite. The potential exists for these materials to be handled in sufficient quantities during the transition process to pose an offsite hazard. The most important potential contributor to radiation dose from these materials is alpha radiation emitted by plutonium, americium, and uranium.

Because of the low penetrating ability of alpha radiation, these materials pose a potential internal radiation dose hazard; that is, the radioactive material must be taken into the body for the alpha radiation to be harmful. For this reason, environmental protection at RFP focuses on minimizing release of radioactive materials to the environment. Environmental monitoring focuses on pathways by which the materials could enter the body, such as air inhalation and water ingestion. A pathway is a potential route for exposure to radioactive or hazardous materials.

Appendix A, "Perspective on Radiation," describes the basic concepts of radiation. Readers unfamiliar with the types and sources of ionizing radiation are encouraged to read Appendix A for a better understanding of environmental monitoring data and radiation dose assessment at RFP. A detailed assessment of radiation dose to the public from RFP is presented in Section 6, "Radiation Dose Assessment." 


\section{Compliance Summary}

The Rocky Flats Plant is a closely regulated and monitored facility. Thousands of samples of air. soil, and water are collected and analyzed annually to ensure that operations are conducted in a manner that protects employee and public health, and the environment. The results of these analyses are reported during monthly public meetings and to various local, state, and federal regulatory authorities. This section is designed to summarize compliance activities related to environmental statutes, regulations, orders, and agreements. 
$\cdot$ 
NATIONAL ENVIRONMENTAL POLICY ACT

Environmental Assessment
National Environmental Policy Act (NEPA) is a general statute that declares a national environmental policy and requires federal agencies to consider the environmental impacts of their plans and activities. Federal regulations require NEPA documentation, which may include a categorical exclusion (CX), an Environmental Assessment (EA), or an Environmental Impact Statement (EIS).

The RFP established a NEPA Compliance Committee (NCC) in February 1989 to provide an integrated review, guidance, and oversight function for plantwide activities. The NCC created an RFP Environmental Checklist (EC), which is prepared for all proposed actions with potential environmental impacts. The EC provides an initial screening and review of construction and engineering projects to determine whether submission of an Action Description Memorandum (ADM) is required. $A D M s$ are submitted to DOE for a determination of the level of NEPA documentation required. DOE provides guidance regarding NEPA compliance in Code of Federal Regulations, 10 CFR 1021, and in DOE Order 5440.1E.

In 1993, the NCC provided information and recommendations on approximately 50 projects related to construction, refurbishment, and upgrade of RFP facilities.

If there is the likelihood that a proposed federal action will not cause a significant impact to the human environment, then an Environmental Assessment (EA) is prepared as an alternative to a more costly, time-consuming EIS. If, after considering comments from regulators and the public, the federal agency determines that no EIS is required, a Finding of No Significant Impact (FONSI) that documents this decision is prepared. Before preparation of an EA, the proposed federal action is evaluated as a possible CX. The CX is a category of actions that do not individually or cumulatively have a significant effect on the human environment and do not require either an EA or an EIS. Sixteen CXs were approved for RFP in 1993. 
Environmental Impact Statement
EAs lor the following proposed actions are in various stages of preparation and review.

- New Sanitary Landfill

- Surface Water Structures Maintenance

- Drill Cuttings Drum Storage Facility

- Resumption of Thermal Stabilization of Plutonium Oxide in Building 707

When there is potential for a proposed action to have a significant impact on the environment, an EIS is prepared. The EIS identifies alternatives to the proposed action, including the possibility of the "no action" alternative, and provides a detailed assessment of the impact of each alternative on all aspects of the environment and human heaith.

Although RFP is involved with small pieces of programmatic EISs within the DOE complex. the most recent site-specific EIS for the plant was the EIS published in 1980. In 1993, a contract was awarded by DOE for a new Sitewide EIS. Preliminary work was begun on the Community Relations Plan (CRP), and a Notice of Intent (NOI) stating that an EIS will be prepared for RFP. These are projected for publication in the Spring of 1994.

The implementation of NEPA focuses on the predecisional aspects of an action. Mitigation is part of the postdecisional phase of NEPA. "NEPA Implementing Procedures and Guidance," 10 CFR 1021, requires the publication of a Mitigation Action Plan (MAP) for EAs and EISs that include mitigation commitments before the EA/FONSI is completed and after the EIS/Record of Decision (ROD) has been issued. The MAP documents environmental commitments made in an EIS/ROD or an EA/FONSI and reports implementation of those commitments.

The MAP for the Supercompactor and Repacking Facility (SARF), approved in January 1992, is the only RFP MAP in effect. An annual report is prepared each vear to verify and validate that the commitments made for mitigating actions are being done. No MAPS were published for RFP in 1993. 


\section{ECOLOGICAL ENVIRON- MENTAL STATUTES AND REGULATIONS}

In 1.992, RFP initiated the Ecological Monitoring Program (EcMP) to demonstrate compliance with the Bald and Golden Eagle Protection Act; the Endangered Species Act; the Fish and Wildlife Coordination Act; the Migratory Bird Treaty Act; the Colorado NonGame, Threatened, and Endangered Species Conservation Act; and 10 CFR Part 1022, Compliance with Floodplain/Wetlands Environmental Review Requirements.

One of the primary goals of the EcMp is to gather baseline ecological data from potentially impacted and nonimpacted areas. This ecological database also supports compliance with 43 CFR Part 11, Natural Resources Damage Assessments.

On January 27, 1993, a Public Notice of Wetland/ Floodplain Involvement was published in the Federal Register, as required by CFR 1022, which established DOE policy with respect to compliance with Executive Order (EO) 11990, Protection of Wetlands and EO 11988, Floodplain Management. DOE accommodates the requirements of these two EOs through the incorporation of floodplain management goals and wetlands protection considerations into its planning, regulatory, and decision making processes.

Two 3-year surveys were initiated in 1992 for the Ute Ladies'-Tresses orchid, a federally listed threatened species, and the Preble's Meadow Jumping Mouse, which is listed as a federal Category 2 species. Category 2 indicates that the Preble's Meadow Jumping Mouse is presently neither threatened nor endangered, but is under consideration for threatened status. The Colorado Butterfly plant, a State of Colorado Category 2 species of concern, was added to the survey for Ute Ladies'-Tresses in 1993. A permit to trap small mammals, including the Preble's Meadow Jumping Mouse, was obtained from the Colorado Division of Wildlife to facilitate the survey. Monthly surveys on migratory birds were also conducted.

In 1993, a pair of bald eagles built a nest at Operable Unit (OU) 3 near Standley Lake. The Colorado Bird Observatory was contracted to collect behavior and habitat-use data. The birds abandoned the nest in midMarch but had returned to the RFP vicinity by November 1993. 
NATIONAL HISTORIC PRESERVATION ACT
Preservation and management of prehistoric, historic, and cultural resources on lands administered by the DOE are mandated under Sections 106 and 110 of the National Historic Preservation Act (NHPA). The NHPA requires a federal agency, before undertaking any project, to adopt measures to mitigate potential adverse effects of that project on sites, structures, or objects eligible for inclusion in the National Register of Historic Places. A sitewide archaeological survey at RFP was originally conducted in 1991. This survey evaluated all cultural resources against criteria for nomination to the National Register of Historic Places. Survey results were reported in "Cultural Resources Class III Survey of Department of Energy, Rocky Flats Plant, Northern Jefferson and Boulder Counties, Colorado" (Version 1.0, August 1, 1991). Although no new archaeological data were generated during 1993, information from the report continues to be used in planning remediation and other construction activities to prevent damage to, or destruction of, cultural resources at RFP.

The Clean Air Act (CAA), as amended by the Clean Air Act Amendments of 1990 (CAAA), sets standards for ambient air quality and for air emissions of hazardous air pollutants. The federal regulatory agency of authority is the Environmental Protection Agency (EPA). Under the CAA, states may administer and enforce CAA provisions by obtaining EPA approval of a State Implementation Plan (SIP). Colorado has been granted such CAA primacy by the EPA for air pollutants other than radioactive materials. The 1992 Colorado Air Pollution Prevention and Control Act (formerly the Colorado Air Quality Control Act) establishes Colorado's program of air pollution control, with implementing regulations promulgated by the Colorado Air Quality Control Commission (CAQCC).
National Emission Standards for Hazardous Air Pollutants
National Emission Standards for Hazardous Air Pollutants (NESHAPs) govern radioactive and other hazardous air pollutants. In Colorado, the Colorado Department of Health (CDH) has been granted authority by EPA to regulate several hazardous pollutants including beryllium. mercury, vinyl chloride, and asbestos. Authority to regulate radionuclides remains 
with EPA. Under regulations promulgated in 1989 , NESHAPs have limited the radiation dose to the public from airborne radionuclide emissions from DOE facilities to 10 millirem per year (mrem/yr) effective dose equivalent (EDE). A compliance report with dose calculations is due to EPA by June 30 of each year for the previous calendar year. The 1992 report showed an EDE to the public of 0.0016 mrem from radiologically contaminated soil and building emissions. The 1993 data from previous and new sources indicate an EDE of 0.0016 mrem from the same sources. Dose calculations for the 1993 calendar year are provided in Section 6, "Radiation Dose Assessment."

Duct assessment reports (DARs) based on several air quality studies were submitted to EPA as required by a March 1992 Administrative Compliance Order. A Clean Air Act Section 114 letter requesting additional information about the RFP sampling systems was issued by EPA in September, 1993. EG\&G provided the requested information in November 1993. EPA Region VIII is still considering whether the monitoring procedures of the locations are acceptable.

Regulation No. 8 implements NESHAPs for nonradioactive hazardous air pollutants in Colorado. Work standards, emission limitations, and ambient air standards for hazardous air pollutants including asbestos, beryllium, mercury, benzene, vinyl chloride, lead, and hydrogen sulfide are specified in this regulation. Potential hazardous air pollutants at RFP include asbestos and beryllium. Asbestos was used as insulation in older facilities and is handled according to NESHAPs regulations during demolition, renovation, or disposal. Beryllium is machined at RFP. The emissions standard is 10 grams $(\mathrm{g}$ ) of beryllium over a 24-hour period. Beryllium emissions did not exceed this standard in 1993 (see Section 3.2, "Air Monitoring").

Beryllium compliance tests were to be conducted on five air effluent ducts that had the highest potential beryllium emissions in 1991, upon resumption of plutonium operations at RFP. The tests were to measure beryllium emissions from each of the five locations over a 24-hour period in accordance with EPA Reference Method 104 and to serve as the basis of an application for a waiver of the emissions testing and 
Site Environmental Report for 1993

sampling protocol. Because of the change of plant mission in 1992, suspended plutonium and beryllium manufacturing operations have not resumed. As a result, in December 1993, RFP requested a review and reassessment of testing requirements by $\mathrm{CDH}$, Air Pollution Control Division (APCD). To date, only a partial reply has been received.

Air Pollutant Emission Notice (APEN) - Enforcement, maintenance. and implementation of air regulations concerning nonradionuclide air pollutant emissions have been delegated by the state to the $\mathrm{CDH}$, APCD. Under the provisions of Regulation No. 3 , $\mathrm{CDH}$ must receive an APEN for any existing or new source of air pollutants resulting from construction or alteration of any facility, process, or activity from which regulated air pollutants are emitted. APENs provide (1) source-specific data, (2) an estimate of the quantity and composition of the air emissions generated from source operations, and (3) supporting information for Colorado Air Permit regulations. When viewed as a related body of information, APENs make up the RFP nonradionuclide air emission inventory and reflect the dynamics of plant operations.

Approximately 240 APENs were filed with the state between 1990 and 1992, including the baseline air emission inventory completed in June 1991. Under the June 1989 Agreement in Principle (AIP) between DOE and $C D H, R F P$ was required to complete a baseline air emission inventory of plant operations and submit the inventory data to $\mathrm{CDH}$ by June 1991. Between June 1989 and June 1991, RFP conducted an air emission survey of full manufacturing and plutonium production activities, evaluated process operations, and prepared APENs and supporting building/process documentation for submittal to CDH. Since the completion of this initial effort, EG\&G's Air Quality Division (AQD) has provided additional APENs for new processes and revised existing APENs to reflect the changes in plant mission and operations.

Colorado Senate Bill 105, signed into law in June 1992, amended the Colorado Air Pollution Prevention and Control Act to comply with and implement the federal CAAA. One of the new provisions of the revised statute is the requirement for all existing industries within the state to re-inventory operations and file 
updated APENs with current operational information in preparation for the state major source operating permit program. Additionally, in both 1992 and 1993, the CAQCC established minimum reporting thresholds and expanded reporting requirements for both criteria and hazardous air pollutants. The regulatory due date for updated APENs for sources of criteria pollutants was December 31, 1992; sources of hazardous air pollutants were deferred until December 1993.

1992 APEN Update Submittal. In October 1992, the CAQCC established, through an emergency rule, temporary air pollutant de minimis reporting thresholds and specific reporting guidelines for the December 1992 APEN Update submittal. In accordance with the emergency rule, 116 APEN Update forms representing 192 emission sources and 46 supporting building APEN reports were submitted to the APCD in December 1992. Also, 72 APENs on file with the state for sources of crite-. ria pollutants (primarily diesel storage tanks) were identified for withdrawal because they did not exceed the minimum reporting requirements. This submittal reflected RFP operations under full production conditions.

1993 APEN Update Submittal. In August 1992, the CAQCC established, through the revision to CAQCC Regulation No. 3, final air pollutant de minimis reporting thresholds, source category exemptions, and specific reporting guidelines. In accordance with the revised provisions of Regulation No. 3, 12 APENs and 26 building APEN reports were submitted for sources of hazardous air pollutants to the APCD on December 15, 1993. In addition, 54 APENs on file with the state for sources of criteria pollutants were identified for withdrawal because they were no longer in operation or did not exceed the minimum reporting requirements. This submittal reflects RFP operations under transition conditions. A list of the buildings and operations for which APENs and reports were submitted in 1993 is provided in Table 2-1. 
Table 2-1

Air Pollutant Emission Notices and/or Reports Submitted or Resubmitted in 1993

Buildings/Operations for Which Air Pollutant Emission Notices Were Submitted or Resubmitted in 1993

Building

Reference Number(s)

374 (Revision 2)

442 (Revision 2)

442 (Revision 2)

444 (Revision 2)

707 (Revision 2)

707 (Revision 2)

776 Complex (Revision 2)

865 Complex (Revision 2)

865 Complex (Revision 2)

990 Complex (Revision 3)

RFP Plantwide

Supercompactor/TWS (Revision 2)

\section{Building/Operation Description}

Waste Treatment Process

Filter Test Penetrometers

Filter Test Penetrometers

Beryllium Machining

Foundry-Casting Operations

Production Operations

Low.level Waste Baler

Beryllium Forming

Beryllium Forming

Sanitary Wastewater Treatment

Beryllium Emission Points

Repackaging Facility/Tru-Waste Shredder
Date Submitted

To $\mathrm{CDH}$

$12 / 15 / 93$

$12 / 15 / 93$

$12 / 15 / 93$

$12 / 15 / 93$

$12 / 15 / 93$

$12 / 15 / 93$

$12 / 15 / 93$

$12 / 15 / 93$

$12 / 15 / 93$

$12 / 15 / 93$

$12 / 15 / 93$

$12 / 15 / 93$

Buildings/Operations for Which Air Pollutant Emission Reports Were Submitted or Resubmitted in 1993

Building

Reference Number(s)

111 (Revision 1)

123 (Revision 3)

218 (Revision 1)

331(Revision 2)

333 (Revision 2)

334 (Revision 2)

371 (Revision 3)

374 (Revision 2)

440 (Revision 2)

442 (Revision 3)

444 Complex (Revision 2)

447 Complex (Revision 2)

460 (Revision 3)

559/561 (Revision 2)

705 (Revision 2)

707 (Revision 2)

771 (Revision 3)

774 (Revision 2)

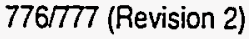

865 Complex (Revision 2)

881 (Revision 2)

889 (Revision 2)

990 Complex (Revision 3 )

991 (Revision 2)

RFP - Plantwide

Supercompactor/TWS (Revision 2)
Building/Operation Description

Media Arts/Photography

Analytical Laboratory

Nitric Acid/Industrial Storage

Vehicle Maintenance Garage

Major Paint Shop

Central Maintenance Facility

Plutonium RecoveryMaste Treatment

Process Wastewater Treatment

Modification/Fabrication Facility

Filter Test Facility

Manufacturing/Machining

Manufacturing/Machining

Non-nuclear Manufacturing

Analytical Laboratory

R\&D Laboratory

Plutonium Manufacturing Facility

Plutonium Recovery Facility

Process Waste Treatment

Manufacturing/Waste Handling

Beryllium/Metal Fabrication

Analytical/R\&D Laboratories

Waste Reduction Facility

Sanitary Wastewater Treatment

Shipping/Receiving Components

Beryllium Emission Points

Repackaging Facility/Tru-Waste Shredder
Date Submitted

$\underline{\mathrm{To} C D H}$

$12 / 15 / 93$

$12 / 15 / 93$

$12 / 15 / 93$

$12 / 15 / 93$

$12 / 15 / 93$

$12 / 15 / 93$

$12 / 15 / 93$

$12 / 15 / 93$

$12 / 15 / 93$

$12 / 15 / 93$

$12 / 15 / 93$

$12 / 15 / 93$

$12 / 15 / 93$

$12 / 15 / 93$

$12 / 15 / 93$

$12 / 15 / 93$

$12 / 15 / 93$

$12 / 15 / 93$

$12 / 15 / 93$

$12 / 15 / 93$

$12 / 15 / 93$

$12 / 15 / 93$

$12 / 15 / 93$

$12 / 15 / 93$

$12 / 15 / 93$

$12 / 15 / 93$ 


\section{Table 2-1 (continued) \\ Air Pollųtant Emission Notices and/or Reports Submitted or Resubmitted in 1993}

$\because$

Other Air Pollutant Emission Notice Submittals for New Sources for 1993

\author{
Building \\ Reterence Number(s) \\ 900 Complex (Revision 2) \\ Portable Backup Compressor \\ (Revision 0) \\ OU - 2 Generator (Revision 0) \\ Portable Env Rest (Revision 0) \\ Portable Env Rest (Revision 0)
}

\author{
Building/Operation Description \\ Bldg 995 Sullivan Air Compressor \\ Davey Air Compressor \\ Stewart/Stevenson Generator $250 \mathrm{~kW}$ \\ Detroit Diesel Generator Set $200 \mathrm{~kW}$ \\ Detroit Diesel Generator Sel 400 kW
}

\author{
Date Submitted \\ To $\mathrm{COH}$ \\ $06 / 24 / 93$ \\ $06 / 01 / 93$ \\ $07 / 30 / 93$ \\ $10 / 15 / 93$ \\ $10 / 15 / 93$
}

Other Air Pollutant Emission Reports Submitted in 1993

\section{Building \\ Reference Number(s)}

990 Complex (Revision 2)

Portable Backup )

Compressor (Revision 0

OU - 2 Generator (Revision 0)

Portable Generators Revision 0)

Portable Generators (Revision 0)

\section{Building/Operation Description}

Bldg 995 Sullivan Air Compressor

Davey Air Compressor

Stewart/Stevenson Generator $200 \mathrm{~kW}$

Detroit Generator Set $200 \mathrm{~kW}$

Detroit Generator Set, $400 \mathrm{~kW}$

\begin{tabular}{|c|}
\hline $\begin{array}{c}\text { Date Submittec } \\
\text { To } \mathrm{CDH}\end{array}$ \\
\hline $06 / 24 / 93$ \\
\hline $06 / 01 / 93$ \\
\hline $07 / 30 / 93$ \\
\hline $\begin{array}{l}10 / 15 / 93 \\
10 / 15 / 93\end{array}$ \\
\hline
\end{tabular}

1993 APENs Submitted for New Sources. During 1993, five APENs and supporting APEN reports were submitted for diesel fueled internal combustion engines used to power generators and compressors. Lists of these sources are provided in Table 2-1.

Colorado Air Permits - Under CAQCC Regulation No. 3 , an air emission permit must be obtained for each source of regulated air pollutants before the construction, modification, or operation of the source, unless the source was in existence before February 1, 1972. As part of the recent changes to CAQCC Regulation No. 3, certain source categories, such as support laboratories and maintenance painting operations, as well as sources emitting regulated pollutants below de minimus reporting thresholds, were also deemed to have a negligible impact on air quality and were thus exempt from permit requirements. In response to this regulatory change, a request was made to $\mathrm{CDH}$ to cancel 19 air emission permits for sources now exempt from permit requirements or no longer in service. After these cancellations have been granted, RFP will have 12 active air emission permits for sources currently in operation. Table 2-2 lists the status of the current air emission permits for RFP. 


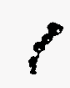

$\because$

Permit/Application

Building 122 Incinerator (3/25/82)

Building 771 Incinerator (8/28/85)

Building 776 Incinerator (3/25/82)

Fugitive Dust Renewed (12/6/91)

Urinalysis Laboratory Fume Hood

Bld́g. 123

750 Pad, pondcrete operations

$904 \mathrm{Pad}$, pondcrete operations

Building 776 Supercompactor and Repackaging Facility (SARF)/transuranic Waste Shredder-HEPA filter

Building 333 paint spray booth (2 units)

Building 333, grit blaster

Building 910 three natural gas generators

Building 910 one natural gas water heater

Building 995 natural gas fired sludge dryer 91JE430 Air

Building 440 paint spray booth

91JE537-1 Air

Building 440 paint spray booth

91JE537-2 Air

Building 460 machining and product

inspection processes

Open Burn Permit

Building 374 , saltcrete operations

OU 2 diesel generator

86JE018 Air

90JE045 (1 \& 2) Air

90JE045 (3\& 4) Alr

91JE047 Air
Table 2-2

Air Permits and Permit Applications

$\mathrm{CDH} \quad$ Initial permit issued in $12 / 91$.

$\mathrm{CDH}$ Categorical source exemption. Request permit cancellation 12/93:

$\mathrm{CDH}$ Initial permit issued $7 / 92$.

$\mathrm{CDH}$ Awaiting final permit.

$\mathrm{CDH} \quad$ Final permit issued $2 / 93$.

$\mathrm{CDH}$ Below reporting thresholds. Requested permit cancellation $12 / 93$.

$\mathrm{CDH}$ Below reporting thresholds. Requested permit cancellation $12 / 93$.

$\mathrm{CDH}$ Below reporting thresholds. Requested permit cancellation $12 / 93$.

$\mathrm{CDH}$ Below reporting thresholds. Requested permit cancellation 2/94.

CDH Permit expired 10/31/93. Assessing future need for open burn permit.

$\mathrm{CDH}$ Initial permit issued 11/93.

$\mathrm{CDH}$ Initial permit issued 3/94. 
Table 2-2 (continued) Air Permits and Permit Applications

Permivapplication

Building 443 sleam plant bollers (4 units)

Building 776 natural gas engines ( 4 units)

Building 702 natural gas engines (4 units)

Emergency generators - Buildings 120 , 566, 708(B), 708(C), 715A, 776, 881G (2 units), 920, 762A (PACS-1), 372A (PACS-2) 792A (PACS-3), Portals $A$ and $B .124,127,371,427,443$ (2 units), 559, 562, 708(A), 715, 727, 729, 779, 827,989 , and the Environmental Restoration generator trailer, Diesel-fired pumps - Buildings 373, 708, 771, and 928, Air compressors - Buildings 995 and 331

Number
92JE833(1-4) Air
92JE833 (5-8) Air

92JE833 (-12) Air

93JE1349

\section{Medium}

Air

Air
Issuing

Agency

$\mathrm{CDH}$ Initial permits issued $2 / 94$.

$\mathrm{CDH}$ Initial permit issued 2/94. Inactive sources. Requested permit cancellation $3 / 94$.

$\mathrm{CDH}$ Initial permit issued 2/94. Inactive sources. Requested permit cancellation $3 / 94$.

$\mathrm{CDH}$ Initial permit issued $3 / 94$.

Operating Permit Program - The 1992 Colorado Air Pollution Prevention and Control Act includes provisions to comply with the CAAA. As a result, CAQCC passed revisions to Regulation No. 3 that include a stateadministered operating permit program meeting the requirements of Title $\mathrm{V}$ of the CAAA. Under the provisions of these new regulations, RFP will need to develop a facility operating permit that includes all emissions limitations and standards applicable to plant sources, record-keeping and reporting requirements, and provisions to demonstrate that RFP is in compliance with all applicable air quality requirements. A planning effort is now underway to identify and resolve the issues associated with the preparation of an operating permit application for RFP. The submittal date for the RFP operating permit application will be one year after EPA approval of the Colorado permit program. For planning purposes, the submittal date for RFP's operating permit application to $\mathrm{CDH}$ is assumed to be November 1995. 
CAQCC Regulation No. 7

\section{Stratospheric Ozone Protection}

CAQCE Regulation No. 7, "Regulation to Control Emissions of Volatile Organic Compounds," was revised in 1993. Provisions of Regulation No. 7 apply only to ozone nonattainment areas, with the exception of requirements for disposal of volatile organic compounds (VOCs), which apply statewide. Although RFP is in an air quality control region where the ozone levels are within attainment requirements, the application for reclassification of the region has not been completed by the state for submittal to EPA. Therefore, RFP is still subject to the requirements of Regulation No. 7, and all new sources of VOCs at RFP must comply with the work practice standards and control technology provisions of the regulation on commencement of operations.

In response to a compliance provision of this regulation, RFP submitted a report to the APCD in 1991, which inventoried plantwide sources of VOCs and evaluated source-specific emission control methods to determine compliance. This inventory was representative of plant operations under full production and provided an assessment of reasonably available control technology (RACT) for sources of VOCs. Since 1991, all new sources or modifications to existing sources have been reviewed for applicability to the work practice standards and control technology provisions of this regulation.

Regulations concerning the use of ozone-depleting substances (ODSs) at RFP include 40 CFR Part 82, "Protection of Stratospheric Ozone," and CAQCC Regulation No. 15, "Regulation to Control Emissions of Ozone Depleting Compounds." 40 CFR Part 82 is the implementing regulation for Title VI of the CAAA, "Stratospheric Ozone Protection," and its subparts are listed as follows.

- Subpart A, Production and Consumption Controls, 58 FR 65018, published December 10, 1993 and effective January 1, 1994.

- Subpart B, Servicing of Motor Vehicle Air Conditioners, 57 FR 31242, published July 14, 1992 and effective August 13, 1992.

- Subpart C, Ban on Nonessential Products, 58 FR 69672, published December 30, 1993 and effective February 28. 1994. 
- Subpart D, Federal Procurement, 58 FR 54892, published October 22, 1993 and effective November 22, 1993.

- Subpart E, Labeling of Products Using Ozone Depleting Substances, 58 FR 8136, published February 11, 1993 and effective March 15, 1993.

- Subpart F, Recycling and Emissions Reduction, 58 FR 28660, published May 14, 1993 and effective June 14, 1993.

- Subpart G, Significant New Alternatives Policy Program, 58 FR 28094, proposed publication May 12, 1993.

40 CFR Part 82, Subpart A, requires the phase-out of production of class I ODSs by the end of 1995, except for methyl bromide, which will be phased out in the year 2000. Class I ODSs include halons, hydrobromofluorocarbons (HBFCs), carbon tetrachloride $\left(\mathrm{CCl}_{4}\right)$ 1,1,1-trichloroethane (TCA), and many commonly used refrigerants or chlorofluorocarbons (CFCs) such as Freon-11 and Freon-12. Production of class II ODSs, hydrochlorofluorocarbons (HCFCs), will be phased out from 2003 through 2030. The HCFC phase-out involves freezing or banning production of specified HCFCs after various dates and restricting the use of the compounds during the phase-out period.

On January 30, 1993, CAQCC Regulation No. 15, "Regulation to Control Emissions of Ozone Depleting Compounds" became effective. This regulation requires refrigerant reclaiming and recycle preventive maintenance plans, semi-annual inspections, equipment registration, refrigerant tracking, annual reporting, and registration of personnel handling refrigerants. CAQCC Regulation No. 15 was revised in May and November of 1993 to incorporate House Bill (HB) 93-1141 and 40 CFR Part 82, Subpart F. The revisions include a stationary equipment registration fee structure, a modified stationary equipment registration schedule, mandatory stationary technician certification, restrictions limiting the sale of refrigerant to only certified technicians, maximum leakage rates for refrigeration and air conditioning systems, and required use of approved recovery equipment and methods. CAQCC Regulation No. 15 requires registration of refrigeration systems with a 
compressor rating of 100 horsepower (hp) or greater, according to the following schedule:

$\begin{array}{ll}>500 \mathrm{hp} & \text { November } 15,1993 \\ >350 \mathrm{hp} & \text { January } 1,1994 \\ >200 \mathrm{hp} & \text { July 1,1994 } \\ >100 \mathrm{hp} & \text { January } 1,1995\end{array}$

RFP Procedure 1-D61-EPR-AQ.01, Stratospheric Ozone Protection, describes the responsibilities and requirements at RFP to ensure compliance with these regulations. This procedure was finalized in December 1993.

The AQD completed a report detailing "Essential Uses of Ozone-Depleting Substances Proposed Chlorofluorocarbon Banking Program" and an "Ozone-Depleting Substance Phaseout Activities 1993 Update Report" for submittal to DOE, RFO and DOE, HQ during February 1993 and November 1993, respectively.

Summaries of RFP usage of ODSs and the compliance activities related to stratospheric ozone protection regulations are provided below.

Stationary Refrigeration Sources. Section 608(c)(1) of the CAAA requires that, as of July 1, 1992, ODSs released during the servicing, repair, or disposal of appliances or industrial process refrigeration must be collected by equipment that recovers the refrigerant, or otherwise be evacuated into a container, or back into the appliance. Twenty-two refrigerant reclamation systems, fifteen backpack recovery units, and ten portable recovery units have been procured and are being used by maintenance personnel for high-pressure refrigeration systems. Four 1.500 pound reclaimers, and one 2,500 pound reclaimer have been procured for use with low-pressure refrigeration systems. An Acquisition Certification Form for this equipment was submitted to EPA in August 1993, as required by 40 CFR Part 82 Subpart F. Nineteen RFP technicians were registered with the state before July 1, 1993, according to requirements of CAQCC Regulation No. 15. Registration forms for six stationary refrigeration systems with compressor ratings greater than 500 hp were submitted to the state in November 1993, as required by CAQCC Regulation No. 15. 
Approximately 1,800 pieces of refrigerant-using equipment were identified in a comprehensive inventory completed in April 1993. A breakdown of the number and type of equipment included in the inventory is listed below. This list accounts for 1,607 pieces of equipment. Some of the inventory forms did not provide sufficient information to determine the equipment type. RFP ODS-using equipment is summarized below.

\section{Type of Equipment Number of Units}

$\begin{array}{lr}\text { Air Conditioners } & 309 \\ \text { Air Dryers } & 44 \\ \text { Drinking Fountains } & 117 \\ \text { Freezers } & 36 \\ \text { Heat Pumps } & 386 \\ \text { Oil Chillers } & 15 \\ \text { Process Chillers } & 24 \\ \text { Refrigerators } & 344 \\ \text { Vending Machines } & 58 \\ \text { Water Coolers } & 274\end{array}$

Tracking numbers have been assigned to each piece of equipment to facilitate refrigerant tracking. A refrigerant tracking form and computer database have been established to maintain records of refrigerant usage at RFP. The tracking form has been incorporated into the routine integrated work control package (IWCP) program. Preventive maintenance plans are being established for each type of refrigeration equipment and each maintenance area. Equipment registration forms will continue to be submitted to the state, as required.

Funding to procure and install high-efficiency purges and reseating pressure relief valves for nine low-pressure refrigeration systems or chillers was approved. These upgrades, which will help minimize emissions to the lowest achievable level and conserve refrigerants, are planned for the spring of 1994.

A preliminary scope and estimate to retrofit or replace 19 large chillers was conducted in FY93. The scope and estimate was completed in September 1993, and is broken out by individual chiller cost so that the work can be divided into different work packages (i.e., building or operational areas) if necessary. No funding for equipment retrofits or replacements was awarded for FY94. Because of the accelerated production phaseout, RFP could face a refrigerant shortage before the 
large sy'stems are retrofitted or replaced. The AQD is providing guidance to Facility Operations to minimize the impacts of the refrigerant production phase-out: however, the Maintenance Department is building their supply of refrigerants in the interim.

Mobile Sources. 40 CFR Part 82. Subpart B, requires technicians who service motor vehicle air conditioners to be certified, to use approved recovery equipment, and to maintain service records. The RFP Garage has established a tracking system to maintain accurate and complete records of air conditioner servicing and refrigerant usage of the RFP vehicle fleet. Garage personnel acquired approved motor vehicle air conditioner (MVAC) recovery equipment in 1990. An MVAC Recover/Recycle or Recover Equipment Certification Form was submitted to EPA in January 1993, in compliance with Subpart B. Nine RFP technicians have completed approved certification programs and are authorized to operate the recovery equipment; all were registered with the state before July 1, 1993, according to requirements of CAQCC Regulation No. 15.

The vehicles in the RFP fleet are leased through the General Services Administration (GSA) of the federal government. There are approximately 315 vehicles in the RFP fleet, including tractor trailers, etc., roughly 80 percent of which have air conditioners that use Freon-12. As the automobile industry phases in new refrigerants and new air conditioning systems, the new vehicles purchased by GSA and leased to the plant will be updated.

Halon Fire Suppression Systems. Production of halon was phased out in 1993, as required by 40 CFR Part 82, Subpart A. The RFP Fire Department uses Halon 1211 in plant fire extinguishers and Halon 1301 in building fire suppression systems. There are approximately 1,300 halon fire extinguishers and $14 \mathrm{Halon}$ Fixed Fire Suppression Systems (HFFSSs) on plantsite. The RFP Fire Department has purchased a halon recovery unit for Halon 1211 fire extinguishers. Replacement extinguishers will consist of dry chemical, carbon dioxide $\left(\mathrm{CO}_{2}\right)$, and pressurized water units, as applicable. The Fire Protection Engineering Department assessed the 14 HFFSSs, in accordance with DOE guidelines, and has proposed that one HFFSS will remain automatic with no modifications, four HFFSSs 
will remain automatic until alternate protection is provided, six HFFSSs will be converted to manual discharge only, one HFFSS will be disconnected, and two HFFSSs will be completely removed.

General Solvent Applications. Historically, carbon tetrachloride $\left(\mathrm{CCl}_{4}\right)$, Freon-113, and trichloroethane (TCA) have been used in various laboratory and production processes at RFP as cleaning agents or solvents. When plutonium operations were suspended in 1989 , most of these use points were eliminated. Efforts to eliminate chlorinated solvents, $\mathrm{CCl}_{4}, \mathrm{TCA}$, and Freon-113, used in many areas at RFP, have been ongoing since November 1987. Efforts to phase-out chlorinated solvent usage have included investigations of alternative cleaning methods and alternative density determination methods.

CLEAN WATER ACT
The Clean Water Act (CWA), originally passed by Congress in 1972, established ambitious goals to control pollutants discharged to United States' surface waters. Among the main elements of the CWA were nationally applicable, technology-based effluent limitations set by the EPA for specific industry categories and water quality standards set by states. The CWA also provided for the National Pollutant Discharge Elimination System (NPDES), a program requiring permits for discharges from a point source into surface waters of the United States. The first phase for expanding the NPDES to nonpoint sources is now underway with the issuance of storm water discharge permits to medium and large municipalities and sites with industrial activity.

The EPA and the State of Colorado both have roles in RFP's compliance with the CWA. While EPA Region VIII issues and administers the NPDES permit for RFP, the state, through the Colorado Water Quality Control Commission (CWQCC), sets surface water quality standards for receiving streams and bodies of water, including standards for the creek segments immediately downstream of RFP. The state also ratifies issuance of the federal permit within its borders and has the ability to veto the permit if it does not contain sufficient terms to protect all ambient segment water quality standards in the receiving stream. 


\section{National Pollutant Discharge Elimination System Permit}

The NFDES permit program controls the release of poliutarts into the waters of the United States and requires routine monitoring of point source discharges and reporting of results. RFP's first NPDES permit was issued by the EPA in 1974. The permit was reissued by EPA in 1984, expircu in 1989, and was extended administratively until renewed. An updated renewal application was submitted in March 1993.

The NPDES permit for RFP (\#CO-0001333) identifies seven monitoring points for control of discharges (EPA84). Three of these discharge points, Ponds A-4, $B-5$, and C-2, are capable of discharging water offsite. The NPDES permit terms were modified by the NPDES Federal Facility Compliance Agreement (FFCA), signed on March 25, 1991, by DOE and EPA, to eliminate two discharge points that were inactive (the Reverse Osmosis Pilot Plant and the Reverse Osmosis Plant), and to include new monitoring parameters at the other discharge locations. The current requirements, which went into effect in April 1991, are summarized in Appendix B (Table B-4). The NPDES FFCA also required submittal of three compliance plans addressing administrative and physical changes to the plant. Of the three plans, two have been submitted and approved (the Groundwater Monitoring Plan for the Sewage Treatment Plant Sludge Drying Beds and the Final Chromic Acid Incident Plan). A third plan to bring the Sewage Treatment Plant (STP) into compliance with the FFCA has been submitted but is awaiting approval. Other revisions to the NPDES monitoring requirements included changing one "point of compliance" location from Pond B-3 to the Wastewater Treatment Plant (WWTP) (also known as STP) discharge for most parameters. Also added were monitoring requirements for total chromium and whole effluent toxicity (WET) at the terminal ponds and monitoring for metals, VOCs, and WET at the WWTP discharge.

In July 1993, EPA began to draft a renewal of the RFP NPDES permit. EPA has stated that there will be a change in the number of authorized discharge points, limiting new permit coverage to the WWTP and storm water monitoring locations. Potentially, other discharge locations will be regulated under the Comprehensive Environmental Response. Compensation, and Liability Act (CERCLA) and will require Pond Management Interim Measure/Interim 
Remediation Action (IM/IRA). Permit preparation continued through the end of 1993 , but no draft document was released.

No Notices of Violation (NOVs) were issued to RFP in 1993 for violation of NPDES standards. One exceedance was reported by RFP for December 28 . 1993. The $\mathrm{pH}$ of WWTP effluent was measured at 5.78 standard unit (s.u.), below the allowable lower limit ( 6.0 s.u.) of the allowable operational range. The cause was attributed to pump problems which resulted in temporary low flow conditions. Corrective actions were taken to prevent a recurrence of this problem.

The AIP between DOE and CDH, approved June of 1989 , established a procedure whereby RFP would provide $\mathrm{CDH}$ with split samples of water proposed for discharge from the terminal ponds. This allows $\mathrm{CDH}$ to assess water quality before a discharge. Samples are split for analysis by CDH and RFP (or a subcontracted EPA-approved laboratory). When $\mathrm{CDH}$ makes its assessment and gives concurrence for discharge, pond waters are discharged directly to the Broomfield Diversion Ditch.

The NPDES permit recommends, as a Best Management Practice (BMP), the maintenance of terminal pond water levels at a maximum of 10 percent of capacity to allow sufficient storage volume for spill containment and flood control. Because of inherent delays caused by concurrent sampling and analysis and continuing storage of inflows, Ponds A-4, B-5, and C-2 often hold more than 10 percent of pond capacity.

During 1993, project work continued to progress in relation to the three compliance plans required by the NPDES FFCA. The FFCA requires submittal of quarterly progress reports to the EPA updating the status and schedule of projects within each compliance plan. Accomplishments and activities that occurred in 1993 on the compliance plans are provided below.

Groundwater Monitoring Plan for the WWTP Sludge Drying Beds. A draft Groundwater Monitoring Plan was initially submitted to EPA in July 1990. The plan proposed a method for characterizing groundwater beneath the sludge drying beds located east of the WWTP. The EPA subsequently recommended a phased approach, beginning with monitoring 
and chaiacterization of soil and water in the vadose zone. The Vadose Zone Monitoring Plan was submitted to EPA and approved in June 1991. An addendum to the monitoring plan was submitted for two additional sludge drying heds located east of Building 910. Field work was initiated during 1992 and completed as scheduled in February 1993. Monitoring activities are currently ongoing at both sites for a 1 -year period, with completion expected in March 1994.

Sewage Treatment Plant Compliance Plan. The Sewage Treatment Plant Compliance Plan (EGG90c), submitted to EPA in July 1990 , described planned improvements to the WWTP necessary to meet NPDES water quality standards and FFCA criteria. Completed work includes implementation of recommendations from diagnostic studies of treatment plant operations, installation of an autochlorination/dechlorination system, and additional influent and effluent instrumentation. Other planned improvements are included in a treatment plant upgrade project, which consists of three phases.

- Phase I includes construction of a mechanical sludge drying system and modifications to existing sludge beds to improve the efficiency of the sludge drying process. Construction was completed in April 1993, and the system was ready for routine operations in December 1993.

- Phase II includes electrical improvements for improved reliability and additional capacity, emergency electrical power provisions, construction of an addition to the existing laboratory building, addition of equipment and controls at the equalization basins, upgrades to existing structures and equipment within the WWTP including the polymer feed system and sand filters, and additional chemical storage. Construction is expected to begin in 1994.

- Phase III includes construction of additional influent and effluent storage for the WWTP, modification of the existing plant to provide for nitrification, and construction of a new denitrification system. The final scope and schedule of Phase III will be contained in the renewed NPDES permit.

Chromic Acid Incident Plan and Implementation Schedule. A Draft Chromic Acid Incident Plan was prepared in response to recommendations made follow- 
ing a DOE investigation of an unplanned release of chromic acid solution from Building 444 in 1989 . The plan addressed physical and administrative changes to reduce the possibility and impact of future spill events. A number of proposed actions were completed, and EPA agreed to refocus the scope of the plan to emphasize issues relevant to surface water protection and source control. A draft plan incorporating the revised approach was submitted to EPA during the second quarter of 1992 and was approved in October 1992. Work was initiated in October 1992 on plan activities and is expected to continue through 1998. These activities include the identification of all connections to the sanitary collection system at RFP, the Drain Identification Study, and a comprehensive inventory of all tanks on RFP, the Tank Management Plan (TMP).

Spill Prevention Control and Countermeasures/Best Management Practices Plan
The Spill Prevention Control and Countermeasures/ Best Management Practices (SPCC/BMP) Plan is a compilation of existing facility improvements, operational procedures, policies, and requirements for control of hazardous substance and oil spills. The current SPCC/BMP Plan was completed in September 1992. Updates to this plan were initiated in 1993 to meet anticipated requirements of the Oil Pollution Act of 1990 and Storm Water Pollution Prevention Plan (SWPPP) provisions expected in the renewed NPDES permit.

Since RFP is a site with industrial activity, it is required to submit an NPDES storm water permit application under regulations promulgated in November 1990. A network of six storm water monitoring locations was established during 1991 with the approval of EPA. providing storm water quality information for runoff that leaves the Industrial Area of RFP. Automated sampling equipment collected flow-composited samples to characterize the runoff, while data loggers collected the stored flow information at each monitoring location. The storm water permit application was submitted in 1992 on schedule. EPA has indicated that the renewed NPDES permit will include the storm water requirements, and that permit provisions will be similar to those contained in the "General Permit" for storm water published in the Federal Register (FR) on September 9, 1992. 


\section{Colorado Water Quality Control Commission Water Quality Standards}

The Cuiorado Water Quality Control Commission (CWQC.C.) originally conducted a hearing in December 1989, on the standards for Big Dry Creek drainage basin surface waters draining into Standley Lake and Great Western Reservoir. These waters include Woman Creek and Walnut Creek, RFP's principle drainages. As a result of this hearing, the resegmentation of $\mathrm{Big}$ Dry Creek and revised use classifications and water quality standards for Woman Creek, Walnut Creek, Standley Lake, and Great Western Reservoir became effective in March 1990. This action by the CWQCC established goal stream standards for Segment 5 of Big Dry Creek (tributaries from source to Ponds A-4, B-5, and C-2) and stringent stream standards for Segment 4 of Big Dry Creek (from pond outlets to Standley Lake and Great Western Reservoir). Goal standards differ from stream standards in that "goal" indicates that the waters are presently not fully suitable for classified use, and that a temporary modification for one or more of the underlying numeric standards was granted. Stream standards were adopted for organic and inorganic chemicals, metals, radionuclides, and certain physical and biological parameters.

In October 1992, the CWQCC heard a petition by DOE to reconsider the standards placed on Segment 5 of Big Dry Creek, which consists primarily of drainages from the RFP Industrial Area. The standards are based on the designated use, or classification, of a water body segment (e.g., aquatic life, drinking water supply, recreational, agricultural). At this hearing, DOE and RFP requested an extension of the goal qualifiers and temporary modifications and asked the CWQCC to revise the site-specific organic standards to achieve consistency with the statewide numeric standards for organic chemicals. In December 1992, the CWQCC rejected the proposal to continue the narrative ambient modifiers for 3 additional years, and instead agreed to impose Segment 4 standards on Segment 5, but with temporary modifications for nine parameters. The CWQCC did accept several additional modifications to Segment 4 and 5 standards put forth by DOE/EG\&G to make the specific standards consistent with statewide standards for organic constituents. The Commission also adopted a standard for beryllium. This action became final in March 1993. 
SAFE DRINKING WATER ACT

FEDERAL INSECTICIDE, FUNGICIDE, AND RODENTICIDE ACT
The Safe Drinking Water Act (SDWA) establishes primary drinking water standards for water delivered by a pubiic water supply system, defined as a system that supplies drinking water to either 15 or more connections or 25 individuals for at least 60 days per year.

The RFP water supply system meets these criteria and is termed a noncommunity, nontransient system because persons who use the water do so on a daily basis but do not live at the site.

RFP periodically evaluates plant drinking water for various water quality parameters including primary and secondary water contaminants, inorganics, VOCs, and radionuclides. Results of these analyses are reported to the $\mathrm{CDH}$ weekly, monthly, quarterly, and annually depending on the type of analyses performed. A complete description of the Drinking Water Monitoring Program at RFP is given in the 1992 Rocky Flats Plant Environmental Monitoring Plan (EGG92e).

The Federal Insecticide, Fungicide, and Rodenticide Act (FIFRA) governs the registration and use of pesticides, herbicides, and rodenticides. The FIFRA program at RFP tracks the materials from their initial purchase to final disposal and helps ensure that all pesticides on plantsite are registered with the EPA, are applied by licensed contractors, and that waste is properly disposed.

Approval of the FIFRA Program Management Plan and Level I Procedure drafted in 1993 is anticipated by mid-1994. Elements of the plan include preparation of a database of information regarding the application of pesticides on plantsite; an annual meeting with DOE concerning use of pesticides; monitoring of the FIFRA for updates and changes, as well as monitoring of changes in pesticide approvals and regulations by the EPA; coordination with the Chemical Tracking and Control System (CT\&CS) Division for tracking of pesticides on plantsite; ongoing evaluations of chemical use and efficacy; and a continual search for alternatives to pesticide use on plantsite. 
TOXIC SUBSTANCES CONTROL ACT
The Tuxic Substances Control Act (TSCA), administered by the EPA. addresses potential risks associated with the manufacture, use, and handling of toxic substances. TSCA supplements sections of the CAAA, the CWA, and the Occupational Safety and Health Act (OSHA). Compliance with TSCA at RFP is directed at management of polychlorinated biphenyls (PCBs) and containerized waste asbestos from abatement projects.

In 1993, 49 drums of radioactive asbestos were shipped to the DOE Hanford site in Washington for disposal. These drums consisted of low-level radioactively contaminated asbestos generated at several locations throughout RFP. RFP has small-quantity generator status with Hanford and also is continuing efforts to ship low-level asbestos for disposal at the Nevada Test Site (NTS).

RFP continues to manage three PCB storage areas and two PCB transformers. The PCB storage areas contain radioactive $P C B$ wastes which cannot be shipped offsite because currently there are no DOE facilities or commercial facilities which can accept RFP's radioactive PCB wastes for disposal. EG\&G, DOE, and EPA Region VIII negotiated a draft compliance agreement in 1993 for the continued storage of these wastes until offsire disposal for radioactive PCB wastes can be achieved. The compliance agreement is expected to be finalized in 1994.

The remaining two $\mathrm{PCB}$ transformers are currently being managed in accordance with the TSCA regulations for $\mathrm{PCB}$ transformers. Both transformers are in service and operational.

Two federal laws govern the majority of the cleanup activities at RFP: the Resource Conservation and Recovery Act (RCRA), and the Comprehensive Environmental Response, Compensation, and Recovery Act (CERCLA). Although pure radioactive waste is monitored internally by DOE due to an Atomic Energy Act exemption, RCRA regulates all activities at the facility associated with hazardous waste and mixed waste. CERCLA requires cleanup at sites that have contamination and are recognized as sufficiently high priority sites by EPA. The RFP site is in this category 
and was added to the National Priorities List (NPL) in 1989. and therefore falls under CERCLA as well, in some areas.

EPA is responsible for overseeing cleanup activities at NPL sites, but DOE is responsible for the implementation of the CERCLA requirements. EPA, the promulgating agency for RCRA regulations, has delegated the authority for implementation of the RCRA requirements to $\mathrm{CDH}$. This is accomplished through authority of the Colorado Hazardous Waste Act (CHWA) and other implementing regulations. The Interagency Agreement (IAG) signed in 1991 by EPA, CDH, and DOE defines how the overlapping cleanup authority of RCRA, CERCLA, and CHWA are to be integrated and how oversight authorities by EPA and $C D H$ will be conducted to ensure compliance with all regulatory requirements.

RCRA, as amended by the Hazardous and Solid Waste Amendments (HSWA), provides cradle-to-grave control of hazardous waste by imposing management requirements on generators and transporters of hazardous wastes and on owners and operators of treatment, storage, and disposal facilities.

In response to a NOV issued by $\mathrm{CDH}$ on June 17 , 1992, EG\&G has developed more than 100 individual corrective action tasks to address the findings. In 1993, there were no RCRA-related NOVs issued by CDH.

DOE, RFO and EG\&G also initiated additional actions designed to enhance regulatory compliance. Among these were the development of the Environmental Compliance Pilot Program (ECPP) and the Hazardous Waste Compliance Program Plan (HWCPP).

RFP initiated a pilot program in two buildings to develop a more effective means to achieve and maintain regulatory compliance. The pilot program involved Buildings 559 and 460 . These two buildings were selected as being representative of an operating plutonium facility and an operating non-plutonium facility. Systems and processes that proved successful in the pilot effort will be implemented in the remaining RFP facilities. The scope of the effort was to develop more formalized methods for ensuring compliance with RCRA requirements. 


\section{RCRA Part $A$ and Par' B Permits}

Also developed was the HWCPP, which describes how RFP will institute a more effective waste management program designed to achieve and maintain strict adherence with RCRA. The purpose of the plan is to describe tasks necessary for sustained, comprehensive sitewide RCRA hazardous waste compliance, (e.g., addressing known deficiencies, discovering and correcting new deficiencies, and avoiding their recurrence). The HWCPP describes changes and upgrades which RFP will use to achieve compliance from an overall organizational perspective. Plantwide RCRA compliance will occur through procedures and integration of programs and support organizations with line operations. The plan provides upgrades to programmatic systems and operational systems to facilitate regulatory compliance.

The RCRA Part A permit application identifies (1) the facility location, (2) the facility owner and operator, (3) the hazardous and mixed wastes to be managed. and (4) the specific storage treatment units at the facility, design capacities and process descriptions. A facility that has submitted a RCRA Part A permit application is allowed to manage hazardous wastes under transitional regulations known as interim status pending issuance of a RCRA Operating Permit. The RCRA Part B permit application consists of a detailed narrative description of all facilities and procedures related to hazardous waste management. The RCRA Operating Permit is based on the RCRA Part B permit application and contains specific detailed operating conditions for the waste management units addressed by the permit. RCRA Parts A and $B$ permit applications for RFP cover hazardous waste treatment and storage operations. RFP does not dispose of hazardous wastes onsite.

Part A Permit. Since the early 1980s, a series of RCRA Part A permit applications have been submitted to the CDH. During 1993, the Part A permit was revised three times to request changes to interim status and to support Part B permit modification requests. The revisions, dates submitted to $\mathrm{CDH}$, and changes requested, are provided below.

Revision 11 - Submitted May 1993, Combined Hazardous, Low-Level Mixed, Transuranic (TRU)Mixed, and Mixed Residues Part A, requesting a portion of Unit 15 be designated as a "Waste Pile." 
Revision 12 - Submitted December 1993, Combined Hazardous, Low-Level Mixed, TRU-Mixed, and Mixed Residues Part A with Permit Modification Request Number 10. requesting changes to the RCRA Part $B$ Permit Contingency Plan and the addition of waste codes to units $1,10,13$, and $15 \mathrm{~A}$.

Revision 13 - Submitted November 1993, Combined Hazardous, Low-Level Mixed, TRU-Mixed, and Mixed Residues Part A, requesting the addition of solar pond sludge storage in tanks to Unit 25.

Part B Permit. CDH issued a Part B Operating Permit to RFP on September 30, 1991. Currently, the permit includes 15 drum storage areas. During 1993, four requests for modifications to the RFP RCRA Part $B$ Operating Permit were submitted to $\mathrm{CDH}$. These requests are summarized below.

Permit Modification Request Number 10 - December 1993, a Class II permit modification that included contingency plan and waste code additions. Public comment period began on December 24, 1993.

Permit Modification Request Number 14 - June 1993, a Class I permit modification that incorporated previous modifications $1,2,3,4,6$, and 7 . No public meeting required; $\mathrm{CDH}$ has approved.

Permit Modification Request Number 15 - May 1993, a Class III permit modification that added one mixed residue storage tank and made modifications to the listing of tanks included in the compliance schedule table of Mixed Residues Permit Modification \#8, submitted June 30, 1992. A public meeting was held in September 1993. The request has not yet been approved by $\mathrm{CDH}$.

Permit Modification Request Number 18 - December 1993, a Class I permit modification that incorporated previously approved Interagency Agreement (IAG) milestones into the Corrective Action portion of the RCRA permit.

Other permit modification requests are being prepared to add all interim status units and newly planned hazardous waste units to the RFP RCRA Part B Operating Permit. 
RCRA Closure Plans
RCRA ilosure plans identify procedures for removing hazardous waste management units from service to prevent both short- and long-term threats to human health and the environment. These plans describe measures to eliminate or minimize future maintenance of hazardous waste management units, to control releases of hazardous constituents, and to close these units permanently. Post-closure monitoring is required if "clean closure" of a unit cannot be achieved.

Hazardous waste management units that operate under interim status (40 CFR Part 265) and units that operate under a permit (40 CFR Part 264) must be addressed in RCRA closure plans (40 CFR Parts 264 and 265, Subpart $G)$. The closure plans for the 15 permitted units are included in the RFP RCRA Part B Operating Permit. The closure plans for most interim status units are included in Part B Operating Permit modification requests submitted to $\mathrm{CDH}$ or in preparation at RFP. Land-based hazardous waste management units that discontinue operation during the interim status period and that cannot be "clean closed" in accordance with applicable RCRA regulations must submit RCRA Part $B$ post-closure care permit applications for interim status units. These are units that have been removed from service but require post-closure monitoring and maintenance. Closure plans for the Solar Evaporation Ponds, Present Landfill, Original Process Waste Lines, and West Spray Field were originally submitted to the CDH in 1986 and 1988. These closure plans were later superseded by the January 1991 IAG.

The IAG requires interim status closure units to use a combination of RCRA and Comprehensive Environmental Response, Compensation, and Liability Act (CERCLA) criteria. The IAG requires RCRA Facility Investigations/Remedial Investigations (RFIRI) work plans as a function of characterizing the source of the contamination and the soils of an interim status closure unit. Draft Phase I RFI/RI work plans were submitted to the CDH and EPA in 1990 for several hazardous waste management units. In 1993, regulatory agencies denied the extension request for two IAG milestones in OU 2, submission of the Draft and of the Final Phase II RFIRI reports. DOE is subject to stipulated penalties for each missed milestone (which could include fines of $\$ 5,000$ the first week and $\$ 10,000$ per 
weck thereafter). A temporary work stoppage pending resolution of risk assessment issues has delayed the IAG schedules for OU 1 through 7 .

The Draft Phase I RFI/RI Report for the Solar Evaporation Ponds was submitted to DOE, RFO on September 14, 1993. A preliminary submittal date of October 1993 for the Draft Phase I RFI/RI for the Present Landfill is currently being renegotiated in an effort to combine multiple scopes which will ultimately compress the IAG milestones. There were no IAG milestones for either the Original Process Waste Lines or the West Spray Field during FY93.

Quarterly groundwater monitoring continued in 1993 for wells within three RCRA-regulated units scheduled for Interim Status Closure: the Solar Evaporation Ponds, West Spray Field, and Present Landfill. Several new groundwater monitoring wells also were installed during 1993. Quarterly Assessment Reports were prepared that highlighted results of ground-water sampling. The 1993 Annual RCRA Groundwater Monitoring Report was prepared for submittal to CDH and EPA in early 1994. Analysis and interpretation of groundwater monitoring data was used in this report to assess the impact on groundwater quality resulting from waste management activities at the RCRA units.

Quarterly sampling splits were performed during 1993 in which groundwater samples from wells downgradient of RFP were split to allow independent analysis by the $\mathrm{CDH}$. Audits of field sampling activities and quarterly reporting also were performed in conjunction with $\mathrm{CDH}$ to ensure compliance with applicable regulations.

\section{RCRA Contingency Plan}

The RFP RCRA Contingency Plan (Part VI of the Part $\mathrm{B}$ Permit) is designed to minimize the hazards to human health and the environment from fires and explosions, or any unplanned sudden or gradual releases of a hazardous waste or hazardous waste constituent to the environment (i.e., air, soil, surface water or groundwater.) In 1993, the RFP Contingency Plan was implemented to cover the following situations.

- A release of a hazardous waste that results in an injury requiring more than first aid. 
- A spill or leak of hazardous waste to the environment (i.e., air, soil. or surface water outside of a building) greater than one pint or one pound.

- A spill, leak, or other release of a hazardous waste inside a building that results in (1) a release that exceeds a reportable quantity (RQ) as defined in 40 CFR Part 302, or (2) a release from a hazardous waste tank system that is not removed from secondary containment within 24 hours.

- A fire that involves a hazardous waste management unit or the release of hazardous waste.

- Situations other than those outlined above can result in the implementation of the RCRA Contingency Plan at the discretion of the Emergency Coordinator.

In 1993 the RCRA Contingency Plan was implemented on 10 occasions as compared with 23 occasions in 1992. The Contingency Plan Implementation Reports (CPIR [RCRA CPIRs]) were forwarded to $\mathrm{CDH}$ and the EPA Region VIII and described the nature and magnitude of the releases, the actual or potential threat to human health and the environment, and the corrective actions taken to remediate the affected areas and/or systems.

- RCRA CPIR 93-001 - Approximately one teaspoon of hazardous waste was discovered within a piece of plastic wrap that covered an elbow leading from a RCRA regulated tank. The report was made due to the fact that the waste was not removed within the 24 hour time-frame, as required by the regulations. The release was completely contained and there was no release to the environment.

- RCRA CPIR 93-002 - Approximately 50 gallons of contaminated surface water were released from a treatment unit in the area of the $903 \mathrm{Pad}$. " $\mathrm{F}$ " listed solvents were detected in the water at levels slightly above regulatory safe drinking water contamination levels. The report was made since the water had been managed as a hazardous waste and was released to the environment. The water soaked into the soil and was not recovered. 
- CPIR 93-003 - Two to four quarts of lead-contaminated sulfuric acid were released to the environment when a forklift crushed a used storage battery that was being moved from a cargo container where it was being stored for recycle. The acid was neutralized and the waste was managed as a lead-contaminated waste until the laboratory analysis was available and showed that the waste was not hazardous.

- RCRA CPIR 93-004 - One gallon of contaminated water containing " $F$ " listed solvents was released from a hose on a tanker used to transport contaminated water from the footings in Building 559. The contaminated water was released to an asphalt pad, absorbed with Oil-Dri, and managed as RCRA-regulated waste. All visible liquids were removed; therefore, no contamination should remain since contamination levels in the water were at parts per million (ppm) levels.

- RCRA CPIR 93-005 - A well being installed in the area of the 903 Pad overflowed when a casing was placed in the hole as a liner. " $F$ " listed solvents were detected in the water at levels slightly above drinking water levels. The report was made since the water had been managed as a hazardous waste and was released to the environment. The water soaked into the soil and was not recovered.

- RCRA CPIR 93-006 - Two to three teaspoons of hazardous waste were released into secondary containment. The release, which was not cleaned up within 24 hours, occurred through a drain line attached to two RCRA-regulated tanks. The tanks (RCRA Units 44.01 and 44.02) were located in Building 776. The secondary containment was found to be intact and no release to the environment occurred.

- RCRA CPIR 93-007 - Approximately 4700 gallons of interceptor trench water were released into secondary containment. The water contained " $F$ " listed solvents and as a result, the RCRA Contingency Plan was implemented as a precautionary measure because there was a possibility of a release to the environment. The waste was released to the interceptor trench system sump and the secondary containment system of the waste transfer pipeline. The 
waste in the sump was pumped back into the modular tanks. but the material in the secondary containment system was not removed within 24 hours. No release to the environment was evident. No further testing has been completed to determine if there is a leak path from the sump. Approximately three to four million gallons of water are collected in the sump annually; therefore if there is a leak path, the impact of $4,700 \mathrm{gal}$ lons being recycled to the sump would not result in an increased threat to the environment.

- RCRA CPIR 93-008 - A leak from a RCRA-regulated tank system was not cleaned up within 24 hours. The leak originated from a waste TCA and waste machine coolant/used oil transfer line in Building 776 . The quantity released was less than one teaspoon. The release was to the building floor which is painted (containment).

- RCRA CPIR 93-009 - Approximately 25 gallons of liquid waste were released in the vicinity of Building 460 as a result of a tanker being overfilled. The tanker truck was being used to transfer hazardous waste from Building 460 to Building 374 for treatment. It is believed that the overfill was caused due to the fact that the tanker contained rain water from a previous transfer (nonhazardous). The RCRA Contingency Plan was implemented as a precaution because hazardous waste could have been released. Laboratory results indicated that the released material was not a hazardous waste.

- RCRA CPIR 93-010 - Approximately 10 gallons of contaminated water were released from an influent pipeline from the surface water treatment unit at the $903 \mathrm{Pad}$. Approximately 30 to 40 gallons of contaminated water was released to the secondary containment system of the influent pipeline. Approximately 10 gallons was released to soil. " $F$ " listed solvents were detected in the water at levels slightly above regulatory safe drinking water contamination levels. The report was made since the water had been managed as a hazardous waste and was released to the environment. The water soaked into the soil and was not recovered. 


\section{National Response Center Notifications}

In 1993, per the requirements of 40 CFR 302.6, the National Response Center (NRC) was notified of six releases at the RFP. Of these notifications, five were the result of releases of ethylene glycol for automobile antifreeze. Two incidents involved privately owned vehicles. Two incidents involved government owned vehicles. One incident involved a portable piece of equipment. The sixth incident was from the release of mineral oil that caused a sheen on surface water. In contrast, there were 32 notifications to the NRC in 1992. Waste Regulatory Programs issued a Continuous Release Report for the release of ethylene glycol. This report increased the reportable quantity of ethylene gly$\mathrm{col}$ from one pound to one hundred pounds. This report was issued April 21, 1993 (Report Number 168777) and from that time RFP has had no releases of ethylene glycol that were reportable to the NRC.

Waste minimization at RFP continued to improve in 1993. The following information summarizes the major accomplishments in 1993.

- The carbon dioxide pellet cleaning system cleaned and decontaminated over 22,000 kilogram $(\mathrm{kg})$ of scrap metal, which was recycled through an offsite vendor. The system was tested during 1993 and is ready for full-scale production in 1994. Significant amounts of materials that were once deemed lowlevel waste can now be decontaminated through this technology and recycled offsite.

- The Waste Minimization Program has procured and tested a device known as the Dustless Decon System (DDS). This device is designed to remove radioactive contamination from concrete surfaces without the use of chemicals, and without the generation of airborne radioactive contamination. The original unit will be used in the uranium-contaminated buildings with plans to purchase another unit in 1994 for use in the plutonium-contaminated buildings. The units will be put into full service as soon as formal operating procedures are completed in early 1994.

- The "Zero Waste" machine coolant management program was expanded to all nonweapons buildings and also to the Precision Joining Center on Ward Road. This program uses a synthetic, bacteria- 
resistani, water-based coolant and a filtration system to remove solids. The original coolants required periodic biocide treatments to combat bacteria. The bacteria, as well as the biocide. created a hazard to the machinist and the coolant eventually had to be changed. The new synthetic coolant does not require biocide treatment and, because of its bacteria resistance, is a lesser hazard to the machinist. This program has been very successful in reducing coolant waste and has eliminated the disposal of approximately 5,000 gallons of coolant waste during 1993.

- A task team evaluated Building 460 , a stainless steel machining facility, with the intent of reducing or eliminating waste. Successes included the substitution of a nonhazardous dye penetrant for the hazardous product that was being used, and recharacterization of cleaning system rinse water as nonhazardous, and elimination of $\mathrm{CCl}_{4}$ in all building processes.

- Recycling activities included 372.01 tons of office paper, 25.25 tons of cardboard, 897.64 tons of scrap metals, 2,585 gallons of used oils, 1.38 tons of used oil/fuel filters, 2,371 toner cartridges, and 23.57 tons of lead/acid batteries.

- Changes in process and products in the Laundry facility will result in a reduction of approximately $18,000 \mathrm{~kg}$ of detergent over the next year and approximately 537,000 gallons of rinse water.

- Total radioactive waste generation increased 4.6 percent from $1,141.56$ cubic meters $\left(\mathrm{m}^{3}\right)$ to $1,194.33 \mathrm{~m}^{3}$. TSCA waste increased over 600 percent from $1,506.39 \mathrm{~kg}$ to $10,904.2 \mathrm{~kg}$. Total nonhazardous wastes increased 32 percent from $21,786.5 \mathrm{~kg}$ to $28,774.9 \mathrm{~kg}$. The increases in waste generation reflect the beginning of cleanup activities at the site. RFP is in the process of redefining its waste minimization goals to account for the change in the plant's mission.

- RFP received two external awards in 1993 in recognition of the plant's waste minimization and pollution prevention efforts. RFP received the 1992 Colorado Center for Environmental Management Certificate of Achievement for success in "Zero Waste" Coolant 
Adminstrative and Judicial Orders Governing Mixed Residues
Marnagement. The second award was presented by the DOE. HQ Office of Environmental Restoration and Waste Management in recognition of the plant's achievements in recycling.

Since 1989, the management of RFP's mixed residues has been governed by a series of administrative and judicial orders issued in response to allegations by $\mathrm{CDH}$ and the Sierra Club that residues mixed with hazardous waste are subject to Colorado's RCRA regulations.

In Settlement Agreement and Compliance Order on Consent No. 89-10-30-01 (November 11, 1989), CDH directed DOE to develop a Mixed Residues Compliance Plan by Seplember 28, 1990. The explicit purpose of the plan was to outline the actions that would be taken to (1) bring mixed residues into compliance with Colorado's RCRA regulations, (2) reduce the existing inventory of mixed residues, and (3) minimize the generation of any additional mixed residues.

Subsequent to DOE's timely submission of the plan, $\mathrm{CDH}$ issued Settlement Agreement and Compliance Order on Consent No. 91-07-31-01 (July 31, 1991), instructing DOE to remove all backlog mixed residues from RFP by January 1, 1999. This order was superseded by Settlement Agreement and Compliance Order on Consent No. 93-04-23-01 (April 23, 1993), which directed DOE and EG\&G to implement a Mixed Residue Reduction Program (MRRP). The MRRP was defined to include a Mixed Residue Reduction Report (MRRR), with quarterly and annual updates; a Mixed Residue Tank Systems Management Plan, also with annual updates; and a Mixed Waste Storage Space Analysis Report.

Within this same timeframe, the Sierra Club filed a citizen's enforcement action in U.S. District Court for the District of Colorado (Civil Action No. 89-B-181), seeking declarations that residues mixed with hazardous wastes are RCRA-regulated wastes. The Sierra Club's request was granted by Judge Lewis T. Babcock on April 12, 1990 (734 F.Supp. 946, D.Colo. 1989). Subsequently, the Sierra Club amended its complaint, leading to a second judicial order, which was issued on August 13, 1991. In this order, Judge Babcock directed DOEE to obtain a RCRA permit for the existing inventory of 
certain rixed residues within two years (by August 21, 1993), or suspend all operations that generate mixed wastes (770 F.Supp. 578, D.Colo. 1991).

Although DOE submitted a RCRA permit modification request to $\mathrm{CDH}$ on June 30,1992 , the outstanding mixed residue storage issues were not resolved. and $\mathrm{CDH}$ did not issue a modified RCRA permit by the August 1993 deadline. In response to the missed deadline, Judge Babcock issued a new judicial order on February 17 , 1994, mandating a new permit schedule and requiring DOE to submit several technical documents to $\mathrm{CDH}$, including revised room drawings, results from smoke and air flow pattern tests, proposed permit conditions for relabeling, and a schedule for container closure activities. Efforts are now underway to meet the requirements of this new order.

The essential goal of RFP as outlined in the settlement agreements and in the judicial orders remains the safe storage of backlog mixed residues (and the TRU-mixed wastes generated by their processing) until their ultimate treatment and/or removal from the plant for final offsite disposal. The implementation strategy still consists of the three paths (Ship-as-Waste, Ship-as-Residue, and Treatment/Disposal of Stored Liquids) as defined by the Annual Mixed Residue Reduction Report (AMRRR). Refinements and progress that have been made in mixed residue management are documented in the monthly and quarterly MRRP reports and in monthly Program Manager meetings among $C D H . D O E$, and EG\&G as required by the Settlement Agreement.

During 1993, efforts were undertaken to improve compliance for storage of mixed residues. Physical compliance with the June 1992, RCRA Part B Permit Modification for Mixed Residues was achieved in all units that store mixed residues. This effort included the establishment of secondary containment for container storage areas in Buildings $771,371,776,777,779$, and 559: and establishment of proper signs, labels, markings, inspection documentation, and inventory control for all mixed residue areas.

Physical compliance with Revision 2 of the Mixed Residue Tank System Management Plan was achieved for mixed residue tank systems. This effort included emptying pencil tanks in Building 777, the SR-3 tank in Building 776, and the C-pit tanks in Building 707, and 
veriying liquid levels in Category B (non-empty tanks destined for closure) and Category C (operationally empty tanks destined for closure) tanks. Ancillary equipment for Category B and Category D tanks (tanks destined for permitting) was also walked down, verified, and documented on engineering drawings.

Five Notice of Deficiency (NOD) assessments regarding the content of the permit modifications were issued by $\mathrm{CDH}$. Current activities center around addressing these findings. A development schedule has been prepared and a project team assembled to prepare an inventory and analysis of potential/available waste storage space at RFP, a requirement of the Settlement Agreement due to $\mathrm{CDH}$ on October 1, 1994.

In the upcoming year, mixed residue tank systems and container storage areas will continue to be assessed and in some cases, upgraded to resolve outstanding permitting issues.

Federal Facility Compliance Agreement for Land Disposal Restricted Waste
The Federal Facility Compliance Agreement (FFCA) dealing with land disposal restricted (LDR) waste was signed by DOE, EPA, and the State of Colorado in September 1989. A second compliance agreement, referred to as Federal Facility Compliance AgreementII (FFCA-II) was signed in May 1991 by DOE and EPA. FFCA-II provided a 24-month period for DOE to demonstrate achievements toward compliance with the LDR portions of RCRA's Hazardous and Solid Waste Amendments (HSWA) and Colorado's hazardous waste regulations.

FFCA-II superseded the 1989 compliance agreement and provided the mechanism for DOE to achieve compliance with the LDR requirements. During the period of FFCA-II, DOE agreed to take all feasible steps to ensure accurate identification, safe storage, and minimization of restricted waste prohibited from land disposal.

The 1993 expiration date for FFCA-II was reached before negotiations on a replacement agreement could be completed, because of competing priorities within the regulatory agencies (namely, renegotiations on the Mixed Residue Compliance Order). RFP is still pursuing the requirements of FFCA-II as if it were still in effect and is implementing programs initiated under 
Federal Facility Compliance Act
FFCA. If to achieve LDR compliance. Progress toward compliance achievement is reported annually in the RFP LDR Progress Report.

Another reason that a new compliance agreement has not been aggressively pursued is due to the passage of the Federal Facility Compliance Act (FFC Act) in October of 1992. In this Act, DOE has specifically been tasked with preparation and implementation of plans that describe how and when DOE will develop mixed waste treatment capacities and technologies to treat mixed waste to meet the LDR treatment standards.

Pursuant to the FFC Act, DOE published a schedule in the Federal Register (FR) for submitting the plans required of each DOE facility that generates or stores mixed waste (58 FR 17875) April 6, 1993. A threephased approach was proposed to develop these plans, collectively referred to as "Site Treatment Plans." These three plans are briefly summarized below.

- The Conceptual Site Treatment Plan - Issued in October of 1993, the conceptual plan provides information on treatment technology needs and treatment capacities for RFP's mixed wastes. The plan contains a preliminary identification of treatment options, which may include onsite, commercial. and offsite facilities, as well as potential barriers to these options, if known. In addition to providing RFP with the information necessary to continue to formulate strategies for LDR compliance, the conceptual plan provides information to other DOE sites for use in identifying common technology needs and potential options for treating their wastes. The plan is also being utilized in conjunction with conceptual plans from other sites as a basis for nationwide discussions among state and federal regulators and other interested parties to conduct technical and equity discussions regarding national treatment of DOE mixed wastes.

- The Draft Site Treatment Plan - This plan constitutes the second phase of the approach and is scheduled for delivery in August of 1994. This plan will identify the current preferred option for treating RFP's mixed wastes; the specific treatment facilities for treating mixed wastes, including location; and will propose schedules as required by the FFC Act. The proposal in this draft plan will reflect the results of discussions among individual states, EPA, DOE, and others. 
- The Final Site Treatment Plan - This plan will build on the two previous plan versions described above; provide more detail for treating mixed waste for which identified treatment technologies exist; and provide a schedule for submitting permit applications, entering into contracts, initiating construction, conducting systems operational testing, starting operations, and processing of mixed waste. For mixed waste without an identified treatment technology, the plan will include a schedule for identifying and developing technologies, identifying funding requirements for research and development, submitting treatability study exemptions, and submitting research and development permit applications. The final plan may provide for centralized, regional, or onsite treatment of mixed waste, or any combination thereof. The final plan will allow the appropriate regulatory agency $(\mathrm{CDH}$, in the case of RFP) to approve/disapprove and upon approval, issue an order requiring compliance with the approved plan. The Final Site Treatment Plan will supersede the existing Comprehensive Treatment and Management Plan (CTMP) that currently defines RFP activities in the area of LDR waste treatment.

COMPREHENSIVE ENVIRON- The Comprehensive Environmental Response, MENTAL RESPONSE, COMPEN- Compensation, and Liability Act (CERCLA) and its SATION, AND LIABILITY ACT

major amendments (Superfund Amendment and Reauthorization Act [SARA]) provide funding and enforcement authority for restoration of hazardous substance sites (primarily inactive sites) and for responding to hazardous substance spills. Sites contaminated by past activities must be investigated and remediation plans developed and implemented. The intent of these actions is to minimize the release of hazardous substances, pollutants, or contaminants, thereby protecting human health and the environment. CERCLA requirements are addressed in phases designed to investigate, remediate, and complete the restoration of contaminated sites. CERCLA activities at RFP are generally applied through the IAG.

RFP was initially added to CERCLA's National Priorities List (NPL) on October 4, 1989. The NPL is an ordered ranking of CERCLA sites evaluated using 


\section{INTERAGENCY AGREEMENT}

the Ha7.drdous Ranking System. If a site scores above a certair, threshold level established by EPA, the site is placed on the NPL

SARA also provided for the assessment of natural resource injury and for the recovery of natural resource damages (monetary compensation for injuries) under 43 CFR Part 11. The Natural Resource Damage Assessment (NRDA) Rule is a key issue at RFP. A draft Memorandum of Understanding (MOU) between DOE and Federal/State trustees was sent to DOE, HQ for review in September 1993. The approved MOU will govern the mutual cooperation between DOE and the co-trustees. Once the MOU is signed, trustee review of RCRA/CERCLA activities will take place as provided for under the IAG.

The Interagency Agreement ( $\mathrm{AAG}$ ) for environmental restoration activities at RFP was signed on January 22, 1991 , by DOE, EPA, and CDH. Officially called a Federal Facility Agreement and Compliance Order, the agreement replaced the 1986 RCRA-CERCLA Compliance Agreement and clarifies the responsibilities and authorities of the three agencies, standardizes requirements, describes the procedures to be followed, and helps to ensure compliance with orders and permits. The agreement also specifies delivery of major reports, project management activities and milestones, and includes community involvement and decision-making responsibilities. The agreement outlines each agency's role in, and integrates the authority/jurisdiction of, RCRA and CERCLA over the study and cleanup process. It also provides mechanisms for resolving issues that may arise among the participants during cleanup activities.

The draft IAG was originally issued for public comment in December 1989 and submitted for official approval in August 1990, with changes reflecting comments received from the public. The final IAG was substantially the same as the draft IAG. The most visible modifications wore the reprioritization of the RFP Operable Units (OUs) and changes in the OU milestone schedules. (The current prioritization of OUs is provided in Table 2-3.) The OU reprioritization necessitated adjustments in the timelines associated with the individual OUs to reflect more realistic schedules for completion of the various 
sturties required. The $I A G$ requires that DOE notify the public of any changes to the schedule set forth in the final IAG. The final IAG also stipulates that various additional measures be taken for improved public involvement and directs DOE to address these public involvement commitments in the Community Relations Plan (CRP).

Table 2-3

Prioritization of Operable Units by the IAG

\begin{tabular}{|c|c|}
\hline $\begin{array}{c}\text { OU Number } \\
\text { Under Final IAG } \\
\text { (effective 1-11-91) }\end{array}$ & Description \\
\hline $\begin{array}{l}01 \\
02 \\
03 \\
04 \\
05 \\
06 \\
07 \\
08 \\
09 \\
10 \\
11 \\
12 \\
13 \\
14 \\
15 \\
16\end{array}$ & $\begin{array}{l}881 \text { Hillside Area } \\
903 \text { Pad Area } \\
\text { Offsite Areas } \\
\text { Solar Ponds } \\
\text { Woman Creek } \\
\text { Walnut Creek } \\
\text { Present Landill } \\
700 \text { Area } \\
\text { Original Process Waste Lines } \\
\text { Other Outside Closures } \\
\text { West Spray Field } \\
400 / 800 \text { Area } \\
100 \text { Area } \\
\text { Radioactive Sites } \\
\text { Inside Building Closures } \\
\text { Low-Priority Sites }\end{array}$ \\
\hline
\end{tabular}

Remediation Goals

Documents prepared in accordance with the IAG cover a range of topics including remedial investigation work plans, interim remedial action decisions, community survey plans, project management plans, and health and safety plans. A series of monthly and quarterly Environmental Compliance Action reports document progress against IAG milestones (DOE92a, DOE92b). Table 2-4 lists the IAG milestones completed during 1993. Section 4 of this report, "Environmental Remediation Programs," describes remediation activities accomplished at RFP during 1993.

CERCLA requires that remediation goals comply with applicable or relevant and appropriate requirements (ARARs) of federal laws or more stringent promulgated state laws in relation to cleanup standards. ARARs are generally dynamic in nature in that they evolve from general to very specific during the CERCLA Remedial Investigation/Facilities Study (RU/FS) process. Final remediation objectives are comprised of both ARARs 
and rish assessment information. The development of cleanup standards at RFP follows the general procedures described below.

\section{Table 2-4}

\section{IAG Milestones Completed in 1993}

\section{IAG Milestone}

Submit Draft Treatability Study Report Complete IM/IRAa Construction (Treatment Plant) Complete IM/RA Construction (French Drain) Submit Draft Phase III RFI/R'b Report Submit Draft Treatability Test Report (Phase 1 GAC c) Complete IM/IRA Construction (Rads Removal System) Begin Field Treatability Testing (Rads Pemoval System) Submit Final Treatability Test Report (Phase I GAC) Submit Subsuriace Final RS ${ }^{d}$ and IM/RAP/EAe Submit Subsurface Site 1 Draft Test Plan Submit Draft Phase I RFI/RI Work Plan Submit Final Phase I RFI/RI Work Plan Submit Final Phase I RFI/RI Work Plan Submit Final Phase I RFI/RI Work Plan Submit Draft Phase I RFI/RI Work Plan Submit Final Phase i RFI/RI Work Plan Submit Draft Phase ! RFI/RI Work Plan Submit Final Phase I RFI/RI Work Plan Submit Draft Phase I RFI/RI Work Plan Submit Final Phase I RFI/RI Work Plan Submit Draft Phase I RFI/RI Work Plan Submit Final Phase I RFI/RI Work Plan Submit Draft No Further Action Justification Document Submit Final No Further Action Justification Document Submit Draft Historical Release Report Submit RS Discharge Limits for Radionuclides Submit Final Historical Release Report

\section{Operable Unit}

Sitewide

1

1

1

2

2

2

2

2

8

8

10

11

12

12

13

13

14

14

15

15

16

16

Sitewide

Sitewide

Sitewide

a. Interim Measures/Interim Remedial Action

b. RCRA Facility Investigation/Remedial Investigation

c. Granular Activated Carbon

d. Responsiveness Summary

e. Interim Measures/Interim Remedial Action Plan/Environmental Assessment

Initially, during the RFIRI work plan stage, potential chemical-specific ARARs are identified, usually based on a limited amount of data. Chemical-specific ARARs at this point have meaning only in that they may be used to establish appropriate detection limits so that data collected during the RFI/RI may be compared to ARAR standards. As more information becomes available during the RFIRI stage, chemical-specific ARARs may become more refined as constituents are added or deleted. Detailed, location-specific ARARs 
arc proposed in the RFI/RI report as the result of the RFI/RI process. This is followed by action-specific ARARs and remediation goals that are identified through the Corrective Measures Study/Feasibility Study (CMS/FS). A discussion is provided in the CMS/FS report for each remedial alternative regarding the rationale for all ARAR determinations. Once a preferred remedial action alternative is formally selected in the Record of Decision (ROD), all chemical-, location-, and action-specific ARARs are also defined in final form. CERCLA requires that remediation programs attain ARARs that are protective of human health and the environment.

The IAG establishes the authority of $\mathrm{CDH}$ and EPA to request IM/IRA documents that identify, screen, and evaluate appropriate interim remedial action alternatives. "Interim Measures" is a RCRA term for corrective actions, generally of short term, taken to respond to immediate threats to public health, welfare, or the environment. "Interim Remedial Action" is the CERCLA term for an expedited response action taken in accordance with remedial action authorities to abate an actual or potential threat. The IM/IRA process considers ARARs for existing and proposed actions, comprehensively reviews existing management approaches and evaluates a broad spectrum of alternatives to determine the best means of protecting human health and the environment.

EMERGENCY PLANNING AND COMMUNITY RIGHT-TOKNOW ACT
The Emergency Planning and Community Right-toKnow Act (EPCRA) was enacted as a freestanding provision of SARA in 1986. Also known as SARA Title III, EPCRA contains four major provisions.

- Chemical emergencies planning

- Emergency notification of chemical accidents and releases

- Hazardous chemical inventories reporting

- Toxic chemical release reporting

These provisions require RFP to notify state and local emergency planning entities of the presence of potentially hazardous substances on their sites and to report on the inventories and environmental releases of those 


\section{Sections 301 and 302}

substinces. The intent of these requirements is to provide the public with information on hazardous chemicals in their communities, enhance public awareness of chemical hazards. and facilitate development of state and local emergency response plans.

Under Sections 301 and 302, the EPA requires the establishment of a State Emergency Response Commission (SERC), which is responsible for the formation of emergency planning districts, and Local Emergency Planning Committees (LEPCs). Also under these requirements. facilities that produce, use, or store listed substances above the threshold planning quantity must notify the SERC and the LEPCs. RFP participates in the activities of the LEPCs established under these sections for emergency planning at the county level of government. RFP also maintains an emergency preparedness document for the plant and conducts annual mock emergency response scenarios to determine the effectiveness of the plan and the ability of plant organizations to respond.

EPA has provided a guidance manual on radiological protection to assist officials in establishing emergency response plans and in making decisions during a nuclear incident. The Manual of Protective Action Guides and Protective Actions for Nuclear Incidents (EPA91a) details protective actions to safeguard public health and is distinct from regulatory requirements for emergency response as established by DOE.

Section 303 requires LEPCs to complete emergency response plans. At the committee's request, the facility owner or operator must provide information necessary for developing and implementing the emergency plan.

Section 304 applies to releases of extremely hazardous substances listed under EPCRA Section 302 and hazardous substances designated under Section 102 of CERCLA that exceed their reportable quantities and have the potential for impact beyond the plant boundaries. If the release is determined not to pose a potential impact beyond the plant boundaries, then reporting is not required under SARA Section 304. However, if a material is listed on the CERCLA Hazardous Substances List, reporting to the $N R C$ is required under CERCLA 
Section 103(d), if the quantity released to the environment exceeds the reportable quantity (RQ). When a release occurs that is subject to Section 304, the facility owner or operator must notify the SERC and LEPC immediately by telephone and again in writing as soon as practicable. Section 304 requirements apply specifically to facilities such as RFP that produce, use, or store one or more hazardous chemicals as defined by the OSHA Hazard Communication Standard. RFP's Waste Programs Department directs EG\&G's Emergency Operations Center Notification Officer (EOCNO) to complete these notifications if such releases occur.

In 1993, there were no releases of extremely hazardous substances or CERCLA hazardous substances that posed a polential impact beyond RFP boundaries and required notification to the SERC and LEPCs.

Section 311

Section 312
Under Section 311, RFP must submit to the SERC, LEPC, and RFP Fire Department copies of Material Safety Data Sheets (MSDSs) for chemicals above thresholds that are defined as hazardous by the OSHA Hazardous Communication Standard (HAZCOM). Section 311 requires the submittal of an update on new chemicals within 3 months of their becoming subject to OSHA HAZCOM or on discovery of new information. The Industrial Hygiene Department has provided this information to the Colorado Emergency Planning Commission, Jefferson County Emergency Planning Committee, Boulder County Emergency Planning Committee, and RFP Fire Department since 1987 and provides updates to these agencies in accordance with the requirements of Section 311.

Section 312 of EPCRA requires RFP to prepare an annual report titled "The Emergency and Hazardous Chemical Inventory Tier II," by March 1 of each year.

The Tier II report lists storage quantity ranges for reportable chemicals stored on plantsite, their physical state, and locations. Reporting is required for those chemicals covered under HAZCOM (with limited exceptions) that are stored on plantsite in excess of 10,000 pounds. Section 312 also requires reporting 
Section 313

on extremely hazardous substances (EHSs) that exceed the chemical-specific regulatory Threshold Planning Quantity (TPQ) or 500 pounds, whichever is lower. RFP has been submitting the Tier II Report to the Colorado Emergency Planning Commission, Jefferson County Emergency Planning Committee, Boulder County Emergency Planning Committee, and the RFP Fire Department since 1988.

Section 313 of EPCRA requires RFP to prepare an annual report titled "Toxic Chemical Release Inventory, Form R," by July 1 of each year. The Form $R$ lists quantities of both routine and accidental releases of toxic chemicals, as well as the maximum amount of the listed toxic chemical onsite during the calendar year and the amount contained in waste transferred offsite for those chemicals that exceed certain use, manufacture or process thresholds. The threshold reporting level for listed chemicals that are either manufactured or processed is 25,000 pounds. If the listed chemical is otherwise used, the reporting threshold is 10,000 pounds. RFP has submitted the Form $R$ to the EPA and to the State of Colorado since 1989. Table 2-5 details chemical releases to the environment for the reporting years 1991 and 1992.

Table 2-5

Chemicals and Quantities (lbs) Released to the Environment in 1991 and 1992 as Reported on the Form $R$

Chemical
Nitric acid
Sulfuric Acid
Hydrochloric acid

$\begin{array}{cc}1991 & 1992 \\ 4,146 & 2,960 \\ - & 12 \\ - & 625\end{array}$

\section{AGREEMENT IN PRINCIPLE}

An Agreement in Principle (AIP) was executed between DOE and the State of Colorado on June 28, 1989. This agreement identified additional technical and financial support by DOE to Colorado for environmental oversight, monitoring, remediation, emergency response, and health-related initiatives associated with RFP. The agreement also addressed RFP environmental monitoring initiatives and accelerated cleanup where contamination may present an imminent threat to human health 
or the environment. The agreement is designed to ensure citizens of Colorado that public health, safety, and the environment are being protected through accelerated existing programs and substantial new commitments by $D O E$ and through vigorous programs of independent monitoring and oversight by Colorado officials.

Programs and projects put in place under this agreement include the air emissions inventory (see CAA earlier in this section), concurrent sampling of pond discharges (see CWA earlier in this section), and the Rocky Flats Toxicologic Review and Dose Reconstruction Study (CDH92a). This two-phased study, conducted by $\mathrm{CDH}$, and funded by DOE under the AIP, is intended to examine chemical and radionuclide emissions from RFP and assess what health impacts, if any, there may have been on the public. Comprised of eight technical tasks, Phase I was begun in July 1990 and completed with the issuance of the Final Draft Report of the Reconstruction of Historical Rocky Flats Operations \& Identification of Release Points, in August 1992 (CDH92b). According to $\mathrm{CDH}$, the final draft of Phase II is not anticipated until 1995 or possibly 1996. Of the six tasks in the Phase II study, draft reports on only two had been issued by December 1993.

On June 6, 1989, DOE mobilized a Special Assignment Team (Tiger Team and currently known as Progress Assessment Team) to provide an independent audit of operations and practices at RFP. This followed initiation of a search warrant by the EPA, Federal Bureau of Investigation (FBI), and the Justice Department based on an affidavit alleging regulatory and criminal violations of environmental laws at the RFP. The Justice Department conducted the investigation, and a federal grand jury was convened to review RFP compliance with applicable environmental laws. In March 1992, former RFP Management and Operating (M\&O) contractor Rockwell International Corporation agreed to plead guilty to 10 counts of environmental violations during its operation of RFP and agreed to pay $\$ 18.5$ million in fines. Rockwell pled guilty to four felony violations of RCRA and to one felony and five misdemeanor violations of the CWA. The plea agreement was subsequently approved by the U.S. District Court. 
The original Tiger Team audit was completed on July 21,1989 , and results were reported in the Assessment of Environmental Conditions at the Rocky Flats Plant (DOE89). The objectives of the audit were to determine whether any imminent threat existed to public health or the environment as a result of RFP activities; whether RFP operations were being conducted in accordance with applicable environmental requirements and best management practices; and the current status of previously identified environmental problems. Areas examined included environmental monitoring, site remediation, waste management, quality assurance, sewage treatment plant operation, waste stream characterization, and environmental impact analysis. The audit resulted in the identification of 52 findings, 43 recommendations for best management practices, and 4 noteworthy practices. No situations were observed that posed an imminent threat to public health or the environment. The 52 findings were identified among air monitoring programs (5), surface water (7), groundwater (2), waste management activities (10), toxic and chemical materials (9), radiation (5), quality assurance (2), inactive waste sites and releases (6), and NEPA (6).

EG\&G Rocky Flats, Inc., responded to findings of the Tiger Team in the Corrective Action Plan in Response to the August 1989 Assessment of Environmental Conditions at the Rocky Flats Plant (EGG90c). That document outlined 93 separate action plans containing descriptions of measures to be taken by RFP to address findings and included schedules, milestones, associated costs, and parties responsible for implementing planned actions. Many of the activities described in the plan overlap, or are similar to actions specified in the AIP and IAG and to the RFP Five-Year Plan (FYP) for environmental and waste programs (EGG93a). Progress associated with these action plans has been described in quarterly reports titled DOE Quarterly Environmental Compliance Action Report (DOE92b). 
Over 200 sub-tasks have been initiated to carry out the 93 action plans, and each is monitored and tracked in the Plant Action Tracking System (PATS), managed by the Commitments Management Department. The RFP status of these tasks, as of March 25, 1994, and still subject to DOE closure acceptance, is shown below.

$\begin{array}{lr}\text { Verified Closed } & 69 \\ \text { Closed } & 133 \\ \text { Completed } & 27 \\ \text { On Hold } & 18 \\ \text { Delinquent } & 2 \\ \text { Referenced } & 3 \\ \text { Re-Opened } & 14 \\ \text { Open } & 14 \\ & \\ \text { Total } & 280\end{array}$

In April and May of 1993, a 17-member DOE Progress Assessment Team did a follow-up to the 1989 "Tiger Team" as well as to past Technical Safety Appraisals. This independent assessment focused on environment, safety and health issues, corrective actions, and programs across plantsite. The team concluded that while "significant progress" had been made in correcting the deficiencies identified in the Tiger Team assessment, much remained to be done.

Of the five strengths noted in the draft report, four were in environmental programs. The standards of the Sewage Treatment Plant operations, solid radioactive waste generator training program, and the ERM Sample Management were cited as examples for other areas of plant performance to emulate. The report also outlined two concerns and three weaknesses in the environmental programs.

The report did not reflect as well on the areas of safety and health, and management systems. Team members outlined nine concerns and one strength in management systems and two concerns and one weakness in safety and health programs. All issues have corrective action plans in progress. 


\section{Environmental Monitoring Programs}

Environmental Protecrion Management activities at RFP are designed to minimize and, where practical, eliminate the release of radioactive and nonradioactive hazardous materials, and to enhance and restore the environment in and around the plantsite. A variety of monitoring programs are in place to measure the plant's performance in meeting these objectives. This section provides an overview of existing environmental monitoring programs; the following subsections describe the individual programs in greater detail and present results of monitoring activities conducted in 1993. 
OVERVIEW
Specific operations at RFP involve or produce liquids, solids, and gases containing radioactive and nonradioactive potentially hazardous materials. Various environmental programs monitor penetrating ionizing radiation and pertinent radioactive, chemical, and biological pollutants. Data on air, surface water, groundwater, and soils provide information to assess immediate and long-term environmental consequences of normal and unplanned effluent discharges and actual or potential exposures to critical populations. Site-specific data are used to evaluate risk to humans and to assist in the warning of unusual or unforeseen conditions.

Routine reports to local, state, and federal agencies and to the public provide information on the performance of these programs in maintaining and improving environmental quality and public health and safery. Table 3-1 provides a list of these reports. Table 3-2 contains the primary environmental compliance standards and applicable regulations for environmental monitoring programs at RFP. Additional compliance standards for air, surface water, and groundwater programs are given under references EGG92f, EGG92b, and EGG91h, respectively.

Among the reports prepared annually is the Rocky Flats Plant Environmental Monitoring Plan (EGG92e) which describes environmental monitoring programs at RFP. Monitoring programs provide current information on impacts to the environment and characterize environmental degradation at sites throughout RFP to identify contaminated areas and to design and monitor restoration activities.

Sections 3.1 through 3.6 of this report summarize results of routine environmental monitoring programs during 1993. Appendix D provides a detailed explanation of the sampling procedures used by laboratories and defines detection limits and error term propagation. Results are commonly compared to appropriate guides and standards that establish limits for radioactive and nonradioactive effluents. Persons unfamiliar with these standards are encouraged to review Appendix B, "Applicable Guides and Standards." 
Table 3-1

RFP Environmental Reports

\section{Requlatory Report- ${ }^{\text {a }}$}

Air Compliance Fisoort (40 CFR 61.94)

Effluent Information System/Onsite Discharge Information System

Environmental Protection Implementation Plan

Emergency and Hazardous Che! lical Inventory Forms (Tier II)

Toxic Chemical Release Inventory (Form R)

National Pollutant Discharge Elimination System/Discharge Monitoring Report

Polychlorinated Biphenyls (PCB) Inventory

Resource Conservation and Recovery Act Groundwater Monitoring Report

Rocky Flats Monthly Environmental Monitoring Report

Rocky Flats Plant Site Environmental Report

Environmental Monitonng Plan

Groundwater Protection and Monitoring Program Plan

Background Geochemical Characterization Report
Agency $^{b}$

Frequency

EPA

Annual

DOE

Annual

DOE

Annual

c

Annual

EPA

Annual

EPACOH

Monthly/

Annual

EPA

Annual

EPACDH

Annual

Quarterly

DOEIEPACDHI

County/City Monthly

$\begin{array}{ll}\text { DOE } & \text { Annual } \\ \text { DOE } & \text { Annual } \\ \text { DOE } & \text { Annual }\end{array}$

EPANCDH

Annual ${ }^{d}$

a. Reports on major environmental programs prepared on a periodic basis

b. EPA - Environmental Protection Agency; DOE - Department of Energy; CDH - Colorado Department of Health; County - Jefferson Cities - Arvada, Broomfield, Westminster, Denver, Boulder, Northglenn, Fort Collins, Thornton

c. Colorado Emergency Planning Commission Jefferson County Emergency Planning Committee Boulder County Emergency Planning Committee Rocky Flats Fire Department

d. Final Annual Report was submitted in September 1993; no additional reports are planned. 


\section{Table 3-2 \\ Primary Compliance Standards and Applicable Regulations for Environmental Monitoring Programs}

\section{Monitoring Program \\ AIR Effluent Air \\ Nonradioactive Ambient Air \\ Radioactive Ambient Air \\ SURFACE WATER Surface Waler}

Community Water

GROUNDWATER

RADIATION DOSE

SOILS

\author{
Compliance Standards
}

- Standards for Performance for New Stationary Sources (40 CFR 60)

- National Emission Standards for Hazardous Air Pollutants (40 CFR 61)

- Colorado Air Quality Control Regulations \#3, \#6, \#7, \#8, and \#15 (5 CCR 1001)

- General Environmental Protection Program (DOE Order 5400.1)

- Environmental, Safety. and Health Program for Department of Energy Operations (DOE Order 5480.18)

- National Ambient Air Quality Standards and State Implementation Plans (40 CFR 50), Requirements for Preparation. Adoption. and Submittal of Implementation Plans ( 40 CFR 51), and Approval and Promulgation of Implementation Plans (40 CFA 52)

- Colorado Air Quality Control Commission Regulations \#1, \#2, \#3, and \#8 (5 CCR 1001)

- Colorado Air Pollution Control and Prevention Act, 1992 (25 CRS, Article 7, Part 1)

- General Environmental Prolection Program (DOE Order 5400.1)

- Environmental, Salety, and Health Program for Department of Energy Operations (DOE Order 5480.1B)

- General Environmental Prolection Program (DOE Order 5400.1)

- Environmental, Safety, and Health Program for Department of Energy Operations (DOE Order 5480.1B)

- National Emission Standards for Hazardous Air Pollutants (40 CFR 61. Subpart H)

- National Pollutant Discharge Elimination System $(40$ CFR 22, 125)

- Colorado Water Quality Control Commission Suriace Water Standards (5 CCR 1000)

- General Environmental Protection Program (DOE Order 5400.1)

- Environmental, Safety, and Health Program for Department of Energy Operations (DOE Order 5480.1B)

- National Interim Primary Drinking Water Regulations (40 CFR 141)

- Colorado Primary Drinking Water Regulations (5 CCR 1002)

- General Environmental Protection Program (DOE Order 5400.1)

- Environmental, Safety, and Health Program for Department of Energy Operations (DOE Order 5480.18)

- Comprehensive Environmental Response, Compensation, and Liability Act (42 U.S.C. 9601)

- Resource Conservation and Recovery Act (42 U.S.C. 6901)

- Colorado Hazardous Waste Management Act (25 CRS, Article 15)

- General Environmental Protection Program (DOE Order 5400.1)

- Environmental, Safety, and Health Program for Department of Energy Operations (DOE Order 5480.18)

- Colorado Water Quality Control Commission Groundwater Standards

- Agreement in Principle to Sample Boundary Wells.

- United States Atomic Energy Commission, Rocky Flats Plant, 1973 Environmental Surveillance Summary Report

- General Environmental Protection Program (DOE Order 5400.1)

- Environmental, Safety, and Health Program for Department of Energy Operations (DOE Order 5480.18)

- Radiation Protection of the Public and the Environment (DOE Order 5400.5)

- General Environmental Protection Program (DOE Order 5400.1)

- Environmental, Salety, and Health Program for Department of Energy Operations (DOE Order 5480.1B) 
THE FIVE-YEAR PLAN AND THE SITE-SPECIFIC PLAN
In addition to the environmental programs perforyned by EG\&G Rocky Flats, several loçal, state, and federal government agencies conduct independent audits and environmental surveys within and adjacent to RFP. The CDH, DOE. and the cities of Broomfield and Westminster conduct various air, water, and soil monitoring programs. Data are reported collectively at monthly Environmental Monitoring Information Exchange Meetings. RFP provides monthly environmental monitoring summaries at these meetings, which are open to the public and have been ongoing since the early 1970 s.

The purpose of the Five-Year Plan (FYP) is to establish an agenda for compliance and cleanup against which progress can be measured. The plan is revised annually, incorporating a five-year planning horizon, and supports an annual national plan that is issued under the same title. A draft plan for fiscal years 1995-1999, titled Rocky Flats Plant Draft FY95-99 Five-Year Plan (EGG93d), was prepared for review in the first part of 1993. The FYP encompasses total program activities and costs for DOE Environmental Restoration. Waste Management, and Technology Development activities. Hazardous. radioactive, mixed (hazardous and radioactive), and sanitary wastes are addressed, as well as facilities and sites that are either contaminated with wastes or used in the management of those wastes.

A Site-Specific Plan (SSP) is prepared to describe how activities shown in the FYP would be implemented at RFP. This plan is revised annually and emphasizes near-term activities, primarily those to be accomplished in a fiscal year. The final plan for FY93 was prepared for distribution in the first quarter of calendar year (CY) 93. 


\section{Environmental Monitoring Programs}

\subsection{Meteorological Monitoring and Climatology}

This section presents meteorological data collected at the Rocky Flats Plant from January 1 through December 31, 1993 from instrumentation installed on a 67-meter (200-foot) tower located in the west buffer zone. The tower is instrumented at 10,25, and 60 meters to measure horizontal wind speed, direction, vertical wind speed, and temperature. Temperature, relative humidity, and the upward and downward components of solar and long-wave radiation are measured at the 1.5-meter level. Soil temperature is also recorded. Atmospheric pressure and precipitation are measured at ground level. 
$\therefore \quad \therefore *^{*}$ 


\section{OVERVIEW}

RFP's climate is temperate and semiarid, characteristic of Colorado's Front Range. The climate also is continental. since temperatures are largely determined by air masses that form over the land of North America. This results in large seasonal temperature variations and, occasionally, dramatic short-term temperature changes. The thin, dry atmosphere at the 6,000-foot elevation of RFP also causes wide temperature ranges, with strong daytime warming and nighttime cooling. High temperatures are typically in the mid-80 degrees Fahrenheit $\left({ }^{\circ} \mathrm{F}\right)$ during the summer months and occasionally exceed $90^{\circ} \mathrm{F}$. The heat, however, is rarely oppressive because of low relative humidities. Even after extremely warm days, strong cooling allows temperatures to fall to $60^{\circ} \mathrm{F}$ or lower during the night.

Temperatures also are relatively mild during the winter months, ranging from $40^{\circ} \mathrm{F}$ to $45^{\circ} \mathrm{F}$ during the day and $15^{\circ} \mathrm{F}$ to $25^{\circ} \mathrm{F}$ at night. Arctic and Siberian air masses occasionally bring frigid air during the winter. Low temperatures may drop to $-5^{\circ} \mathrm{F}$ to $-12^{\circ} \mathrm{F}$ or lower several times a year, while high temperatures can fail to exceed $0{ }^{\circ} \mathrm{F}$ during the coldest outbreaks.

Normal annual precipitation at RFP is nearly 15.5 inches, including rainfall and melted snow. Nearly 42 percent of the annual precipitation falls from April through June. Migratory storms often affect RFP during these months, transporting moisture from the Gulf of Mexico. Precipitation is enhanced during upslope conditions, as the air cools and becomes saturated. Precipitation falls primarily as snow from late October through early April. Arctic air masses occasionally combine with snowfall and may produce blizzard conditions. Annual snowfall averages between 70 and 75 inches, with the highest monthly snowfall (an average of 16 inches) falling in March. Summer precipitation results from showers and thundershowers. Severe thunderstorms occasionally affect areas east of the Front Range but occur infrequently at RFP. Tornadoes are unlikely to occur at RFP, although a weak tornado is theoretically possible. Drought conditions occasionally develop along the Front Range and can lead to prairie wildfires that can sometimes affect the RFP buffer zone and surrounding areas.

High wind events are common along the Front Range during the winter months. So-called "Chinook" winds are forced over and accelerate as they cross the eastern slopes of the Continental Divide. The air warms, dries 
as it sinks, and compresses on the eastern side of the mountains. Chinook winds can cause ground blizzards during periods of snow cover. RFP normally experiences several days a year with peak wind gusts exceeding 60 miles per hour (mph); gusts reaching $80 \mathrm{mph}$ or inore occur less frequently.

The combination of fair skies, light winds, and gently sloping terrain allows local winds to form and predominate over the region. Daytime heating causes upslope winds to form, with northeasterly winds common over the broad South Platte River Valley, including RFP. More local, southeasterly winds also occasionally occur during the day at RFP because the terrain slope line is oriented along the southeast direction toward Standley Lake and the city of Arvada. The winds reverse at night, with a shallow, westerly drainage wind forming over RFP and a broad, southerly drainage wind forming over the South Platte Valley Basin. The locally produced winds are important to consider for estimating the transport and dispersion of potential pollutants in the region. The nighttime convergence of drainage winds toward the South Platte River Valley is largely responsible for Denver's "Brown Cloud."

CLIMATE SUMMARY

The meteorological monitoring program supports various operations at RFP. Meteorological information is necessary for (1) assessing transport and diffusion characteristics of the atmosphere used in emergency response and environmental impact assessment, (2) designing other environmental monitoring networks, and (3) developing site-specific weather forecasts. Meteorological data are also used for climatological analyses, hydrological studies, and various designbased engineering studies.

The meteorological data provided in this report were taken from the 61 -meter $(\mathrm{m})$ tower located to the northwest of the main plantsite (Figure 3.1-1). The tower site is approximately 6,140 feet (1,870 meters) above sea level. Data recovery exceeded 99 percent for all variables during 1993, with the exception of solar radiation, atmospheric pressure, and relative humidity (dew point). 
Figure 3.1-1. Location of the RFP 61-Meter Meteorological Tower

Annual climate summaries during 1993 are provided in Figure 3.1-2 and Table 3.1-1. The 1993 mean temperature of $45.7^{\circ} \mathrm{F}$ was over $2^{\circ} \mathrm{F}$ below normal. The annual temperature extremes ranged from a high of $91^{\circ} \mathrm{F}$ on July 10 and 29 to a low of $-10^{\circ} \mathrm{F}$ on February 16 and November 25. The 1993 peak wind gust of 82 mph occurred on December 31. Precipitation during the year was over 3 inches below normal, totaling 12.07 inches. The largest daily precipitation fell on June 7 when 1.15 inches of rain was recorded. The largest 15 -minute rainfall of 0.15 inches was recorded on March 28 . Monthly precipitation ranged from 1.79 inches in June to 0.13 inches in January.

The annual weather highlights included a continuation of cold weather during the 1992/1993 winter. February was the third coldest February and fourth coldest month ever recorded at RFP. In addition, the winter (December through February) of 1992/1993 was the coldest ever recorded at RFP. May precipitation was uncharacteristically light, totaling 1.13 inches, or less than half of normal. May is typically the wettest month of the year. An unseasonably intense storm slammed across the front range on the afternoon of July 3 , causing a peak wind gust of $73 \mathrm{mph}$. While RFP received only strong winds, the highest, nearby mountain peaks received heavy snow. August was another especially dry month, with precipitation totaling only 0.42 inches, or one quarter of normal. Unusually warm weather occurred on four days in September, with high temperatures of at least $81^{\circ} \mathrm{F}$. After reaching $84^{\circ} \mathrm{F}$ during the afternoon of September 12 , a storm system accompanied by Arctic air and upslope winds caused temperatures to plunge and 3.6 inches of wet snow to fall on September 13. The snowfall was unusually early, but not unprecedented. October weather also experienced large temperature extremes. Very warm weather occurred during the first week as high temperatures equaled or exceeded $80^{\circ} \mathrm{F}$ on October 4 through October 6 , including $83^{\circ} \mathrm{F}$ on October 6 . However, an Arctic air mass kept the high 
$1^{\circ} \mathrm{F}$

Temperature

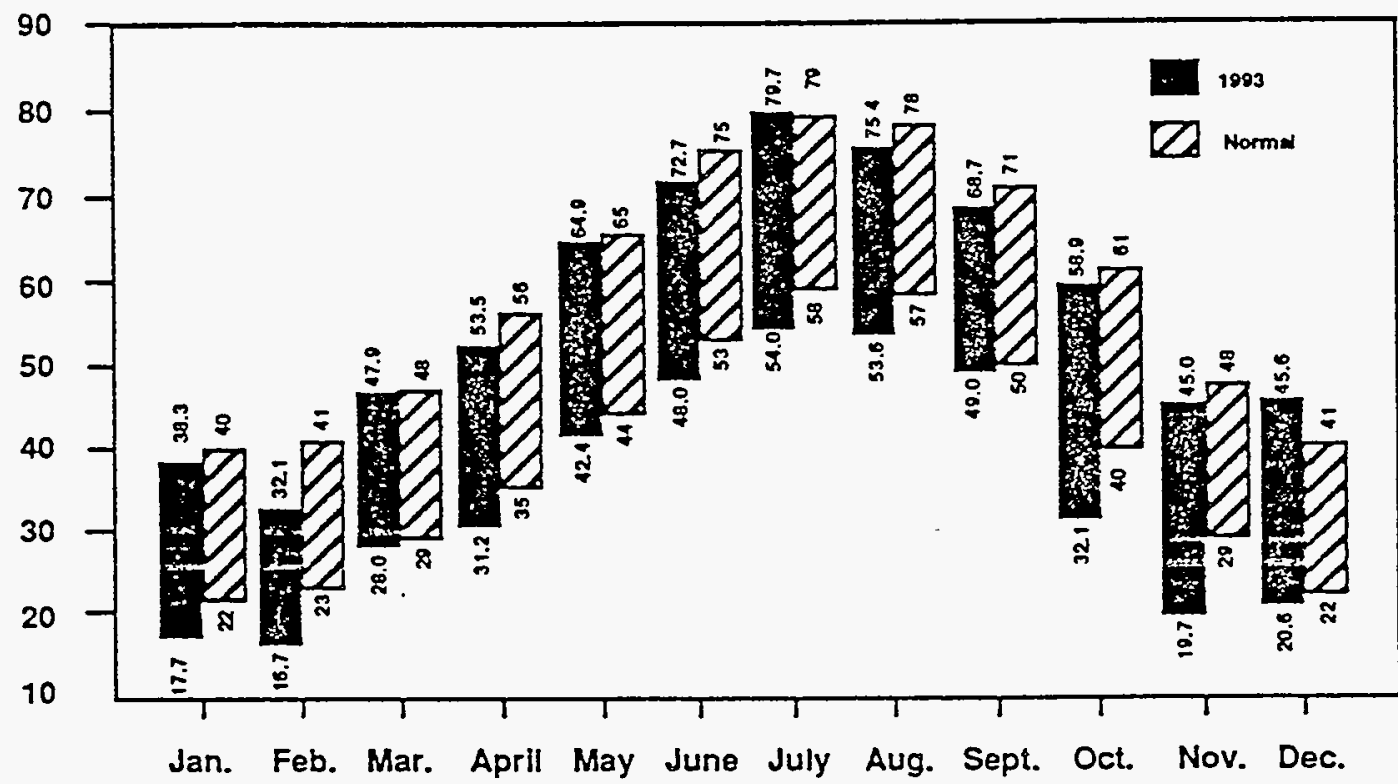

(inches)

Precipitation

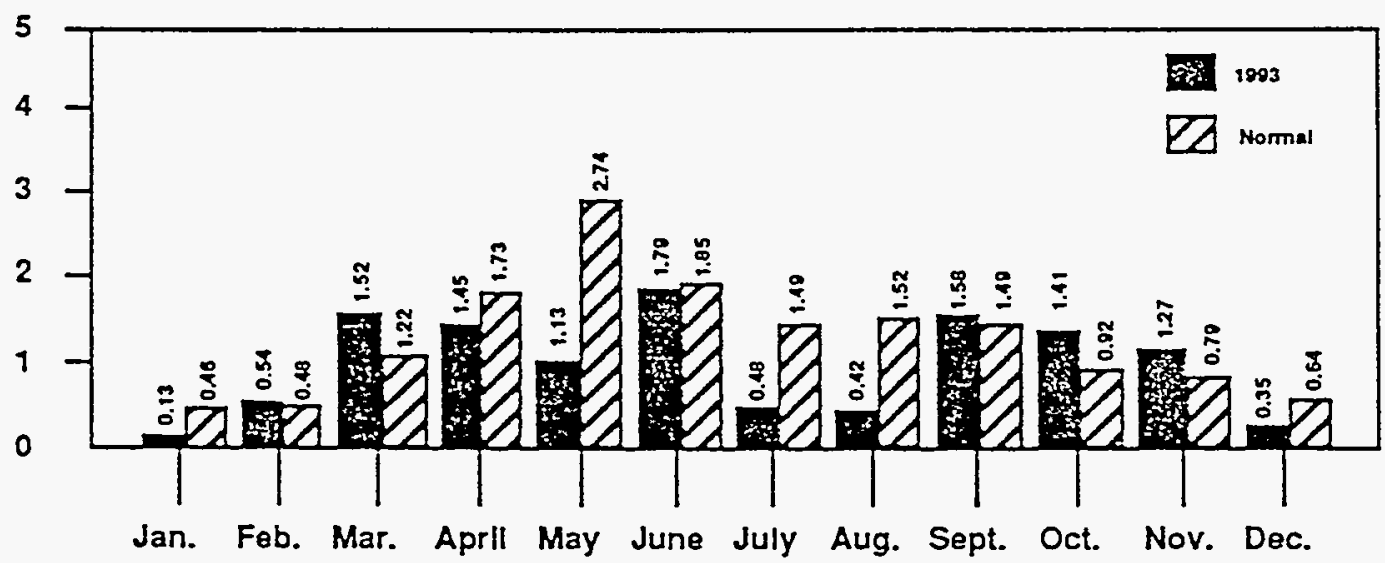

Figure 3.1-2 1993 RFP Climate Summary 
Table 3.1-1

1953 Annual Climatic Summary

Temperatures $(\mathrm{F})^{\mathrm{a}}$

\begin{tabular}{|c|c|c|c|c|c|c|c|c|c|}
\hline \multirow[b]{2}{*}{ Month } & \multicolumn{3}{|c|}{ Means } & \multicolumn{4}{|c|}{ Extremes } & \multirow{2}{*}{$\begin{array}{l}\text { Mean Dew } \\
\text { Point }\left(1^{\circ} \mathrm{F}\right)\end{array}$} & \multirow{2}{*}{$\begin{array}{r}\text { Mean. R } \\
\text { Humidity }\end{array}$} \\
\hline & High & Low & Average & High & Date & Low & Date & & \\
\hline January & 38.3 & 17.7 & 28.0 & 56 & 22,27 & -4 & 10 & 5.9 & 38 \\
\hline February & 32.1 & 16.7 & 24.4 & 53 & 19 & -10 & 16 & 6.1 & 44 \\
\hline March & 47.9 & 28.0 & 38.0 & 67 & 25 & 5 & 13 & 13.3 & 36 \\
\hline April & 53.5 & 31.2 & 42.4 & 68 & 22 & 22 & 12 & $-999^{c}$ & $-999^{c}$ \\
\hline May & 64.9 & 42.4 & 53.7 & 82 & 26 & 28 & 1 & $-999^{c}$ & $.999^{c}$ \\
\hline June & 72.7 & 48.0 & 60.4 & 90 & 15 & 35 & 4 & 35.1 & 38 \\
\hline July & 79.7 & 54.0 & 66.8 & 91 & 10.29 & 49 & 5,7 & 40.5 & 40 \\
\hline August & 75.4 & 53.6 & 64.5 & 87 & 24 & 43 & 30 & 40.9 & 42 \\
\hline September & 68.7 & 49.0 & 58.8 & 85 & 11 & 31 & 13 & 31.6 & 36 \\
\hline October & 58.9 & 32.1 & 45.5 & 83 & 6 & 1 & 30 & 29.3 & 52 \\
\hline November & 45.0 & 19.7 & 32.4 & 64 & 10 & -10 & 25 & 15.2 & 50 \\
\hline December & 45.6 & 20.6 & 33.1 & 60 & 26 & .5 & 22 & 11.5 & 40 \\
\hline Annual & 56.9 & 34.4 & 45.7 & 91 & $7 / 10,7 / 29$ & -10 & $2 / 16,11 / 25$ & $24.4^{b}$ & $42^{b}$ \\
\hline
\end{tabular}

\begin{tabular}{|c|c|c|c|c|}
\hline \multirow[b]{2}{*}{ Month } & \multicolumn{2}{|c|}{ Wind Speed (mph) } & \multirow{2}{*}{$\begin{array}{l}\text { Atmos. Pressure } \\
\text { Mean (mb) }\end{array}$} & \multirow{2}{*}{$\begin{array}{l}\text { Solar Toto } \\
\mathrm{kW} \mathrm{V}^{2} \mathrm{~m}^{2}\end{array}$} \\
\hline & Mean & Peak & & \\
\hline January & 8.5 & 75 & 808.3 & 68.4 \\
\hline February & 6.7 & 70 & 808.2 & 85.8 \\
\hline March & 9.2 & 50 & 811.0 & 137.2 \\
\hline April & 9.3 & 67 & 808.3 & 206.3 \\
\hline May & 7.9 & 60 & 812.5 & 186.2 \\
\hline June & 8.5 & 58 & 812.3 & 210.8 \\
\hline July & 8.9 & 73 & 814.1 & 203.5 \\
\hline August & 7.5 & 47 & 817.2 & 156.7 \\
\hline September & 8.2 & 58 & $-999^{c}$ & $-999^{c}$ \\
\hline October & 7.6 & 66 & 814.3 & 108.4 \\
\hline November & 9.8 & 66 & 810.7 & 84.4 \\
\hline December & 12.3 & 82 & 809.7 & 76.8 \\
\hline Annual & 8.7 & 82 & $812.0^{\circ}$ & $165.6^{\circ}$ \\
\hline
\end{tabular}

\begin{tabular}{|c|c|c|c|c|c|c|c|c|}
\hline \multirow[b]{2}{*}{ Month } & \multicolumn{5}{|c|}{ Precipitation (inches) } & & \multicolumn{2}{|c|}{ Number of Days } \\
\hline & Total & $\begin{array}{l}\text { Daily } \\
\text { Max. }\end{array}$ & Date & $\begin{array}{l}\text { 15-Min. } \\
\text { Max. }\end{array}$ & $\begin{array}{l}\text { Snowfall } \\
\text { Inches }\end{array}$ & $\begin{array}{l}\text { Precip. } \\
\geq 0.10^{n}\end{array}$ & $\begin{array}{l}\text { Max. } \\
\text { Temp. } \\
\geq 90^{\circ} \mathrm{F}\end{array}$ & $\begin{array}{l}\text { Min. } \\
\text { Temp. } \\
\leq 32^{\circ} \mathrm{F}\end{array}$ \\
\hline January & 0.13 & 0.04 & 8 & 0.02 & 3.0 & 0 & 0 & 24 \\
\hline February & 0.54 & 0.15 & 15 & 0.02 & 8.7 & 2 & 0 & 26 \\
\hline March & 1.52 & 0.50 & 28 & 0.15 & 7.9 & 4 & 0 & 23 \\
\hline April & 1.45 & 0.53 & 12 & 0.04 & 9.1 & 4 & 0 & 17 \\
\hline May & 1.13 & 0.44 & 17 & 0.12 & 0.0 & 4 & 0 & 3 \\
\hline June & 1.79 & 1.15 & 17 & 0.14 & & 2 & 1 & 0 \\
\hline July & 0.48 & 0.23 & 14 & 0.06 & - & 2 & 3 & 0 \\
\hline August & 0.42 & 0.14 & 5 & 0.04 & - & 2 & 0 & 0 \\
\hline September & 1.58 & 0.57 & 13 & 0.09 & 3.6 & 5 & 0 & 1 \\
\hline October & 1.41 & 0.61 & 17 & 0.10 & 6.5 & 4 & 0 & 12 \\
\hline November & 1.27 & 0.50 & 14 & 0.03 & 23.8 & 4 & 0 & 28 \\
\hline December & 0.35 & 0.13 & 21 & 0.02 & 5.6 & 2 & 0 & 24 \\
\hline Annual & 12.07 & 1.15 & $6 / 7$ & 0.15 & 68.2 & 35 & 4 & 158 \\
\hline
\end{tabular}

a. Temperatures and relative humidity were measured at 10-m through August and at 1.5-m beginning September 1, 1993.

b. Estimated

c. Data invalid or not available. 
temperature to $34^{\circ} \mathrm{F}$ on October 9. After another earlyseason snowfall of 6.5 inches on October 28 and 29 , the low temperature reached $1^{\circ} \mathrm{F}$ on the morning of October 30. Unusually cold temperatures continued into November, along with heavy snowfall. A strong Arctic outbreak dropped the high temperature to only $9^{\circ} \mathrm{F}$ on November 24 and the overnight low temperature to $-10^{\circ} \mathrm{F}$ on the following morning. The nearly 24 inches of snowfall was twice the normal and the snowiest month of 1993 by far. Milder and drier weather occurred in December. Temperatures were especially mild around Christmas, with the high temperature reaching $60^{\circ} \mathrm{F}$ on December 26. Chinook winds on December 31 caused the year's highest peak gust of $82 \mathrm{mph}$.

The annual summary of wind direction and speed frequencies measured at the $10-\mathrm{m}$ height are provided in Table 3.1-2 and are shown graphically by a wind rose in Figure 3.1-3. Compass point designations indicate the direction from which the wind blew (wind along each vector blows toward the center). Wind directions most frequently are from the west-southwest through northerly directions. Wind speeds above $18 \mathrm{mph}(8$ meters per second $[\mathrm{m} / \mathrm{s}]$ ) occur primarily with westerly winds and, to a lesser extent, northerly winds.

Table 3.1-2

RFP Wind Direction Frequency (Percent) by Four Wind-Speed Classes

(15 - Minute Averages - Annual 1993)

N

NNE

NE

ENE

E

ESE

SE

SSE

$S$

SSW

SW

WSW

W

WNW

NW

NNW

TOTALS
$0.5 \cdot 2.5 \mathrm{~m} / \mathrm{s}$

$(1.1-5.6 \mathrm{mph})$

$<0.5 \mathrm{~m} / \mathrm{s}$

( $\leq 1.1 \mathrm{mph}$ )

2.74

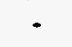

2.23

2.21

2.09

1.85

1.82

1.70

2.02

1.87

1.84

1.67

1.59

1.73

1.86

2.16

2.24

2.00

30.89

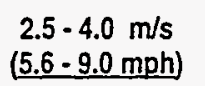

$4.0-8.0 \mathrm{~m} / \mathrm{s})$
$(9.0-18 \mathrm{moh})$

2.42

2.21

1.77

1.33

1.34

1.67

2.35

2.22

2.03

1.74

1.91

2.06

1.81

2.09

2.26

2.75

31.95

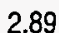

1.64

0.82

0.43

0.39

0.44

0.97

1.62

1.29

1.15

1.65

2.16

2.47

3.82

2.44

2.54

26.72
$(9.0-18 \mathrm{mph}) \quad(\geq 18 \mathrm{mph})$
Total

$\begin{array}{lr}\begin{array}{cc}>8.0 \mathrm{~m} / \mathrm{s} \\ (\geq 18 \mathrm{mph})\end{array} & \text { Total } \\ & \\ & 2.74 \\ 0.18 & 7.72 \\ 0.06 & 6.13 \\ 0.03 & 4.71 \\ 0.00 & 3.61 \\ 0.00 & 3.55 \\ 0.01 & 3.82 \\ 0.01 & 5.35 \\ 0.01 & 5.72 \\ 0.05 & 5.22 \\ 0.06 & 4.62 \\ 0.08 & 5.23 \\ 0.45 & 6.40 \\ 2.24 & 8.38 \\ 3.59 & 11.67 \\ 0.78 & 7.72 \\ 0.13 & 7.42\end{array}$

7.07
4.71

3.61

3.55

5.35

5.72

5.22

4.62
5.23

6.40

11.67

7.72
7.42

100.00 
The change in winds is illustrated in Figures $3.1-4$ and 3. $:-5$. Day is defined as the period between 1 hour atter sunrise to 1 hour before sunset. Night is defined as the remainder of the time. Locally and regionally produced, thermally driven winds are apparent during the day, with northeasterly up-valley and southeasterly upslope winds. Locally produced winds usually have wind speeds of $11 \mathrm{mph}(5 \mathrm{~m} / \mathrm{s})$ or less. Stronger, larger-scale winds occur from the west and, to a lesser extent, northerly directions.

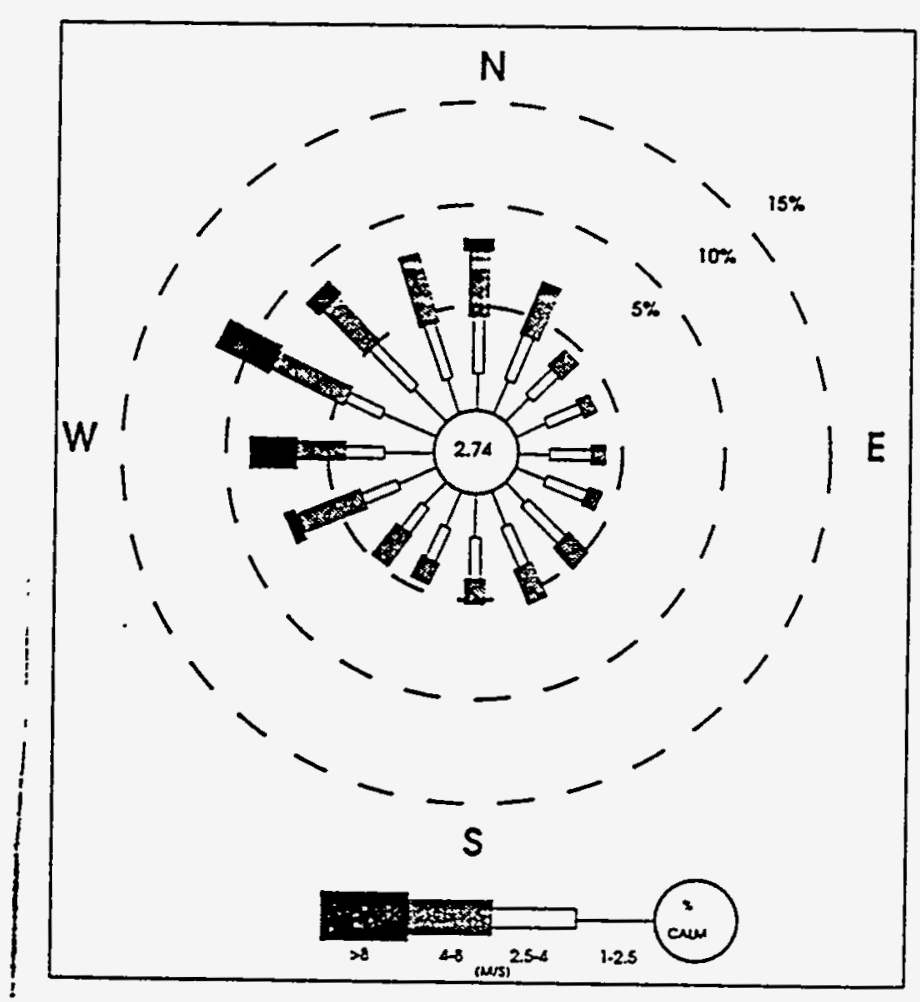

Figure 3.1-3. RFP 1993 Wind Rose - 24-Hour
The distribution of nighttime winds is nearly reversed, with Rocky Flats drainage winds causing a high frequency of westerly winds. The South Platte Valley drainage also contributes to the high frequency of southwesterly winds. The frequency of stronger, larger-scale winds is similar to the daytime distribution.

Pasquill-Gifford stability classes are used to estimate horizontal and vertical dispersion and are input into atmospheric dispersion models. Stability classes at RFP were estimated using the sigma theta technique, where the stability is determined from the standard deviation of horizontal wind, mean horizontal wind speed, and whether day or night (EPA86). Another EPA-recommended technique, the sigma phi method, results in an unrealistically high number of neutral and stable cases, thereby underestimating RFP dispersion and generally overestimating atmospheric concentrations resulting from potential releases. The stability classes range from $A$ to $F$, or extremely unstable to very stable, respectively. The D class represents neutral stability. By definition, daytime stability ranges from $A$ to $D$ and nighttime stability ranges from $D$ to $F$. The stability category is defined as $D$ whenever the wind speed equals or exceeds $6 \mathrm{~m} / \mathrm{s}$ (13.4 mph). The 1993 percent occurrence of winds by stability class is shown in Table 3.1-3. 


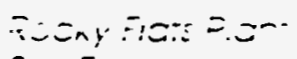

She Environment a report tor 1993

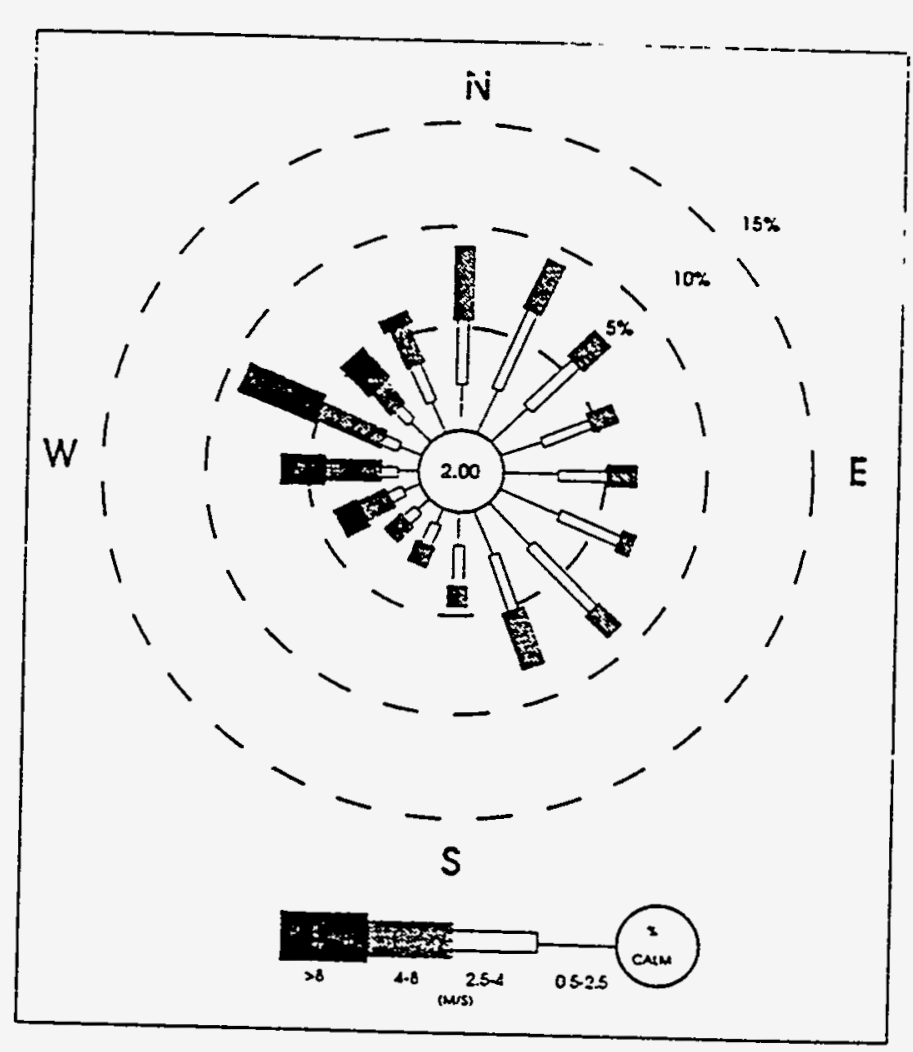

Figure 3.1-4. RFP 1993 Wind Rose - Day

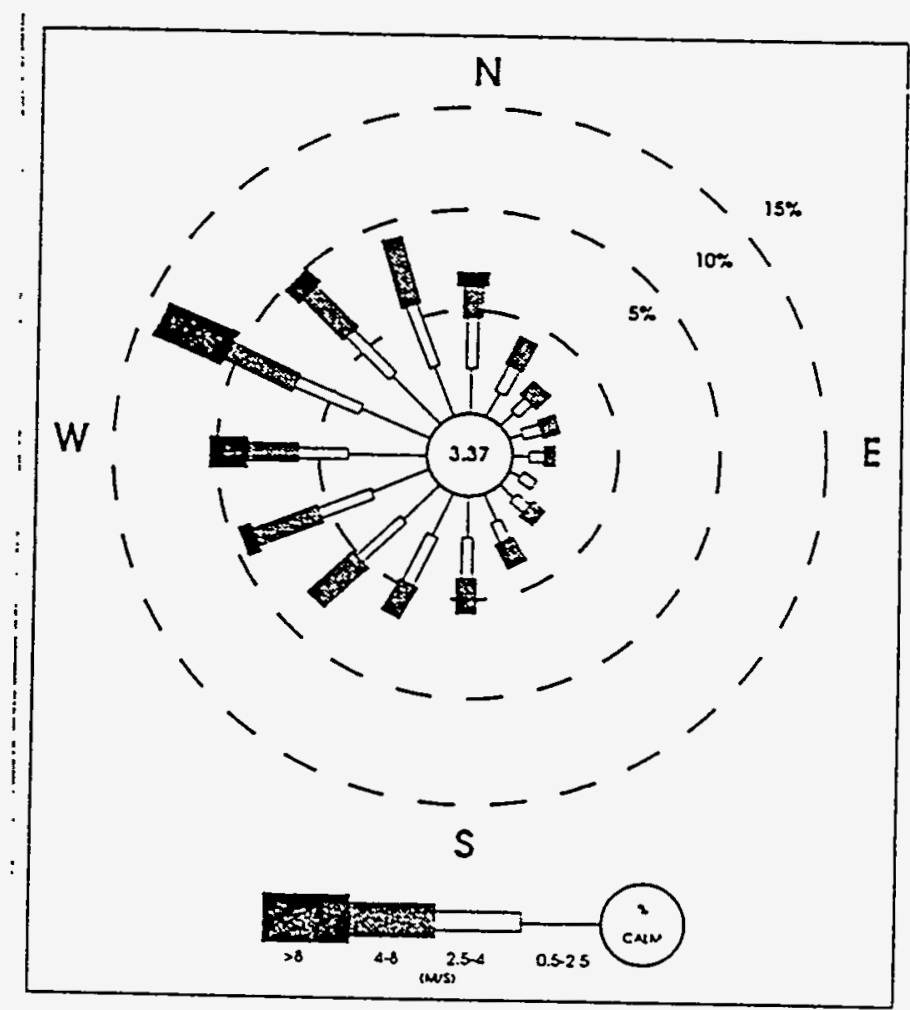

Figure 3.1-5. RFP 1993 Wind Rose - Night

76 
Results show that unstable categories (A through C) occur 24 percent of the time, and stable categories ( $E$ through F) occur 33 percent of the time. Neutral stability occurs most frequently, more than 43 percent of the time. Frequency distributions of wind speed direction for each stability category are presented in Appendix C. The speed classes (knots) follow the guidelines for the STAR (Stability Array) deck used as input for various regulatory dispersion models. Calms were distributed according to STAR deck procedures.

Table 3.1-3

Percent Occurrence of Winds by Stability Class

Slability Class

A
B
C
D
E
F
Percent Occurrence
9.3
6.0
8.8
43.2
21.2
11.5 


\section{Environmental Monitoring Programs}

\subsection{Air Monitoring}

An extensive monitoring program is in place at RFP to measure radiological and nonradiological air emissions from individual buildings and in the surrounding environment. The data generated by the monitoring are used to support compliance with applicable state and federal air quality regulations, and to help provide assurances that protection of the health of plant workers and the general public is being maintained. This section provides the results of monitoring of effluent air, and of radioactive and nonradioactive ambient air. 


\section{EFFLUENT AIR MONITORING}

\section{Overview}

The term "effluent" refers to something that flows out into the environment. An effluent could be a stream flowing out of a lake or other body of water. It also can refer to the release of air to the environment. At RFP, effluent refers to air emissions released to the environment from processing and laboratory facilities, and to the release of water (liquid effluents), particularly surface-water runoff and treated sanitary wastewater. (Liquid effluents are discussed further in Section 3.3, Surface-Water Monitoring.)

At RFP, several protective measures and controls are in place to minimize releases of radioactive or hazardous material to the environment. Ventilation and filtration systems constantly filter the air while monitoring equipment measures building emmisions to the environment. Air pressure in the buildings is controlled to prevent unplanned releases. The system was designed so that if a leak were to develop in a glovebox, the radioactive material would be contained in the glovebox and filtered for radioactive particles (see Figure 3.2-1).

Plutonium, uranium, and americium, the primary radioactive materials used and handled at $R F P$, are in a solid particle form. As a result, particle filtration of the airborne effluent streams is an important and effective means of preventing the release of these materials to the environment. Radioactive particles generated by RFP activities enter exhaust air streams that are attached to the glovebox system where the particulate materials are removed by highly efficient filters. These High Efficiency Particulate Air (HEPA) filters, referred to as absolute filters in the electronics industry, must meet strict construction and performance criteria before they are accepted for use at RFP.

HEPA filters are designed to be fire- and chemicalresistant. They are constructed of tiny glass fibers combined with a small amount of organic material added for strength and water repellency. Upon arrival at the plant, HEPA filters are tested to ensure a minimum efficiency of 99.97 percent for all particle sizes. After installation, the filters are tested again to guard against any damage during installation and to ensure proper seating in the filter's housing. 


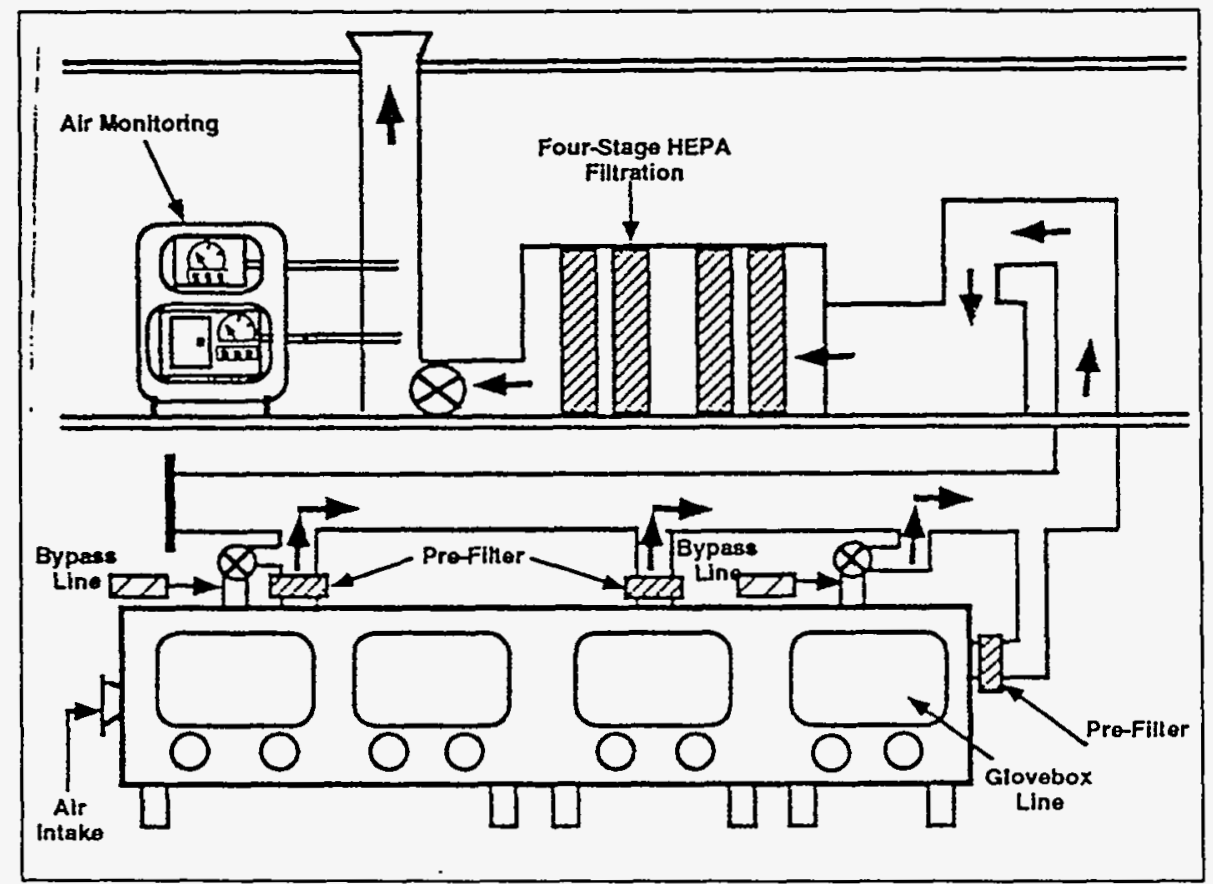

Figure 3.2-1. Glovebox Ventilation/Filtration Exhaust System 
Muliple banks of HEPA filters, called filter plenums, are installed in series in air exhaust systems (see Figure 3.2-2). In general, plutonium processing exhaust systems are equipped with four to six stages of HEPA filter banks, while uranium processing exhaust systems are equipped with a minimum of two stages of filter banks. These filter banks, combined with other protective measures, help ensure that airborne releases of radioactive material from RFP are minimal and do not pose any significant health risk to the public or the environment. (Building air not associated with the glovebox system and processing operations is controlled, filtered, and monitored before it is released to the environment.)

RFP continuously monitors radionuclide air emissions at 63 emission points in 17 buildings. The radiological particulate monitoring and sampling program uses a three-tier approach, comprising Selective Alpha Air Monitors (SAAMs), total long-lived alpha screening of routine air duct emission sample filters, and radiochemical analysis of isotopes collected for air duct emission samples. This approach balances both detectability and timeliness of results.

For immediate detection of abnormal conditions, RFP building ventilation systems that service areas containing plutonium are equipped with SAAMs. SAAMs are sensitive to specific alpha particle energies and are set to detect plutonium-239 and -240 . These detectors are subjected to daily operational checks, monthly performance testing and calibration for airflow, and an annual radioactive source calibration to maintain sensitivity and reliability (see Figure 3.2-3). Monitors alarm automatically if any out-of-tolerance conditions are detected. No such condition occurred during 1993.

At regular intervals, particulate material samples from the continuous sampling systems are removed from the exhaust systems and radiometrically analyzed for longlived alpha emitters. The concentration of long-lived alpha emitters is indicative of effluent quality and overall performance of the HEPA filtration system. If the total long-lived alpha concentration for an effluent sample exceeds the RFP action value of $0.020 \times 10^{-12}$ microcuries per milliliter $(\mu \mathrm{Ci} / \mathrm{ml})\left(7.4 \times 10^{-4}\right.$ Becquerels per cubic meter $\left.\left[\mathrm{Bq} / \mathrm{m}^{3}\right]\right)$, a follow-up investigation is conducted to determine the cause and 
Figure 3.2-2. High Efficiency Particulate Air Filter Banks 
to evaluate the need for corrective action. The action guide value is equal to the most restrictive offsite Derived Concentration Guide (DCG) for plutonium activity in air. (See Appendix B for an explanation of the action guide.)

At the end of each month, individual samples from each exhaust system are composited into larger samples by location. A portion of each dissolved composite sample is analyzed for beryllium particulate materials. The remainder of the dissolved sample is subjected to radiochemical separation and alpha spectral analysis, which quantifies specific alpha-emitting radionuclides. Analyses for uranium isotopes are conducted for each composite sample.

Forty-one of the ventilation exhaust systems are located in buildings where plutonium processing is conducted. Particulate material samples from these exhaust systems are analyzed for specific isotopes of plutonium and americium. Typically, americium contributes only a small fraction of the total alpha activity release from RFP. Processes that are ventilated from several exhaust systems potentially exhibit trace quantities of tritium contamination. Bubble-type samplers are used to collect samples generally three times each week from the monitored locations. Tritium concentrations in the sample are measured using a liquid scintillation photospectrometer.

Results

Projected doses to the public from radionuclide emissions were within the NESHAP limits of $10 \mathrm{mrem} /$ year EDE. A discussion of radiation dose estimates from air emissions is included in Section 6, "Radiation Dose Assessment."

Plutonium and Uranium. During 1993, total quantities of plutonium and uranium discharged to the atmosphere from RFP processing and support buildings were $0.1607 \mu \mathrm{Ci}\left(5.95 \times 10^{3} \mathrm{~Bq}\right)$ and $1.597 \mu \mathrm{Ci}\left(5.91 \times 10^{4}\right.$ $\mathrm{Bq}$ ), respectively (Tables $3.2-1$ and 3.2-2). These values were corrected for background radiation. Annual plutonium-239, -240 and uranium-233/-234, and -238 emissions for the 1989 to 1993 period are provided in Figures 3.2-4 and 3.2-5, respectively. 


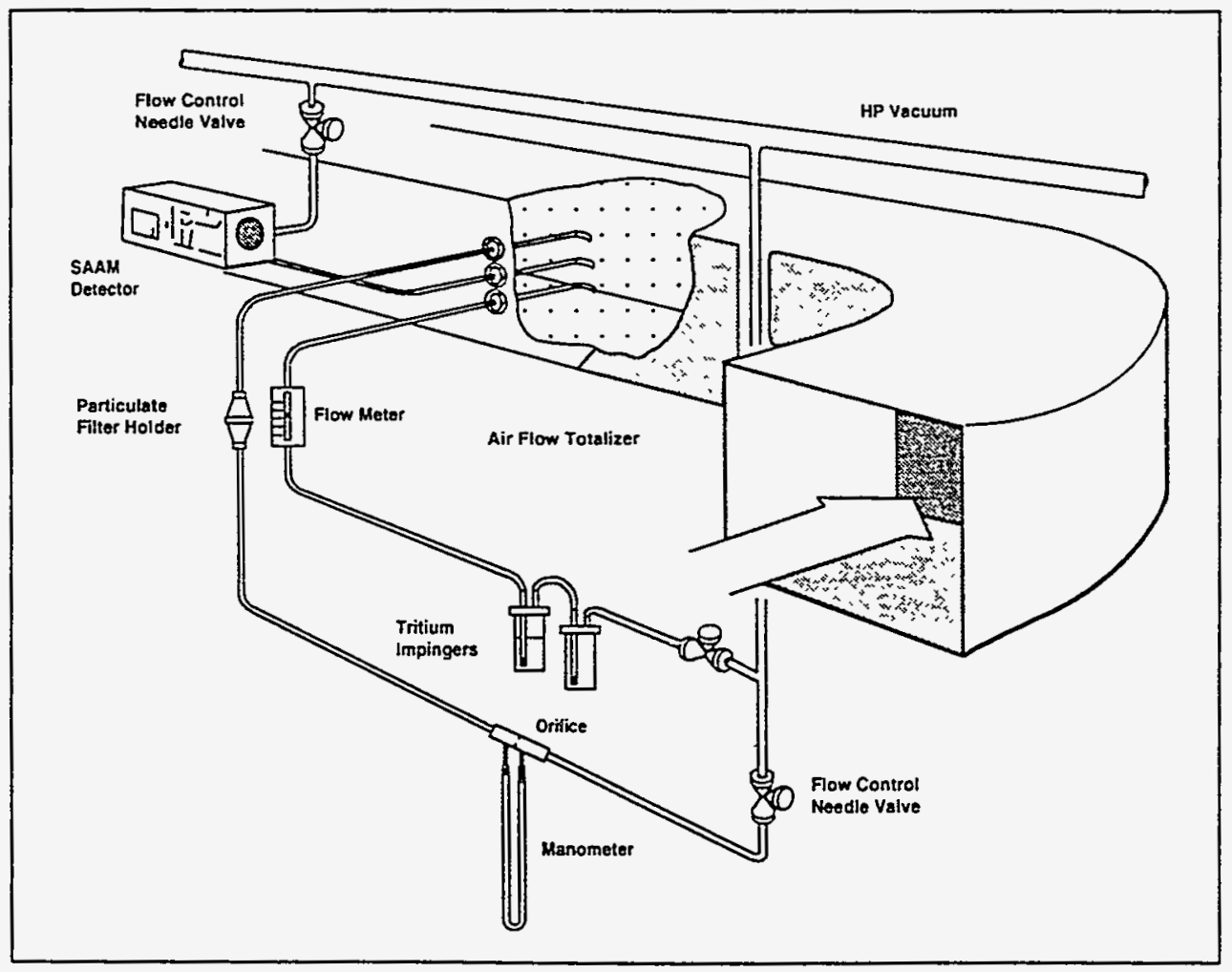

Figure 3.2-3. Radiological Effluent Air Sampling System (top) Selective Alpha Air Monitor (bottom) 


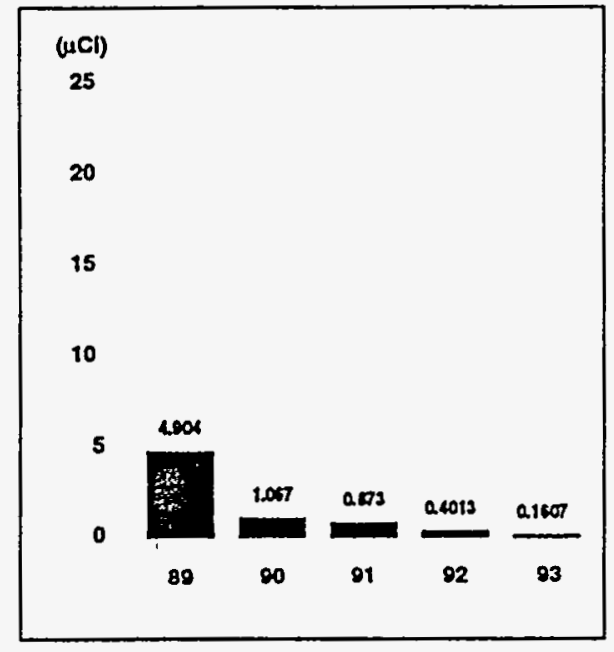

Figure 3.2-4. Plutonium-239, -240

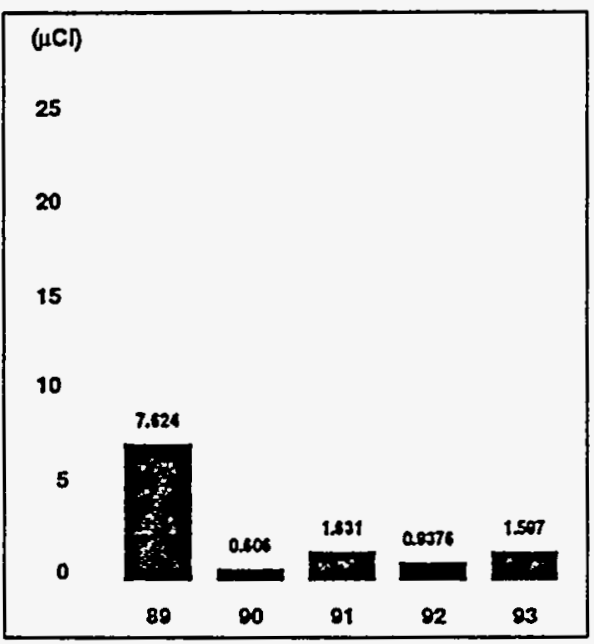

Figure 3.2-5. Uranium-233/-234, -238

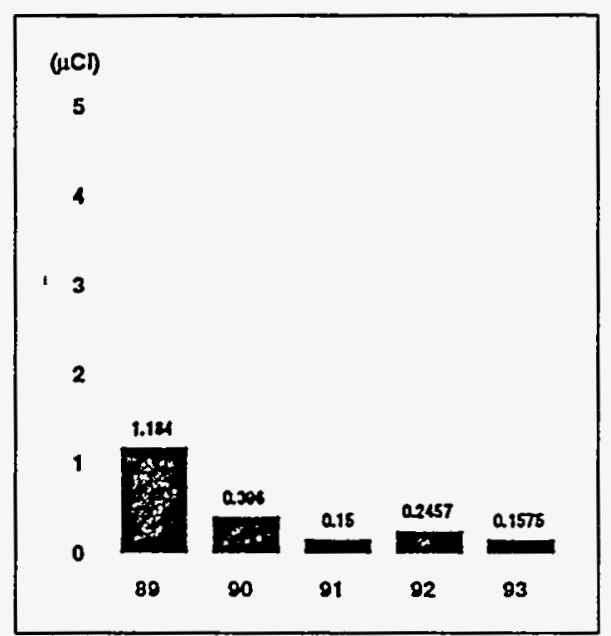

The overall decrease in radionuclide emissions since 1989 is a reflection of reduced propuction activities at RFP that resulted when plutonium production operations were curtailed in late 1989. Many of these operations have not resumed because of the subsequent cancellation of new weapons systems and the change in plant mission from a production-oriented mission to a new mission focusing on environmental restoration and decontamination of facilities.

Values reported for total quantities of plutonium and uranium discharges for 1993 may vary from the monthly environmental monitoring reports because of rounding in calculations and because the annual report includes plutonium-238/-239, and -240. Plutonium -238 represents 7.1 percent of the total plutonium discharged in 1993.

Americium. Total americium discharged in 1993 was $0.1575 \mu \mathrm{Ci}\left(5.83^{\circ} \times 10^{3} \mathrm{~Bq}\right)$ (Table 3.2-3). The maximum concentration was $.000088 \times 10^{-12} \mu \mathrm{Ci} / \mathrm{ml}$, observed in samples taken in September. Americium values were corrected for background radiation. Annual americium emissions for the period 1989 to 1993 are provided in Figure 3.2-6.

Tritium. Total tritium discharged during 1993 from ventilation systems in which tritium is routinely measured was $0.0037 \mathrm{Ci}\left(1.38 \times 10^{8} \mathrm{~Bq}\right)$ (Table 3.2-4). The maximum tritium concentration of $3135 \times 10^{-12}$ $\mu \mathrm{Ci} / \mathrm{ml}\left(115.99 \mathrm{~Bq} / \mathrm{m}^{3}\right)$ was observed during September during a one-day repackaging project for some sources in preparation for shipment to another DOE facility. Each month is divided into a series of individual sampling periods. The sum of the discharges for these sampling periods is the total tritium discharge for the month. Tritium values include a small, unquantified contribution attributed to natural background sources (i.e., nonplant sources). Annual measured tritium emissions for the period 1989 to 1993 are provided in Figure 3.2-7. In addition, Buildings 123, 881, and 374 have low-level tritium emissions for which monitoring is not performed. These emissions are estimated using emission factors as provided in $40 \mathrm{CFR}$, Part 61 . The total of the measured and estimated tritium emissions also is provided in Table 3.2-4.

Figure 3.2-6. Americium-241 
Beryllium. The total quantity of beryllium discharged from ventilation exhaust systems was 3.293 grams $(\mathrm{g})$. The maximum concentration was 0.00081 microgram per cubic meter $\left(\mu \mathrm{g} / \mathrm{m}^{3}\right)$ observed in September. These values were not significantly above background levels associated with the analyses. The beryllium stationarysource enission standard is $10 \mathrm{~g}$ during a 24-hour period. Table 3.2-5 presents the beryllium airborne effluent data for 1993.

The total quantity of beryllium discharged during 1993 varies from the monthly environmental monitoring reports. The annual report includes values for all 49 exhaust systems while the monthly report provides discharges for six exhaust systems on buildings where beryllium is processed. Beryllium discharges are monitored monthly at the remaining 43 locations, but are only provided in monthly reports if they exceed a screening level of $0.1 \mathrm{~g}$. Annual beryllium emission for the period 1989 to 1993 are shown in Figure 3.2-8. RFP ceased using analytical blanks in laboratory analysis to correct sample beryllium concentrations in September 1989. As a result, reported beryllium values measure both background and actual emission levels.

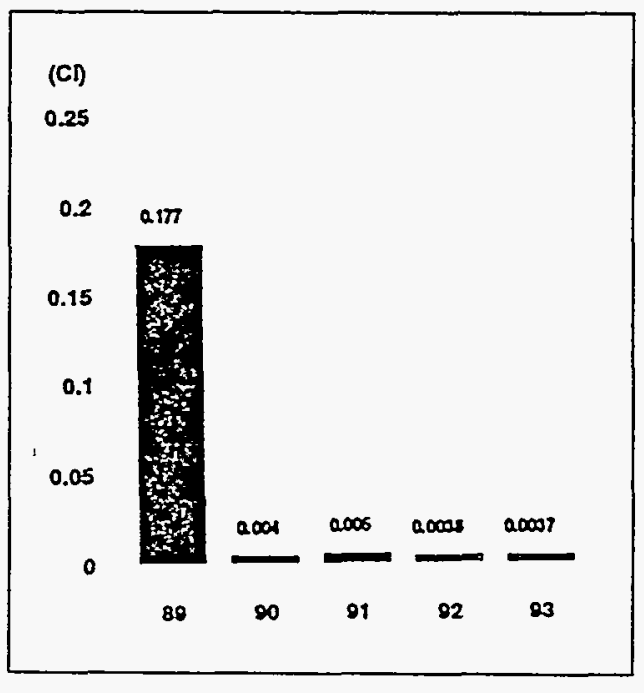

Figure 3.2-7. Tritium

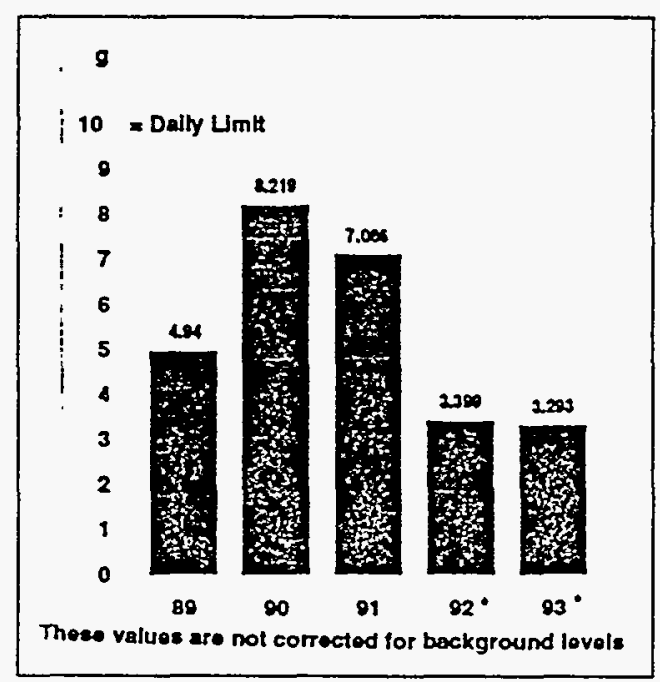

Figure 3.2-8. Beryllium 
Table 3.2-1

Plutonium in Effluent Air

Plutonium-238

Number of Total Discharge

Month Analyses ( $\mu \mathrm{Ci}$

\begin{tabular}{|c|c|c|c|c|c|c|c|}
\hline \multirow{2}{*}{$\begin{array}{l}\text { Month } \\
\text { January }\end{array}$} & \multirow{2}{*}{$\begin{array}{c}\text { Number of } \\
\text { Analyses } \\
46\end{array}$} & \multicolumn{3}{|c|}{$\begin{array}{c}\text { Total Discharge } \\
\text { (스) }\end{array}$} & \multicolumn{3}{|c|}{$\begin{array}{c}\text { C maximum } \\
\left(\times 10^{-12} \mu \mathrm{Ci} / \mathrm{ml}\right)\end{array}$} \\
\hline & & 0.0013 & \pm & 0.0015 & 0.0000 & \pm & 0.0000 \\
\hline February & 46 & 0.0019 & \pm & 0.0014 & 0.0000 & \pm & 0.0000 \\
\hline March & 46 & 0.0007 & \pm & 0.0012 & 0.0000 & \pm & 0.0000 \\
\hline April & 46 & 0.0013 & \pm & 0.0011 & 0.0000 & \pm & 0.0000 \\
\hline May & 46 & 0.0001 & \pm & 0.0015 & 0.0000 & \pm & 0.0000 \\
\hline June & 46 & 0.0015 & \pm & 0.0014 & 0.0000 & $=$ & 0.0000 \\
\hline July & 46 & 0.0001 & \pm & 0.0013 & 0.0000 & \pm & 0.0000 \\
\hline August & 46 & 0.0009 & \pm & 0.0007 & 0.0000 & \pm & 0.0000 \\
\hline September & 46 & 0.0007 & \pm & 0.0008 & 0.0000 & \pm & 0.0000 \\
\hline October & 46 & 0.0010 & \pm & 0.0011 & 0.0000 & \pm & 0.0000 \\
\hline November & 46 & 0.0005 & \pm & 0.0008 & 0.0000 & \pm & 0.0000 \\
\hline December & 46 & 0.0014 & \pm & 0.0015 & 0.0000 & \pm & 0.0000 \\
\hline Overall & 552 & $0.0115^{b}$ & \pm & $0.0142^{\circ}$ & 0.0000 & \pm & 0.0000 \\
\hline
\end{tabular}

Plutonium-239,-240

Total Discharge

(uCi)
C maximum ${ }^{\mathrm{a}}$

$\left(\underline{x}^{-12} \underline{\mu \mathrm{Ci} / \mathrm{ml})}\right.$

\begin{tabular}{|c|c|c|c|c|c|}
\hline 0.0325 & \pm & 0.0043 & 0.0006 & \pm & 0.0001 \\
\hline 0.0194 & $=$ & 0.0035 & 0.0003 & \pm & 0.0001 \\
\hline 0.0075 & \pm & 0.0024 & 0.0003 & \pm & 0.00 \\
\hline 0.0017 & \pm & 0.0022 & 0.0000 & $=$ & 0.000 \\
\hline 0.0092 & \pm & 0.0023 & 0.0004 & \pm & 0.00 \\
\hline 0.0107 & $=$ & 0.0027 & 0.0001 & \pm & 0.00 \\
\hline 0.0156 & \pm & 0.0028 & 0.0001 & \pm & 0.00 \\
\hline 0.0108 & \pm & 0.0018 & 0.0001 & \pm & 0.00 \\
\hline 0.0104 & \pm & 0.0016 & 0.0001 & $=$ & 0.00 \\
\hline 0.0087 & \pm & 0.0019 & 0.0001 & \pm & 0.00 \\
\hline 0.0127 & \pm & 0.0019 & 0.0001 & \pm & 0.0 \\
\hline 0.0101 & \pm & 0.0025 & 0.0000 & \pm & 0.00 \\
\hline $0.1492^{b}$ & & 0.02 & 0.0006 & & \\
\hline
\end{tabular}

a. Maximum sample concentration.

b. Minor discrepancies in total discharge values result from rounding errors in calculations.

c. One or more values contributing to this total are based on best estimates of release activities because sample analytical results that met all quality assurance criteria were unavailable.

Table 3.2-2

Uranium in Effluent Air

Uranium-233/-234

\begin{tabular}{|c|c|c|c|c|c|c|c|}
\hline \multirow{2}{*}{$\begin{array}{l}\text { Month } \\
\text { January }\end{array}$} & $\begin{array}{c}\text { Number of } \\
\text { Analyses }\end{array}$ & \multicolumn{3}{|c|}{$\begin{array}{c}\text { Total Discharge } \\
\text { (uCi) }\end{array}$} & \multicolumn{3}{|c|}{$\begin{array}{c}C \text { maximum } \\
\left(\times 10^{-12} \mu \mathrm{Ci} / \mathrm{ml}\right)\end{array}$} \\
\hline & 54 & 0.0234 & \pm & 0.0076 & 0.0001 & \pm & 0.0000 \\
\hline February & 54 & 0.0437 & \pm & 0.0097 & 0.0001 & \pm & 0.0000 \\
\hline March & 54 & 0.0559 & \pm & 0.0109 & 0.0001 & \pm & 0.0000 \\
\hline April & 54 & -0.0056 & \pm & 0.0075 & 0.0000 & \pm & 0.0000 \\
\hline May & 53 & 0.0551 & \pm & 0.0106 & 0.0001 & \pm & 0.000 \\
\hline June & 54 & 0.0519 & \pm & 0.0102 & 0.0001 & \pm & 0.00 \\
\hline July & 54 & 0.0291 & \pm & 0.0088 & 0.0000 & \pm & 0.00 \\
\hline August & 54 & 0.0561 & \pm & 0.0085 & 0.0001 & \pm & 0.00 \\
\hline September & 54 & 0.0829 & \pm & 0.0101 & 0.0004 & \pm & 0.00 \\
\hline October & 54 & 0.1456 & \pm & 0.0112 & 0.0002 & \pm & 0.00 \\
\hline November & 54 & 0.1162 & \pm & 0.0153 & 0.0002 & \pm & 0.00 \\
\hline December & 54 & 0.0485 & \pm & 0.0097 & 0.0001 & \pm & 0.00 \\
\hline Overa & 648 & $0.7029^{b . c}$ & \pm & 0.1200 & 0.0004 & & \\
\hline
\end{tabular}

Uranium-238

\begin{tabular}{|c|c|c|c|c|c|}
\hline \multicolumn{3}{|c|}{$\begin{array}{l}\text { Total Discharge } \\
\qquad(\mu \mathrm{Ci})\end{array}$} & \multicolumn{3}{|c|}{$\begin{array}{c}C \text { maximum }{ }^{a} \\
\left(\underline{10^{-12}} \underline{\mu \mathrm{Ci} / \mathrm{ml})}\right)\end{array}$} \\
\hline 0.0526 & \pm & 0.0089 & 0.0004 & $=$ & 0.0001 \\
\hline 0.0550 & \pm & 0.0093 & 0.0001 & & 0.0001 \\
\hline 0.0733 & \pm & 0.0110 & 0.0001 & \pm & 0.0001 \\
\hline 0.0047 & \pm & 0.0076 & 0.0000 & \pm & 0.0000 \\
\hline 0.0741 & \pm & 0.0107 & 0.0001 & - & 0.0001 \\
\hline 0.0839 & \pm & 0.0109 & 0.0001 & \pm & 0.0000 \\
\hline 0.0512 & \pm & 0.0092 & 0.0001 & \pm & 0.0000 \\
\hline 0.0768 & \pm & 0.0087 & 0.0001 & \pm & 0.0000 \\
\hline 0.0941 & \pm & 0.0113 & 0.0005 & $=$ & 0.0004 \\
\hline 0.1460 & \pm & 0.0115 & 0.0003 & \pm & 0.0001 \\
\hline 0.1296 & \pm & 0.0170 & 0.0001 & & 0.0000 \\
\hline 0.0527 & \pm & 0.0096 & 0.0001 & $=$ & 0.0001 \\
\hline 0.8940 & & 0.1257 & 0.0005 & & 0.0004 \\
\hline
\end{tabular}

a. Maximum sample concentration.

b. Minor discrepancies in total discharge values result from rounding errors in calculations.

c. One or more values contributing to this total are based on best estimates of release activities because sample analytical results that met all quality assurance criteria were unavailable. 
Table 3.2-3

Americium in Effluent Air

\begin{tabular}{|c|c|c|c|c|c|c|c|}
\hline \multirow{3}{*}{$\begin{array}{l}\text { Month } \\
\text { January }\end{array}$} & \multicolumn{4}{|c|}{ Americium-241 } & & & \\
\hline & \multirow{2}{*}{$\begin{array}{c}\text { Number of } \\
\text { Analyses } \\
46\end{array}$} & \multicolumn{3}{|c|}{$\begin{array}{l}\text { Total Discharge } \\
\text { (스) }\end{array}$} & \multicolumn{3}{|c|}{$\begin{array}{c}C \text { maximum } \\
\left(\times 10^{-12} \mu \mathrm{Ci} / \mathrm{ml}\right)\end{array}$} \\
\hline & & 0.0060 & \pm & 0.0028 & 0.0000 & \pm & 0.0000 \\
\hline February & 46 & 0.0070 & \pm & 0.0029 & 0.0000 & \pm & 0.0000 \\
\hline March & 46 & 0.0091 & \pm & 0.0033 & 0.0001 & \pm & 0.0001 \\
\hline April & 46 & 0.0053 & \pm & 0.0026 & 0.0000 & \pm & 0.0000 \\
\hline May & 46 & 0.0049 & \pm & 0.0031 & 0.0000 & \pm & 0.0000 \\
\hline June & 46 & 0.0091 & \pm & 0.0030 & 0.0000 & \pm & 0.0000 \\
\hline July & 46 & 0.0059 & \pm & 0.0025 & 0.0000 & \pm & 0.0000 \\
\hline August & 46 & 0.0082 & \pm & 0.0020 & 0.0001 & $=$ & 0.0000 \\
\hline September & 46 & 0.0323 & \pm & 0.0039 & 0.0001 & \pm & 0.0000 \\
\hline October & 46 & 0.0376 & \pm & 0.0050 & 0.0001 & \pm & 0.0000 \\
\hline November & 46 & 0.0143 & \pm & 0.0052 & 0.0001 & \pm & 0.0000 \\
\hline December & 46 & 0.0277 & \pm & 0.0044 & 0.0001 & $=$ & 0.0000 \\
\hline Overall & 552 & $0.1575^{b . c}$ & \pm & 0.0407 & 0.0001 & \pm & 0.0000 \\
\hline
\end{tabular}

a. Maximum sample concentration.

b. Minor discrepancies in total discharge values result from rounding errors in calculations.

c. One or more values contributing to this total are based on best estimates of release activities because sample analytical results that met all quality assurance criteria were unavailable.

Table 3.2-4

Tritium in Effluent Air

\begin{tabular}{|c|c|c|c|c|c|}
\hline \multirow{3}{*}{ Month } & \multicolumn{2}{|l|}{ Iritium } & \multirow{2}{*}{\multicolumn{3}{|c|}{$\begin{array}{c}C \text { maximum } \\
\left(\times 10^{-12} \mu \mathrm{Ci} / \mathrm{ml}\right)\end{array}$}} \\
\hline & $\begin{array}{c}\text { Number of } \\
\text { Analyses }\end{array}$ & $\begin{array}{l}\text { Total Discharge } \\
\text { (Ci) }\end{array}$ & & & \\
\hline & 76 & 0.00019 & 51 & \pm & 7 \\
\hline February & 71 & 0.00088 & 91 & \pm & 7 \\
\hline March & 96 & 0.00049 & 32 & \pm & 7 \\
\hline April & 38 & 0.00017 & 22 & \pm & 3 \\
\hline May & 72 & 0.00010 & 32 & \pm & 4 \\
\hline June & 66 & 0.00033 & 102 & \pm & 8 \\
\hline July & 72 & 0.00021 & 45 & \pm & 7 \\
\hline August & 72 & 0.00044 & 35 & \pm & 6 \\
\hline September & 66 & 0.00084 & 3135 & \pm & 38 \\
\hline October & 78 & 0.00017 & 25 & \pm & 6 \\
\hline November & 72 & -0.00013 & 17 & \pm & 6 \\
\hline December & 78 & 0.00004 & 24 & \pm & 11 \\
\hline Overall & 857 & $0.00373^{b}$ & 3135 & \pm & 38 \\
\hline
\end{tabular}

a. Maximum sample concentration.

b. Minor discrepancies in total discharge values result from rounding errors in calculations. 
Table 3.2-5

Beryllium in Effluent Air

\begin{tabular}{|c|c|c|c|c|c|}
\hline \multirow[b]{2}{*}{ Month } & \multicolumn{4}{|c|}{ Beryllium $^{a, b}$} & \multirow[b]{2}{*}{$\underset{\left(\mu \mathrm{g} / \mathrm{m}^{3}\right)}{C \operatorname{maxim}^{\mathrm{m}}}$} \\
\hline & $\begin{array}{c}\text { Number of } \\
\text { Analyses }\end{array}$ & \multicolumn{3}{|c|}{$\begin{array}{c}\text { Total Discharge } \\
\text { (g) }\end{array}$} & \\
\hline January & 54 & 0.1674 & \pm & 0.0046 & 0.00038 \\
\hline February & 54 & 0.3066 & \pm & 0.0087 & 0.00045 \\
\hline March & 54 & 0.2843 & \pm & 0.0084 & 0.00043 \\
\hline April & 54 & $0.1918^{8}$ & \pm & 0.0063 & 0.00025 \\
\hline May & 53 & 0.3213 & \pm & 0.0096 & 0.00045 \\
\hline June & 54 & 0.2899 & \pm & 0.0081 & 0.00037 \\
\hline July & 54 & 0.3071 & \pm & 0.0085 & 0.00034 \\
\hline August & 54 & 0.3476 & \pm & 0.0104 & 0.00039 \\
\hline September & 54 & 0.3627 & \pm & 0.0121 & 0.00081 \\
\hline October & 54 & 0.2615 & \pm & 0.0080 & 0.00028 \\
\hline November & 54 & 0.2610 & \pm & 0.0073 & 0.00024 \\
\hline December & 54 & 0.1916 & \pm & 0.0059 & 0.00036 \\
\hline Overall & 647 & $3.2926^{e}$ & \pm & 0.0979 & 0.00081 \\
\hline
\end{tabular}

a. The beryllium stationary source is no more than 10 grams of beryllium over a 24 -hour period under the provisions of subpart $\mathrm{C}$ of 40 CFR, Part 61.32(a).

b. Beginning in June 1989, concentrations and emission values were not corrected for background contribution.

c. These values are not significantly different from the background associated with the analysis.

d. Maximum sample concentration.

e. One value only contributing to this total was based on best estimates of release activities because sample analytical results that mel all quality assurance criteria were unavailable.

NONRADIOACTIVE AMBIENT AIR MONITORING

\section{Overview}

In addition to effluent sampling from individual buildings, RFP also performs monitoring of ambient air in the surrounding environment. This includes sampling for nonradioactive particulates as well as radioactive materials. (Results of the radioactive ambient air monitoring program are provided in the following section.)

Nonradioactive ambient air monitoring was conducted in 1993 for total suspended particulates (TSPs) and respirable particulates (less than or equal to 10 micrometers $[\mu \mathrm{m}])$ in diameter. Ambient particulates are regulated by the EPA and CDH under the CAA and its amendments, as defined by the National Ambient Air Quality Standards (NAAQS) and Colorado Air Quality Control Commission Ambient Air Standards. Regulation is based on regional rather than site-specific air 
Results

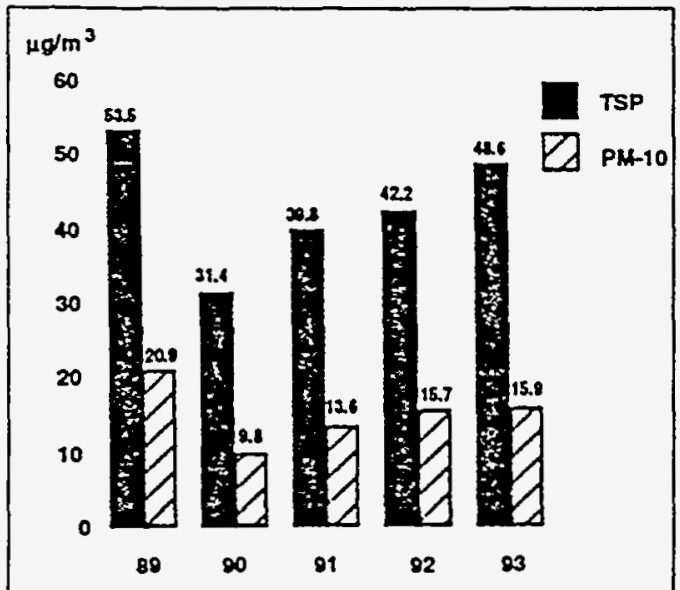

60 = TSP (Reforence) 50 = PA-10 (NAAOS)

Figure 3.2-9. TSP and PM-10 quality parameters. In the past, EPA particulate standards (NAAQS) were based on TSP, a measure of total particulate recovery. regardless of particulate size. The present EPA standards, referred to as Particulate Matter-10 (PM-10), are based on respirable particulates, those particles less than or equal to $10 \mu \mathrm{m}$ in diameter. Final EPA respirable particulate standards were issued on July 1, 1987 (EPA87a), and reference methods were issued on October 6 and December 1 , 1987. PM-10 samplers at RFP were procured to meet EPA design specifications.

Nonradioactive ambient air monitoring is performed in an area near the east entrance to RFP and provides baseline information on particulate levels. Table 3.2-6 identifies sampling equipment used for measuring particulates. TSP and PM-10 samplers are collocated at the monitoring site. The location is unobscured by structures, is near a traffic zone, and is generally downwind from plant facilities. Samplers are operated on an EPA sampling schedule of 1 day per every 6th day.

TSP is measured by the EPA-referenced, high-volume air sampling method, and continues to be collected for reference purposes.

Particulate data are provided in Table 3.2-7. (Current PM-10 NAAQS standards are provided in Appendix B.) The highest TSP value recorded in 1993 (24-hour sample) was $90.0 \mu \mathrm{g} / \mathrm{m}^{3}$, which was 35 percent of the former TSP 24-hour primary standard. The annual geometric mean value was $48.6 \mu \mathrm{g} / \mathrm{m}^{3}$, which was 65 percent of the former TSP primary annual geometric mean standard. The observed 24 -hour maximum for the PM-10 sampler was $51.9 \mu \mathrm{g} / \mathrm{m}^{3}$ (34.6 percent of the primary 24-hour standard), and the annual arithmetic mean was $15.9 \mu \mathrm{g} / \mathrm{m}^{3}$ (31.8 percent of the primary annual arithmetic mean standard). Mean annual concentrations of particulates for onsite ambient TSP samplers and PM-10 samplers for the period 1989 to 1993 are shown in Figure 3.2-9. 
Table 3.2-6

Ambient Air Monitoring Detection Methods

Parameter

Particulate Matter less than 10 micrometers in diameter (PM-10)

Total Suspended Particulates (TSP)
Detection Methods

Wedding PM-10 Sampler

24-Hour Sampling (6th-day scheduling)

High-Volume Sampling

24-Hour Sampling (6th-day scheduling)

Table 3.2-7

Ambient Air Quality Data for Nonradioactive Particulates

Total Suspended Particulates

\begin{tabular}{|c|c|c|c|c|c|c|}
\hline & $\begin{array}{l}\text { Total No. } \\
\text { of Samples }\end{array}$ & $\begin{array}{c}\text { Annual } \\
\text { Geometric } \\
\text { Mean }\left(\mu \mathrm{g} / \mathrm{m}^{3}\right)\end{array}$ & $\begin{array}{c}\text { Standard } \\
\text { Deviation } \\
\left(\mathrm{\mu g} / \mathrm{m}^{3}\right)\end{array}$ & $\begin{array}{l}\text { Observed } \\
24-\mathrm{hr} \mathrm{Max.}^{2} \\
\left(\mu \mathrm{g} / \mathrm{m}^{3}\right)\end{array}$ & $\begin{array}{c}\text { Second } \\
\text { Highest } \\
\text { Max. }\left(\mu \mathrm{g} / \mathrm{m}^{3}\right)\end{array}$ & $\begin{array}{c}\text { Lowest } \\
\text { Observed } \\
\text { Value }\left(\mu \mathrm{g} / \mathrm{m}^{3}\right)\end{array}$ \\
\hline $\begin{array}{l}\text { Primary Ambient Air TSP Particulate } \\
\text { Sampler; Primary Unit }\end{array}$ & 52 & 48.6 & 18.6 & 90.0 & 81.8 & 19.3 \\
\hline Collocated Duplicate TSP Sampler & 50 & 45.1 & 18.1 & 85.4 & 80.9 & 18.6 \\
\hline \multicolumn{7}{|c|}{ Respirable Particulates (PM-10) } \\
\hline & \multicolumn{2}{|c|}{$\begin{array}{l}\text { Total No. } \\
\text { of Samples }\end{array}$} & $\begin{array}{c}\text { Annual } \\
\text { Arithmetic } \\
\text { Mean }\left(\mu \mathrm{g} / \mathrm{m}^{3}\right)\end{array}$ & $\begin{array}{c}\text { Observed } \\
24-\mathrm{hr} \mathrm{Max}^{3} \\
\left(\mu \mathrm{g}^{3} \mathrm{~m}^{3}\right)\end{array}$ & \multicolumn{2}{|c|}{$\begin{array}{c}\text { Second } \\
\text { Highest } \\
\text { Max. }\left(\mu \mathrm{g} / \mathrm{m}^{3}\right)\end{array}$} \\
\hline Primary Ambient Air PM-10 Sampler & \multicolumn{2}{|c|}{53} & 15.9 & \multicolumn{2}{|c|}{51.9} & 24.6 \\
\hline Collocated Duplicate PM-10 Sampler & \multicolumn{2}{|c|}{48} & 15.4 & \multicolumn{2}{|c|}{50.3} & 24.1 \\
\hline
\end{tabular}




\section{Overview}

Results
Ambient air samplers located on the plantsite, at the plant perimeter, and in surrounding communities monitor airborne dispersion of radioactive materials from RFP into the surrounding environment. These samplers are positioned at 21 locations on the plantsite, at 14 locations around the plant boundary, and in 11 neighboring communities. Figure 3.2-10 illustrates the locations of plantsite samplers and samplers located at the plant boundary. Community ambient air samplers are illustrated in Figure 3.2-11. The $\mathrm{CDH}$ also maintains an independent sampling network with a different instrument design in and around the plantsite to verify the RFP data.

The high-volume air samplers operate continuously at a volumetric flow rate of approximately 12 liters per second $(\mathrm{l} / \mathrm{s})\left(25\right.$ cubic feet per minute [ $\left.\left.\mathrm{ft}^{3} / \mathrm{min}\right]\right)$, collecting air particulates on highly efficient 20 - by 25 -centimeter (8- by 10 -inch) fiberglass filters. Manufacturer's test specifications rate this filrer media to be 99.97 percent efficient for relevant particle sizes under conditions typically encountered in routine ambient air sampling (SCH82).

Ambient air filters are collected biweekly and composited monthly by location before isotopic analysis. All routine ambient air filters are analyzed for plutonium -239 and -240 .

Plutonium concentrations for onsite samplers are provided in Table 3.2-8. Plutonium concentrations for perimeter and community samplers are provided in Table 3.2-9. Overall mean plutonium concentration for onsite samplers was $0.056 \times 10^{-15} \mu \mathrm{Ci} / \mathrm{ml}\left(2.07 \times 10^{-6}\right.$ $\left.\mathrm{Bq} / \mathrm{m}^{3}\right), 0.28$ percent of the offsite $\mathrm{DCG}$ for plutonium in air (Appendix B). Overall mean plutonium concentration for perimeter samplers was $0.002 \times 10^{-15} \mu \mathrm{Ci} / \mathrm{ml}(5.5$ $\left.x 10^{-8} \mathrm{~Bq} / \mathrm{m}^{3}\right)$, which is 0.012 percent of the offsite $D C G$ for plutonium in air. Overall mean plutonium concentration for community samplers was $0.001 \times 10^{-15} \mu \mathrm{Ci} / \mathrm{ml}$ $\left(3.7 \times 10^{-8} \mathrm{~Bq} / \mathrm{m}^{3}\right)$, or 0.006 percent of the offsite DCG for plutonium in air. 


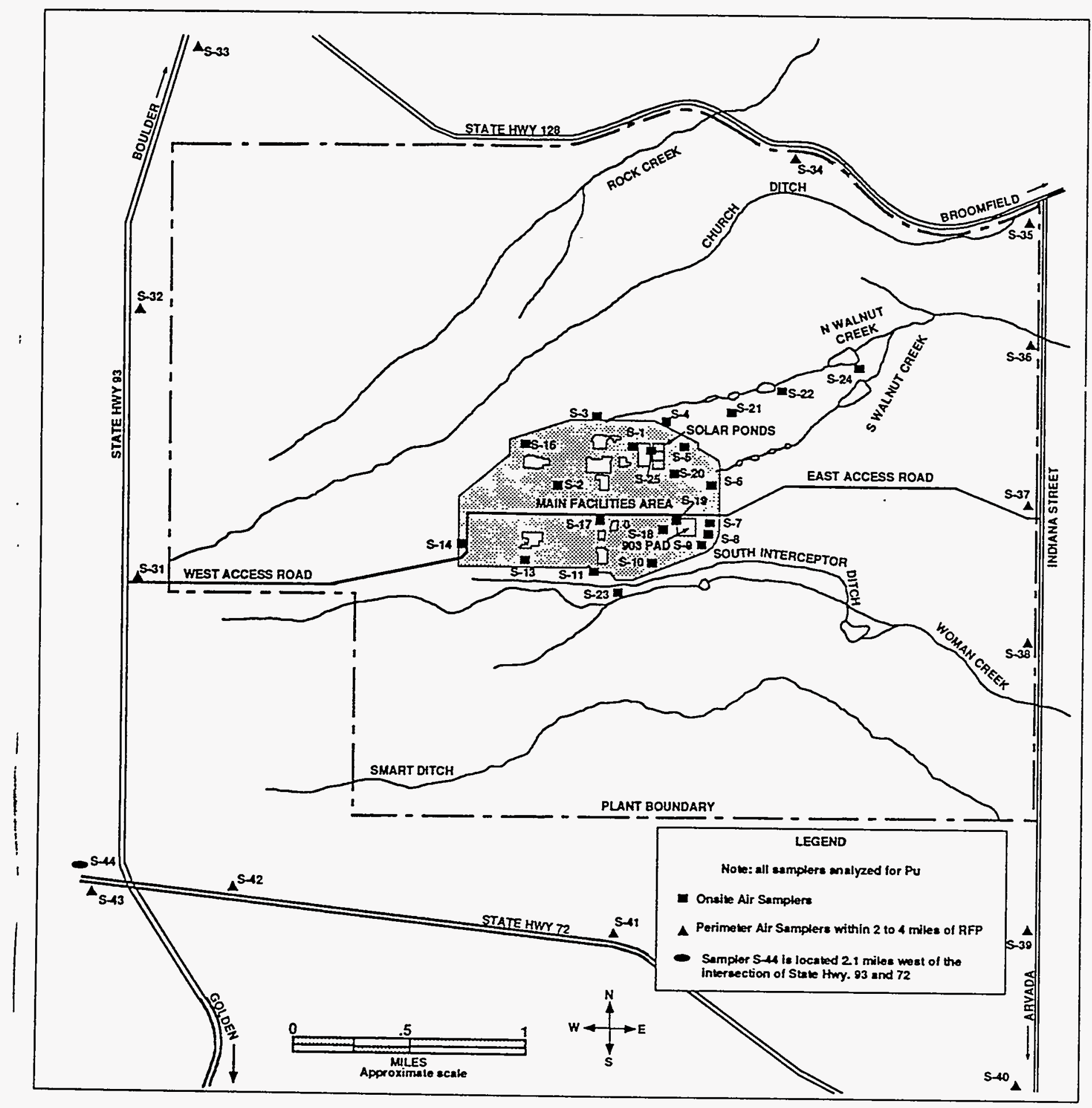

Figure 3.2-10. 1993 Onsite and Perimeter Air Samplers 


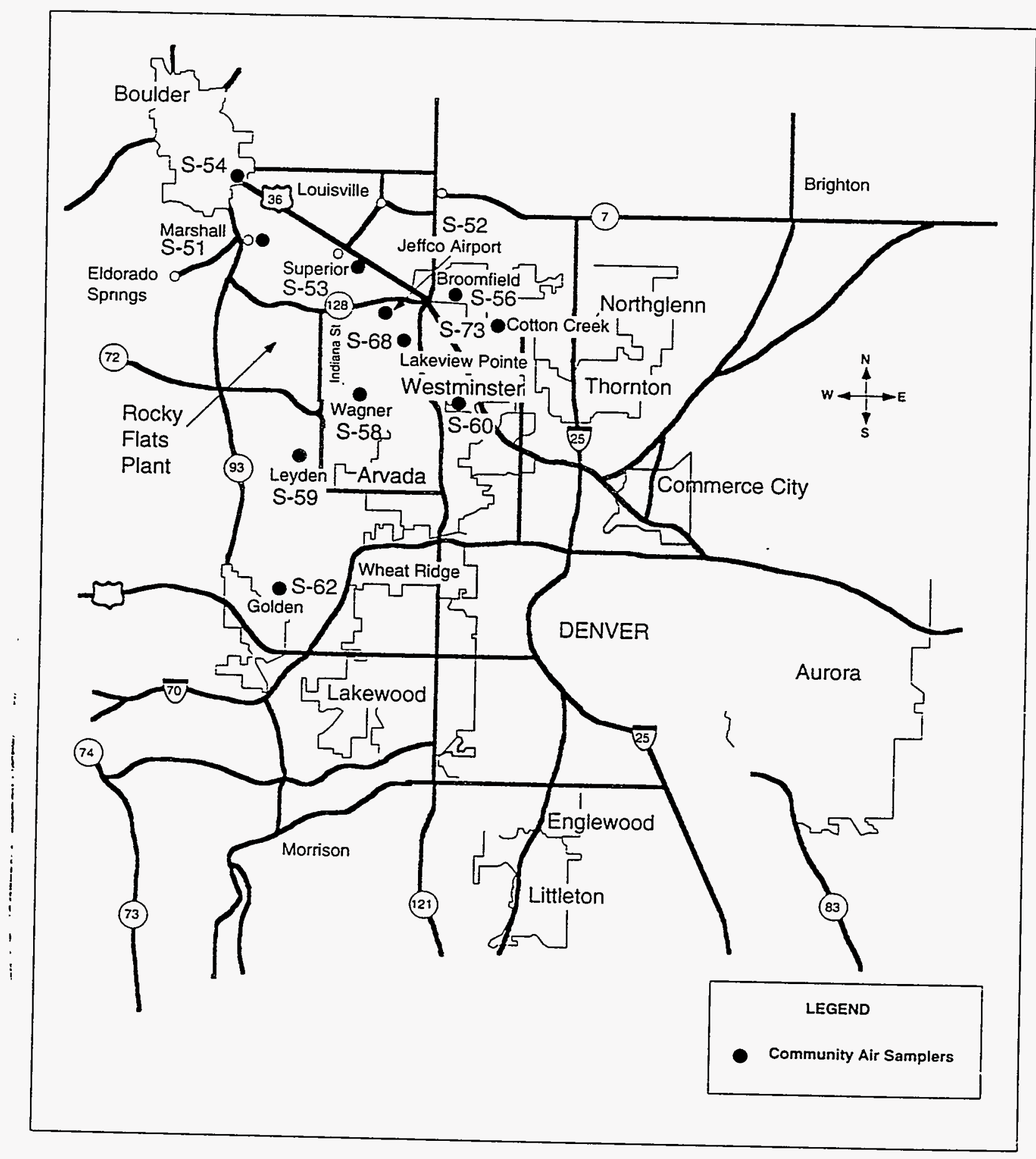

Figure 3.2-11. 1993 Community Air Samplers 
Table 3.2-8

Onsite Air Sampler Plutonium Concentrations

\begin{tabular}{|c|c|c|c|c|c|c|}
\hline \multirow[b]{2}{*}{ Station } & \multirow{2}{*}{$\begin{array}{c}\text { Number } \\
\text { of Samples }\end{array}$} & \multicolumn{3}{|c|}{ Concentration $\left(\times 10^{-15} \mu \mathrm{Ci} / \mathrm{ml}\right)^{\mathrm{d}}$} & \multirow{2}{*}{$\begin{array}{l}\text { Standard } \\
\text { Deviation } \\
\text { (C standard) }\end{array}$} & \multirow{2}{*}{$\begin{array}{l}\text { Percent } \\
\text { of } D_{C G}{ }^{e} \\
\text { (C mean) }\end{array}$} \\
\hline & & $\underline{\text { Cminimum }}$ & C maximum & $\underline{\text { C mean }}$ & & \\
\hline S-3 & 12 & .00000 & .02200 & .00333 & .00602 & .01667 \\
\hline$S-4$ & $10^{\mathrm{a}}$ & .00500 & .03500 & .01280 & .00932 & .06400 \\
\hline S-5 & 12 & .01400 & . 12700 & .03567 & .03256 & .17833 \\
\hline S-6 & $10^{b}$ & .01600 & .24100 & .07810 & .07846 & .39050 \\
\hline S-7 & 12 & .01900 & . 46900 & .16267 & (13297. & .81333 \\
\hline S-8 & 12 & 03000 & .84900 & .35333 & .25008 & 1.76667 \\
\hline S-9 & 12 & .03200 & .38100 & .17142 & .11485 & .85708 \\
\hline$S-10$ & $11^{c}$ & .00100 & .01600 & .00491 & .00411 & .02455 \\
\hline$S-11$ & $11^{c}$ & .00100 & .06400 & .01273 & .01798 & .06364 \\
\hline S-13 & $11^{c}$ & .00100 & .02000 & .00418 & .00540 & .02091 \\
\hline S-14 & $11^{c}$ & .00000 & .02000 & .00264 & .00582 & .01318 \\
\hline S-16 & $11^{c}$ & .00100 & .02100 & .00445 & .00635 & .02227 \\
\hline S-17 & $10^{b, c}$ & .00200 & .07100 & .001230 & .02073 & .06150 \\
\hline S-18 & 12 & .00000 & .02300 & .01433 & .00673 & .07167 \\
\hline$S-19$ & $11^{c}$ & .00700 & .09200 & .02400 & .02379 & .12000 \\
\hline$S \cdot 20$ & $10^{b}$ & .00600 & .10000 & .02100 & .02840 & .10500 \\
\hline S-21 & 12 & .00200 & .03400 & .00792 & .00850 & .03958 \\
\hline S-22 & 12 & .00100 & .03700 & .00833 & .00975 & .04167 \\
\hline S-23 & 12 & .00000 & .02100 & .00375 & .00571 & .01875 \\
\hline S-24 & 12 & .00000 & .01900 & .00292 & .00530 & .01458 \\
\hline S-25 & $11^{b}$ & .03700 & .46000 & .21480 & .15210 & 1.07400 \\
\hline & 237 & -.00100 & .84900 & .05566. & 111893 & 27831 \\
\hline
\end{tabular}

a. Sampler was not in place.

b. Equipment failure.

c. No lab data available.

d. Concentrations reflect monthly composites of biweekly station concentrations; $\mathrm{C}$ minimum = minimum composited concentration; $\mathrm{C}$ maximum $=$ maximum composited concerntration; $\mathrm{C}$ mean $=$ mean composited concentration.

e. The DOE Derived Concentration Guide (DCG) for inhalation of class W plutonium by members of the public is $20 \times 10^{-15} \mu \mathrm{Ci} / \mathrm{ml}$ (Appendix B). Protection standards for members of the public are applicable for offsite locations. All locations in this table are on RFP property. DCGs for the public are presented here for comparison purposes only. 
Table 3.2-9

Perimeter Air Sampler Plutonium Concentrations

\begin{tabular}{|c|c|c|c|c|c|c|}
\hline Station & $\begin{array}{l}\text { Number } \\
\text { of Samples }\end{array}$ & \multicolumn{3}{|c|}{ Concentration $\left.\left(\times 10^{-15} \mu \mathrm{Ci} / \mathrm{ml}\right)\right)^{\mathrm{d}}$} & $\begin{array}{l}\text { Standard } \\
\text { Deviation } \\
\text { (C standard) }\end{array}$ & $\begin{array}{l}\text { Percent } \\
\text { of } D C G^{\mathrm{e}} \\
\text { (C mean }\end{array}$ \\
\hline S-31 & $10^{\mathrm{a}}$ & .00000 & .05200 & .00680 & .01598 & .03400 \\
\hline S-32 & 12 & .00000 & .00300 & .00067 & .00098 & .00333 \\
\hline S-33 & 12 & -.00100 & .00500 & .00100 & .00160 & .00500 \\
\hline S.34 & 12 & .00000 & .00700 & .00150 & .00215 & .00750 \\
\hline S-35 & $11^{\mathrm{a}}$ & .00000 & .00600 & .00073 & .00179 & .00364 \\
\hline S-36 & $11^{b}$ & .00000 & .00400 & .00127 & .00135 & .00636 \\
\hline S-37 & $9^{a, b}$ & .00000 & .00400 & .00200 & .00150 & .01000 \\
\hline S-38 & $9^{\mathrm{a}}$ & .00000 & .10900 & .01378 & .03573 & .06889 \\
\hline S-39 & 11 & .00000 & .00400 & .00108 & .00124 & .00542 \\
\hline S-40 & 12 & .00000 & .00300 & .00108 & .00100 & .00542 \\
\hline$S-41$ & 12 & .00000 & .00800 & .00125 & .00222 & .00625 \\
\hline$S-42$ & 12 & .00000 & .02600 & .00375 & .00764 & .01875 \\
\hline S-43 & $11^{\mathrm{a}}$ & -.00100 & .00500 & .00100 & .00155 & .00500 \\
\hline S-44 & 12 & -.00100 & .00300 & .00075 & .00106 & .00375 \\
\hline Overall & 157 & -.00100 & 10900 & .00239 & .00982 & . 01197. \\
\hline
\end{tabular}

\section{Community Air Sampler Plutonium Concentrations}

\begin{tabular}{|c|c|c|c|c|c|c|c|}
\hline \multirow{2}{*}{ Station } & \multirow{2}{*}{$\begin{array}{l}\text { Community } \\
\text { Name }\end{array}$} & \multirow{2}{*}{$\begin{array}{c}\text { Number } \\
\text { of Samples }\end{array}$} & \multicolumn{3}{|c|}{ Concentration $\left(\times 10^{-15} \mu \mathrm{Cl} / \mathrm{ml}\right)^{d}$} & \multirow{2}{*}{$\begin{array}{c}\text { Standard } \\
\text { Deviation } \\
\text { (C standard) }\end{array}$} & \multirow{2}{*}{$\begin{array}{l}\text { Percent } \\
\text { of } \mathrm{DCG}^{\mathrm{e}} \\
\text { (C mean }\end{array}$} \\
\hline & & & C minimum & C maximum & Cmean & & \\
\hline S-51 & Marshall & 12 & .00001 & .00500 & .00083 & .00185 & .00417 \\
\hline S-52 & Jeffco Airport & 12 & .00000 & .00200 & .00092 & .00079 & .00458 \\
\hline S-53 & Supenor & 12 & .00000 & .02100 & .00258 & .00582 & .01292 \\
\hline S-54 & Boulder & 12 & .00000 & .00700 & .00125 & .00201 & .00625 \\
\hline S-56 & Broomfield & 12 & .00000 & .00300 & .00100 & .00104 & .00500 \\
\hline S-58 & Wagner & 12 & .00000 & .00300 & .00100 & .00104 & .00500 \\
\hline S-59 & Leyden & $9^{a}$ & .00000 & .00600 & .00133 & .00180 & .00667 \\
\hline$S-60$ & Westminster & $11^{c}$ & .00000 & .00000 & .00000 & .00000 & .00000 \\
\hline S-62 & Golden & 12 & .00000 & .00200 & .00042 & .00079 & .00208 \\
\hline S-68 & Lakeview Pointe & 12 & .00000 & .00700 & .00150 & .00198 & .00750 \\
\hline S-73 & Cotton Creek & 12 & -.00100 & .00600 & .00133 & .00215 & .00667 \\
\hline Overall & & 118 & -.00100 & .02100 & .00120 & .00236 & .00602 \\
\hline
\end{tabular}

a. Equipment failure.

b. No lab data available.

c. This sampler was removed.

d. Concentrations reflect monthly composites of biweekly station concentrations; $C$ minimum = minimum composited concentration; $\mathrm{C}$ maximum = maximum composited concerntration; $\mathrm{C}$ mean $=$ mean composited concentration.

e. The DOE Derived Concentration Guide (DCG) for inhalation of class $W$ plutonium by members of the public is $20 \times 10^{-15} \mathrm{\mu Ci} / \mathrm{ml}$ (Appendix B). Protection slandards for members of the public are applicable for offsite locations. All locations in this table are on RFP property. DCGs for the public are pre: ented here for comparison purposes only. 
Mean annual concentrations of plutonium for the 1989 to 1993 period are shown in Figure 3.2-12 (onsite samplers) and Figure 3.2-13 (perimeter and community samplers). The onsite data are based on the mean of the annual concentrations from five locations, S-5 through $S-9$, which represent the areas where the highest concentrations would most likely be observed. Isotope-specific analyses were not reported for other onsite locations until 1990. The perimeter data points are the annual averages of 14 locations, and the community data points are the annual average of 11 locations.

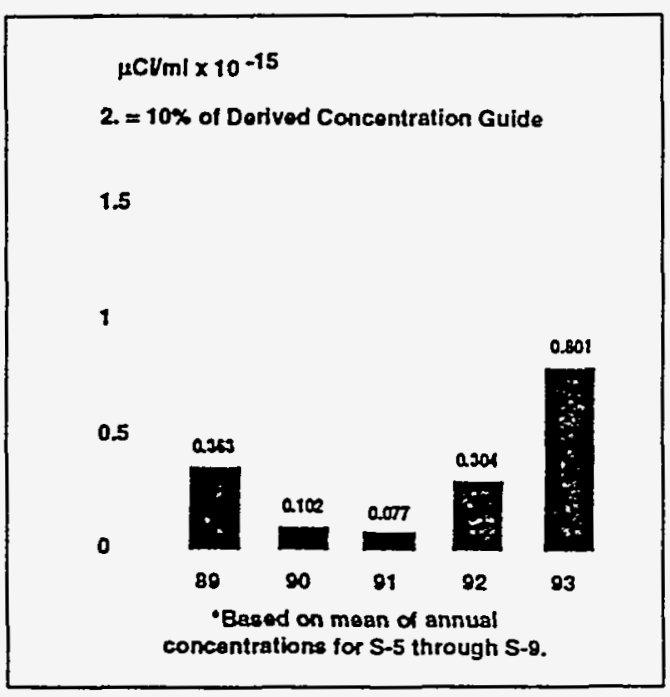

Figure 3.2-12. Plutonium-239, -240 (Onsite Samplers)

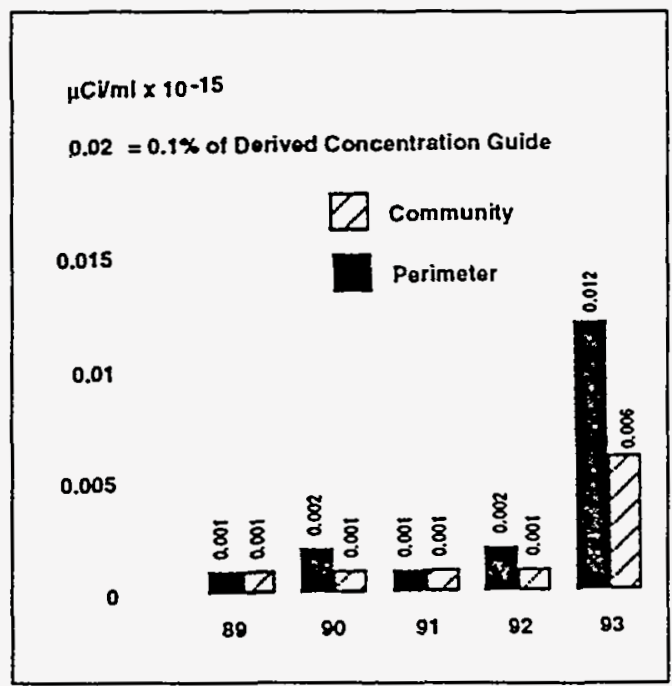

Figure 3.2-13. Plutonium-239, -240 (Perimeter and Community Samplers) 
3. Environmental Monitoring Programs

\subsection{Surface-Water Monitoring}

Surface waters at the Rocky Flats Plant are extensively analyzed to ensure that water quality standards are met, to characterize background water quality, and to evaluate potential contaminant releases from specific locations. Surface-water management at Rocky Flats focuses on the North Wainut Creek. South Walnut Creek, and Woman Creek drainages. Samples are routinely collected and analyzed from these drainages, seeps, and surface impoundments within the plantsite. This section provides results of the surface-water monitoring program. 
OVERVIEW

DRAINAGE SYSTEMS
Liguid effluents originating from RFP are carefully controlled and monitored as part of the plant's environmental protection program. Two types of liquid effluents, treated sanitary water, and surface-water runoff are collected, controlled, and monitored in a series of ponds before discharge offsite. Surface runoff at RFP moves from west to east and is carried from the plant by three major drainage basins: North Walnut Creek, South Walnut Creek, and Woman Creek.
North Walnut Creek
North Walnut Creek receives surface-water runoff and some seepage water from the northern portion of the main facilities area and from the adjacent grounds associated with the drainage. The drainage area associated with North Walnut Creek includes the north portion of plantsite from First Street at Sage Avenue to Pond A-4 and encompasses approximately 378 acres (Figure 3.31). The length of North Walnut Creek from the West Interceptor Ditch to the outfall of Pond A-4 is approximately 10,500 feet. Ponds A-1 and A-2 are isolated from Walnut Creek at the $A-1$ bypass. The gate valves at the A-1 bypass have the capability to divert the North Walnut Creek stream flow by way of an underground pipeline to Ponds A-3 or A-4. Ponds A-1 and A-2 are maintained for emergency spill control for the northern portion of the main facility. Under routine circumstances, the water comprising Pond A-2 is direct precipitation, minimal runoff, or water transferred from Ponds A-1, B-1, and B-2. Pond A-2 volume is maintained by spray evaporation; fog nozzles direct the spray over the surface of the ponds. Pond A-3 on North Walnut Creek is used to impound the surface runoff for water quality analysis prior to discharge to Pond $A-4$ and subsequent release offsite to the Broomfield Diversion Ditch. Pond A-4 is located downstream of Pond A-3 on North Walnut Creek and provides the capability for additional water quality' monitoring, additional detention capacity during storm or flood conditions, and water treatment if required. The volumetric capacity of Pond A-1 is 1.40 million gallons; Pond A-2, 6.00 million gallons; Pond A-3, 12.37 million gallons; and Pond $A-4,32.50$ million gallons. 


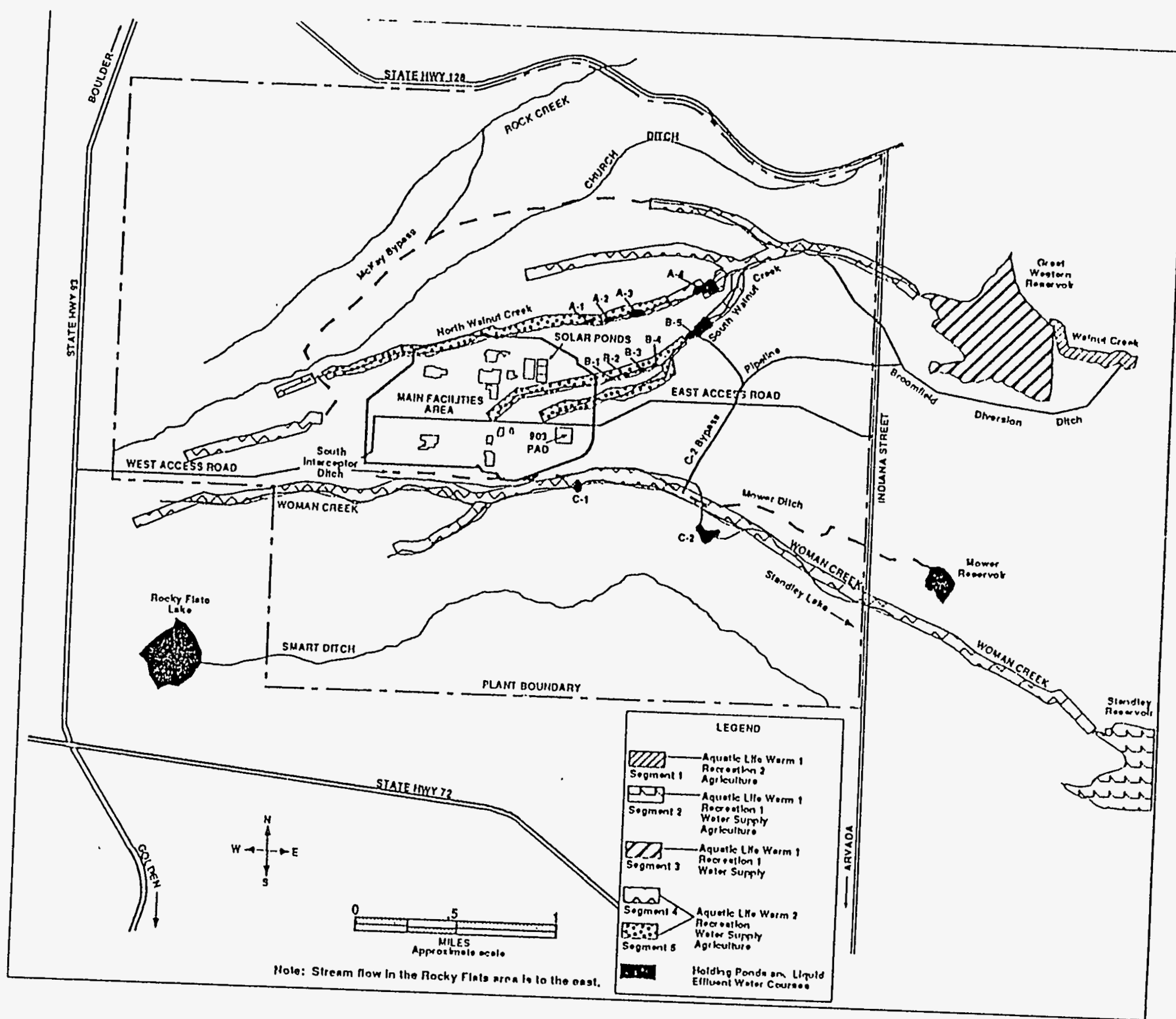

Figure 3.3-1. Ilolding Ponds and Liquid Ellluent Waler Courses 
South Walnut Creek
South Walnut Creek receives surface-water runoff and some seepage water from the central portion of the main facilities area and from the adjacent grounds associated with the drainage. The drainage area associated with this portion of South Walnut Creek extends from RFP's First Street to Pond B-5 and is approximately 338 acres (Figure 3.3-1). The length of South Walnut Creek from Building 131 at First Street to Pond B-5 is approximately 9,625 feet. Ponds B- 1 and $B-2$ are isolated from South Walnut Creek at the B-1 bypass. Ponds B-1 and B-2 are maintained for emergency spill control for the central portion of the main facility. In the event of a spill emergency, the gate valves at the B-1 bypass have the capability of diverting South Walnut Creek flows to Pond B-1, and succeeding overflow to Pond B-2. The Waste Water Treatment Plant (WWTP), also referred to as the Sewage Treatment Plant, has bypass capabilities to Ponds B-1 and B-2 in the event of an upset condition or emergency. Ponds B-1 and B-2 will be replaced as emergency containment by off-channel tankage with at least 500,000 gallons of effluent storage capacity. A schedule, with milestones for completion of the effluent storage project, will be developed during FY94. During normal operations, the $\mathrm{B}-1$ bypass conveys surfacewater runoff by an underground pipeline from the bypass to Pond B-4 and subsequently to Pond B-5. During major precipitation events, storm water may be diverted prior to the B-1 bypass at the Central Avenue splitter box. These high flows are diverted directly to Pond B-5.

The WWTP discharges treated sanitary effluent to Pond B-3. Pond B-3 is impounded during evening hours and is released to Pond B-4 during daylight hours on a daily basis. Pond B-4 is a controlled flow-through pond, and all flow is conveyed to Pond B-5. Pond B-5 is the terminal pond of the B series on South Walnut Creek. In the past, water was discharged from Pond B-5 offsite. As part of current operations, water quality analysis and sampling is conducted on Pond B-5 prior to transfer to Pond A-4, for final discharge offsite. The volumetric capacity of Pond B-1 is 0.50 million gallons; Pond B-2, 1.50 million gallons; Pond B-3, 0.57 million gallons; Pond B-4, 0.18 million gallons; and Pond B-5, 24.19 million gallons. 
Woman Creek

\section{MONITORING PROGRAMS}

Defention Ponds Monitoring
Woman Creek flows south of the main plant facility. The drainage associated with Woman Creek includes an area from the Boulder Diversion Canal just west of plantsite to Indiana Street just east of plantsite, encompassing approximately 1,400 acres (Figure 3.3-1). The length of Woman Creek from the RFP West Gate to Indiana Street is approximately 22,000 feet. The three sources of flow to Woman Creek are precipitation and surface runoff, seepage from Antelope Springs and lesser seeps, and conveyance flows as a result of water rights agreements. These flows are from Kinear Ditch, Smart Ditch \#1, and/or Smart Ditch \#2 into Woman Creek. The Woman Creek stream flows through Pond $\mathrm{C}-1$ and is then diverted around Pond $\mathrm{C}-2$ by way of the Woman Creek Bypass Canal. Woman Creek flows are either diverted into the Mower Diversion Ditch or proceed in Woman Creek to Indiana Street and offsite.

Surface-water runoff from the southern portion of RFP is collected by the South Interceptor Ditch and conveyed to Pond C-2. The drainage area associated with the South Interceptor Ditch and Pond C-2 is approximately 193 acres. The South Interceptor Ditch is approximately 7,700 feet in length. Water is impounded in Pond $\mathrm{C}-2$ and held for quality analysis. Upon completion of analysis, water is discharged by pipeline to the Broomfield Diversion Ditch. In the past, water was discharged to Woman Creek and entered Standley Lake. The volumetric capacity of Pond C-1 is 1.70 million gallons. The capacity of Pond C-2 is 22.60 million gallons.
Prior to discharging Ponds A-4 and C-2, samples are taken and split for analysis among CDH and EG\&G. As of August 1993, all predischarge split samples collected for RFP analysis were performed at onsite laboratories for most analytes. However, at the beginning of October 1993, analysis by EPA-registered laboratories was replaced by the onsite General Laboratories (located in Building 881) with the exception of pesticide and herbicide analysis. The change in laboratory use was mandated by budgetary considerations. Discharges are monitored for parameters listed in Appendix B in compliance with the NPDES permit limitations. In 
addition, water quality is tested before release to ensure that the water meets CWQCC stream standards (listed in Appendix B) for segment 4 of Big Dry Creek (Figure 3.3-1). Water is released with concurrence from $\mathrm{CDH}$.

During discharge. Ponds $\mathrm{A}-4$ and $\mathrm{C}-2$ are monitored for plutonium $(\mathrm{Pu})$, americium $(\mathrm{Am})$, uranium $(\mathrm{U})$, and tritium (H3). Tritium, $\mathrm{pH}$, gross alpha/beta, nitrate (as nitrogen), and nonvolatile suspended solids are analyzed daily. Pond C-2 is sampled on a weekly basis four to six weeks prior to pond discharge with the samples being sent to the onsite Radiological Health Laboratory (located in Building 123). Weekly radiological monitoring of Pond A-4 prior to discharge was performed until November 1993 when monitoring was shifted to Pond B-5. The shift in monitoring was in response to $\mathrm{CDH}$ concerns for the quality of the water that was transferred from Pond B-5 to Pond A-4.

Plutonium, americium, and uranium samples are collected as daily composites for weekly analysis during all discharges from Ponds $\mathrm{A}-4$ and $\mathrm{C}-2$. Tritium, $\mathrm{pH}$, nitrate (as nitrogen), and nonvolatile suspended solids are also collected and analyzed daily from Ponds A-4 and $\mathrm{C}-2$ discharges. Daily samples are collected in a similar manner at a sampling station on Walnut Creek near its intersection with Indiana Street. Chromium samples are analyzed monthly while Whole Effluent Toxicity (WET) samples are analyzed quarterly when discharge occurs at Ponds A-4, C-2, and transfer of Pond B-5. 
Discharges from Pond A-4, which include transfers from Pund B-5, enter Walnut Creek and are diverted around Great Western Reservoir by means of the Broomfield Diversion Ditch. Discharges from Pond C2 are pumped through an 8,000-foot pipeline into the Broomfield Diversion Ditch. Monthly flow volumes and summaries of data from discharges for 1993 at Ponds A-4, C-2, C-1, Walnut Creek at Indiana, and Pond B-5 transfers are provided in Tables 3.3-1, 3.3-2, 3.3-3, 3.3-4, and 3.3-5.

If the need should ever arise, carbon adsorption and filtration facilities are available for additional treatment of waters before release. Treatment capacity at Ponds $\mathrm{A}-4$ and $\mathrm{C}-2$ are 1,400 gallons per minute (gpm) and $750 \mathrm{gpm}$, respectively.

Table 3.3-1

Monthly Flow and Discharges for 1993 (gallons)

$\begin{array}{lrrrrr}\text { Month } & \begin{array}{c}\text { Walnut Creek } \\ \text { at Indiana }\end{array} & \text { Pond A-4 } & \text { Pond B-5 } & \text { Pond C-2 } & \text { Pond C-1 } \\ \text { January } & \text { No Flow } & \text { No Discharge } & \text { No Discharge } & \text { No Discharge } & 5,560,000 \\ \text { February } & 11,290,000 & 13,000,000 & \text { No Discharge } & \text { No Discharge } & 5,486,000 \\ \text { March } & 6,988,000 & 8,056,000 & \text { No Discharge } & \text { No Discharge } & 4,750,000 \\ \text { April } & 45,940,000 & 45,926,000 & \text { No Discharge } & 5,782,000 & 7,585,000 \\ \text { May } & \text { No Flow } & \text { No Dischage } & \text { No Discharge } & \text { No Discharge } & 4,376,000 \\ \text { June } & 6,480,000 & 7,600,000 & \text { No Discharge } & \text { No Discharge } & 1,218,000^{a^{a}} \\ \text { July } & 9,666,000 & 10,665,000 & \text { No Discharge } & \text { No Discharge } & \text { No Flow } \\ \text { August } & 14,108,000 & 14,507,000 & \text { No Discharge } & \text { No Discharge } & \text { No Flow } \\ \text { September } & \text { No Flow } & \text { No Discharge } & \text { No Discharge } & \text { No Discharge } & \text { Low Flow } \\ \text { October } & \text { No Flow } & \text { No Dlscharge } & \text { No Discharge } & \text { No Discharge } & 1,946,000^{\circ} \\ \text { November } & 17,520,000 & 21,128,000 & \text { No Discharge } & \text { No Discharge } & 4,841,000 \\ \text { December } & \text { No Flow } & \text { No Discharge } & \text { No Discharge } & \text { No Discharge } & 3,458,000 \\ \text { Total } & 111,992,000 & 120,882,000 & \text { No Discharge } & 5,782,000 & 39,220,000\end{array}$

a. Total volume is an estimate; flow was too low to quantify for the majority of the month.

b. Low flow observed during most of month; too low to quantify. 
Table 3.3-2

Chemical and Biological Constituents in Surface-Water Effluents at NPDES Permit Discharge Locations, $1993^{\text {a, } b}$

\begin{tabular}{|c|c|c|c|c|}
\hline Parameters & $\begin{array}{l}\text { Number of } \\
\text { Analyses }\end{array}$ & $\underline{C \text { minimum }}^{c}$ & $\mathrm{C}$ maximum $^{\mathrm{C}}$ & Cmean ${ }^{c_{1} d}$ \\
\hline \multicolumn{5}{|l|}{ Discharge 001 (Pond B-3) } \\
\hline Nitrate as $\mathrm{N}, \mathrm{mgh}$ & 105 & 0.28 & 6.27 & 2.10 \\
\hline Total Residual Chlorine, $\mathrm{mgn}$ & 365 & 0 & 0.20 & 0.04 \\
\hline \multicolumn{5}{|l|}{ Discharge 002 (Pond A-3) } \\
\hline $\mathrm{pH}$, standard units & 35 & 7.0 & 8.3 & N/A \\
\hline Nitrate as $\mathrm{N}, \mathrm{mg} / \mathrm{l}$ & 36 & 0.66 & 4.4 & 1.6 \\
\hline
\end{tabular}

Discharge 003 (Reverse Osmosis Pilot Plant) During 1993 there were no discharges.

Discharge 004 (Reverse Osmosis Plant) During 1993 there were no discharges.

Discharge 005 (Pond A-4)

Total Chromium, $\mu g$ l

7

$<4.0$

$<8$

$<5.1$

Discharge 006 (Pond B-5) During 1993 there were no discharges.

Discharge 007 (Pond C-2)

Total Chromium, $\mu g /$

$<5$

$<5$

$<5$

Discharge 995 (Wastewater Treatment Plant)

$\mathrm{pH}$, standard units $\quad 365$

Total Suspended Solids, $\mathrm{mg} / \quad 152$

Oil and Grease, $\mathrm{mg} / \mathrm{I}$

Total Phosphorus, $\mathrm{mg} /$

Total Chromium, $\mu \mathrm{g} /$

151

Fecal Coliform, $\# / 100 \mathrm{~m}$ !

52

153

Carbonaceous Biochemical

147

5.8
3
0
0.066
$<2.6$
$<1$
0

7.5

13

4.58

19.8

1100

9.6

1.6

Oxygen Demand, mg/

a. NPDES permit limitations are presented in Appendix B.

b. Average annual concentration reported for each parameter is an estimate of central tendency (mean value) for all samples collected during the year. This provides an estimate of average effluent water quality for the entire year. The maximum values listed are the highest values observed and represent the worst-case scenario for the entire year. The NPDES permit limits are specified as "Monthly Average" and "Weekly Average" and are measures of central tendency for the shorter time periods as required by the permit. The "Daily Maximum" is the largest value measured during the month. EPA has established limits for these required reporting intervals.

c. $\mathrm{C}$ minimum $=$ minimum measured concentration; $\mathrm{C}$ maximum $=$ maximum measured concentration; $\mathrm{C}$ mean $=$ mean measured concentration.

d. For Fecal Coliform, $\# / 100 \mathrm{ml}$ geometric mean used. 
Table 3.3-3 with corrected error terms Plutonium, Uranium, and Americium Concentrations in Surface-Water Effluents

\begin{tabular}{|c|c|c|c|c|c|c|c|}
\hline Location & $\begin{array}{l}\text { Number of } \\
\text { Analyses }\end{array}$ & $\underline{\mathrm{C} \text { mini }}$ & mum $^{a, b, c}$ & $\underline{\mathrm{C} \text { maximum }}^{\mathrm{a}, \mathrm{b}}$ & \multicolumn{2}{|c|}{$\underline{\mathrm{C} \text { mean }}^{\mathrm{a}, \mathrm{c}}$} & $\begin{array}{c}\text { Percent of } \\
\text { DCG (C mean) }\end{array}$ \\
\hline \multicolumn{8}{|c|}{ Plutonium-239, -240 Concentration $\left(\times 10^{-9} \mu \mathrm{Ci} / \mathrm{ml}\right)^{d}$} \\
\hline Pono A-4 & 16 & -0.009 & \pm 0.011 & $0.011 \pm 0.006$ & 0.002 & \pm 0.002 & 0.01 \\
\hline Pond C-1 & 41 & -0.008 & \pm 0.007 & $0.034 \pm 0.018$ & 0.008 & \pm 0.003 & 0.03 \\
\hline Pond $\mathrm{C}-2$ & 2 & 0.012 & \pm 0.012 & $0.025 \pm 0.008$ & 0.022 & \pm 0.007 & 0.07 \\
\hline Walnut Creek at Indiana Street & 15 & -0.011 & \pm 0.009 & $0.024 \pm 0.009$ & 0.003 & \pm 0.002 & 0.01 \\
\hline \multicolumn{8}{|c|}{ Americium-241 Concentration $\left(\times 10^{-9} \mu \mathrm{Ci} / \mathrm{ml}\right)^{f}$} \\
\hline Pond A-4 & 16 & -0.003 & \pm 0.021 & $0.056 \pm 0.035$ & 0.007 & \pm 0.003 & 0.02 \\
\hline Pond C.1 & 41 & -0.021 & \pm 0.007 & $0.015 \pm 0.014$ & 0.001 & $=0.002$ & 0.00 \\
\hline Pond C-2 & 2 & 0.003 & \pm 0.004 & $0.004 \pm 0.006$ & 0.003 & \pm 0.003 & 0.01 \\
\hline Wainut Creek at Indiana Street & 15 & -0.011 & \pm 0.021 & $0.013 \pm 0.006$ & 0.018 & \pm 0.002 & 0.06 \\
\hline \multicolumn{8}{|c|}{ Uranium-233, -234 Concentration $\left(\times 10^{-9} \mu \mathrm{Ci} / \mathrm{ml}\right)^{e}$} \\
\hline Pond A-4 & 16 & 0.30 & \pm 0.06 & $1.04 \pm 0.29$ & 0.64 & 0.06 & 0.13 \\
\hline Pond C-1 & 41 & 0.38 & \pm 0.17 & $2.29 \pm 0.44$ & 1.19 & 0.14 & 0.24 \\
\hline Pond C-2 & 2 & 1.08 & \pm 0.21 & $1.08 \pm 0.23$ & 1.08 & 0.18 & 0.22 \\
\hline Walnut Creek at Indiana Street & 15 & 0.33 & \pm 0.16 & $1.00 \pm 0.38$ & 0.69 & $=0.07$ & 0.14 \\
\hline \multicolumn{8}{|c|}{ Uranium-238 Concentration $\left(\times 10^{-9} \mu \mathrm{Ci} / \mathrm{ml}\right)^{\mathrm{e}}$} \\
\hline Pond A-4 & 16 & 0.30 & \pm 0.06 & $1.25 \pm 0.31$ & 0.72 & 0.06 & 0.12 \\
\hline Pond $\mathrm{C}-1$ & 41 & 0.30 & $=0.14$ & $1.71 \pm 0.36$ & 0.87 & 0.10 & 0.14 \\
\hline Pond C-2 & 2 & 1.12 & \pm 0.20 & $1.25 \pm 0.23$ & 1.22 & 0.18 & 0.20 \\
\hline Walnut Creek at Indiana Street & 15 & 0.30 & 0.14 & $1.17 \pm 0.30$ & 0.71 & 0.06 & 0.12 \\
\hline
\end{tabular}

a. $\quad$ minimum $=$ minimum measured concentration; $C$ maximum $=$ maximum measured concentration. For Pond $C-1, C$ mean refers to calculated mean concentration. Because of intermittent flow meter operations at Pond C-1 during 1993, a volume weighted average was not possible to calculate. For Ponds A-4, C-2, and flow at Walnut Creek at Indiana Street, C mean refers to volume weighted averages.

b. Calculated as 1.96 standard deviations of the individual measurement.

c. Calculated as 1.96 standard deviations of the mean (95\% Contidence Interval).

d. Radiochemically determined as plutonium-239 and -240 . The DOE Derived Concentration Guide (DCG) for plutonium in water available to members of the public is $30 \times 10^{-9} \mu \mathrm{Ci} / \mathrm{ml}$ (Appendix B).

e. Radiochemically determıned as uranium-233, -234 , and -238 . The DOE DCG for uranium-233, -234 in water available to members of the public is $500 \times 10^{-9} \mu \mathrm{Ci} / \mathrm{ml}$. The DCG for uranium-238 in water is $600 \times 10^{-9} \mu \mathrm{Ci} / \mathrm{ml}$ (Appendix B).

1. Radiochemically determined as americium-241. The standard calculated DCG for americium in water available to members of the public is $30 \times 10^{-9} \mu \mathrm{C} / \mathrm{ml}$ (Appendix B). 


\section{Table 3.3-4 with corrected error terms}

\section{Tritium Concentrations in Surface-Water Effluents}

Location $\quad \begin{gathered}\text { Number of } \\ \text { Analyses }\end{gathered} \quad$ Cminimum $^{\mathrm{a}, \mathrm{b}} \quad \underline{\mathrm{C} \text { maximum }}^{\mathrm{a}, \mathrm{b}} \quad \underline{\mathrm{Cmean}}{ }^{\mathrm{a}, \mathrm{c}} \quad \begin{gathered}\text { Percent of } \\ \text { DCG (Cmean) }\end{gathered}$

Tritium Concentration $\left(\times 10^{-9} \mu \mathrm{Ci} / \mathrm{ml}\right)^{\mathrm{d}}$

$\begin{array}{lllllllll}\text { Pond A-4 } & 90 & -304 & \pm 161 & 200 \pm 170 & 12 \pm 18 & 0.00 \\ \text { Pond C-1 } & 40 & -248 \pm 172 & 394 \pm 201 & 4 \pm \pm 35 & 0.02 \\ \text { Pond C-2 } & 10 & -174 \pm 145 & 189 \pm 152 & -4 \pm \pm 47 & 0.00 \\ \text { Walnut Creek at Inqiana Street } & 87 & -353 \pm 154 & 245 \pm 177 & -5 \pm \pm 18 & 0.00\end{array}$

a. $\mathrm{C}$ minimum $=$ minimum measured concentration; $\mathrm{C}$ maximum $=$ maximum measured concentration. For Pond $\mathrm{C}-1, \mathrm{C}$ mean refers to calculated mean concentration. Due to iritermittent flow meter operations at Pond C-1 during 1993, a volume weighted average was not possible to calculate. For Ponds $A-4, C-2$, and flow at Walnut Creek at Indiana Street, $\mathrm{C}$ mean refers to volume weighted averages.

b. Calculated as 1.96 standard deviations of the individual measurement.

c. Calculated as 1.96 standard deviations of the mean (95\% Confidence interval).

d. The DOE DCG for tritium in water available to the members of the public is $2,000,000 \times 10^{-9} \mu \mathrm{Ci} / \mathrm{ml}$ (Appendix B).

Analyte

Plutonium Concentration $\left(\times 10^{-9} \mu \mathrm{Ci} / \mathrm{ml}\right)^{d}$

Americium Concentration $\left(\times 10^{-9} \mu \mathrm{Ci} / \mathrm{ml}\right)^{f}$

Uranium-233, -234

Concentration $\left(\times 10^{-9} \mu \mathrm{Ci} / \mathrm{ml}\right)^{e}$

Uranium-238 Concenlration $\left(\times 10^{-9} \mu \mathrm{Ci} / \mathrm{ml}\right)^{6}$

Table 3.3-5 with error terms

\section{Plutonium, Americium, and Uranium Concentrations in the} Raw Water Supply

Number

of Analyses

12

12

12

12 
Sitewide Monitoring Discontinued
HYDROLOGICAL CHARACTERIZATION
The sitewide surface-water sampling programs initiated in early 1989 to evaluate potential contaminant releases and to characterize baseline water quality were concluded during 1993. These programs were intended to assess trends and changing conditions in surface-water quality, detect extreme values or excursions beyond a limit, assess the relationship between water quality and flow, identify new contaminant sources and releases, and address surface-water sediment interactions.

The sitewide surface-water sampling programs focused on measuring potential contaminants to surface water from suspected source areas such as designated CERCLA OUs by examining flow information for seeps and drainages in the main facilities area and buffer zone that may be affected by plant operations. Results from the sitewide sampling programs were reported in the 1989 Surface-Water and Sediment Geochemical Characterization Report (EGG91a) and the 1990 Surface-Water and Sediment Geochemical Characterization Report (EGG92a).

These annual sitewide programs have now provided data for 5 years of monitoring. EG\&G Rocky Flats, Inc., is confident these data are of adequate quality and quantity to meet DOE Order 5400.1 characterization requirements.

Hydrological characterization of the RFP site will be accomplished through storm-event monitoring at a network of approximately 21 stream gages located plantwide. Stream gages are equipped with continuously recording stream flow monitors and automatic samplers that are programmed to sample storm-event flows. Because the potential for contaminant transport is greatest during storm events, storm-event monitoring will supplement sitewide information for characterization of contaminant fate and transport. DOE, RFO entered into a new IAG with the United States Geological Survey (USGS) in May 1993. The USGS has been incorporated into the RFP monitoring program to upgrade and operate existing gaging stations and provide expertise for hydrologic data collection activities. The USGS will publish RFP hydrologic records starting next year. 
MONITORING RESULTS

Nonradiological Monitoring The release of pollutants into United States waters is controlled by the NPDES permit program, which requires routine monitoring of point source discharges and reporting of results. An updated renewal application has been submitted for the RFP NPDES permit, which expired in 1989 and was extended administratively until renewed. In addition, the NPDES permit terms were modified by the NPDES FFCA that was signed by the DOE and EPA in 1991. That FFCA established an additional monitoring point at the WWTP, and added certain monitoring requirements. No Notices of Violation (NOVs) were received by RFP in 1993 for violation of NPDES standards.

Annual average concentrations of chemical and biological constituents measured in surface-water effluent samples as part of the NPDES FFCA are provided in Table 3.3-2. Concentrations are indicative of the overall quality of effluent discharges. Certain discharges must meet NPDES permit monitoring and compliance limitations described in Appendix B.

Radiological Monitoring

Concentrations of plutonium, uranium, americium. and tritium in water samples from the outfalls of Ponds A-4, C-1, C-2, and from Walnut Creek at Indiana Street are presented in Tables 3.3-3 and 3.3-4. Mean plutonium, uranium, americium, and tritium concentrations at all sample locations were less than 0.24 percent of applicable DCGs (Appendix B). 
The annual cumulative total amodint of plutonium, uranium, and americium discharged to offsite waters during the year was calculated using each individual discharge concentration and flow measurement. Following are the cumulative discharge amounts for 1993.

\section{Pond A-4}

$\mathrm{Pu}-\mathrm{Ci}(\mathrm{Bq})$

$A m \cdot C i(B q)$

$\mathrm{U}-234-\mathrm{Ci}(\mathrm{Bq})$

$\mathrm{U}-238 \cdot \mathrm{Ci}(\mathrm{Bq})$

$$
\left.\begin{array}{lll}
7.60 & \times 10^{-7} \\
\left(2.81 \times 10^{4}\right.
\end{array}\right)
$$$$
3.03 \times 10^{-6}
$$$$
\left(1.12 \times 10^{5}\right)
$$

$$
\begin{aligned}
& 3.01 \times 10^{-4} \\
& \left(1.11 \times 10^{7}\right)
\end{aligned}
$$$$
3.35 \times 10^{-4}
$$$$
\left(1.24 \times 10^{7}\right)
$$

Pond $\mathrm{C}-2$

$4.78 \times 10^{-7}$

$\left(1.77 \times 10^{4}\right)$

$7.10 \times 10^{-8}$

$\left(2.63 \times 10^{3}\right)$

$2.36 \times 10^{-5}$

$\left(8.76 \times 10^{5}\right)$

$2.67 \times 10^{-5}$

$\left(9.87 \times 10^{5}\right)$

Volume weighted average tritium concentrations in water discharged from these ponds were at background levels $(11 \pm 10 \mu \mathrm{Ci} / \mathrm{ml}$ for Pond $\mathrm{A}-4$ and $-4 \pm 24 \mu \mathrm{Ci} / \mathrm{ml}$ for Pond $\mathrm{C}-2)$; therefore, cumulative discharge amounts were not calculated. Average annual concentrations of plutonium, uranium, and americium from Ponds A-4 and C-2 for 1989 through 1993 are presented in Figures 3.3-2, 3.3.-3, and 3.3-4. These graphs provide a comparison of five-year historical data for Ponds A-4 and C-2.

During 1993, RFP's raw water supply was obtained from Ralston Reservoir and from the South Boulder Diversion Canal. Ralston Reservoir water usually contains more natural uranium radioactivity than the water flowing from the South Boulder Diversion Canal. During the year, uranium. plutonium, americium, and tritium analyses were performed monthly on samples of RFP raw water. Concentrations are presented in Table 3.3-5. These values can be used for comparison with the values measured in the RFP downstream discharge locations (Tables 3.3-3 and 3.3-4). 


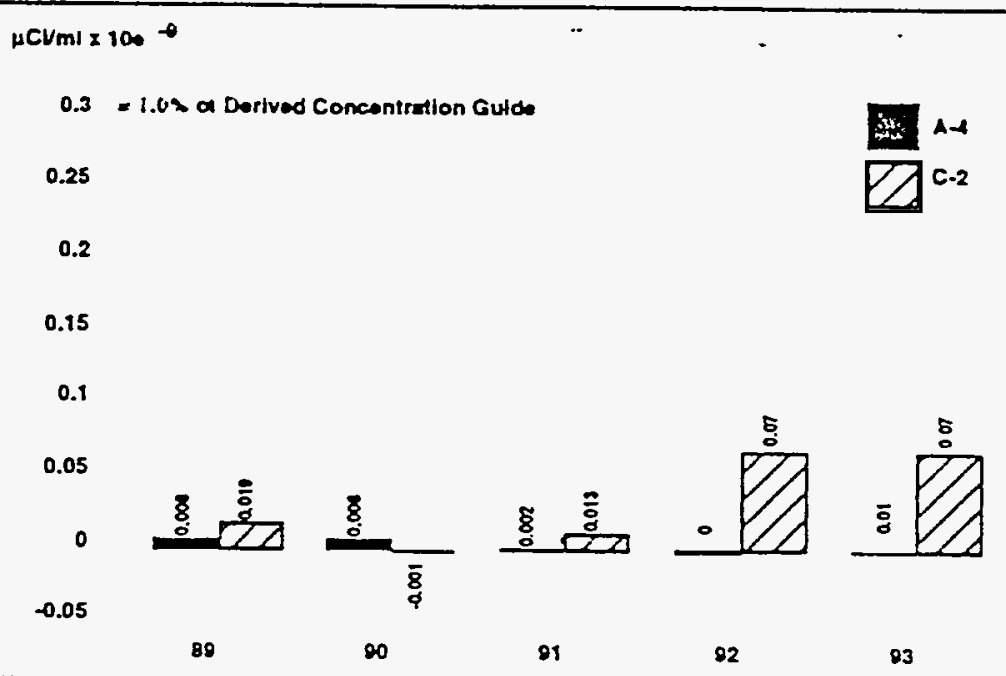

Figure 3.3-2. Plutonium-239, -240

$\mu \mathrm{CVml} \times 100^{-9}$

$60=10 \%$ of Derived Concentration Guide for U-238
$50=10 \%$ of Derived Concentration Gulde for U-233, -234

40

30

20

10

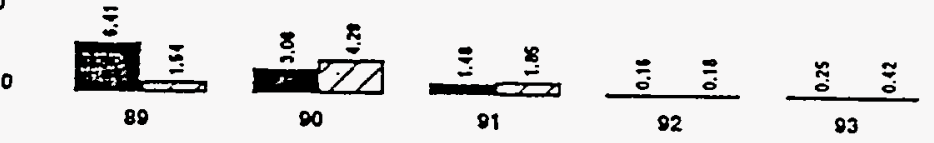

Figure 3.3-3. Uranium-233/-234, -238 Composited

$\mu \mathrm{CV}$ ml $\times 100^{-0}$

$0.3=1.0 \times$ of Derived Concentration Guide

0.25

0.15

0.7

0.05

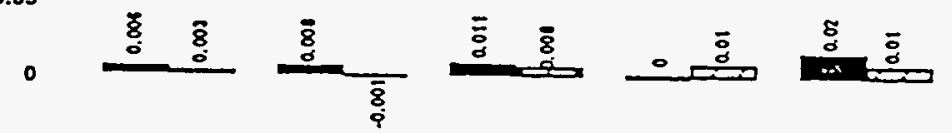

$-0.05$

$\infty$

91

92

93

Figure 3.3-4. Americium 
WATERSHED MANAGEMENT PLAN

Weed Control Program

Pesticide Control Program
The Wilershed Management Plan (WMP) was completed in April 1993 at the request of DOE. This Plan establishes guidelines and provides specific programs that will result in effective and integrated management of watersheds at RFP. In the past, water quality, vegetation, and soils components of the watershed were managed independently.

The WMP maintains and protects the watershed with programs that complement and support each other. The major components of the plan are weed control, vegetation stabilization, erosion control, monitoring, pesticide control, and ecology and NEPA field work.

During 1993, the herbicide program was restarted at RFP. This coordinated effort of vegetation control at RFP involves Plant Services. Safeguards \& Securities, and the Surface Water Division (SWD).

The Weed Control Program instituted the application of approved herbicides at selected areas on plantsite to manage undesirable vegetation under federal, state, and county weed control regulations. In addition, biological and mechanical weed control methods were utilized to integrate the program fully and reduce chemical usage. The weed control program was directed by SWD in support of plant Maintenance und Safeguards $\&$ Security while providing protection to surface water.

The Pesticide Control Program is designed to ensure that RFP is in compliance with the Federal Insecticide, Fungicide, and Rodenticide Act (FIFRA), the Colorado Pesticide Act, and the Colorado Pesticide Applicator's Act. Under the terms and definitions of the referenced regulations, and based on the amount of pesticides used, RFP is considered as a "household." As such, it is primarily a pesticide record-keeping and tracking program. The SWD's Pesticide Control Program Manager (PM) oversees the central FIFRA documentation file, and approves the use of all pesticides on plantsite whether by sub-contractor applicator or EG\&G personnel, and acts as Subject-Matter Expert (SME) and point-of-contact for FIFRA concerns. 
The Pesticide Control Program was expanded in 1993 to inciude new record-keeping and oversight responsibilities. The PM now receives monthly reports on pesticides arriving on plantsite from the Chemical Tracking and Control Systems (CT\&CS) organization and biweekly updates from the Federal Register concerning FIFRA from the Environmental Library. The FIFRA management program includes reviews of pesticide procurement actions through the Chemical Management Steering Committee and FIFRA training and qualification of building Environmental Coordinators and Facilities Process Managers.

Dam Management/RFP Dam Reinforcement

The twelve earthen dams at RFP are subject to federal and state regulations pertaining to the Federal Guidelines for Dam Safety and Colorado State Dam Safety 2CRF-402-1.

The RFP Dam Rehabilitation work package has been expanded to provide for recommendations in the Federal Guidelines for Dam Safety pursuant to federal and state regulations. SWD and Plant Civil Engineering groups received and evaluated the Draft Final Stability Analysis for Dam A-4, B-5, and C-2 at Rocky Flats, prepared by the U.S. Army Corps of Engineers; the 1993 Federal Energy Regulatory Commission Inspection Report; and the 1993 Office of the State Engineer Inspection Report concerning dams at RFP. SWD provided DOE, RFO with the Proposed Rocky Flats Dam Inspection Program that satisfies recommendations in the Federal Guidelines for Dam Safety by establishing internal EG\&G dam inspections, increased dam monitoring, identification of deficiencies or maintenance items, and dam improvement recommendations. 


\section{Environmental Monitoring Programs}

\subsection{Groundwater Monitoring}

The groundwater monitoring program at RFP is designed to serve several important functions. It determines background values, measures the concentration of hazardous constituents, measures hydrologic parameters of the aquifers, and estimates the rate of movement and extent of any contaminant plumes in the uppermost aquifer within the plant boundaries. The analyses derived from the groundwater monitoring program provide the means of evaluating the impacts of plant operations on groundwater and limiting activities that may adversely affect the quality of groundwater in the area. 
Rocky Flats Plant

Site Environmental Report for 1993 


\section{OVERVIEW}

The current RFP Groundwater Monitoring Program includes a network of wells installed to characterize groundwater quality and hydrogeology. The monitoring program has been designed and implemented to satisfy dual objectives related to both compliance monitoring and site characterization. Monitoring objectives include providing information on the presence, nature, areal extent, fate, and transport of contaminated groundwater, and providing data for trend evaluation, site characterization, and treatability studies. Groundwater data is provided to government agencies and surrounding communities and is maintained in the Rocky Flats Environmental Database (RFEDS).

Characterization objectives include identifying hydrostratigraphic units, evaluating groundwater pathways and migration characteristics, qualifying and quantifying the interrelationships between groundwater and surface water at RFP, and the relationship among precipitation, infiltration, and groundwater recharge. Additional objectives include establishing background analyte concentrations and characterizing background groundwater geochemical interactions.

The following section provides information related to the RFP Groundwater Monitoring Program, including information on the geologic setting, hydrogeology, monitoring procedures, and results recorded during 1993.

Underlying RFP is a series of stratigraphic units at increasing depths from surface deposits (composed of recent valley fill and loose rock debris) through the Rocky Flats Alluvium, Arapahoe Formation, Laramie Formation, and Fox Hills Sandstone to the Pierre Shale (Figure 3.4-1). The Rocky Flats Alluvium, colluvium, Valley Fill Aluvium, and weathered bedrock comprise the uppermost hydrologic unit where potential groundwater contamination might occur at RFP. A description of the geology of RFP is provided in the Geologic Characterization of the Rocky Flats Plant (EGG9lf).

The Rocky Flats Alluvium is composed of cobbles, coarse gravel, sand, and gravely clay, varying in thickness across RFP from approximately 103 feet on the west side, to less than 10 feet in the central area, and 45 feet on the east side. The Arapahoe Formation is approximately 120 feet thick in the central portion of RFP. It consists 


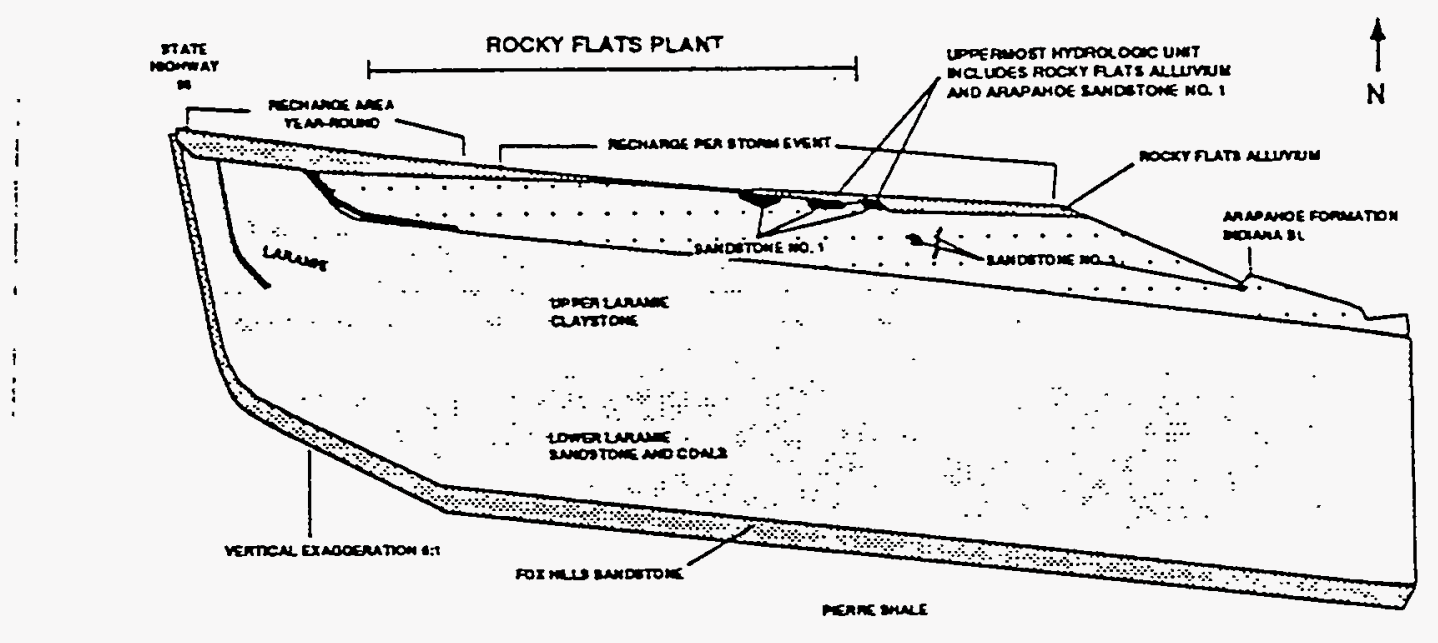

Figure 3.4-1. Generalized Cross Section of the Stratigraphy Underlying RFP

\section{Hydrogeology}

primarily of fluvial claystone overbank deposits and lesser amounts of sandstone channel deposits. The sandstones range from very fine grained to conglomerate.

The Rocky Flats Alluvium and the weathered portion of the subcropping Arapahoe Sandstones are in hydraulic connection and together represent the "uppermost aquifer." which is an unconfined flow system (Figure 3.4-1). The bedrock sandstones of the Laramie Formation are isolated within intervals of claystone. Groundwater contained in those bedrock sandstones is confined and represents a lower flow system. Table 3.4-1 provides the relative hydraulic conductivities associated with the lithologic units present at RFP. Hydraulic conductivity is a measure of the capacity of a porous medium to transmit water. It helps determine how fast groundwater and any accompanying contamination travel beneath the surface.

In the spring and early summer, the Rocky Flats Alluvium and Arapahoe Formation, located in the central and eastern portion of RFP, are recharged by precipitation and groundwater lateral flow. In the late summer and early fall, these formations are recharged primarily by groundwater lateral flow. In the stream drainages, groundwater discharges as seeps which typically occur at the base of the Rocky Flats Alluvium and where individual sandstone lenses become exposed to the surface. 
Table 3.4-1

Hydraulic Conductivities of Lithologic Units

Lithologic Unit

Rocky Flats Alluvium

Subcropping Arapahoe sandstones

Unweathered sandstones

Weathered and unweathered claystone
Hydraulic Conductivity

$1.5 \times 10^{-4} \mathrm{~cm} / \mathrm{sec}(160 \mathrm{ft} / \mathrm{yr})^{*}$

$1 \times 10^{-5} \mathrm{~cm} / \mathrm{sec}(10.4 \mathrm{ft} / \mathrm{yr})$

$1 \times 10^{-6} \mathrm{~cm} / \mathrm{sec}(1.04 \mathrm{ft} / \mathrm{yr})$

$1 \times 10^{-7}$ to $10^{-8} \mathrm{~cm} / \mathrm{sec}$

$(0.104$ to $0.0104 \mathrm{ft} / \mathrm{yr})$

- 1993 Status Report: Sitewide Groundwater Flow Modeling at RFP.

The present understanding of the hydrogeologic relationships indicates that there are no known bedrock pathways through which groundwater contamination can directly leave RFP and migrate into a confined aquifer system offsite (EGG91f).

Monitoring Program and Procedures
By the end of 1993, there were 676 wells in existence at RFP, 430 of which are sampled on a regular basis (Figure 3.4-2). Approximately 150 new wells were installed during 1993. These new wells support increased groundwater monitoring activities in the Woman Creek drainage (OU 5), Walnut Creek drainage (OU 6), and Present Landfill (OU 7).

Groundwater samples are collected quarterly from alluvial and bedrock wells. These samples are analyzed at several offsite laboratories for parameters shown in Table 3.4-2. These wells are spatially distributed throughout RFP to provide the necessary coverage to satisfy RCRA/CERCLA and plant protection guidelines for monitoring groundwater at hazardous waste sites. Some wells are used to help characterize hydrogeologic conditions at RFP, while others are used to monitor background groundwater quality. Wells in the RFP Groundwater Monitoring Program are subdivided into six subsets according to purpose and regulatory requirements. Each well in the network has been classified as either background, RCRA regulatory, RCRA characterization, CERCLA, boundary, or special purpose.

- Background wells monitor the groundwater in areas upgradient or cogradient to RFP.

- RCRA regulatory wells characterize and/or monitor the uppermost aquifer for RCRA units. 


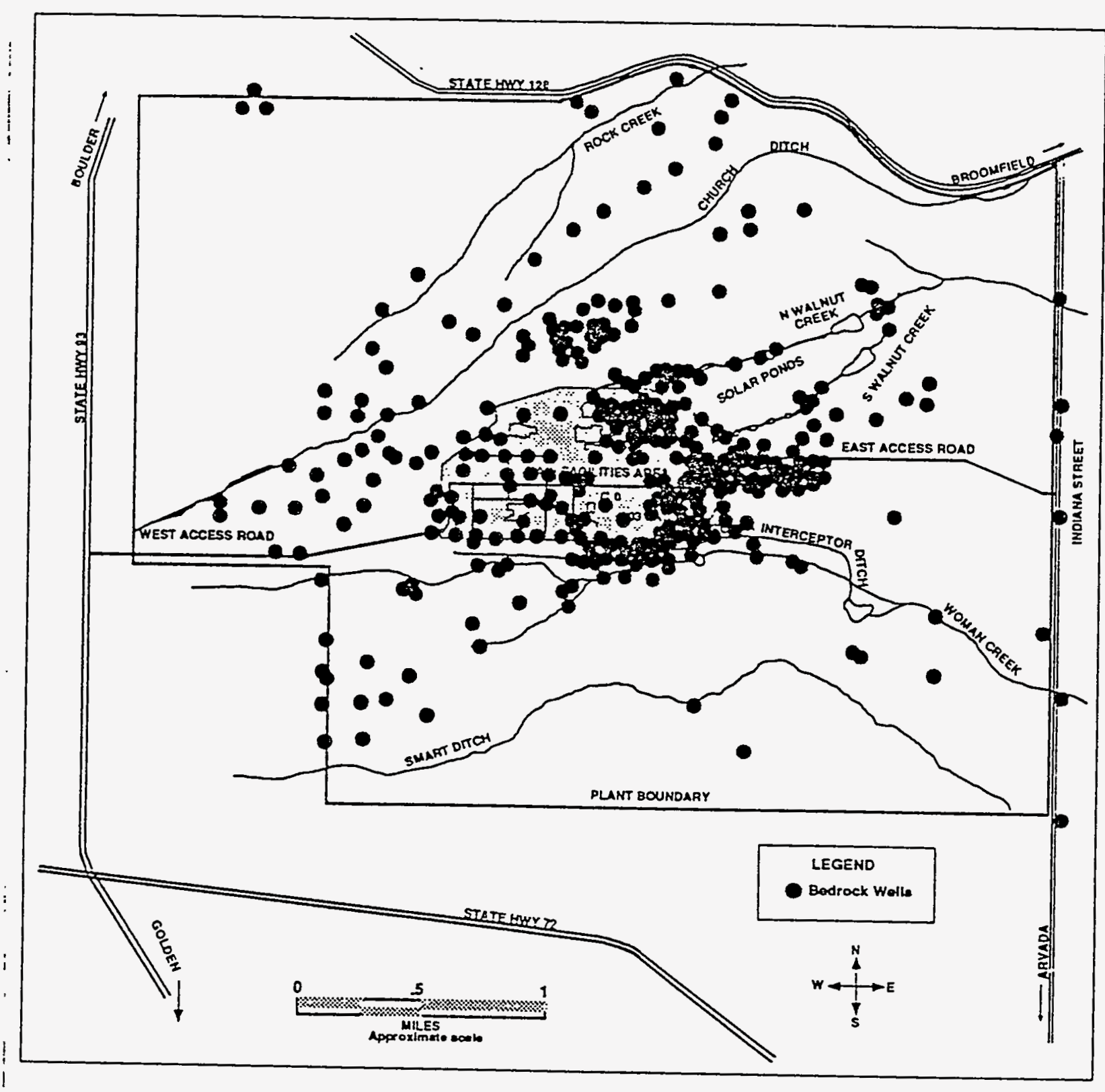

Figure 3.4-2. Location of Monitoring Wells 
Table 3.4-2

Site Chemical Constituents Monitored in Groundwater

。

Dissolved Metals

Cesium

Lithium $^{\text {a }}$

Molybdenum

Strontium

$\operatorname{Tin}^{b}$

Target Analyte List:

Aluminum

Antimony

Arsenic

Barium

Beryllium

Cadmium

Calcium

Chromium

Cobalt

Copper

Iron

Lead

Magnesium

Manganese

Mercury

Nickel

Potassium

Selenium

Silver

Sodium

Thallium

Vanadium

Zinc

Organics $^{c}$

Target Compound List - Vojatiles:

Chloromethane

Bromomethane

\author{
Vinyl Chloride \\ Chloroethane \\ Methylene Chloride \\ Acetone \\ Carbon Disulfide \\ 1,1-Dichloroethane \\ 1,1, -Dichloroethene \\ trans-1,2-Dichloroethene \\ 1,2-Dichloroethene (total) \\ Chloroform \\ 1,2-Dichloroethane \\ 2-Butanone \\ 1,1,1-Trichloroethane \\ Carbon Tetrachloride \\ Vinyl Acetate \\ Bromodichloromethane \\ 1,1,2,2-Tetrachloroethane \\ 1,2-Dichloropropane \\ trans-1,3-Dichloropropene \\ Trichloroethene \\ Dibromochloromethane \\ 1,1,2-Trichloroethane \\ Benzene \\ cis-1,3-Dichloropropene \\ Bromoform \\ 2-Hexanone \\ 4-Methyl-2-pentanone \\ Tetrachloroethene \\ Toluene \\ Chlorobenzene \\ Ethyl Benzene \\ Styrene \\ Total Xylenes
}

Dissolved Radionuclides ${ }^{d}$

Gross Alpha

Gross Beta

Uranium-233/-234, -235, and -238
Strontium-89, $-90^{\mathrm{e}}$

Cesium-137

Tritium

Radium-226, $-228^{\prime}$

Total Radionuclides

Americium-241

Plutonium-239, -240

Indicators

Total Dissolved Solids

$\mathrm{pH}^{\mathrm{b}}$

Field Parameters

pH

Specific Conductance

Temperature- - ...

Dissolved Oxygen (discontinued in 1993)

Alkalinity

Anions

Carbonate

Bicarbonate

Chloride

Sulfate

Nitrate/Nitrite

Cyanide $^{9}$

Fluoride

Orthophosphates

a. Before 1989, lithium was only analyzed during fourth quarter 1987 and first quarter 1988.

b. Not analyzed before 1989 .

c. Not analyzed in background samples in 1989 .

d. Dissolved radionuclides replaces total radionuclides (except tritium) beginning with the third quarter 1987; however, total Pu and Am were collected starting in third quarter 1990.

e. Strontium-89, -90 was not analyzed during first quarter 1988 .

f. Not analyzed before 1989, and only analyzed if gross alpha exceeds $5 \mathrm{pCil}$.

g. Cyanide was not analyzed during fourth quarter 1987.

NOTES:

- Total suspended solids and phosphate were analyzed in 1986 only; orthophosphates were analyzed in 1990 and 1991.

- Chromium (VI) was analyzed during fourth quarter 1987 only. 
- RCKA characterization wells characterize and/or monitor aquifers other than the uppermost aquifer at or near RCRA units.

- CERCLA wells characterize and/or monitor the groundwater for CERCLA units.

- Boundary wells monitor the movement and quality of groundwater at the downgradient boundaries of RFP.

- Special purpose wells include other wells installed at RFP that are used to characterize groundwater and hydrogeology for a variety of purposes.

Quarterly water-level measurements are taken to adequately assess groundwater flow directions. These data are used to evaluate trends in groundwater quality and contaminant migration in the uppermost, unconfined aquifer.

During 1993, RFP performed monitoring well abandonment and replacement under the Well Abandonment and Replacement Program (WARP). WARP was developed to mitigate the potential for contaminant migration through improperly constructed or damaged wells. Thirty-four monitoring wells were abandoned and eight replacement wells were installed under WARP during 1993.

\section{RESULTS}

Groundwater investigation and restoration activities at RFP follow a five-phase approach to identify contamination, design and implement treatment procedures, and monitor the adequacy of restoration actions. This process includes establishment of groundwater quality standards that are specific to each OU and reflect state and federal requirements. No specific standards have been established for OUs at RFP, although possible limits have been identified pursuant to CERCLA requirements that remedial actions comply with Applicable or Relevant and Appropriate Requirement (ARAR) federal laws or more stringent, promulgated state laws. Sitespecific groundwater standards and classifications have been established by the CWQCC. The standards apply to all unconfined groundwater in the alluvial materials, the Arapahoe aquifer, and the Laramie-Fox Hills aquifer. The alluvial aquifers are classified Domestic and 
Agrisultural Use - Quality and Surface Water Protection. The Arapahoe and Laramie-Fox Hills aquifers are classified Domestic and Agricultural Use - Quality.

The Final IAG (Section 2, "Compliance Summary") divides RFP into 16 OUs for study and restoration. Individual maps of all 16 OUs are located at the end of Section 4, "Remediation." The following sections discuss results of groundwater investigations in OUs 1,2 , 4,7 , and 11 .

Operable Unit 1

\section{Operable Unif 2}

881 Hillside. The report titled Phase III RFI/RI Work Plan, Rocky Flats Plant, 881 Hillside Area, Operable Unit No. I (EGG91c) contains information on groundwater quality at OU 1 . No new wells were drilled in OU 1 in 1993. Based on the most recently completed Phase III RFI/RI, it is apparent that groundwater contamination posing the most significant public health risk arises from VOCs (i.e., carbon tetrachloride, perchloroethylene, trichloroethylene). These VOCs are historically linked to storage of drums containing cleaning solvents at individual hazardous substance site (IHSS) 119.1 from 1967 to 1972 (Figure 4-1, Section 4). Figure 3.4-3 shows approximate outlines of VOC groundwater contaminant plumes on the plantsite and depicts the extent of contaminant movement under the 881 Hillside.

Concentrations of VOCs diminish downgradient of IHSS 119.1, becoming equal to or below detection limits $(5 \mu \mathrm{g} / \mathrm{l})$ within 200 feet of the original storage area. Slightly elevated concentrations of inorganic constituents also were found in the eastern portion of $\mathrm{OU}$ 1 , where analytes detected above background levels included total dissolved solids (TDS), metals (nickel, strontium, selenium, zinc, and copper), and uranium.

903 Pad, Mound, and East Trenches Areas. The report titled Phase II RFI/RI Work Plan, Rocky Flats Plant, 903 Pad, Mound, and East Trenches Areas, Operable Unit No. 2 (EGG91d) contains information on groundwater quality at OU 2. Groundwater in the upper hydrostratigraphic unit, which is composed of alluvial materials and shallow subcropping sandstones, is contaminated with VOCs. inorganics, dissolved metals, and some radionuclides. 


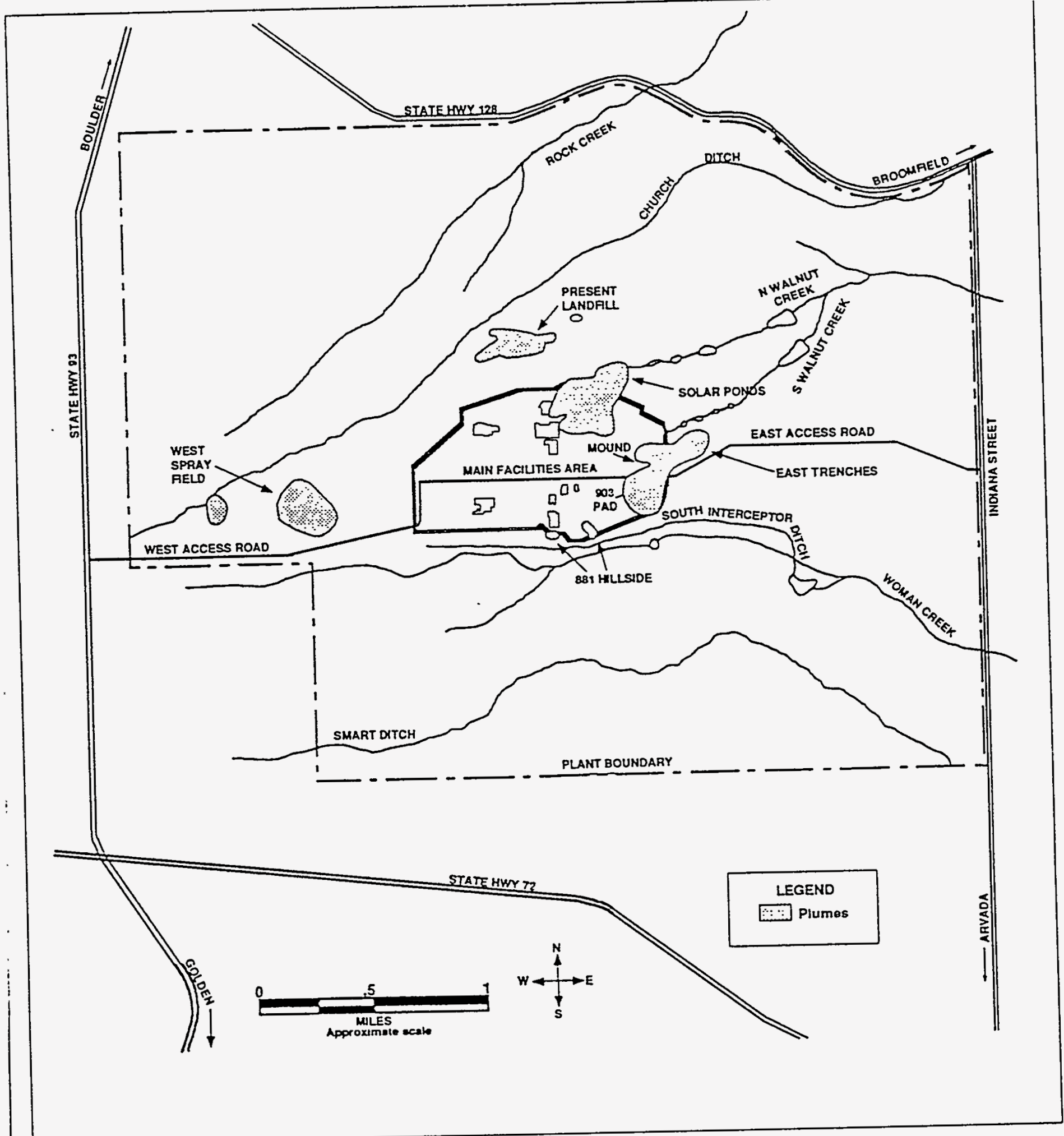

Figure 3.4-3. Location of Areas Known To Have Groundwater Contamination Plumes 
Inoryanics and dissolved metals commonly occurring above background levels include TDS, strontium, barium, copper, and nickel, and to a lesser extent, chromium, manganese, selenium, lead, zinc, and molybdenum. Most of the radionuclide contamination is uranium -238. Americium and plutonium are also present in some groundwater samples.

Contaminants of most concern are VOCs. Those detected include tetrachloroethene, trichloroethene, and carbon tetrachloride. Figure 3.4-3 depicts general groundwater contaminant plumes on the plantsite and indicates the approximate extent of contamination at OU 2. Certain inorganic parameters and radionuclides are elevated above background levels in OU 2, but they do not appear to exist as a well-defined plume of contamination.

Investigations are continuing to further characterize these plumes and the magnitude and extent of contamination.

Operable Units 4, 7, and 11 (RCRA-Regulated Units)
The Solar Evaporation Ponds, Present Landfill, and West Spray Field (OUs 4, 7, and 11). The purpose of groundwater monitoring in these RCRA-regulated units is to assess impacts of waste management activities on groundwater quality in the uppermost aquifer beneath these units. The report titled 1993 Annual RCRA Groundwater Monitoring Report for Regulated Units at Rocky Flats Plant (EGG94a) presents results of 1993 interim-status quarterly groundwater monitoring. Data are presented for groundwater elevations, flow rates, and quality analyses. A comparison is made between analyte concentrations upgradient of the unit and those downgradient of the unit to evaluate the impact of waste management activities on groundwater quality. The following sections highlight results of groundwater monitoring in each respective unit.

Solar Evaporation Ponds (OU 4). Groundwater assessment monitoring continues to be performed at the Solar Evaporation Ponds area to further assess the levels, extent, and migration characteristics of contamination in the uppermost aquifer beneath this unit. Water elevation data collected throughout 1993 reveal that groundwater flow across the Solar Evaporation Ponds area is generally in an easterly direction, although it diverges along two major subsurface flowpaths. One flowpath is northeasterly toward North Walnut Creek and the other is southeasterly toward South Walnut Creek. There are also large areas where surficial materials are unsaturated. The most prominent of these areas coincides with the 
location of the Interceptor Trench System, which collects groundwater downgradient of the Solar Evaporation Ponds and diverts it back to one of the ponds. Groundwater flow velocities calculated for surficial materials are between 10 and 39 feet per year and are topographically controlled. Groundwater elevations are presented in Figure 3.4-4 for surficial materials during the second quarter of 1993. In 1993, twenty-five pieziometers were installed, six RCRA wells were abandoned, and four replacement wells were drilled.

A statistical comparison of downgradient water with upgradient groundwater quality, using Analysis of Variance (ANOVA), indicates that groundwater in downgradient wells screened in the uppermost aquifer north, east, and southwest of the ponds is impacted with nitrate/nitrite, total dissolved solids, fluoride, bicarbonate, sulfate, dissolved radionuclides, and several dissolved metals. Dissolved radionuclides detected in surficial wells downgradient and in the immediate vicinity of the Solar Evaporation Ponds during 1993 include uranium-233/-234 (as high as $210.0 \mathrm{pCi} / 1$ ), uranium-235, uranium-238 (120.0 pCi/1), and tritium. Total radionuclides detected in the uppermost aquifer include americium-241 $(0.65 \mathrm{pCi} / \mathrm{l})$ and plutonium $239,-240(4.82 \mathrm{pCi} / 1)$. Concentrations and distribution of uranium-233/-234, plutonium-239, -240 , and americium-241 (reported in $\mathrm{pCi} / \mathrm{l}$ ) in the Solar Evaporation Ponds area are presented in Figures 3.4-5 A and B. VOCs detected in surficial wells in the vicinity of the Solar Evaporation Ponds are shown in Figure 3.4-6 and include trichloroethene, tetrachloroethene, carbon tetrachloride, chloroform, and several others.

Present Landfill (OU 7). The Present Landfill is undergoing groundwater monitoring to assess the level, extent, and migration characteristics of contamination in the uppermost aquifer beneath the unit. Sixteen wells were installed in OU 7 in 1993. Groundwater elevation data collected in 1993 indicate that groundwater beneath the landfill tends to flow easterly through surficial geologic materials toward the landfill pond. This flow, as recorded in the second quarter 1993, is illustrated in Figure 3.4-7. Close to the pond, groundwater flows southeasterly and northeasterly toward the pond. Calculated average linear-flow velocities in fill materials ranged from approximately four feet per year at the west end of the landfill to approximately 150 feet 


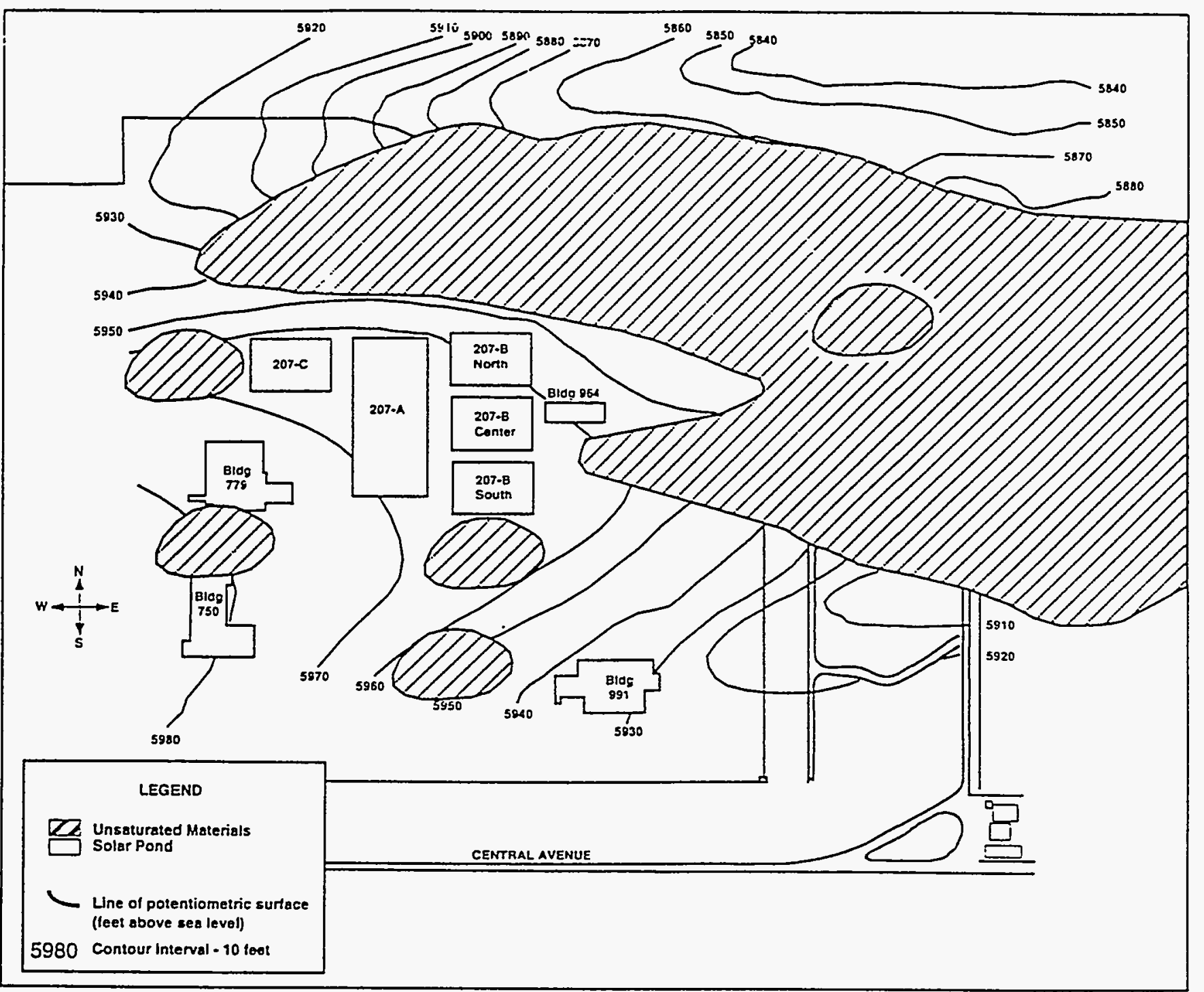

Figure 3.4-4. Solar Evaporation Ponds Potentiometric Surface in Surficial Materials 


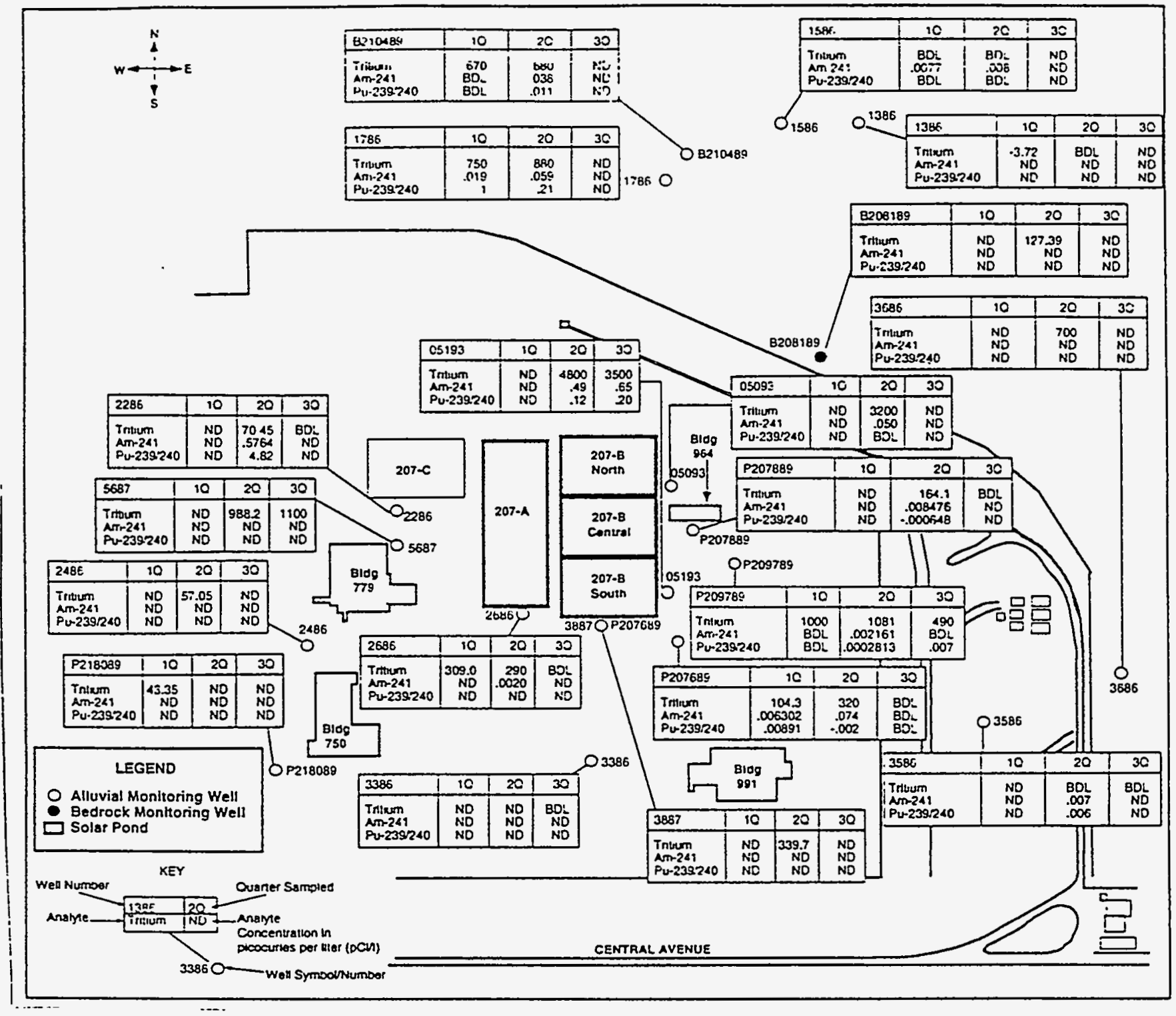

Figure 3.4-5 A. Solar Evaporation Ponds Dissolved Plutonium-239, -240, Americium-241, and Tritium Detected in the Uppermost Aquifer 


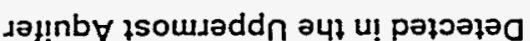

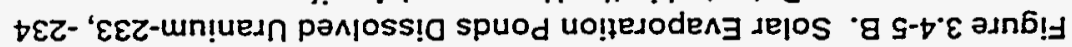

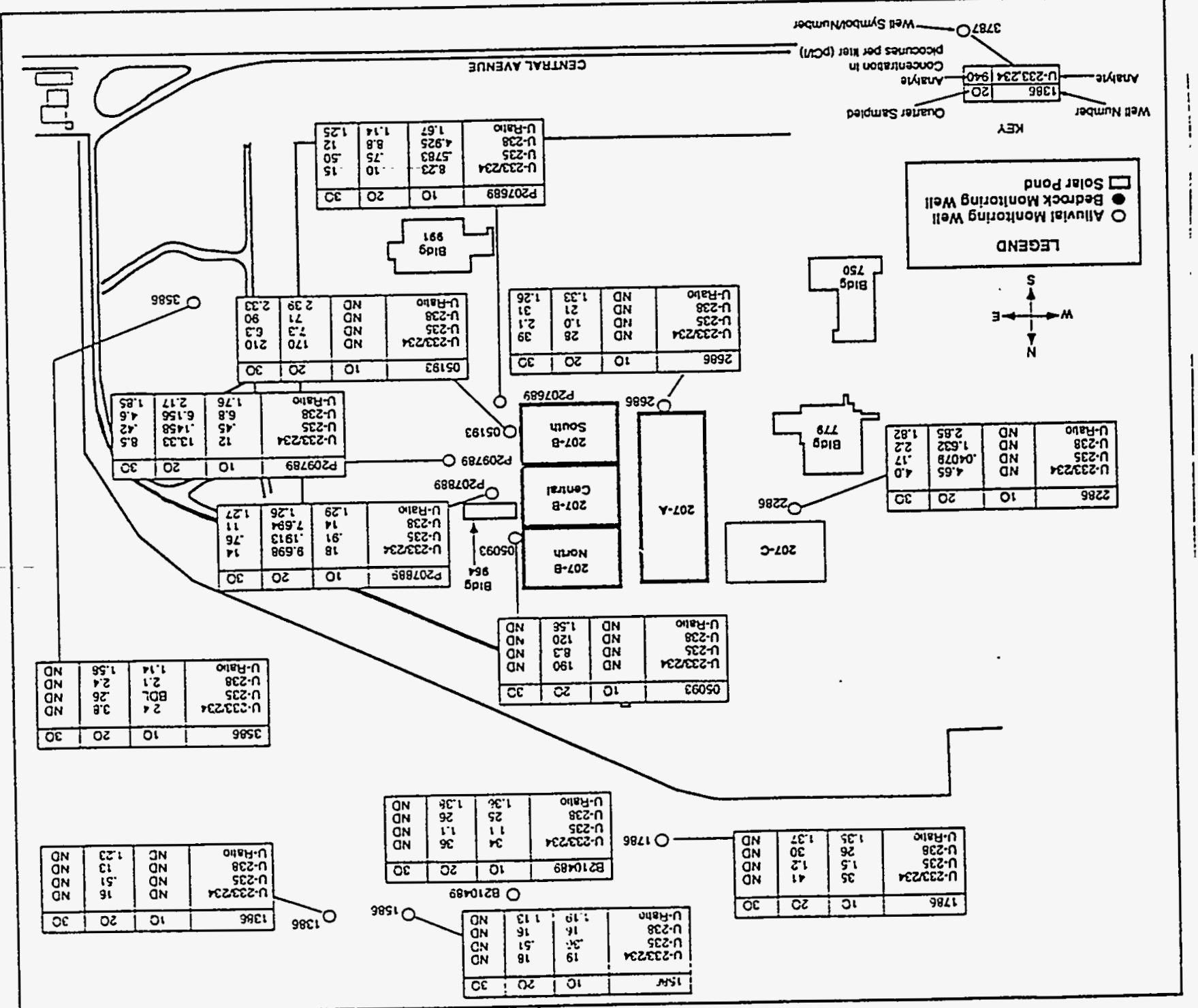




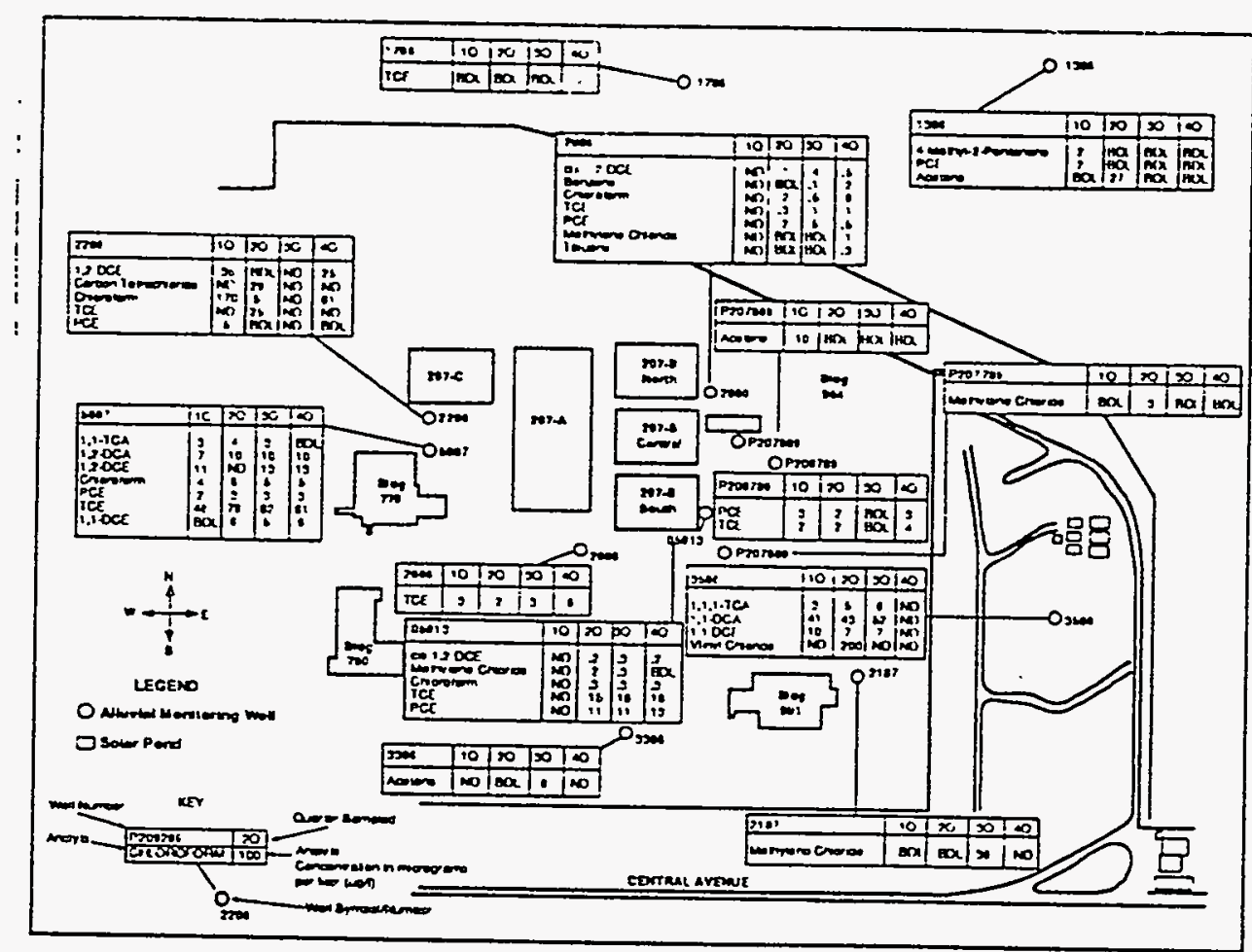

Figure 3.4-6. Solar Evaporation Ponds Volatile Organic Compounds Detected in the Uppermost Aquifer

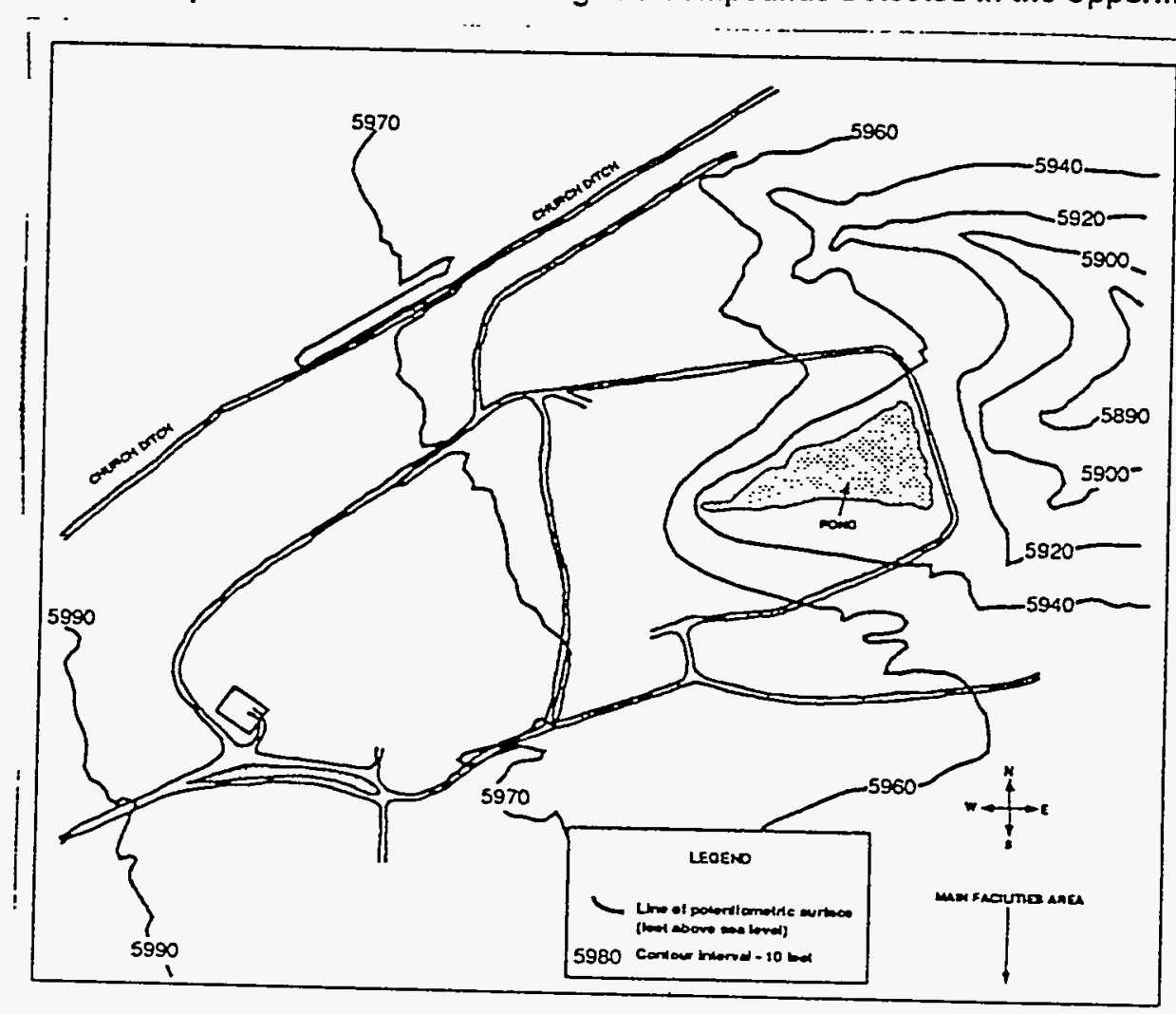

Figure 3.4-7. Present Landfill Potentiometric Surface in Surficial Materials 
per year at the advancing face of the landfill. Calculated average linear-flow velocities in bedrock of the Upper Hydrostratigraphic Unit (UHSU) at the Present Landfill ranged from approximately 0.18 feet to 0.21 feet per year beneath the landfill to approximately 0.08 feet to 0.42 feet per year downgradient of the landfill. Calculated groundwater-flow velocties for UHSU bedrock in 1993 are also slower than 1992 average velocities for 1992. Calculated groundwater-flow velocities in bedrock of the Lower Hydrostratigraphic Unit (LHSU) at the Present Landfill ranged from approximately 0.00 feet to 0.08 feet per year beneath the landfill to approximately 0.08 feet per year downgradient of the landfill.

Assessment of the 1993 data suggests that groundwater outside of the landfill is diverted around the landfill wastes and discharged into the landfill pond. Landfill contaminants migrate with the groundwater flow through the leachate collection system toward the landfill pond. Water is retained within the pond, where it either evaporates directly or is evaporated by spray irrigation onto the hillsides adjacent to the pond. Data from 1993 suggest that the groundwater intercept system may not be diverting all groundwater away from the north and south sides of the landfill, and the leachate collection system may function intermittently on the north side of the landfill.

In 1993, six wells were installed inside the landfill and two wells along the perimeter. These wells provide additional potentiometric data regarding the effectiveness of the groundwater-intercept/diversion system. The more detailed potentiometric-surface maps constructed for 1993 show higher water-table elevations in the northern part of the landfill along the groundwater-intercept system. The intercept system does not appear to function as effectively on the northwest side of the landfill as along the southwest side; groundwater appears to migrate into the landfill along the north side.

Shallow surficial and deep bedrock groundwater wells are monitored quarterly at the Present Landfill. Groundwater quality data in downgradient wells were statistically compared to those upgradient of the landfill in 1993. In the UHSU bedrock, ANOVA testing demonstrated statistically significant differences at the 5-percent significance level in upgradient versus downgradient groundwater quality for dissolved metals (calcium, 
lithiur, magnesium, potassium, sodium, and strontium) and inorganic parameters (chloride and sulfate).

Concentrations of radioruclides were not statistically different (at the 5-percent significance level) in upgradient versus downgradient groundwater from the entire UHSU or from UHSU bedrock. These results indicate that concentrations of some dissolved metals (calcium, lithium. magnesium, potassium, sodium, and strontium) and inorganic parameters (chloride and sulfate) are higher in groundwater downgradient of the landfill. Only one detection of a VOC (methylene chloride) occurred in UHSU groundwater downgradient of the Present Landfill.

Within the confines of the Present Landfill, the nature of groundwater contamination is characterized by the detection of VOCs, radionuclides, and concentrations of metals and inorganic analytes higher than in upgradient wells. Dissolved radionuclides detected in 1993 in and adjacent to the landfill include tritium (up to $3500 \mathrm{pCi} / \mathrm{l})$ and strontium-89, $-90(3.83 \mathrm{pCi} / \mathrm{l})$. Total radionuclides detected include americium-241 (0.34 $\mathrm{pCi} / \mathrm{l}$ ) and plutonium-239, -240 (up to $1.2 \mathrm{pCi} / \mathrm{l}$ ). Radionuclides were detected in a wide area across the landfill site. Figure 3.4-8 shows the distribution and concentration of radionuclides at the landfill with concentrations given in $\mathrm{pCi} / \mathrm{l}$. Detection of VOCs during 1993 occurred primarily in wells in the southern portion of the landfill. A number of different compounds were detected, including carbon tetrachloride, trichloroethene, tetrachloroethene, and others. The distribution and concentrations (reported in $\mu \mathrm{g} / \mathrm{l}$ ) of detected VOCs are presented in Figure 3.4-9.

Conditions at the Present Landfill in 1993 appear generally consistent with those of 1992 . However, in 1993 , fewer metals and inorganic parameters, and no radionuclides, displayed statistically significant increases in concentration downgradient of the RCRArelated unit. This may be the result of different data populations being available for statistical analysis. The groundwater-intercept system appears effective in limiting the downgradient transport of contaminants. The presence of contaminants detected in monitoring wells southeast of the Present Landfill may be caused by an inadequately functioning groundwater-intercept system in this area. emplacement of wastes beyond the limit of the intercept system, or impacts associated with other IHSSs adjacent to the landfill. 
$\because$

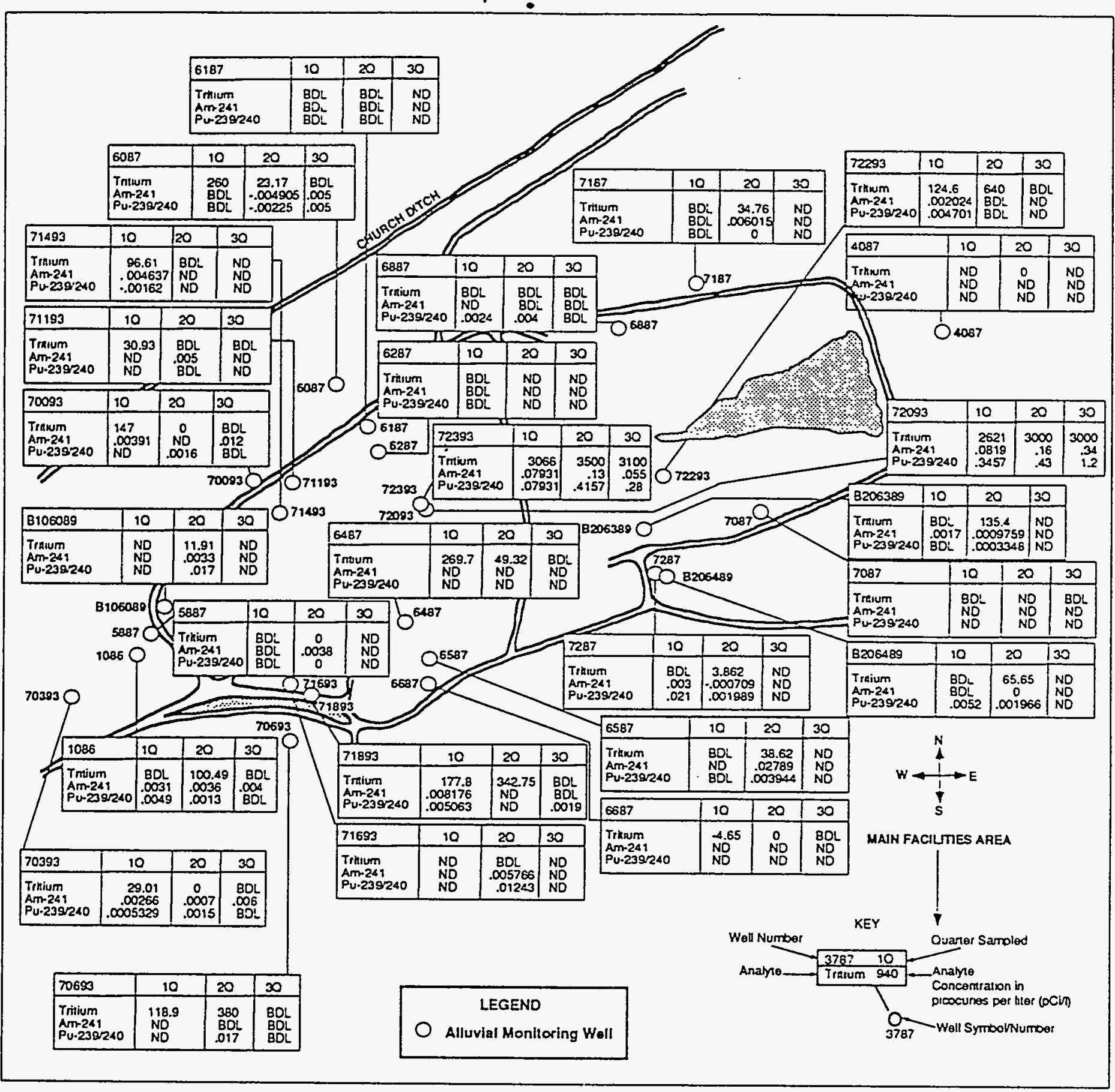

Figure 3.4-8. Present Landfill Radionuclides in the Uppermost Aquifer 


\section{Fest}

$\because \quad$ West Spray Field (OU 11). Gr.undwater monitoring at the West Spray Field is conducted to provide data for assessment of the level, extent, and migration characteristics of contamination in the uppermost aquifer beneath this unit. Groundwater flow in the uppermost aquifer is relatively uniform and occurs in an eastnortheasterly direction. Average linear-flow velocities calculated (using 1993 data) for groundwater in alluvial materials ranged from approximately 60 to 70 feet per year. Flow velocities for alluvium downgradient of the West Spray Field typically ranged from 25 to 75 feet per year. The highest calculated flow velocity (108 feet per year) occurs along a linear path from the West Spray Field toward Woman Creek along a steep hydraulic gradient. Flow velocities calculated for UHSU bedrock are approximately 1.5 feet per year. Alluvial wells and bedrock wells are routinely sampled at the West Spray Field. A potentiometric surface map showing groundwater elevations in the uppermost aquifer is presented in Figure 3.4-10. 


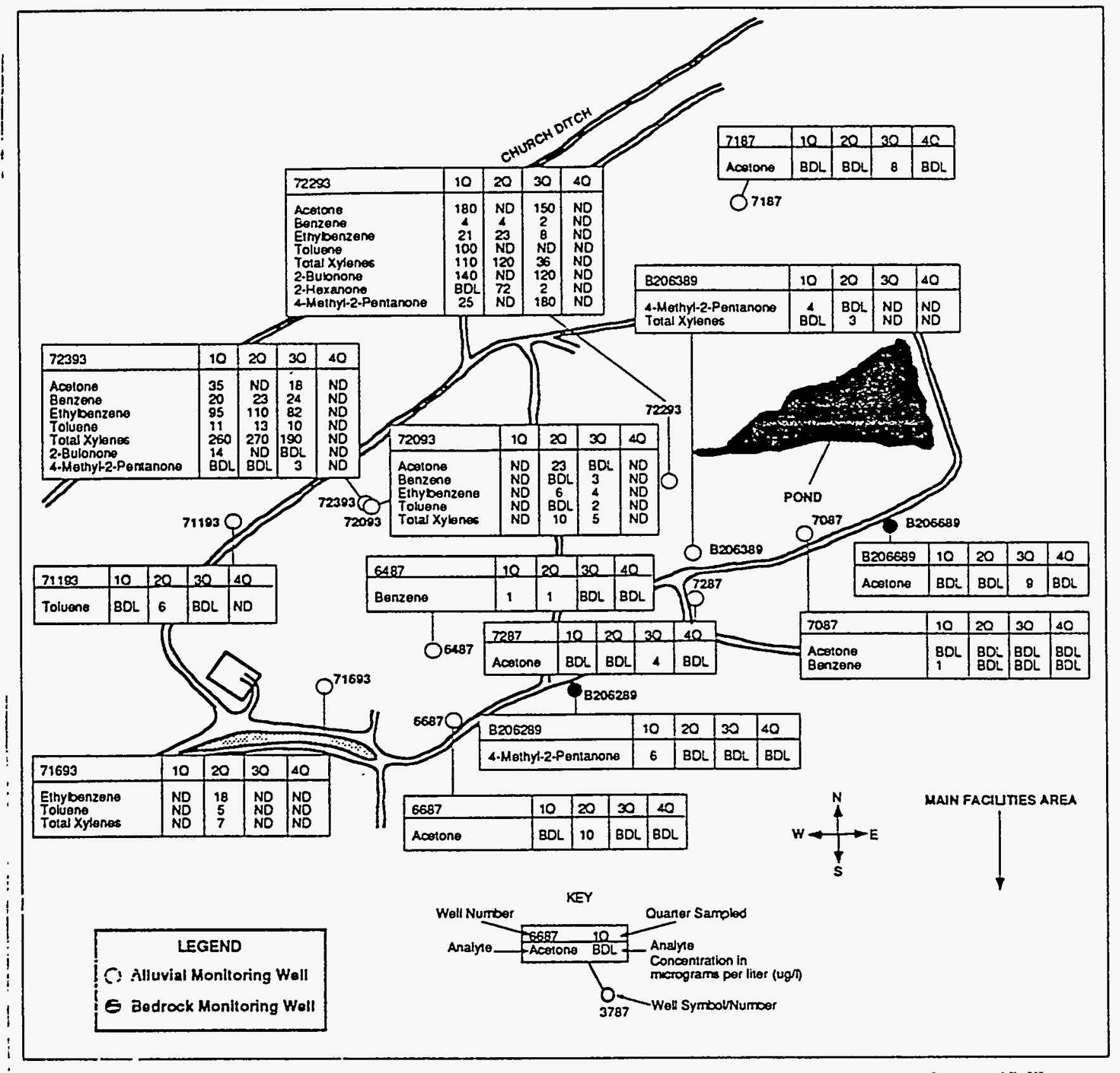

Figure 3.4-9. Present Landfill Volatile Organic Compounds Detected in the Uppermost Aquifer 


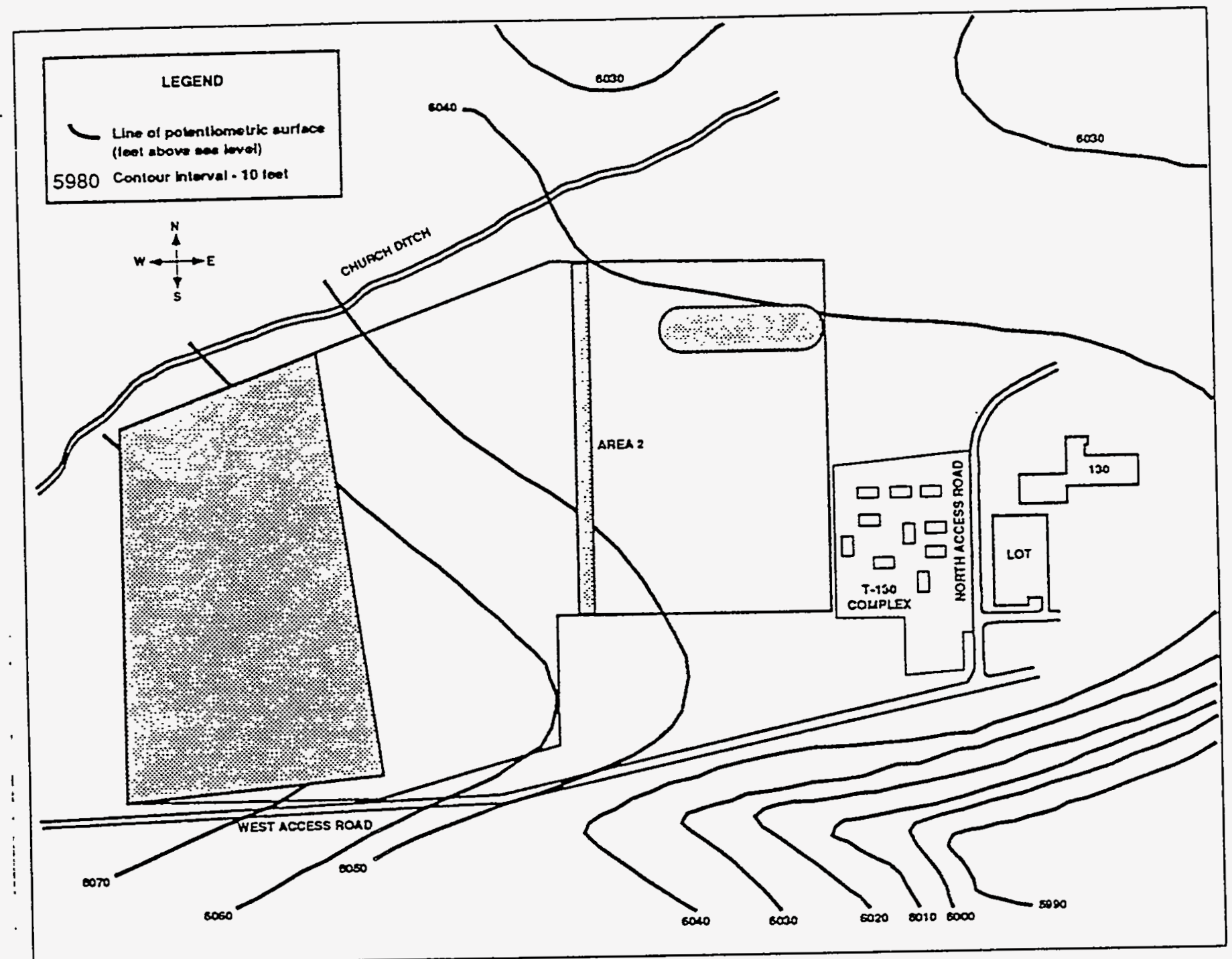

Figure 3.4-10. West Spray Field Potentiometric Surface in Surficial Materials 
Witnin and adjacent to the West Spray Field, groundwater quality has been impacted by dissolved radionuclides. a few dissolved metals, and inorganic analytes. Dissolved radionuclides detected include uranium $-233 /-234$ (at $0.8991 \mathrm{pCi} / \mathrm{l}$ ), and uranium-238 (0.97 $\mathrm{pCi} / \mathrm{l})$. Total radionuclides in the uppermost aquifer within the West Spray Field include americium-241 $(0.012 \mathrm{pCi} / \mathrm{l})$ and plutonium-239 (0.0047 pCi/l). The distribution and concentrations of radionuclides (reported in $\mathrm{pCi} / \mathrm{l}$ ) detected during 1993 in the uppermost aquifer are shown in Figures 3.4-11 A and B.

Inorganic analytes detected at elevated levels within the West Spray Field include fluoride, chloride, bicarbonate, sodium, sulfate, nitrate/nitrite, orthophosphate, and total suspended solids.

Boundary Wells

Groundwater quality is monitored quarterly in a series of wells downgradient of RFP, along the plant's eastern boundary at Indiana Street. Eight boundary wells are routinely sampled to measure water quality in three separate hydrostratigraphic units. These include the valleyfill alluvium, colluvium, and the sandstones, siltstones, and claystones of the Arapahoe and Laramie Formations. Laboratory results from samples collected during 1993 were compared with background upper tolerance limits that had been previously calculated for each of the three hydrostratigraphic units. Selected results of water quality analyses for VOCs, dissolved metals of interest, and total radionuclides are provided in Tables 3.4-3, 3.4-4, and 3.4-5, respectively.

Valley-fill alluvium groundwater is monitored by three wells (\#0186, \#41491, and \#41691). VOCs were detected in several of the wells. Among the detected compounds were acetone and methylene chloride, which are considered laboratory contaminants because of their presence in blanks. Some dissolved metals (cadmium, lead, and cobalt) were measured at levels just above the detection limit.

No dissolved radionuclides were detected above background upper tolerance limits. However. total (dissolved plus suspended) plutonium-239, -240 and total americium-241 were measured at activities above background upper tolerance limits in two wells (\#0486 and \#41691). The highest reported activity was plutonium-239, -240 at $1.3 \mathrm{pCi} / \mathrm{l}$ in Well \#41691. An independent quality control check on this result concluded that it is acceptable 


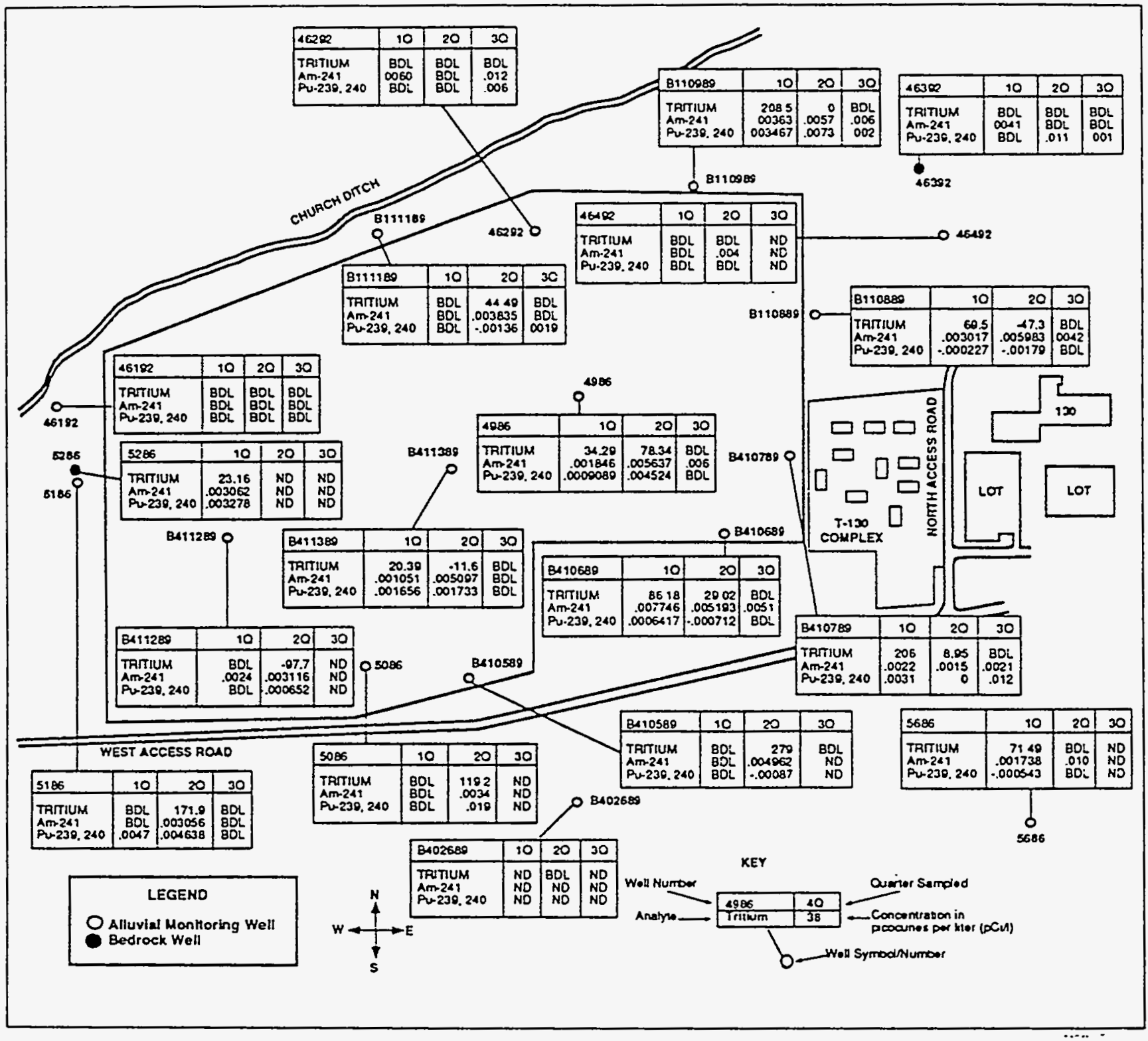

Figure 3.4-11 A. West Spray Field Radionuclides Plutonium-239, -240, Americium-241, and Tritium Detected in the Uppermost Aquifer 


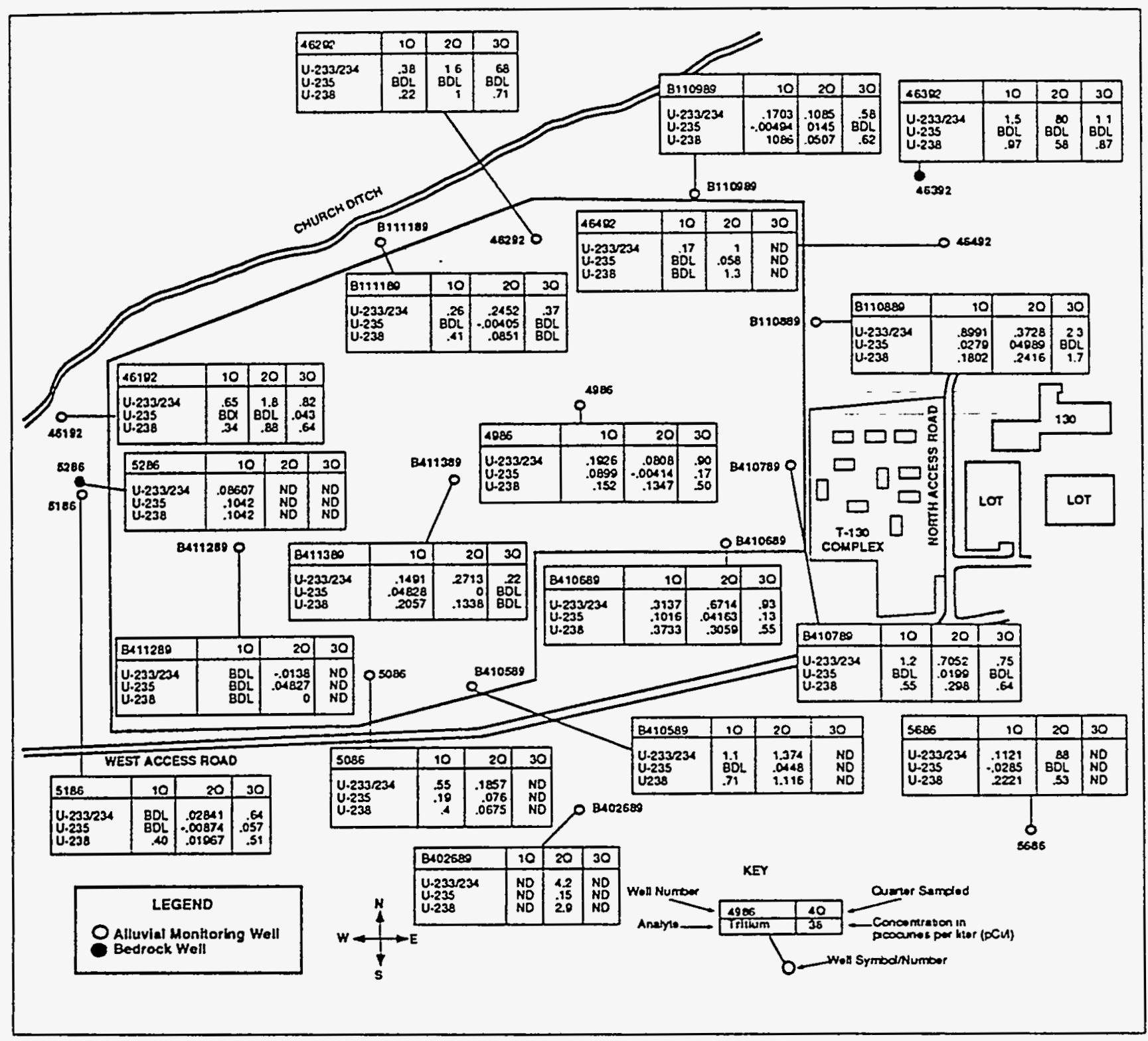

Figure 3.4-11 B. West Spray Field RadionuclidesUranium-233/-234, Uranium-235, and Uranium-238 Detected in the Uppermost Aquiter 
Table 3.4-3

Volatile Organic Compounds Detected in Boundary Wells

Well Number Analyte Sampled $\quad$ Result $(\mu g /)^{a} \quad \begin{gathered}\text { Contract } \\ \text { Detection Limit }(\mu g))^{b}\end{gathered}$

Vallev-till Alluvium

$\begin{array}{llll}41091^{c} & \text { Carbon Disulfide } & 1.0 & 5.0 \\ 41091^{\mathrm{C}} & \text { Methylene Chloride } & 3.0 & 5.0 \\ 41091^{\mathrm{d}} & \text { Styrene } & 0.11 & 0.10 \\ 41091^{\mathrm{c}, \mathrm{d}} & \text { Acetone } & 2.00 & 10.00 \\ 41091^{\mathrm{N}} & \text { Chlorolorm } & 0.2 & 0.10\end{array}$

Arapahoe/Laramie Formation

$\begin{array}{llrr}\mathrm{B} 303089 & \text { Acetone } & 21.0 & 10.0 \\ \mathrm{~B} 303089^{\mathrm{C}} & \text { Carbon Disulfide } & 1.0 & 5.0 \\ \mathrm{~B}^{\mathrm{C}} 03089^{\mathrm{d}} & \text { Methylene Chloride } & 6.0 & 5.0\end{array}$

a. Results column refers to laboratory results, showing analysis accuracy or equipment accuracy.

b. Contract detection limit refers to the detection limit specified by RFP with the independent testing laboratory.

c. Indicates an estimated value for either a tentatively identified compound or an analyte that meets the identification criteria, but the result is less than the specified detection limit.

d. Indicates the compound was found in the blank and the sample.

Table 3.4-4

Dissolved Metals of Interest Detected in Boundary Wells

Well Number Analyte Sampled $\quad$ Result $(\mu \mathrm{g} / 1)^{\mathrm{a}}$ Detection Limil $(\mu \mathrm{g} / 1)^{\mathrm{b}}$

Valley-fill Alluvium

$\begin{array}{llll}0486^{\text {c.d.e }} & \text { Cadmium } & 0.66 & 6.6 \\ 41691 & \text { Lead } & 1.0 & 3.0 \\ 41691 & \text { Cobalt } & 3.0 & 5.0\end{array}$

Arapahoel aramie Formation

$\begin{array}{llrr}0386^{c} & \text { Selenium } & 69.6 & 2.0 \\ 0386 & \text { Selenium } & 52.4 & 5.0 \\ 0386^{c} & \text { Selenium } & 56.8 & 2.0 \\ 0386 & \text { Selenium } & 53.1 & 2.0 \\ 06491 & \text { Arsenic } & 1.0 & 10.0 \\ 06491 & \text { Lead } & 1.0 & 3.0 \\ \text { B217289 } & \text { Arsenic } & 2.0 & 2.0\end{array}$

Colluvium

41591

Arsenic

2.0

2.0

a. Results column refers to laboratory results, showing analysis accuracy or equipment accuracy.

b. Contract detection limit refers to the detection limit specificed by RFP with the independent testing laboratory.

c. Reported value was determined by method of standard additions.

d. Second quarter results; abandoned in second half of 1993.

e. Acceptable with qualifications. 
Table 3.4-5

Total Radionuclides Greater Than Background Upper Tolerance Limits Detected in Boundary Wells

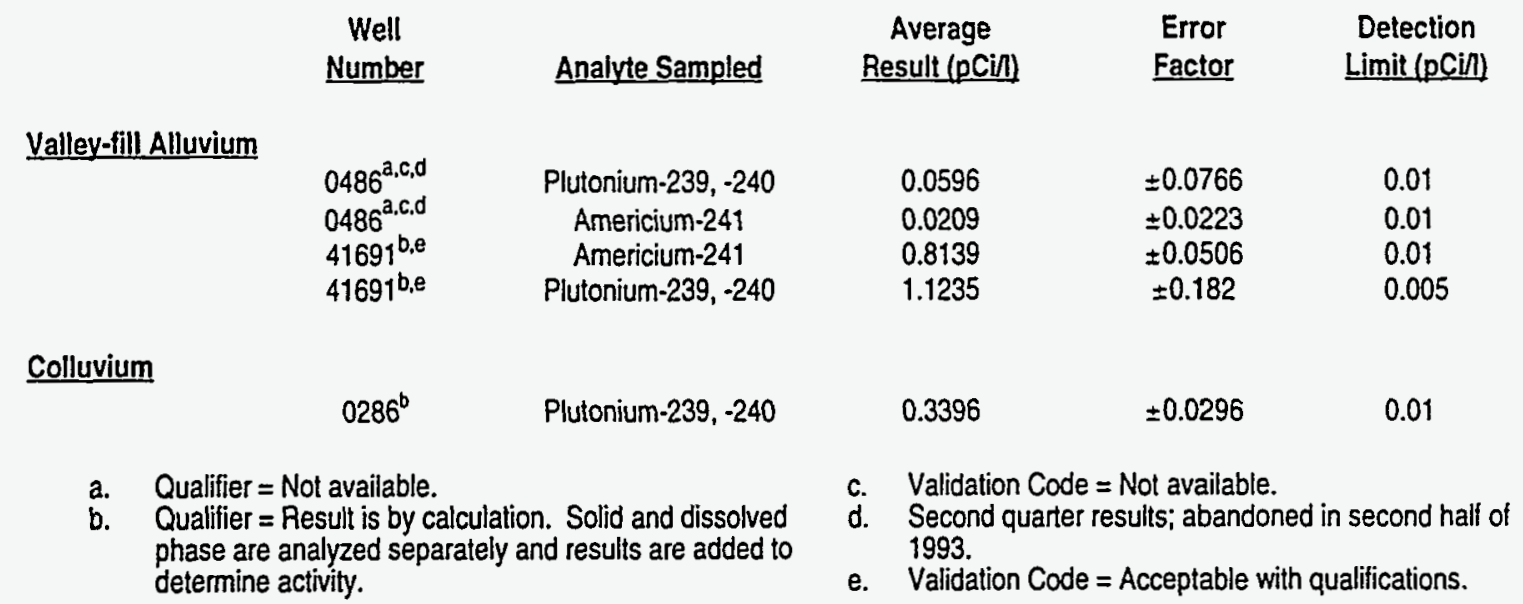

with qualifications (Validation Code is provided in the footnotes of Table 3.4-5). Results were calculated by the laboratory in two cases (Lab Qualifier in Table 3.4-5). Wells \#0486 and \#41691 are screened in the shallow valley-fill alluvium (from approximately 4 to 15 feet below the surface) and are located next to one another in the Walnut Creek drainage. Low levels of plutonium-239, -240 are known to exist in sediment along this reach of Walnut Creek. The plutonium detected in Wells \#0486 and \#41691 is believed to be associated with the stream sediments that may have been a source of high suspended solids found in the wells and/or surficial soil contamination.

Groundwater quality in the colluvium is monitored in two boundary wells ( $\# 0286$ and \#41591). No VOCs were detected in samples of colluvial groundwater. The only dissolved metal of interest detected was arsenic in Well \#41591 at the detection limit. No dissolved radionuclides were detected above background upper tolerance limits in the colluvium. These results suggest that groundwater in the colluvium is unaffected by RFP activities.

Wells \#0386, \#06491, and \#B217289 monitor groundwater contained in the Arapahoe and Laramie Formation sandstones, siltstones, and claystones. Several dissolved metals, including selenium. arsenic, and lead, were detected at levels just above the detection limit.

Selenium is naturally occurring, and measurable levels in 
Well \#0386 may represent natural differences in concentrations at different locations. Several dissolved radionuclides. including isotopes of uranium and gross alpha, were measured at activities above background upper tolerance limits. Detections of dissolved radionuclides in the deeper hydrostratigraphic units may reflect the variability of uranium concentrations in natural materials and not represent contamination. Water-quality results for Arapahoe and Laramie Formation materials suggest that operations at RFP have not impacted these hydrostratigraphic units, and that detections of metals and radionuclides reflect natural variability within native materials.

Results of groundwater monitoring in the Indiana Street boundary wells during 1993 suggest that RFP activities have had little effect on groundwater quality along the eastern border of RFP. VOCs and dissolved metals of concern that were detected in the valley-fill alluvium, colluvium, and Arapahoe and Laramie Formations exhibited concentrations only slightly above detection limits. Radionuclides detected in boundary wells along Walnut Creek are believed to be associated with high suspended solids in those wells derived from stream sediments. There is no direct hydraulic connection between this shallow alluvial aquifer and deeper aquifers in the Denver Basin used for domestic water supplies. Continued quarterly monitoring of boundary wells will be performed and results will be used to assess potential changes in concentrations for analytes of interest. 


\section{Environmental Moniłoring Programs}

\subsection{Soil Monitoring}

Soll Monitoring is conducted annually at Rocky Flats to evaluate any changes in plutonium concentrations that might occur through soll resuspension or other mechanisms, and to compare plutonium concentrations in soils from year to year. The data acquired from soil sampling are provided in this section. 
OVERVIEW

RESULTS
The Soil Monitoring Program at RFP has been conducted since 1972, with the exception of the years 1978 through 1983. Soils were sampled at RFP in December 1993 at 40 sites located within concentric circles, approximately $1.6-$ and $3.2-\mathrm{km}$ radii ( 1 and 2 miles) from the center of RFP (Figure 3.5-1). Along each circle, sampling locations were spaced at $18^{\circ}$ increments and designated accordingly (e.g., location 1-018 refers to the inner circle [\#1] at $18^{\circ}$ northeast). The soil samples were collected by driving a 10 - by 10 -centimeter (4- by 4 -inch) cutting tool 5 centimeters ( 2 inches) deep into undisturbed soil. The soil sample within the tool cavity was collected and placed into a new 1-gallon stainless steel can. Five subsamples were collected from the corners and the center of a 1-meter square for soil radionuclides analysis. Laboratory analysis was performed to determine the plutonium concentration, expressed as picocuries per gram ( $\mathrm{pCi} / \mathrm{g}$ ).

Soil plutonium concentrations for 1984 through 1993 are presented in Table 3.5-1. Figure 3.5-1 depicts the location of the soil sample sites, as well as the mean and standard deviation of soil plutonium concentrations from 1984 through 1993. Samples taken in 1993 from the inner concentric circle (1.6 km radius) ranged from 0.04 $\mathrm{pCi} / \mathrm{g}$ to $18.8 \mathrm{pCi} / \mathrm{g}$. In previous years, the highest soil plutonium concentration was found at sites 1-090 and 1108 (Figure 3.5-1). Since the 1990 annual soil sampling, the site at 1-090 has been relocated approximately 200 meters to the north. The older site is located in an area currently under intensive study as part of the IAG.

Samples from the outer concentric circle ( $3.2 \mathrm{~km}$ radius) ranged from $0.02 \mathrm{pCi} / \mathrm{g}$ to $4.5 \mathrm{pCi} / \mathrm{g}$. The highest plutonium concentrations were found in soil samples taken from the eastern portion of the buffer zone. These sample locations are east and southeast of the major source of plutonium contamination in the soil environment at RFP. Plutonium contamination probably originated from the area known as the $903 \mathrm{Pad}$ (OU 2), where steel drums were used to store plutonium-contaminated industrial oils from 1958 to 1968 . Leakage from these drums contaminated surface soils and plants. Plutonium particles entrapped in the fine fraction of top soil horizons were subsequently airlifted by winds and deposited on soils in an east and southeast-trending plume (KRE70). 


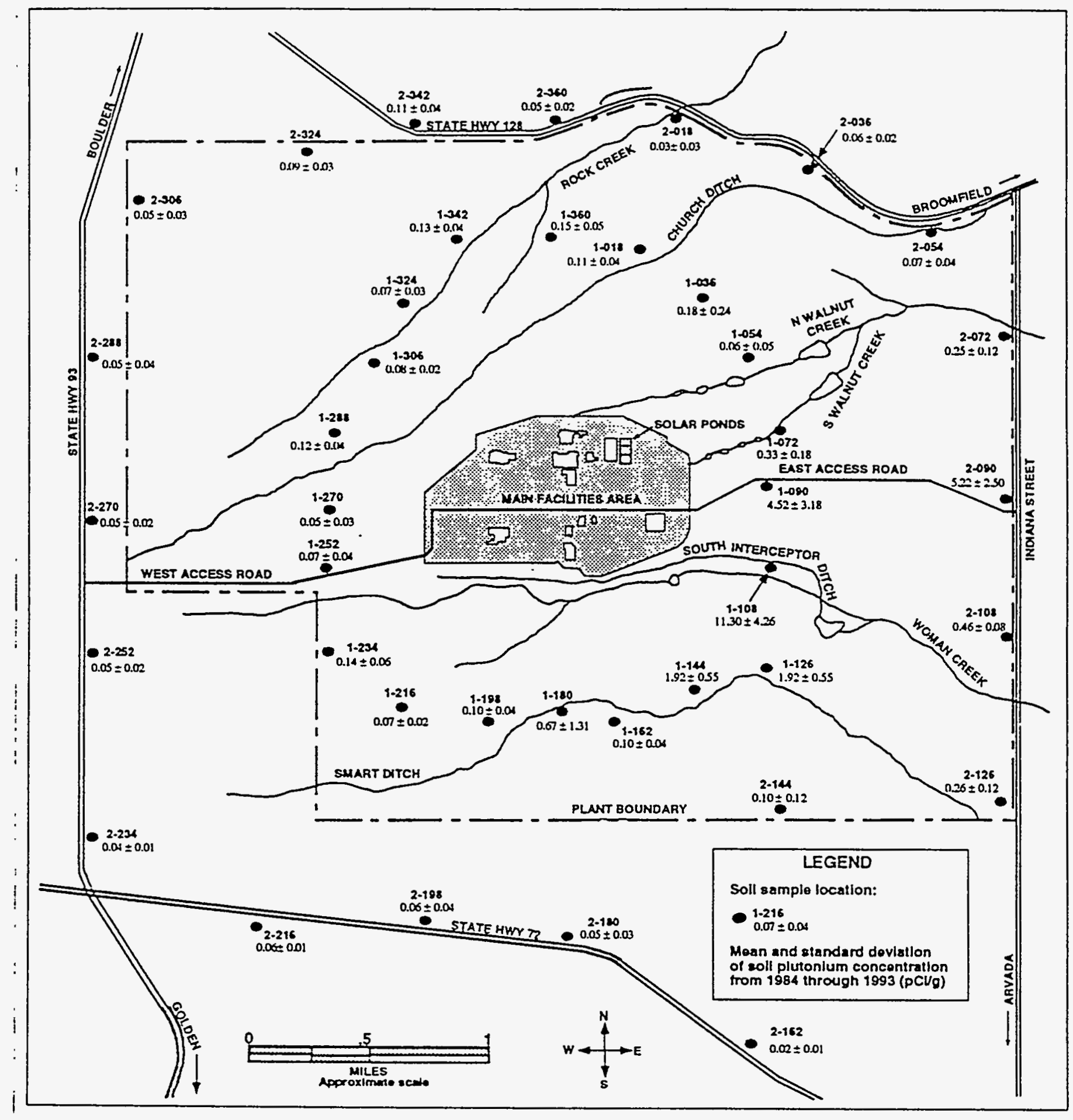

Figure 3.5-1. Soil Sampling Locations 
The plutonium concentrations in soils east and southeast of the 903 Pad Area varied somewhat between years. Each monitoring site was adequately sized ( 30 by 30 meters) to allow annual selection of nonoverlapping sample areas. Since the sampling location varied between years, small microtopographical variation was introduced, which affected wind deposition and resuspension rates of plutonium. In addition, natural variability in erosional and faunal activities, as well as sampling and analytical error, contributed to the observed variability. Other investigators (PIN80) have observed high variability in soil plutonium concentrations in other contaminated sites, especially near the release source. Investigators ascribed these variations in plutonium-239, -240 to varying distances from point of release ( 75 percent), microtopographical variations (20 percent), and sampling error, which included subsampling and analytical error (5 percent). Variability in plutonium concentrations in soils taken from the two radial grids at $18^{\circ}$ to $36^{\circ}$ and $162^{\circ}$ to $360^{\circ}$ was extremely small.

Background Soils Characterization Program
Baseline soils data from background areas are needed to evaluate the effects of RFP on the soils at the site. Many materials, such as uranium and other metals that are thought of as contaminants generated by RFP, may be natural components of the soil to a certain extent. Other constituents such as plutonium and selected organic compounds are also distributed over the earth. Generally, these constituents are attributable to atmospheric fallout and other nonpoint industrial sources. The objective of the Background Soils Characterization Project is to determine the background concentrations of the various soil constituents accurately. These values will then be used as a comparison to the concentrations that are found in and around RFP.

Background locations which have topography, soil type, and climate similar to the RFP have been selected. These locations will be sampled during the 1994 field season. The background information that is collected will be compared with similar data that has been collected at RFP. These comparisons will allow an accurate assessment of the nature and extent of contamination at the site. Similarly, these data will be utilized in the determination of risk as well as in the evaluation of remedial action. 
Table 3.5-1

Plutonium Concentration in Soil Samples at 1 and 2 Miles from the Plant Center

Inner Circle:

\begin{tabular}{|c|c|c|c|c|c|c|c|c|c|c|c|c|c|c|c|}
\hline \multirow{2}{*}{$\begin{array}{l}\text { Location } \\
1.018\end{array}$} & \multicolumn{3}{|c|}{$\begin{array}{c}1984 \\
\mathrm{Pu}\end{array}$} & $\mathrm{pCi}$ & $\begin{array}{l}985 \\
\mathrm{Pu}\end{array}$ & & & $\begin{array}{l}1986 \\
\mathrm{Pu}\end{array}$ & & & $\begin{array}{l}1987 \\
\mathrm{Pu} \\
1 \mathrm{a}^{\mathrm{a}, \mathrm{b}}\end{array}$ & & & $\begin{array}{r}198 \\
\mathrm{Pu}\end{array}$ & \\
\hline & 0.08 & \pm & 0.02 & 0.15 & \pm & $0.02 d$ & 0.15 & \pm & 0.02 & 0.18 & \pm & 0.02 & 0.10 & \pm & 0.01 \\
\hline $1-036$ & 0.03 & \pm & 0.01 & 0.08 & \pm & 0.01 & 0.10 & \pm & 0.02 & 0.06 & \pm & 0.01 & 0.88 & \pm & 0.01 \\
\hline $1-054$ & 0.00 & \pm & 0.01 & 0.02 & \pm & 0.01 & 0.04 & \pm & 0.01 & 0.04 & \pm & 0.01 & 0.03 & \pm & 0.01 \\
\hline $1-072$ & 0.6 & \pm & 0.05 & 0.32 & \pm & 0.03 & 0.63 & \pm & 0.06 & 0.51 & \pm & 0.05 & 0.37 & \pm & 0.04 \\
\hline $1-090$ & 7.7 & \pm & 0.5 & 1.00 & \pm & 0.09 & 7.40 & \pm & 0.62 & 7.05 & \pm & 0.77 & 10.6 & $=$ & 0.98 \\
\hline $1-108$ & 15.0 & \pm & 0.9 & 13.0 & \pm & 1.30 & 15.0 & \pm & 1.40 & 2.37 & \pm & 0.21 & 10.4 & \pm & 0.94 \\
\hline $1-126$ & 2.1 & \pm & 0.1 & 1.90 & \pm & 0.17 & 1.90 & \pm & 0.18 & 2.75 & \pm & 0.28 & 1.55 & $=$ & 0.14 \\
\hline $1-144$ & 0.29 & \pm & 0.03 & 0.32 & \pm & 0.03 & 0.27 & \pm & 0.02 & 0.36 & \pm & 0.04 & 0.20 & \pm & 0.02 \\
\hline $1-162$ & 0.14 & \pm & 0.02 & 0.10 & \pm & 0.01 & 0.08 & \pm & 0.01 & 0.17 & \pm & 0.02 & 0.09 & \pm & 0.01 \\
\hline $1-180$ & 0.09 & \pm & 0.02 & 0.06 & \pm & 0.01 & 0.06 & \pm & 0.01 & 0.10 & \pm & 0.01 & 0.06 & \pm & 0.01 \\
\hline $1-198$ & 0.22 & \pm & 0.03 & 0.16 & \pm & 0.02 & 0.16 & \pm & 0.02 & 0.21 & \pm & 0.02 & 0.10 & \pm & 0.01 \\
\hline $1-216$ & 0.05 & \pm & 0.02 & 0.05 & \pm & 0.01 & 0.10 & \pm & 0.01 & 0.16 & \pm & 0.02 & 0.05 & \pm & 0.01 \\
\hline $1-234$ & 0.13 & \pm & 0.02 & 0.05 & \pm & 0.01 & 0.04 & \pm & 0.01 & 0.05 & \pm & 0.01 & 0.05 & \pm & 0.01 \\
\hline $1-252$ & 0.17 & \pm & 0.02 & 0.14 & \pm & 0.02 & 0.11 & \pm & 0.01 & 0.21 & \pm & 0.03 & 0.09 & \pm & 0.01 \\
\hline $1-270$ & 0.06 & \pm & 0.02 & 0.07 & \pm & 0.01 & 0.08 & \pm & 0.01 & 0.09 & \pm & 0.01 & 0.07 & \pm & 0.01 \\
\hline $1-288$ & 0.04 & \pm & 0.01 & 0.05 & \pm & 0.01 & 0.05 & \pm & 0.01 & 0.06 & \pm & 0.01 & 0.03 & \pm & 0.01 \\
\hline $1-306$ & 0.14 & \pm & 0.02 & 0.09 & \pm & 0.01 & 0.17 & \pm & 0.02 & 0.21 & \pm & 0.03 & 0.12 & \pm & 0.01 \\
\hline $1-324$ & 0.13 & \pm & 0.02 & 0.15 & \pm & 0.02 & 0.21 & \pm & 0.02 & 0.24 & \pm & 0.03 & 0.16 & \pm & 0.02 \\
\hline $1-342$ & 0.04 & \pm & 0.01 & 0.02 & \pm & 0.01 & 0.03 & \pm & 0.01 & 0.03 & \pm & 0.01 & 0.02 & \pm & 0.01 \\
\hline $1-360$ & 0.10 & \pm & 0.02 & 0.11 & \pm & 0.01 & 0.19 & \pm & 0.02 & 0.16 & \pm & 0.02 & 0.12 & \pm & 0.02 \\
\hline
\end{tabular}

Outer Circle:

\begin{tabular}{|c|c|c|c|c|c|c|c|c|c|c|c|c|c|c|c|}
\hline $2-018$ & 0.00 & \pm & 0.01 & 0.04 & \pm & 0.01 & 0.03 & \pm & 0.01 & 0.04 & \pm & 0.01 & 0.02 & \pm & 0.00 \\
\hline $2-036$ & 0.02 & $=$ & 0.01 & 0.02 & \pm & 0.01 & 0.07 & \pm & 0.01 & 0.10 & \pm & 0.01 & 0.07 & \pm & 0.01 \\
\hline $2-054$ & 0.03 & \pm & 0.01 & 0.03 & \pm & 0.01 & 0.05 & \pm & 0.01 & 0.10 & \pm & 0.01 & 0.03 & \pm & 0.01 \\
\hline $2-072$ & 0.4 & $=$ & 0.04 & 0.33 & \pm & 0.03 & 0.23 & \pm & 0.02 & 0.36 & \pm & 0.04 & 0.11 & \pm & 0.01 \\
\hline $2-090$ & 10.0 & \pm & 0.6 & 2.50 & \pm & 0.25 & 5.30 & \pm & 0.48 & 4.48 & \pm & 0.52 & 7.12 & \pm & 0.67 \\
\hline $2-108$ & 0.46 & \pm & 0.04 & 0.41 & \pm & 0.04 & 0.46 & \pm & 0.04 & 0.57 & \pm & 0.06 & 0.47 & \pm & 0.05 \\
\hline $2-126$ & 0.14 & \pm & 0.02 & 0.42 & \pm & 0.04 & 0.44 & \pm & 0.05 & 0.40 & \pm & 0.04 & 0.03 & \pm & 0.01 \\
\hline $2-144$ & 0.02 & \pm & 0.01 & 0.04 & \pm & 0.01 & 0.04 & \pm & 0.01 & 0.08 & \pm & 0.01 & 0.35 & \pm & 0.03 \\
\hline $2-162$ & 0.00 & \pm & 0.01 & 0.01 & \pm & 0.00 & 0.02 & \pm & 0.01 & 0.03 & \pm & 0.01 & 0.02 & \pm & 0.01 \\
\hline $2-180$ & 0.02 & \pm & 0.01 & 0.11 & \pm & 0.01 & 0.04 & \pm & 0.01 & 0.03 & \pm & 0.01 & 0.03 & \pm & 0.01 \\
\hline $2-198$ & 0.05 & $=$ & 0.02 & 0.02 & \pm & 0.01 & 0.08 & \pm & 0.01 & 0.14 & \pm & 0.02 & 0.10 & \pm & 0.01 \\
\hline $2-216$ & 0.04 & \pm & 0.01 & 0.04 & \pm & 0.01 & 0.06 & \pm & 0.01 & 0.07 & \pm & 0.01 & 0.07 & \pm & 0.01 \\
\hline $2-234$ & 0.04 & \pm & 0.01 & 0.05 & \pm & 0.01 & 0.05 & \pm & 0.01 & 0.07 & \pm & 0.01 & 0.03 & \pm & 0.01 \\
\hline $2-252$ & 0.09 & \pm & 0.01 & 0.04 & \pm & 0.01 & 0.07 & \pm & 0.01 & 0.06 & \pm & 0.01 & 0.04 & \pm & 0.01 \\
\hline $2-270$ & 0.04 & \pm & 0.01 & 0.04 & \pm & 0.01 & 0.06 & \pm & 0.01 & 0.08 & \pm & 0.01 & 0.06 & \pm & 0.01 \\
\hline $2-288$ & 0.01 & \pm & 0.01 & 0.04 & \pm & 0.01 & 0.05 & \pm & 0.01 & 0.13 & \pm & 0.02 & 0.07 & \pm & 0.01 \\
\hline $2 \cdot 306$ & 0.00 & $=$ & 0.01 & 0.06 & \pm & 0.01 & 0.02 & \pm & 0.01 & 0.08 & \pm & 0.01 & 0.02 & \pm & 0.00 \\
\hline $2-324$ & 0.08 & \pm & 0.02 & 0.04 & \pm & 0.01 & 0.09 & \pm & 0.01 & 0.08 & \pm & 0.01 & 0.14 & \pm & 0.02 \\
\hline $2-342$ & 0.13 & \pm & 0.02 & 0.13 & \pm & 0.01 & 0.12 & \pm & 0.01 & 0.14 & \pm & 0.02 & 0.10 & \pm & 0.01 \\
\hline $2-360$ & 0.02 & \pm & 0.01 & 0.09 & \pm & 0.01 & 0.05 & \pm & 0.01 & 0.08 & \pm & 0.01 & 0.05 & \pm & 0.01 \\
\hline
\end{tabular}

a. Not blank corrected.

b. Samples to a depth of $5 \mathrm{~cm}$.

c. Concentrations are for the fraction of soil measuring less than $2 \mathrm{~mm}$ diameter.

d. Error ierm represents two standard deviations. 


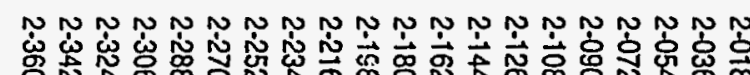

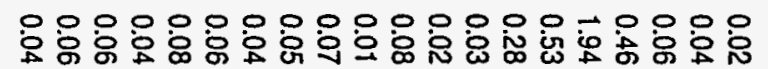

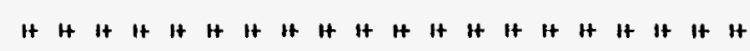

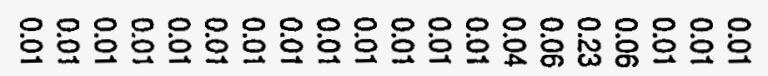

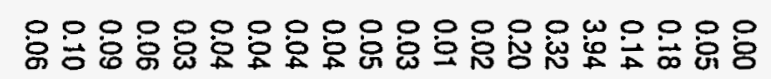
It it It it it it it it it it it it it it $\mathrm{H}$ it it it it it

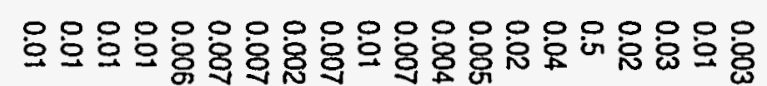

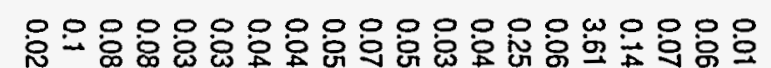
it it it it it It it it it it it it it it it it it it it it

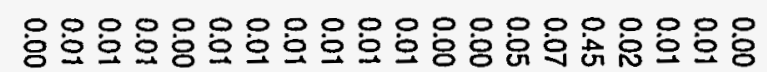

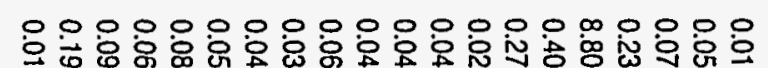
it it it it it He It it it it it it it it it it it it It it

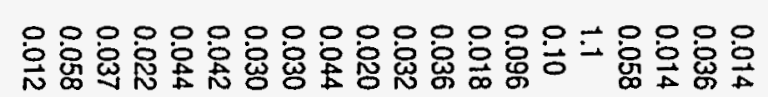

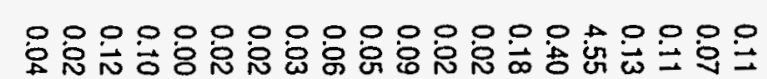
it it it it it it it it it it it it it it it it it it it it

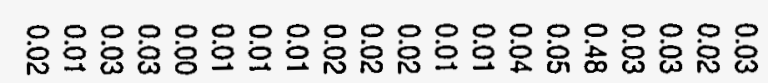

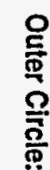

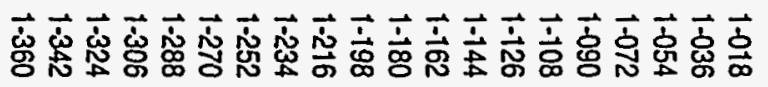

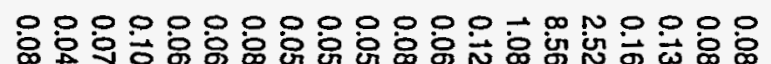

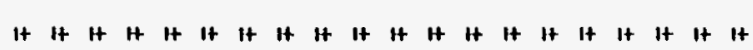

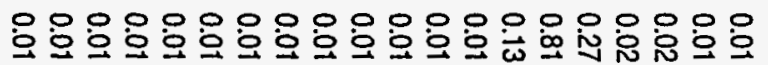

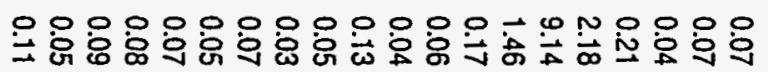
it it it it it it it it it it it it it it it it it it it it

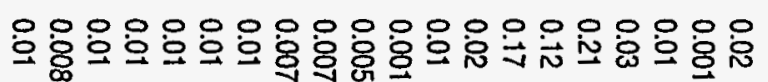

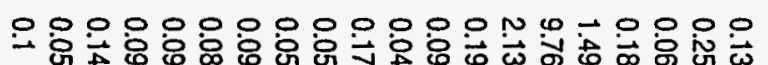
it it it it it it it it it it it it it it it it it it it it

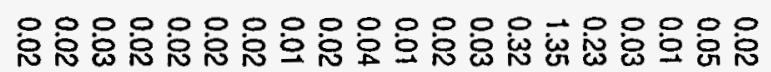

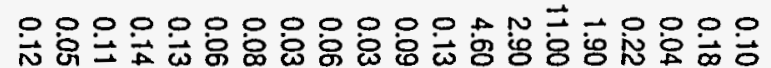
it it it it it it it it it it it it it + it it it it it it

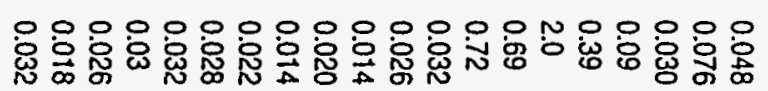

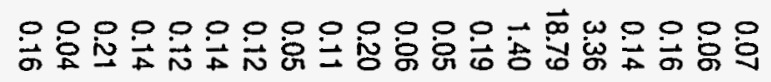
it it it it it it it it it it it it it it it it it it it h

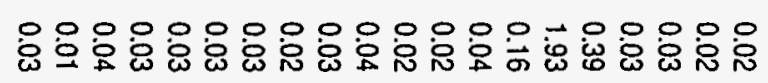


Fate and Transport of Plutonium and Americium Residing in the Soils at RFP
Past $u$ aste storage practices at RFP have contaminated the soi! in some areas with plutonium and americium. It has been accepted that once actinides are deposited on the soil surface. they are largely immobile. However, soil studies at other sites indicate that plutonium and americium may eventually leach from the surface soil and move to deeper locations. If actinide transport is significant, it will affect the cost and scheduling of remediation.

To determine the soil physicochemical properties that control the behavior of fate and transport of actinides, a soil water monitoring system was installed. Figures $3.5-2,3.5-3$, and $3.5-4$ show the monitoring system location, the data collection process, and the pit instrumentation, respectively. The soil water monitoring system is designed to collect real-time data on interstitial waters, water content, matric potential, soil temperature, and precipitation. By measuring these physical properties, collecting soil solutions, and analyzing for actinide activity, transport of the actinides can be assessed.

Analysis of vertical flow utilizing natural and simulated rainfall events indicates that the precipitation flows through the soil profile in a matter of hours. This minimal residence time inhibits reactions between the soil, water, actinides. and other constituents that may be present. The soil water monitoring system also suggests that preferential water flow occurs under both saturated and unsaturated conditions.

Analysis of information and data collected in this program indicate that the actinide concentrations are significantly higher in the upper 30 centimeters of the soil than in lower sections of the soil. Validation of this type of information using the soil water monitoring system will support sitewide as well as OU remediation activities. 


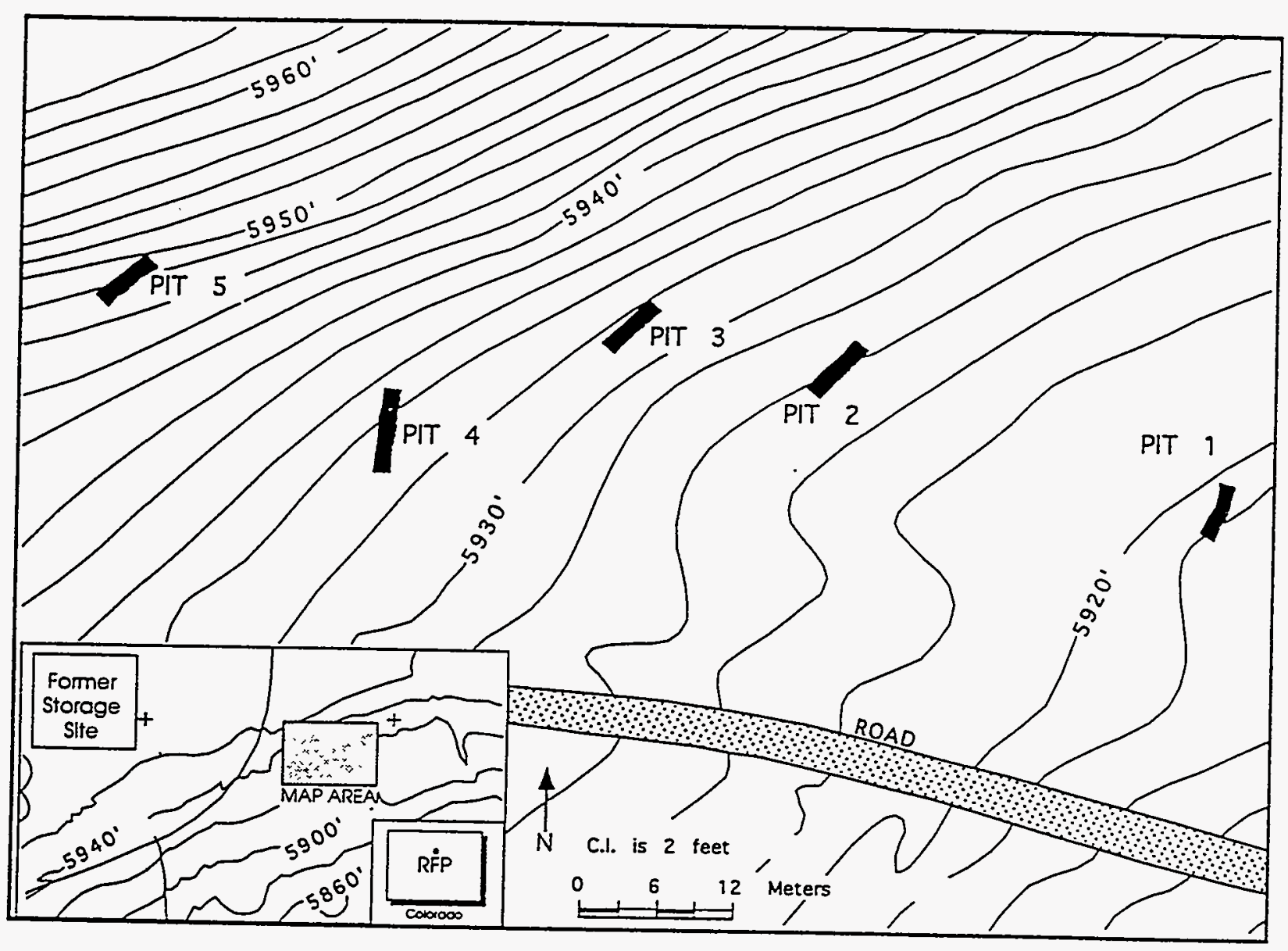

Figure 3.5-2. Location of Soil Pits 


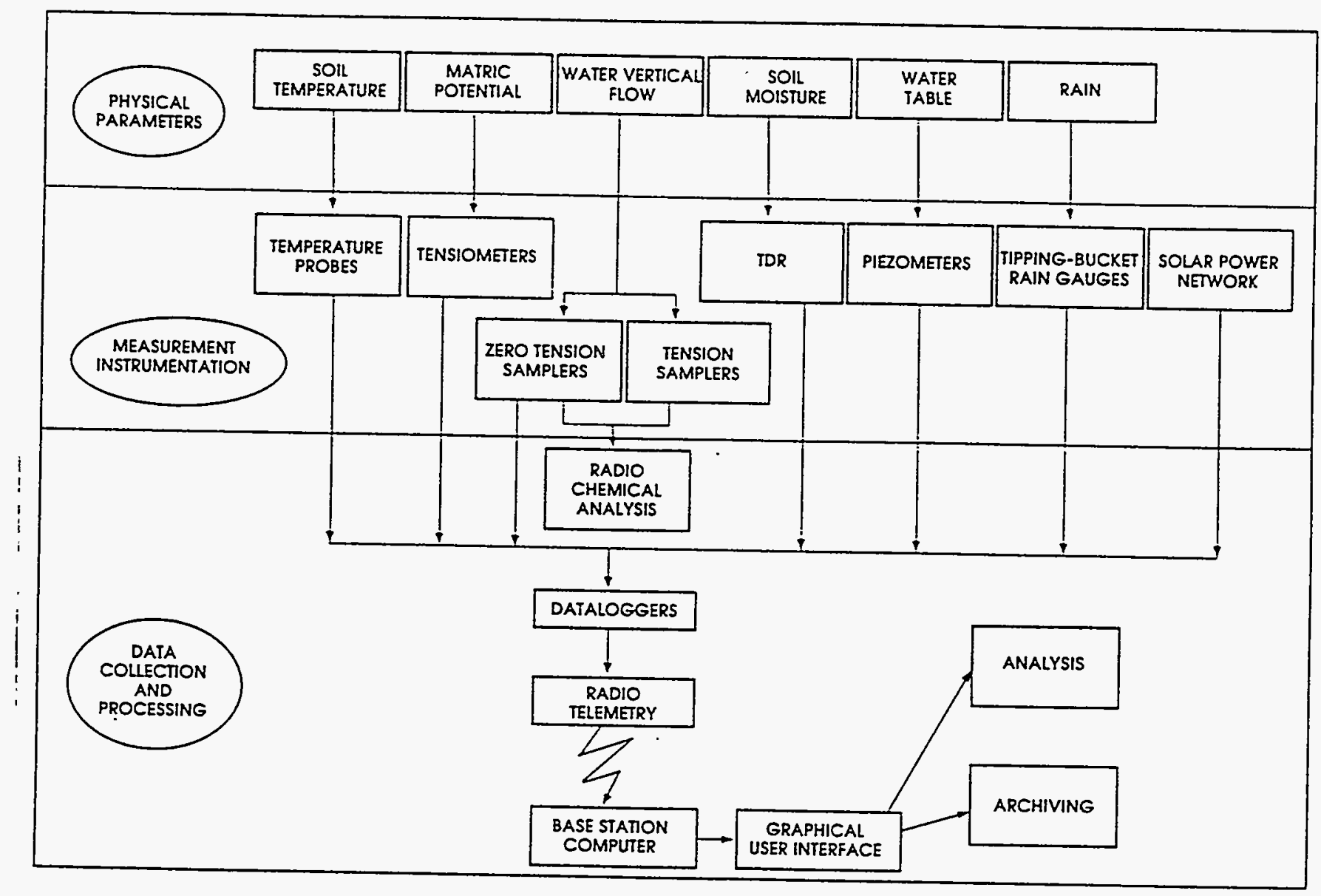

Figure 3.5-3. Data Collection and Processing Schematic 

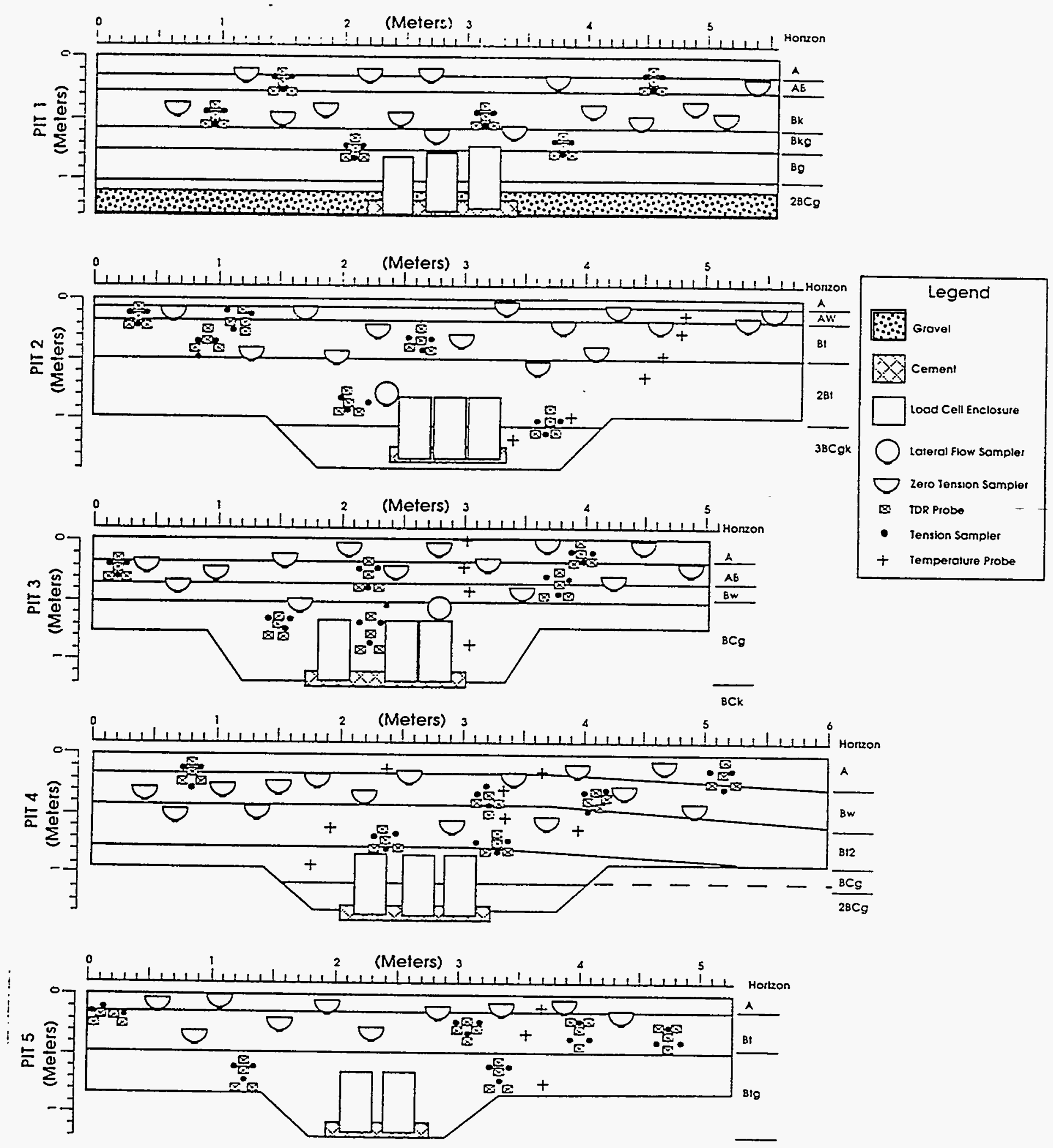

Figure 3.5-4. Soil Pit Instrumentation 
Rocky Flats Plant

Site Environmental Report for 1993 
$\bullet$

\section{Environmental Monitoring Programs}

\subsection{Ecological Studies}

Ecological studies are performed to assess the short- and long-term implications of impacts to ecological resources that have occurred, are occurring, or may have occurred at the Rocky Flats Plant as a result of past operations. Ecological studies also are performed to support compliance with all applicable biological regulations. A detailed description of current and future ecological studies is provided in the following pages. 
$\because \quad$. 
OVERVIEW
Ecological studies are an ongoing part of routine operations at RFP. These studies focus on the presence, abundance, and spatial distribution of onsite plant and animal life (biota) and are fundamental in identifying adverse or positive impacts of RFP activities relative to NEPA and other state and federal regulations and guidelines. Specialized studies, including floodplain and wetland identification, assist in investigating perturbations to the unique ecological aspects of the RFP.

The most recent comprehensive study of the environment at RFP was the Baseline Biological Characterization of the Terrestrial and Aquatic Habitats at the Rocky Flats Plant - Final Report (DOE92c). Current information on specific natural resources at RFP results from studies such as the Threatened and Endangered Species Evaluation, Rocky Flats Plantsite (EGG93d). The scope of the current ecological studies program has been determined by public demand for current information on RFP impacts and increased emphasis on requirements for NEPA pursuant to 10 CFR Part 1021. In addition, ecological risk assessment determinations are required by federal statutes, such as CERCLA and RCRA. The ecology program at RFP consists of three programs: the Ecological Monitoring Program (EcMP), the Resource Protection Program (RPP), and the Environmental Evaluation (EE) Program.

\section{ECOLOGICAL MONITORING PROGRAM}

A formalized ecological monitoring program, the EcMP, was initiated in 1992 to meet a growing priority for comprehensive, long-term ecological information concerning the plantsite. Primary goals of the EcMP are to (1) thoroughly assess trends in terrestrial and aquatic media, (2) demonstrate compliance with applicable federal, state, and local environmental regulations, (3) confirm adherence to ecological aspects of DOE environmental protection policies, (4) support riskbased, cost-effective environmental management decisions, and (5) monitor ecological resources both before and after remedial activities have been implemented.

In 1993, the first full season of sampling under the new program, the EcMP gathered baseline ecological data from potentially impacted and nonimpacted areas using standardized methods established by the Environmental Monitoring and Assessment Division's Operating 
Manual. Vol. 5: Ecology (5-2120-OPS-EE). Much of the 1993 sampling took place in the nonimpacted areas in the Buffer Zone to assess baseline conditions. Samples were also obtained from sites in Operable Unit (OU) 11 that were potentially contaminated with nitrates to allow for valid comparisons between these sites to determine both ecological exposure and effects assessments.

The following seven technical modules and databases were developed in the initial year of the EcMP: Terrestrial Vegetation, Plant Nutrients, Aquatic Ecology, Small Mammals, Soil Physical and Chemical Properties, Soil Invertebrates, and Ecosystem Functions.

Data collected under this program constitute a highly integrated and high quality data set that describes the ecology of the RFP Buffer Zone. The level of detail combined with the integration of so many ecological subdisciplines is unusual, especially for nonresearch studies. These data and their interpretation provide a good ecological understanding of potential reference sites for IAG compliance. All data will be stored in an ecological database, as well as achieved in the Rocky Flats Environmental Database System (RFEDS), and will be available for other purposes such as Feasibility Studies, Future Land Use Studies, Ecological Risk Assessments, and compliance with Natural Resource Damage Assessments (NRDA) under 43 CFR, Part 11 (EPA92).

The NRDA regulations are mandates by which federal and state appointed trustees assess "injury" to natural resources and pursue compensation or "damages" on behalf of the public. DOE has a dual role at its sites. The agency serves both as a CERCLA response agency and as the primary federal Natural Resource Trustee.

Although statistical analyses are not complete, sound preliminary observations can be made. The plant communities in the Buffer Zone appear to have a diversity of plant species. reflecting the wide range of habitats available at RFP. Dominant species, based on herbaceous production data, vary considerably among the 12 study sites. Metals and nutrient elements in plant tissue are within acceptable phytotoxicity standards for agricultural plants, and species that bioaccumulate and 
exclude various elements have been identified. The small mammal community is dominated by the deer mouse (Peromyscus maniculatus) in all habitats. A new species was also captured, the olive-backed pocket mouse (Perognathus fasciatus), as well as a single Preble's Meadow jumping mouse (Zapus hudsonius preblei), a Colorado species of concern. Radiation screening of surface soil from several sites in the Buffer Zone has found total activity (alpha + beta) to range from 29 to $76 \mathrm{pCi} / \mathrm{g}$, levels that are believed to be too low to cause ecological effects. Because of such low levels, Buffer Zone soils were excluded from further screening in 1993 by Radiological Engineering.

At this time, no effects on Buffer Zone ecosystems due to RFP activities have been documented. The preliminary picture of the RFP is that of a healthy, diverse, protected area that supports a unique combination of fauna and flora in the Front Range region.

\section{RESOURCE PROTECTION PROGRAM}

Under the Resource Protection Program (RPP), biological surveys and assessments are conducted to ensure compliance with environmental regulations (Endangered Species Act; Fish and Wildlife Coordination Act; Migratory Bird Treaty Act; Bald and Golden Eagle Protection Act; State of Colorado Wildlife Statute, Title 33, Article II, Endangered Wildlife, and Article III, Threatened Wildlife) for OUs and sitewide projects (DOE91a, DOE91b, DOE91c, and DOE91d).

Three surveys related to the Endangered Species Act were conducted in August 1993 - for the Ute Ladies'Tresses, a wild orchid listed as a federal threatened species; for the Colorado Butterfly plant, a Category 2 species; and for the Preble's Meadow Jumping Mouse, a Category 2 species. No Ute Ladies'-Tresses or Colorado Butterfly plants were found, but Preble's Meadow Jumping Mice were found in riparian zones of Walnut Creek, Woman Creek, and Rock Creek.

Other wildlife surveys conducted throughout the year included: birds, breeding birds, waterfowl, migratory birds, raptors, nocturnal animals, big game camivores, and small mammals. EG\&G collaborated with the Jefferson County Open Space Department and the 
Colorato Division of Wildlife to perform a prairie dog census to identify the prey-base for the visiting eagles at Standley Lake.

In 1993, a pair of bald eagles built a nest at OU 3 near Standley Lake. The Colorado Bird Observatory was contracted to collect behavior and habitat-use data. The birds abandoned the nest in mid-March but had returned to the RFP vicinity by November 1993.

The Army Corps of Engineers completed the field portion of a Wetland Delineation Project to identify all of the wetlands on plantsite. A map and report are expected to be finalized by mid-1994. The map will aid project managers for remediation and other activities in avoiding wetland impacts.

A wetland was created in OU 1 to replace one that had been disturbed by remediation activity (installation of a french drain) at the 881 Hillside. The success of the revegetation effort on the OU 1 hillside is being monitored, and the area is being reseeded as necessary.

ENVIRONMENTAL EVALUATION PROGRAM
An Environmental Evaluation (EE) is an assessment of actual or potential adverse effects of one or more stressors on plants and animals (other than domesticated species) at hazardous waste sites. EEs of hazardous waste sites are conducted as part of the Baseline Risk Assessments required by CERCLA, which refers to EEs as Ecological Assessments.

The IAG defined the reporting of this work, identified the Individual Hazardous Substance Sites (IHSSs) and Solid Waste Management Units (SWMUs) at RFP, and grouped them into 16 OUs (see Section 4, Environmental Remediation Programs). EEs provide detailed information regarding environmental impacts associated with remedial alternatives, including the "no action" alternative. This information is used in conjunction with other analyses to determine the form, feasibility, and if required, the extent of remediation activities necessary for RFP to comply with applicable state and federal regulations.

A standardized ecological approach and individual OUspecific EE work plans provide focused investigations of potential adverse effects of contamination on the 
biotis of RFP and the surrounding area. Results of the studies are presented in the EE reports submitted as a chapter of the RCRA/CERCLA Facility Investigations/Remedial Investigations (RFI/RI) Report for each OU.

Field sampling has been completed for OUs 3 and 4, and preliminary field work completed for OU 11 .

The draft version of the OU 1 RFIRI report was submitted to DOE, EPA, and CDH for review in October 1992. Their comments are being incorporated into the final report. 
irocky flats Plant

Site Environmental Report for 1993 


\section{Environmental Remediation Programs}

Characterization and cleanup of inactive waste sites such as the 881 Hillside Area are the focus of Environmental Remediation (ER) Programs at the Rocky Flats Plant. Various environmental laws, regulations, Executive Orders, DOE Orders, and state and federal facility agreements and consent orders apply to ER activities. This section describes the various Operable Units identified at Rocky Flats and the status of remediation activities in those areas. 
The ER Program at RFP began in 1986 and has continued to grow in recent years with the FY93 program reaching $\$ 156,441,000$. The program specifically includes inactive site identification and characterization, remedial design and cleanup action, and post-closure activities of inactive radioactive, hazardous, and mixed waste sites. The primary objective of the program is to bring all known waste sites at RFP into compliance with applicable federal, state, and local environmental laws and regulations, and at the same time ensure that risks to human health and the environment are reduced to prescribed levels or eliminated entirely.

Various environmental laws, regulations, Executive Orders, DOE Orders, and state and federal facility agreements and consent orders apply to ER Programs. DOE negotiated several agreements with EPA and $\mathrm{CDH}$ that address compliance with environmental regulations, scope of work, and timetables that require DOE compliance. The legal framework that establishes the scope and schedule for projects in the ER Program is the IAG, which was signed by DOE, EPA, and CDH on January 22, 1991. EPA's Land Disposal Restrictions (LDRs) are addressed by an FFCA, while the AIP between DOE and the State of Colorado imposes additional monitoring requirements and requires acceleration of cleanup activities where contamination presents a potential threat to human health or the environment.

The IAG and its attachments address details on specific response requirements that must be met during the CERCLA and RCRA processes used to assess and remediate identified IHSSs on or adjacent to RFP. These 178 IHSSs have been grouped into 16 OUs based on cleanup priorities, waste type, and geographic location (Table 4-1). The IAG Statement of Work (SOW) provides details on the activities that must occur and the sequence of those activities to satisfy the requirements of the IAG.

As of the end of FY93, a total of 66 milestones were met, 22 were extended and met, 6 were extended to a future date, and 1 milestone was missed after the extension requested was denied for a total of 95 IAG enforceable milestones scheduled to date. The need to 
bring tine regulatory agencies to the negotiating table to develop a more workable agreement became more critical as it became apparent that 110 future IAG milestones would be met on the original IAG schedule because of increasing scope, changing requirements, and technical and policy issues. On August 12, 1993, the regulatory agencies agreed to a stop work order on portions of the baseline risk assessments for OUs 1, 2, $3,4,5,6$, and 7 . Work stopped until an agreement among the parties to the IAG is reached concerning guidance on the methodology for the baseline risk assessments and preparation of the RFI/RI Reports. DOE has approached the regulatory agencies to amend the schedules and milestones in the IAG. These negotiations are currently ongoing.

Work on the OU 1 Feasibility Study (FS) was restarted in July 1993 with an evaluation list of remediation alternatives based on the revised interpretations of the nature and extent of contamination in the final RI. The majority of the FS work could not be resumed until the revision of the risk assessment had progressed enough to determine the final Containment of Concern (COC) list. That resolution was reached and a meeting was held to begin the revision of Technical Memorandum (TM) \#10, Preliminary Remediation Goals.

The July 13, 1993 milestone for delivery of the OU 2 Draft Surface Water Field Treatability Report to the regulatory agencies was met. OU 2 is the $903 \mathrm{Pad}$, Mound, and East Trenches Area. This report was originally scheduled for completion on May 18, 1993, and was given an extension by the regulatory agencies because the regulatory agencies and RFO requested changes to the report format and project scope.

In OU 3, the Offsite Areas, the Wind Tunnel field work was completed during July 1993. The study is designed to quantitatively determine the resuspension potential of OU 3 surface soils. The resuspension potential is a component in the inhalation pathway section of the Human Health Risk Assessment (HHRA).

The OU 4 Solar Ponds Interium Measures/Interium Remedial (IM/IRA) Action July 1, 1993, milestone, Complete Building 910 Construction, was completed on schedule. This milestone was achieved upon completion of remedial construction activities necessary for Building 910 to become fully operational. 
Preparation of the Design Criteria package for accelerated pond sludge removal first formal draft of the overall project schedule was issued on August 27, 1993. The schedule was reviewed with the various plant groups that would be involved in its execution. The cleanout plan was finalized on September 7, 1993.

On September 15, 1993, the EPA and RFO presented a Superfund Innovative Technology Evaluation (SITE) demonstration. The EPA SITE project has highest priority in the ER Sitewide Treatability Program. The Colloid Polishing Filter Method (CPFM) technology was demonstrated at RFP from September 13, 1993, through September 17, 1993. The demonstration determined how effectively the CPFM technology removes certain radionuclides from ground water.

The following sections describe the 16 OUs and address the major activities conducted during 1993. Individual maps of all OUs (Figures 4-1 through 4-16) are located at the end of this section. 


\section{Table 4-1}

Organization of Individual Hazardous Substance Sites (IHSSs) into Operable Units (OUs)

$1 \quad 102,103,104,105.1,105.2,106,107,119.1,119.2,130,145$

2

3

$4 \quad 101$

$5 \quad 115,133.1,133.2,133.3,133.4,133.5,133.6,142.10,142.11,209$

$6 \quad 141,142.1,142.2,142.3,142.4,142.5,142.6,142.7,142.8,142.9,142.12,143,156.2,165,166.1,166.2,166.3$, $167.1,167.2,167.3,216.1$

7

114,203

8

$118.1,118.2,123.1,135,137,138,139.1,139.2,144,150.1,150.2,150.3,150.4,150.6,150.7,150.8,151,163.1$, 163.2. $172,173,184,188$

9

$121,122,123.2,124.1,124.2,124.3,125,126,127,132,146,147.1,149,159,215$

10

$129,170,174,175,176,177,181,182,205,206,207,208,210,213,214$

$11 \quad 168$

$12 \quad 116.1,116.2,120.1,120.2,136.1,136.2,147.2,157.2,187,189$

$13 \quad 117.1,117.2,117.3,128,134,148,152,157.1,158,169,171,186,190,191,197$

$14 \quad 131,156.1,160,161,162,164.1,164.2,164.3$

$15 \quad 178,179,180,204,211,212,217$

$16 \quad 185,192,193,194,195,196,197$

OU 1 - 881 HILLSIDE

ASSESSMENT/REMEDIATION

\section{OU Description}

The alluvial groundwater at the 881 Hillside Area, located north of Woman Creek in the southeast section of RFP, was contaminated in the 1950s, 1960s, and 1970 s with solvents and some radionuclides. Naturally occurring uranium also is present in the area. The 881 Hillside Area is almost 2 miles from the eastern, outer edge of the plant's buffer zone at Indiana Street, and poses no immediate threat to public health because it is contained within the plant's boundaries. The various IHSSs that make up OU 1 are being investigated and treated as high-priority sites because of elevated concentrations of organic compounds in shallow 
groundwater and the proximity of the contamination to a drainage system (Woman Creek) that leads to an offsite drinking water supply (Standley Lake). The selected IRA at OU 1 involved the construction of an underground drainage system called a French drain to intercept and contain contaminated groundwater flowing from the OU 1 area. The contaminated water is treated at the Building 891 treatment facility, designed for this purpose, and released onsite into the South Interceptor Ditch. The RI/FS to determine the final remedial actions is continuing in parallel with the interim activities. Depending upon future analyses, the IRAs may represent the final remedial action.

The IRA for OU 1 was completed April 1992. Approximately 1.7 million gallons of water have been treated and released through the end of FY93.

Work continued during FY93 among the regulatory agencies, DOE, and EG\&G on the Final RI Report for OU 1. Several sections of the report were reviewed: Section 4, Nature and Extent of Contaminants; Section 5, Fate and Transport of Contaminants; and Section 6, Ecological Risk Assessment and Human Health Risk Assessment. The EE and HHRA sections of the report were completed and underwent document production. In August 1993, the regulatory agencies directed all work to stop on the RI Reports. After EG\&G completed its review process of the reports in September 1993, it complied with the stop work order.

Work was stopped until parties to the IAG agree on guidance for (1) methodology for baseline risk assessment and (2) preparation of RFI/RI Reports. Work stopped for OU 1 as of June 21, 1993. Other portions of the risk assessment, including data evaluation, identification of exposure scenarios, selection of exposure parameters, and ecological effects assessment, will proceed as scheduled.

Work on the FS Report restarted in July 1993 with an evaluation of the list of remediation alternatives based on the revised interpretations of the nature and content of contamination in the Final RI. TM \#10, Preliminary Remediation Goals, was received by RFO on August 15, 1993. The revised initial screening of technologies 
and process options were reviewed. Work was progressing towards October 1993 delivery date on TM \#11, Alternative Array, by was put on hold pending the stop work in the RI Report. This submittal will be renegotiated based on the duration of the stop work.

OU 2 - 903 PAD, MOUND, AND EAST TRENCHES ASSESSMENT/REMEDIATION

OU Description
Contamination at the 903 Pad Area is largely attributed to the storage in the 1950s and 1960s of waste drums containing cutting oils and carbon tetrachloride contaminated with plutonium. The drums were removed in 1967 and 1968; however, drums that had corroded allowed hazardous and radioactive material to leak onto the surrounding soil. Additional contamination may have resulted from wind dispersion during drum removal and soil movement activities when the area was covered with an asphalt pad in 1969 to provide containment. In the 1960 s, similar barrels contaminated with uranium were stored at the Mound Area. Preliminary cleanup of the Mound Area was accomplished in 1970, and the barrels and material removed were packaged and shipped offsite as radioactive waste. The East Trenches Area was used for disposal of plutonium- and uranium-contaminated waste and sanitary sewage sludge from 1954 to 1968. Two areas adjacent to the trenches were used for spray irrigation of STP effluent, some of which may have had contaminants that were not removed by the treatment system.

A Phase I RI of OU 2 was initially completed in 1986. This was followed by an IM/IRA that provides for surface water in source areas of contamination to be collected, treated, and discharged to the surface water drainage. Operation of a field-scale treatability unit for the South Walnut Creek drainage began in May 1991.

The OU 2 IM/IRA Field Treatability Unit (FTU) has treated (through the end of FY93), approximately 18 million gallons of surface water collected from the seep stations. In the future, sampling will be reduced at the OU 2 FTU. Since most of this sampling was performed in the past to provide data for the OU 2 
Treatability Study Report (draft submitted on July 13, 1993). there is no need to continue the intense and costly sampling. Since the weekly sample taken at the effluent of the lead Granular Activated Carbon (GAC) unit is used to monitor the performance of the GAC, monitoring is still required at this location. Onsite gaschromatograph equipment will be substituted for the costly offsite examples that are currently being taken.

The July 13, 1993 delivery of the OU 2 Draft Surface Water Field Treatability Report to regulatory agencies was met. This report was originally due on May 18 , 1993 and was given an extension by the regulators due to report format and scope changes desired by the regulators and RFO.

The single IM/IRA originally planned for OU 2 was divided into two IRAs in FY90 as a result of public review of the plans and following agreement among DOE, EPA, and CDH.

A second IM/IRA was established in late 1991. This Subsurface Investigation Interium Measure/Interium Remedial Action Plan/Environmental Assessment (IM/TRAP/EA) is north of Woman Creek and encompasses the $903 \mathrm{Pad}$, the Mound Area, and the East Trenches Area of OU 2. This IR/IRAP/EA identifies and evaluates interium remedial actions for removal of residual free-phase VOC contamination from three distinct subsurface environments at OU 2. Each of the VOC-removal actions involve in situ vacuum-enhanced vapor extraction technology. The IRAs for the collection of information will aid in the selection and design of final remedial actions that address subsurface, residual free-phase VOC contamination at OU 2. The pilot test plan for the first stage of this project was delivered to the regulatory agencies on October 19, 1992. The project went into the field in the Spring of 1993 at IHSS 100, the East Trenches Area. By September 1993, the mobile vapor extraction system had been installed and operational tests had begun.

\title{
OU 3 - OFFSITE AREA
} ASSESSMENT

\author{
OU Description
}

OU 3 remedial activities are divided into two main categories. In the first category, the IAG directs activities according to CERCLA. This involves assessment of contamination in offsite IHSSs. The second category 
responds to a 1985 settlement agreement among DOE, former plant operators Rockwell International and the Dow Chemical Company, local governments, and private landowners. The 1985 Settlement Agreement requires remediation actions to reduce plutonium concentrations in areas adjacent to the eastern boundary of RFP. Remedial activities in response to the settlement agreement (deep disc plowing) began in 1985. The soil disturbed by remediation is being revegetated with limited success. The overall schedule for this activity is determined by the year-to-year success of the revegetation effort and requirements of the landowners.

The Historical Information and Preliminary Health Risk Assessment Report and Past Remedy Report for OU 3 were completed and approved by DOE and the regulatory agencies in FY91. The Past Remedy Report details the history of the remedy ordered by the United States District Court pursuant to the Settlement Agree-ment, the implementation of the remedy, and the effectiveness of the remedy. The Final Historical Information Summary and Preliminary Health Risk Assessment Report provided known data describing contamination within three offsite reservoirs: Great Western Reservoir, Standley Lake Reservoir, and Mower Reservoir.

Draft and Final Offsite Area RFI/RI Work Plans were delivered to EPA and CDH in 1991. The revised final RI Work Plan was approved by the regulatory agencies on March 17, 1992. RI field work began in May 1992. The first of three joint soil sampling events were conducted for OU 3 on March 31, 1993 with representatives from the three organizations currently conducting studies on offsite contamination: DOE, Colorado State University (CSU), and the $\mathrm{CDH}$-sponsored Health Advisory Board.

The Wind Tunnel field work was for OU 3 completed during July 1993. The study is designed to quantitatively determine the resuspension potential of OU 3 surface soils. The resuspension potential is a component in the inhalation pathway section of the HHRA.

In Mid-August 1993, the regulatory agencies agreed with the stop work on the baseline HHRA for OU 3 because subjects related to this topic could not be resolved through debate, negotiation, or formal review for approval. Work stopped until parties to the IAG 
agrec on guidance for (1) methodology for baseline risk assessment and (2) preparation of RFI/RI Reports. Work stopped for OU 2 retroactive to July 23, 1993. Other portions of the risk assessment, including evaluation, identification of exposure scenarios, selection of exposure parameters, and ecological effects assessment, will proceed as scheduled.

OU 4 - SOLAR PONDS ASSESSMENT

OU Description
OU 4 is comprised of five solar evaporation ponds: 207A, 207B series (north, center, south), and 207C. Beginning in the late 1950 s and continuing until 1986 , the ponds were used to store and evaporate low-level radioactive process water containing high concentrations of nitrates and treated acidic wastes. The sludge and sediments that resulted from the process were periodically removed and disposed at the Nevada Test Site (NTS).

As technology improved through the 1960s and 1970s, the ponds were relined with various upgraded materials; however, leakage from the ponds into the soil and groundwater was detected. Interceptor trenches were installed in 1971 to collect and recycle groundwater contaminated by the ponds and to prevent natural seepage and pond leakage from entering North Walnut Creek. In 1981, these trenches were replaced by the current and larger Interceptor Trench System (ITS), which recycles approximately 4 million gallons of groundwater each year back into the solar evaporation ponds.

No additional process water has been pumped into the ponds since 1986. However, the ITS collected and returned groundwater into the solar evaporation ponds until the new storage tanks were completed and placed in operation in April 1993. Once the tanks were installed, contaminated groundwater was no longer placed into the ponds. This placement of water into the ponds had been occurring without meeting LDRs and Minimum Technology Requirements of RCRA. A new, dedicated Building 910 evaporation-treatment facility became operational in July 1993. This building will process water stored in the modular tanks. 
The Solar Evaporation Ponds Project is composed of four subprojects: (1) pond sludge processing by means of the AIP between RFO and CDH; (2) a water management/treatment by means of the IM/IRA Decision Document signed by EPA, CDH, and RFO; (3) the OU 4 assessment and remediation by means of the IAG, which identified the ponds as 1 of 16 OUs to be remediated at RFP and incorporated the 1988 Ponds-Closure Plan submitted by RFO to the regulators: and (4) pad operations and storage activities that are necessary precursors to the OU 4 assessment and remediation (pad operations are necessary support activities at least until the pond sludge waste is disposed.)

The four subprojects were planned to close the ponds and remediate the ponds area. In chronological sequence, the project was scoped to (1) remove water from the ponds, (2) provide a treatment facility to replace the ponds as evaporation-treatment and storage units for pond-related contamination groundwater, (3) remove and dispose of pond sludge in compliance with all regulations such as the LDRs of RCRA, (4) assess the nature and extent of contamination at the ponds; (5) complete a RCRA closure of the impoundments; and (6) remediate the ponds as needed.

The April 1993 IM/IRA was developed as a regulatory agency requirement that was out of scope from the tasks outlined in the IAG. RFO attempted to modify an existing permit for water removal and treatment for liquids on the solar ponds and groundwater collected by the ITS, but the regulatory agencies rejected permit modification and required development of an IM/IRA to document operation and use of the proposed water treatment system and provide the permitting mechanism for the system. The development and implementation of the IM/IRA precedes and overlaps the IAG scheduled Phase I RFI/RI field work.

The RCRA/CERCLA investigation Phase I field work began in FY93 and will continue through construction of the final corrective/remedial action. The technical scope to be performed by means of the IAG is funded through the OU 4 Assessment and Remediation Area, with the other areas funded to provide necessary precursor and support activities to allow that IAG scope to be completed. There is an IM/IRA scheduled in the IAG that will be completed after results are collected 
and analyzed from the Phase I RFI/RI field work. The first draft of the IAG IM/IRA is scheduled for delivery in April 1994.

In August 1993, the regulatory agencies agreed with the need to stop work on the baseline HHRA for OU 4 because subjects related to this topic could not be resolved through debate, negotiation, or formal review and approval. Work was stopped until all parties to the IAG agree on guidance for (1) methodology for baseline risk assessment and (2) preparation of RFI/RI Reports. Work stopped for OU 4 as of August 12, 1993. Other portions of the risk assessment, including data evaluation, identification of exposure scenarios, selection of exposure parameters, and ecological effects assessment, will proceed as scheduled.

OU 5 - WOMAN CREEK ASSESSMENT

\section{OU Description}

This activity encompasses assessment and remediation of 10 IHSSs in the Woman Creek drainage: Original Landfill (IHSS 115); Ash Pits (IHSS 133.1 - 1333.4); Incinerator (IHSS) 133.5); Concrete Wash Pad (IHSS 133.6); and the Detention ponds C-1 and C-2 southeast of Building 881 . Two additional surface disturbances have been identified and are located, one south of the Ash Pits and a second west of IHSS 209. These last two sites have been included in the OU 5 Work Plan. Possible contamination in this OU was caused by landfill operations, storm-water runoff into holding ponds, and ash-pit operations. Constituents in OU 5 are believed to include nitrates, plutonium, uranium, metals, beryllium, solvents, pesticides, oils. and paints. Media affected include soils, sediments, surface water, groundwater, and air resuspension.

During 1993, several additional wells were installed at OU 5 to support increased groundwater monitoring activities.

In August 1993, work on OU 5 was stopped until parties to the IAG agree on guidance for (1) methodology for the baseline risk assessment and (2) preparation of the RFI/RI Reports. The effect of the work stoppage was minimal for OU 5 because the aggregation of data and selection of contaminants of concern (COC) had not yet 
OU 6 - WALNUT CREEK ASSESSMENT

\section{OU Description}

begun. Other portions of the risk assessment, including data evaluation, identification of exposure scenarios, selection of exposure parameters, and ecological effects assessment, will proceed as scheduled.

A Cost/Productivity Improvement (PI) Program cost savings initiative was held on September 27, 1993 with the Plant Change Control Board (PCCB). Through process improvements (e.g., using screening techniques such as High Purity Germanium (HPGe) surveys and geophysical surveys rather that drilling) the cost of the boring program at IHSSs 133.1 through 133.4 was reduced.

This activity encompasses assessment and remediation in the Walnut Creek Drainage of 21 IHSSs: A-series Detention Ponds, Ponds A-1 through A-4 (IHSS 142.1 through 142.4 and 142.12); the B-series Detention Ponds, Ponds B-1 through B-5 (IHSS 142.5 through 142.9); the North, Pond, and South Area Spray Fields (IHSS 167.1, 167.2 and 167.3); the East Area Spray Field (IHSS

216.1), the Trenches A, B, and C (IHSS 166.1, 166.2 and 166.3); the Sludge Dispersal Area (IHSS 141); the Triangle Area (IHSS 165); the Old Outfall Area (IIHSS 143 ); and the Soil Dump Area (IHSS 156.2).

Completion of field operations resulted in obtaining the following samples from the IHSSs in OU 6: stream sediment, pond sediment, surface soil, subsurface soil, stream water, pond water, and groundwater.

Eleven new groundwater monitoring wells, installed in OU 6 to supplement four existing wells, were sampled each quarter for a minimum of 1 year. Geophysical surveys and radiation surveys were performed in selected areas to supplement the sampling activities.

The regulatory agencies have proposed a new IM/IRA on the operation of the RFP Ponds. If approved, this IM/IRA would affect the RFP ponds, including OU 6 , placing them under CERCLA rather than the NPDES. 
DOE requested an 11 -month extension from the EPA for the OU 6 Draft and Final Phase I RFURI Reports. The extension was requested because (1) the Work Plan was not approved on schedule, (2) the procurement process for the implementation of the Work Plan was not in the IAG schedule, (3) an approved HSP was required prior to field work and it was not included in the IAG schedule, and (4) an unexpected Organization Conflict of Interest (OCI) issue arose. The combination of all these issues lead to a late start of field operations for OU 6 .

The regulatory agencies reviewed the 11 -month extension schedule request and concluded that there was good cause for a 10-month extension for the submittal of the Draft and Final RFI/RI Reports for OU 6. RFP accepted the 10-month extension and the new milestone delivery dates for submittal of the reports are June 10, 1994 and November 18, 1994.

EPA approval of TM \#1 for OU 6 on January 8, 1993 resulted in a cost savings of approximately $\$ 1$ million. TM \#1 eliminated the following field work:

- Five bedrock monitoring wells and the associated analytical work required during drilling.

- Four quarters of groundwater sampling and associated analytical work for five monitoring wells.

- Three propane-generator-powered, continuous running ambient air monitoring stations and the associated sample analysis and maintenance.

- Radiation surveys in IHSS 143 and a portion of IHSS 165 where the areas are covered with gravel or asphalt.

TM \#1 also provided for a technically superior stream sediment and surface water sampling program that will enhance fate and transport modeling.

All soil borings and monitoring wells in the buffer zone were completed in January of 1993. TM \#3, Modeling Surface and Ground Water, and TM \#2, Exposure Scenarios, were submitted to the regulatory agencies for comments. Work continued on RFEDS tables to sort the data by IHSSs and contaminants and perform 
quality assurance (QA) activities. Data comparisons will be made against the Background Geochemical Report and upper tolerance limits (UTLs) to determine the possibility of removing some of the IHSSs from the remainder of the RI/FS process. All HPGe surveys for OU 6 were completed and the survey data processed. EE sampling is also complete. Storm event sampling of Walnut Creek was completed in May 1993.

The regulatory agencies agreed to stop work on the baseline HHRA for OU 6 . Work has stopped until parties to the IAG can agree on guidance for (1) methodology for baseline risk assessment and (2) preparation of RFI/RI Reports. Work stopped for OU 6 as of August 12,1993 . Other portions of the risk assessment, including data evaluation, identification of exposure scenarios, selection of exposure parameters, and ecological-effects assessment, will proceed as scheduled.

\section{OU 7 - PRESENT LANDFILL}

\section{OU Description}

The Present Landfill, OU 7, is located north of the plant complex on the western edge of an unnamed tributary of North Walnut Creek. OU 7 is comprised of two IHSSs. IHSS 114 includes landfill waste and leachate at the Present Landfill, soils beneath the landfill potentially contaminated with leachate, and sediments and water in the East Landfill Pond. IHSS 203 contains potentially contaminated soils at the Inactive Hazardous Waste Storage Area. The Present Landfill began operations in August 1968 and was originally constructed to provide for disposal of RFP's nonradioactive and nonhazardous wastes. In September 1973, tritium was detected in leachate from the landfill. Extensive investigations conducted in the mid-1980s on the waste being disposed at the landfill subsequently led to the identification of hazardous wastes and hazardous constituents. Although currently operating as a nonhazardous sanitary landfill, the facility is considered to be an inactive hazardous waste disposal unit undergoing RCRA closure.

Mobilization for the Phase I investigation began in September 1992 with actual drilling and sampling started in October. All Phase I investigative field work was completed in April 1993. 
A meeting was held June 8, 1993 with CDH, EPA and DOE to discuss the streamlining of OU 7 work to accelerate the IAG schedule. The strategy would integrate the Phase II Work Plan and field work with Phase I, eliminate the IM/IRA process, and move directly into the Corrective Action Decision/Record of Decision (CAD/ROD) process. The proposal will also include removing the HHRA from the Phase I RI Report. The HHRA is not required to drive the IM/RRA Decision Document because the Colorado Hazardous Waste Act (CHWA) closure requirements already mandate the IMs. This would, in effect, allow OU 7 to rescope the Phase I HHRA to include assessment of all pathways while not impacting IM/IRA work. The scope of the Phase I investigation would need to be revised so that sufficient data could be collected to support the revised HHRA. Initial feedback was positive and a formal proposal and schedule is under development.

The regulatory agencies have agreed to stop work on the baseline HHRA for OU 7. Work was stopped as of June 21,1993 until parties to the IAG agree on guidance for (1) methodology for baseline risk assessment and (2) preparation of RFI/RI Reports. Other portions of the risk assessment, including data evaluation, identification of exposure scenarios, selection of exposure parameters, and ecological effects assessment, will proceed as scheduled.

\section{OU Description}

OU 8 consists of IHSSs inside and around former production areas in the 700 Area of RFP. Contamination sources within the various IHSSs include above-ground and underground tanks, equipment washing areas, and releases inside buildings that potentially affected areas outside of buildings. Contaminants from these sources may have been introduced into the environment through spills on the ground surface, underground leakage and infiltration, and in some cases, through precipitation runoff. The chemical composition of the contaminants varies widely among the IHSSs, ranging from low-level radioactive mixed wastes to nonradioactive organic and inorganic compounds. 
During April 1992, 14 IHSSs were deleted from OU 8 and addec to OU 9 as part of an IHSS realignment pursuant to Part 32 of the IAG. The IHSS changes were recommended by the DOE in the now-approved OU 9 Phase I RFI/RI Work Plan and approved by the CDH and EPA in April 1992.

The regulatory agencies' comments submitted to RFO in January 1993 on the OU 8 Final Phise I RFURI Work Plan (dated December 1, 1992) were not extensive. The agencies' request that responses and revisions to the Work Plan be completed by February 1993 was met.

A meeting with the regulatory agencies and DOE was held on April 14, 1993 to discuss additional comments and approval status of OU 8 . Comments received at this meeting were incorporated. A major result of the this meeting was the response from the regulatory agencies on DOE's position that the "residential use scenario" for the risk assessments for the Industrial Area (IA) OUs not be used. The regulatory agencies stated that the residential use scenario must be used, and if DOE refuses to use this scenario, then approval of the OU 8 Phase I RFI/RI Work Plan will be withheld and additional enforcement action may be taken by $\mathrm{CDH}$.

The comment responsiveness summary and inserts for the Final Phase I RFIRI Work Plan for OU 8 were delivered to the regulatory agencies on August 17, 1993. The inserts resulted from comments made by $\mathrm{CDH}$ during a comment resolution meeting.

A kick-off meeting was held with the implementing subcontractor for the field work in the IA on August 4, 1992 and a follow-up meeting was held on August 26, 1993. RFO comments on the HSP were finalized by September 10,1993 and field work began on September 26, 1993.

The activities for FY94 continue to be entered into a software scheduling program, along with logic ties, to facilitate the integration of activities with the other integrated OUs $(8,9,10,12,13$, and 14). This exercise will lead into development of the scope and schedule for activities beginning in FY95 and beyond. 
OU 9 - ORIGINȦL PROCESS WASTE LINES ASSESSMENT
The Original Process Waste Lines (OPWL), OU 9, consists of a system of 57 designated pipe sections extending between 73 tanks and 24 buildings connected by 35,000 feet of buried pipeline. The pipeline transferred process wastes from points of origin to onsite treatment facilities. The system was originally placed into operation in 1952, with additions and modifications occurring through 1975 . The original system was replaced during the 1975 to 1983 period by the new process waste system. Some tanks and lines from the original system were incorporated into the new process waste system or into the fire water deluge collection system.

The original system is known to have transported or stored various aqueous process wastes containing lowlevel radioactive materials, nitrates. caustics, and acids. Small quantities of other liquids also were introduced into the system, including pickling liquor from foundry operations, medical decontamination fluids, miscellaneous laboratory liquids from Building 123, and laundry effluent from Buildings 730 and 778.

The revised Phase I RFI/RI Work Plan submitted February 25, 1992 includes inspection and sampling of the original system's tanks and pipelines that are accessible and soil sampling to determine the extent of contamination in the vadose zone. The soil sampling will be performed by installing test pits and borings where known or suspected releases occurred, near pipe joints and valves, at approximately 200 -foot intervals along the pipeline route, and by installing borings around outdoor tanks. Soil characterization studies will determine the need for soil removal and/or treatment. The results of the RFI/RI will determine the need for interim and/or final remediation activities.

OU 9 experienced a significant scope increase in April 1992 when 20 IHSSs were added to the work plan from other OUs. Fourteen IHSSs were added from OU 8 , three from OU 10 , and one each from OUs 12, 13, and 15. The Health and Safety Plan (HSP), Implementation Plan, and Field Sampling Plan (FSP) were developed during 1992. A letter contract was awarded on May 13,1993 to a subcontractor to begin the Integrated OU nonintrusive field work. 
Additiorial data compilation tasks began on July 14 , 1993. Work was prioritized as follows:

1. Preparation of TM \#1, FSP, Part 1 Outside Tanks, will not begin until after site walks and the crossreferencing of existing information in the OU 9 Work Plan and Work Plan Appendices are completed. Work on this section of TM \# 1 was accelerated in an effort to collect and ship samples to the laboratories in FY93.

2. TM \#1, FSP, Part 2 Pipelines, required gathering data from engineering drawings and other sources, posting proposed test pit locations on the maps, and verifying accessibility in the field by site walks. This section of the FSP is the second priority.

3. FSP sections dealing with soil contamination by subsurface injections are the third priority; UnderBuilding Contamination (UBC) and the Sanitary Sewer System are lowest priority.

Site walk portions of data compilation started in August 1993. This includes visiting each tank site to prepare a sketch map and indicate specific locations to take soil samples, residue samples, etc. Tanks in the 100 Area, north of 771, and east of 774, and tanks in the 500 area were visited. Tanks in the 700 Area and all of the outside tanks were completed. This data compilation will form the basis for TM \#1, Field Sampling Plan, Part 1 Tanks. Within TM \#1, Part 1, for each tank site, the following will be reconciled: Work Plan, Work Plan Appendices, IAG Table 5, Historical Release Report (HRR), and site walk results. Other information will include proposed activities for this site, which samples will be collected, where they will be collected, and which analytes will be run.

RFO notified $\mathrm{CDH}$ that IAG Milestones will not be met at OU 9. On July 16, 1993, RFO wrote a letter to $\mathrm{CDH}$, stating that the surface radiation survey, tank sampling/inspection, and additional data compilation tasks have not been completed because of limited funding in FY93. RFP plans to initiate as much RFI/RI field work as possible at OU 9; however, FY94 funding will be inadequate to meet all IAG commitments. 
OU 10 - OTHER OUTSIDE CLOSURES ASSESSMENT
OU 10 is comprised of IHSSs scattered throughout the plan! that consist of various hazardous waste units. Five of the IHSSs are located in the protected area (PA), two are in the buffer zone near the Present Landfill, and the remaining are located near various buildings throughout the plant. The types of wastes identified at these sites range from pondcrete/saltcrete storage and drum storage, to a utilization yard where waste spills occurred.

The Draft Final RFI/RI Work Plan was submitted to the regulatory agencies on May 1, 1992 and conditional approval was received in September. The primary components of the Work Plan include a FSP, Baseline Risk Assessment Plan (BRAP), and an EE Work Plan.

IHSSs $170,174,176,210$, and 214 all contained hazardous waste and surplus plant materials that had to be removed before Phase I characterization could begin in OU 10 in the spring of 1993 . Work on characterizing IHSSs 213 and 214, which store low-level waste, will be delayed because of the lack of a suitable destination for their wastes. However, IHSSs 170, 174, 176, and 210 primarily contain plant surplus materials that can be moved.

The boundaries of IHSSs $170,174,176$, and 210 were marked to delineate the waste and surplus materials that need to be removed, and a schedule was developed for the removal of materials out of the Property Utilization and Disposal (PU\&D) yard (IHSS 170 and 174), the 964 "laydown" area (IHSS 176), and IHSS 210. Work began the end of March 1993 to remove the excess materials out of IHSS 170 .

On April 16, 1993, CDH participated in a field inspection of OU 10 and was concerned with the lack of progress made in preparing the IHSSs for characterization activities. RFO immediately started efforts to correct problems observed by $\mathrm{CDH}$, and the efforts were successful. All of the waste storage items in the PU\&D yard were removed by the June 1, 1993 deadline. Storage items were also removed from IHSS 176, the 964 "laydown" area, within the PA. Implementation of OU 10 Phase I field work began as scheduled in these areas. 
The impiementation of the radiation survey/HPGe) task began on June 1, 1993. All Stage I HPGe survey data outside of the PA have been collected for OUs 10.12, 13, and 14. The portions of OU 8 outside the PA have been surveyed. The survey data were analyzed and completed by the end of September 1993. Results from this data evaluation will provide direction for future HPGe and sodium iodide survey points, if needed.

Preliminary review of the HPGe data revealed the possible presence of americium-241 at two locations outside the boundary of IHSS 170/174. Upon recalibration of the HPGe instrumentation, the field crews collected data at the locations with anomalous readings. This additional survey failed to confirm the presence of Am-241 around the IHSS boundary. However, additional HPGe data collection analysis may be needed in order to more fully characterize each IHSS in the IA.

A site walk of OU 10 IHSSs was conducted on August 20, 1993 to discuss specific sampling location points and other logistical concerns regarding implementation of field activities. Field crews began collectirg surficial soil samples at OU 10 beginning the week of August 30, 1993.

OU II - WEST SPRAY FIELD ASSESSMENT
The West Spray Field is located within the RFP property boundary immediately west of the main facilities area. The West Spray Field was in operation from April 1982 to October 1985. During operation, excess liquids from solar evaporation ponds $207 \mathrm{~B}$ north and center (containing contaminated groundwater in the vicinity of the ponds and treated sanitary sewage effluent) were pumped periodically to the West Spray Field for spray application. The spray field boundary covers an area of approximately 105 acres, of which approximately 38 acres received direct application of hazardous waste.

The Final RFI/RI Work Plan was submitted to the regulatory agencies on January 2, 1992 and conditional approval was received on May 26, 1992.

A rescoping of the OU 11 field activities was proposed and approved by DOE and took place during the first half of FY93. The scope change did not require additional FY93 funding, although it required funding shifts within the work package. 
EPA and $\mathrm{CDH}$ were informed by DOE on the direction that the OU 11 project is taking with respect to identifying preliminary remediation goals by means of back calculating COC concentrations to identify ARAR exceedance or risk exceedance within the OU boundary. A meeting was held June 8, 1993 with CDH, EPA, and DOE to discuss the streamlining of OU 11 work to accelerate the IAG schedule. The strategy would integrate the Phase II Work Plan and field work with Phase I, eliminate the IM/IRA process, and move directly into the CAD/ROD Process.

The schedule acceleration proposal to combine the two phases of OU 11 's FSP was presented to $\mathrm{CDH}$ and concurred with by the regulatory agencies. It was recommended that the OU documentation be rescoped to be an IM/IRA Closure Plan. This recommendation will be examined and compared to the original idea to follow the IAG schedule and delete milestones that do not apply. The regulatory agencies agreed to this evaluation and will approve the plan that is the most schedule- and cost-effective. These issues and resolutions will be documented in an official memorandum from the regulatory agencies.

The revised FSP was completed in the fall of 1993 and approved by the agencies..

\section{OU 12 THROUGH OU 16}

The following OUs consist of lower priority areas for which various remedial activities will continue during 1994.

OU 12 - 400/800 Area. Contamination in the OU 12 area originates from cooling tower ponds, chemicals from fiberglass operations, leaks, and multiple solvent spills that may have contaminated the soils with VOCs and other organics, metals, and acids. The Draft Phase I RFI/RI Work Plan was submitted on May 8, 1992, revised in response to agency comments, and resubmitted on December 18, 1992.

CDH informed DOE that the Final OU 12 RFIRI Work Plan will be removed from conditional approval status and be considered final approved pending resolution of the HPGe standard operating procedure (SOP) and the Benchmark Table. All other issues relevant to the Final OU 12 Work Plan have been resolved. 
The proprosal for the IA OU field work was received on March 25. 1993. In order to limit the schedule impacts, a letter contract was issued on May 13, 1993. The letter contract was awarded for limited scope including development of the subcontractor's HSP and Implementation Plan. The contract for the integrated OUs was awarded on August 13, 1993.

All Stage I HPGe survey data outside of the PA have been collected for OUs 10,12,13, and 14. The portions of OU 8 outside the PA have also been surveyed. The survey data were analyzed and completed by the end of September 1993. Results from this data evaluation will provide direction for future HPGe and sodium iodide survey points, if needed.

OU 12 requested a milestone extension for the Draft RFI/RI Report due on April 20, 1994, and the Final RFI/RI Report due on September 15, 1994. The extension was requested because field work activities were postponed as a result of funding limitations in FY93, and because of the coordination of IHSS cleanup with the RFP D\&D/Transition Planning which was included in the RFO-approved FY95-99 FYP.

OU 13 - 100 Area. OU 13 comprises chemical storage areas, an underground tank, waste destruction areas, a valve vault, and locations where minor leaks or spills occurred. The soil has received VOCs and other organics, depleted uranium, acids, caustics, and metals from these IHSSs. The Draft RFI/RI Work Plan was submitted on May 15, 1992, and the final was submitted on October 12, 1992. The FSP was revised to provide more comprehensive surficial soils components, and $\mathrm{CDH}$ requested an increase of surficial soil sampling from 54 to 130 samples.

The revised OU 13 Work Plan was submitted to the regulatory agencies to meet the deadline of March 10, 1993. The regulatory agencies approved the Work Plan in August 1993. As part of the approval, the $M \& O$ contractor committed to preparing a Compendium for In Situ Radionuclide Characterization Methods and Applications that will answer the concerns of the regulatory agencies about the use of the HPGe and other detector devices. The Compendium of In Situ Radiologic Characterization Methods and Analysis was completed and submitted to the regulatory agencies on April 2, 1993. 
HPGie activities in OU 13 were completed on August 9. 1993. The data acquisition is complete but analysis of the data may need further evaluation.

A new issue is developing in several of the IA OUS including OU 13. Several of the IHSSs within OU 13 (IHSSs 117.1, 117.2, 158,186, and 197) are used as storage areas for a variety of materials such as scrap metal, building supplies, and other various items. These items must be relocated out of the IHSS (or at least shuffled about) in order for remedial investigations to begin. It appears that RFP will be able to work around many of the stored items. Schedule problems may arise from having to relocate materials.

The proposed OU 13 budget for FY93 allowed the nonintrusive field activities (Stage 1) in OU 13 to begin. However, it was not sufficient to fund all of the Stage 1 portion of the Phase I RFI/RI field work. The next IAG milestone delivery of the Draft Phase I RFI/RI Report on August 8, 1994 will require an extension.

OU 14 - Radioactive Sites. OU 14 consists of eight IHSSs: Radioactive Site - 700 Area Site \#1 and \#2 (IHSS 131 and 162); Radioactive Soil Burial - Building 334 Parking Lot and Soil Dump Area (IHSS 156.1); Building 444 Parking Lot (IHSS 160) and Building 664 (IHSS 161); and Radioactive Sites - 800 Area which includes the Concrete Slab, Building 886 Spills, and Building 889 Storage Pad (IHSS 164.1, 164.2, and 164.3).

The Final RFI/RI Work Plan for OU 14 was scheduled for approval by the regulatory agencies in November 1992. EPA notified DOE that approval was being withheld until a scope and schedule for performing the IA/Interim Remedial Action Plan (IRAP) was agreed upon by the regulatory agencies and DOE. The Final RFI/RI Work Plan was approved in December 1993.

The current FYP indicates that TM \#1, Human Health Risk Assessment - Exposure Assessment, and TM \#2, Human Health Risk Assessment - Modeling are scheduled for completion in March 1994. These tasks will require rescheduling due to the integration of OUs 8,9 . $10,12,13$, and 14. Currently, only nonintrusive RI field work is scheduled for OU 14 in FY94. Preparation of the TMs will not begin until FY95. 
OU 15 - Inside Building Closures. OU 15 includes structures within buildings where hazardous materials were stored or processed. Types of waste include oils, coolants, and solvents containing chlorinated hydrocarbons, and waste paints and waste metals contaminated with solvents. Hazardous constituents include chlorinated solvents, beryllium, and uranium. The draft work plan was submitted on June 1, 1992 and the final work plan was submitted on October 26, 1992.

Conditional agency approval, with comments, was received on December 11, 1992.

Negotiations with the regulatory agencies were instrumental in a reduction of scope that resulted in a cost savings of approximately $\$ 1.7$ million in FY93 budget requirements for OU 15. The SOW of the IAG for OU 15 includes the requirement that Closure Plans be prepared for the seven IHSSs included within OL 15; negotiations led to the elimination of the OU 15 Closure Plans and subsequent implementation activities. As a result, additional cost savings will be realized for out-year budgets included in the FY93 updated FYP.

The technical evaluation (TE) of proposals for implementation of the Phase I RFI/RI Work Plan was completed January 2, 1993. Award of a subcontract for implementation of the Phase I RFI/RI Work Plan was completed on March 3, 1993. Unconditional approval of the Phase I RFI/RI Work Plan for OU 15 was received from EPA and CDH on May 4, 1993. On June 18,1993 , OU 15 field work mobilization was initiated with inspection of the IHSSs.

During the fourth quarter of FY93 the following field work activities were accomplished: floor/equipment hot water rinsate sampling and direct radiological surveys in Building 881 and 883; radiological surveys for removable radionuclides (smear/swipe sampling) in Building 865; and floor/equipment hot water rinsate sampling equipment was mobilized into Building 865 . Sampling began on September 9, 1993.

OU 16 - Low Priority Sites. OU 16 covers miscellaneous leak and waste treatment sites that are considered 
the least likely to cause health or environmental problenus. The soils at these sites may have been contaminated by organics, solvents, and nickel carbonyl. A draft No Further Action Justification (NFAJ) document was submitled on March 5, 1992 and a final on July 30, 1992. The document provides technical justification for no additional investigation or remediation at seven individual IHSSs.

CDH granted approval of the NFAJ Document in March 1993. Regulatory agencies, DOE, and EG\&G have held discussions focused on the following required steps to administratively close out the OU:

- Prepare a Proposed Plan (PP)/Draft Permit Modification based on the draft model provided by EPA.

- Distribute the proposed plan, schedule a 60-day public comment period regarding the proposed plan, and hold a public meeting during the 60-day

- period to discuss the plan.

- Draft a Responsiveness Summary to reply to the comments received during the review period.

- Prepare the ROD document with guidance from the regulatory agencies.

A model draft proposed plan was prepared by EPA and submitted to RFO for comments. RFO's comments were submitted to EPA on May 17, 1993. A meeting was held on May 19, 1993 at EPA to finalize the PP and layout schedules for the public comment period and ROD development.

The Administrative Record (AR) continued to be updated with documents provided by various plantsite departments in preparation for the OU 16 PP/Draft RCRA Permit Modification being released for public comments. The comment and review period continued through August 1993.

RFO comments on the draft PP, the schedule for completion of the PP, the public comment period, the responsiveness summary, and the ROD were distributed to the regulatory agencies. The public comment period was scheduled for October 17, 1993. 
SITEWIDE ACTIVITIES

Sitewide Treatability Studies
Sitewide activities include a wide variety of plans, procedures. reports, studies, and other tasks required by the IAG and that also apply to RFP environmental restoration activities in general.

The Sitewide Treatability Studies Annual Report, an IAG milestone delivered to the regulatory agencies, includes a summary of the status of each of the sitewide projects, a literature review of new and emerging technologies, and a summary of other relevant environmental projects at RFP.

The RFP Environmental Science \& Engineering (ESE) group is working with Technology Development and the Los Alamos Technology Office (LATO) to develop a Technical Task Plan (TTP) to study Plutonium Solubilization for Remediation Applications. The purpose of this TTP is to develop an understanding of the soil chemistry at RFP and the relationship to how plutonium is found in the RFP soils. The TTP will be submitted to LATO.

The following Sitewide Treatability Studies activities began or were in process during 1993: physical separation, chemical separation, potassium ferrate precipitation, adsorption, colloid filter polishing method, plasma melter, solar detoxification, annual report preparation, pondcrete evaluation report, bioremediation literature search and technical proposal preparation, colloid studies, flow pump testing, seep study, and the acquisition of an inductively coupled plasma - mass spectrometer (ICP-MS).

Several enhancements were implemented in 1993 to correct identified deficiencies in the ER sample management process and in the RFEDS. Sample management staff was increased to include two additional support chemists. Cost management of the large ER sample analysis budget was addressed. The ER staff is working with EG\&G Procurement, Accounting, and Central Planning and has implemented a customized system for handling analysis accruals and invoices so that accurate, up-to-date charges are assessed against ER projects for sample analysis. 
Several major improvements were made to RFEDS during 1993. These included the addition of hardware and software to initiate and Environmental Data Collection Network (EDCN). When fully implemented in 1994, this system will capture laboratory and validation sample information electronically. Several improvements were made to the data upload programs to provide better data quality and upload efficiency. Groundwork was laid to interface the onsite Laboratory Information Management System (LIMS) to RFEDS. This will capture data from the Rocky Flats laboratories electronically. Much of the historical RFEDS data was also improved by identifying areas of inconsistencies and by taking corrective actions.

Community Relations Plan

Groundwater Monitoring
The Community Relations Plan (CRP) was approved by EPA and CDH and issued in December 1991. All requirements associated with the CRP were completed on schedule during 1993. Major activities completed during 1993 are provided below.

- Monthly coordination meetings continued to be held with the EPA and CDH.

- Six Environmental Restoration Update newsletters were issued to the public.

- Four quarterly public information meetings, as required by the IAG, were conducted in 1993 .

- A Technical Review Group (TRG), composed of representatives from local municipalities and local environmental groups, met monthly to provide public input on draft work plans and other documents.

- All required documents were placed in the Rocky Flats Public Reading Room and other public repositories.

- As required by the CRP, numerous tours, presentations, and briefings were conducted during the year.

A comprehensive groundwater monitoring program that began at RFP in 1986 was expanded significantly in recent years. Seventy new wells were added in 1986 to the existing 30 wells; an additional 67 wells were added in 1987; and 160 wells were added in 1989 , bringing the 


\section{Administrative Record}

total to $: 60$ wells after some older wells were abandoned. In 1991, approximately 150 new wells were added, and in 1992. approximately 30 new wells from the OUs 1 and 2 drilling programs were added, bringing the total to 430 wells.

During 1993, approximately 40 new wells were installed. These new wells support increased groundwater monitoring activities in the $903 \mathrm{Pad}$, Mound, and East Trenches (OU 2), the Woman Creek Drainage (OU 5), Walnut Creek Drainage (OU 6), and the Present Landfill (OU 7).

In 1993, 38 monitoring wells were abandoned and 8 replacement wells were installed to provide new data. By the end of 1993, there were approximately 500 groundwater wells in the monitoring program, 432 of which are sampled on a regular basis.

The IAG and Section 113 of CERCLA require the establishment of an Administrative Record (AR) for the ER Program in accordance with EPA policy and guidelines. The AR serves two primary purposes. First, it contains the documents that were considered or relied on as the basis for the selection of a response action. Judicial review of any issue concerning the adequacy of a response action is limited to the $A R$. Second, it acts as a vehicle for public participation in selecting a response action. The AR contains documents that reflect the participation of the public as well as the lead agency's consideration of the public's concern.

The RFP AR program began in 1990 and currently encompasses sixteen discreet OUs and a sitewide file. The AR contains 3,800 documents ( 122,000 pages), and is in a constant state of growth. Hundreds of documents are reviewed every week for possible inclusion into the AR. A descriptive index is maintained to enable Environmental Restoration Management (ERM) staff and the public to locate and retrieve documents. Microfiche copies of the AR and its associated index are updated quarterly and distributed to four public repositories. Each repository houses a microfiche reader/printer to allow the public to view and copy documents contained in the AR. 
Historical Release Report
The Historical Release Report (HRR), an IAG milestone. was prepared and the final draft was delivered to the regulatory agencies on June 3, 1992. The HRR documents all contaminant spills and releases at RFP since the beginning of plant operalions.

This document is updated on a quarterly basis to report current spills and or previously unknown findings. As of January, 1994, six updates to the HRR have been transmitted to the regulatory agencies. 


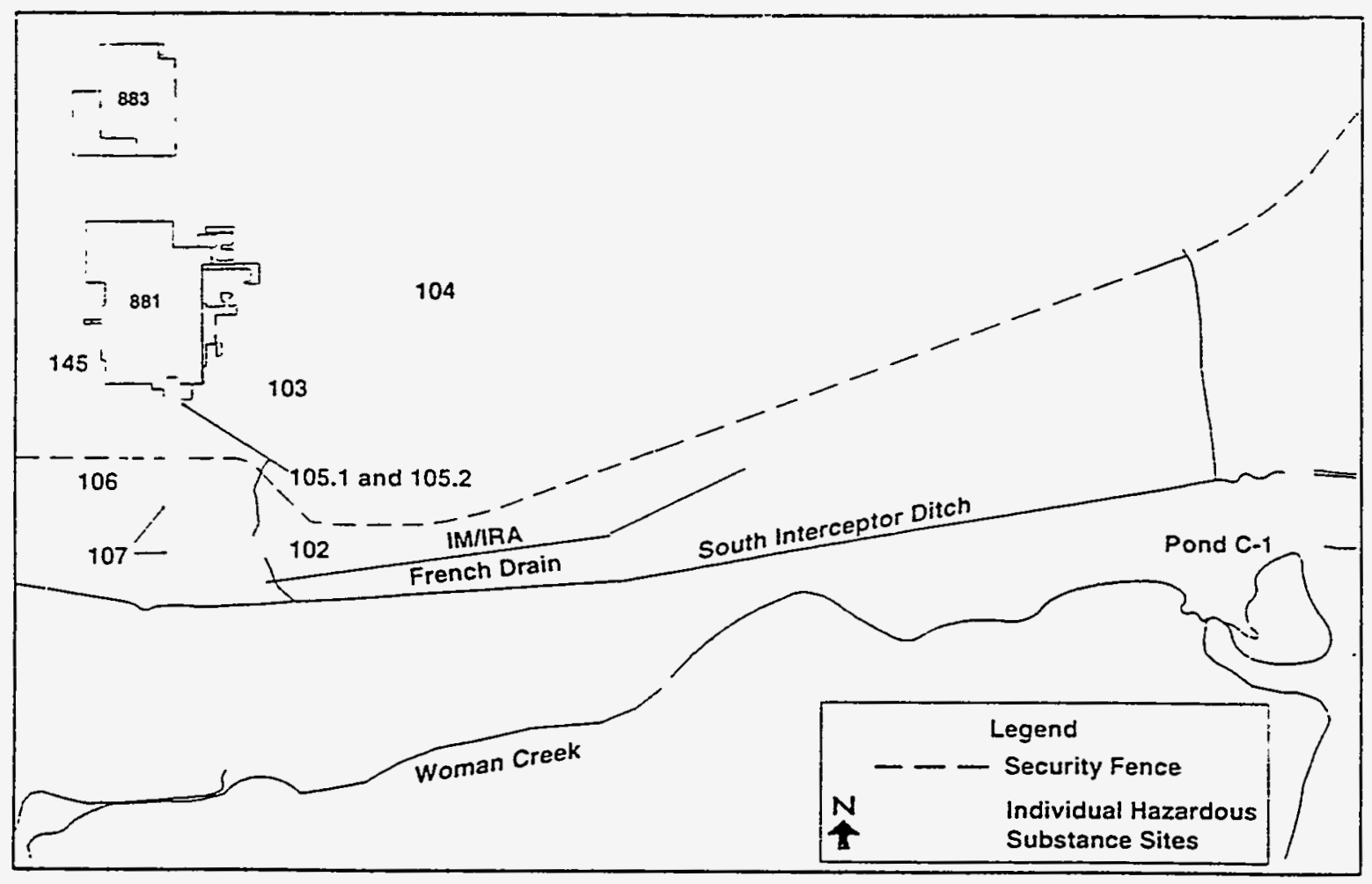

Figure 4-1. Operable Unit 1 - 881 Hillside

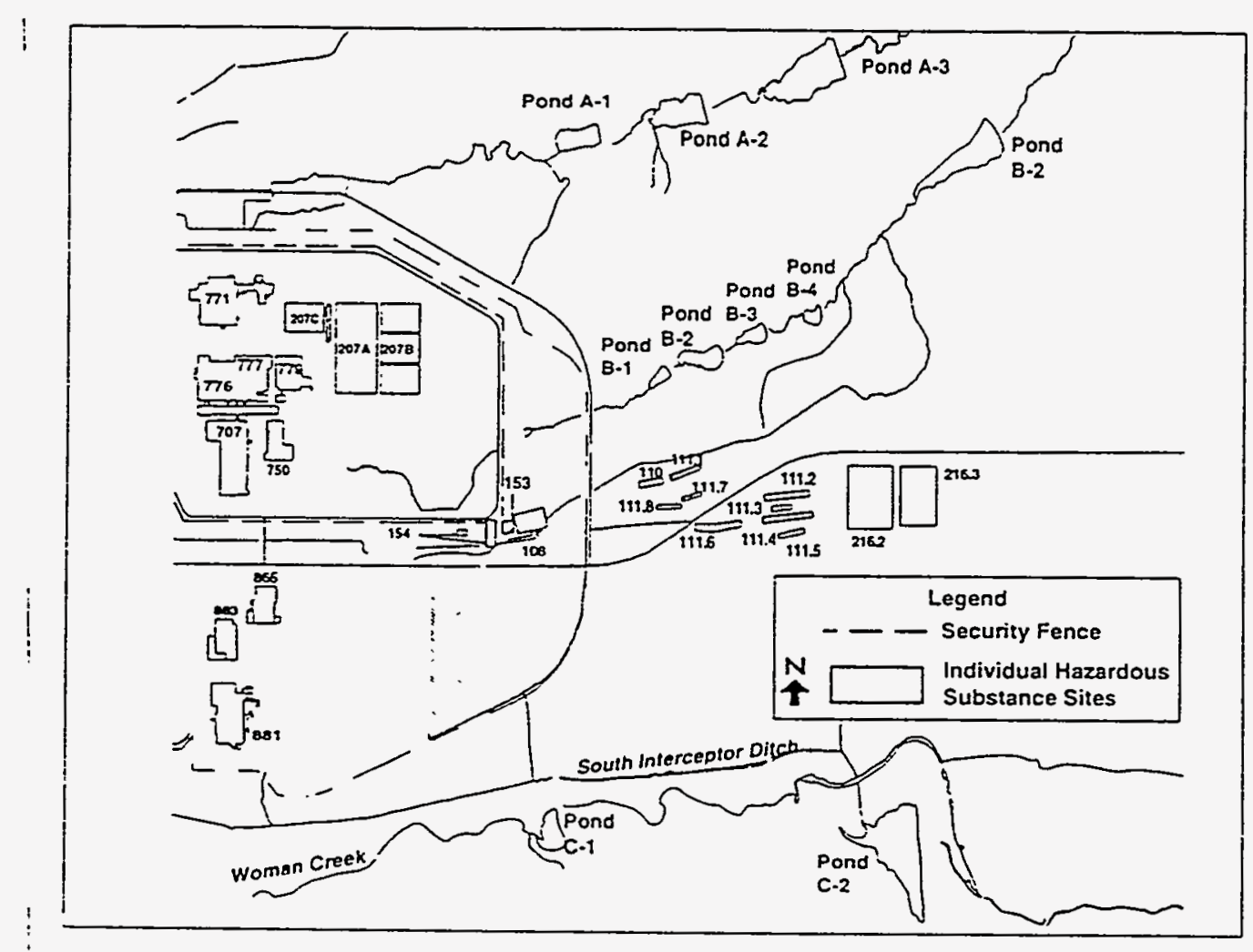

Figure 4-2. Operable Unit 2-903 Pad, Mound, East Trenches 


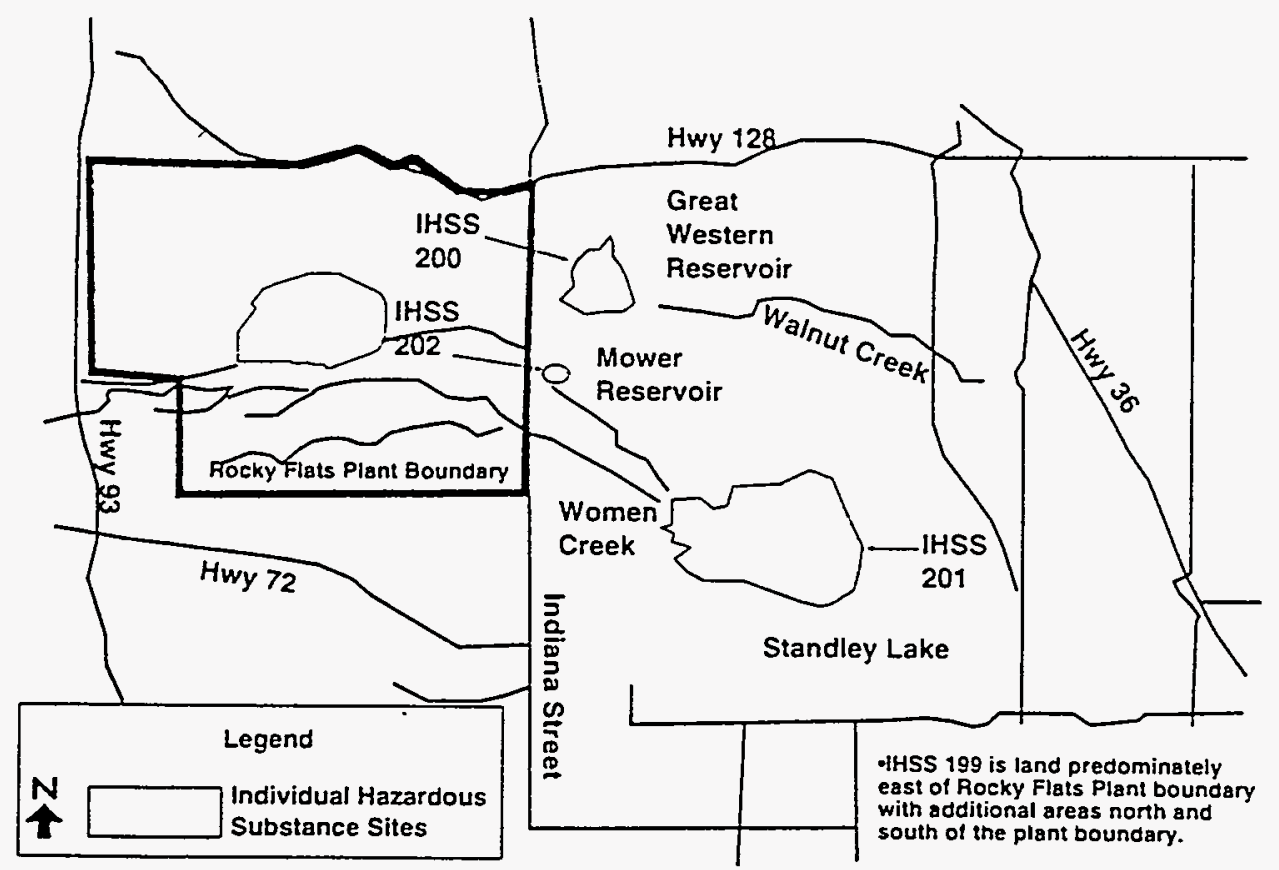

Figure 4-3. Operable Unit 3 - Offsite Releases

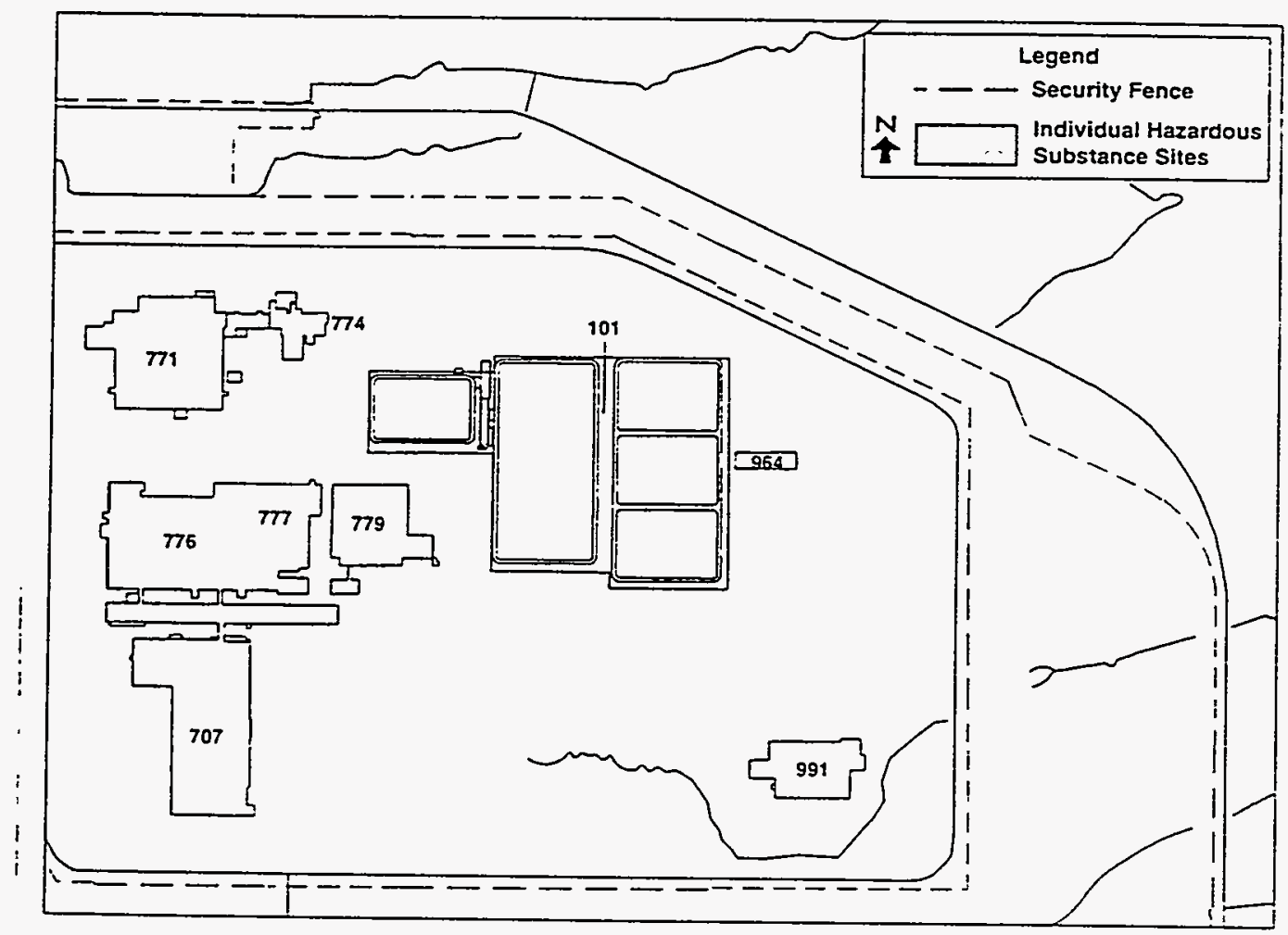

Figure 4-4. Operable Unit 4 - Solar Evaporation Ponds 


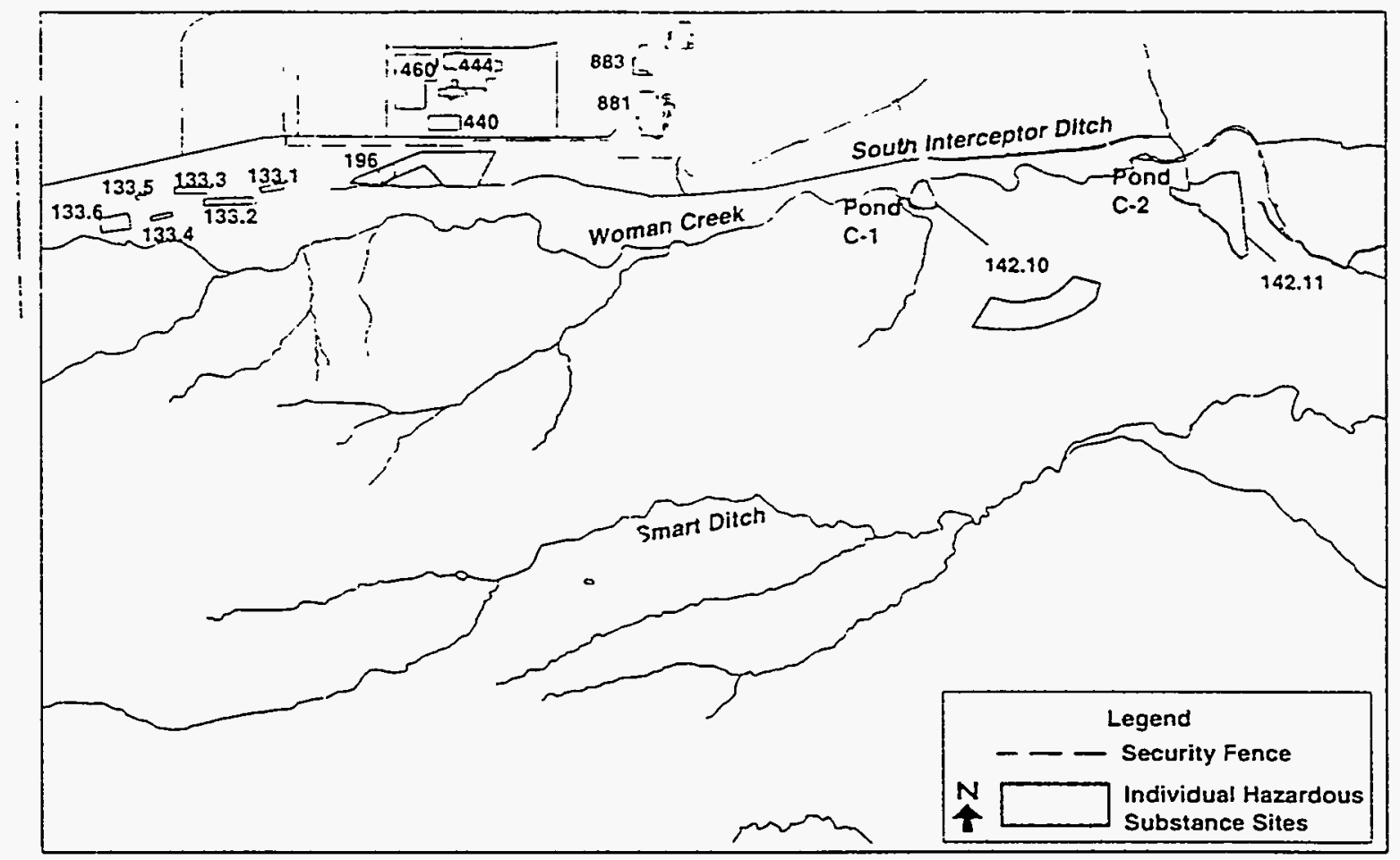

Figure 4-5. Operable Unit 5 - Woman Creek

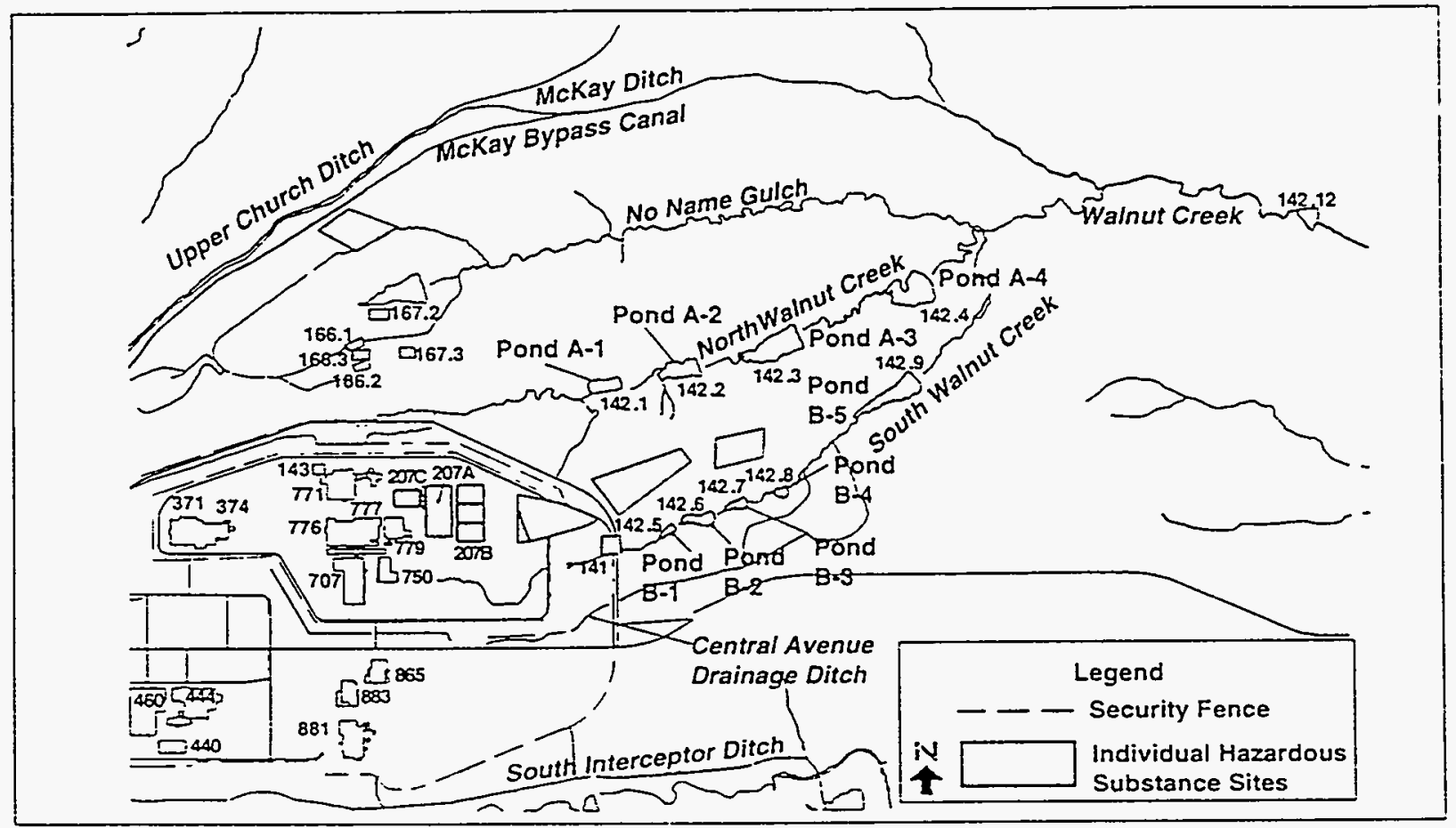

Figure 4-6. Operable Unit 6 - Walnut Creek 


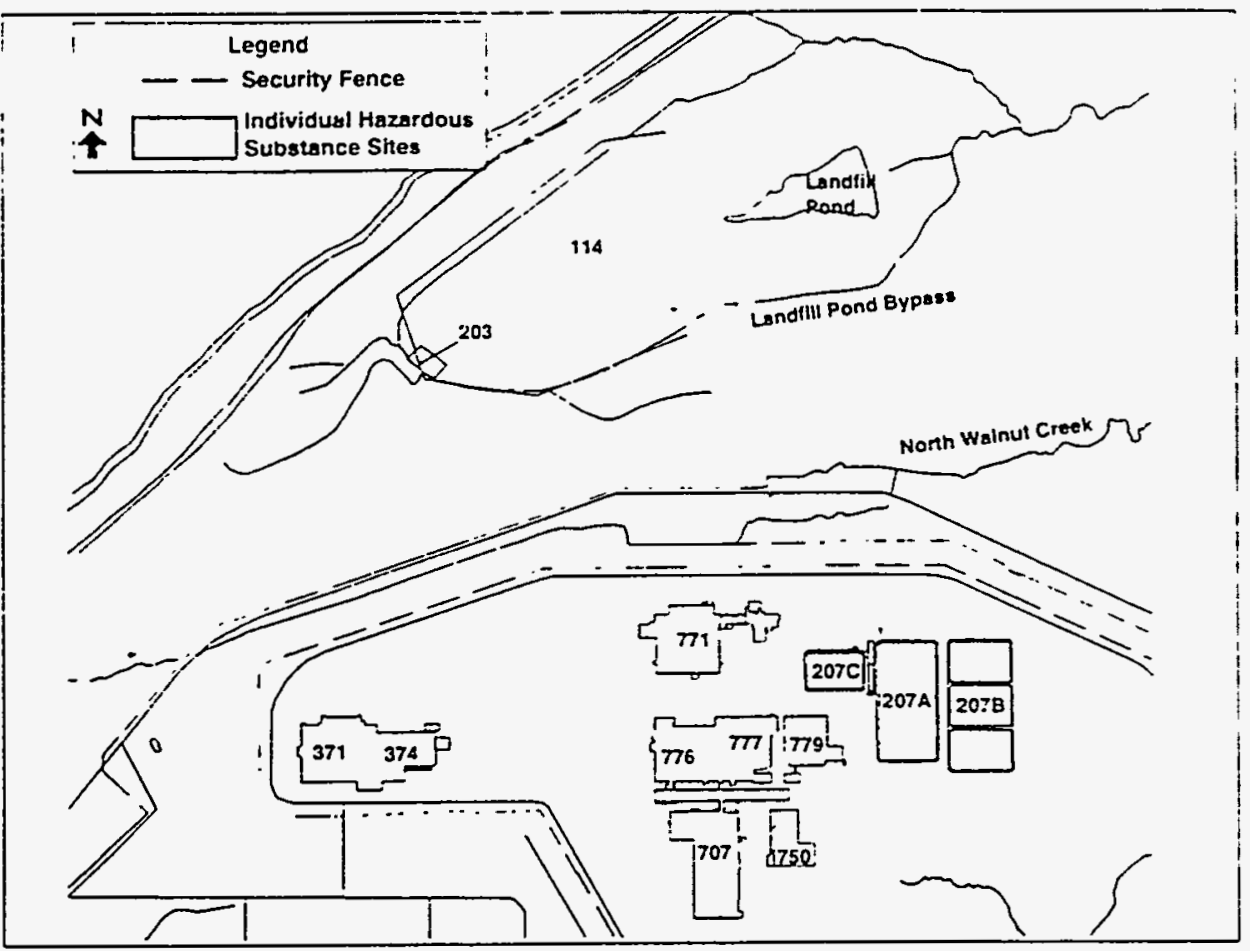

Figure 4-7. Operable Unit 7 - Present Landfill

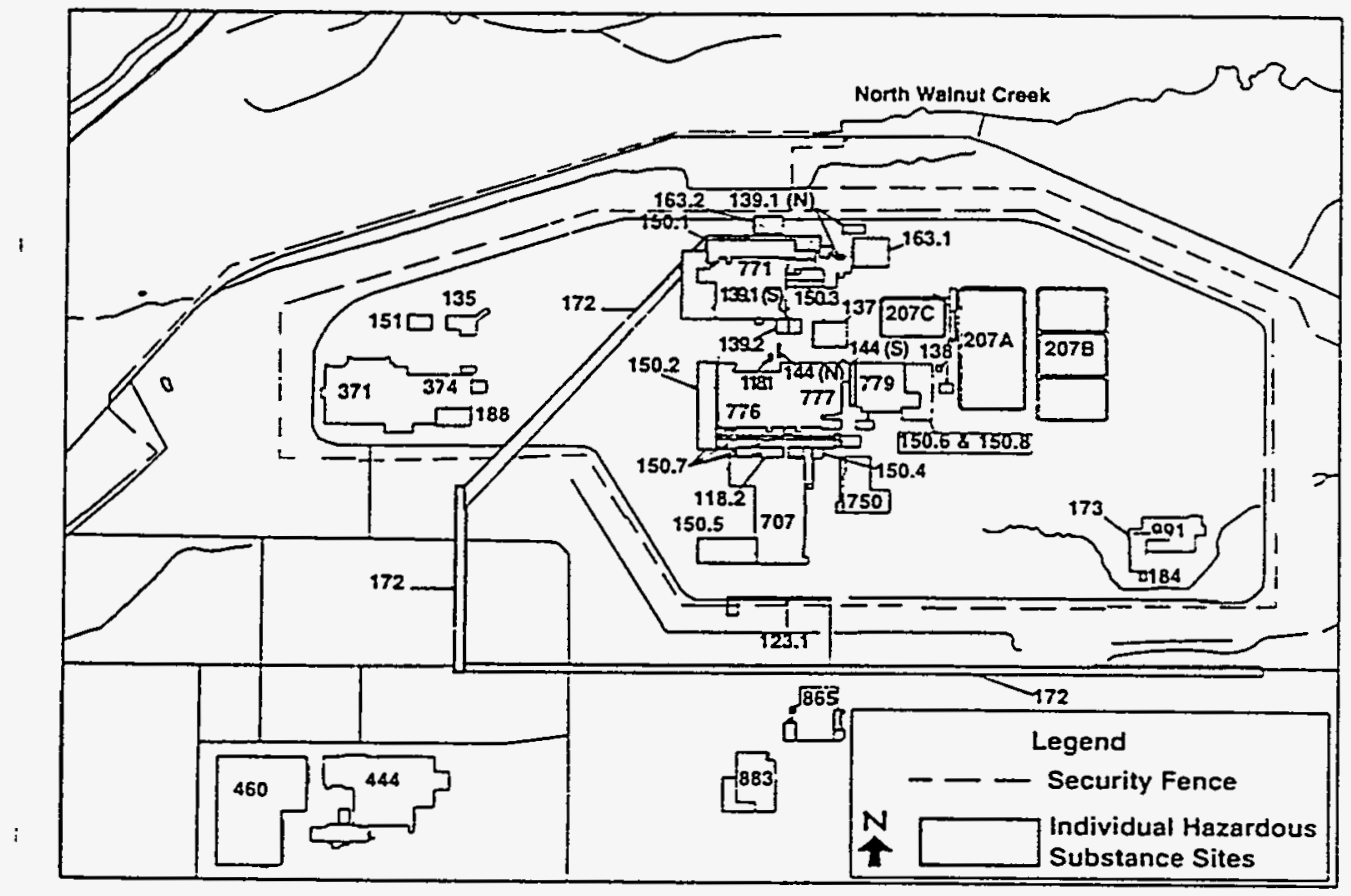

Figure 4-8. Operable Unit 8 - 700 Area 


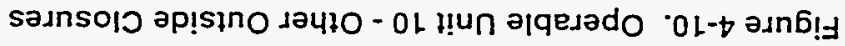

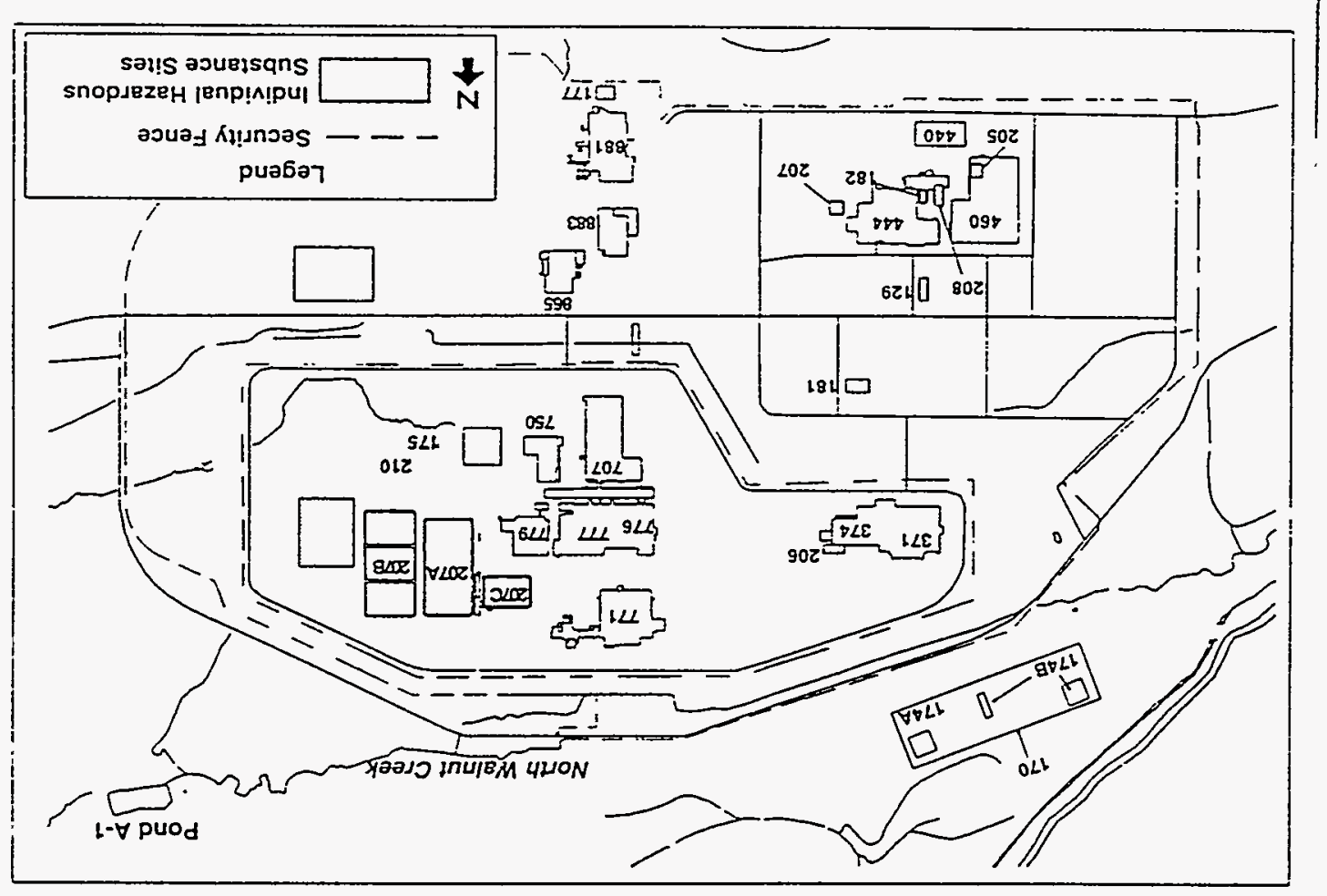

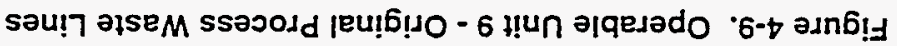

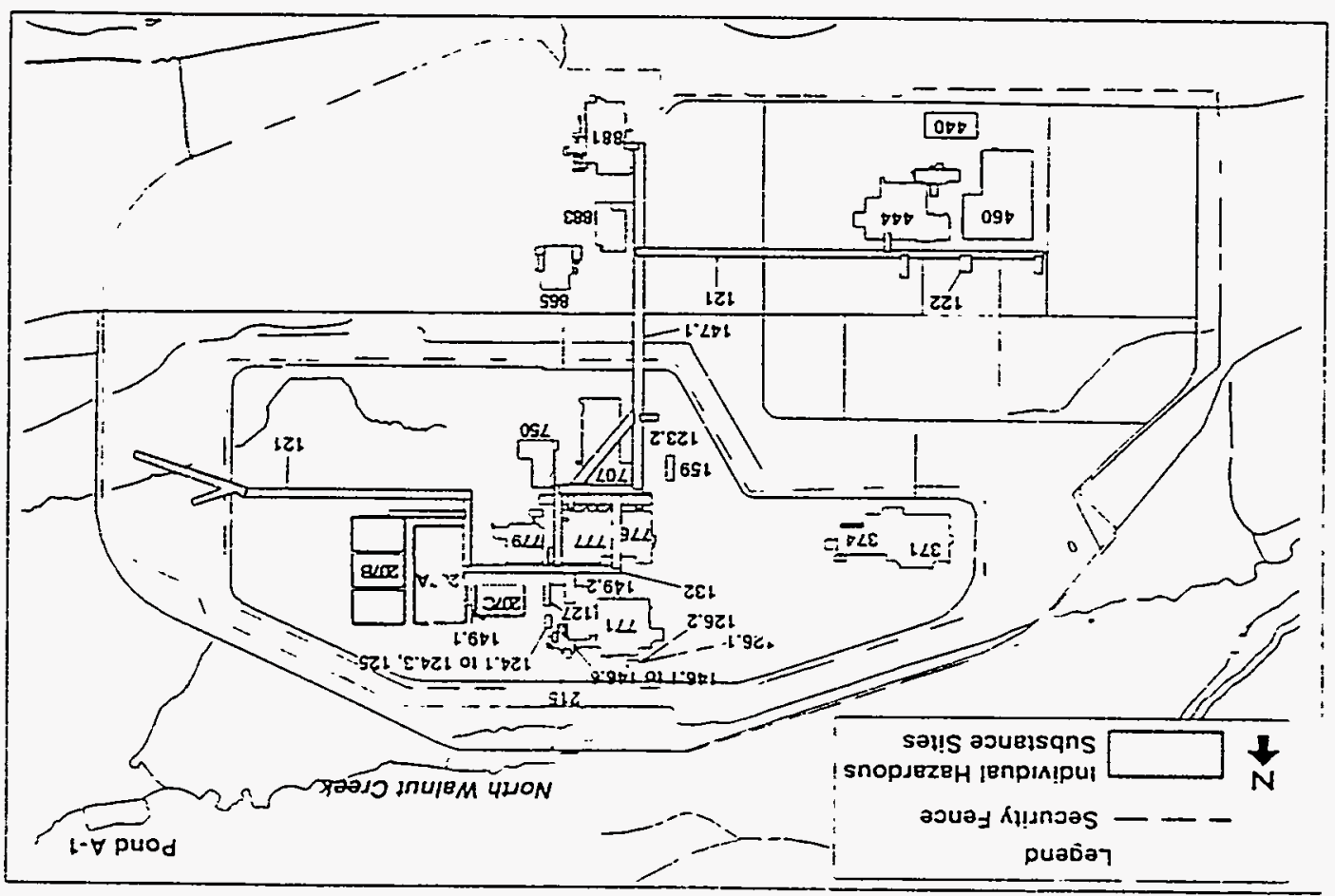




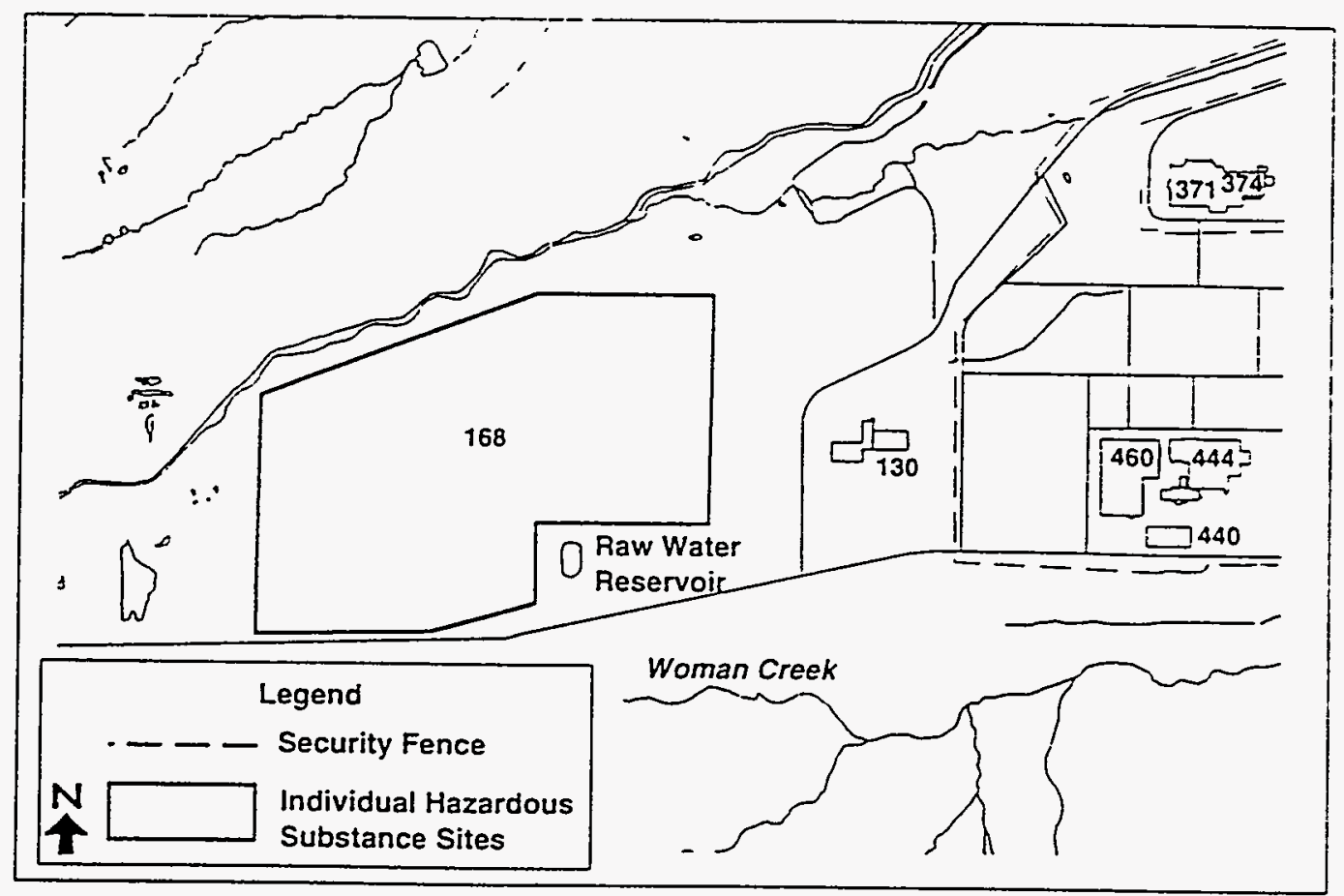

Figure 4-11. Operable Unit 11 - West Spray Field

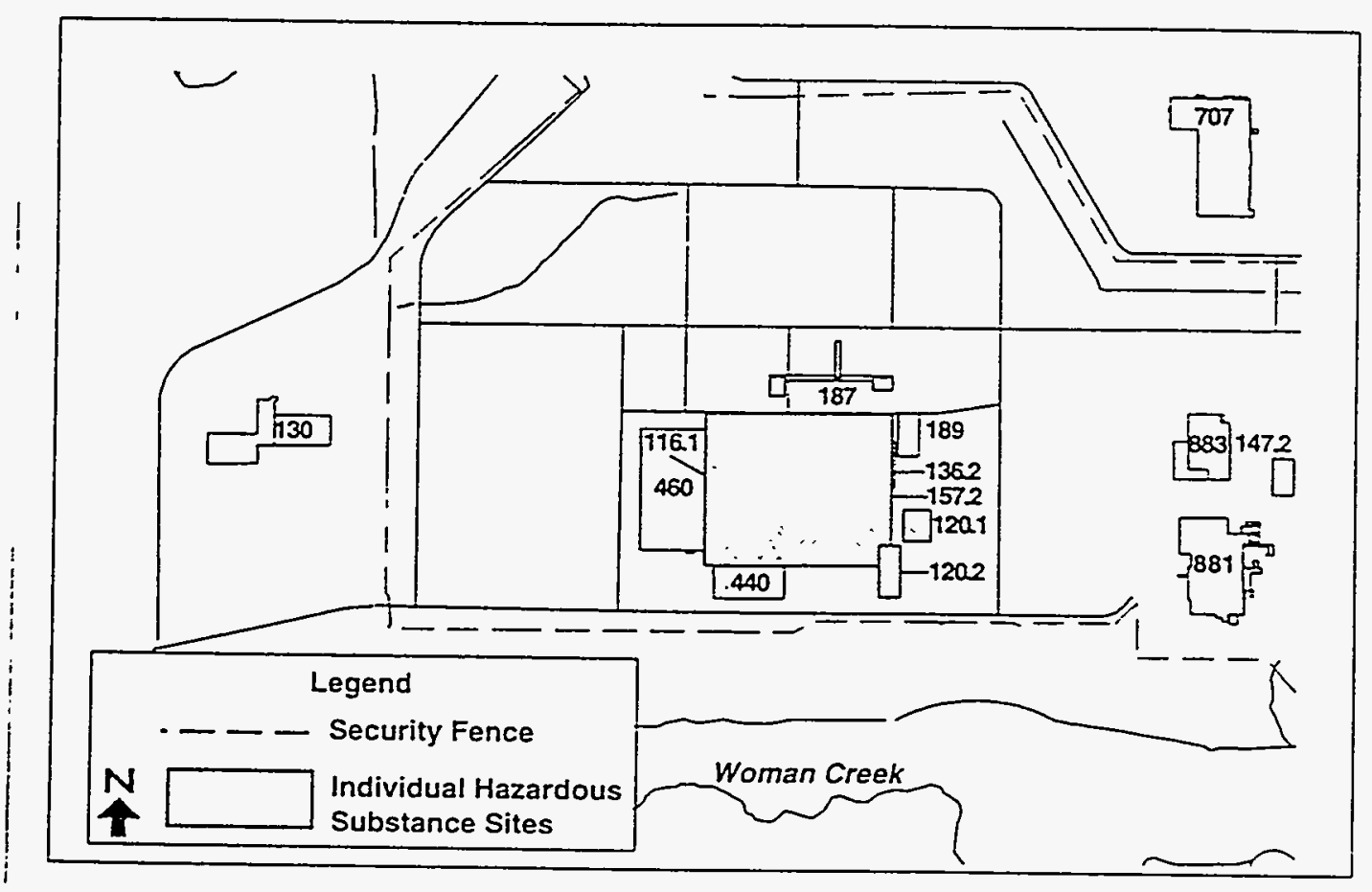

Figure 4-12. Operable Unit $12-400 / 800$ Area 


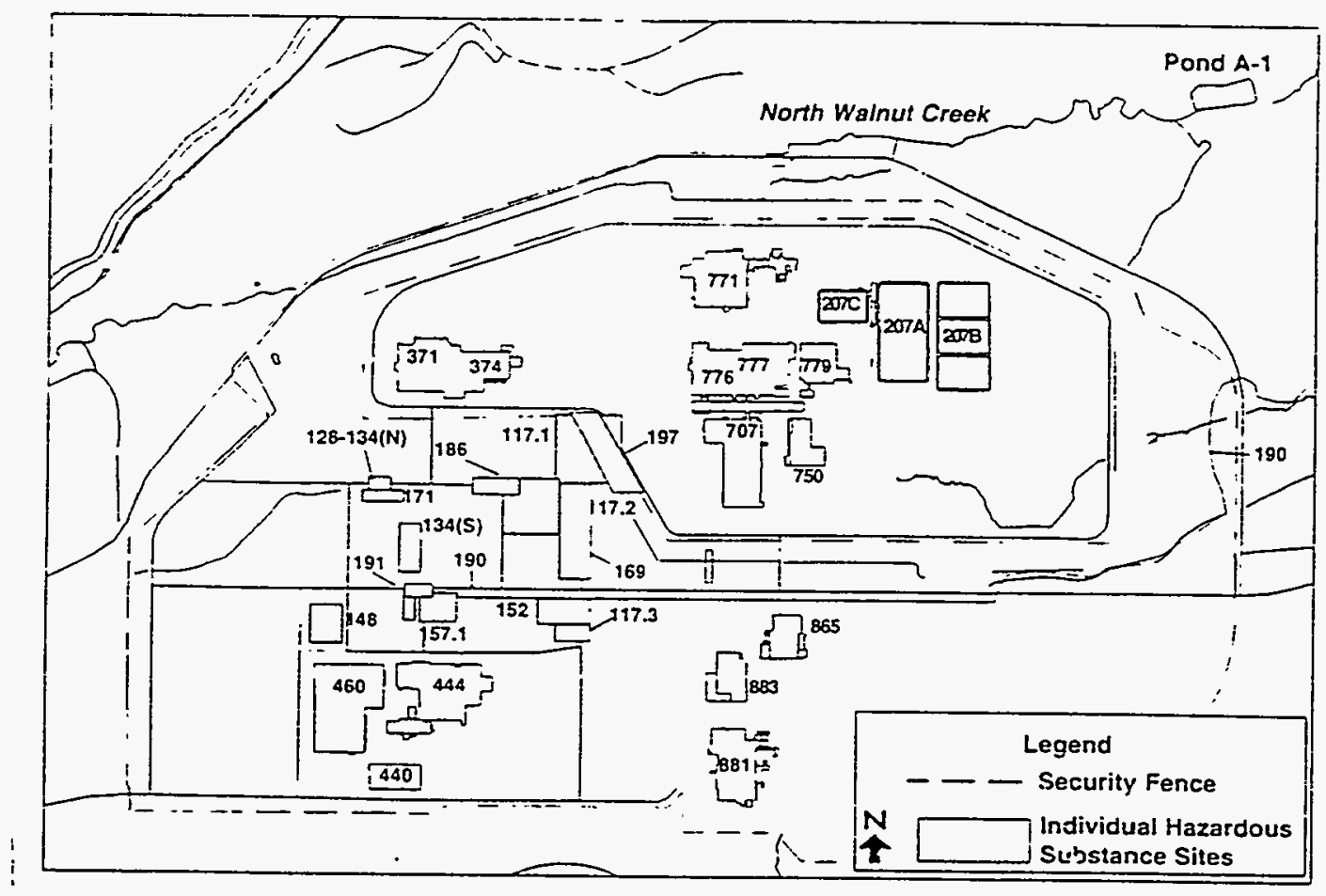

Figure 4-13. Operable Unit 13 - 100 Area

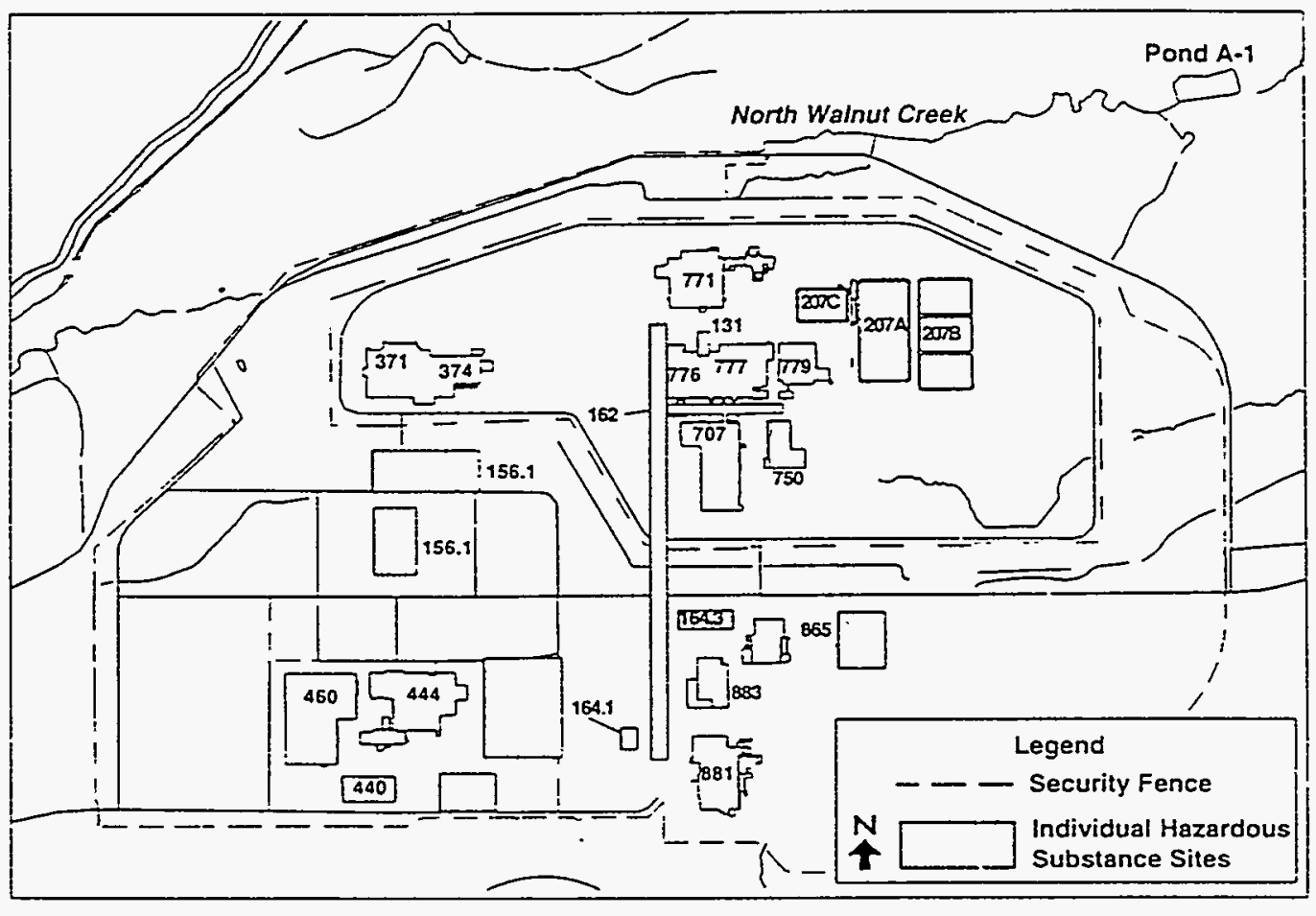

Figure 4-14. Operable Unit 14 - Radioactive Sites 


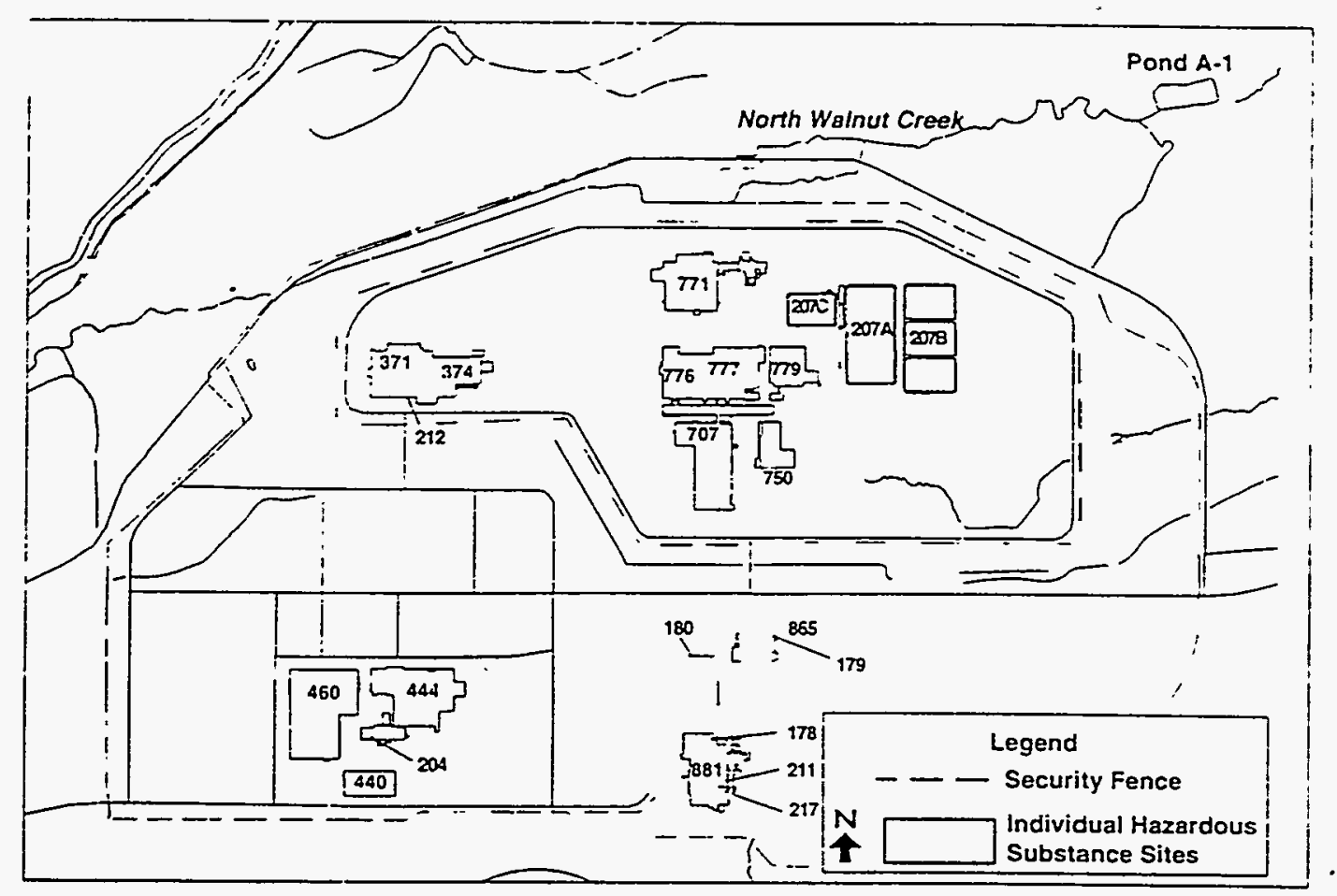

Figure 4-15. Operable Unit 15 - Inside Building Closures

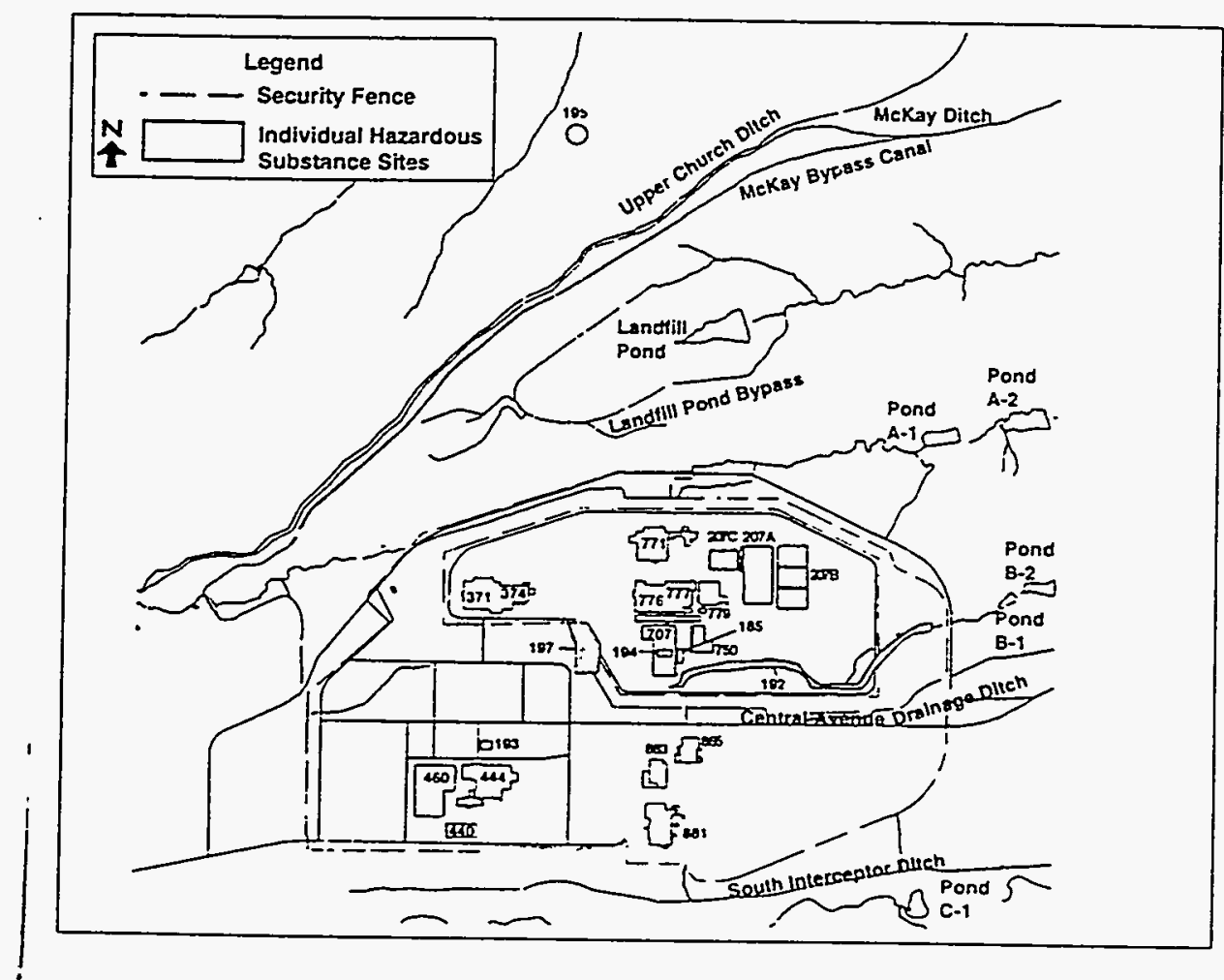

Figure 4-16. Operable Unit 16 - Low Priority Sites 


\section{External Gamma \\ Radiation Dose Monitoring}

The External Gamma Radiation Dose Monitoring Program provides information on background environmental gamma radiation exposure levels, as well as a capability for assessment of gamma radiation that might be associated with a criticality accident emergency situation at RFP. A network of 50 thermoluminescent dosimeters (TLDs) is used to measure the background gamma radiation dose levels on the plantsite, at the plant's perimeter, and in area communities. The following section describes the External Gamma Radiation Dose Monitoring Program and provides results of the TLD measurements recorded during 1993. 
RFP activities emit relatively little penetrating gamma radiation to which the public might be exposed. The most important potential source of radiation dose to the public from RFP activities is alpha radiation that could potentially result from inhalation or ingestion of plutonium, americium, or uranium. Although penetrating gamma radiation is not an important component of the materials handled at RFP, a network of thermoluminescent dosimeters (TLDs) is maintained on the plantsite, at the plant's perimeter, and in area communities to measure external gamma radiation. Gamma radiation measured as part of the RFP program is primarily from naturally occurring cosmic and primordial sources.

TLDs contain a luminescing material that absorbs energy from exposures to ionizing radiation. When the TLD is later heated unde controlled conditions, the energy is released as visible light. This light is measured and can be used to indicate the external gamma radiation dose that a person could receive under the same exposure conditions.

RFP has 50 TLD monitoring locations with replicate TLDs at each location. Five of the 50 TLD locations are within Building 123 at RFP, the laboratory in which the TLDs are prepared and read out. All five locations are included in the reported onsite data in Table 5-1. In addition, each location is reported separately in Table 5-2.

TLDs are replaced following an exposure period of approximately 3 months. The TLDs are placed at 22 locations within the main plantsite, including the 5 locations within Building 123 (Figure 5-1). Measurements also are made at 16 perimeter locations 2 to 4 miles from the center of RFP (Figure 5-2) and in 12 communities located within 30 miles of RFP (Figure 5$3)$. The TLDs are placed approximately 3 feet above ground level.

During 1993, RFP continued activities begun in 1991 to upgrade the environmental TLD program. In 1991 new processing hardware and software were acquired for the Panasonic equipment used to read out the TLDs. In 1992, RFP purchased a storage shield for the background TLDs and TLDs not in use, as well as Panasonic Model UD-814AS TLDS, specifically designed for environmental monitoring. The model 
Table 5-1

CY 1993 Environmental Thermoluminescent Dosimeter Measurements by Location Category

\begin{tabular}{|c|c|c|c|c|c|}
\hline \multirow{2}{*}{$\begin{array}{l}\text { Location } \\
\text { Categony }\end{array}$} & \multirow{2}{*}{$\begin{array}{l}\text { Number of } \\
\text { Locations }\end{array}$} & \multirow{2}{*}{$\begin{array}{c}\text { Number of } \\
\text { Measurements } \\
\text { UD-802AS }\end{array}$} & \multirow{2}{*}{$\begin{array}{c}\text { Number of } \\
\text { Measurements } \\
\text { UD.814AS }\end{array}$} & \multicolumn{2}{|c|}{$\begin{array}{c}\text { Mean Annual } \\
\text { Measured Dose (mrem) }\end{array}$} \\
\hline & & & & UD-802AS & UD-814AS \\
\hline & 22 & 176 & 528 & $137 \pm 3$ & $142 \pm 3$ \\
\hline Perime & 16 & 128 & 384 & $122 \pm 2$ & $127 \pm 3$ \\
\hline Community & 12 & 196 & 288 & $132 \pm 1$ & $137 \pm 2$ \\
\hline
\end{tabular}

Note: Total filtration over the Panasonic model US-802AS dosimeter elements is about $178.5 \mathrm{mg} / \mathrm{cm}^{2}$; filtration over the model UD-814AS dosimeter elements is about $1185 \mathrm{mg} / \mathrm{cm}^{2}$.

Table 5-2

\section{CY 1993 Onsite Environmental TLD Measurements ${ }^{a}$}

\begin{tabular}{|c|c|c|c|c|}
\hline \multirow[b]{2}{*}{ Location } & \multicolumn{2}{|c|}{ Panasonic UD-802AS } & \multicolumn{2}{|c|}{ Panasonic UD-814AS ${ }^{\mathrm{b}}$} \\
\hline & $\begin{array}{l}\text { Average } \\
\text { (mrem) }\end{array}$ & $\begin{array}{l}1.96 \text { Standard } \\
\text { Deviations }\end{array}$ & $\begin{array}{l}\text { Average } \\
\text { (mrem) }\end{array}$ & $\begin{array}{l}1.96 \text { Standard } \\
\text { Deviations }\end{array}$ \\
\hline 2 & 138 & 38 & 136 & 41 \\
\hline 3 & 131 & 24 & 130 & 46 \\
\hline 4 & 122 & 35 & 116 & 43 \\
\hline 5 & 129 & 42 & 135 & 38 \\
\hline 6 & 170 & 30 & 177 & 39 \\
\hline 7 & 121 & 31 & 124 & 39 \\
\hline 8 & 143 & 31 & 130 & 34 \\
\hline 9 & 155 & 41 & 162 & 44 \\
\hline 10 & 132 & 26 & 138 & 42 \\
\hline 50 & 137 & 27 & 137 & 36 \\
\hline 51 & 117 & 35 & 114 & 28 \\
\hline 52 & 127 & 29 & 125 & 33 \\
\hline 53 & 127 & 20 & 129 & 32 \\
\hline 54 & 139 & 33 & 139 & 34 \\
\hline 55 & 152 & 35 & 151 & 38 \\
\hline 56 & 127 & 41 & 132 & 38 \\
\hline 134 & 147 & 59 & 161 & 39 \\
\hline 135 & 159 & 34 & 175 & 32 \\
\hline 136 & 146 & 30 & 168 & 26 \\
\hline 137 & 127 & 52 & 149 & 29 \\
\hline $1 \mathrm{~A}$ & 140 & 20 & 147 & 37 \\
\hline R133 & 127 & 36 & 142 & 33 \\
\hline
\end{tabular}

a. Average mrem $=137,1.96$ standard deviations of the individual measurements $=42$, 1.96 standard deviations of the mean $=3$

b. Average mean $=142,1.96$ standard deviations of the individual measurements $=49$ 1.96 standard deviations of the mean $=3$ 


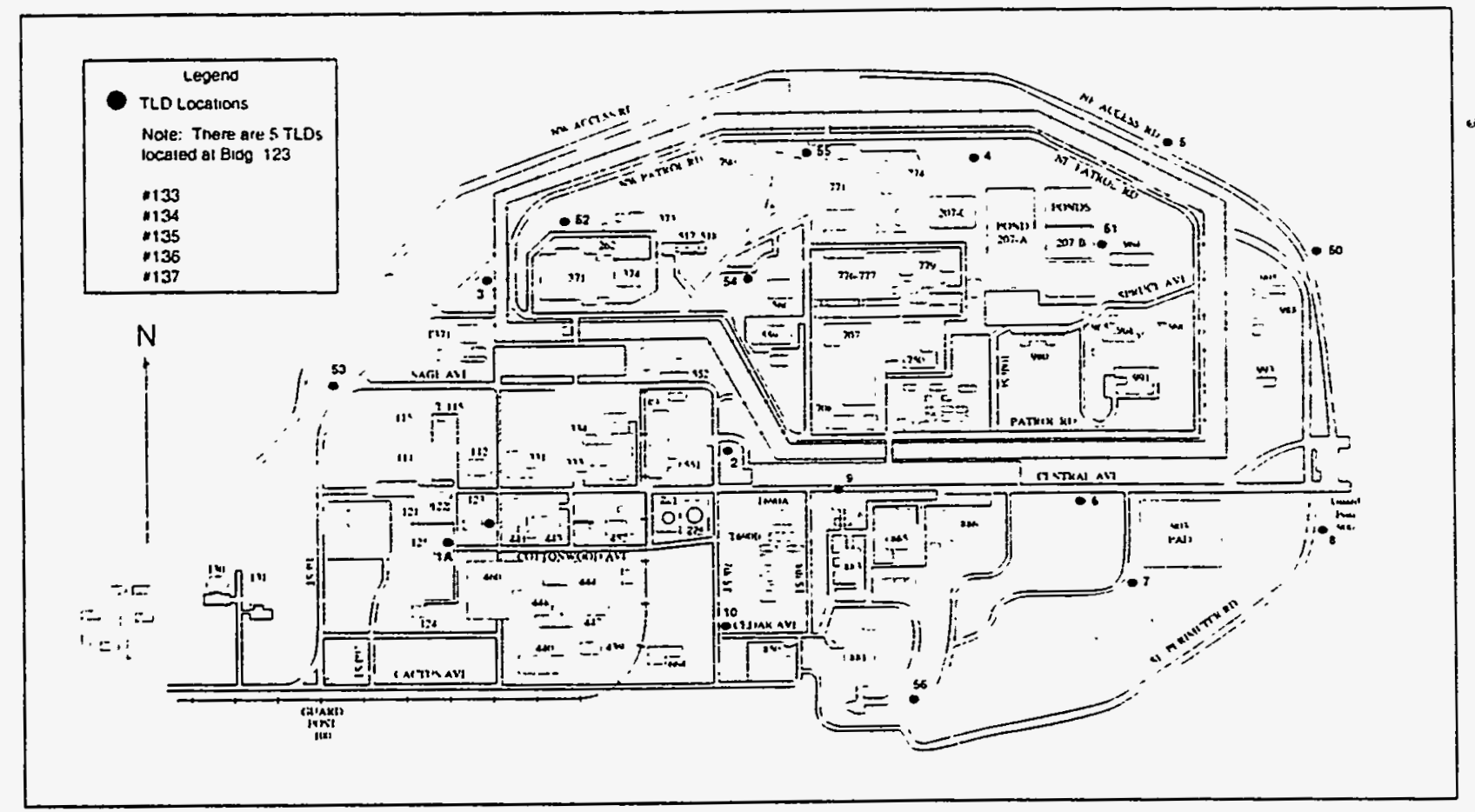

Figure 5-1. 22 TLD Locations within the Main Facilities Area

UD-814AS dosimeters contain three detector elements comprised of calcium sulfate with thulium doping as an activator $\left(\mathrm{CaSO}_{4}: \mathrm{Tm}\right)$. Calcium sulfate elements are used for routine environmental gamma monitoring by RFP because they are especially sensitive to the low gamma radiation exposures that are typical of environmental background radiation.

During 1993, two model UD-814AS TLDs and two model UD-802AS TLDs were installed at each monitoring location. Only the model UD-802AS TLDs had been used for environmental gamma monitoring from 1984 through 1992. Tables 5-1 through 5-4 provide CY 1993 monitoring data for both the six elements of the model UD-814AS TLDs and the two elements of the model UD-802AS TLDs that are comprised of $\mathrm{CaSO}_{4}: \mathrm{Tm}$ with the $1000 \mathrm{mg} / \mathrm{cm}^{2}$ filtration.

All of the dosimeters have been calibrated individually against onsite cesium-137 gamma calibration sources. Linearity studies have confirmed that TLD responses are linear for exposure levels ranging from $10 \mathrm{mrem}$ to 1000 mrem. An element calibration factor (ECF) is applied to each measurement taken with a particular 


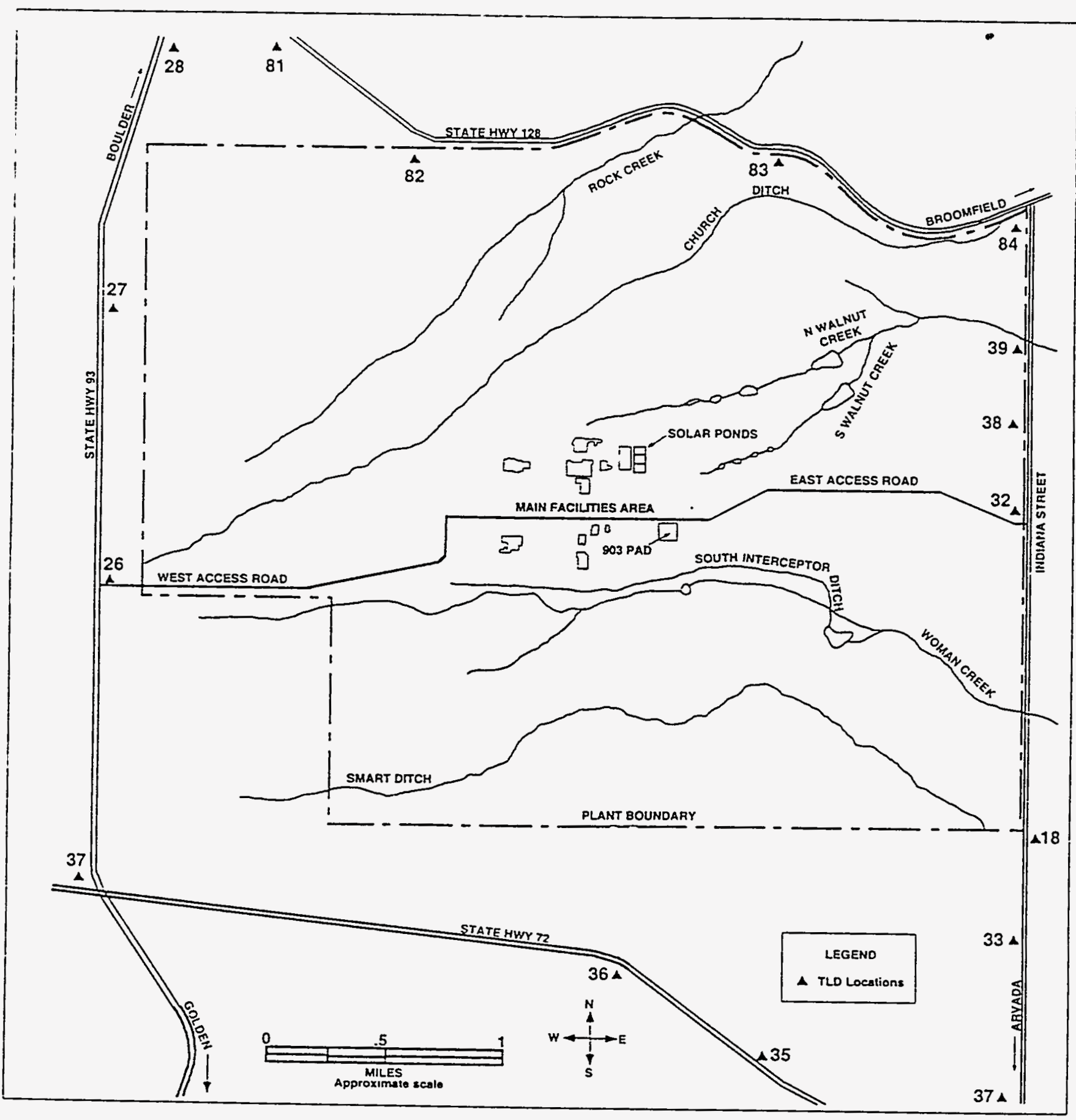

Figure 5-2. 16 TLD Locations Within a 2- to 4-Mile Radius of RFP 


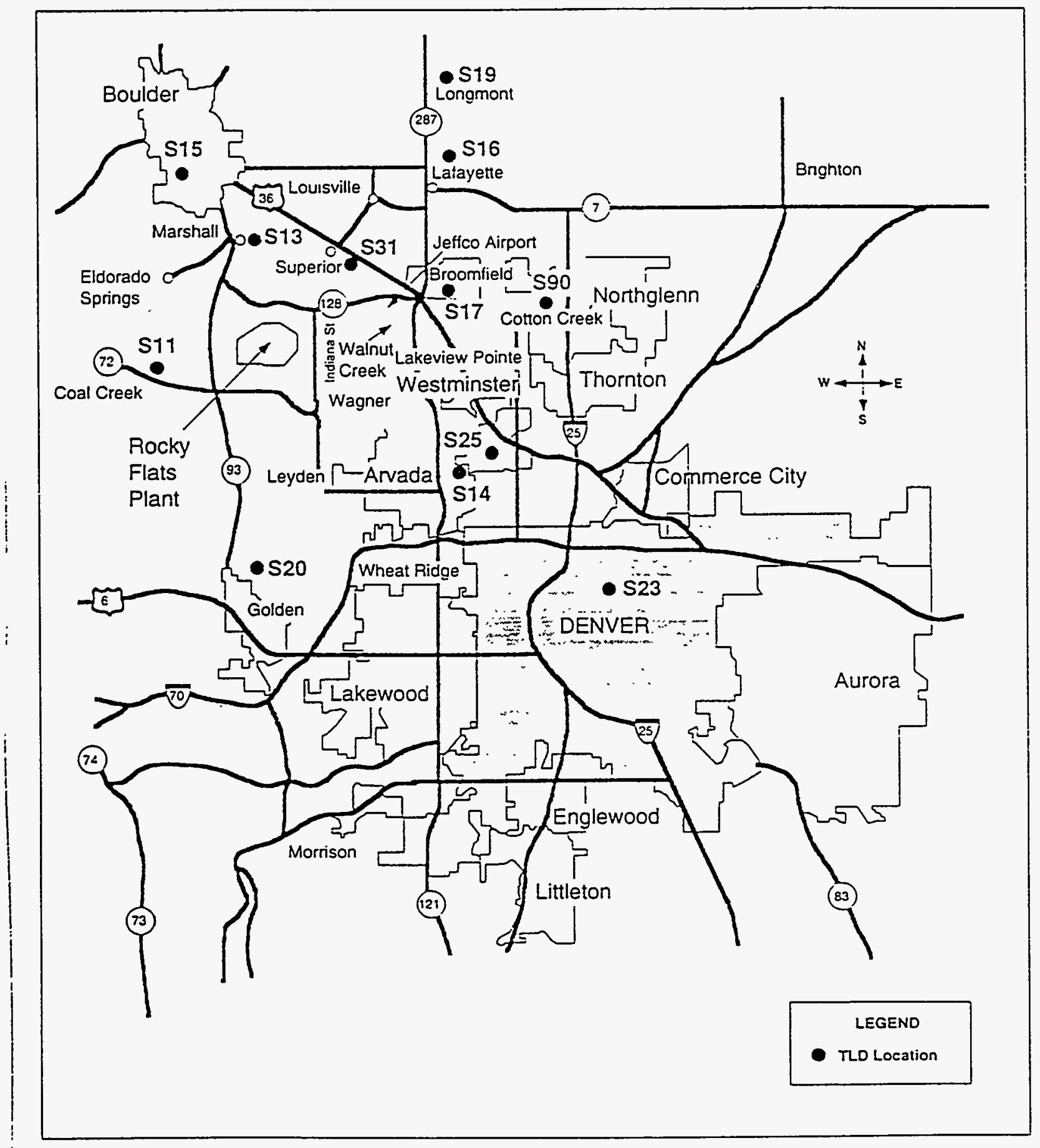

Figure 5-3. 12 TLD Locations in Communities Located Within a 30-Mile Radius of RFP 
RESULTS

dosimeter. Quality control dosimeters are also read with each processing file to ensure that the variability in the dosimeter readers is within established limits. The annual dose equivalent for each location category (Table 5-1) or individual location (Tables 5-2 through $5-4)$ is calculated by determining the average millirem per day (mrem/day), using data from the four quarters of 1993. These values are then multiplied by 365.25 to obtain yearly totals.

The 1993 environmental gamma measurements using TLDs are summarized in Table 5-1. The average annual dose equivalents, as measured onsite, in the perimeter environments, and in local communities using model UD-802AS Panasonic TLDs were 137, 122 and 132 mrem, (1.37, 1.22, and 1.32 milliSieverts [mSv]), respectively. The model UD-814AS dosimeters resulted in measurements of 142,127 , and 137 mrem. (1.42, 1.27 , and $1.37 \mathrm{mSv}$ ), respectively. These values are similar to those reported by the National Council on Radiation Protection and Measurements (NCRP) for background gamma radiation in the Denver area. The NCRP reported an annual range of 125 to $190 \mathrm{mrem}$ (1.25 to $1.90 \mathrm{mSv}$ ) (NAT87b). The average annual dose equivalent by monitoring location is provided in Tables 5-2, 5-3, and 5-4. 
Table 5-3

CY 1993 Perimeter Environmental TLD Measurements

\begin{tabular}{ccccr} 
Location & \multicolumn{2}{c}{$\begin{array}{c}\text { Panasonic UD-802AS } \\
\text { Average } \\
\text { (mrem) }\end{array}$} & $\begin{array}{c}\text { 1.96 Standard } \\
\text { Deviations }\end{array}$ & \multicolumn{2}{c}{$\begin{array}{c}\text { Panasonic } \\
\text { Average } \\
\text { (mrem) }\end{array}$} & $\begin{array}{r}\text { UD-814AS } \\
\text { 1.96 Stand } \\
\text { Deviations }\end{array}$ \\
\cline { 1 - 2 } 18 & 140 & 20 & 143 & 35 \\
26 & 123 & 31 & 130 & 32 \\
27 & 127 & 32 & 136 & 34 \\
28 & 129 & 18 & 134 & 37 \\
32 & 118 & 28 & 120 & 40 \\
33 & 138 & 40 & 134 & 42 \\
34 & 125 & 41 & 138 & 43 \\
35 & 105 & 31 & 123 & 41 \\
36 & 114 & 50 & 121 & 39 \\
37 & 112 & 23 & 119 & 38 \\
38 & 126 & 27 & 128 & 42 \\
39 & 122 & 36 & 125 & 36 \\
81 & 117 & 37 & 123 & 36 \\
82 & 118 & 47 & 123 & 40 \\
83 & 120 & 48 & 122 & 26 \\
84 & 115 & 31 & 120 & 26
\end{tabular}

a. Average mrem $=122,1.96$ standard deviations of the individual measurements $=36$. 1.96 standard deviations of the mean $=2$

b. Average mean $=127,1.96$ standard deviations of the individual measurements $=49$ 1.96 standard deviations of the mean $=3$

Table 5-4

CY 1993 Community Environmental TLD Measurements

\begin{tabular}{|c|c|c|c|c|c|}
\hline \multirow[b]{2}{*}{ Location } & \multirow[b]{2}{*}{ Community } & \multicolumn{2}{|c|}{ Panasonic UD-802AS ${ }^{\mathrm{a}}$} & \multicolumn{2}{|c|}{ Panasonic UD-814AS ${ }^{b}$} \\
\hline & & $\begin{array}{l}\text { Average } \\
\text { (mrem) }\end{array}$ & $\begin{array}{l}1.96 \text { Standard } \\
\text { Deviations }\end{array}$ & $\begin{array}{l}\text { Average } \\
\text { (mrem) }\end{array}$ & $\begin{array}{c}1.96 \text { Standard } \\
\text { Deviations }\end{array}$ \\
\hline S11 & Coal Creek & 131 & 34 & 143 & 35 \\
\hline S13 & Marshall & 135 & 22 & 137 & 39 \\
\hline S14 & Arvada & 114 & 33 & 128 & 45 \\
\hline S15 & Boulder & 136 & 26 & 136 & 33 \\
\hline S16 & Laiayette & 142 & 35 & 148 & 39 \\
\hline S17 & Broomfield & 138 & 31 & 133 & 36 \\
\hline S19 & Longmont & 146 & 34 & 145 & 38 \\
\hline $\mathrm{S} 20$ & Golden & 131 & 12 & 137 & 37 \\
\hline S23 & Denver & 127 & 29 & 156 & 39 \\
\hline S25 & Westminster & 133 & 22 & 136 & 42 \\
\hline S31 & Superior & 124 & 15 & 125 & 39 \\
\hline S90 & Northglenn & 128 & 39 & 121 & 33 \\
\hline
\end{tabular}

a. Average mrem $=132,1.96$ standard deviations of the individual measurements $=30,1.96$ standard deviations of the mean $=1$.

b. Average mrem $=137,1.96$ standard deviations of the individual measurements $=40,1.96$ standard deviations of the mean $=2$. 


\section{Radiation Dose Assessment}

Radiation dose assessment for the Rocky Flats Plant is based on monitoring data from air, water, and soil sampling programs. The 1993 assessment of dose to the public from RFP activities indicates that the radiation dose to the maximally exposed individual in the public is estimated to be 0.48 millirem effective dose equivalent (EDE). For comparison, the average person in the United States receives approximately 300 millirem EDE from natural background radiation sources. 
- 
ROCKY FLATS PLANT RADIOACTIVE MATERIALS
Radicactive materials included in estimating radiation dose to the public from RFP activities are plutonium, uranium, americium, and tritium. Plutonium and americium in RFP environs are the combined result of residual fallout deposition from global atmospheric nuclear weapons testing and releases from the plant. Uranium, a naturally occurring element, is indigenous to many parts of Colorado and is used in RFP operations in various isotopic ratios. Tritium, which is both naturally occurring and produced artificially, is sometimes handled in RFP operations.

In the dose assessment performed for CY93, internal exposure to alpha radiation emissions from water ingestion of plutonium, uranium, and americium is the primary contributor to the projected radiation dose. Typically, radiation doses that members of the public might receive as a result of RFP activities are much less than those doses received from naturally occurring radiation sources, and are well below applicable limits of the public.

The 1993 radiation dose assessment includes modifications to assumptions used in pre-1991 annual site environmental reports for potential pathways of exposure to the public. The 1993 assumptions are intended to reflect potential exposure conditions more accurately. In pre-1991 annual RFP site environmental reports, the approach taken for dose assessment was extremely conservative, based on assumptions for a hypothetical individual that would tend to maximize the resulting dose estimate, but which were known to be unrepresentative of actual living habits in the RFP area. DOE Order 5400.5 encourages the use of more realistic, but still conservative, approaches to dose assessment. The approach documented in this 1993 report is believed to be more realistic than in previous reports in reflecting actual residential areas and pathways of exposure in the RFP vicinity. However, the 1993 report approach continues to employ conservative assumptions of intake rates, exposure duration, and solubility of radioactive contaminants. Adding to the conservatism is the lack of subtraction of background (non-RFP related) contributions of radioactive contaminants in air and soil concentrations and in water concentrations for radionuclides other than uranium. 
Background is not subtracted from the nonuranium concentrations because these materials are not distributed uniformly in the environment and it is difficult to define concentrations that could be used to represent background contributions. Since radiation dose to the public from these radioactive materials is extremely low even when including the background component. it is considered preferable to include background in the dose assessment, rather than risk subtracting a nonrepresentative background value.

The assumptions made for the water ingestion pathway also continue to be conservative. The source of potential water ingestion, Pond $\mathrm{C}-2$ discharges, was chosen to provide an upper bound to radioactivity concentrations for water ingestion, although it is known that no individual is actually using Pond $\mathrm{C}-2$ as a drinking water supply at this location. Throughout 1993, RFP surface water effluents were diverted around nearby municipal raw water supplies to the South Platte River. As data for other monitoring locations become available in the future, more realistic assumptions regarding this pathway may be made. Background subtraction is performed only for uranium concentrations in this water source term. Correction for background uranium concentrations in water is made because of the large relative contribution to this pathway from naturally occurring uranium.

Beginning in 1991, direct ingestion of soil was added to the exposure scenario, consistent with recommendations by the EPA for performance of risk assessments (EPA89a).

Previous pathway assessments in the Environmental impact Statement, Rocky Flats Plant Site indicate that swimming and consumption of foodstuffs are relatively insignificant contributors to public radiation dose (DOE80). Swimming and fishing are limited in the area, and most locally consumed food is produced at considerable distances from the plant. A pathway analysis review performed under contract to RFP by the Colorado State University (CSU) Department of Radiological Health Sciences confirmed the relative insignificance of these pathways (FRA92).

The results of the 1993 assessment of dose to the public from RFP activities indicate that the radiation dose 
to be maximally exposed individual in the public is estimated to be 0.48 millirem $\left(4.8 \times 10^{-3} \mathrm{mSv}\right)$ effective dose equivalent (EDE). The greatest contributor (more than 74 percent) to the estimated dose to the maximally exposed individual is ingestion of uranium ( 56 percent), plutonium ( 16 percent), and americium ( 2 percent) in water. The collective population dose to a distance of 80 kilometers (50 miles) is estimated as 0.1 person-rem $\left(0.1 \times 10^{-2}\right.$ person-sievert [Sv]). These calculated radiation doses are believed to be conservative estimates that would be an upper bound for any radiation doses actually received by the public. More specific information regarding the 1993 radiation dose assessment follows.

Radiation Protection Standards for the Public
Standards for protection of the public from radiation are based on radiation dose, which is a means of quantifying the biological effect or risk of ionizing radiation. In this report, the term "dose" is used broadly to refer to the radiation protection concepts of dose equivalent and effective dose equivalent, which are described later in the report. In the United States, the unit commonly used to express radiation dose is the rem or the millirem ( $1 \mathrm{rem}=1,000 \mathrm{mrem}$ ). The comparable International System (le Systeme International D'Unites or SI) unit of radiation dose is the sievert (1 sievert $[\mathrm{Sv}]=100 \mathrm{rem}$ ). Radiation protection standards for the public are annual standards, based on the projected radiation dose from a one-year exposure to radiation or intake of radioactive materials.

Radiation protection standards applicable to DOE facilities are based on recommendations of national and international radiation protection advisory groups and on radiation protection standards set by other federal agencies. On February 8, 1990, DOE adopted revised radiation protection standards for DOE environmental activities (DOE90a). These standards incorporate guidance from the NCRP, the International Commission on Radiological Protection (ICRP), and the EPA Clean Air Act NESHAP, as implemented in 40 CFR Part 61, Subpart H (EPA85). Effective December 15, 1989, EPA revised NESHAP standards for airborne emissions of radionuclides from DOE facilities (EPA89a). These new NESHAP standards apply to air emissions from RFP in 1993 and are incorporated into the revised DOE standards. 
Table 6-6 and Appendix B, Table B-1, summarize the revised $D O E$ radiation protection standards for the public as established in 1990. The revised NESHAP standards of December 15, 1989 are also included.

Radiation Dose

In this 1993 dose assessment, radiation dose is calculated by multiplying radioactivity concentrations in air, water. and soil by DOE prescribed intake rates (for internal exposures) or exposure times (for external exposure to penetrating radiation). These products then are multiplied by the appropriate radiation dose conversion factors as follows:

\section{Radiation Dose $=$ (Radioactivity Concentration) $\mathrm{X}$ (Intake Rate or Exposure Time) X (Radiation Dose Conversion Factor)}

In calculating radiation dose equivalent, differences in the biological effect of different types of ionizing radiation (e.g., alpha, beta, gamma rays, or X rays) are accounted for in the dose conversion factor. Radiation energy absorbed in the tissue of interest is calculated and then multiplied by a modification factor based on the type and energy of the ionizing radiation involved. One millirem of dose equivalent from alpha radiation would have the same biological effectiveness on a particular organ as one millirem of dose equivalent from gamma radiation. Dose equivalent can be calculated for the whole body when there is uniform irradiation of all tissues, or for individual organs when selected tissues are irradiated nonuniformly.

In $1985, \mathrm{DOE}$ adopted radiation protection standards for the public based on the concept of EDE. The December 15, 1989 NESHAP standards also incorporate EDE as the basis for radiation protection for the public from airborne emissions of radioactivity. Previously, whole body dose equivalent and individual organ dose equivalent, as described above, were used for this purpose. The following dose assessment for 1993 uses EDE as the basis for radiation protection of the public, but it includes some individual organ dose equivalents for comparison with previous RFP annual reports.

EDE is a means of calculating radiation dose that allows comparisons of the total health risk of cancer mortality and serious genetic effects from exposures of 
different types of ionizing radiation to different body organs. EDE is calculated by first determining the dose equivalent to those organs receiving significant exposures. multiplying each organ dose equivalent by a health risk weighting factor, and summing those products. The health risk weighting factors used in the calculation of EDE normalize the risk against a whole body radiation dose. Therefore, the health risk (from cancer mortality and genetic damage) that is associated with 1 mrem of EDE is comparable to the risk associated with 1 mrem of whole body dose equivalent. Likewise, 1 mrem of EDE from natural background radiation would have the same health risk as 1 mrem of EDE from artificially produced sources of radiation, regardless of which organ(s) receives the dose.

Radioactivity concentrations or source terms used in calculating dose can be determined from actual samples and measurements in the environment taken at the locations of interest. Alternatively, for airborne releases, these concentrations can be calculated by modeling the atmospheric dispersion of air emissions from buildings and contaminated land areas.

In the following dose assessment, actual environmental measurements near locations of interest are used to determine compliance with the DOE radiation standard for all pathways. These measurements are used to calculate annual average concentrations of radioactive materials in air and soil at the RFP boundary and for the water pathway at the Pond $\mathrm{C}-2$ discharge point.

As required in federal regulation 40 CFR Part 61, an EPA-approved computer code is used to determine compliance with NESHAP radionuclide emissions standards for the air pathway only. The EPA-approved code, CAP88-PC, includes air dispersion modeling of measured air emissions from buildings and contaminated land areas, as well as dose conversion factors for calculating final radiation dose.

Intake Rate or

Intake rates of radioactive materials used to represent Exposure Time air inhalation and water ingestion for 1 year are prescribed by DOE (DOE88b, DOE90a). The rates for air and water are based on recommendations of the ICRP (INT75). The breathing and water ingestion rates for 1 year are 8,400 cubic meters and 730 liters, 


\section{Radiation Dose Conversion Factors}

respectively. The EPA provides recommendations for soil ingestion rates in Risk Assessment Guidance for Superfund, Volume I, Human Health Evaluation Manual (Part A) (EPA89b). The EPA guidance for direct ingestion of soil by an adult is 100 milligrams per day. Exposure times for external penetrating radiation are assumed to be 1 year, as prescribed by DOE (DOE90a).

Radiation dose conversion factors used for determining compliance with DOE standards for all pathways are prescribed by DOE (DOE88a, DOE88b, DOE90a). Dose conversion factors for internal exposures are based on recommendations of the ICRP (INT79). Dose conversion factors for external exposures to penetrating radiation are based on a methodology developed at Oak Ridge National Laboratory (ORNL) (KOC8 1, KOC83), with modifications by the original author (DOE88a).

The plutonium handled at RFP is a mixture of plutonium isotopes having different atomic masses and may include americium-241. Relative abundances of plutonium and americium isotopes in plutonium typically used at RFP (Table 6-1) were used to calculate composite dose conversion factors for plutonium and americium in air and for plutonium in water and soil. The relative abundances used in developing the composite dose conversion factors were based on the isotopic activity fractions of plutonium-239 and -240 , since these are the isotopes measured in environmental monitoring sample analyses. Fractions of ingested radionuclides absorbed from the gastrointestinal tract and lung clearance classes for inhaled radionuclides were chosen to maximize the associated internal dose conversion factors and the resulting radiation dose. Each internal dose conversion factor is for a 50-year dose commitment from 1 year of chronic exposure; that is, the dose that an individual could receive for 50 years from 1 year of chronic intake of radioactive material is calculated. The dose conversion factors used in this assessment are listed in Table 6-2. These dose conversion factors incorporate the intake rates and exposure times discussed above. 
Table 6-1

Isotopic Composition of Plutonium Used at RFP

\begin{tabular}{|c|c|c|c|c|c|}
\hline Isotope & $\begin{array}{l}\text { Relative Weight } \\
\text { (Percent) }\end{array}$ & $\begin{array}{l}\text { Specific Activity } \\
\text { (Ci/g) }\end{array}$ & $\begin{array}{l}\text { Relative Activity }{ }^{a} \\
\text { (Ci/g) }\end{array}$ & $\begin{array}{l}\text { Contribution } \\
\text { Compared } \\
\text { to } \mathrm{Pu} \\
\text { Alpha Activity }\end{array}$ & $\begin{array}{c}\text { Contribution } \\
\text { Compared } \\
\text { to Pu-239, } \\
-240 \text { Activity }^{c}\end{array}$ \\
\hline Pu-238 & 0.01 & 17.1 & 0.00171 & 0.0233 & 0.0239 \\
\hline Pu-239 & 93.79 & 0.0622 & 0.05834 & 0.7962 & 0.8153 \\
\hline Pu-240 & 5.80 & 0.228 & 0.01322 & 0.1804 & 0.1847 \\
\hline Pu-241 & 0.36 & $103.5^{\mathrm{d}}$ & $0.37260^{\circ}$ & $5.085^{d}$ & 5.207 \\
\hline Pu-242 & 0.03 & 0.00393 & $1.18 \times 10^{-6}$ & $1.61 \times 10^{-5}$ & $1.65 \times 10^{-5}$ \\
\hline Am-241 & - & - & - & $0.20^{\epsilon}$ & 0.205 \\
\hline
\end{tabular}

a. Obtained by multiplying the relative weight percent by the specific activity.

b. Obtained by dividing the relative activity by the sum of the relative activities for the plutonium alpha emitters.

c. Obtained by dividing the relative activity by the sum of the relative activities of Pu-239 and Pu-240.

d. Beta activity.

e. The value for Am-241 is taken to be 20 percent of the plutonium alpha activity. 


\section{Table 6-2}

\section{Dose Conversion Factors Used in Dose Assessment Calculations}

for RFP in 1993

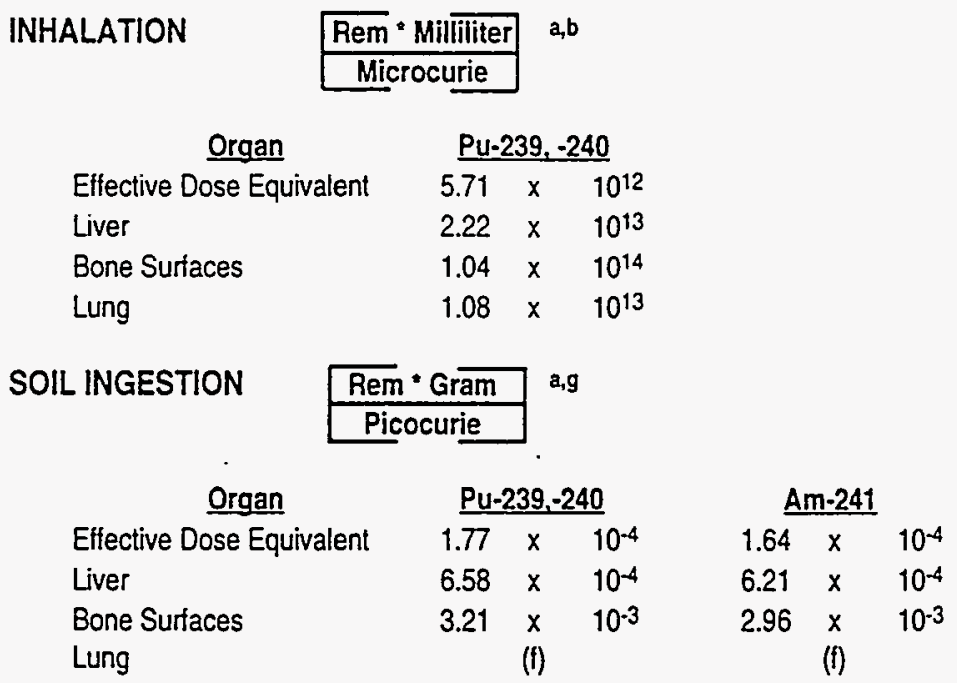

\section{WATER INGESTION $\overline{\text { Rem }} \cdot$ Milliliter $a, c$ Microcurie}

\begin{tabular}{|c|c|c|c|c|c|c|c|c|c|c|c|c|}
\hline Organ & \multicolumn{3}{|c|}{ Pu-239,-240 } & \multicolumn{3}{|c|}{ Am-241 } & \multicolumn{3}{|c|}{$\mathrm{U}-233 /-234$} & \multicolumn{3}{|c|}{$\underline{U-238}$} \\
\hline Effective Dose Equivalent & 3.53 & $x$ & $10^{6}$ & 3.29 & $x$ & $10^{6}$ & 1.90 & $\mathrm{x}$ & $10^{5}$ & 1.70 & $x$ & $10^{5}$ \\
\hline Liver & 1.32 & $x$ & $10^{7}$ & 1.24 & $x$ & $10^{7}$ & & (e) & & & (e) & \\
\hline $\begin{array}{l}\text { Bone Surfaces } \\
\text { Lung }\end{array}$ & 6.42 & $\begin{array}{l}x \\
\text { (f) }\end{array}$ & $10^{7}$ & 5.91 & $\begin{array}{c}x \\
\text { (i) }\end{array}$ & $10^{7}$ & 2.99 & $\begin{array}{c}x \\
\text { (f) }\end{array}$ & $10^{6}$ & 2.70 & $\begin{array}{c}x \\
\text { (f) }\end{array}$ & \\
\hline
\end{tabular}

\section{GROUND-PLANE IRRADIATION $\frac{\text { Rem } * \text { Square Meter }}{\text { Microcurie }}$ d}

\begin{tabular}{llllllll}
\multicolumn{1}{c}{ Organ } & \multicolumn{3}{c}{ Pu-239.-240 } & \multicolumn{3}{c}{ Am-241 } \\
Effective Dose Equivalent & 4.80 & $\times$ & $10^{-5}$ & & 2.99 & $\times$ & $10^{-3}$ \\
Liver & 4.53 & $\times$ & $10^{-6}$ & & 1.78 & $\times$ & $10^{-3}$ \\
Bone Surfaces & 1.62 & $\times$ & $10^{-5}$ & & 3.69 & $\times$ & $10^{-3}$ \\
Lung & 9.78 & $\times$ & $10^{-6}$ & & 2.01 & $\times$ & $10^{-3}$
\end{tabular}

a Inhalation, water, and soil ingestion dose conversion factors were adapted from DOE/EH-0071 (DOE88b) and are for a 50-yr dose commitment period and a 1-micrometer $(\mu \mathrm{m})$ Activity Median Aerodynamic Diameter (AMAD) particle size. Gastrointestinal (GI) absorption fractions and lung clearance classes were chosen to maximize the dose conversion factors.

b. An inhalation rate of $2.66 \times 10^{2}$ milliliters per second $(\mathrm{ml} / \mathrm{s})$ for 1 year was assumed and incorporated into the dose conversion factor.

c. A water intake rate of $2 \times 10^{3} \mathrm{ml}(2.1$ quarts) per day for 1 year was assumed.

d. Ground-plane irradiation dose conversion factors were adapted from DOE/EH-0070 (DOE88a). For Pu-239 and -240, the higher of the factors for the two isotopes was used. A 1-year exposure period was assumed.

e. The liver receives no significant dose from this pathway.

f. The lung receives no significant dose from this pathway.

g. A soil ingestion rate of 100 milligrams per day for 1 year was assumed and incorporated into the dose conversion factor. 
The EPA-approved computer code CAP88-PC, used to determine compliance with the NESHAP standard for the air pathway, incorporates EPAss own approved dose conversion factors. Measured plutonium emissions were modeled for the isotopes plutonium-238/-239 and -240 . Specific analyses for plutonium-241 and -242 are not performed on environmental samples but these isotopes would be relatively insignificant contributors to total dose. Plutonium-241 emits primarily beta radiation with a very small internal dose conversion factor; plutonium-242 emits primarily alpha radiation, but is a small component of the total plutonium activity mix (Table 6-1). The CAP88-PC default values for lung clearance class and gastrointestinal uptake fraction were used when running this code.

Maximum Plant Boundary Dose
A dose assessment for 1993 was conducted for the RFP property boundary and several sites to a distance of 80 kilometers (50 miles). DOE Order 5400.5 (DOE90a) requires that doses calculated for demonstration of compliance with applicable standards "...be as realistic as practicable. Consequently, all factors germane to dose determination should be applied. Alternatively, if available data are not sufficient to evaluate these factors or if they are too costly to determine, the assumed parametric values shall be sufficiently conservative so that it is unlikely that individuals would actually receive a dose that would exceed the dose calculated using the values assumed."

In pre-1991 annual RFP site environmental reports, the approach taken for dose assessment was extremely conservative based on assumptions for a hypothetical individual that would tend to maximize the resulting dose estimate; however, these assumptions were known to be unrepresentative of actual living habits in the RFP area. For example, it was assumed that the hypothetical member of the public was residing continuously during the year at the RFP boundary at the location for which the highest average plutonium in air concentration was measured for the year. The location might change from year to year, depending on where that maximum concentration was measured. The maximum plutonium and americium soil concentrations measured near the RFP boundary were used in calculating potential exposure from contaminated soil, even though noindividual actually lived near the location for those maxima. 
In this 1993 report, more realistic, but stil conservative, assumptions are made for dose assessment in conformance with the DOE Order $\$ 400.5$ guidance.

Environmental monitoring data are used from sample locations nearer areas of actual residence. The nearest housing to RFP is located near the southeast boundary of the plant. Sampling locations were chosen that are near this boundary but generally upwind or upgradient of existing housing, and between the housing and RFP processing facilities. Following is a description of the radionuclide concentrations (source terms) used for calculating the maximum radiation dose to the public for all pathways and the results of that calculation.

The soil ingestion source terms and the ground-plane source terms of penetrating radiation exposure from contaminated soil areas are based on measured concentrations of plutonium in soil and an assumed ratio of 0.20 for the americium-241 to plutonium-239, -240 activity. Inhalation source terms for the 1993 dose assessment were based on plutonium-239, -240 concentrations measured in ambient air samples. Although it is known that some of this plutonium in soil and air is from residual fallout from past global atmospheric weapons testing, for the purposes of this dose assessment it was conservatively assumed that all plutonium originated from RFP.

The maximum site boundary dose assessment assumes that an individual is present continuously at the RFP perimeter. This assumption of an individual residing continuously at the plant boundary is used to provide a conservative upper bound on any radiation dose to the public that might originate from RFP.

The plutonium inhalation source term of $1.4 \times 10^{-17}$ $\mu \mathrm{Ci} / \mathrm{ml}\left(5.1 \times 10^{-7} \mathrm{~Bq} / \mathrm{m}^{3}\right)$ was the annual average concentration of plutonium-239 and -240 , as measured at the S-38 location in the perimeter ambient air sampling network. The S-38 location is the closest plant perimeter air sampling location upwind of housing located nearest to the plant in the southeast direction. This housing is near the RFP boundary.

The water supply for a hypothetical individual at the RFP boundary was assumed to be Pond C-2, which receives surface-water runoff and, potentially, some seepage of contaminated alluvial groundwater from 
RFP. Pond C-2 is intermittently discharged offsite. It should be noted that the assumption that someone may drink this water is believed to be extremely conservative, leading to an overestimate of dose to the individual. No individual uses Pond C-2 water effluent at its discharge point as a finished drinking water supply, and during 1993 no surface-water effluent from RFP went directly to any drinking water supply. Plant surfacewater effluents were diverted around Great Western Reservoir and Standley Lake during 1993. Following diversion, these waters flowed from Walnut Creek to Big Dry Creek and subsequently to the South Platte River. The RFP contribution to total flow in the South Platte River would be less than 0.2 percent based on South Platte River flow, as measured at the Henderson, Colorado, gaging station during water year 1993 (October 1992 - September 1993) (UGL94).

Municipal water supplies near RFP do not serve the residences nearest the plant. For these residences, drinking water is likely from well water or bottled water sources. Currently, evidence suggests that no offsite drinking water wells have been contaminated with radioactive materials as a result of RFP activities. Extensive characterization of background radioactivity concentrations in groundwater and the hydrogeology of RFP are in progress.

During 1993, plutonium concentrations in Pond C-2 averaged $2.3 \times 10^{-11} \mu \mathrm{Ci} / \mathrm{ml}\left(8.1 \times 10^{-4} \mathrm{~Bq} / \mathrm{l}\right)$. Average americium concentration was $3.0 \times 10^{-12} \mu \mathrm{Ci} / \mathrm{ml}(1.1 \times$ $\left.10^{-4} \mathrm{~Bq} / \mathrm{l}\right)$. These concentrations were used as the water ingestion source term for the maximum individual dose assessment. Uranium-233/-234 average concentration in Pond C-2 was $1.1 \times 10^{-9} \mu \mathrm{Ci} / \mathrm{ml}\left(4.0 \times 10^{-2} \mathrm{~Bq} / \mathrm{l}\right)$ and the average concentration of uranium-238 in Pond C-2 was $1.2 \times 10^{-9} \mu \mathrm{Ci} / \mathrm{ml}\left(4.5 \times 10^{-2} \mathrm{~Bq} / \mathrm{l}\right)$. The average concentrations of uranium-233/-234 and -238 in incoming raw water were $4.5 \times 10^{-10} \mu \mathrm{Ci} / \mathrm{ml}(1.7 \mathrm{x}$ $\left.10^{-2} \mathrm{~Bq} / \mathrm{I}\right)$ and $3.6 \times 10^{-10} \mu \mathrm{Ci} / \mathrm{ml}\left(1.3 \times 10^{-2} \mathrm{~Bq} / \mathrm{l}\right)$, respectively. The source terms used for uranium ingestion were the difference between the Pond C-2 and raw water concentrations for each of the two uranium isotope categories: $6.3 \times 10^{-10} \mu \mathrm{Ci} / \mathrm{ml}\left(2.3 \times 10^{-2} \mathrm{~Bq} / \mathrm{l}\right)$ for uranium-233/-234 and $8.6 \times 10^{-9} \mu \mathrm{Ci} / \mathrm{ml}\left(3.2 \times 10^{-2}\right.$ $\mathrm{Bq} / \mathrm{l})$ for uranium-238. The average tritium concentration in Pond C-2 was less than zero, reflecting the statistical variation that can occur when measuring nearzero concentrations of radioactive materials. (See Appendix $D$ for further explanation of negative values.) 
Tritiun is a relatively insignificant contributor to dose at low' concentrations because the radiation it emits is a very low energy beta radiation that has a relatively small dose conversion factor.

A potential exposure pathway added to the RFP radiation dose assessment in 1991 is direct ingestion of contaminated soil. Inclusion of this pathway is consistent with approaches to risk assessment suggested by the EPA in Risk Assessment Guidance for Superfund, Volume I, Human Health Evaluation Manual (Part A) (EPA89b). An intake rate of $100 \mathrm{mg} /$ day is assumed for this pathway. The plutonium-239, -240 in soil concentration from onsite sampling location 2-126 was taken as conservatively representative of soil for residences nearest RFP. Americium-241 was calculated to be 20 percent of the plutonium-239, -240 concentration, based on maximum ingrowth of americium-241 from plutonium-241 in typical RFP weapons-grade plutonium (DOE80). The 1993 measured plutonium-239, -240 concentration in soil at the $2-126$ location is $0.18 \mathrm{pCi} / \mathrm{g}$ $\left(6.7 \times 10^{-3} \mathrm{Bg} / \mathrm{g}\right.$ ) (see Figure 3.5-1 and Table 3.5-1 in Section 3.5, "Soil Monitoring.") The calculated americium-241 concentration is $3.6 \times 10^{-2} \mathrm{pCi} / \mathrm{g}\left(1.3 \times 10^{-3}\right.$ $\mathrm{Bq} / \mathrm{g})$.

Ground-plane irradiation by external penetrating radiation from contaminated soil areas is included as a potential pathway of exposure, although it is a relatively small contributor to dose. External penetrating radiation associated with radioactive materials of importance at RFP is generally of low energy and intensity. The ground-plane irradiation source term used for this assessment is again based on the plutonium concentration in soil measured at the onsite 2-126 location and an assumed soil density of 1 gram per cubic centimeter $\left(\mathrm{g} / \mathrm{cm}^{3}\right)$, and a sampling depth of $5 \mathrm{~cm}$ used to determine areal concentration. The plutonium-239, -240 areal source term is $9.0 \times 10^{-3} \mu \mathrm{Ci} / \mathrm{m}^{2}\left(3.3 \times 10^{2}\right.$ $\left.\mathrm{Bq} / \mathrm{m}^{2}\right)$. The americium source term is estimated at 1.8 $\times 10^{-3} \mu \mathrm{Ci} / \mathrm{m}^{2}\left(6.7 \times 10^{1} \mathrm{~Bq} / \mathrm{m}^{2}\right)$.

Table 6-3 summarizes the radionuclide concentrations used for calculating the estimate of maximum radiation dose to an individual member of the public from all the identified potential pathways of exposure. From these concentrations and dose conversion factors given in Table 6-2, a 50-year dose commitment of $4.8 \times 10^{-1}$ mrem $\left(4.8 \times 10^{-3} \mathrm{mSv}\right)$ is calculated as the EDE from all 
pattiways. The bone surfaces receive the highest calculated individual organ dose, $7.9 \mathrm{mrem}\left(7.9 \times 10^{-2} \mathrm{mSv}\right)$ (Table 6-4). The DOE radiation protection standard for members of the public for all pathways and for prolonged periods of exposure is $100 \mathrm{mrem} / \mathrm{yr}$ ( $1 \mathrm{mSv} / \mathrm{yr})$ EDE. The maximum site boundary dose in 1993 represents 0.48 percent of the standard for all pathways for EDE. This is in accordance with the DOE objective expressed in DOE Order 5400.5 that potential exposures to members of the public be as low as reasonably achievable (ALARA).

Table 6-3

Radioactivity Concentrations Used in Maximum Site Boundary Dose Calculations for All Pathways for 1993

\begin{tabular}{|c|c|c|c|c|c|c|c|c|}
\hline $\begin{array}{c}\text { Air } \\
(\mu \mathrm{Ci} / \mathrm{ml})\end{array}$ & \multicolumn{2}{|c|}{$\begin{array}{c}\text { Soil } \\
\text { (pCigg) }\end{array}$} & \multicolumn{2}{|c|}{$\begin{array}{l}\text { Surface Deposition } \\
\left(\mu \mathrm{Ci} / \mathrm{m}^{2}\right)\end{array}$} & \multicolumn{4}{|c|}{$\begin{array}{l}\text { Water } \\
(\mu \mathrm{Ci} / \mathrm{ml})\end{array}$} \\
\hline Pu-239,-240 & $\mathrm{Pu}_{\mathrm{u}-239,-240}$ & Am-241 & Pu-239,-240 & Am-241 & Pu-239,-240 & Am-241 & $\underline{U-233 /-234}$ & $\underline{U}-238$ \\
\hline $1.4 \times 10^{-17}$ & $1.8 \times 10^{-1}$ & $3.6 \times 10^{-2}$ & $9.0 \times 10^{-3}$ & $1.8 \times 10^{-3}$ & $2.2 \times 10^{-11}$ & $3.0 \times 10^{-12}$ & $6.3 \times 10^{-10}$ & $8.6 \times 10^{-10}$ \\
\hline
\end{tabular}

Table 6-4

50-Year Committed Dose Equivalent from 1 Year of Chronic Intake/Exposure from RFP in 1993

Radiation Dose from Air Pathway Only
EPA-approved methodology (EPA89a) is used to demonstrate compliance with NESHAP standards for airborne radioactivity emissions. As of December 15, 1989, the EPA-approved standard is based on meteorological/dose modeling of air emissions using the AIRDOS or CAP88-PC computer codes. Table 6-5 lists the 1993 radioactivity air emissions used as input to the CAP88-PC computer code. These emissions include building air effluent release values for the year as discussed in Section 3.2 and an estimate of resuspension of contaminated soil from RFP OUs. 
Table 6-5

Radionuclide Air Emissions for Input to CAP88-PC Computer Code 1993

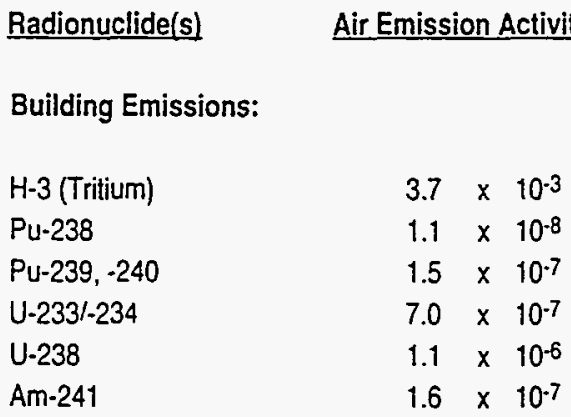

Estimated Soil Resuspension:

$\begin{array}{ll}\text { Pu-239, } 240 & 3.4 \times 10^{-5} \\ \text { Am-241 } & 5.7 \times 10^{-6} \\ \text { U-233/-234 } & 1.1 \times 10^{-6} \\ \text { U-235 } & 2.2 \times 10^{-7} \\ \text { U-238 } & 3.0 \times 10^{-8}\end{array}$

The RFP annual site environmental reports for 1989 and 1990 included an estimate of 903 Pad area (OU 2) soil resuspension that was developed in the RFP EIS. published in 1980 (DOE80). More recent field studies completed by RFP indicate that the EIS-estimated soil resuspension rate is likely to be considerably higher than is actually occurring, leading to a greatly conservative overestimate of radiation dose to the public using the EIS values. The $903 \mathrm{Pad}$ area soil resuspension source term used in the 1993 radiation dose assessment was based on more recent RFP field studies and is considered a more realistic estimate of resuspension (LAN91).

Beginning with the 1992 Site Environmental Report, estimates of soil resuspension were expanded to include OUs $1,4,5,6,7,8,9,10,11,12,13$, and 14 , in addition to the $903 \mathrm{Pad}$ area (OU 2). The resuspension rate developed from the $903 \mathrm{Pad}$ area field studies was used for the added OUs. These other OUs have lesser soil contamination levels, and soil concentration data for them is much more limited than for the $903 \mathrm{Pad}$ area. The estimates of resuspended contamination 
should only be considered preliminary and will be further refined as RFP site characterization is completed.

Meteorological input data for 1993, which were reformatted as required for input to the CAP88-PC calculations, are given in Tables $\mathrm{Cl}$ through $\mathrm{C7}$, Appendix $\mathrm{C}$. CAP88-PC default values for lung clearance class and gastrointestinal uptake fractions were used when running the code. The CAP88-PC default assumption of a $1-\mu \mathrm{m}$ activity median aerodynamic diameter (AMAD) particle size also was used.

The CAP88-PC computer code calculated an EDE from building air emissions of $1.7 \times 10^{-5} \mathrm{mrem}\left(1.7 \times 10^{-7}\right.$ $\mathrm{mSv}$ ) to the maximally exposed individual residing approximately 2.45 miles from the plant emissions points. The EDE from estimated soil resuspension was calculated as $1.6 \times 10^{-3}$ mrem $\left(1.6 \times 10^{-5} \mathrm{mSv}\right)$ to the maximally exposed individual residing approximately 2.1 miles from the $903 \mathrm{Pad}$ area.

\section{Collective Population Dose}

DOE Order 5400.5, promulgated February 8, 1990 , requires the assessment of collective population radiation dose to a distance of 80 kilometers ( 50 miles) from the center of a DOE facility (DOE90a). The assessment of maximum community dose (i.e., maximum dose to an individual in a neighboring community) that was presented in RFP annual site reports prior to 1990 is no longer included in the DOE approach to radiation dose assessment.

Collective population dose is calculated as the average radiation dose to an individual in a specified area, multiplied by the number of individuals in that area. In assessing the 1993 collective population dose to the public within a radius of 50 miles of RFP, the assessment was limited to airborne emissions of radioactive materials from the plant as the major contributor to population dose. Only two public raw water supplies, Great Western Reservoir and Standley Lake, can receive water directly from drainages crossing RFP, and all surface-water effluent from RFP was diverted around these water supplies during 1993. Soil contamination decreases rapidly with distance from RFP. In addition, most residential areas within this radius are likely to have new topsoil, sod, or otherwise modified soil conditions; agricultural areas represent a relatively small population. 
$\bullet$

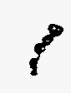

Population estimates provided by the Denver Regional Council of Governments (DRCOG). the State of Colorado, and some local municipalities near RFP were used to determine the 1993 population residing within 50 miles of RFP. An area defined by a circle of 50 -mile radius around the center of RFP was further divided into 16 equal se -tors, with segments formed by the intersection of the sectors and a total of 10 radial distances of $1,2,3,4,5,10,20,30,40$, and 50 miles (see Figure 6-1). The population within each segment for 1993 was based on 1990 U. S. census data and growth projections furnished by DRCOG, the State of Colorado, and local municipalities. In addition, for segments within a 10 -mile radius, segment populations were determined using the 1989 Population, Economic, and Land Use Database for Rocky Flats Plant (DOE90b) to modify population distributions. This was necessary because even the census tract data of DRCOG lacked the necessary spatial resolution for reasonable segment population estimates at distances near to RFP. Aerial photographs taken in May 1993 were used to verify the reasonableness of the population estimates for distances from 0 to 5 miles based on housing distribution as seen in these photographs.

The estimates of 1993 segment populations are given in Figure 6-1. Because the census-based estimates are for political jurisdictions that do not correspond to the geographical boundaries of the segments, the population estimates of Figure 6-1 should be considered approximations only. Total population for the area within a radius of 50 miles for 1993 was estimated at 2.2 million people.

The EPA atmospheric dispersion/radiation dose calculation computer code CAP88-PC was used to calculate the collective population dose within 50 miles of RFP. CAP88-PC is the same computer code that is used by RFP to demonstrate compliance with NESHAP requirements, as promulgated at 40 CFR Part 61 , Subpart H (EPA89a). Meteorological data that were collected for RFP during 1993, population estimates as discussed above. building air effluent radioactivity data, and estimates of soil resuspension radioactivity were used as input to the CAP88-PC code. EDEs were calculated by CAP88-PC to the midpoint of each segment's radial distance. These EDEs were used as estimates of the average radiation dose to an individual residing within the segment. 
These population estimates were calculated from 1990 census trac: data adjusted for yearly change through 1993, assuming unisorm population distribution throughout each section.

Concentric circles represent

1- 10 2-, 2-10 3-, 3- 10 4-.

4- to 5-, and 5-10 10-mile bands.
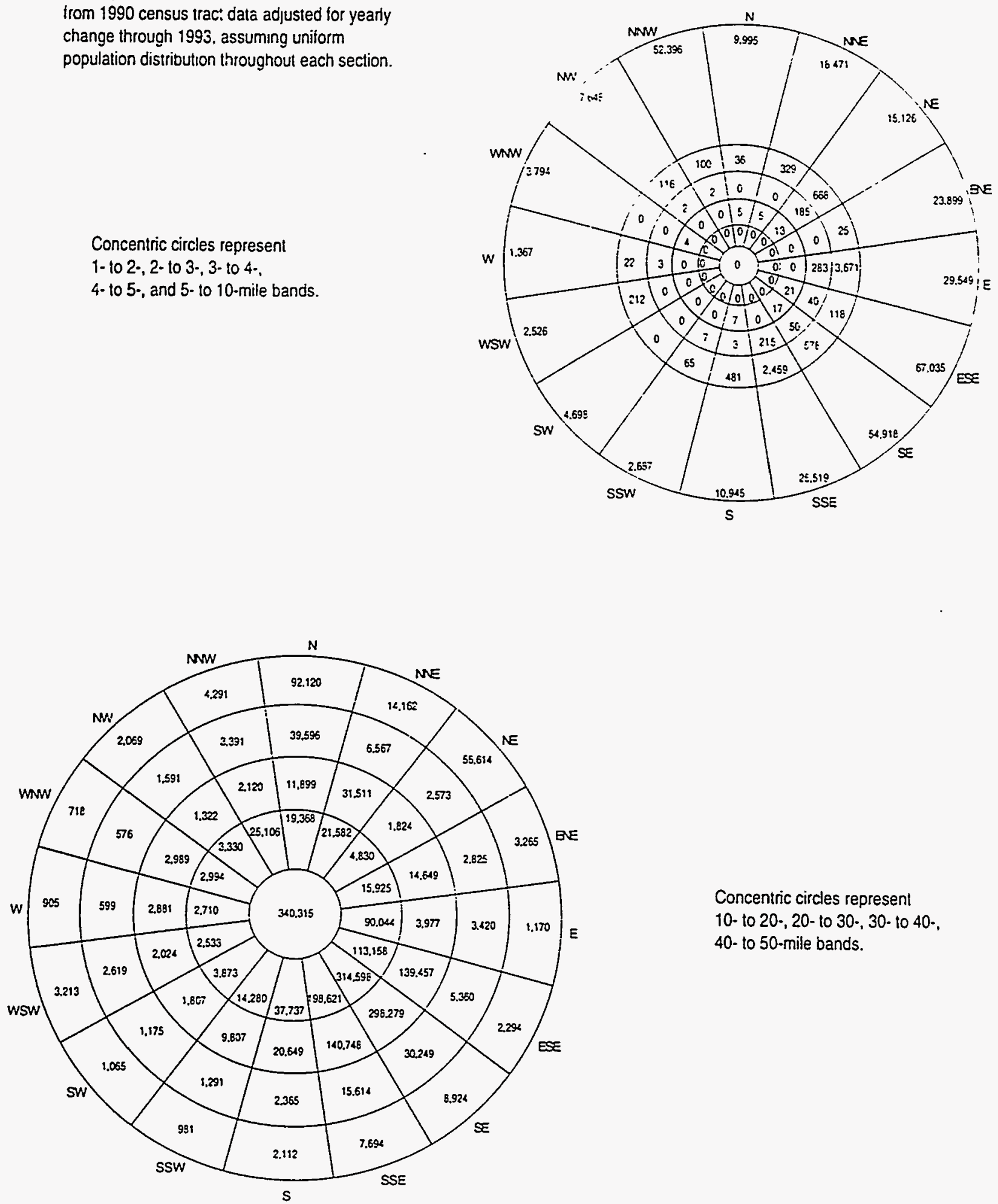

Concentric circles represent

10- to 20-, 20- 10 30-, 30- to 40-, 40- to 50 -mile bands.

Figure 6-1. 1993 Demographic Estimates for Areas $0-10$ and $10-50$ Miles from RFP 


\section{Natural Background Radiation Dose}

Multiplying the population (number of persons) within a segment by the average individual dose (in rem or sieverts. $1 \mathrm{~Sv}=100 \mathrm{rem}$ ) within the segment results in a calculated collective population dose for each segment in units of person-rem (or person-Sv). The total person-rem for all segments is the collective population dose for a distance of 50 miles around RFP, as presented in Table 6-6 for 1993. The collective population dose within 50 miles of RFP was calculated using the code CAP88-PC as 0.1 person-rem $\left(0.1 \times 10^{-2}\right.$ personSv). Significantly, the majority of this collective population dose results from estimated contaminated soil resuspension from the OUs of RFP. A very small contribution $\left(3 \times 10^{-3}\right.$ person-rem [ $3 \times 10^{-5}$ person-Sv]) is attributable to building air emissions for 1993.

EDEs from RFP may be compared to an average annual EDE for the Denver area currently estimated to be about 350 mrem ( $3.5 \mathrm{mSv}$ ) from natural background radiation (NAT87b) (Table 6-7). Natural background radiation for Denver is higher than shown for the total body in RFP annual reports prior to 1985 and also higher than shown for EDE in the 1985 and 1986 annual reports. The level reflects the most recent assessment of natural background radiation exposure of the population of the United States by the NCRP. It includes the significant contribution to EDE from inhaled indoor radon, as well as the adoption of the ICRP 30 methodology of radiation dosimetry. Cosmic radiation and external primordial nuclides sources shown in Table 6-7 reflect the regional dose levels for the Denver area from the higher elevation and greater concentration of naturally occurring uranium and thorium in soil. The internal primordial nuclides source includes the average dose from indoor radon estimated by the NCRP for the entire United States. Investigations are now being conducted to determine whether any regional differences in indoor radon doses exist. After these studies are completed and published, the estimates of natural background radiation dose for the Denver area may be modified to reflect indoor radon doses specific to this region. It is likely that estimates of the total radiation dose from naturally occurring radiation in the Denver area will increase as a result of these studies. Indoor radon concentrations appear to be higher in the Denver area than the national average, based on preliminary study results. 
Table 6-6

Calculated Radiation Dose to the Public

from 1 Year of Chronic Intake/Exposure from RFP in 1993

MAXIMUM INDIVIDUAL DOSE:

\begin{tabular}{|c|c|}
\hline All Pathways ${ }^{a}$ & $4.8 \times 10^{-1}$ mrem $\left(4.8 \times 10^{-3} \mathrm{mSv}\right.$ ) Effective Dose Equivalent (EDE) \\
\hline Building air emissions ${ }^{b}$ & $1.7 \times 10^{-5} \mathrm{mrem}\left(1.7 \times 10^{-7} \mathrm{mSv}\right) \mathrm{EDE}$ \\
\hline Estimated soil resuspension ${ }^{c}$ & $1.6 \times 10^{-3} \mathrm{mrem}\left(1.6 \times 10^{-5} \mathrm{mSv}\right) \mathrm{EDE}$ \\
\hline
\end{tabular}

COLLECTIVE POPULATION DOSE

TO $80 \mathrm{~km}$ (50 mi):

Building air emissions ${ }^{b}$

Estimated soil resuspension ${ }^{c}$

$3 \times 10^{-3}$ person-rem $\left(3 \times 10^{-5}\right.$ person-Sv) EDE

Total

0.1 person-rem $\left(0.1 \times 10^{-2}\right.$ person-Sv) EDE

0.1 person-rem $\left(0.1 \times 10^{-2}\right.$ person-Sv) EDE

ESTIMATED TOTAL POPULATION

WITHIN $80 \mathrm{~km}$ (50 mi):

$2.2 \times 10^{6}$ persons

DOE RADIATION PROTECTION

STANDARDS FOR THE PUBLIC: ${ }^{e}$

\section{All Pathways'}

Air Pathway only 9

ESTIMATED ANNUAL NATURAL BACKGROUND INDIVIDUAL RADIATION DOSE FOR THE DENVER METROPOLITAN AREA: ${ }^{h}$

\section{ESTIMATED ANNUAL NATURAL BACKGROUND COLLECTIVE POPULATION DOSE WITHI3 $80 \mathrm{~km}$ (50 mi):}

100 mrem ( $1 \mathrm{mSv}$ ) EDE, normal operations 500 mrem ( $5 \mathrm{mSv}$ ) EDE, temporary increase (only with prior approval of DOE EH-2) $10 \mathrm{mrem}\left(1 \times 10^{-1} \mathrm{mSv}\right)$ EDE

350 mrem (3.5 mSv) EDE

$7.7 \times 10^{5}$ person-rem $\left(7.7 \times 10^{3}\right.$ person-Sv) EDE

a. Calculated using environmental monitoring input data.

b. Calculated using CAP88-PC modeling of estimated and measured building air emissions.

c. Calculated using CAP88-PC modeling of estimated soil resuspension from RFP OUs 1-12.

d Based on estimates from information provided by the State of Colorado, the Denver Regional Council of Governments, and local municipalities.

e. From DOE Order 5400.5 . Excludes medical sources, consumer products, residual fallout from past nuclear accidents and weapons tests, and naturally occurring radiation sources (DOE90a).

f. Based on recommendations of the International Commission on Radiological Protection (ICRP) and the National Council on Radiation Protection and Measurements (NCRP).

9. Based on EPA Clean Air Act National Emission Standards for Hazardous Air Pollutants.

h. See Table 6-7 for further explanation of natural background radiation dose in the Denver Metropolitan area.

Note: In addition to the numerical dose standards listed above, it is the objective of DOE to maintain potential exposures to members of the public to ALARA levels. 


\section{Table 6-7}

Estimated Annual Natural Background Radiation Dose for the Denver Metropolitan Area

\begin{tabular}{lc}
\multicolumn{1}{c}{ Source } & $\begin{array}{c}\text { Effective Dose Equivalent } \\
\text { (mrem) }\end{array}$ \\
Cosmic Radiation $^{\mathrm{b}}$ & 50 \\
Cosmogenic Nuclides $^{\text {Prmordial Nuclides - External }}{ }^{\mathrm{C}}$ & 1 \\
Primordial Nuclides - Internal $^{\mathrm{d}}$ & 63 \\
Total for 1 Year (rounded) & 239
\end{tabular}

a. National Council on Radiation Protection and Measurements, Exposure of the Popoulation on the United States and Canada from Natural Background Radiation, NCRP Report No. 94, Bethesda, Maryland, December 30, 1987.

b. Includes regional increase over U.S. average as a result of the greater elevation of the Denver area.

c. Includes regional increase over U.S. average as a result of the higher concentrations of uranium and thorium in soil in the Denver area.

d. Includes U.S. average indoor radon dose contribution. This value likely will increase when regional indoor radon differences for the Denver area are determined. 


\section{Quality Assurance and Quality Control}

Continuous improvement in Rocky Flats' comprehensive environmental programs is the goal of Quality Assurance. It helps ensure that work is performed in a manner that protects worker and public health and safety, provides the quality of products and services necessary to meet program and project objectives, minimizes risk and environmental impacts, and helps ensure that programs are conducted in accordance with all applicable regulatory requirements. This section provides a detailed description of Quality Assurance measures in place at Rocky Flats. 


\section{OVERVIEW}

In October 1992, the Environmental Management (EM) Department was reorganized to separate environmental restoration and environmental monitoring functions into two organizational units. Environmental Restoration Management (ERM) became responsible for restoration activities, while Environmental Protection Management (EPM) maintained responsibility for various environmental monitoring, permitting, and reporting activities performed at RFP. As a result of the reorganization, it became necessary to revise the upper level environmental quality assurance (QA) documents to clearly define the scope of work and the division of responsibilities. Those revisions are currently in progress within ERM and have been completed within EPM.

Fundamentally, the Quality Assurance Plan Description (QAPD) (EGG92c) is used as the foundation QA document for ERM activities. A revision to the QAPD and associated support procedures to more accurately reflect the new organizational structure is scheduled for completion in 1994. The RFP Sitewide Quality Assurance Project Plan (QAPjP) (EGG91b), implements the requirements in the Interagency Agreement (IAG) between DOE, EPA, and CDH, and reflects the guidance of EPA's Interim Guidelines and specifications for preparing QAPjPs (QAM5-005/80). The QAPD is a flowdown from the site Quality Assurance Manual (QAM) and incorporates the requirements of the IAG, QAM, and DOE Order 5700.6C (which supersedes DOE Order $5480.6 \mathrm{~B}$ ). The QAPD is structured in accordance with the American Society of Mechanical Engineers NQA-1, Quality Assurance for Nuclear Facilities (ASM89) and will be used to set requirements for ERM activities.

QA requirements are established by the DOE, RFP, $\mathrm{CDH}$, and EPA and apply to both EPM and ERM activities. DOE Order 5400.1, General Environmental Protection Program, establishes QA requirements that apply to all DOE environmental monitoring and surveillance programs. The QAM consists of 22 quality requirements that are potentially applicable to all RFP programs, including environmental restoration and monitoring programs. Both DOE Order 5400.1 and the QAM reference $Q A$ requirements of DOE Order 
5700.6C, Quality Assurance. DOE Order 5700.6C endorses the 10 QA criteria and still implements the 18 QA criteria and supplemental requirements of the American Sociery of Mechanical Engineers NQA-1, Quality Assurance for Nuclear Facilities (ASM89). The IAG requires DOE to prepare and implement a QA Project Plan for the ER program activities specified in the IAG, which incorporates the 16 quality elements of EPA's Interim Guidelines and Specifications for Preparing Quality Assurance Project Plans (EPA80), as implemented through the QAPjP.

RFP received notification from DOE on December 31, 1991 to begin implementation of DOE Order 5700.6C, which facilitates the approach for empowerment of line management to achieve and maintain quality, as opposed to the approach used in DOE Order 5700.6B. The QAM was revised because of the implementation of DOE Order $5700.6 \mathrm{C}$ and because of the greater emphasis on environmental issues at RFP. The revision integrates the $10 \mathrm{QA}$ criteria of $5700.6 \mathrm{C}$ and the $18 \mathrm{QA}$ requirements of ASME NQA-1 into $22 \mathrm{QA}$ requirements. The QAM also incorporates the environmental requirements contained in EPA QAMS-005 and ANSIASQC E-4. Issuance of the ERM QAPD is anticipated by early 1994 and will implement DOE Order $5700.6 \mathrm{C}$ and fulfill the program-specific components for ERM.

\section{QA PROGRAM}

Both the EPM and ERM implement the RFP Quality Assurance Program and the QAM through their own respective Quality Assurance Plans. The Environmental Protection Management Plan (EPMP) (EGG93e) for EPM and the QAPD for ERM consist of a statement regarding the respective organizations' commitment to quality, an introduction, and sections which address the applicable and specific quality requirements of the QAM.

The following are some of the concepts and requirements for each QA Plan.

1) A graded approach is used to apply QA to environmental programs and projects, based on the risk of failure, loss, and human or environmental harm.

2) Procedures are prepared, reviewed, and approved for every environmental activity affecting quality. 
3) Organizational structures, functional responsibilities, levels of authority and interfaces are provided.

4) Individuals responsible for performing the work are responsible for achieving and maintaining quality.

5) Written personnel qualifications, training/indoctrination activities, and position descriptions are prepared for all personnel.

6) Responsibility for work may be delegated to other organizations, but ultimate responsibility is retained by the organization originally assigned.

7) Verification of overall quality performed by qualified persons or organizations not responsible for performing the work.

8) Environmental activities, including those performed by subcontractors and suppliers, are subject to audit and surveillance by the Site QA Organizations, which is in a department independent from environmental organizations.

9) Processes and activities will include means of preventing problems and improving quality.

Development of the QA process for environmental activities was initiated in 1990 . The process identified QA requirements that applied to environmental programs and projects, and established methods, controls, and responsibilities for meeting those requirements.

The EPM QA program approach, in implementation of QAM requirements, is described in the EPMP. The EPMP describes the roles, responsibilities, and interfaces of EPM as well as the means for achieving and ensuring quality of work and work products. Lower level EPM procedures on project plan development, training, inspections, and document review were issued in the fall of 1993. Issuance of procedures on program plan development and nonconformance reporting is anticipated by early 1994 . QA requirements for data collection, sampling, and chain of custody requirements are contained in lower level procedures which implement specific programs. 
The ER:M QA process integrated quality requirements established by DOE, RFP, EPA, and CDH. The ERM QA process consisted of (1) the QAPD, (2) the RFP Sitewide QAPJP for CERCLA RI/FS and RCRA FI/CMS Activities, and (3) Administrative and Operating Procedures. The requirements, methods, controls, and responsibilities established in the QAPD apply to all ERM programs and projects. Additionally, for RFP Environmental Remediation (ER) program activities required by the IAG, the QAPjP requirements also apply. Activities performed by EPM which support ERM meet the QA requirement specified in the QAPjP and QAPD.

The administrative procedures provide controls and direction for the performance of a program, project, or activity, while the operating procedures provide controls and direction for performance of routine operations and for the collection and analysis of environmental samples. ERM procedures are being developed to implement environmental programs in accordance with requirements of the IAG.

The QAPjP was approved by the EPA and $\mathrm{CDH}$ in May 1991. Based on a review by the EG\&G Rocky Flats QA Organization, the QAPD was revised significantly during 1993; approval and issuance is anticipated by early 1994 .

The QAPjP is supplemented by QA Addenda (QAA) that are prepared for each ER program work plan. QAA specify any additional quality requirements, quality controls, and methods that are specific to the work activities addressed by the respective work plan. QAA also address project-specific data quality objectives and reference applicable operating procedures. Additional quality requirements, data quality objectives, quality control, and methods are found in Technical Memoranda, Work Plans, and Sampling and Analysis Plans.

Environmental analyses are performed at RFP by the Analytical Laboratories, which are made up of subordinate laboratories. These include the Environmental Radiochemistry Laboratory located in Building 123 
and the General Organic, General Inorganic, and Gentral Radiochemistry Laboratories, which comprise the General Laboratories located in Building 881.

The Analytical Laboratories Quality Assurance Plan provides comprehensive guidance to ensure the quality of environmental data. This plan includes a description of the laboratory organization, functions, responsibilities, policies, and programs that comprise the overall QA program. Highlights of the program are provided below.

- Staff qualification and training

- Analytical procedure development, control, and compliance

- Laboratory records and sample handling protocols

- Analytical instrument calibration, control, and maintenance

- Reagent purity and standardization

- Measurement control (intralaboratory and interlaboratory programs) and data review

- Self-appraisals and corrective actions

Detailed quality control for the reliability of analytical data is provided in each analytical operating procedure. Typically, samples are analyzed in daily batches containing approximately 25 percent control samples. Control samples consist of various blanks, duplicates, standards, and spikes. This batching of samples and controls ensures reproducible, quality measurements. Traceable standards are prepared both independently and within the laboratory. Statistical evaluation in the form of precision and accuracy of the control samples determines the acceptability of the sample batch data relative to the data quality specifications agreed upon with the customer. If any samples require reanalysis, those samples are included in another Quality Control (QC) batch.

Any unusual condition that may affect the resuits, observed during sample collection, analysis, or QA review, is reported to appropriate management officials. QA provides written notification to management to suspend the analytical operation, pending review and corrective actions, when process control charts or other statistical evaluations indicate that the process is not in control (i.e., out of control). 
The Analytical Labor:turies participate in a number of independent blind sample programs to control and assess analytical measurements. More than 275 blind samples are submitted monthly to the Laboratory for the RFP Interactive Measurement Evaluation and Control System. This program provides feedback on analyses as well as monthly reports and meetings to review analytical results. Performance samples from EPA for the NPDES program are analyzed and evaluated annually. Environmental samples from the United States Geological Survey (USGS) are evaluated biunnually. The Laboratory participates in radiochemistry programs conducted by the EPA Environmental Monitoring Systems Laboratory and the DOE Environmental Measurements Laboratory (EML). The General Laboratory also purchases (from an independent commercial laboratory) a suite of water samples for a quarterly program administered by the laboratory QA officer. 


\section{References}


Rocky Flats Plant

Site Environmental Report for 1993 
ASME89 American Society of Mechanical Engineers NQA-1, Quality Assurance Program Requirements for Nuclear Facilities, New York, New York, 1989.

CDH73 Colorado Department of Health, State of Colorado Division of Occupational and Radiological Health, Denver, Colorado, 1973.

CDH77 Colorado Department of Health, State of Colorado, Water Quality Control Division, Primary Drinking Water Regulations Handbook, Denver, Colorado, effective December 15, 1977.

CDH78 Colorado Department of Health, Rules and Regulations Pertaining to Radiation Control, Part IV, Denver, Colorado, 1978 (as revised through December 30, 1985).

CDH81 Colorado Department of Health, State of Colorado, Water Quality Control Division, Colorado Primary Drinking Water Regulations, Denver, Colorado, effective October 30, 1981.

CDH92a Colorado Department of Health, Rocky Flats History (Draft) - Rocky Flats Toxicologic Review and Dose Reconstruction Task 3/4 Report, Denver, Colorado, February 1992.

$\mathrm{CDH} 92 \mathrm{~b}$ Colorado Department of Health, State of Colorado Reconstruction of Historical Rocky Flats Operations and Identification of Release Points, Project Tasks 3 \& 4, Final Draft Report prepared by ChemRisk, Alameda, California, August, 1992.

CSU92a Colorado State University, Progress Report on Radioecological Investigations at Rocky Flats, The Distribution and Concentration of Plutonium in Small Mammals Residing on a Contaminated Soil Site, Fort Collins, Colorado, February 1992.

CSU92b Colorado State University, Progress Report on Radioecological Investigations at Rocky Flats, A Study of Plutonium in Soil and Vegetation at the Rocky Flats Plant, Fort Collins, Colorado, April 1992.

CSU92c Colorado State University, Second Progress Report on Deer Habitat Use and Population Dynamics at Rocky Flats Plant, Fort Collins, Colorado, 1992.

DOE80 United States Department of Energy, Environmental Impact Statement, Rocky Flats Plant Site, DOE/EIS-0064, Washington, D.C., October 1980.

DOE88a United States Department of Energy, External Dose-Rate Conversion Factors for Calculation of Dose to the Public, DOE/EH-0070, Washington, D.C., July 1988.

DOE88b United States Department of Energy, Internal Dose Conversion Factors for Calculation of Dose to the Public, DOE/EH-0071. Washington, D.C., July 1988. 
DOE89 United States Department of Energy, Assessment of Environmental Conditions at the Rocky Flats Plant, Golden, Colorado, August 1989.

DOE90a United States Department of Energy, Order 5400.5, Radiation Protection of the Public and the Environment, Washington, D.C., February 8, 1990.

DOE90b United States Department of Energy, 1989 Population, Economic, and Land Use Database for Rocky Flats Plant, Golden, Colorado, August 1990.

DOE9 1a United States Department of Energy, Endangered Species Act Compliance, Proposed South Interceptor Ditch (SID) Maintenance Project - Final Biological Survey Report, Golden, Colorado, October 1991.

DOE91b United States Department of Energy, Fish and Wildlife Coordination Act/ Migratory Bird Treaty Act Compliance, Proposed South Interceptor Ditch (SID) Project - Final Habitat Survey Report, Golden, Colorado, October 1991.

DOE91c United States Department of Energy, Endangered Species Act Compliance, 881 - Hillside French Drain (881-HFD) Project - Final Biological Survey Report, Golden, Colorado, November 1991.

DOE91d United States Department of Energy, Fish and Wildlife Coordination Act/Migratory Bird Treaty Act Compliance, 881 Hillside French Drain (881HFD) Project - Final Biological Survey Report, Golden, Colorado, November 1991.

DOE92a United States Department of Energy, Monthly Environmental Compliance Action Report, Golden, Colorado, January through December Report, 1992.

DOE92b United States Department of Energy, Quarterly Environmental Compliance Action Report, January - March 1992, April - June 1992, July - September 1992, October - December 1992.

DOE92c United States Department of Energy, Baseline Characterization of Terrestrial and Aquatic Ecosystems at the Rocky Flats Plant, Golden, Colorado, August 1992.

DOE93 United States Department of Energy, Rocky Flats Plant Ecological Monitoring Program Annual Report, Golden, Colorado, January 1993.

EGG90a EG\&G Rocky Flats, Inc., Draft Environmental Analysis Report, Rocky Flats Plantsite, Golden, Colorado, February 1990.

EGG90b EG\&G Rocky Flats, Inc., Wetland Assessment, Rocky Flats Site, Golden, Colorado, April 1990. 
EGG90c EG\&G Rocky Flats, Inc., Federal Facilities Compliance Agreement Sewage Treatment Plant Compliance Plan, Golden, Colorado, July 1990.

EGG90d EG\&G Rocky Flats, Inc., Corrective Action Plan in Response to the August 1989 Assessment of Environmental Conditions at the Rocky Flats Plant, Golden, Colorado, September 1990.

EGG90e EG\&G Rocky Flats. Inc., Background Geochemical Characterization Report for 1989, Golden, Colorado, December 1990.

EGG91a EG\&G Rocky Flats, Inc., 1989 Surface-Water and Sediment Geochemical Characterization Report, Golden, Colorado, February 1991.

EGG91b EG\&G Rocky Flats, Inc., Rocky Flats Plant Site-Wide Quality Assurance Project Plan for CERCLA Remedial Investigation/Feasibility Studies and RCRA Facility Investigations/Corrective Measures Studies Activities, Golden, Colorado, May 7, 1991.

EGG91c EG\&G Rocky Flats, Inc., Phase III RFI/RI Work Plan, Rocky Flats Plant, 881 Hillside Area, Operable Unit No. 1, Golden, Colorado, March 1991.

EGG91d EG\&G Rocky Flats, Inc., Phase II RFI/RI Work Plan, Rocky Flats Plant, 903 Pad, Mound, and East Trenches Areas, Operable Unit No. 2, Golden, Colorado, March 1991.

EGG91e EG\&G Rocky Flats, Inc., Threatened and Endangered Species Evaluation, Rocky Flats Plantsite, Golden, Colorado, April 1991.

EGG91f EG\&G Rocky Flats, Inc., Geologic Characterization of the Rocky Flats Plant, July 1991.

EGG91g EG\&G Rocky Flats, Inc., Volatile Organic Compound (VOC) Emissions Report, Golden, Colorado, December 1991.

EGG91h EG\&G Rocky Flats, Inc., Groundwater Protection and Monitoring Plan for the Rocky Flats Plant, Golden, Colorado, November 1991.

EGG92a EG\&G Rocky Flats, Inc., 1990 Surface-Water and Sediment Geochemical Characterization Report, Golden, Colorado, 1992.

EGG92b EG\&G Rocky Flats, Inc., Draft Surface-Water Management Plan, Golden, Colorado, 1992.

EGG92c EG\&G Rocky Flats, Inc., Ozone-Depleting Substance Phase-Out Plan, Golden, Colorado, October 16, 1992.

EGG92d EG\&G Rocky Flats, Inc., Rocky Flats Plant Environmental Monitoring Plan. Golden, Colorado, November 1992. 
EGG92e EG\&G Rocky Flats. Inc.. Rocky Flats Plant Air Quality Management Plan. Golden. Colorado, November 1992.

EGG92f EG\&G Rocky Flats. Inc.. Review' of Specifications and Requirements for Ozune-Depleting Substance Usage, Golden. Colorado, November 9, 1992.

EGG93a EG\&G Rocky Flats. Inc., Rochy Flats Plant FY94-98 Five-Year Plan, Golden, Colorado. January 1993.

EGG93b EG\&G Rocky Flats, Inc., Draft Rocky Flats Plant FY95-99 Five-Year Plan, Golden. Colorado, May 1993.

EGG93c EG\&G Rocky Flats, Inc..Quality Assurance Plan Description, Golden, Colorado, August 16, 1993.

EGG93d EG\&C Rocky Flats, Inc., Threatened and Endangered Species Evaluation, Rocky Flats Plantsite. Golden, Colorado, September, 1993.

EGG93e EG\&G Rocky Flats, Inc., Rocky Flats Plant Environmental Protection Management Plan, Golden, Colorado, September, 1993.

EGG94a EG\&G Rocky Flats, Inc., 1993 Annual RCRA Groundwater Monitoring Report for Regulated Units at Rocky Flats Plant, Golden, Colorado, March 1994.

EPA76a United States Environmental Protection Agency, "Drinking Water Regulations. Radionuclides," Federal Register, 41, No. 133, Washington, D.C., July 9, 1976.

EPA76b United States Environmental Protection Agency: "Principles," Volume I, EPA-600/9-76-005, March 1976; "Ambient Air Specific Methods," Volume II, EPA-600/4-77-027a; The Quality Assurance Handbook for Air Pollution Measurements Systems, Research Triangle Park, North Carolina, May 1977.

EPA77 United States Environmental Protection Agency. Proposed Guidance on Date Limits for Persons Exposed to Transuranium Elements in General Environment, Federal Register Notice, Washington, D.C., October 1977.

EPA80 United States Environmental Protection Agency, Interim Guidelines and Specifications for Preparing Quality Assurance Project Plans, QAMS/005/80, December 1980.

EPA81 United States Environmental Protection Agency, "National Primary and Secondary Ambient Air Quality Standards." United States Code of Federal Regulations, Title 40, Part 50, Subchapter C, Air Programs, Washington. D.C., 1981. 
EPA84

EPA85

EPA86

EPA87a

EPA87b

EPA89a

EPA89a

EPA89b United States Environmental Protection Agency, Risk Assessment Guidance for Superfund Volume I Human Health Evaluation Manual (Part A), Interim Final, EPA/540/1-89/002, December 1989.

EPA91a United States Environmental Protection Agency, Manual of Protection Action Guides and Protective Actions for Nuclear Incidents, Washington, D.C., Revised 1991.

EPA92 United States Environmental Protection Agency, "Natural Resource Damage Assessments," United States Code of Federal Regulations Title 43, Part 1, Washington, D.C., 1992.

FRA92 Fraley, Jr., L., et al., Analysis of the Dose Assessinent Program from Routine Releases of Radioactive Effluent at the Rocky Flats Plant in Colorado, Department of Radiological Health Sciences, Colorado State University, Fort Collins, Colorado, January 1992.

HAC83 Hach Company, DPD Method for Chlorine, Loveland, Colorado, 1983.

HAR72 Harley, J.H., Ed., Procedures Manual and Supplements 1-4, Health and Safety Laboratory, United States Atomic Energy Commission, Washington. D.C., 1972. 
HEA85

Health Physics Society Subcommittee WG 2.5, Performance Crite fia for Radiobioassay, Draft American .National Standards Imstitute N13.30, November 1985.

INT75 International Commission on Radiological Protection (ICRP), Reference Manual, ICRP Publication 23, Pergamon Press, New York, New York, 1975.

INT79 International Commission on Radiological Protection (ICRP), Limits for Intakes of Rudionuclides by Workers, ICRP Publication 30, Parts 1 through 4 (including supplements and addenda), Pergamon Press, New York, New York, 1979-1988.

INT86 International Commission on Radiological Protection (ICRP), The Metabolism of Plutonium and Related Elements, ICRP Publication 48, Pergamon Press, New York, New York, 1986.

KOC81 Kocher, D.C., Dose-Rate Conversion Factors for External Exposure to Photons and Electrons, NUREG/CR-1918, ORNL/NUREG-79, Oak Ridge National Laboratory, Oak Ridge, Tennessee, 1981.

KOC83 Kocher, D.C., Dose-Rate Conversion Factors for External Exposure to Photons and Electrons, Health Physics, 45, 665, Oak Ridge National Laboratory, Oak Ridge, Tennessee, 1983.

KRE70 Krey, P.W., and Hardy, E.P., Plutonium in Soil Around the Rocky Flats Plant, United States Atomic Energy Commission Report, HASL-235, New York, August 1, 1970.

LAN91 Langer, G., Resuspension of Soil Particles from Rocky Flats Containing Plutonium Particulates, Environmental Management, Air Quality and Chemical Tracking Division, EG\&G Rocky Flats, Inc., Golden, Colorado, October 1991.

LIT76 Little, C.A., Plutonium in a Grassland Ecosystem, Dissertation, Colorado State University, Fort Collins, Colorado, 1976.

NAT80 National Academy of Sciences, National Research Council, Report of the Biological Effects of Ionizing Radiation, "The Effects on Populations of Exposure to Low Levels of Ionizing Radiation," 1980.

NAT87a National Council on Radiation Protection and Measurements, Ionizing Radiation Exposure of the Population of the United States, NCRP Report No. 93, Bethesda, Maryland, Seplember 1, 1987.

NAT87b National Council on Radiation Protection and Measurements, Exposure of the Population in the United States and Canada from Natural Background Radiation. NCRP Report No. 94, Bethesda, Maryland, December 30, 1987. 
PIN80

$\mathrm{SCH} 82$

UGL94

UNI83

WIL82
Pinder, J.E., and Paine, D.. "Sources of Variation in Soil Plutonium Concentrations," Hanson. W.C., (ed.). Transuranic Elements in the Environment, DOE/TIC-22800, 1980.

Schleicher \& Schuell, Publication No. 500, Innovative Products for Separation Science, March 1982.

Uglund, R.C., et al., Water Resources Data for Colorado, Water Year 1993, Missouri River Basin, Arkansas River Basin, and Rio Grande Basin, Volume I, Water Data Report CO-91-1, United States Geological Survey, Water Resources Division, Lakewood, Colorado, 1994.

United States Congress, Clean Air Act, Sections 112 and 301(a), as amended in 1983 (42 USC 7412, 7601a), Washington, D.C., 1983.

Williams, W.F., Health, Safety, and Environmental Laboratories Procedures and Practices Manual, RFP-HS\&EL-82, Rockwell International, Rocky Flats Plant, Golden, Colorado, 1982. 
Rocky Flats Plant

Site Environmental Report for 1993 
9. Useful Information

4 
Rocky Flats Plant

Site Environmental Report for 1993 


\section{ABBREVIATIONS}

\section{Units of Measure}

\begin{tabular}{|c|c|}
\hline $\mathrm{Bq}$ & Becquerel \\
\hline $\mathrm{Bq} / \mathrm{l}$ & Becquerel per liter \\
\hline $\mathrm{Bq} / \mathrm{m}^{2}$ & Becquerel per square meter \\
\hline $\mathrm{Bq} / \mathrm{m}^{3}$ & Becquerel per cubic meter \\
\hline${ }^{\circ} \mathrm{C}$ & Degree Celsius \\
\hline $\mathrm{Ci}$ & Curie \\
\hline $\mathrm{Ci} / \mathrm{g}$ & Curie per gram \\
\hline $\mathrm{cm}$ & Centimeter \\
\hline $\mathrm{cm}^{3}$ & Cubic centimeter \\
\hline $\mathrm{d} / \mathrm{m} / \mu \mathrm{Ci}$ & Disintegration per minute per microcurie \\
\hline $\mathrm{d} / \mathrm{m} / \mathrm{pCi}$ & Disintegration per minute per picocurie \\
\hline $\mathrm{d} / \mathrm{m} / \mathrm{f}$ & Disintegration per minute per filter \\
\hline $\mathrm{d} / \mathrm{m} / \mathrm{l}$ & Disintegration per minute per liter \\
\hline $\mathrm{dpm} / \mathrm{g}$ & Disintegration per minute per gram \\
\hline dps & Disintegration per second \\
\hline${ }^{\circ} \mathrm{F}$ & Degree Fahrenheit \\
\hline $\mathrm{ft}^{2}$ & Square Foot \\
\hline $\mathrm{ft}^{3} / \mathrm{min}$ & Cubic foot per minute \\
\hline fpm & Foot per mile \\
\hline g & Gram \\
\hline gal & Gallon \\
\hline $\mathrm{g} / \mathrm{cm}^{2}$ & Gram per square centimeter \\
\hline g/day & Gram per day \\
\hline gpm & Gallon per minute \\
\hline ha & Hectare \\
\hline $\mathrm{kg}$ & Kilogram \\
\hline $\mathrm{km}$ & Kilometer \\
\hline 1 & Liter \\
\hline $1 / \mathrm{d}$ & Liter per disintegration \\
\hline $1 / \mathrm{s}$ & Liter per second \\
\hline $\mathrm{lb}$ & Pound \\
\hline $\mathrm{m}^{2}$ & Square meter \\
\hline $\mathrm{m}^{3}$ & Cubic meter \\
\hline $\mathrm{m}^{3} / \mathrm{s}$ & Cubic meter per second \\
\hline $\mathrm{mg} / \mathrm{cm}^{2}$ & Milligram per square centimeter \\
\hline $\mathrm{mg} / \mathrm{l}$ & Milligram per liter \\
\hline $\mathrm{ml}$ & Milliliter \\
\hline $\mathrm{ml} /$ day & Milliliter per day \\
\hline $\mathrm{ml} / \mathrm{s}$ & Milliliter per second \\
\hline $\mathrm{mph}$ & Mile per hour \\
\hline mrem & Millirem \\
\hline mrem/day & Millirem per day \\
\hline $\mathrm{mrem} / \mathrm{yr}$ & Millirem per year \\
\hline $\mathrm{m} / \mathrm{s}$ & Meter per second \\
\hline $\mathrm{m}^{3} / \mathrm{s}$ & Cubic meter per second \\
\hline
\end{tabular}




$\begin{array}{ll}\mathrm{mSv} & \text { Millisievert } \\ \mathrm{mSv} / \mathrm{y}^{\mathrm{r}} & \text { Millisievert per year } \\ \mu \mathrm{Ci} & \text { Microcurie } \\ \mu \mathrm{Ci} / \mathrm{m}^{2} & \text { Microcurie per square meter } \\ \mu \mathrm{Ci} / \mathrm{ml} & \text { Microcurie per milliliter } \\ \mu \mathrm{g} & \text { Microgram } \\ \mu \mathrm{g} / \mathrm{f} & \text { Microgram per filter } \\ \mu \mathrm{g} / \mathrm{l} & \text { Microgram per liter } \\ \mu \mathrm{g} / \mathrm{m}^{3} & \text { Microgram per cubic meter } \\ \mu \mathrm{g} / \mathrm{ml}^{2} & \text { Microgram per milliliter } \\ \mathrm{pCi} & \text { Picocurie } \\ \mathrm{pCi} / \mathrm{g} & \text { Picocurie per gram } \\ \mathrm{pCi} / \mathrm{l} & \text { Picocurie per liter } \\ \mathrm{ppb} & \text { Part per billion } \\ \mathrm{ppm} & \text { Part per million } \\ \mathrm{pt} & \text { Pint } \\ \% & \text { Percent } \\ \mathrm{rem} & \text { Roentgen equivalent man } \\ \mathrm{rem} / \mathrm{yr} & \text { Roentgen equivalent man per year } \\ \mathrm{s} & \text { second } \\ \mathrm{SI} & \text { International Standard } \\ \mathrm{Sv} & \text { Sievert } \\ \mathrm{yd} & \text { Cubic yard } \\ \end{array}$




\section{Chemical Elements and Compounds}

\begin{tabular}{|c|c|}
\hline Am & Americium \\
\hline $\mathrm{Ba}$ & Barium \\
\hline $\mathrm{Be}$ & Beryllium \\
\hline $\mathrm{Ca}$ & Calcium \\
\hline $\mathrm{CCl}_{4}$ & Carbon Tetrachloride \\
\hline $\mathrm{Cl}$ & Chlorine \\
\hline $\mathrm{Cm}$ & Curium \\
\hline $\mathrm{CO}$ & Carbon Monoxide \\
\hline Co & Cobalt \\
\hline $\mathrm{Cr}$ & Chromium \\
\hline Cs & Cesium \\
\hline $\mathrm{Fe}$ & Iron \\
\hline $\mathrm{H}-3$ & Hydrogen-3 (Also called Tritium) \\
\hline $\mathrm{Mg}$ & Magnesium \\
\hline $\mathrm{Mn}$ & Manganese \\
\hline Mo & Molybdenum \\
\hline$N$ & Nitrogen \\
\hline $\mathrm{Na}$ & Sodium \\
\hline $\mathrm{NO}_{2}$ & Nitrogen Dioxide \\
\hline $\mathrm{NO}_{3}$ & Nitrate \\
\hline $\mathrm{O}_{3}$ & Ozone \\
\hline $\mathrm{Pb}$ & Lead \\
\hline PCB & Polychlorinated Biphenyls \\
\hline PCE & Tetrachloroethene \\
\hline $\mathrm{Pu}$ & Plutonium \\
\hline $\mathrm{Ru}$ & Ruthenium \\
\hline $\mathrm{Se}$ & Selenium \\
\hline $\mathrm{SO}_{2}$ & Sulfur Dioxide \\
\hline $\mathrm{SO}_{4}$ & Sulfate \\
\hline $\mathrm{Sr}$ & Strontium \\
\hline TCA & 1,1,1 - Trichloroethane \\
\hline TCE & Trichloroethene \\
\hline $\operatorname{Tm}$ & Thulium \\
\hline U & Uranium \\
\hline $\mathrm{Zn}$ & Zinc \\
\hline
\end{tabular}


Rocky Flats Plant

Site Environmental Report for 1993 


\section{ACRONYMS AND INITIALISMS}

ACO

ADM

AEC

AIP

ALARA

AMAD

AMRRR

ANOVA

ANSI

APCD

APEN

APR

AQCC

AQD

AR

ARAR

ASME

BAT

BEAR

BEIR

BMP

$\mathrm{BOD}_{5}$

BRAP

CAA

CAAA

CAD

CAQCC

CCR

$\mathrm{CDH}$

CEQ

CERCLA

CFR

CHWA

CLP

CMS/FS

COC

COMRAD

CPDWR

CPFM

CPIR

CRP

CSU

CT\&CS

CTMP

CWA

CWQCC
Administrative Compliance Order

Action Description Memorandum

Atomic Energy Commission

Agreement In Principle

As Low As Reasonably Achievable

Activity Median Aerodynamic Diameter

Annual Mixed Residue Reduction Report

Analysis of Variance

American National Standards Institute

Air Pollution Control Division

Air Pollutant Emission Notice

Annual Progress Report

Air Quality Control Commission

Air Quality Division

Administrative Record

Applicable or Relevant and Appropriate Requirement

American Society of Mechanical Engineers

Best Available Technology

Biological Effects of Atomic Radiation

Biological Effects of Ionizing Radiation

Best Management Practices

Biochemical Oxygen Demand, 5-day incubation period

Baseline Risk Assessment Plan

Clean Air Act

Clean Air Act Amendments

Corrective Action Decision

Colorado Air Quality Control Commission

Colorado Code of Regulations

Colorado Department of Health

Council on Environmental Quality

Comprehensive Environmental Response, Compensation, and

Liability Act

Code of Federal Regulations

Colorado Hazardous Waste Act

Contract Laboratory Program

Corrective Measures Study/Feasibility Study

Contaminant of Concern

Community Radiaiton Monitoring Program

Colorado Primary Drinking Water Regulations

Colloid Polishing Filter Method

Contingency Plan Implementation Report

Community Relations Plan

Colorado State University

Chemical Tracking and Control System

Comprehensive Treatment and Management Plan

Clean Water Act

Colorado Water Quality Control Commission 


\begin{tabular}{|c|c|}
\hline$C X$ & Categorical Exclusion \\
\hline CY & Calendar Year \\
\hline DAR & Duct Assessment Report \\
\hline $\mathrm{DCG}$ & Derived Concentration Guide \\
\hline $\mathrm{D} \& \mathrm{D}$ & Decontamination and Decommissioning \\
\hline DDS & Dustless Decon System \\
\hline DMR & Discharge Monitoring Report \\
\hline DOE & Department of Energy \\
\hline DOE. HQ & Department of Energy Headquarters \\
\hline DOE, RFO & Department of Energy Rocky Flats Office \\
\hline DRCOG & Denver Regional Council of Governments \\
\hline EA & Environmental Assessment \\
\hline $\mathrm{EC}$ & Environmental Checklist \\
\hline ECF & Element Correction Factors \\
\hline EcMP & Ecological Monitoring Program \\
\hline ECPP & Environmental Compliance Pilot Program \\
\hline EDCN & Environmental Data Collection Network \\
\hline EDE & Effective Dose Equivalent \\
\hline $\mathrm{EE}$ & Environmerital Evaluation \\
\hline EHS & Extemely Hazardous Substance \\
\hline EIS & Environmental Impact Statement \\
\hline EIS/ODIS & Effluent Information System/Onsite Discharge Information System \\
\hline EM & Environmental Management \\
\hline EML & Environmental Measurements Laboratory \\
\hline $\mathrm{EO}$ & Executive Order \\
\hline EOCNO & Emergency Operations Center Notification Officer \\
\hline EPA & Environmental Protection Agency \\
\hline EPCRA & Emergency Planning and Community Right-to-Know Act \\
\hline EPM & Environmental Protection Management \\
\hline EPMP & Environmental Protection Management Plan \\
\hline ER & Environmental Remediation \\
\hline ERDA & Energy Research and Development Administration \\
\hline ERM & Environmental Restoration Management \\
\hline ERWM & Environmental Restoration and Waste Management \\
\hline ESE & Environmental Science and Engineering \\
\hline FBI & Federal Bureau of Investigation \\
\hline FFCA & Federal Facility Compliance Agreement \\
\hline FFCA-II & Federal Facility Compliance Agreement-II \\
\hline FFC Act & Federal Facility Compliance Act \\
\hline FIDLER & Field Instrument for the Detection of Low-Energy Radiation \\
\hline FIFRA & Federal Insecticide, Fungicide, and Rodenticide Act \\
\hline FONSI & Finding of No Significant Impact \\
\hline FR & Federal Register \\
\hline FS & Feasibility Study \\
\hline FSP & Field Sampling Plan \\
\hline FTU & Field Treatability Unit \\
\hline FY & Fiscal Year \\
\hline FYP & Five-Year Plan \\
\hline
\end{tabular}




\begin{tabular}{|c|c|}
\hline GAC & Granular Activited Carbon \\
\hline GAO & General Accounting Office \\
\hline GI & Gastrointestinal \\
\hline GSA & General Services Administration \\
\hline $\mathrm{H} \& \mathrm{~S}$ & Health and Safety \\
\hline HAZCOM & Hazardous Communication Standard \\
\hline $\mathrm{HB}$ & House Bill \\
\hline HEPA & High Efficiency Particulate Air \\
\hline HFFSS & Halon Fixed Fire Suppression Systems \\
\hline HHRA & Human Health Risk Assessment \\
\hline $\mathrm{HPGe}$ & High Purity Germanium \\
\hline HSP & Health and Safety Plan \\
\hline HSWA & Hazardous and Solid Waste Amendments \\
\hline $\mathrm{HQ}$ & Headquarters \\
\hline HRR & Historical Release Report \\
\hline $\mathrm{HS}$ & Hazardous Substance \\
\hline HWCPP & Hazardous Waste Compliance Program Plan \\
\hline IA & Industrial Area \\
\hline IAG & Interagency Agreement \\
\hline ICP & Inductively Coupled Plasma \\
\hline ICP-MS & Inductively Coupled Plasma Mass Spectrometer \\
\hline ICRP & International Commission on Radiological Protection \\
\hline IHSS & Individual Hazardous Substance Site \\
\hline IM/IRA & Interim Measures/Interim Remedial Action \\
\hline IRA & Interim Remedial Action \\
\hline IRAP & Interim Remedial Action Plan \\
\hline ITS & Interceptor Trench Ditch \\
\hline IWCP & Integrated Work Control Program \\
\hline LATO & Los Alamos Technical Office \\
\hline LDR & Land Disposal Restrictions \\
\hline LEPC & Local Emergency Planning Committee \\
\hline LHSU & Lower Hydrostatigraphic Units \\
\hline LIMS & Laboratory Information Management System \\
\hline LLW & Low-level Waste \\
\hline $\mathrm{M} \& \mathrm{O}$ & Management \& Operating \\
\hline MAP & Mitigation Action Plan \\
\hline $\mathrm{MDA}$ & Minimum Detectable Amount \\
\hline MDL & Minimum Detection Limit \\
\hline MRRP & Mixed Residue Reduction Program \\
\hline MRRR & Mixed Residue Reduction Report \\
\hline MSDS & Material Safety Data Sheet \\
\hline MVAC & Motor Vehicle Air Conditioner \\
\hline NAAQS & National Ambient Air Quality Standards \\
\hline NAS & National Academy of Sciences \\
\hline NCC & NEPA Compliance Committee \\
\hline NCRP & National Council on Radiation Protection and Measurements \\
\hline NDA & Non-Destructive Assay \\
\hline NEPA & National Environmental Policy Act \\
\hline NESHAP & National Emission Standards for Hazardous Air Pollutants \\
\hline
\end{tabular}




\begin{tabular}{|c|c|}
\hline NFAJ & No Futher Action Justification \\
\hline NHPA & National Historic Pieservation Act \\
\hline NOD. & Notice of Deficiency \\
\hline NOI ${ }^{-}$ & Notice of Intent \\
\hline NOID & Notice of Intent to Deny \\
\hline NOV & Notice of Violation \\
\hline NPDES & National Pollutant Discharge Elimination System \\
\hline NPL & National Priorities List \\
\hline NQA & Nuclear Quality Assurance \\
\hline NRC & Nuclear Regulatory Commission; National Response Center \\
\hline NRDA & Natural Resource Damage Assesment \\
\hline NTS & Nevada Test Site \\
\hline ODS & Ozone-Depleting Substances \\
\hline OPWL & Original Process Waste Lines \\
\hline ORNL & Oak Ridge National Laboratory \\
\hline OSHA & Occupational Safety and Health Act \\
\hline OU & Operable Unit \\
\hline PA & Protected Area \\
\hline PATS & Plant Action Tracking System \\
\hline PEIS & Programmatic Environmental Impact Statement \\
\hline $\mathrm{PM}-10$ & Particulate Matter less than 10 micrometers in diameter \\
\hline PP & Proposed Plan \\
\hline PPCD & Plan for Prevention of Contaminant Dispersion \\
\hline PRMP EIS & $\begin{array}{l}\text { Plutonium Recovery Modification Project Environmental Impact } \\
\text { Statement }\end{array}$ \\
\hline QA & Quality Assurance \\
\hline QAA & Quality Assurance Agenda \\
\hline QAVC & Quality Assurance/Quality Control \\
\hline QAM & Quality Assurance Manual \\
\hline QAMS & Quality Assurance Management Staff \\
\hline QAPD & Quality Assurance Program Description \\
\hline QAPjP & Quality Assurance Project Plan \\
\hline QAPM & Quality Assurance Program Manager \\
\hline QAPP & Quality Assurance Program Plan \\
\hline QAR & Quality Assurance Requirements \\
\hline QC & Quality Control \\
\hline RACT & Reasonable Available Control Technology \\
\hline RCRA & Resource Conservation and Recovery Act \\
\hline RDLWP & Radionuclides Discharge Limits Work Plan \\
\hline RFI/RI & RCRA Facility Investigation/Remedial Investigation \\
\hline RFAO & Rocky Flats Area Office \\
\hline RFEDS & Rocky Flats Environmental Database System \\
\hline RFO & Rocky Flats Office \\
\hline RFP & Rocky Flats Plant \\
\hline RFQAM & Rocky Flats Quality Assurance Manual \\
\hline RHL & Radiological Health Laboratories \\
\hline RI/FS & Remedial Investigation/Feasibility Study \\
\hline ROD & Record of Decision \\
\hline RPP & Resource Protection Program \\
\hline
\end{tabular}


RQ

RS

SAAM

SAR

SARA

SARF

SDWA

SER

SERC

SI

SIP

SITE

SOP

SOW

SPCC/BMP

SSP

STAR

STP

SU

SWD

SWMU

SWPPP

T\&ESA

TCLP

TDS

TE

TLD

TM

TMP

TPQ

TRG

TRU

TSCA

TSP

TSWP

TTP

UBC

UHSU

USGS

VOC

WARP

WET

WMP

WSRIC

WWTP
Reportable Quantity

Responsiveness Summary

Selective Alpha Air Monitor

Safety Analysis Report

Superfund Amendment and Reauthorization Act

Supercompactor and Repackaging Facility

Safe Drinking Water Act

Site Environmental Report

State Emergency Response Commission

International Standard

State Implementation Plan

Superfund Innovative Technology Evaluation

Standard Operating Procedure

Statement of Work

Spill Prevention Control and Countermeasures/Best Management

Practices

Site-Specific Plan

Stability Array

Sewage Treatment Plant

Standard Units

Surface Water Division

Solid Waste Management Unit

Storm Water Pollution Prevention Plan

Threatened and Endangered Species Act:

Toxicity Characteristic Leaching Procedure

Total Dissolved Solids

Technical Evaluation

Thermoluminescent Dosimeter

Technical Memorandum

Tank Management Plan

Threshold Planning Quantity

Technical Review Group

Transuranic

Toxic Substances Control Act

Total Suspended Particulates

Treatability Study Work Plan

Technical Task Plan

Under-Building Contaminant

Upper Hydrostratigraphic Units

United States Geological Survey

Volatile Organic Compound

Well Abandonment \& Replacement Program

Whole Effluent Toxicity

Watershed Management Plan

Waste Stream and Residue Identification and Characterization

Waste Water Treatment Plant (previously referred to as STP) 


\section{GLOSSARY}

activity. See radioactivity.

air pollutant. Any fume, smoke, particulate matter, vapor, gas, or combination thereof that is emitted into or otherwise enters the atmosphere, including, but not limited to, any physical. chemical, biological, radioactive (including source material, special nuclear material, and by-product materials) substance, or material, but does not include water vapor or steam condensate.

aliquot. Of, pertaining to, or designating an exact divisor or factor of a quantity, especially of an integer.

alpha particle. A positively charged particle emitted from the nucleus of an atom having the same charge and mass as that of a helium nucleus ( 2 protons, 2 neutrons).

atom. Smallest particle of an element capable of entering into a chemical reaction.

beta particle. A negatively charged particle emitted from the nucleus of an atom having a mass and charge equal to that of an electron.

concentration. The amount of a specified substance or amount of radioactivity in a given volume or mass.

contamination. The deposition of unwanted radioactive or hazardous material on the surfaces of structures, areas, objects, or personnel.

cosmic radiation. Radiation of many types with very high energies, originating outside the earth's atmosphere. Cosmic radiation is one source contributing to natural background radiation.

curie (Ci). The traditional unit for measurement of radioactivity based on the rate of radioactive disintegration. One curie is defined as $3.7 \times 10^{10}$ (37 billion) disintegrations per second. Several fractions and multiples of the curie are in common usage.

millicurie (mCi). $10^{-3} \mathrm{Ci}$, one-thousandth of a curie; $3.7 \times 10^{7}$ disintegrations per second.

microcurie $(\mu \mathrm{Ci}) \cdot 10^{-6} \mathrm{Ci}$, one-millionth of a curie: $3.7 \times 10^{4}$ disintegrations per second.

nanocurie ( $\mathrm{nCi}$ ). $10^{-9} \mathrm{Ci}$, one-billionth of a curie; 37 disintegrations per second.

picocurie (pCi). $10^{-12} \mathrm{Ci}$, one-trillionth of a curie; $3.7 \times 10^{-2}$ disintegrations per second.

femtocurie (fCi). $10^{-15} \mathrm{Ci}$, one-quadrillionth of a curie: $3.7 \times 10^{-5}$ disintegrations per second. 
attocurie (aCi). $10^{-18} \mathrm{Ci}$, one-quinti'l second.

decay, radioactive. The spontaneous transfomation of one radionuclide into a different radioactive or nonradioactive nuclide, or into a different energy' state of the same radionuclide.

Derived Concentration Guide (DCG). Secondary radioactivity in air and water concentration guides used for comparison to measured radioactivity concentrations. Calculation of DCG assumes that the exposed individual inhales 8.400 cubic meters of air per year or ingests 730 liters of water per year at the specified radioactivity DCG with a resulting radiation dose of 0.1 rem (i00 mrem) EDE.

disintegration, nuclear. A spontaneous nuclear transformation (radioactivity) characterized by the emission of energy and/or mass from the nucleus of an atom.

dose. In this report, the term dose is used broadly to refer to the radiation protection concepts of dose equivalent and effective dose equivalent below.

dose, absorbed. The amount of energy deposited by radiation in a given mass of material. The unit of absorbed dose is the rad or the gray ( 1 gray $=100 \mathrm{rad}$ ).

dose commitment. The total radiation dose projected to be received from an exposure to radiation or intake of radioactive material throughout the specified remaining lifetime of an individual. In theoretical calculations, this specified lifetime is usually assumed to be 50 years.

dose equivalent. A modification to absorbed dose that expresses the biological effects of all types of radiation (e.g.. alpha, beta, gamma) on a common scale. The unit of dose equivalent is the rem or the sievert ( 1 sievert $=100 \mathrm{rem})$.

effective dose equivalent(EDE). A calculated value used to allow comparisons of total health risk, based on cancer mortality and genetic damage, from exposure of different types of ionizing radiation to different body organs. It is calculated by first calculating the dose equivalent to those organs receiving significant exposures, multiplying each organ dose equivalent by a health risk weighting factor,and then summing those products. One milllirem EDE from natural backround radiation would have the same health risk as one millirem EDE from an artificially produced source of radiation.

ephemeral. Lasting for a brief period of time; short-lived, transitory.

exposure. A measure of the ionization produced in air by $\mathrm{X}$-ray or gamma + radiation. The special unit of exposure is the roentgen $(R)$.

friable. Readily crumbled; brittle.

gamma ray. High-energy. short-wavelength electromagnetic radiation emitted from the nucleus of an atom. Gamma radiation frequently accompanies the emission of alpha or beta particles. Gamma rays are identical to X-rays except for the source of the emission.

half-life, radioactive. The time required for a given amount of a radionuclide to lose half of 
its activity by radioactive decay. Each racionuclide has a unique half-life.

isotopes. Forms of an element having the same number of protons in their nuclei and differing in the number of neutrons.

minimum detectable concentration (MDC). The smallest amount or concentration of a radioelement that can be distinguished in a sample by a given measurement system in a preselected counting time at a given confidence level.

natural radiation. Radiation arising from cosmic sources and from naturally occurring radionuclides (such as radon) present in the human environment.

outfall. The place where a storm sewer or effluent line discharges to the environment.

part per billion (ppb). Concentration unit approximately equivalent to micrograms per liter.

part per miliion (ppm). Concentration unit approximately equivalent to milligrams per liter.

pathway. Potential route for exposure to radioactive or hazardous materials.

person-rem. The traditional unit of collective dose to a population group. For example, a dose of 1 rem to 10 individuals results in a collective dose of 10 person-rem.

quality factor. The factor by which the absorbed dose (in rad or gray) is multiplied to obtain the dose equivalent (in rem or sievert). The dose equivalent is a unit that expresses on a common scale for all ionizing radiation the biological damage to exposed persons. It is used because some types of radiation, such as alpha particles, are more biologically damaging than others.

rad. A traditional unit of absorbed dose. The International System of Units (SI) unit of absorbed dose is the gray ( 1 gray $=100$ rads).

radioactivity. The spontaneous emission of radiation, generally alpha or beta particles, often accompanied by gamma rays from the unstable nucleus of an atom.

radionuclide. An atom having an unstable ratio of neutrons to protons so that it will tend toward stability by undergoing radioactive decay. A radioactive nuclide.

rem. The traditional unit of dose equivalent. Dose equivalent is frequently reported in units of millirem (mrem), which is one-thousandth of a rem. The International System of Units (SI) unit of dose equivalent is the sievert ( 1 sievert $=100 \mathrm{rem})$.

roentgen (R). The traditional unit of exposure to $X$-ray or gamma radiation based on the ionization in air caused by the radiation. One roentgen is equal to $2.58 \times 10^{-4}$ coulombs per kilogram of air. A common expression of radiation exposure is the milliroentgen ( $R=1000$ $\mathrm{mR}$ ).

sievert (Sv). International System of Units (SI) unit for radiation dose ( 1 sievert $=100 \mathrm{rem}$ ). 
thermoluminescent dosimeter (TLD). A device used to measure external sources (i.e., outside the body) of penetrating radiation such as Xrays or gamma rays.

uncontrolled area. Any area to which access is not controlled for the purpose of protecting individuals from exposure to radiation and radioactive materials. The area beyond the boundary of the RFP is an uncontrolled area.

worldwide fallout. Radioactive debris from atmospheric weapons testing that is either airborne and cycling around the earth or has been deposited on the earth's surface. 
Appendix A

\section{PERSPECTIVE ON RADIATION}


Rocky Flats Plant

Site Environmental Report for 1993 


\section{OVERVIEW}

IONIZING RADIATION

Types of Radiation
Activities at RFP can involve hothling radioactive materials and operating radiation-producing equipment. Environmental monitớring programs include monitoring for potential exposures to the public from RFPrelated radiation sources. This section provides some basic concepts of radiation to assist in the understanding and interpretation of monitoring information and radiation dose assessment.

Further discussion on sources of ionizing radiation can be found in Report No. 93 of the National Council on Radiation Protection and Measurements, Ionizing Radiation Exposure of the Population of the United States (NAT87a), from which much of the information in this section was derived.

Radiation may be thought of as energy in motion. Many kinds of radiation exist in our environment. Visible light and heat radiating from a warm object are examples of radiation. Radiation from radioactive materials and radiation-producing equipment is called ionizing radiation. Ionizing radiation has sufficient energy to separate electrons from atoms of material. That means it can change the physical state, or chemical composition, of atoms which it strikes, causing them to become electrically charged or "ionized." In some circumstances, the ions produced can disrupt normal biological processes and can present a health hazard to humans. Consequently, protective measures may be required to minimize the amount of ionizing radiation to which a person might be exposed.

$\mathrm{X}$ rays, gamma rays, neutrons, and alpha and beta particles are common types of ionizing radiation. While all types of ionizing radiation can produce ionization, they have other differing properties including their ability to penetrate or pass through materials. Alpha radiation penetrates poorly; a piece of paper or the outer skin tissue on a human body can stop it. Beta radiation has low-to-moderate penetrating ability and can be stopped by a thin sheet of aluminum or thick plastic. Gamma, $\mathrm{x}$-ray, and neutron radiation usually have much greater penetrating ability and require more extensive shielding. Radiation produced by medical $x$-ray machines, for example, is able to pass through a human body. 
Production of Radiation

Radiation Dose
The principal radiation hzzard to the public associated with the radioactive materials handled at RFP is from alpha radiation. Alpha radiation is emitted by artificially produced radioactive materials such as plutonium and americium. as well as by naturally occurring materials such as uranium and thorium.

Ionizing radiation is produced by both radioactive materials and by radiation-producing equipment. Radiation-producing equipment includes $\mathrm{x}$-ray machines and linear accelerators. Electrical power must be applied to this equipment to produce radiation. In contrast, radioactive materials will continue to emit ionizing radiation until they have undergone radioactive decay to a nonradioactive, stable state. The time required for a material to reach this stable state depends on a material's radioactive half-life and whether it decays to other radioactive materials on its way to achieving stability.

Half-life is the amount of time required for one-half of the atoms of a radioactive material to experience radioactive decay. Half-life is unique and unchanging for each specific radionuclide. Half-lives for different radionuclides may range from seconds to billions of years. Radioactive iodine-131, used in medical diagnosis and the treatment of some diseases, has a half-life of approximately 8 days, while naturally occurring uranium- 238 has a half-life of more than 4.5 billion years. In general, the half-lives of the radioactive materials handled at RFP are long; plutonium-239 has a half-life of more than 24.000 years. As a result, radioactive materials at RFP are handled and controlled as if they will always be radioactive.

The biological effect of ionizing radiation is called radiation dose. The radiation can be from a penetrating radiation source located outside of the body (external radiation) or from radioactive materials taken into the body (internal radiation). In the United States, radiation dose is measured in the unit called the rem, or millirem ( $1 \mathrm{rem}=1,000$ millirem). The comparable International System (le Systeme International d'Unites or SI) unit of radiation dose is the sievert ( $\mathrm{SV}=100$ rem). A rem is a unit of dose that expresses biological damage on a common scale. The Effective Dose Equivalent (EDE) is a means of calculating radiation dose and is expressed in units of rem or sieverts. 
Principal Hazards
EDE takes into account the total health risk estimated for cancer mortality and serious genetic effects from radiation exposure regardless of which body tissues receive the dose or the sources or types of ionizing radiation producing the dose. One rem EDE from naturally occurring radiation has the same total health risk as one rem from artificially produced sources of radiation.

Scientists have been studying ionizing radiation and its effects on human health for more than 90 years. In 1981, the United States General Accounting Office (GAO) reported that there were more than 80,000 separate scientific studies on the health effects of radiation. According to the National Science Foundation, “...it is fair to say that we have more scientific evidence on the hazards of ionizing radiation than most, if not all, other environmental agents that affect the general public" (NAT80).

The first case of human injury reported as a result of radiation occurred shortly after Wilhelm Roentgen's discovery of $X$ rays in 1895 . Early radiologists often used their hands to focus the primitive fluoroscopic equipment, which exposed them to millions of millirems of radiation. The first case of radiation-induced skin cancer was reported as early as 1902 . In later years, it was shown that physicians, x-ray technicians, and radium handlers had cancer rates higher than normal.

Early efforts to set radiation standards were made by the Roentgen Society formed in 1916. This was followed in 1921 by the newly created British X-ray and Radiation Protection Committee and in 1928 by the International Commission on Radiological Protection (ICRP). In 1929, the Advisory Committee on X-ray and Radium Protection was founded in the United States; this is now the National Council on Radiation Protection and Measurements (NCRP). The ICRP and the NCRP represent the longest continuous experience in the review of radiation health effects and recommendations on guidelines for radiological protection and radiation exposure limits. Additional organizations also have examined radiation levels, including the United Nations Scientific Committee on the Effects of Atomic Radiation and the National Academy of Sciences (NAS). The NAS formed a committee in 
1956 in review the biological effects of atomic radiation (BEAR). A series of reports have since heen issued by this and succeeding NAS committees on the biological effects of ionizing radiation (BEIR). The NAS continues to review the health effects of ionizing radiation.

Exposure to high levels of radiation can cause serious health effects including burns, cell damage. and death. The degree of effect depends on the intensity of radiation dose, length of exposure, and type and number of body cells exposed. Sudden large doses of 100.000 to 150,000 mrem to the whole body can cause radiation sickness, with short-term symptoms including nausea, fatigue, and hair loss. A sudden dose of 500,000 to 600,000 mrem can be fatal.

Among radiation scientists, there is substantial agreement on the health effects and risks following such large radiation doses. What remains in question, however, is the assessment of potential health effects that may result from very small doses of radiation over longer periods of time. Although radiation can damage living cells, this damage does not necessarily cause noticeable health effects. For some types of radiation the body can often repair damage from low doses or from doses received over long periods of time. In other situations, if the radiation dose results in cell death, only a relatively few cells may be affected and there may be no detectable effect on tissue function or overall health.

Some radiation damage to cells can result in an increased risk of cancer later in life. This increased risk has been observed in populations exposed to high doses of radiation. At low doses, however, the increased risk, if it occurs, is too small to be measured against the variability that occurs in the normal cancer incidence. Although it is not known if an increase in cancer risk actually occurs at low doses, for the purpose of radiation protection it is assumed that it does. Radiation protection standards are established assuming that any additional radiation dose carries with it some additional risk and that the degree of risk is proportional to the dose received. At low doses, such as experienced from natural background radiation, this estimated additional risk is very small compared to the normal incidence of cancer. Nevertheless, radiation protection professionals seek to minimize any unnecessary radiation dose and to reduce radiation duses to levels that are as low as reasonably achievable (ALARA). 
The maximum radiation dose to the public as a result of RFP activities typically is far less than that received from natural background radiation.

SOURCES OF RADIATION

Natural Sources
All living things are exposed to naturally occurring ionizing radiation. However, since the discovery of radiation and radioactive materials at the end of the $1800 \mathrm{~s}$, a person might significantly increase this amount of radiation exposure through the use of artificially produced or enhanced sources of radiation.

Naturally occurring sources are the greatest contributors to radiation exposures for the population of the United States. Sources of natural background radiation include cosmic radiation from space and secondary radioactive materials (cosmogenic nuclides) created when cosmic radiation enters the earth's atmosphere. Another source is naturally occurring radioactive materials originating from the earth's crust, referred to as primordial nuclides. These materials may contribute to radiation exposure when located outside the body or when taken into the body through inhalation or ingestion. Radon, a radioactive gas derived from uranium, is an important contributor to internal radiation exposure as a result of inhalation indoors. Trace amounts of uranium and radium also can be found in drinking water, while milk contains naturally radioactive potassium.

Living in different geographical areas can result in more or less exposure to naturally occurring ionizing radiation. Cosmic radiation exposure can increase as altitude increases because less atmosphere exists to shield against the radiation. Some geographical areas have higher concentrations of primordial nuclides such as uranium and thorium. Because the Denver area is located at a relatively high altitude and also has higher concentrations of uranium and thorium in rocks and soil, naturally occurring radiation levels are higher in the area than those in many other regions in the country.

The annual, naturally occurring EDE to a typical resident of the Denver metropolitan area is provided in Section 6. The total for this area, based on current published reports, is about $350 \mathrm{mrem} / \mathrm{yr}$. This estimate is likely to increase as the Denver regional difference in indoor radon concentration is determined. Preliminary studies have indicated that indoor radon concentrations 


\section{Medical Sources}

Consumer Products Sources are higler than the national average and the estimated EDE in the Denver area is likely to be approximately $500-700 \mathrm{mrem} / \mathrm{yr}$ when these local radon concentrations are considered. The estimated total average EDE for a person in the United States from natural sources including radon is about $300 \mathrm{mrem} / \mathrm{yr}$.

Ionizing radiation is used in medicine for the diagnosis and treatment of many medical conditions. This radiation can be produced by equipment such as $\mathrm{x}$-ray machines or linear accelerators, or it can originate from radioactive materials incorporated into pharmaceuticals. Medical diagnosis and treatment account for the largest radiation doses to the United States public from artificially produced sources of radiation. The average EDE to an individual in the United States from medical sources is approximately $50 \mathrm{mrem} / \mathrm{yr}$. However, individual doses from this source vary widely. with some people receiving little or none and others receiving substantially more than the average in any particular year.

Some consumer products, including tobacco, smoke detectors, and fertilizers, have ionizing radiation associated with them. Consumer products are the second largest contributor to radiation dose to the United States population from artificially produced or enhanced sources. The radiation may or may not be intentional and necessary for the product to function. Ionization smoke detectors and $x$-ray baggage inspection systems at airports require ionizing radiation to perform their functions. Tobacco products and fuels such as coal have radiation associated with them even though it is not necessary for their use.

Naturally occurring, medical, and consumer product sources contribute more than 99 percent of the average radiation dose that a person living in the United States receives each year (Figure $A-1$ ). Other sources include occupational exposures, residual fallout from past atmospheric weapons testing, the nuclear fuel cycle, and miscellaneous sources. Combined, these other sources contribute less than 1 percent of the average radiation dose to a person living in the United States. 
$\because$.

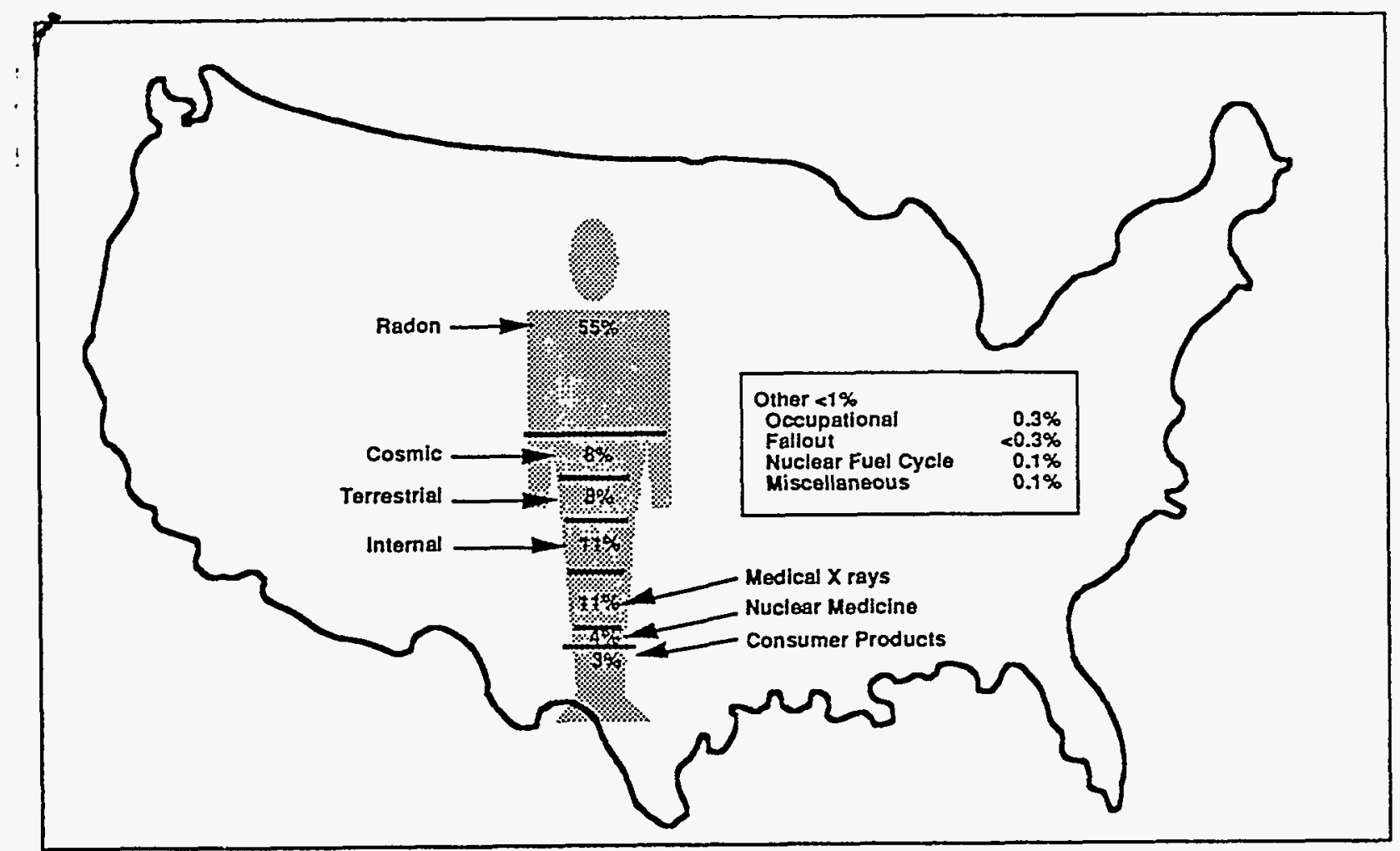

Figure A-1. Contribution of Various Sources to the Total Average Radiation Dose to the United States Population

RFP Contributions to Radiation Dose
The additional radiation dose that a member of the public might receive from RFP activities is typically well within applicable radiation protection limits and far below dose levels received from naturally occurring radiation sources. RFP-related EDE to the maximally exposed member of the public is typically less than 1 mrem for 1 year of chronic exposure. Section 6 discusses the assessment of radiation dose to the public for CY93. 
Ŕocky Fiats Fiant

Site Environmenta. Report for 1993 
Appendix B

APPLICABLE GUIDES AND STANDARDS 
OVERVIEW

\section{AIR STANDARDS}

\section{Effluent Air}

\section{Ambient Air}

WATER STANDARDS
RFF environmental monitoring programs evaluate plant compliance with applicable guides, limits, and standards. Guide values and standards for radionyclides in ambient air and waterborne effluents have been adopted by DOE, CDH, CWQCC (for water only), and the EPA (for the air pathway only) (CDH78, EPA85). Many of these guides are based on recommendations published by the International Commission on Radiological Protection (ICRP) and the National Council on Radiation Protection and Measurements (NCRP).

Air effluent limits are established under the CAA NESHAPs. The limit for radiation dose to the public from radioactive emissions is promulgated by EPA and is listed in Table B-1 (see "Air Pathway Only"). Nonradioactive (but otherwise hazardous) material emissions such as beryllium are regulated by the State of Colorado under Colorado Air Quality Control Regulation \#8. This regulation sets a limit for beryllium emissions of 10 grams in a 24-hour period per stationary source.

Ambient air data for nonradioactive particulates have been collected historically at RFP for comparison to criteria pollutants listed under the EPA NAAQS (EPA81) established by the CAA (UNI83) (Table B-2). Instrumentation and methodology follow requirements established by the EPA in the Quality Assurance Handbook for Air Pollution Measurement Systems (EPA76b).

Ambient air data for radioactive particulates are compared with Derived Concentration Guides (DCGs) provided in Table B-3. A further explanation of DCG is provided at the end of this Appendix.

The most restrictive DCGs for surface-water effluents are provided in Table B-3. 
Table B-1

DOE Radiation Protection Standards for the Public

ICRP-RECOMMENDED STANDARDS FOR ALL PATHWAYS:

Temporary Increase

500 mrem/year EDE

(with pior approval of DOE EH-2)

Normal Operations

100 mrem/year EDE

EPA CLEAN AIR ACT NESHAP STANDARDS FOR THE AIR PATHWAY ONLY:

10 mrem/year EDE

Note: In addition to the numerical dose standards listed above. it is the objective of

DOE to maintain potential exposures to members of the public to ALARA levels.

\section{Table B-2}

National Ambient Air Quality Standards (NAAQS) for Particulates ${ }^{8}$

\section{NAAQS Averaging Time}

PM-10: Annual Arithmetic Mean 24-hr Average
Concentration

$$
50 \mu \mathrm{g} / \mathrm{m}^{3}
$$$$
150 \mu \mathrm{g} / \mathrm{m}^{3}
$$

a. TSP no longer used for determining compliance with NAAQS. Sampling and reporting continues for comparison purposes and general interest.

b. Not to be exceeded more than once per year.

\section{Table B-3}

DOE Derived Concentration Guides for Radionuclides of Interest at RFP

Alr Inhalation: $\quad$ Radionuclide $\quad$ DCG $(\mu \mathrm{Ci} / \mathrm{mi})$

Plutonium-239, -240

$20 \times 10^{-15}$

Water Ingestion: Radionuclide

$\underline{D C G}(\mu \mathrm{Ci} / \mathrm{ml})$

Plutonium-239, -240
Americium-241
Uranium-233/-234
Uranium-238
Hydrogen-3 (Tritium)

$30 \times 10^{-9}$

$30 \times 10^{-9}$

$500 \times 10^{-9}$

$600 \times 10^{-9}$

$2,000,000 \times 10^{-9}$

a. Based on most restrictive assumptions for lung clearance class and gastrointestinal uptake fraction. 
National Pollutant Discharge Elimination System (NPDES). The NPDES program is a uniform national system, administered by the EPA, which limits the discharge of pollutants into United States surface waters. The RFP NPDES permit expired in 1989 and was extended administratively until renewed. An updated renewal application was submitted. The terms of the existing permit were modified by the NPDES FFCA, signed March 24, 1991 by DOE and EPA. to eliminate two discharge points that were inactive (the Reverse Osmosis Pilot Plant and the Reverse Osmosis Plant) and to include new monitoring parameters at the other discharge locations. NPDES discharge limitations for RFP are provided in Table B-4.

\section{Colorado Water Quality Control Commission} Water Quality Standards. The CWQCC established stream standards with some temporary modifications for Segment 5 of Big Dry Creek (tributaries from source to Ponds A-4, B-5, and C-2) as well as stream standards for Segment 4 of Big Dry Creek (from pond outlets to Standley Lake and Great Western Reservoir). These standards became effective in March 1990 with the resegmentation of Big Dry Creek, revision of classifications, and adoption of water quality standards for Woman and Walnut Creek tributaries to Standley Lake and Great Western Reservoir. Stream standards were established for organic and inorganic chemicals, metals, radionuclides, and certain physical and biological parameters (Table B-5).

A goal qualifier was applied by the CWQCC to Segment 5 , indicating that at the time standards were established, the waters were not suitable but are intended to become fully suitable for the classified use. The CWQCC conducted a Rulemaking Hearing in late 1992 and finalized revised standards in March 1993, including the adoption of segment 4 stream standards in segment 5 , with the exception of nine parameters for which temporary modifications were established. 
Table B-4

NPDES Permit Limits and Reporting Requirements as modified by the FFCA Effective April 1991

\section{Location/Parameter}

Discharge 001 (Pond B-3)

Total Suspended Solids (mg/)

Biological Oxygen Demand 5-Day (mg/)

Carbonaceous Biologıcal Oxygen Demand 5-Day (mg/)

Nitrates as $\mathrm{N}(\mathrm{mg} /)$

Total Residual Chlorine (mgl)

\section{Discharge 002 (Pond A-3)}

$\mathrm{pH}(\mathrm{SU})$

Nitrates as $\mathrm{N}(\mathrm{mg} /)$

\section{Discharge 005 (Pond A-4)}

Nonvolatile Suspended Solids (mgl)

Flow - million gallons per day (mgd)

Whole Effluent Toxicity $\left(\mathrm{LC}_{50}\right)^{d}$

Total Chromium $(\mu \mathrm{g} /)$

\section{Discharge 006 (Pond B-5)}

Total Chromium ( $\mu \mathrm{g} /)$

Nonvolatile Suspended Solids (mg/)

Flow (mgd)

Whole Effiluent Toxicity $\left(L C_{50}\right)^{d}$

\section{Discharge 007 (Pond C-2)}

Total Chromium $(\mu \mathrm{g} /)$

Nonvolatile Suspended Solids (mgl)

Flow (mgd)

Whole Effluent Toxicity $\left(\mathrm{LC}_{50}\right)^{d}$

\section{Discharge STP (995 Effluent)}

$\mathrm{pH}$ (SU)

Total Suspended Solids (mg/)

Oil \& Grease (mg/l)

Total Phosphorus (mg/)

Total Chromium $(\mu \mathrm{g} /)$

Carbonaceous Biological Oxygen Demand 5-Day (mgl)

Total Residual Chlorine (mgl)

Fecal Coliform (\#/100 ml)

$\begin{array}{ccc}\begin{array}{c}\text { Daily } \\ \text { Maximum }\end{array} & \begin{array}{c}\text { 7-Day Max. } \\ \text { Average }\end{array} & \begin{array}{c}\text { 30-Day Max. } \\ \text { Average }\end{array}\end{array}$

Repor ${ }^{b}$
Report
Repor
N/A
0.5

N/A

N/A

N/A

20

N/A

RPT $^{\mathrm{b}}$

RPT $^{b}$

RPT $^{\mathrm{b}}$

10

N/A

$\begin{array}{lll}9.0^{\circ} & \text { N/A } & \text { N/A } \\ 20 & \text { N/A } & 10\end{array}$

$\begin{array}{lll}\text { Report }^{b} & \text { N/A } & \text { N/A } \\ \text { Report }^{b} & \text { N/A } & \text { N/A } \\ \text { Report } & \text { N/A } & \text { N/A } \\ 50 & \text { N/A } & \text { N/A }\end{array}$

$\begin{array}{lll}50 & \text { N/A } & \text { N/A } \\ \text { Report } & \text { N/A } & \text { N/A } \\ \text { Report } & \text { N/A } & \text { N/A } \\ \text { Report } & \text { N/A } & \text { N/A }\end{array}$

$50 \quad$ N/A N/A

Report ${ }^{\circ}$ N/A N/A

Report ${ }^{b} \quad$ N/A N/A

Report ${ }^{b}$ N/A N/A

$\begin{array}{lll}9.0^{\mathrm{C}} & \text { N/A } & \text { N/A } \\ \text { N/A } & 45 & 30 \\ \text { No Visual } & \text { N/A } & \text { N/A } \\ 12 & \text { N/A } & 8 \\ 100 & \text { N/A } & 50 \\ 25 & \text { N/A } & 10 \\ \text { N/A } & \text { RPT }^{\mathrm{b}} & \text { RPT }^{\circ} \\ \text { N/A } & 400^{\mathrm{C}} & 200\end{array}$

a. The FFCA also requires reporting but does not specity discharge limitations for the following VOCs and metals: antimony, arsenic, beryllium, cadmium, copper, iron, lead, manganese, mercury, nickel, silver, zinc, benzene, bromoform, carbon telrachloride, chlorobenzene, chlorodibromomethane, chloroethane, chloroform, dichlorobromomethane, 1,1-dichloroethane, 1,2-dichloroethane, 1,1-dichloroethylene, 1,2-dichlooopropane, 1,3-dichloropropylene, ethylbenzene, methyl bromide, methyl chloride, methylene chloride, 1,1,2,2-tetrachloroethane, tetrachloroethylene, toluene, 1,2-trans-dichloroethylene, 1,1,1-trichloroethane, 1,1,2-trichloroethane, trichloroethylene, vinyl chloride.

b. Report only, no limitation placed on this analyte by permit.

c. $\mathrm{pH}$ daily minimum value $=6.0$.

d. WET test results are reported as the percentage of effluent concentration required to cause lethality to half the test organisms within the time period specilied $\left(L C_{50}\right)$. Ceriodaphnia are tested for 48 hours, fathead minnows for 96 hours.

e. Fecal coliform averages calculated by geometric rather than normal mean. 
Table B-5

Water Quality Standards at Rocky Flats Plant

\section{Parameter \\ Organics}

4-Chloro-3-methylphenol

Acenaphthene

Acenaphthylene

Acrolein

Acrylonitrile

Aldicarb

Aldrin

Anthracene

Atrazine

Benzene

Benzidine

Benzo(a)anthracene

Benzo(a)pyrene

Benzo(b)fluoranthene

Benzo(ghi)peryiene

Benzo(k)fluoranthene

Bromodichloromethane

Bromoform

Butyl benzyl phthalate

Carbofuran

Carbon telrachloride

Chlordane

Chlorobenzene

Chloroethyl ether (bis-2)

Chloroform

Chloromethyl ether (bis)

Chlorophenol

Chloropyrifos

Chrysene

DDD 4'4

DDE 44

DDT 4'4

Demeton

Di-n-butyl phthalate

Dibenzo(a,h)anthracene

Dibromochloromethane

Dichlorobenzene 1,2

Dichlorobenzene 1,3

Dichlorobenzene 1,4

Dichlorobenzidine

Dichloroethane 1,2

Dichloroethylene 1,1

Dichloroethylene 1,2-cis

Dichloroethylene 1,2-Irans

Dichlorophenol 2,4

Dichlorophenoxyacetic acid (2,4-D)

Dichloropropane 1,2

Dieldrin

Diethyl phthalate

\section{CURRENT
Segment 5
Standard \\ $\mu \mathrm{g} / \mathrm{l}$}

30

520

0.0028

21

0.058

10

0.00013

0.0028

3
1
0.00012

0.00012

0.0028

0.0028

0.0028

0.0028

0.0028

0.3
4

3000

36

18

0.00058

100

0.03

6.0

0.0000037

2000

0.041

0.0028

0.00083

0.001

0.00059

0.1

2700

0.0028

6

620

400

75

0.039

0.4

0.057

70

100

21

70

0.56

0.00014

23000

\section{CURRENT}
Segment 4
Standard
ㅆ.

$$
\begin{array}{r}
30 \\
520 \\
0.0028 \\
21 \\
0.058
\end{array}
$$

10

0.00013

0.0028

3

0.00012

0.0028

0.0028

0.0028

0.0028

0.0028

0.3

4

3000

36

0.25

0.00058

100

0.03

6.0

0.0000037

2000

0.041

0.0028

0.00083

0.001

0.00059

0.1

2700

0.0028

$$
\begin{array}{r}
6 \\
620 \\
400 \\
75 \\
0.039 \\
0.4 \\
0.057 \\
70 \\
100 \\
21 \\
70 \\
0.56 \\
0.00014 \\
23000
\end{array}
$$

\section{footnotes}

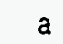

a

b

a

b

c

b,d

b

b

c

c

b

b

b

b

b

b

b

a

c

$b, d$

c

b,c

b

b

a

a

b

a

c

b.d

b

a

b

b

c

C

c

b

c

c

c

c

a

b,d

c

b,d 
Table B-5 (continued)

Water Quality Standards at Rocky Flats Plant

\begin{tabular}{|c|c|c|c|}
\hline & CURRENT & CURRENT & \\
\hline Parameter & $\begin{array}{c}\text { Segment } 5 \\
\text { Standard }\end{array}$ & $\begin{array}{c}\text { Segment } 4 \\
\text { Standard }\end{array}$ & \\
\hline Organics & $\mu \mathrm{g} / 1$ & $\mu g / 1$ & footnote \\
\hline Dimethylphenol 2,4 & 2120 & 2120 & a \\
\hline Dinitro-o-cresole & 13 & 13 & a \\
\hline Dinitrophenol 2,4 & 14 & 14 & c \\
\hline Dinitrololuene 2,4 & 0.11 & 0.11 & a \\
\hline Dinitrotoluene 2,6 & 230 & 230 & a \\
\hline Dioxin $(2,3,7,8-T C D D)$ & 0.000000013 & 0.000000013 & $b, d$ \\
\hline Diphenylhydrazine 1,2 & 0.04 & 0.04 & c \\
\hline Endosulfan & 0.056 & 0.056 & b \\
\hline Endrin & 0.0023 & 0.0023 & $b, d$ \\
\hline Endrin aldehyde & 0.2 & 0.2 & a \\
\hline Ethylbenzene & 680 & 680 & c \\
\hline Ethylhexyl phthalate (bis-2) & 1.8 & 1.8 & a \\
\hline Fluoranthene & 42 & 42 & b \\
\hline Fluorene & 0.0028 & 0.0028 & $b$ \\
\hline Guthion & 0.01 & 0.01 & b \\
\hline Heptachior & 0.00021 & 0.00021 & $b, d$ \\
\hline Heptachlor epoxide & 0.0001 & 0.0001 & c \\
\hline Hexachlorobenzene & 0.00072 & 0.00072 & $b, d$ \\
\hline Hexachlorobutadiene & 0.45 & 0.45 & $b, d$ \\
\hline Hexachlorocyctohexane, alpha (BHC) & 0.0039 & 0.0039 & b \\
\hline Hexachlorocyclohexane, beta $(\mathrm{BHC})$ & 0.014 & 0.014 & $b$ \\
\hline Hexachlorocyclohexane, gamma (BHC) & 0.019 & 0.019 & $b, d$ \\
\hline Hexachlorocyclohexane, technical (BHC) & 0.012 & 0.012 & b \\
\hline Hexachloroethane & 1.9 & 1.9 & $b$ \\
\hline Hexachlororocyclopentadiene & 5 & 5 & $\mathrm{c}$ \\
\hline Indeno(1,2,3-cd)pyrene & 0.0028 & 0.0028 & b \\
\hline Isophorone & 8.4 & 8.4 & c \\
\hline Malathion & 0.1 & 0.1 & b \\
\hline Methoxychlor & 0.03 & 0.03 & b.d \\
\hline Methyl bromide & 48 & 48 & b \\
\hline Methyl chloride & 5.7 & 5.7 & b \\
\hline Methylene chloride & 4.7 & 4.7 & b \\
\hline Mirex & 0.001 & 0.001 & b \\
\hline Naphthalene & 0.0028 & 0.0028 & $b$ \\
\hline Nitrobenzene & 3.5 & 3.5 & c \\
\hline Nitroso-di-n-propylamine-n & 0.005 & 0.005 & a \\
\hline Nitrosodi-n-butylamine-n & 0.0064 & 0.0064 & $b$ \\
\hline Nitrosodiethylamine-n & 0.0008 & 0.0008 & b \\
\hline Nitrosodimethylamine-n & 0.00069 & 0.00069 & $\mathrm{~b}$ \\
\hline Nitrosodiphenylamine-n & 4.9 & 4.9 & $b$ \\
\hline Nitrosopyrrolidine- $n$ & 0.016 & 0.016 & b \\
\hline Parathion & 0.4 & 0.4 & b \\
\hline PCBs & 0.000044 & 0.000044 & $b, d$ \\
\hline
\end{tabular}


Table B-5 (continued)

Water Quality Standards at Rocky Flats Plant

\begin{tabular}{|c|c|c|c|}
\hline & CURRENT & CURRENT & \\
\hline Parameter & $\begin{array}{l}\text { Segment } 5 \\
\text { Standard }\end{array}$ & $\begin{array}{c}\text { Segment } 4 \\
\text { Standard }\end{array}$ & \\
\hline Organics & $\mu q /$ & $\mu g \|$ & footnote \\
\hline Pentachlorobenzene & 6 & 6 & c \\
\hline Pentachlorophenol & 5.7 & 5.7 & c \\
\hline Phenanthrene & 0.0028 & 0.0028 & b \\
\hline Pyrene & 0.0028 & 0.0028 & $b$ \\
\hline Simazine & 4 & 4 & $b$ \\
\hline Tetrachlorobenzene 1,2,4,5 & 2 & 2 & c \\
\hline Tetrachloroethane 1,1,2,2 & 0.17 & 0.17 & a \\
\hline Tetrachloroethylene & 76 & 0.8 & $b, d, e$ \\
\hline Toluene & 1000 & 1000 & c \\
\hline Toxaphene & 0.0002 & 0.0002 & c \\
\hline Trichloroethane $1,1,1$ & 200 & 200 & c \\
\hline Trichloroethane $1,1,2$ & 0.6 & 0.6 & c \\
\hline Trichloroethylene & 66 & 2.7 & $c, e$ \\
\hline Trichlorophenol 2,4,5 & 700 & 700 & c \\
\hline Trichlorophenol 2,4,6 & 2.0 & 2.0 & $c$ \\
\hline Trichlorophenoxypropionic $(2,4,5-\mathrm{tp})$ & 50.0 & 50.0 & b \\
\hline Vinyl Chloride & 2 & 2 & c \\
\hline \multicolumn{4}{|l|}{ Metals } \\
\hline Aluminum & 150 & 150 & a \\
\hline Arsenic & 50 & 50 & c \\
\hline Barium & 1000 & 1000 & c \\
\hline Beryllium & 4 & 4 & i \\
\hline Cadmium & TVS $=1.50^{* *}$ & TVS $=1.50$ & $f, c$ \\
\hline Chromium III & 50 & 50 & $c$ \\
\hline Chromium VI & 11 & 11 & $c$ \\
\hline Copper & 23 & TVS $=16$ & $i, d$ \\
\hline Iron (") & 300 & 300 & c \\
\hline Iron & 13200 & 1000 & $a, e$ \\
\hline Lead & 28 & TVS $=6.5$ & c \\
\hline Manganese (") & 560 & 50 & c \\
\hline Manganese & 1000 & 1000 & f \\
\hline Mercury & 0.01 & 0.01 & c \\
\hline Nickel & TVS $=125$ & TVS $=125$ & i \\
\hline Selenium & 10 & 10 & c \\
\hline Silver & TVS $=0.59$ & TVS $=0.59$ & c \\
\hline Thallium & 0.012 & 0.012 & c \\
\hline Zinc & 350 & TVS=45 & $d, f$ \\
\hline
\end{tabular}

$\left({ }^{\circ}\right)=$ DISSOLVED METAL

"TVS = TABLE VALUE STANDARD - TVSs, promulgated by the Colorado Water Quality Control Commission, are variable standards subject to the measured values for other parameters, such as total hardness. 
Table B-5 (continued)

Water Quality Standards at Rocky Flats Plant

\begin{tabular}{|c|c|c|c|}
\hline & CURRENT & CURRENT & \\
\hline Parameter & $\begin{array}{l}\text { Segment } 5 \\
\text { Standard }\end{array}$ & $\begin{array}{c}\text { Segment } 4 \\
\text { Standard }\end{array}$ & \\
\hline Physical \& Biological & $\mu \mathrm{g} / 1$ & $\mu g l$ & footn \\
\hline Minimum Dissolved Oxygen (mgl) & 5.0 & 5.0 & $c, t$ \\
\hline $\mathrm{pH}$ (s.u.) & $6.5-9.0$ & $6.5-9.0$ & c \\
\hline Fecal Coliforms per $100 \mathrm{ml}$ & 2000 & 2000 & c \\
\hline \multicolumn{4}{|l|}{ Inorganics } \\
\hline Unionized Ammonia - March Through June & 1800 & calculated & $c, f, g$ \\
\hline Unionized Ammonia - July Through February & 700 & calculated & $c, g$ \\
\hline Ammonia & 100 & 100 & \\
\hline Boron & 750 & 750 & 1 \\
\hline Chloride & 250000 & 250000 & c \\
\hline Chlorine (Acute) & 19 & 19 & a \\
\hline Chlorine (Chronic) & 11 & 11 & a \\
\hline Cyanide (Free) & 5 & 5 & $c, t$ \\
\hline Fluoride & 2000 & & \\
\hline Nitrate & 10000 & 10000 & c \\
\hline Nitrite & 500 & 500 & c \\
\hline Sulfate & 250000 & 250000 & c \\
\hline Sulfide (as $\mathrm{H}_{2} \mathrm{~S}$ ) & 2 & 2 & c \\
\hline
\end{tabular}

\section{CURRENT CURRENT}

Parameter

Radionuclides

Gross alpha

Gross bete

Americium-241

Curium-244

Neptunium-237

Plutonium-239, -240

Uranium

Uranium-233/-234

Uranium-238

Cesium- 134

Radium-226, -228

Strontium-90

Thorium-230, -232

Tritium

\section{Segment 5 Standard Segment 4 Standard Woman Creek Walnut Creek pCiI pCill}

$\begin{array}{rr}7 & 11 \\ 5 & 19 \\ 0.05 & 0.05 \\ 60 & 60 \\ 30 & 30 \\ 0.05 & 0.05 \\ 5 & 10\end{array}$
a. Siatewide aquatic standard.
b. Site specific standard.
c. Statewide water supply standard.
d. This standard is more restrictive than the stewide water supply standard.
e. Segment 5 standard is a temporary modification, established $3 / 93$.
f. Statewide agricultural standard.
g. Statewide water supply unionized ammonia standard of $0.5 \mathrm{jg} / \mathrm{l}$ applied at water supply intake. 


\section{Drinking Water}

SOIL STANDARDS

\section{RADIOLOGICAL DOSE STANDARDS}

The EPA promulgated regulations in 1976 for radionuclides in drinking water (EPA76a). These regulations, along with primary drinking water regulations for microbiological, chemical, and physical contaminants, became effective June 24, 1977. The intent of the Safe Drinking Water Act (SDWA) was to ensure that each state has primary responsibility for maintaining drinking water quality. To comply with these requirements, $\mathrm{CDH}$ modified existing state drinking water standards to include radionuclides ( $\mathrm{CDH} 77, \mathrm{CDH} 81$ ). The following two community drinking water standards are of interest in this report.

1. The state standard for gross alpha activity (including radium-226 but excluding radon and uranium) in community water systems is a maximum of $15 \mathrm{pCi} / 1$ or $15 \times 10^{-9} \mu \mathrm{Ci} / \mathrm{ml}\left(5.6 \times 10^{-1} \mathrm{~Bq} / \mathrm{l}\right)$. Plutonium and americium, which are alpha-emitting radionuclides, are included in this limit.

2. The limit for tritium in drinking water is 20,000 $\mathrm{pCi} / 1$ or $20,000 \times 10^{-9} \mu \mathrm{Ci} / \mathrm{ml}(740 \mathrm{~Bq} / 1)$.

The EPA proposed additional National Primary Water Standards for radionuclides in 1991. These standards have not yet been finalized.

There is no standard at the federal level for radionuclides in soil for transuranics. The EPA proposed a screening level for plutonium of 44.4 disintegrations per minute per gram $(\mathrm{dpm} / \mathrm{g})(19.98 \mathrm{pCi} / \mathrm{g})$ for a soil density of 1 gram per square centimeter $\left(\mathrm{g} / \mathrm{cm}^{2}\right)$ for soils sampled to a depth of 1 centimeter ( 0.39 inches) (EPA77).

At the state level, $\mathrm{CDH}$ adopted a standard for plutonium in 1973 of $2.0 \mathrm{dpm} / \mathrm{g}(0.9 \mathrm{pCi} / \mathrm{g})$ for a soil density of $1 \mathrm{~g} / \mathrm{cm}^{2}$ for soils sampled to a depth of 0.64 centimeters (cm) (0.25 inches) (CDH73).

DOE Order 5400.5, Radiation Protection of the Public and the Environment (DOE90a), provides the radiation protection standard for DOE environmental activities. This order, adopted by DOE on February 8, 1990, incorporates guidance from the ICRP as well as from 
the NESHAP standards (as implemented in 40 CFR Part 61. Subpart H) (UNI83. EPA85). Included in DOE Order 5400.5 is a revision of the dose limits for members of the public. Tables for radiation dose conversion factors currently used for calculating dose from intakes of radioactive materials were issued in July 1988 (DOE88a, DOE88b). The dose factors are based on the ICRP Publications 30 and 48 methodology and biological models for radiation dosimetry (INT79, INT86). DOE Order 5400.5 and the dose conversion factor tables are used for assessment of any potential RFP contribution to public radiation dose. In December 1989, EPA published revised NESHAP standards for DOE facilities (EPA89a). DOE radiation standards for protection of the public are given in this Appendix (Table B-1) and include the December 1989 CAA air pathway standards. In addition to the numerical dose limits in DOE Order 5400.5, it is the objective of DOE to maintain potential exposures to members of the public to ALARA levels.

DOE Derived Concentration Guides
Secondary radioactivity concentration guides can be calculated from the primary radiation dose standards and used as comparison values for measured radioactivity concentrations. DOE provides tables of these DCGs in DOE Order 5400.5. DCGs are the concentrations that would result in an EDE of 100 mrem from 1 year of chronic exposure or intake. In calculating air inhalation DCGs, DOE assumes that the exposed individual inhales 8,400 cubic meters of air at the calculated DCG during the year. Ingestion DCGs assume a water intake of 730 liters at the calculated DCG for the year. Table B-3 lists the most restrictive air and water DCGs for the principal radionuclides of interest at RFP.

Plutonium Concentrations. Plutonium concentrations at RFP represent the alpha radioactivity from plutonium-239 and -240 . These constitute more than 97 percent of the alpha radioactivity in plutonium used at the plant.

Uranium Concentrations. Uranium concentrations are the cumulative alpha activity from uranium-233/-234 and -238 . Components containing fully enriched uranium may be handled at RFP. Depleted uranium metal can be fabricated and is also handled as a process waste material. Uranium-235 is the major isotope by weight (93 per- 
cenl) in fully enriched uranium. However, uranium-234 accounts for approximately 97 percent of the alpha activity of fully enriched uranium. In depleted uranium, the combined alpha activity from uranium-234 and -238 accounts for approximately 99 percent of the total alpha activity. Uranium DCGs used in this report for air and water are those for uranium-233/-234 and -238 , which are the most restrictive.

Environmental uranium concentrations can be measured by various laboratory techniques. Nonradiological techniques yield concentration units of mass per unit volume such as milligram per cubic meter and milligram per liter. Uranium concentrations given in this report were derived by measuring radioactivity from alpha-emitting uranium isotopes and are expressed in terms of activity units per unit volume. RFP data include measurements of depleted uranium, fully enriched uranium, and natural uranium.

Conversion factors for specific types of uranium can be used to compare the data in this report to data from other facilities and agencies that are given in units of mass per unit volume; however, the resulting approximations will not have the same assurance of accuracy as that of the original measured values. Uranium in effluent air from plant buildings is primarily depleted uranium. The conversion factor for these data is $2.6 \mathrm{x}$ $10^{6} \mathrm{~g} / \mathrm{Ci}$. Natural uranium is the predominant species found in water. The conversion factor for water data is $1.5 \times 10^{6} \mathrm{~g} / \mathrm{Ci}$. 
Appendix C

WIND STABILITY CLASSES 
+ 


\section{Table C-1}

Wind Frequency Distribution by Percent in 1993, Stability Class $A^{a}$

Wind Speed Classes (Knots)

\begin{tabular}{|c|c|c|c|c|c|c|c|c|}
\hline Wind & $\leq 3.0$ & $3.0-<6.0$ & $6.0<10.0$ & $10.0-<16.0$ & $16.0-<21.0$ & $\geq 21.0$ & Class $^{\circ}$ & Total \\
\hline$N$ & 1.9 & 5.9 & 0 & 0 & 0 & 0 & 7.83 & .73 \\
\hline NNE & 2.3 & 6.8 & 0 & 0 & 0 & 0 & 9.03 & .84 \\
\hline NE & 2.0 & 8.2 & 0 & 0 & 0 & 0 & 10.15 & .94 \\
\hline ENE & 2.1 & 7.9 & 0 & 0 & 0 & 0 & 9.97 & .92 \\
\hline$E$ & 2.5 & 10.2 & 0 & 0 & 0 & 0 & 12.75 & 1.18 \\
\hline ESE & 2.8 & 10.6 & 0 & 0 & 0 & 0 & 13.38 & 1.24 \\
\hline SE & 2.2 & 10.2 & 0 & 0 & 0 & 0 & 12.41 & 1.15 \\
\hline SSE & 2.0 & 5.0 & 0 & 0 & 0 & 0 & 7.02 & .65 \\
\hline s & 1.1 & 2.9 & 0 & 0 & 0 & 0 & 4.04 & .37 \\
\hline SSW & 1.0 & 1.2 & 0 & 0 & 0 & 0 & 2.13 & .20 \\
\hline SW & .5 & .7 & 0 & 0 & 0 & 0 & 1.19 & .11 \\
\hline WSW & .5 & .7 & 0 & 0 & 0 & 0 & 1.22 & .11 \\
\hline W & .6 & .8 & 0 & 0 & 0 & 0 & 1.44 & .13 \\
\hline WNW & .9 & .9 & 0 & 0 & 0 & 0 & 1.70 & .17 \\
\hline NW & .9 & 1.2 & 0 & 0 & 0 & 0 & 2.10 & .19 \\
\hline NNW & . 1.5 & 2.1 & 0 & 0 & 0 & 0 & 3.54 & .33 \\
\hline All & 24.7 & 75.3 & 0 & 0 & 0 & 0 & 100.00 & 9.26 \\
\hline
\end{tabular}

a. Total number of hourly samples in this stability class is 809 .

b. Total percent for this stability class.

c. Total percent relative to all stability classes.

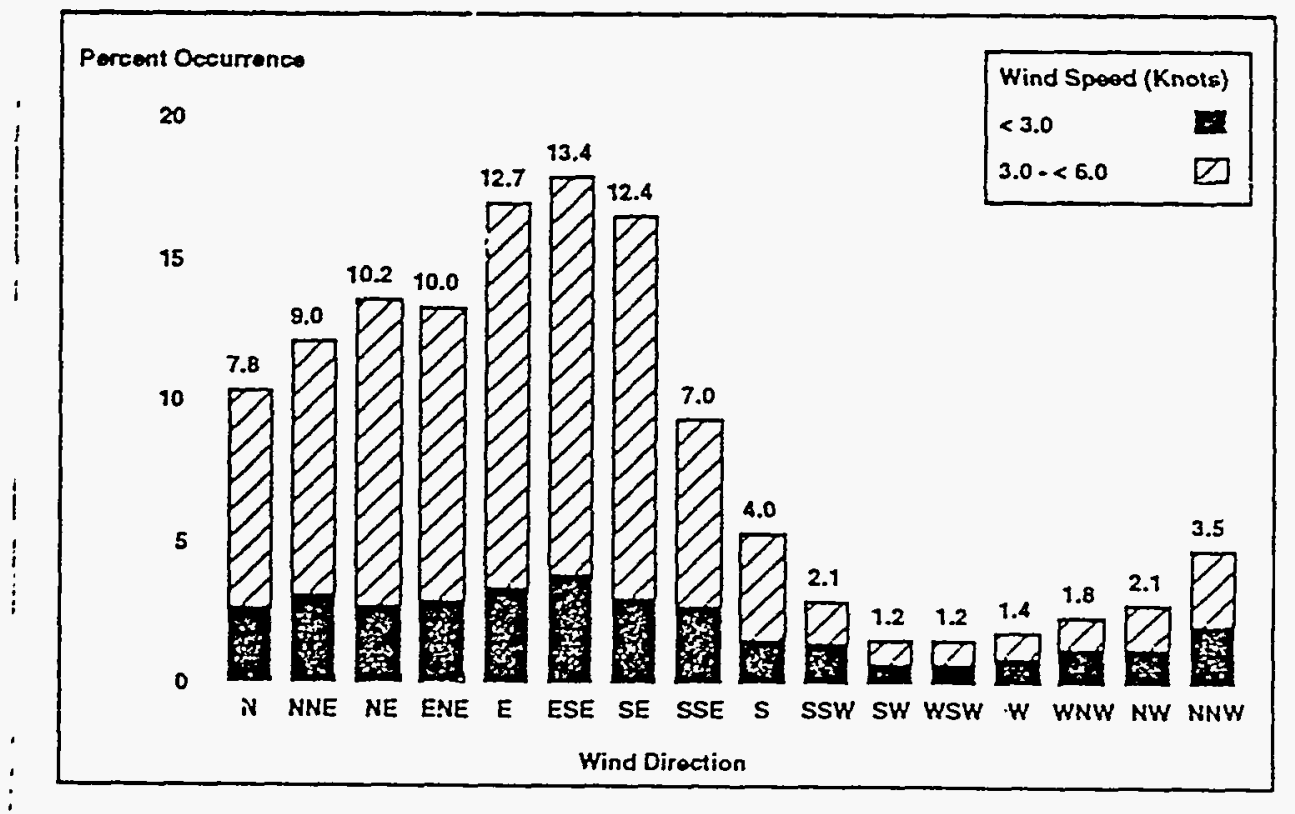

Figure C-1. Stability Class - A 


\section{Table C-2}

Wind Frequency Distribution by Percent in 1993, Stability Class $E^{*}$

Wind Speed Classes (Knots)

\begin{tabular}{|c|c|c|c|c|c|c|c|c|}
\hline Wind & $\leq 3.0$ & $3.0<6.0$ & $6.0<10.0$ & $10.0<16.0$ & $16.0<21.0$ & $\geq 21.0$ & Class $^{\circ}$ & Total $^{6}$ \\
\hline $\mathrm{N}$ & .7 & 3.7 & 6.1 & 0 & 0 & 0 & 10.44 & .63 \\
\hline NNE & .7 & 5.1 & 5.9 & 0 & 0 & 0 & 11.73 & .71 \\
\hline $\mathrm{NE}$ & .6 & 4.4 & 5.0 & 0 & 0 & 0 & 9.97 & .60 \\
\hline ENE & .3 & 3.3 & 3.5 & 0 & 0 & 0 & 7.05 & .42 \\
\hline$E$ & .4 & 3.6 & 4.1 & 0 & 0 & 0 & 8.20 & .49 \\
\hline ESE & .5 & 6.4 & 6.2 & 0 & 0 & 0 & 13.02 & .78 \\
\hline$S E$ & .6 & 6.3 & 7.9 & 0 & 0 & 0 & 14.73 & .89 \\
\hline SSE & .5 & 4.2 & 4.5 & 0 & 0 & 0 & 8.25 & .56 \\
\hline S & .1 & 2.0 & 1.6 & 0 & 0 & 0 & 3.63 & .22 \\
\hline SSW & .3 & .8 & .6 & 0 & 0 & 0 & $i .72$ & .10 \\
\hline SW & .0 & .3 & .4 & 0 & 0 & 0 & .67 & .04 \\
\hline WSW & .1 & .2 & .7 & 0 & 0 & 0 & $i .05$ & .06 \\
\hline W & .2 & .2 & .7 & 0 & 0 & 0 & 1.14 & 07 \\
\hline WNW & .1 & .2 & 1.1 & 0 & 0 & 0 & 1.48 & .09 \\
\hline NW & .3 & .3 & 1.0 & 0 & 0 & 0 & 1.62 & .10 \\
\hline NNWW & .6 & 1.4 & 2.3 & 0 & 0 & 0 & 4.29 & .26 \\
\hline All & 5.9 & 42.5 & 51.5 & 0 & 0 & 0 & 100.00 & 6.01 \\
\hline
\end{tabular}

a. Total number of hourly samples in this stability class is $\mathbf{5 2 5}$.

b. Total percent for this stability class.

c. Total percent relative to all stability classes.

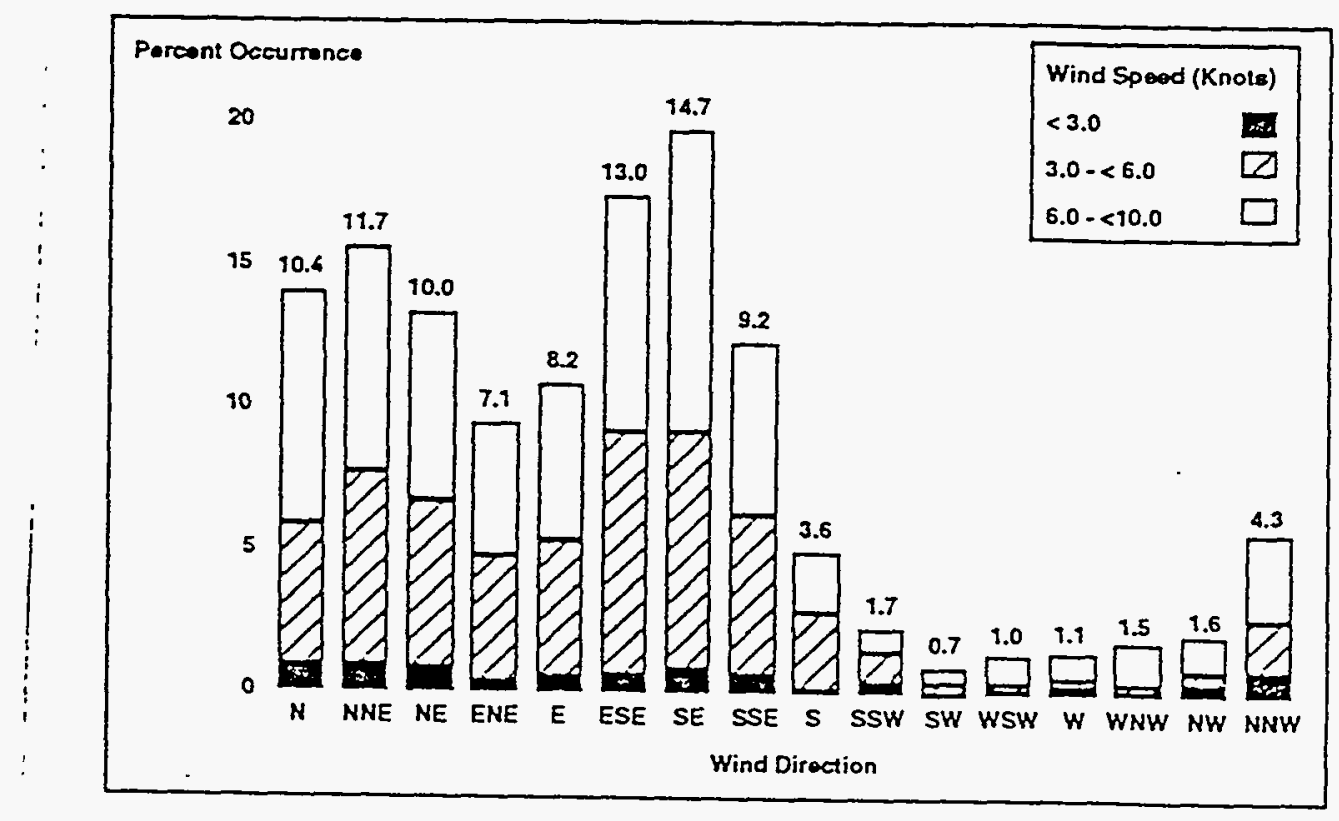

Figure C-2. Stability Class - B 


\section{Table C-3}

Wind Frequency Distribution by Percent in 1993, Stabilitypllass $C^{\circ}$ Wind Speed Classes (Kriots)

\begin{tabular}{|c|c|c|c|c|c|c|c|c|}
\hline Wind & $\leq 3.0$ & $3.0<6.0$ & $6.0<10.0$ & $10.0<16.0$ & $16.0<21.0$ & $\geq 21.0$ & Class $^{\circ}$ & Total $^{\complement}$ \\
\hline$N$ & .4 & 2.5 & 8.6 & 2.2 & 0 & 0 & 13.74 & 1.21 \\
\hline NNE & .5 & 2.9 & 6.5 & 1.0 & 0 & 0 & 10.82 & .95 \\
\hline NE & .2 & 3.1 & 4.3 & .6 & 0 & 0 & 8.22 & .72 \\
\hline ENE & .3 & 1.9 & 2.2 & .4 & 0 & 0 & 4.84 & .43 \\
\hline$E$ & .4 & 2.6 & 2.1 & .2 & 0 & 0 & 5.27 & .46 \\
\hline ESE & .2 & 2.5 & 4.3 & .1 & 0 & 0 & 7.15 & .63 \\
\hline SE & .4 & 3.7 & 6.4 & .8 & 0 & 0 & 11.34 & 1.00 \\
\hline SSE & .2 & 2.5 & 6.7 & .8 & 0 & 0 & 10.30 & .91 \\
\hline s & .3 & 1.3 & 1.5 & .2 & 0 & 0 & 3.32 & .29 \\
\hline SSW & .1 & .5 & .7 & .3 & 0 & 0 & 1.56 & .14 \\
\hline SW & .2 & .3 & .7 & .2 & 0 & 0 & 1.46 & .13 \\
\hline WSW & .1 & .2 & .7 & .9 & 0 & 0 & 1.98 & .17 \\
\hline W & .1 & .3 & 1.8 & 1.6 & 0 & 0 & 3.80 & .33 \\
\hline WNW & .2 & .3 & 2.2 & 2.1 & 0 & 0 & 4.84 & .43 \\
\hline NW & .3 & .7 & 1.9 & 1.2 & $: 0$ & 0 & 4.19 & .37 \\
\hline NNW & .3 & 1.7 & 3.9 & 1.3 & 0 & 0 & 7.18 & .63 \\
\hline All & 4.3 & 27.0 & 54.7 & 14.0 & 0 & 0 & 100.00 & 8.81 \\
\hline
\end{tabular}

\footnotetext{
a. Total number of hourly samples in this stability class is $\mathbf{7 7 0}$.

b. Total percent for this stability class.

c. Total percent relative to all stability classes.
}

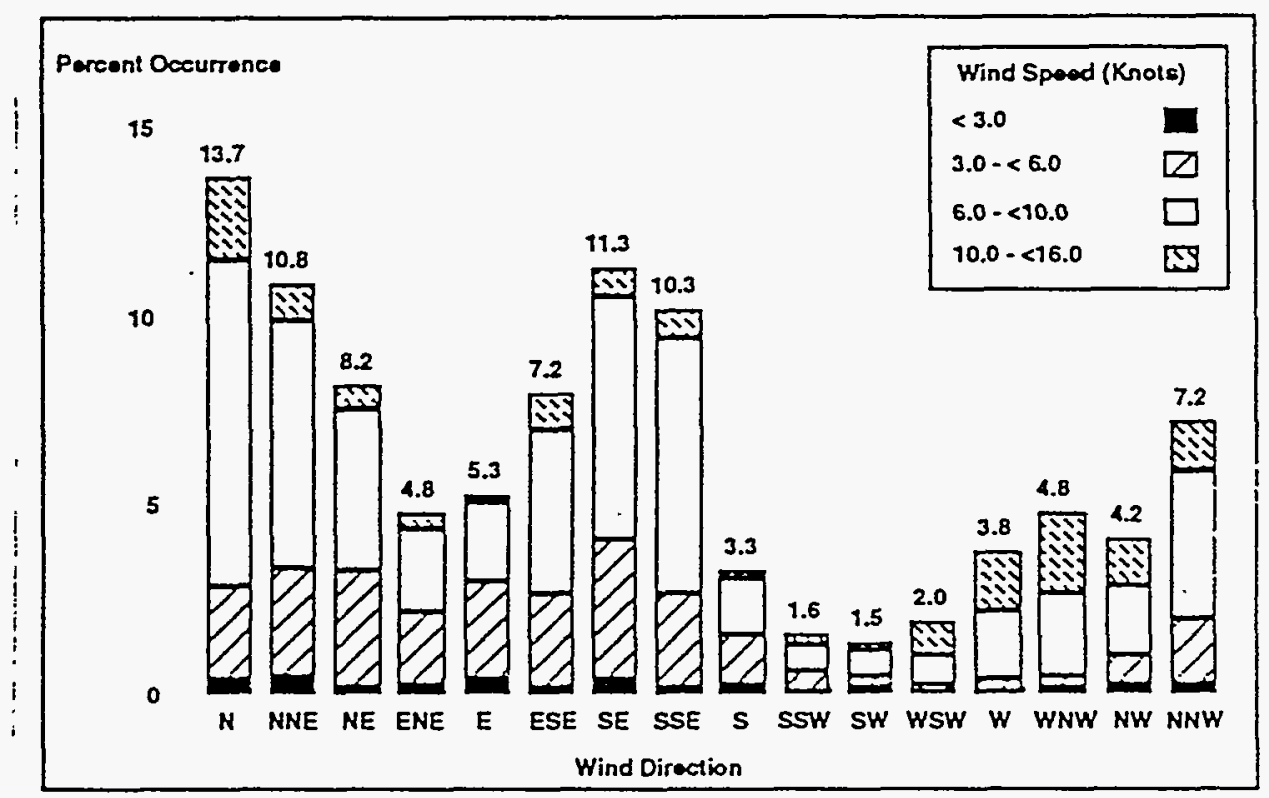

Figure C-3. Stability Class - C 


\section{Table C-4}

Wind Frequency Distribution by Peṛent in 1993, Stability Class $D^{\circ}$

Wind Speed Classes (Knots)

\begin{tabular}{|c|c|c|c|c|c|c|c|c|}
\hline Wind & $\leq 3.0$ & $\underline{3.0<6.0}$ & $6.0<10.0$ & $10.0<16.0$ & $16.0<21.0$ & $\geq 21.0$ & Class $^{\circ}$ & Total \\
\hline $\mathrm{N}$ & .2 & 1.3 & 2.9 & 2.5 & .3 & .0 & 7.34 & 3.17 \\
\hline NNE & .3 & 1.4 & 1.8 & 1.2 & .1 & .0 & 4.76 & 2.05 \\
\hline NE & .3 & 11 & 1.2 & .7 & .0 & .0 & 3.26 & 1.41 \\
\hline ENE & .2 & .2 & .8 & .2 & .0 & .0 & 2.04 & .88 \\
\hline$E$ & .1 & .7 & .7 & .2 & .0 & .0 & 1.68 & .73 \\
\hline ESE & .1 & .7 & .6 & .2 & .0 & .0 & 1.54 & .67 \\
\hline SE & .1 & 1.0 & 1.7 & .4 & .0 & .0 & 3.26 & 1.41 \\
\hline SSE & .2 & 1.2 & 2.5 & 1.0 & .0 & .0 & 4.92 & 2.12 \\
\hline$s$ & .2 & 1.4 & 2.0 & .9 & .1 & .0 & 4.54 & 1.96 \\
\hline SSW & .2 & 1.5 & 1.9 & .8 & .1 & .0 & 4.55 & 1.97 \\
\hline SW & .2 & 1.2 & 1.9 & 1.4 & $\therefore$ & .0 & 4.76 & 2.06 \\
\hline WSW & .3 & 1.1 & 1.8 & 2.5 & .7 & .3 & 6.77 & 2.93 \\
\hline w & .2 & 1.7 & 2.1 & 4.1 & 2.2 & 2.6 & 12.99 & 5.61 \\
\hline WNW & .4 & 2.1 & 2.7 & 6.7: & 3.7 & 4.2 & 19.72 & 8.52 \\
\hline NW & .3 & 2.0 & 2.6 & $3.0^{\circ}$ & 1.0 & .7 & 9.63 & 4.16 \\
\hline NNW & .3 & 1.7 & 3.6 & 2.4 & 0.2 & .1 & 8.24 & 3.56 \\
\hline All & 3.5 & 21.1 & 30.7 & 28.2 & 8.6 & 8.0 & 100.00 & 43.19 \\
\hline
\end{tabular}

a. Total number of hourly samples in this stability class is 3774 .

b. Total percent for this stability class.

c. Total percent relative to all stability classes.

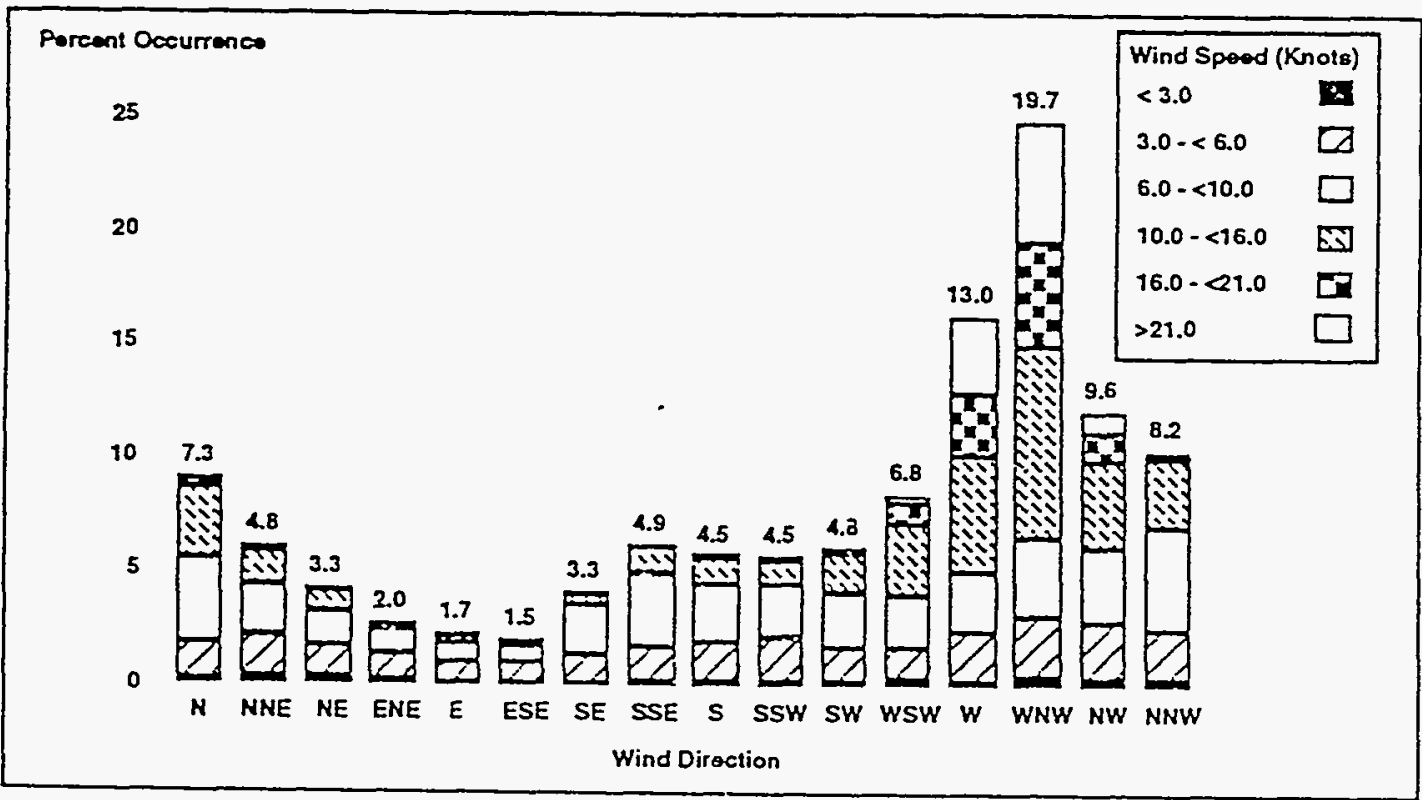

Figure C-4. Stability Class - D 


\section{Table C-5}

Wind Frequency Distribution by Percent in 1993, Stability Class E*

Wind Speed Classes (Knots)

\begin{tabular}{|c|c|c|c|c|c|c|c|c|}
\hline Wind & $\leq 3.0$ & $\underline{3.0<6.0}$ & $6.0<10.0$ & $10.0<16.0$ & $16.0<21.0$ & $\geq 21.0$ & Class $^{\circ}$ & $\underline{\text { Total }}^{\mathrm{c}}$ \\
\hline $\mathrm{N}$ & .7 & 2.4 & 1.9 & .2 & 0 & 0 & 5.24 & 1.11 \\
\hline NNE & .9 & 2.1 & 2.5 & .3 & 0 & 0 & 5.83 & 1.24 \\
\hline$N E$ & .5 & 1.5 & 1.1 & .1 & 0 & 0 & 3.21 & .68 \\
\hline ENE & .5 & 1.7 & .9 & .1 & 0 & 0 & 3.21 & .68 \\
\hline$E$ & .2 & 1.1 & .8 & .1 & 0 & 0 & 2.09 & .44 \\
\hline ESE & .2 & .7 & .4 & .0 & 0 & 0 & 1.33 & .28 \\
\hline SE & .1 & 1.2 & .9 & .0 & 0 & 0 & 2.29 & .49 \\
\hline SSE & .5 & 1.9 & 2.6 & .1 & 0 & 0 & 5.02 & 1.07 \\
\hline$S$ & .5 & 3.2 & 4.7 & .1 & 0 & 0 & 8.47 & 1.80 \\
\hline SSW & .7 & 3.1 & 3.8 & .1 & 0 & 0 & 7.65 & 1.62 \\
\hline SW & .5 & 3.5 & 6.1 & .0 & 0 & 0 & 10.05 & 2.13 \\
\hline WSW & .7 & 3.5 & 6.6 & .0 & 0 & 0 & 10.77 & 2.29 \\
\hline w & .8 & 4.0 & 2.0 & .0 & 0 & 0 & 6.79 & 1.44 \\
\hline WNW & .8 & 4.5 & 2.9 & .0 & 0 & 0 & 8.20 & 1.74 \\
\hline$N W$ & .8 & 4.2 & 4.7 & .1 & 0 & 0 & 9.69 & 2.06 \\
\hline NNW & .8 & 3.2 & 5.9 & .2 & 0 & 0 & 10.16 & 2.16 \\
\hline All & 9.2 & 41.7 & 47.8 & 1.3 & 0 & 0 & 100.00 & 21.22 \\
\hline
\end{tabular}

a. Total number of hourly samples in this stability class is $\mathbf{1 8 5 4 .}$

b. Total percent lor this stability class.

c. Total percent relative to all stability classes.

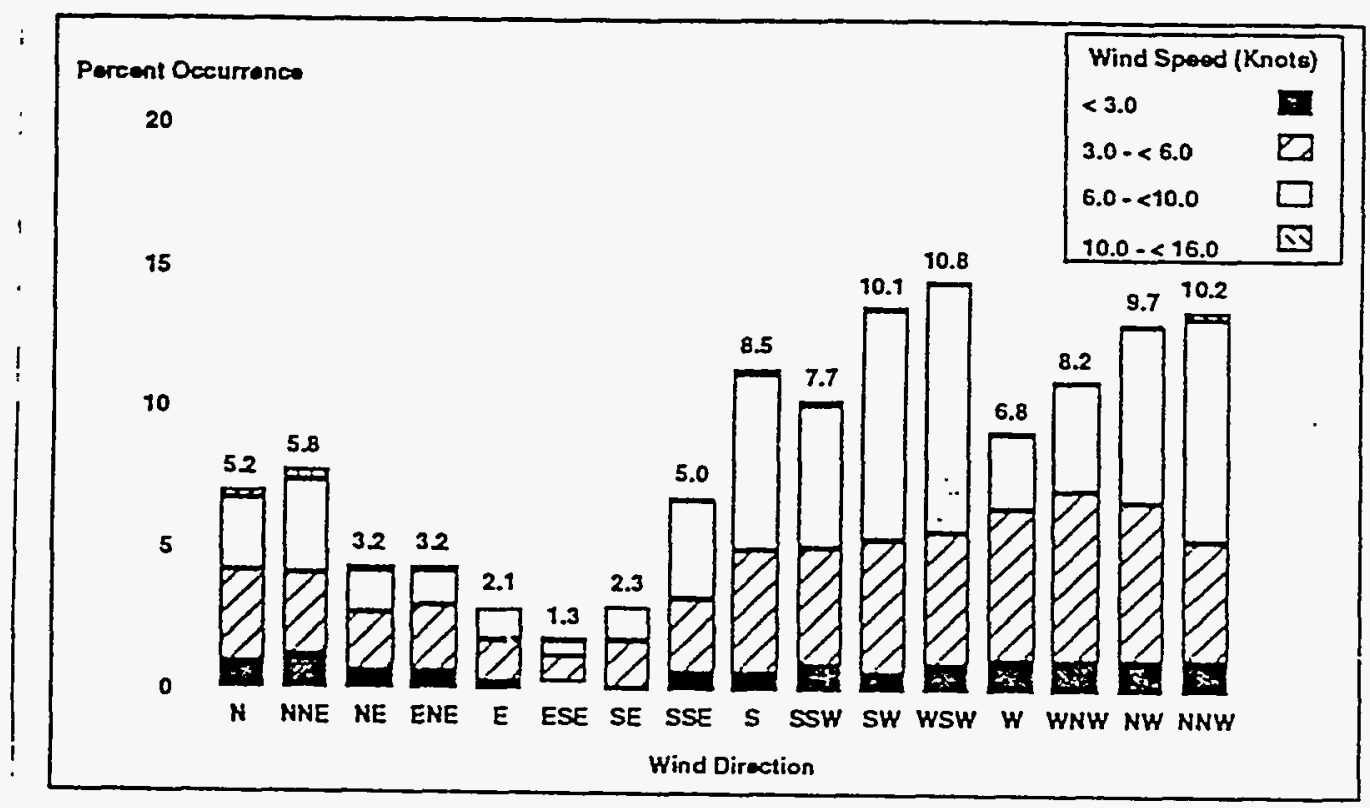

Figure C-5. Stability Class - E 


\section{Table C-6}

Wind Frequency Distribution by Percent in 1993, Stability Class F

Wind Speed Classes (Knots)

\begin{tabular}{|c|c|c|c|c|c|c|c|c|}
\hline Wind & $\leq 3.0$ & $3.0<6.0$ & $6.0<10.0$ & $10.0<16.0$ & $16.0<21.0$ & $\geq 21.0$ & Classs $^{D}$ & Iotal $^{c}$ \\
\hline$N$ & 2.9 & 4.3 & .0 & .0 & .0 & .0 & 7.16 & .82 \\
\hline NNE & 2.1 & 2.3 & .0 & .0 & .0 & .0 & 4.42 & .51 \\
\hline$N E$ & 2.2 & 1.9 & .0 & .0 & .0 & .0 & 4.91 & .47 \\
\hline ENE & 1.7 & $: .7$ & .0 & .0 & .0 & .0 & 3.49 & .40 \\
\hline$E$ & 1.7 & 1.6 & .0 & .0 & .0 & .0 & 3.28 & .38 \\
\hline ESE & 1.5 & 1.7 & .0 & .0 & .0 & .0 & 3.15 & .36 \\
\hline$S E$ & 2.2 & 2.3 & .0 & .0 & .0 & .0 & 4.55 & .52 \\
\hline SSE & 2.1 & 3.0 & .0 & .0 & .0 & .0 & 5.07 & .58 \\
\hline s & 2.5 & 3.5 & .0 & .0 & .0 & .0 & 6.06 & .70 \\
\hline SSW & 2.5 & 4.6 & .0 & .0 & .0 & .0 & 7.10 & .82 \\
\hline SW & 2.9 & 4.6 & .0 & .0 & .0 & .0 & 7.52 & .80 \\
\hline WSW & 3.2 & 5.8 & .0 & .0 & .0 & .0 & 9.05 & 1.04 \\
\hline$w$ & 3.4 & 4.9 & .0 & .0 & .0 & .0 & 8.28 & .95 \\
\hline WNW & 3.7 & 5.1 & .0 & .0 & .0 & .0 & 8.82 & 1.01 \\
\hline NW & 3.7 & 5.3 & .0 & .0 & .0 & .0 & 8.98 & 1.03 \\
\hline NNW & 3.5 & 5.4 & .0 & .0 & .0 & .0 & 8.95 & 1.03 \\
\hline All & 41.9 & 58.1 & .0 & .0 & .0 & .0 & 100.00 & 11.48 \\
\hline
\end{tabular}

2. Total number of hourly samples in this stability class is 1003 .

b. Total percent for this stability class.

c. Toial percent relative to all stability classes.

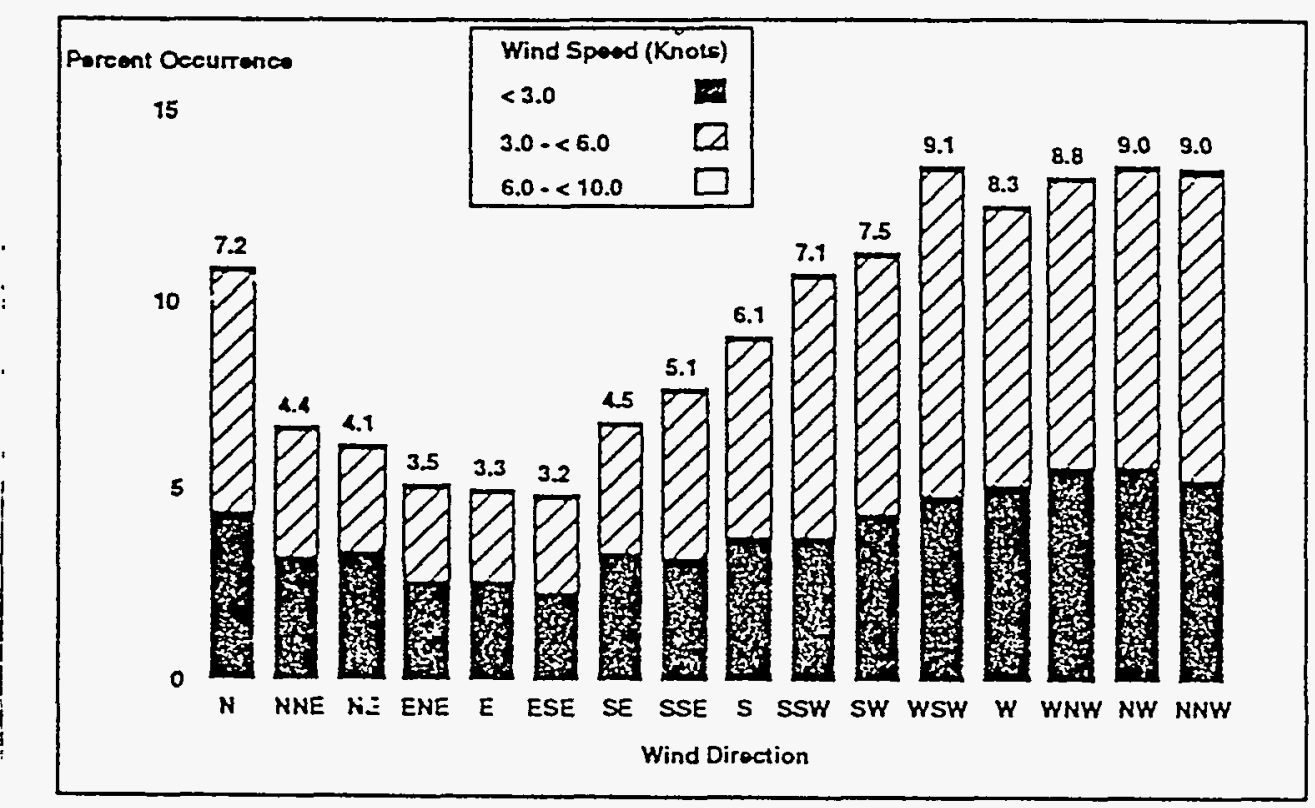

Figure C-6. Stability Class - F 


\section{Table C-7}

Wind Frequency Distribution by Percent in 1993, Stability Class All*

Wind Speed Classes (Knots)

\begin{tabular}{|c|c|c|c|c|c|c|c|c|}
\hline Wind & $\leq 3.0$ & $3.0<6.0$ & $6.0<10.0$ & $10.0<16.0$ & $16.0<21.0$ & $\geq 21.0$ & Class $^{b}$ & ${\underline{T o t a a^{6}}}^{6}$ \\
\hline $\mathbf{N}$ & .9 & 2.5 & 2.8 & 1.3 & .1 & .0 & 7.67 & 7.67 \\
\hline NNE & .9 & 2.5 & 2.2 & .7 & .0 & .0 & 6.30 & 6.29 \\
\hline NE & .7 & 2.3 & 1.4 & .4 & .0 & .0 & 4.82 & 4.82 \\
\hline ENE & .6 & 2.1 & .9 & .1 & .0 & .0 & 3.74 & 3.74 \\
\hline$E$ & .6 & 2.1 & .9 & .1 & .0 & .0 & 3.69 & 3.68 \\
\hline ESE & .5 & 2.2 & 1.1 & .1 & .0 & .0 & 3.96 & 3.90 \\
\hline SE & .6 & 2.6 & 2.0 & .3 & .0 & .0 & 5.45 & 5.45 \\
\hline SSE & .7 & 2.2 & 2.5 & .5 & .0 & .0 & 5.89 & 5.89 \\
\hline S & .6 & 2.2 & 2.1 & .4 & .0 & .0 & 5.34 & 5.34 \\
\hline SSW & .6 & 2.0 & 1.7 & .4 & .0 & .0 & 4.84 & 4.84 \\
\hline SW & .6 & 1.9 & 2.2 & .6 & .0 & .0 & 5.33 & 5.33 \\
\hline WSW & .7 & 2.0 & 2.3 & 1.2 & .3 & .1 & 6.60 & 6.60 \\
\hline w & .7 & 2.3 & 1.5 & 1.9 & 1.0 & 1.1 & 8.54 & 8.54 \\
\hline WNW & .9 & 2.6 & 2.0 & 3.1 & 1.6 & 1.8 & 11.96 & 11.95 \\
\hline NW & .9 & 2.6 & 2.3 & 1.4 & .4 & .3 & 7.91 & 7.91 \\
\hline NNW & .9 & 2.5 & 3.3 & 1.2 & .1 & .1 & 7.96 & 7.96 \\
\hline All & 11.3 & 36.5 & 31.4 & 13.7 & 3.7 & 3.5 & 100.00 & 99.97 \\
\hline
\end{tabular}

a. Total number of hourly samples in all stability classes is $\mathbf{8 7 3 6}$.

b. Total percent for this stability class.

c. Total percent relative to all stability classes. Annual data recovery $=99.9$ percent.

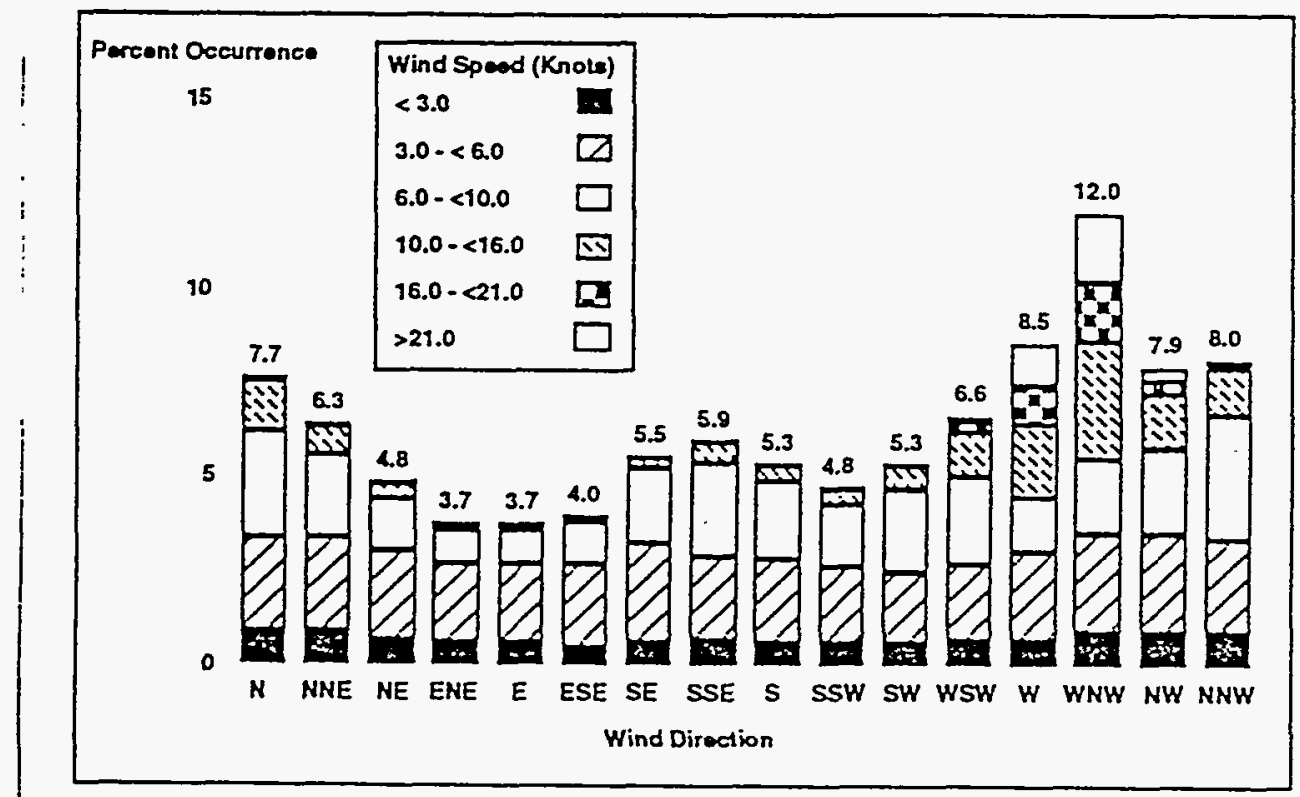

Figure C-7. Stability Class - All 
Rocky Flats Plant

Site Environmental Report for 1993 


\section{Appendix D}

\section{ANALYTICAL PROCEDURES}




$$
-
$$


ENVIRONMENTAL RADIOCHEMISTRY LABORATORY
The Environmental Radiochemistry Laboratory routinely performs analyses on the environmental and effluent samples described below.

1. Total Air Filter Counting (long-lived alpha)

2. Gas Proportional Counting (gross alpha and gross beta)

3. Alpha Spectral Analysis (Plutonium-238/-239; Americium-241; Uranium-233/-234, -235, and 238)

4. Beta Liquid Scintillation (Tritium)

5. Atomic Absorption (Beryllium)

6. Millipore Filtration Method (Fecal and Total Coliform)

Procedures for these analyses are described in the Radiological Health Procedures and Practices Manual (WI82). The procedures for bacteria and chlorine analyses were developed following EPA guidelines. Soil procedures were developed following specifications set forth in Measurements of Radionuclides in the Environment, Sampling and Analysis of Plutonium in Soil, Nuclear Regulatory Commission (NRC) Regulatory Guide 4.5. All new procedures and changes to existing procedures must be thoroughly tested, documented, and approved in writing by the manager of the Environmental Radiochemistry Laboratory before being implemented. Environmental Protection Management (EPM) is notified of any major changes that could affect analytical results. All procedures are reviewed annually (or at any time an analytical problem is suspected) for consistency with state-of-the-art techniques. Copies of all procedures are kept on file in the office of the manager of Environmental Radiochemistry Laboratories.

\section{Analytical Procedures}

Samples received for air filter screening are counted approximately 24 hours and then 48 hours after collection. Samples exceeding specified limits are recounted. If the total long-lived alpha concentration for a screened filter exceeds specified action limits, the filter is directed to individual specific isotope analysis and/or follow-up investigation to determine the cause and any needed corrective action.

All water samples, except those scheduled for tritium analysis, are poured into 1-liter Marinelli containers and sealed before delivery to the gamma counting area. 
Routin:- water samples are counted for approximately 12 hours. Samples requiring a lower detection limit are counted from 16 to 72 hours.

Soil samples scheduled for gamma spectral analysis are dried, put through a 10-mesh sieve, weighed, and the final portion is ball-milled. The fine portion is then placed in a 500-milliliter Marinelli container and counted for at least 16 hours.

All samples scheduled for alpha spectral analysis are analyzed in a similar manner regardless of matrix. Before dissolution, a known quantity of nonindigenous radioactive tracer is added to each sample. The tracer is used to determine the chemical recovery for the analysis. Tracers used include plutonium-242, uranium-232, and curium244. The type and activity level of the tracer used depends on the type and projected activity level of the sample to be analyzed. All refractory or intractable actinides are dissolved by vigorous acid treatment using both oxidizing and complexing acids. After samples are dissolved, the radioisotopes of concern are separated from each other and from the matrix material by various solvent extraction and ion exchange techniques. The purified radioisotopes are electro-deposited onto stainless steel discs. These discs are alpha counted for 24 hours. If a lower minimum detection limit is required, samples may be counted from 72 to 168 hours, depending on the specific sensitivity requirements. Samples that exhibit a chemical recovery of less than 10 percent or greater than 105 percent are automatically scheduled for reanalysis.

Tritium analyses are routinely performed on specified environmental water samples, as well as on stack effluent samples. Ten milliliters of the samples are combined with 10 milliliters of liquid scintillation fluid. Effluent samples are counted for 60 minutes, while environmental samples are counted for 75 minutes.

GENERAL LABORATORY

The General Laboratory routinely performs several analyses in support of environmental monitoring of plant effluent streams, process wastes, and soil residues. The analyses routinely performed are provided below.

1. Metallic elements including tests for 19 cations by inductively coupled plasma spectroscopic techniques and 10 elements by atomic absorption 
spectroscopy techniques (including beryllium in airborne effluent sample filters).

2. Oxygen demand tests on water including total organic carbon, carbonaceous biological oxygen demand, and biological oxygen demand (5-day incubation).

3. Nutrient tests including free ammonia, ortho and total phosphate phosphorus, nitrite, and nitrate anions.

4. Physical tests including $\mathrm{pH}$, conductivity, total dissolved solids, suspended solids, total solids, and nonvolatile suspended solids.

5. Oil and grease residues, by extraction and infrared or gravimetric detection, and by visual observation.

6. Specific chemical property or element including total hardness (as calcium carbonate), alkalinity (as hydroxide, bicarbonate, or carbonate), chloride, fluoride, cyanide, sulfate, and hexavalent chromium.

7. Gross alpha and gross beta analyses by gas proportional counting.

8. Volatile and semivolatile compounds from the EPA Contract Laboratory Program (CLP) Target Analyte List are analyzed by gas chromatography/mass spectrometry. Phenols also are analyzed using spectrophotometry. Polychlorinated biphenyl compounds are analyzed by gas chromatography.

9. Toxicity Characteristic Leaching Procedure (TCLP) extractable metals and organics for compliance with land ban restrictions.

Procedures for these analyses, developed by the General Laboratory analytical technical staff, were adopted from EPA-approved sources or from other recognized authoritative publications where EPAapproved procedures were not available. Laboratory operations procedures are documented in a standard format, approved by the manager of the Rocky Flats Analytical Laboratories, and issued to a controlled distribution list to ensure that proper testing and approval is performed before changes are adopted. The Analytical Laboratories Quality Assurance Plan requires annual 
Analytical Procedures revien of procedures for consistency with state-of-theart techniques and compliance oi laboratory practice with written procedures. In addition, a review is performed whenever an analytical problem is indicated.

Water samples to be tested for chemical and physical parameters are preserved and/or refrigerated, when required. The tests performed include gravimetric, titrametric, calorimetric. chromatographic, or electro-analyticill methods, following procedures specified in the Siandard Methods for the Examination of Water and Waste Water, Methods for Chemical Analysis of Water and Wastes, EPA-SW846, or other authorative publications.

All water samples analyzed for gross alpha/gross beta are acidified immediately upon collection to $\mathrm{pH}$ less than 2 using nitric acid.

Gross alpha and gross beta activities of liquid samples are measured by evaporating an aliquot onto a stainless steel counting planchet and counting in a low background, thin-windowed, gas flow proportional counter. Two planchets are prepared for each sample and the average and propagated uncertainty of the two counts are reported. The detector counting efficiency and selfabsorption effects of the salt residue on the planchet are determined from calibration curves using known alpha and beta standards and increasing amounts of salt. Americium-241 is used to generate the alpha curve and strontium-90 is used for the beta curve.

Water samples to be analyzed for metal ions are preserved with nitric acid and are digested before being analyzed by atomic absorption or inductively coupled plasma (ICP) methods. Organic toxic species are determined by Gas Chromatograph/Mass Spectrometry/Data Systems following EPA protocol for volatile organics and semivolatile organics. Some organics, such as phenol, are determined by developing achromaphoric complex and measuring light absorption at a specific wavelength with a spectrophotometer. Measuring occurs after extraction into an appropriate solvent phase. 
DETECTION LIMITS AND ERROR

TERM PROPAGATION

- Radioactivity Parameters

The Environmental Radiochemistry Laboratory has adopted the following definition for detection limit for isotopic specific analyses, as given by Harley (HAR72). "The smallest amount of sample activity using a given measurement process (i.e., chemical procedure and detector) that will yield a net count for which there is confidence at a predetermined level that activity is present."

The minimum detectable amount (MDA) is the term used to describe the detection limit and is defined as the smallest amount of an analyzed material in a sample that will be detected with a " $\beta$ " probability of nondetection (Type II error), while accepting an " $\alpha$ " probability of erroneously detecting that material in an appropriate blank sample (Type I error). In the formulation below, both $\alpha$ and $\beta$ are equal to 0.05 .

Based on the approach presented in draft ANSI Standard N13.30, Performance Criteria for Radiobioassay (HE85), the formulation of the MDA for radioactive analyses is:

$$
\mathrm{MDA}=\frac{4.65 \mathrm{~S}_{\mathrm{B}}+2.71 /\left(\mathrm{T}_{S} \mathrm{E}_{S} \mathrm{Y}\right)}{\mathrm{aV}}
$$

where $S_{B}=$ standard deviation of the population of appropriate blank values (disintegrations per minute, $\mathrm{d} / \mathrm{m}$ )

$\mathrm{T}_{\mathrm{S}}=$ sample count time (minutes, $\mathrm{m}$ )

$E_{S}=$ absolute detection efficiency of the sample detector

$\mathrm{Y}=$ chemical recovery for the sample

$a=$ conversion factor (disintegrations per minute per unit activity)

$(\mathrm{a}=2.22$ disintegrations per minute per picocurie $[\mathrm{d} / \mathrm{m} / \mathrm{pCi}]$ when $\mathrm{MDA}$ is in units of $\mathrm{pCi}$, and $\mathrm{a}=2.22 \mathrm{x}$ $10^{6}$ disintegrations per minute per microcuries $[\mathrm{d} / \mathrm{m} / \mu \mathrm{Ci}]$ when MDA is in units of $\mu \mathrm{Ci}$ ) 
$V=$ sarnple volume or weight $(V=1$ if the $M D A$ per sample is desired)

The major component of the MDA equation is the variability of the blanks.

Table D-1 shows the various formulas used for alpha data reduction. Table D-2 shows the typical MDA values for the various analyses performed by the Environmental Radiochemistry Laboratories. These values are based on the average sample volume, typical detector efficiency, detector background. count time, and chemical recovery. MDA values calculated for individual analyses may vary significantly depending on actual sample volume, chemical recovery, and analytical blank used.

Nonradioactivity Parameters For nonradioactivity parameters, various means are used to estimate a minimum detection limit (MDL) depending on the parameter measured. MDL is defined as the minimum concentration of a substance that can be measured and reported with 99 percent confidence that the analyte concentration is greater than zero and is determined from analysis of a sample in a given matrix containing the analyte. The MDL for beryllium in effluent air, analyzed using flameless atomic absorption spectroscopy. is based on a sample blank absorbance reading. Total chromium in effluent water samples undergoes a fourfold concentration of the received sample prior to its analysis using flame atomic absorption spectroscopy. Its approximate MDL is based on a net sample absorbance reading of 0.010 .

The parameters of nitrate as $\mathrm{N}$, total phosphorous, suspended solids, oil and grease, and total organic carbon have MDLs determined by procedural methods found in EPA-600, Environmental Monitoring and Support Laboratory; Methods for Chemical Analysis of Water and Wastes (EPA87b). Biochemical oxygen demand and $\mathrm{pH}$ have MDLs determined by the minimal readout capability of the instrumentation that is used. The MDL for residual chlorine is determined by the procedure found in a publication by Hach Company, DPD Method for Chlorine (HAC83). For fecal coliform count, MDL is calculated as 4.65 times the standard deviation of the blank value from the millipore filter. 
REPORTING OF MINIMUM DETECTABLE CONCENTRATION AND ERROR TERMS
Measured concentrations of plutonium, uranium, americium. tritium, and beryllium are given in this report. Most of the measured concentrations are at or very near background levels, and often there is little or no amount of these materials in the media being analyzed. When this occurs, the results of the laboratory analyses can be expected to show a statistical distribution of positive and negative numbers near zero and numbers that are less than the calculated minimum detectable concentration for the analyses. The laboratory analytical blanks, used to correct for background contributions to the measurements, show a similar statistical distribution around their average values. Negative sample values result when the measured value for a laboratory analytical blank is subtracted from a sample analytical result that is smaller than the analytical blank value. Results that are less than calculated minimum detectable levels indicate that the results are below the level of statistical confidence in the actual numerical values. All reported results, including negative values and values that are less than minimum detectable levels, are included in any arithmetic calculations on the data set. Reporting all values allows all of the data to be evaluated using appropriate statistical treatment. This assists in identifying any bias in the analyses, allows better evaluation of distributions and trends in environmental data, and helps in estimating the true sensitivity of the measurement process.

The reader should use caution in interpreting individual values that are negative or less than minimum detectable levels. A negative value has no physical significance. Values less than minimum detectable levels lack statistical confidence as to what the actual number is, although it is known with high confidence that it is below the specified detection level. Such values should not be interpreted as being the actual amount of material in the sample, but should be seen as reflecting a range from zero to the minimum detectable level in which the actual amount would likely lie. These values are significant, however, when taken together with other analytical results that indicate that the distribution is near zero.

Error terms in the form of $a \pm b$ are included with some of the data. For a single sample, "a" is the analytical blank corrected value; for multiple samples, " $a$ " represents the average value (arithmetic mean). The error term "b" accounts for the propagated statistical counting uncertainty for the sample and the associated analytical blanks at the 95 percent confidence level. These error terms represent a minimum estimate of error for the data. 


\section{Table D-1}

Formulas for Activity and Uncertainty Calculations for the Alpha Spectral Analysis Systems

Nonblank Corrected Sample Activity

$$
A_{s i}=\left[\begin{array}{ll}
\frac{C_{s i}}{T_{s}} & -\frac{C_{B i}}{T_{B}} \\
\frac{C_{s j}}{T_{s}} & -C_{B j} \\
\frac{T_{B}}{T_{S j}}
\end{array}\right] \frac{D_{s j}}{v}
$$

Blank Corrected Sample Activity

$$
B_{s i}=A_{s i} \cdot A_{r i}
$$

Nonblank Corrected Sample Uncertainty

Blank Corrected Sample Uncertainty

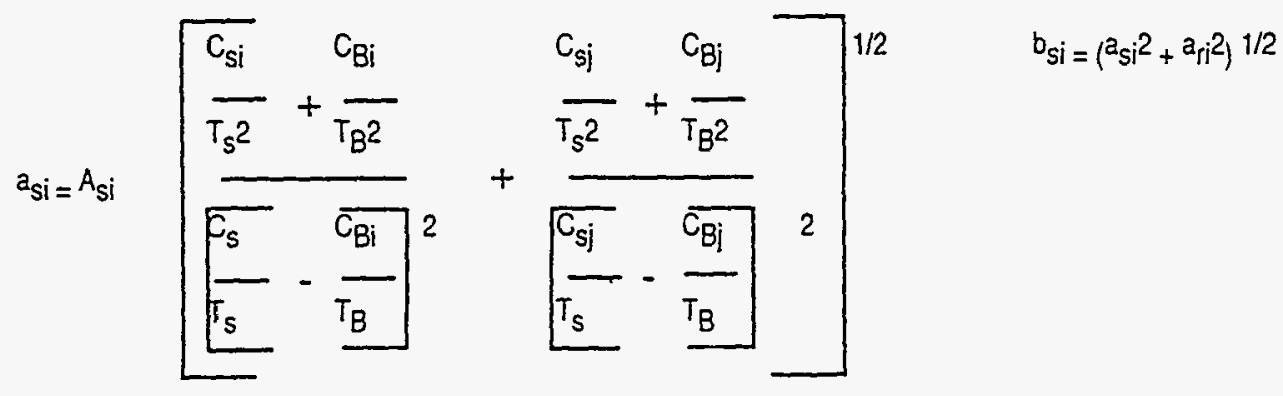

-Sample uncertainty is the propagated standard deviation of sample activity using counting statistics.

$A_{i}=$ Nonblank corrected activity of laboratory reagent blank for isotope i expressed as picocuries (pCi) per unit volume.

$\hat{c}_{i 1}=$ Nonblank corrected uncertainty of laboratory reagent blank expressed as pCi per unit volume.

$A_{s i}=$ Sample activity for isotope $i$ expressed as pCi per unit volume.

$a_{s i}=$ Sample activity uncertainty expressed as pCi per unit volume.

$\mathrm{B}_{\mathrm{si}}=$ Blank corrected sample activity for isotope $\mathrm{i}$ expressed as pCi per unit volume.

$\mathrm{b}_{\mathrm{si}}=$ Blank corrected sample uncertainty expressed as pCi per unit volume.

$D_{s j}=$ Activity (dpm) of internal standard isotope $j$ added to sample.

$C_{s i}=$ Sample gross counts for isotope $i$.

$\mathrm{C}_{\mathrm{sj}}=$ Sample gross counts for internal standard isotope $\mathrm{j}$.

$\mathrm{C}_{\mathrm{Bi}}=$ Detector background gross counts for isotope $\mathrm{i}$.

$C_{B j}=$ Detector background gross counts for internal standard isotope $j$.

$T_{S}=$ Sample count time expressed in minutes.

$T_{B}=$ Detector background count time expressed in minutes.

$V=$ Sample unit volume or sample unit weight. 
Table D-2

Typical Detection Limits for Radioactive and Nonradioactive Materials

Detectable Activity (per sample)

Airborne Effluents

Plutonium-239, -240

Uranium-233/-234

Uranium-238

Americium-241

Tritium (H-3)

Berylium

Ambient Air Samples

Plutonium-239, -240

$$
\begin{aligned}
& 5.9 \times 10^{-8} \mu \mathrm{Ci} \\
& 1.3 \times 10^{-7} \mu \mathrm{Ci} \\
& 1.4 \times 10^{-7} \mu \mathrm{Ci} \\
& 4.3 \times 10^{-8} \mu \mathrm{Ci} \\
& 2.1 \times 10^{-6} \mu \mathrm{Ci} \\
& 2.5 \times 10^{-1} \mu \mathrm{Ci}
\end{aligned}
$$

Parameter

Approximate

Sample Volume Analyzed $^{a}$

$$
\begin{array}{r}
7,340 \mathrm{~m}^{3 b} \\
7,340 \mathrm{~m}^{3 b} \\
7,340 \mathrm{~m}^{30} \\
7,340 \mathrm{~m}^{30} \\
1.4 \mathrm{~m}^{3} \\
7,340 \mathrm{~m}^{30}
\end{array}
$$

$$
9.7 \times 10^{-8} \mu \mathrm{Ci}
$$

$29,000 \mathrm{~m}^{3 \mathrm{c}}$

\section{Effluent Water Samples (Radioactive)}

Plutonium-239, -240

$$
8.1 \times 10^{-8} \mu \mathrm{Ci}
$$

Uranium-233/-234

$0.15 \times 10^{-6} \mu \mathrm{Ci}$

Uranium-238

Americium-241

$0.15 \times 10^{-6} \mu \mathrm{Ci}$

$6.2 \times 10^{-8} \mu \mathrm{Ci}$

Tritium (H-3)

$$
2.1 \times 10^{-6} \mu \mathrm{Ci}
$$

Soil Samples (Radioactive)

Plutonium-239, -240

$$
0.03 \mathrm{pCi} / \mathrm{gm}
$$

$\begin{array}{rr}1,000 \mathrm{ml} & 0.81 \times 10^{-10} \mu{\mathrm{Ci} / \mathrm{ml}^{c}}^{c} \\ 7,000 \mathrm{ml} & 0.12 \times 10^{-10} \mu \mathrm{Ci} / \mathrm{ml}^{c} \\ 1,000 \mathrm{ml} & 0.15 \times 10^{-9} \mu \mathrm{Ci} / \mathrm{ml}^{c} \\ 1,000 \mathrm{ml} & 0.15 \times 10^{-9} \mu \mathrm{Ci} / \mathrm{ml}^{c} \\ 1,000 \mathrm{ml} & 0.62 \times 10^{-10} \mu \mathrm{Ci} / \mathrm{ml}^{c} \\ 7,000 \mathrm{ml} & 0.089 \times 10^{-10} \mu \mathrm{Ci} / \mathrm{ml}^{c} \\ 10 \mathrm{ml} & 2.14 \times 10^{-7} \mu \mathrm{Ci} / \mathrm{ml}^{c}\end{array}$

$1.5 \mathrm{gm}$

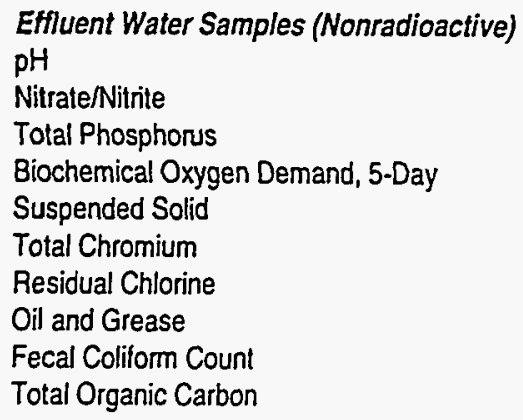

$0.003 \times 10^{-15} \mu \mathrm{Ci} / \mathrm{ml}$

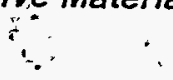

$\therefore$ Minimum Detectable Activity (per unit volume or mass)

$$
\begin{array}{r}
0.008 \times 10^{-15} \mu \mathrm{Ci} / \mathrm{ml} \\
0.018 \times 10^{-15} \mu \mathrm{Ci} / \mathrm{ml} \\
0.020 \times 10^{-15} \mu \mathrm{Ci} / \mathrm{ml} \\
0.006 \times 10^{-15} \mu \mathrm{Ci} / \mathrm{ml} \\
1,530 \times 10^{-15} \mu \mathrm{Ci} / \mathrm{ml} \\
3.0 \times 10^{-5} \mu \mathrm{g} / \mathrm{m}^{3}
\end{array}
$$

Minimum Detection Limit

$0.14 \mathrm{SU}$

$0.05 \mathrm{mgh}$

$0.01 \mathrm{mg} /$

$5.0 \mathrm{mg} /$

$4.0 \mathrm{mgh}$

$0.01 \mathrm{mgh}$

$0.1 \mathrm{mg} /$

$0.5 \mathrm{mg} /$

1 colony/ $100 \mathrm{ml}$

$1.0 \mathrm{mg} /$

a. Volume analyzed is usually an aliquoted fraction of the total sample volume collected.

b. Monthly composite.

c. Composite of two biweekly samples. 